UNIVERSIDADE DE SÃO PAULO

ESCOLA DE ENGENHARIA DE SÃO CARLOS

MARIANA ALHER FERNANDES

ESTUDO DOS MECANISMOS DE INSTABILIZAÇÃO EM UM TALUDE DE SOLO ARENOSO NÃO SATURADO LOCALIZADO NA REGIÃO CENTRO-OESTE PAULISTA

São Carlos 



\section{ESTUDO DOS MECANISMOS DE INSTABILIZAÇÃO EM UM TALUDE DE SOLO ARENOSO NÃO SATURADO LOCALIZADO NA REGIÃO CENTRO-OESTE PAULISTA}

Tese apresentada à Escola de Engenharia de São Carlos da Universidade de São Paulo como parte dos requisitos para a obtenção do Título de Doutora em Geotecnia.

Versão corrigida. Original se encontra disponível na Unidade que aloja o Programa.

Orientador: Prof. Dr. Oswaldo Augusto Filho

São Carlos 
AUTORIZO A REPRODUÇÃO E DIVULGAÇÃO TOTAL OU PARCIAL DESTE TRABALHO, POR QUALQUER MEIO CONVENCIONAL OU ELETRÔNICO, PARA FINS DE ESTUDO E PESQUISA, DESDE QUE CITADA A FONTE.

Tese (Doutorado) - Programa de Pós-Graduação em Geotecnia e Área de concentração em Geotecnia -- Escola de Engenharia de São Carlos da Universidade de São Paulo, 2016 .

1. Estabilidade de talude. 2. Solo não saturado. 3. Formação Botucatu. 4. Caracterização do solo. 5.

Instrumentação e monitoramento. 6. Modelagem numérica. I. Título. 


\section{FOLHA DE JULGAMENTO}

Candidata: Engenheira MARIANA ALHER FERNANDES.

Título da Tese: "Estudo dos mecanismos de instabilização em um talude de solo arenoso não saturado localizado na região Centro-Oeste Paulista".

Data da defesa: 15/09/2016.

\section{Comissão Julgadora:}

Prof. Associado Oswaldo Augusto Filho

(Orientador)

(Escola de Engenharia de São Carlos/EESC)

Prof. Dr. Jefferson Lins da Silva

(Escola de Engenharia de São Carlos/EESC)

Profa. Dra. Miriam Gonçalves Miguel

(Universidade Estadual de Campinas/UNICAMP)

Prof. Dr. Rudney da Conceição Queiroz

(Faculdades Integradas de Araraquara/FIAR)

Prof. Dr. Fábio Augusto Gomes Vieira Reis

(Universidade Estadual Paulista "Júlio de Mesquita Filho"/UNESP - Rio Claro)
Resultado:

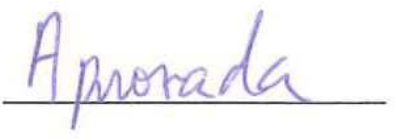

APROVADA

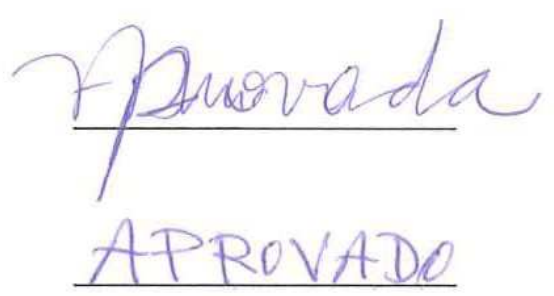



Aos meus queridos pais, Edinéia e Paulo, pelo amor incondicional e apoio durante toda a minha vida, a minha irmã Juliana e aos meus eternos animais de estimação, Tiko (in memoriam) e Nina. 



\section{AGRADECIMENTOS}

À Deus, por permitir concluir mais uma etapa da minha vida com êxito e alcançar mais um sonho da minha vida. Agradeço por me dar sabedoria, paciência e inteligência para concluir mais esse trabalho. "A Ele a glória, a Ele o louvor, a Ele o domínio, Ele é o Senhor".

Aos meus queridos pais, Edinéia e Paulo, por toda a dedicação, amor incondicional, amizade, carinho e apoio durante todos os momentos da minha vida. Gratidão por tudo que vocês me proporcionam e pelos milhares de ensinamentos diários. AMO MUITO VOCÊS!

A minha querida irmã Juliana, pela amizade, companheirismo e brincadeiras ao longo de nossas vidas.

Aos meus animais de estimação, Tiko (in memoriam) e Nina, duas bolinhas de pêlo que nunca deixaram de me amar e me fazer feliz.

Ao meu namorado Igor, pela compreensão, incentivo, paciência e longas viagens/distâncias enfrentadas para nos encontrarmos.

Ao meu orientador e Prof. Dr. Oswaldo Augusto Filho, pela orientação, confiança, incentivo e amizade. Por sempre estar presente em cada etapa desenvolvida nesse trabalho.

Aos Prof. Jefferson Lins da Silva, pelas inúmeras conversas geotécnicas, sugestões, amizade e por disponibilizar o programa GeoStudio 2012. Muito obrigada.

Ao Prof. Dr. Lázaro Valentim Zuquette, pelo empréstimo de diversos equipamentos de campo e pela troca de experiência sobre corrida e atividades físicas.

Ao Prof. Dr. Orencio Monje Vilar, pelas sugestões e ensinamentos referentes aos ensaios de compressão triaxial.

Ao Prof. Dr. Edmundo Rogério Esquivel pela amizade.

A todos os professores do Departamento de Geotecnia da Escola de Engenharia de São Carlos, pelos ensinamentos.

Aos técnicos do Departamento de Geotecnia Sr. Antonio Claret Carriel, Sr. Antonio Garcia, Sr. Benedito Osvaldo de Souza, Sr. Décio Aparecido Lourenço. Em especial agradeço ao Sr. Herivelto Moreira dos Santos, por todo auxílio prestado com as ferramentas computacionais, ao Sr José Luis Guerra, por todo suporte durante os ensaios de compressão triaxial e ao Sr. Oscar dos Santos Neto, pela amizade de anos e disposição em auxiliar no desenvolvimento do trabalho.

Aos funcionários da secretária Sr. Álvaro Luiz Nery e Sra. Maristela Aparecida Zotesso Batissaco. 
Aos técnicos Sr. Paulo Sérgio Batista, Sr. Dorival Piedade Neto, ao Sr. Alex Sandro Contadori, Sr. Geraldo José Manjerona Frigo, Sr. Pedro Donizete Luchesi, Sr. Edson Roberto dos Santos, Sr. Flávio Borges de Oliveira, Sr. Marcelo Carlos Nery, Sr. José Orlando Lombardo, Sr. João do Bonfim Santos, Sr. Ronaldo Izzi, Sr. Ricardo Leite da Silva, Sra. Elena Luzia Palloni Gonçalves e Sra. Flávia Helena Cassin pelo auxílio técnico em diversas etapas do trabalho.

Ao Sr. José Carlos Garcia e sua família, por cuidar do pluviômetro e realizar inúmeras medidas da chuva diária. Muito obrigada.

Ao Manoel Izidoro Neto e Walter Costa, pelas diversas leituras realizadas nos tensiômetros. Muito obrigada.

Aos colegas e amigos da pós-graduação em geotecnia: Ana Elisa Abreu, Camila Eberle, Christopher Fonseca, Fernando Hirose (Sorriso), Filipe Biaggioni, Giovana Bizão, Ingrid Azevedo, Jaqueline Ruiz, João Manoel Sampaio, Jussara Mechetti, Katerin Guerrero, Larissa Vieira, Paula Zuccolo, Nestor Barros, Phillipe Fernandes, Roberto Aguiar, Thaise Morais, Vinicius Peixoto e Zorany Zapata.

Aos integrantes do Movimento dos Focolares da cidade de São Carlos, especialmente a Sra. Maria Elizabeth Maluf. Muito obrigada.

Aos profissionais da área da saúde: Antonio Delfino, Maria Olivia de Oliveira, Helder Fonseca, Gabriel Bagnato, Paulo Mattos e Jaqueline Crusca. Muito obrigada.

Ao Programa de Aperfeiçoamento de Ensino (PAE), pelo aprendizado profissional e suporte financeiro.

À Universidade de São Paulo e à Escola de Engenharia de São Carlos, em especial ao Departamento de Geotecnia.

À Coordenação de Aperfeiçoamento de Pessoal de Nível Superior (CAPES) e à Fundação de Amparo à Pesquisa do Estado de São Paulo (FAPESP), pelo suporte financeiro.

Ao Departamento de Estradas de Rodagem do Estado de São Paulo (DER/SP), regional de Araraquara, por autorizar o uso da área piloto no decorrer desse trabalho. 
"Só o amor nos salvará!"

(Papa Franscico) 



\section{RESUMO}

FERNANDES, M.A. Estudo dos mecanismos de instabilização em um talude de solo arenoso não saturado localizado na região Centro-Oeste Paulista. 2016. $283 \mathrm{f}$. Tese (Doutorado) - Escola de Engenharia de São Carlos, Universidade de São Paulo, São Carlos, 2016.

A presença de encostas com solos na condição não saturada é muito comum na região Sudeste brasileira devida às características climáticas e hidrogeológicas regional. Neste caso, o mecanismo de instabilização pode ser basicamente descrito pela redução da coesão aparente provocada pela infiltração da água da chuva, causada pela diminuição ou até mesmo a anulação dos efeitos da sucção matricial, tornando o talude instável. O presente trabalho apresenta um estudo dos mecanismos instabilizadores em um talude de corte composto por solo residual arenoso localizado na Rodovia Luis Augusto de Oliveira (SP-215) no km 179+300 LE, próximo ao município de Ribeirão Bonito, Brasil. Neste trabalho foi realizado um levantamento dos dados e das propriedades do solo (física, mecânica e hidráulica) da área piloto utilizando métodos de investigação geológico-geotécnica de superfície (levantamento topográfico de detalhe, caminhamentos) e de subsuperfície (sondagem a trado e poços com coleta de amostras); ensaios de laboratório e de campo (índices físicos do solo, resistência ao cisalhamento, permeabilidade); instrumentação e monitoramento (piezômetro, pluviômetro e tensiômetro) e modelagem numérica (análises da infiltração da água da chuva e de estabilidade de talude). $\mathrm{Na}$ área investigada ocorrem solos residuais dos arenitos eólicos da Formação Botucatu (Grupo São Bento, Bacia Sedimentar do Paraná) de idade jurássicocretácea. As modelagens numéricas realizadas no programa GeoStudio versão 2012 (Seep/W e Slope $(W$ ) confirmaram que é possível ocorrer deslizamentos rasos de solo somente pela redução da sucção e perda de coesão aparente. As modelagens do fluxo da água infiltrada no talude apresentaram resultados divergentes das leituras registradas pelos tensiômetros instalados no talude monitorado e os fatores de segurança mostraram serem bem superiores ao unitário, mesmo ocorrendo chuvas de alta intensidade pluviométrica. Estas modelagens numéricas também permitiram estabelecer a configuração geométrica crítica (altura e inclinação) para os taludes de corte em solo residual arenoso da Formação Botucatu.

Palavras-chave: Estabilidade de talude. Solo não saturado. Formação Botucatu. Caracterização do solo. Instrumentação e monitoramento. Modelagem numérica. 



\begin{abstract}
FERNANDES, M.A. Study of the instability mechanisms in a slope of unsaturated sandy soil located in Midwest Paulista region. 2016. $283 \mathrm{f}$. Tese (Doutorado) - Escola de Engenharia de São Carlos, Universidade de São Paulo, São Carlos, 2016.

The presence of slopes with soil in the unsaturated condition is very common in Brazil's Southeast region due to climate and regional hydrogeological characteristics. In this case, the instability mechanism can be basically described by the apparent cohesion loss caused by the rainfall infiltration that induced by the reduction or even annulling the effect of matric suction, making the slope conditionally unstable. This paper presents a study of instabilizing mechanisms in a cut slope composed of sandy residual soil located on Highway Luis Augusto de Oliveira (SP-215) at km $179+300$ LE, near Ribeirão Bonito, Brazil. This work was carried out a survey of the data and soil properties (physical, mechanical and hydraulic) of pilot area using geological and geotechnical research techniques of surface (topographic survey) and subsurface (soil sampling and hand auger drilling); laboratory and field tests (physical indices soil, shear strength, permeability); instrumentation and monitoring (piezometer, rain gauge and tensiometer) and numerical modelling (analysis of rainfall infiltration and slope stability). In the investigated area occur residual soils of aeolian sandstones of Botucatu Formation (São Bento Group, Paraná Sedimentary Basin) JurassicCretaceous age. The numerical modelling performed in GeoStudio version 2012 (Seep/W and Slope/W) confirmed that it is possible to have shallow soil slips just reducing the suction loss and apparent cohesion. The modelling of the infiltrated water flow on the slope showed conflicting results of the readings recorded by tensiometers installed on the monitored slope and the safety factors shown to be well above the unit, even occurring high intensity rainfall. These numerical models also allowed to establish the geometric critical configuration (height and slope angle) for cut slopes in a sandy residual soil of Botucatu Formation.
\end{abstract}

Keywords: Slope stability. Unsaturated soil. Botucatu Formation. Soil characterization. Instrumentation and monitoring. Numerical modelling. 



\section{LISTA DE FIGURAS}

Figura 3.1 - Classificação dos movimentos de massa segundo Sharpe (1938). …..................51

Figura 3.2 - Método das Fatias (a) divisão em fatias e (b) equilíbrio de forças. ......................58

Figura 3.3 - Método de Fellenius (1936) - representação das forças atuantes em uma fatia. ..60 Figura 3.4 - Método de Janbu (1954) - representação das forças atuantes em uma fatia.........61

Figura 3.5 - (a), (b) Fator de correção $\left(\mathrm{f}_{0}\right)$ para o Método de Janbu (1954).

Figura 3.6 - Método de Bishop Simplificado (1955) - representação das forças atuantes em uma fatia. 64

Figura 3.7 - Fator de segurança variando em função da duração da chuva. 68

Figura 3.8 - Fator de segurança variando em função da permeabilidade do solo. 68

Figura 3.9 - Fator de segurança variando em função da anisotropia do solo.

Figura 3.10 - Resultados das análises de fluxo permanente. 70

Figura 3.11 - Distribuição da pressão neutra para condutividade hidráulica saturada correspondente a (a) $5.10^{-5} \mathrm{~m} / \mathrm{s}$ e (b) $5.10^{-6} \mathrm{~m} / \mathrm{s}$. 72

Figura 3.12 - Superfícies críticas de escorregamento em formato circular para condutividade hidráulica saturada correspondente a (a) $5.10^{-5} \mathrm{~m} / \mathrm{s}$ e (b) $5.10^{-6} \mathrm{~m} / \mathrm{s}$. 73 Figura 3.13 - Fator de segurança em função da infiltração da água da chuva para condutividade hidráulica saturada de $5.10^{-5} \mathrm{~m} / \mathrm{s}$ e de $5.10^{-6} \mathrm{~m} / \mathrm{s}$. 73

Figura 3.14 - Distribuição da pressão neutra na crista do talude após o término da chuva para o solo com condutividade hidráulica saturada de $1.10^{-4} \mathrm{~m} / \mathrm{s}$ e perfil inicial de pressão neutra de $-25 \mathrm{kPa}$.

Figura 3.15 - Fator de segurança em função do tempo decorrido da infiltração da chuva correspondente ao cenário 3 para o perfil inicial de pressão neutra de $-25 \mathrm{kPa}$ e nível d'água localizado no pé do talude.

Figura 3.16 - (a) Fator de segurança em função do tempo decorrido e (b) Profundidade da superfície crítica de ruptura em função do tempo decorrido.

Figura 3.17 - Fator de segurança em função da (a) inclinação do talude e (b) altura do talude.

Figura 3.18 - Tipos de perfil de pressão neutra originada ao longo da precipitação. 79

Figura 3.19 - Fator de Segurança em função do tempo para o solo A. 80

Figura 3.20 - Perfil do talude para (a) situação mais crítica e (b) situação mais favorável......81 
Figura 3.21 - Pressão neutra variando em função do tempo e da precipitação para diferentes profundidades no talude com $30^{\circ}$ de inclinação localizado na Serra de Cubatão.

Figura 3.22 - Fator de segurança variando em função do tempo e da precipitação diária para o talude com $20^{\circ}$ de inclinação localizado na região Serrana do Rio de Janeiro. 86

Figura 3.23 - Elemento de um solo não saturado. 88

Figura 3.24 - Diagramas de fases, rigoroso e simplificado para um solo não saturado (a) sistema tetrafásico rigoroso e (b) sistema trifásico simplificado. 88

Figura 3.25 - Esquema da definição de potencial total da água no solo. 90

Figura 3.26 - Potencial matricial - forças de capilaridade e adsorção. 92

Figura 3.27 - Esquema da definição de sucção. 92

Figura 3.28 - Esquema ilustrando a definição de sucção total, matricial e osmótica. 93

Figura 3.29 - Elementos da curva retenção de água do solo para um solo tipicamente siltoso. 95

Figura 3.30 - Efeito da textura do solo na curva de retenção da água do solo. 96

Figura 3.31 - Curva de retenção da água no solo para um solo argiloso, siltoso e arenoso..... 97

Figura 3.32 - Elemento de volume de solo em torno de um ponto M. 101

Figura 3.33 - Perfil de umedecimento do solo durante a infiltração. 104

Figura 3.34 - Critério de ruptura Mohr-Coulomb para solo saturado. 107

Figura 3.35 - Envoltória de ruptura de um solo não saturado para as variáveis de estado de tensão $\sigma-u a$ e $u a-u w$.

Figura 3.36 - Linhas de contorno da envoltória de ruptura representada pela resistência ao cisalhamento versus sucção matricial.

Figura 3.37 - Resistência ao cisalhamento versus sucção (a) areia argilosa de Madri e (b) argila de Guadalix de La Sierra. 114

Figura 3.38 - Resistência ao cisalhamento versus tensão normal líquida (a) areia argilosa de Madri e (b) argila de Guadalix de La Sierra. 114

Figura 3.39 - Resistência ao cisalhamento versus sucção para uma areia argilosa-siltosa.... 115 Figura 3.40 - Curva de retenção da água no solo e a representação da envoltória de resistência não linear. 116

Figura 4.1 - Fluxograma esquemático das etapas de trabalho. 120

Figura 4.2 - Levantamento topográfico de detalhe (a) detalhe do equipamento Estação Total e (b) operador responsável por manusear a estação Total. 122

Figura 4.3 - Levantamento topográfico de detalhe (a) vista do operador mirando a Estação Total no prisma refletor e (b) auxiliares locando o prisma refletor na área piloto. 
Figura 4.4 - Sondagem a trado manual (a) detalhe do trado tipo cavadeira, (b) preparo do préfuro, (c) inserção do trado e da haste no pré-furo, (d) detalhe dos operadores com chave de grifo , (e) equipe manuseando o equipamento, (f) coleta de amostra deformada de solo......124 Figura 4.5 - Amostragem indeformada (a) retirada no pé e na crista do talude e (b) detalhe da caixa metálica. 126

Figura 4.6 - Coleta de bloco de amostra indeformada - (a) pé do talude, (b) retirada da amostra AP-1, profundidade 0,80 metros e (c) retirada da amostra AP-2, profundidade 1,20 metros.

Figura 4.7 - Coleta de bloco de amostra indeformada - (a) topo do talude e (b) retirada das amostras AC-1 e AC-2, ambas na profundidade 0,80 metros.

Figura 4.8 - Análise granulométrica conjunta - sedimentação. 128

Figura 4.9 - Esquema do equipamento - Técnica do Funil de Placa Porosa. 129

Figura 4.10 - Técnica do Funil de Placa Porosa (a) composição do equipamento e (b) da amostra do corpo de prova no interior do funil.

Figura 4.11 - Configuração de ensaio para determinação da (a) sucção total e (b) sucção matricial.

Figura 4.12 - Trajetória de secagem (a) moldagem do corpo de prova e (b) saturação dos corpos de prova.

Figura 4.13 - Trajetória de secagem (a) secagem dos corpos de prova, (b) controle da massa, (c) embalagem dos corpos de prova com papel filtro e (d) armazenamento do conjunto...... 133 Figura 4.14 - Trajetória de umedecimento (a) corpo de prova seco ao ar livre e (b) montagem do procedimento de umedecimento da amostra de solo.

Figura 4.15 - Trajetória de umedecimento (a) processo de gotejamento e (b) equilíbrio da água na amostra de solo antes de embalar com papel filtro.

Figura 4.16 - Ensaio de porosimetria por intrusão de mercúrio (a) corpos de prova e (b) porosímetro. 136

Figura 4.17 - Ensaio de permeabilidade em laboratório (a) moldagem do corpo de prova e (b) corpo de prova talhado e preparado para a montagem do ensaio.

Figura 4.18 - Ensaio de permeabilidade em laboratório - permeâmetro conectado no painel de permeabilidade. 137

Figura 4.19 - Esquema do permeâmetro Guelph. 138

Figura 4.20 - Fator de forma "C": C1 para valores de $\alpha \geq 0,12 \mathrm{~cm}-1$; C2 para valores de $\alpha=0,04 \mathrm{~cm}-1$; e C3 para valores de $\alpha=0,01 \mathrm{~cm}-1$.

Figura 4.21 - Ensaio de permeabilidade em campo - permeâmetro Guelph. 
Figura 4.22 - Ensaio de absorção de água (a) equipamentos utilizados e (b) detalhe do suporte com a placa porosa comum.

Figura 4.23 - Ensaio de perda de massa por imersão (a) submersão dos corpos de prova no tanque com água e (b) detalhe de um corpo de prova submerso.

Figura 4.24 - Prensa mecânica utilizada nos ensaios de compressão triaxial. 144

Figura 4.25 - Sistema de aquisição de dados - canal 1 ao 4. 145

Figura 4.26 - Sistema de aplicação de pressão - ar comprimido. 145

Figura 4.27 - Tensiômetro comum. 152

Figura 4.28 - Etapas da instalação dos tensiômetros (a) perfuração com trado espiral e (b) visor do vacuômetro registrando $0 \mathrm{kPa}$.

Figura 4.29 - Etapas da instalação dos tensiômetros (a) introdução da pasta e do tensiômetro no furo e (b) tensiômetro instalado. 155

Figura 4.30 - Mangueira do medidor de nível d’água de máxima (a) esquema ilustrativo (desenho sem escala) e (b) confecção da magueira. 156 Figura 4.31 - Instalação do equipamento na área piloto (a) perfuração com trado concha e (b) fixação da manta geotextil no tubo de PVC. 156

Figura 4.32 - Instalação do equipamento na área piloto (a) colocação da mangueira e (b) após instalação, próximos aos tensiômetros.

Figura 4.33 - Localização do pluviômetro Ville de Paris. 158

Figura 4.34 - Pluviômetro Ville de Paris (a) medida da chuva na proveta e (b) equipamento instalado em campo. 158

Figura 4.35 - (a) Pluviômetro utilizado para medição da precipitação diária pela Agência Nacional de Águas (b) distância entre o Pluviômetro Ville de Paris e o Pluviômetro ANA. 160 Figura 4.36 - Conjunto de tensiômetros da crista da seção geológico-geotécnica com inclinação de $27^{\circ}$ (a) tensiômetro com comprimento de $0,90 \mathrm{~m}$ afetado por um formigueiro, (b) conjunto de tensiômetros instalados em dezembro de 2013 e (c) conjunto de tensiômetros após reinstalação do equipamento. 161

Figura 4.37 - Conjunto de tensiômetros localizados no pé da seção geológico-geotécnica com inclinação $37^{\circ}$ (a) antes da substituição - tubo do tensiômetro danificado e (b) depois da substituição - tensiômetro substituído.

Figura 4.38 - Seção topográfica com inclinação de (a) $27^{\circ}$ e (b) $37^{\circ}$. 165

Figura 4.39 - Malha de elementos finitos para seção topográfica com inclinação de $27^{\circ}$..... 166

Figura 4.40 - Malha de elementos finitos para seção topográfica com inclinação de $37^{\circ} \ldots 167$

Figura 4.41 - Condição de contorno do fluxo permanente utilizada no Modelo 1. 168 
Figura 4.42 - Condição de contorno do fluxo permanente utilizada no Modelo 2. 169

Figura 4.43 - Condição de contorno do fluxo permanente utilizada no Modelo 3.

Figura 4.44 - Modelagem numérica de seções com diferentes alturas baseada na (a) seção i27º e (b) seção i $37^{\circ}$.

Figura 4.45 - Modelagem numérica de seções com diferentes inclinações baseada na (a) seção i $27^{\circ}$ e (b) seção i $37^{\circ}$.

Figura 4.46 - Delimitação da superfície de ruptura a partir do posicionamento dos possíveis centros de rotação e das linhas que estabelecem o raio da superfície de ruptura - seção geológico-geotécnica com inclinação de $37^{\circ}$

Figura 5.1 - Localização do município de Ribeirão Bonito. 175

Figura 5.2 - Distância entre a área piloto e a cidade de Ribeirão Bonito. 176

Figura 5.3 - Área piloto (a) visão geral da topografia do talude (b) inclinação típica do talude (c) crista do talude - rodovia sentido São Carlos e (d) crista do talude - rodovia sentido Ribeirão Bonito. 177

Figura 5.4 - Precipitação média mensal do município de Ribeirão Bonito. 178

Figura 5.5 - Distribuição das UGRHI no Estado de São Paulo. 178

Figura 5.6 - Sub-bacias da UGRHI do Tietê-Jacaré. 179

Figura 5.7 - Distribuição dos três sistemas de aquíferos presentes na UGRHI 13. 180

Figura 6.1 - Levantamento topográfico parcial da área piloto (sem escala). 182

Figura 6.2 - Seção geológico-geotécnica com inclinação de $27^{\circ}$ também identificada como Seção A-A' (desenho sem escala). 183

Figura 6.3 - Seção geológico-geotécnica com inclinação de $37^{\circ}$ também identificada como Seção B-B' (desenho sem escala). 183

Figura 6.4 - Fotos obtidas com a lupa digital - fração areia fina - solo residual da Formação Botucatu (a) aumento 50 e (b) aumento 75. 186

Figura 6.5 - Fotos obtidas com a lupa digital - fração areia média - solo residual da Formação Botucatu () aumento 22 e (b) aumento 50. 186

Figura 6.6 - Sucção matricial versus teor de umidade gravimétrico. 187

Figura 6.7 - Diâmetro dos poros versus volume acumulado de mercúrio. 189

Figura 6.8 - Diâmetro dos poros versus log intrusão diferencial. 189

Figura 6.9 - Condutividade hidráulica não saturada em função da sucção - permeâmetro Guelph. 
Figura 6.10 - Variação volumétrica versus raiz do tempo para o ensaio adensado-drenado com solo saturado utilizando (a) amostra indeformada do pé do talude e (b) amostra indeformada da crista do talude.

Figura 6.11 - Curva tensão versus deformação do ensaio adensado-drenado com solo saturado utilizando (a) amostra indeformada do pé do talude e (b) amostra indeformada da crista do talude. 196

Figura 6.12 - Envoltória de resistência em termos de tensão efetiva do ensaio adensadodrenado com solo saturado - amostra indeformada do pé do talude.

Figura 6.13 - Envoltória de resistência em termos de tensão efetiva do ensaio adensadodrenado com solo saturado - amostra indeformada da crista do talude. 198 Figura 6.14 - Corpo de prova moldado do bloco de amostra indeformada do pé do talude, após o encerramento do cisalhamento utilizando tensão confinante de $150 \mathrm{kPa}$ no ensaio CD com solo saturado. 198

Figura 6.15 - Variação volumétrica versus raiz do tempo do ensaio com solo no teor de umidade natural utilizando (a) amostra indeformada do pé do talude e (b) amostra indeformada da crista do talude.

Figura 6.16 - Curva tensão versus deformação do ensaio com solo no teor de umidade natural utilizando (a) amostra indeformada do pé do talude e (b) amostra indeformada da crista do talude. 200

Figura 6.17 - Envoltória de resistência em termos de tensão efetiva do ensaio para determinação da resistência do solo com teor de umidade natural - amostra indeformada do pé do talude. 202

Figura 6.18 - Envoltória de resistência em termos de tensão efetiva do ensaio para determinação da resistência do solo com teor de umidade natural - amostra indeformada da crista do talude. 202

Figura 6.19 - Previsão de resistência ao cisalhamento do solo não saturado a partir do método de Vilar (2007) para amostra indeformada do pé e da crista do talude. 203 Figura 6.20 - Corpo de prova moldado do bloco de amostra indeformada da crista do talude após o cisalhamento utilizando tensão confinante de $100 \mathrm{kPa}$. 204 Figura 6.21 - Variação volumétrica versus raiz do tempo para o ensaio adensado-drenado com solo não saturado (sucção de $30 \mathrm{kPa}$ ) utilizando amostra indeformada da crista do talude. . 204 Figura 6.22 - Curvas tensão versus deformação do ensaio adensado-drenado com solo não saturado (sucção de $30 \mathrm{kPa}$ ) para amostra indeformada da crista do talude. 205 
Figura 6.23 - Relação entre $(\sigma 1-\sigma 3) /(u a-u w)$ versus deformação do ensaio adensadodrenado com solo não saturado (sucção de $30 \mathrm{kPa}$ ) para amostra indeformada da crista do talude.

Figura 6.24 - Envoltória de resistência em termos de tensão efetiva do ensaio adensadodrenado com solo não saturado (sucção de $30 \mathrm{kPa}$ ) - amostra indeformada da crista do talude.

Figura 6.25 - Corpos de prova após o encerramento do ensaio adensado-drenado com solo não saturado utilizando sucção inicial de $30 \mathrm{kPa}$ e tensão confinante líquida de (a) $50 \mathrm{kPa}$ e (b) $150 \mathrm{kPa}$.

Figura 6.26 - Leituras de sucção matricial realizadas no pé da Seção A-A' (período de $24 / 12 / 2013$ a $31 / 12 / 2014)$. 208

Figura 6.27 - Leituras de sucção matricial realizadas no pé da Seção A-A' (período de $01 / 01 / 2015$ a $31 / 12 / 2015)$. 209

Figura 6.28 - Leituras de sucção matricial realizadas na face da Seção A-A' (período de $24 / 12 / 2013$ a $31 / 12 / 2014)$

Figura 6.29 - Leituras de sucção matricial realizadas na face da Seção A-A' (período de 01/01/2015 a 31/12/2015).

Figura 6.30 - Leituras de sucção matricial realizadas na crista da Seção A-A' (período de $24 / 12 / 2013$ a $31 / 12 / 2014)$ 212

Figura 6.31 - Leituras de sucção matricial realizadas na crista da Seção A-A' (período de $01 / 01 / 2015$ a $31 / 12 / 2015)$ 213

Figura 6.32 - Leituras de sucção matricial realizadas no pé da Seção B-B' (período de 24/12/2013 a 31/12/2014).

Figura 6.33 - Leituras de sucção matricial realizadas no pé da Seção B-B' (período de $01 / 01 / 2015$ a $31 / 12 / 2015)$. 216

Figura 6.34 - Leituras de sucção matricial realizadas na face da Seção B-B' (período de 24/12/2013 a 31/12/2014). 217

Figura 6.35 - Leituras de sucção matricial realizadas na face da Seção B-B' (período de 01/01/2015 a 31/12/2015) 218

Figura 6.36 - Leituras de sucção matricial realizadas na crista da Seção B-B' (período de 24/12/2013 a 31/12/2014). 219

Figura 6.37 - Leituras de sucção matricial realizadas na crista da Seção B-B' (período de 01/01/2015 a 31/12/2015). 220 
Figura 6.38 - Precipitação pluviométrica diária do Pluviômetro Ville de Paris, Pluviômetro INMET e Pluviômetro ANA (período de 24/12/2013 a 31/12/2014).

Figura 6.39 - Precipitação pluviométrica diária do Pluviômetro Ville de Paris, Pluviômetro INMET e Pluviômetro ANA (período de 01/01/2015 a 31/12/2015). 224

Figura 6.40 - Geometria das duas seções monitoradas em campo (a) seção A-A' e (b) seção B-B' 226

Figura 6.41 - Resultado gráfico das análises de estabilidade de talude na Seção A-A' para (a) coesão $2 \mathrm{kPa}$, (b) coesão $8 \mathrm{kPa}$, (c) coesão $32 \mathrm{kPa}$ e na Seção B-B' para - (d) coesão 2 $\mathrm{kPa},(\mathrm{e})$ coesão $8 \mathrm{kPa}$ e (f) coesão $32 \mathrm{kPa}$. 228

Figura 6.42 - (a) Fator de Segurança versus coesão - Seção A-A' e Seção B-B' - utilizando o método de Bishop Simplificado e o método de Janbu e (b) detalhe do gráfico para o intervalo de coesão entre $0 \mathrm{kPa}$ e $8 \mathrm{kPa}$. 230

Figura 6.43 - Fator de Segurança versus coesão - inclinação constante de $27^{\circ}$ e modificação da altura, baseada na Seção A-A'- utilizando o método de Bishop Simplificado. 232 Figura 6.44 - Fator de Segurança versus coesão - altura constante de 5,40 m e modificação da inclinação baseada na Seção A-A'- utilizando o método de Bishop Simplificado. 232 Figura 6.45 - Fator de Segurança versus coesão - inclinação constante de $37^{\circ}$ e modificação da altura, baseada na Seção B-B'- utilizando o método de Bishop Simplificado. 233 Figura 6.46 - Fator de Segurança versus coesão - altura constante de 5,00 m e modificação da inclinação baseada na Seção B-B'- utilizando o método de Bishop Simplificado. 234 Figura 6.47 - Parâmetros hidráulicos do solo (a) função condutividade hidráulica e (b) curva de retenção da água no solo. 235 Figura 6.48 - Distribuição da pressão neutra do Modelo 1 para (a) steady-state (06/03/2015) e (b) $08 / 03 / 2015$. 237

Figura 6.49 - Análise da estabilidade de talude para o Modelo 1 utilizando o método determinístico de (a) Bishop Simplificado e (b) Janbu. 238 Figura 6.50 - Distribuição da pressão neutra do Modelo 2 para (a) steady-state (06/03/2015) e (b) $08 / 03 / 2015$. 239

Figura 6.51 - Análise da estabilidade de talude para o Modelo 2 utilizando o método determinístico de (a) Bishop Simplificado e (b) Janbu. 240 Figura 6.52 - Distribuição da pressão neutra do Modelo 3 para (a) steady-state (06/03/2015) e (b) $08 / 03 / 2015$. 241

Figura 6.53 - Análise da estabilidade de talude para o Modelo 3 utilizando o método determinístico de (a) Bishop Simplificado e (b) Janbu. 242 
Figura 6.54 - Distribuição da pressão neutra do Modelo 1 para (a) o pé, (b) a face e (c) a crista da seção.

Figura 6.55 - Distribuição da pressão neutra do Modelo 2 para (a) o pé, (b) a face e (c) a crista da seção.

Figura 6.56 - Distribuição da pressão neutra do Modelo 3 para (a) o pé, (b) a face e (c) a crista da seção.

Figura 6.57 - Distribuição da pressão neutra para o steady-state (15/11/2015).

Figura 6.58 - Distribuição da pressão neutra para a precipitação pluviométrica de $14,0 \mathrm{~mm}$ (dia 16/11/2015).

Figura 6.59 - Distribuição da pressão neutra para a precipitação pluviométrica de 8,6 mm (dia $17 / 11 / 2015)$ 246

Figura 6.60 - Distribuição da pressão neutra para a precipitação pluviométrica de $53,5 \mathrm{~mm}$ (dia 19/11/2015). 246

Figura 6.61 - Distribuição da pressão neutra para a precipitação pluviométrica de $30,0 \mathrm{~mm}$ (dia 22/11/2015).

Figura 6.62 - Distribuição da pressão neutra para a precipitação pluviométrica de 35,6 mm (dia 23/11/2015).

Figura 6.63 - Distribuição da pressão neutra para a precipitação pluviométrica de $15,0 \mathrm{~mm}$ (dia 24/11/2015).

Figura 6.64 - Distribuição da pressão neutra para a precipitação pluviométrica de $93,0 \mathrm{~mm}$ (dia 01/12/2015)

Figura 6.65 - Distribuição da pressão neutra sem precipitação pluviométrica (dia 02/12/2015).

Figura 6.66 - Variação do fator de segurança para o período analisado (16/11/2015 a 02/12/2015) a partir dos métodos determinísticos de Bishop Simplificado e Janbu. 249 



\section{LISTA DE TABELAS}

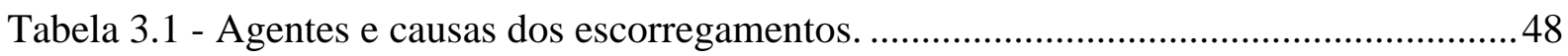

Tabela 3.2 - Fatores deflagradores dos movimentos de massa...........................................49

Tabela 3.3 - Principais causas dos movimentos de massa e seus fenômenos na natureza. .....49

Tabela 3.4 - Classificação dos movimentos de massa segundo Varnes (1978).......................52

Tabela 3.5 - Classificação dos movimentos de massa segundo Augusto Filho (1992)...........53

Tabela 3.6 - Condição de estabilidade do talude em função do Coeficiente de Segurança. ....56

Tabela 3.7 - Fatores de Segurança mínimos para deslizamentos. ..........................................56

Tabela 3.8 - Métodos determinísticos de estabilidade de talude. ...........................................57

Tabela 3.9 - Equações e variáveis associadas ao Método das Fatias. .....................................59

Tabela 3.10 - Condições satisfeitas do equilíbrio estático pelos Métodos do Equilíbrio Limite.

Tabela 3.11 - Técnicas de ensaio para medida de sucção. …................................................ 94

Tabela 3.12 - Equações matemáticas da curva de retenção da água do solo...........................97

Tabela 3.13 - Equações empíricas para obtenção da condutividade hidráulica não saturada.106

Tabela 3.14 - Equações de tensão efetiva para solo não saturado......................................... 109

Tabela 3.15 - Combinações possíveis das variáveis de estado de tensão para um solo não saturado

Tabela 4.1 - Identificação das amostras deformadas de solo coletadas nos furos de sondagem.

Tabela 4.2 - Identificação das amostra indeformadas de solo coletadas no talude................127

Tabela 4.3 - Estimativa do parâmetro $\alpha p g$. ...................................................................... 139

Tabela 4.4 - Profundidade de instalação dos tensiômetros nas duas seções do talude............153

Tabela 4.5 - Pontos de referência dos tensiômetros para as duas seções geológico-geotécnicas.

Tabela 6.1 - Composição textural do solo coletado do furo de sondagem (ST3) da Seção AA'.

Tabela 6.2 - Composição textural do solo coletado do furo de sondagem (ST4) da Seção B-

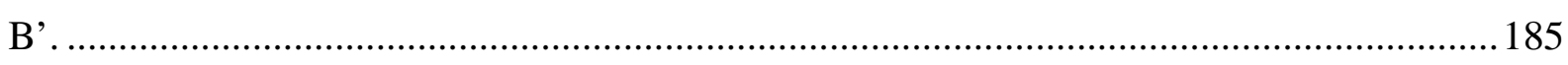

Tabela 6.3 - Curva de retenção da água no solo - parâmetros de ajuste. .............................. 187

Tabela 6.4 - Ensaio de permeabilidade em laboratório - características, índices físicos e condutividade hidráulica saturada dos corpos de prova. 
Tabela 6.5 - Ensaio de permeabilidade em laboratório - condutividade hidráulica saturada dos corpos de prova alguns índices físicos após o ensaio.

Tabela 6.6 - Condutividade hidráulica saturada de campo - permeâmetro Guelph.

Tabela 6.7 - Função condutividade hidráulica não saturada - permeâmetro Guelph.

Tabela 6.8 - Ensaio de erodibilidade - características dos corpos de prova, índice de absorção de água, índice de perda de massa por imersão e índice de erodibilidade.

Tabela 6.9 - Características e índices físicos dos corpos de prova - ensaio adensado-drenado com solo saturado.

Tabela 6.10 - Parâmetros efetivos de ajuste - ensaio adensado-drenado com solo saturado. 198 Tabela 6.11 - Características e índices físicos dos corpos de prova - ensaio para determinação da resistência do solo com teor de umidade natural. 201

Tabela 6.12 - Sucção e teor de umidade gravimétrico dos corpos de prova após o encerramento do ensaio para determinação da resistência do solo com teor de umidade natural. 201

Tabela 6.13 - Parâmetros efetivos de ajuste e previsão da resistência ao cisalhamento do solo não saturado utilizando método de Vilar (2007) - ensaio determinação da resistência do solo com teor de umidade natural. 203

Tabela 6.14 - Características e índices físicos dos corpos de prova - ensaio adensado-drenado com solo não saturado (sucção de $30 \mathrm{kPa}$ ). 206

Tabela 6.15 - Parâmetros efetivos de ajuste - ensaio adensado-drenado com solo não saturado (sucção de $30 \mathrm{kPa}$ ). 206

Tabela 6.16 - Teor de umidade gravimétrico dos corpos de prova após o encerramento do ensaio adensado-drenado com solo não saturado. 207 Tabela 6.17 - Parâmetros mecânicos do solo utilizados nas modelagens numéricas - nível de estabilidade.

Tabela 6.18 - Parâmetros mecânicos do solo utilizados nas modelagens numéricas modificação geometria.

Tabela 6.19 - Parâmetros mecânicos do solo utilizados nas modelagens numéricas infiltração da água e estabilidade de talude. 236

Tabela 6.20 - Período de monitoramento da precipitação pluviométrica diária (mm)......... 236

Tabela 6.21 - Período de monitoramento da sucção matricial $(\mathrm{kPa})$................................... 236

Tabela 6.22 - Período de monitoramento da precipitação pluviométrica diária (mm)......... 244

Tabela 6.23 - Período de monitoramento da sucção matricial (kPa) . ................................... 244 
Tabela 0.1 - Índices físicos dos corpos de prova empregados na técnica do papel filtro para amostra indeformada retirada no pé do talude - Trajetória de Secagem. 279

Tabela 0.2 - Índices físicos dos corpos de prova empregados na técnica do papel filtro para amostra indeformada retirada no pé do talude - Trajetória de Umedecimento. .....................280 Tabela 0.3 - Índices físicos dos corpos de prova empregados no ensaio de Erodibilidade. ..283 



\section{LISTA DE ABREVIATURAS}

\begin{tabular}{|c|c|c|}
\hline $\mathrm{ABNT}$ & - & Associação Brasileira de Normas Técnicas \\
\hline $\mathrm{AC}$ & - & Amostra da crista do talude \\
\hline AI & - & Amostra indeformada \\
\hline $\mathrm{AP}$ & - & Amostra do pé do talude \\
\hline ANA & - & Agência Nacional de Águas \\
\hline BDMEP & - & Banco de Dados Meteorológicos para Ensino e Pesquisa \\
\hline $\mathrm{C}$ & - & Capacidade de infiltração \\
\hline $\mathrm{CD}$ & - & Adensado-drenado \\
\hline $\mathrm{CU}$ & - & Adensado-não drenado \\
\hline $\mathrm{DER} / \mathrm{SP}$ & - & Departamento de Estradas de Rodagem do Estado de São Paulo \\
\hline EESC & - & Escola de Engenharia de São Carlos \\
\hline ES & - & Escoamento superficial \\
\hline $\mathrm{i}$ & - & Taxa de infiltração \\
\hline I & - & Infiltração acumulada \\
\hline IAEG & - & International Association for Engineering Geology \\
\hline IBGE & - & Instituto Brasileiro de Geografia e Estatística \\
\hline INMET & - & Instituto Nacional de Meteorologia \\
\hline ISSMFE & - & $\begin{array}{l}\text { Conferência Internacional de Mecânica dos Solos e Engenharia de } \\
\text { Fundações }\end{array}$ \\
\hline NBR & - & Norma Brasileira \\
\hline PERISI & - & Avaliação preliminar da instabilidade de talude induzida pela chuva \\
\hline SIGRH & - & $\begin{array}{l}\text { Sistema Integrado de Gerenciamento de Recursos Hídricos do Estado } \\
\text { de São Paulo }\end{array}$ \\
\hline ST & - & Sondagem a trado \\
\hline SWRC & - & Soil water retention curve \\
\hline UGRHI & - & Unidades de Gerenciamento de Recursos Hídricos \\
\hline UGRHI-13 & - & Unidade de Gerenciamento de Recursos Hídricos 13 \\
\hline UGRHI-TJ & - & Unidade de Gerenciamento de Recursos Hídricos do Tietê-Jacaré \\
\hline USGS & - & United State Geological Survey \\
\hline USP & - & Universidade de São Paulo \\
\hline UTM & - & Universal Transversa de Mercator \\
\hline
\end{tabular}





\section{LISTA DE SIGLAS}

\section{Símbolos do Alfabeto Latino}

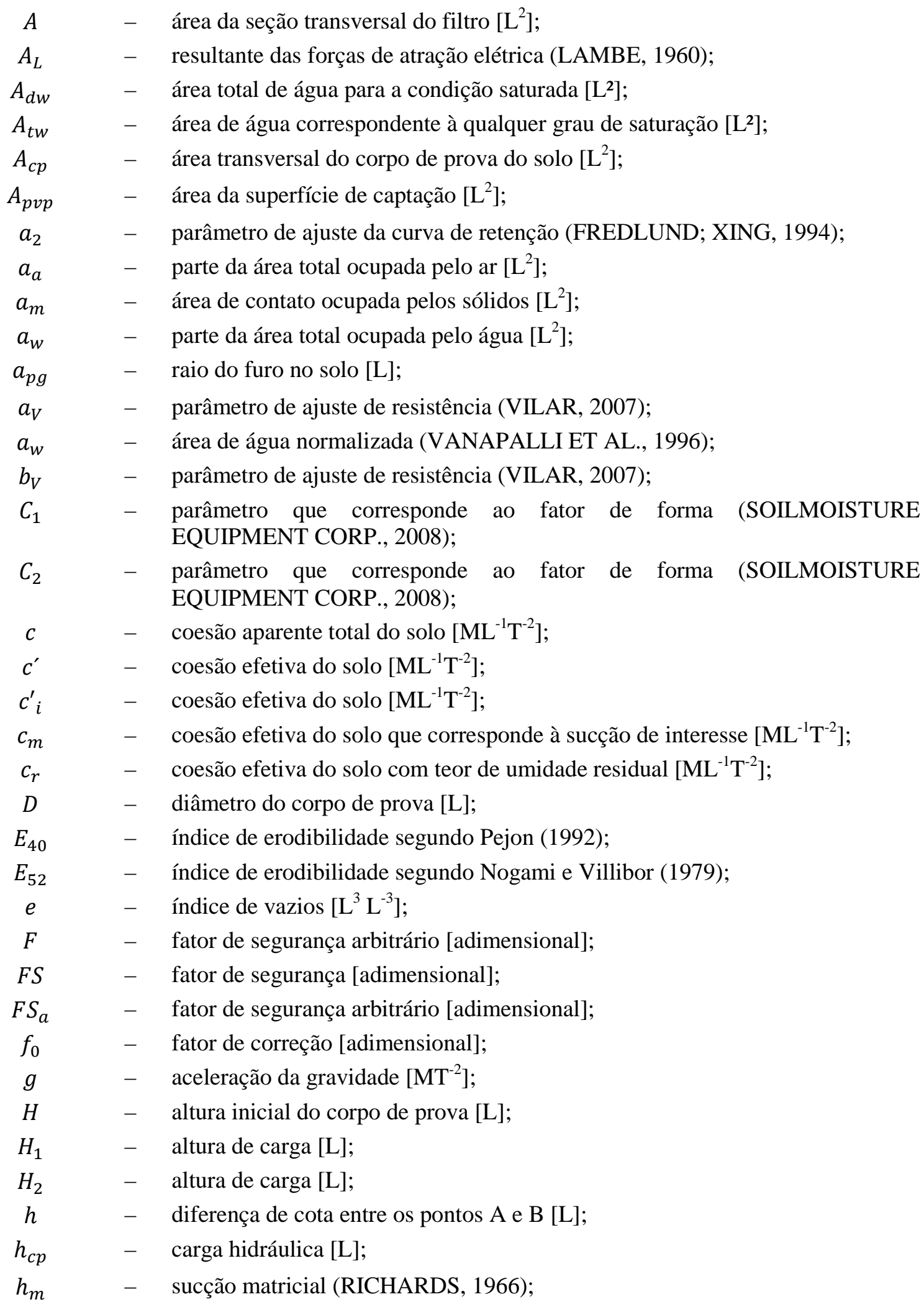




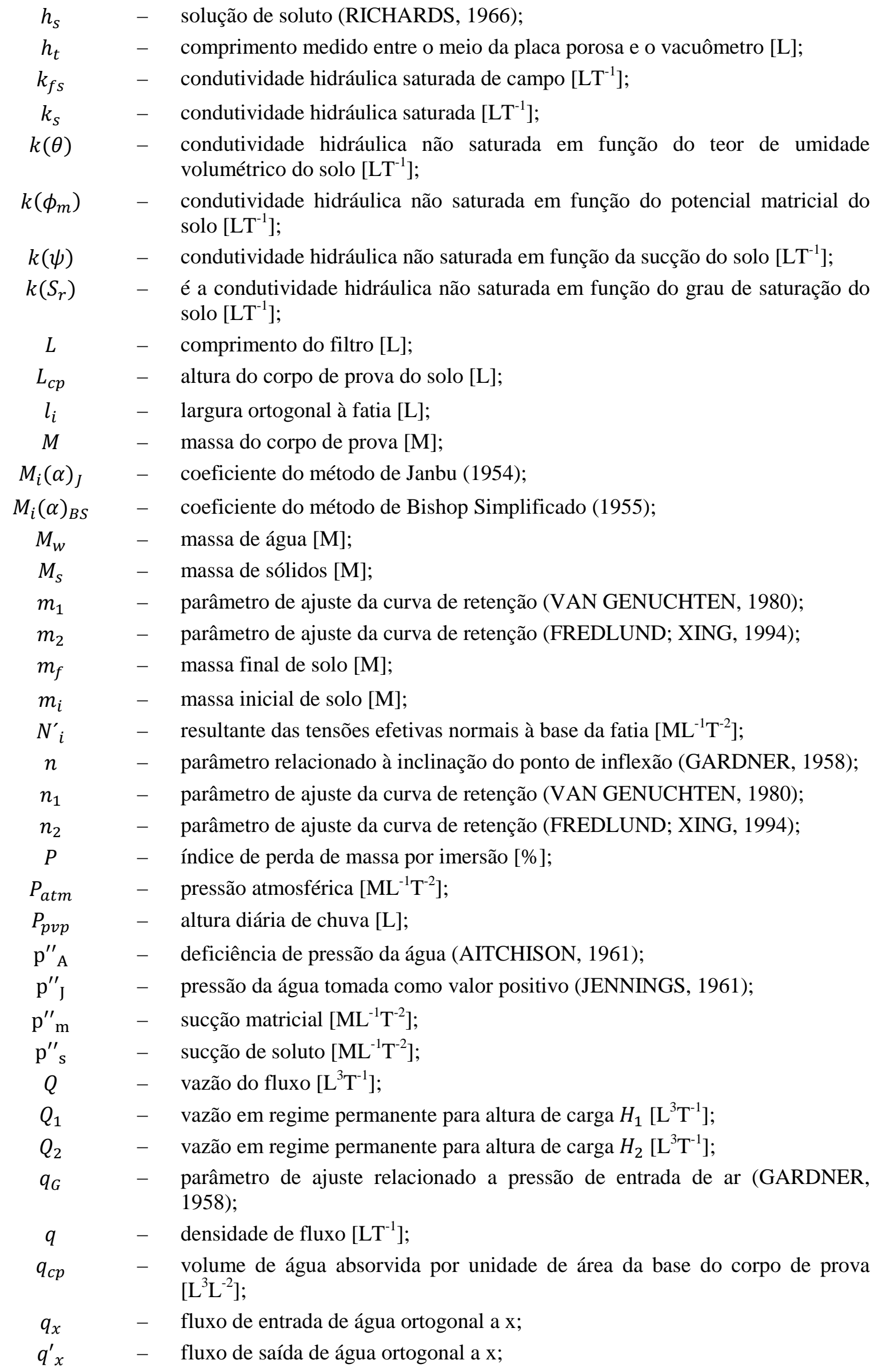




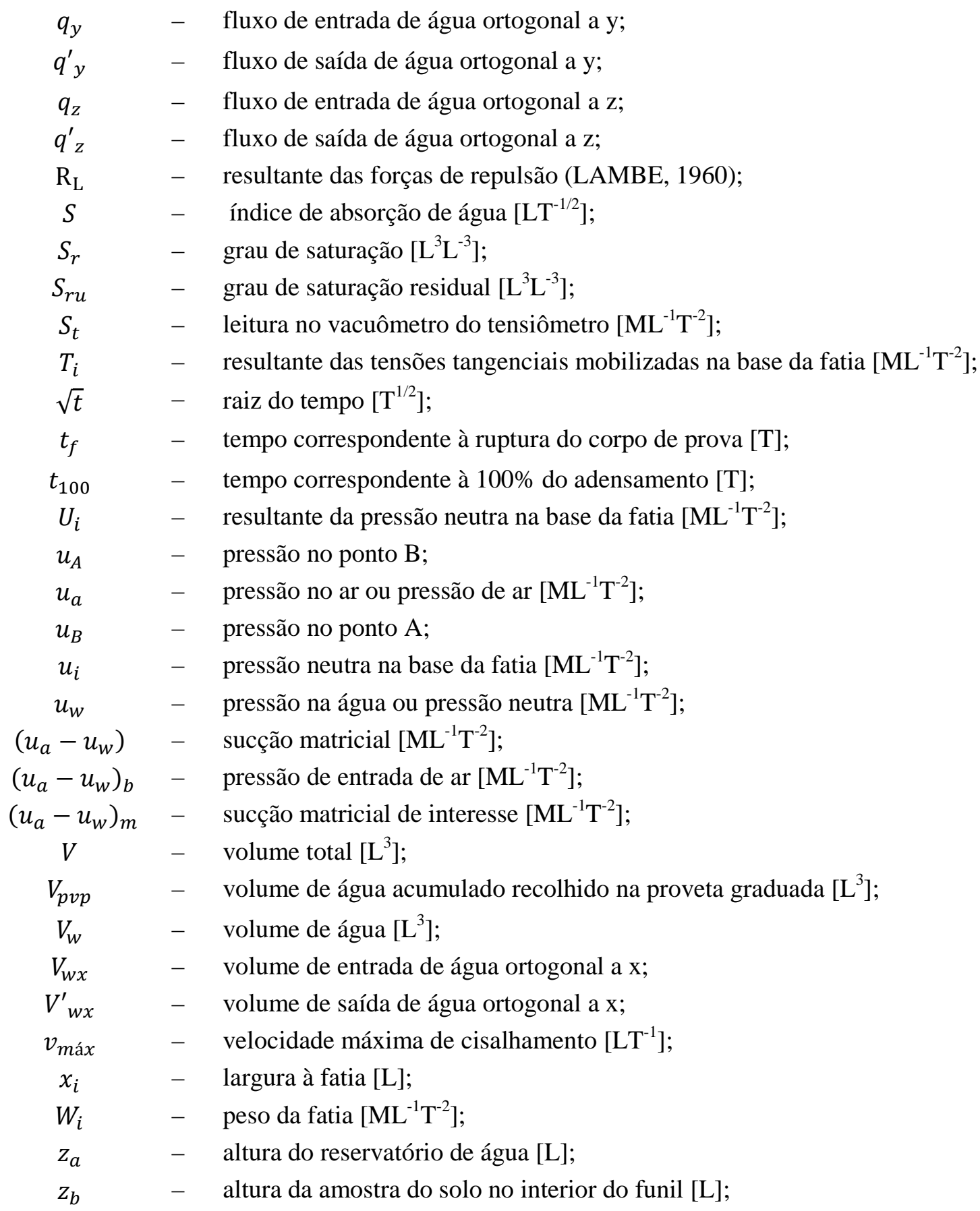

\section{Símbolos do Alfabeto Grego}

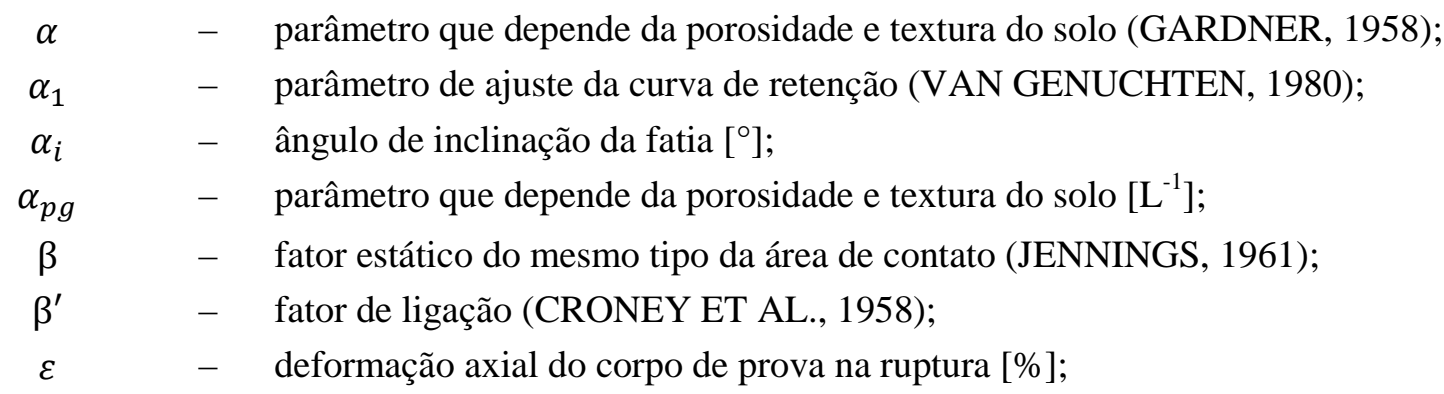




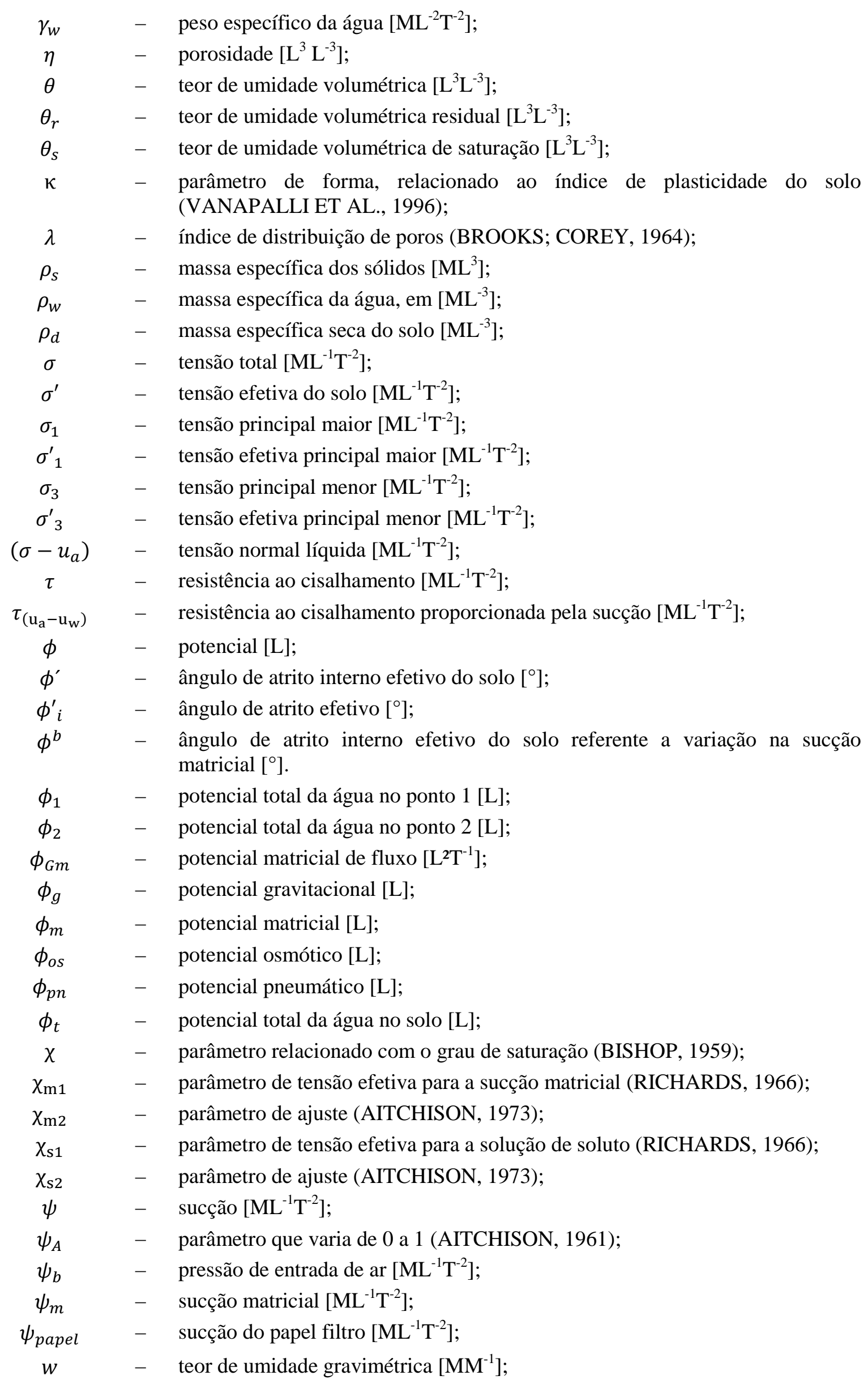


$w_{\text {mold }} \quad-\quad$ teor de umidade gravimétrico de moldagem $\left[\mathrm{MM}^{-1}\right]$;

$w_{\text {papel }} \quad-\quad$ teor de umidade gravimétrica do papel filtro $\left[\mathrm{MM}^{-1}\right]$;

$w_{r} \quad-\quad$ teor de umidade gravimétrico residual $\left[\mathrm{MM}^{-1}\right]$;

$w_{S} \quad-\quad$ teor de umidade gravimétrico de saturação $\left[\mathrm{MM}^{-1}\right]$; 



\section{SUMÁRIO}

1. Introdução

2. Hipóteses de trabalho e objetivos

3. Revisão bibliográfica 47

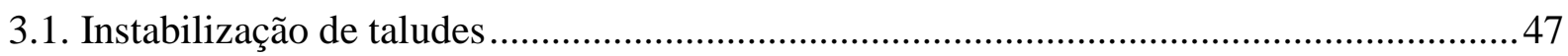

3.1.1. Características gerais e fatores condicionantes dos movimentos de massa....................47

3.1.2. Sistemas de classificação de movimentos de massa......................................................50

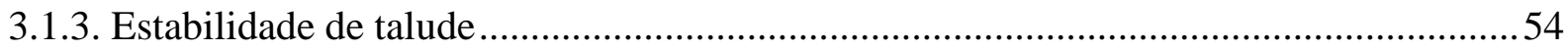

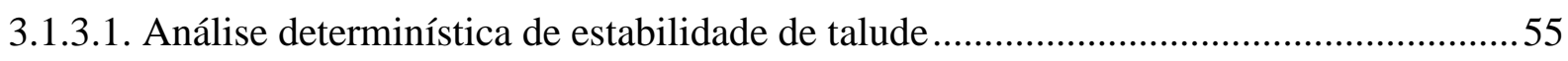

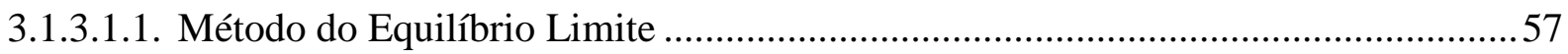

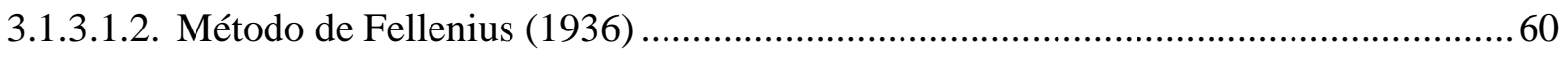

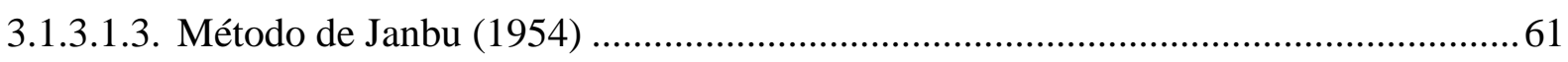

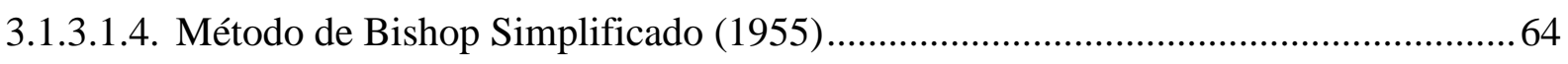

3.1.4. Pesquisas no tema estabilidade de talude em solo não saturado ..................................65

3.2. Conceitos e aspectos gerais da mecânica dos solos não saturados ................................... 86

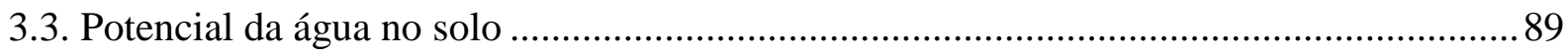

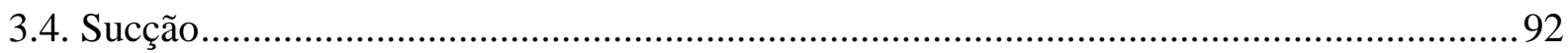

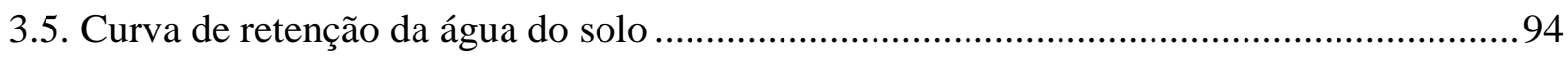

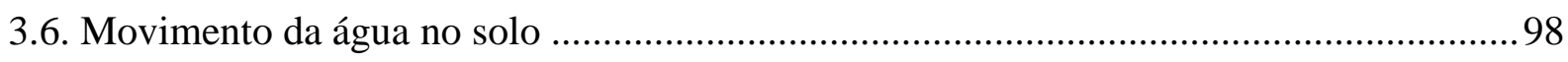

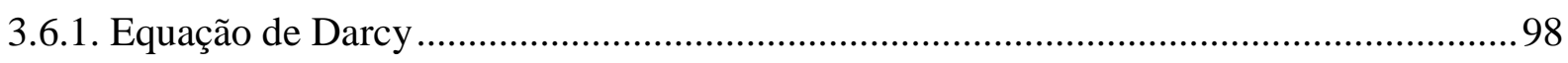

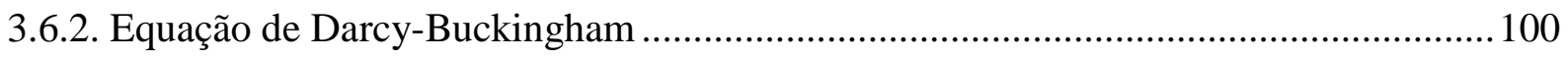

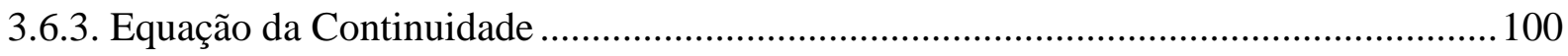

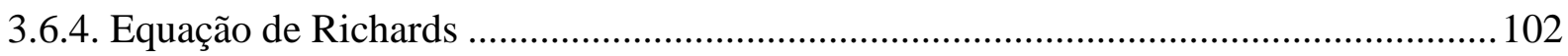

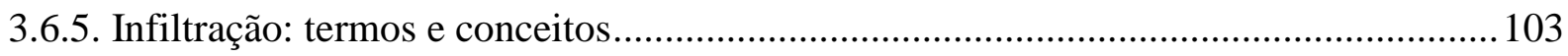

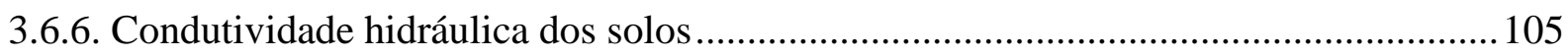

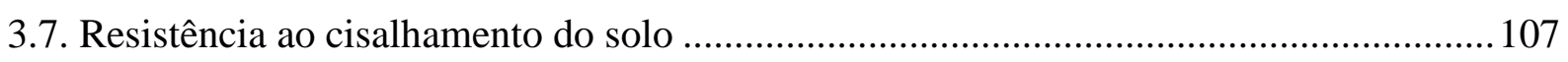

3.7.1. Tensão efetiva, estado de tensão e variáveis de estado de tensão do solo.................... 108

3.7.2. Envoltória de resistência ao cisalhamento para um solo não saturado.........................110

3.7.3. Métodos de previsão da resistência ao cisalhamento do solo não saturado ..................116

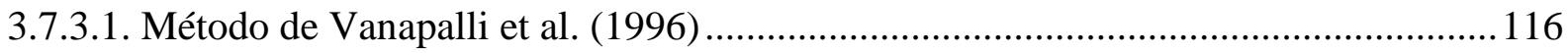


4. Materiais e métodos

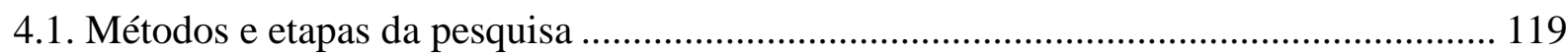

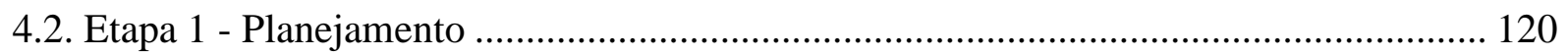

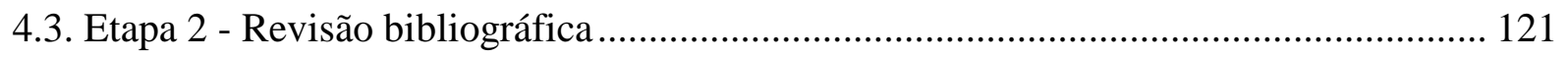

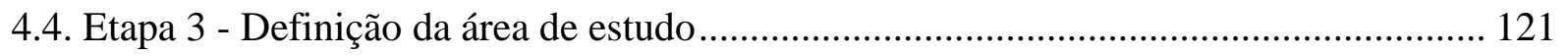

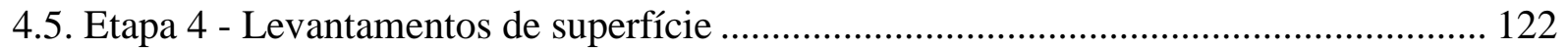

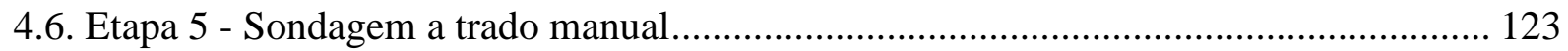

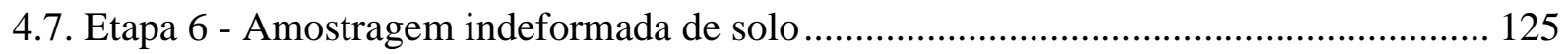

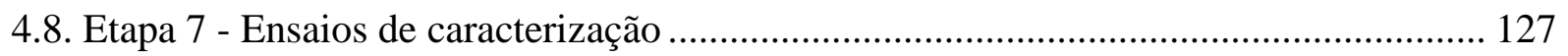

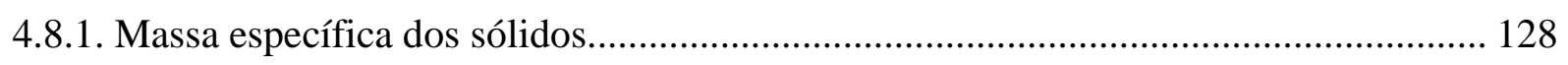

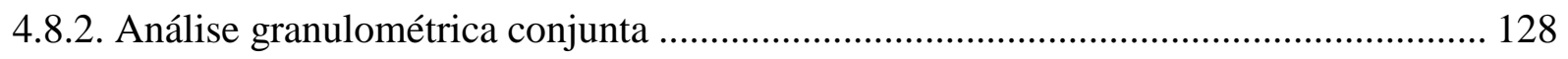

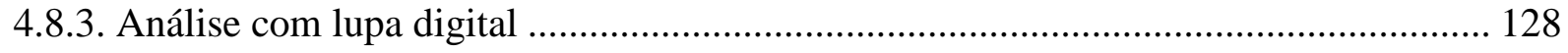

4.8.4. Ensaios para determinação da curva de retenção da água no solo (SWRC) ................ 129

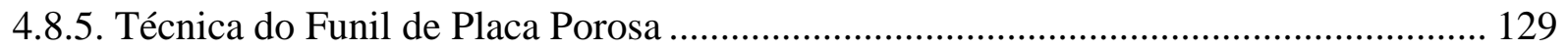

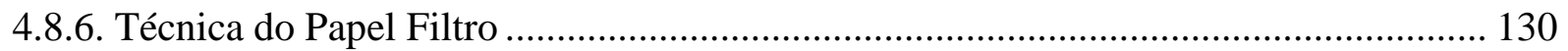

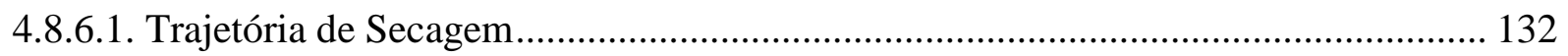

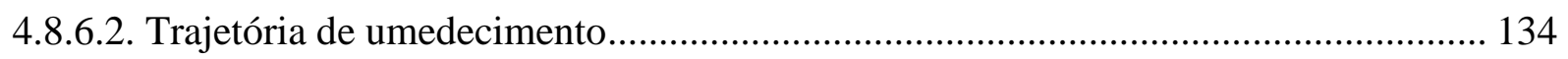

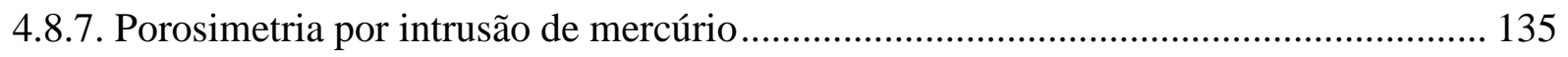

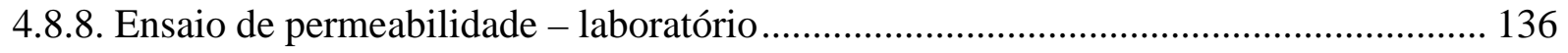

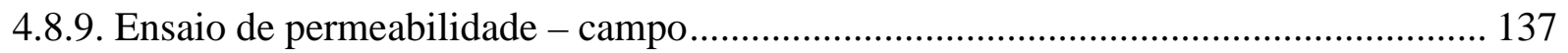

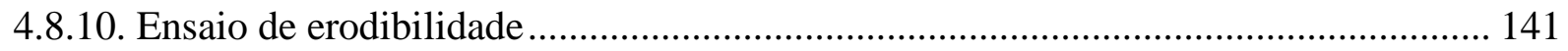

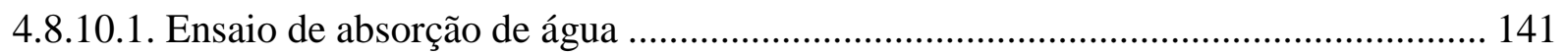

4.8.10.2. Ensaio de perda de massa por imersão............................................................... 142

4.8.11. Ensaios de Resistência ao Cisalhamento ................................................................... 144

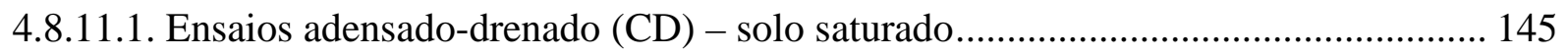

4.8.11.2. Ensaio de compressão triaxial para determinação da resistência do solo com teor de

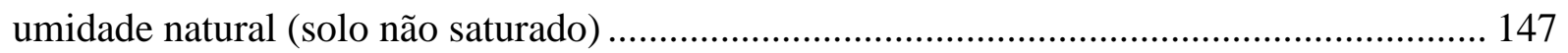

4.8.11.3. Ensaios adensado-drenado (CD) - solo não saturado.............................................. 148

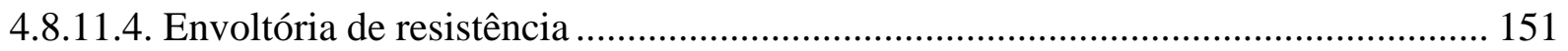

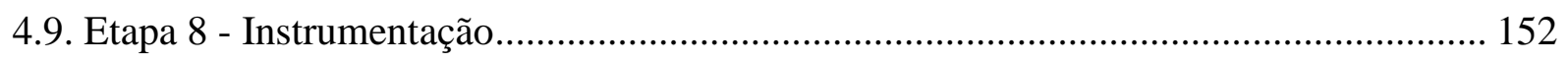

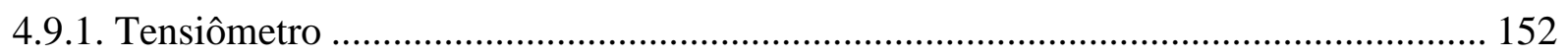

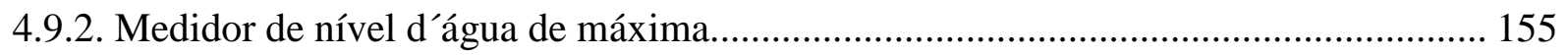




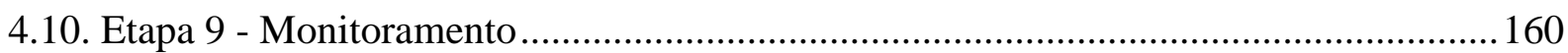

4.11. Etapa 10 - Integração e análise dos resultados ......................................................... 162

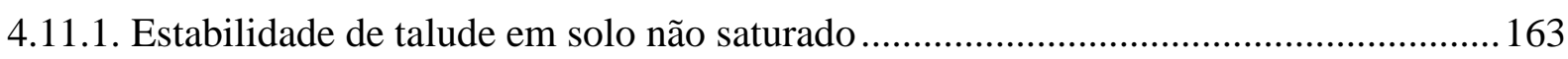

4.11.2. Análises paramétricas da infiltração da água no solo............................................... 163

4.11.2.1. Geometria das seções geológico-geotécnicas........................................................ 164

4.11.2.2. Discretização da malha de elementos finitos........................................................... 166

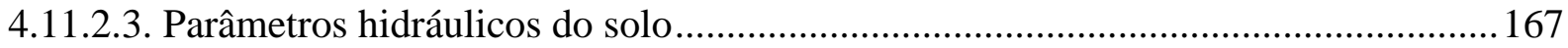

4.11.2.4. Condições de contorno - análises de fluxo ........................................................ 168

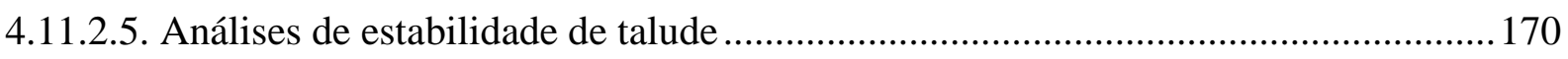

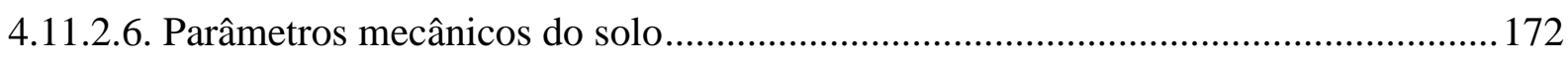

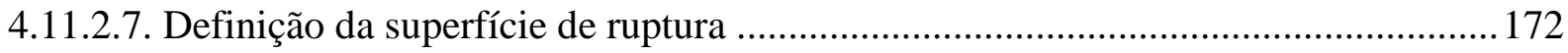

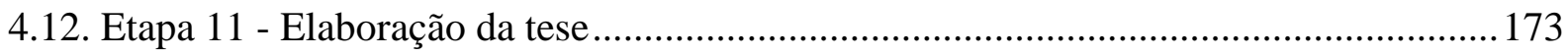

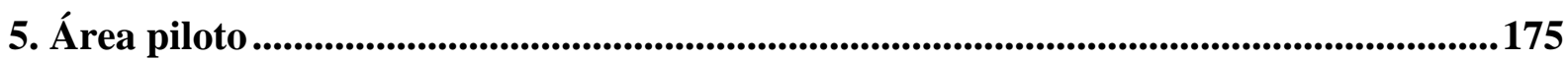

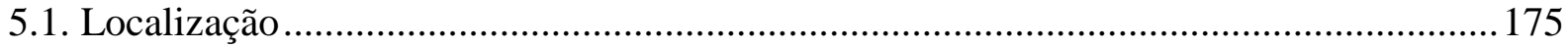

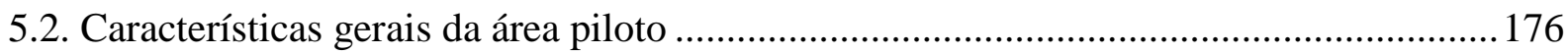

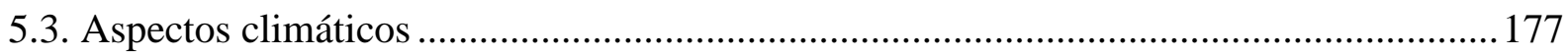

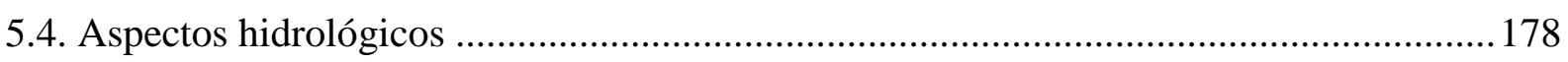

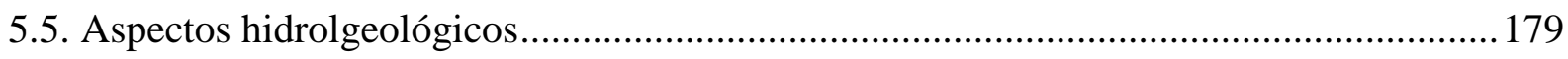

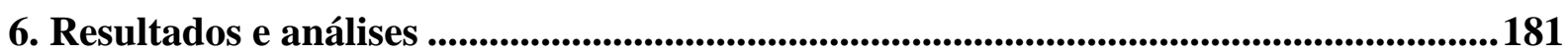

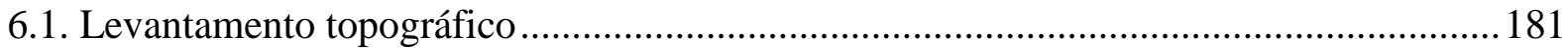

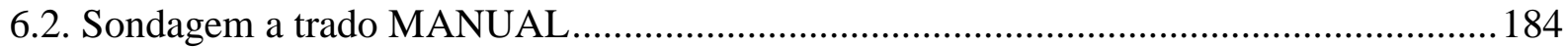

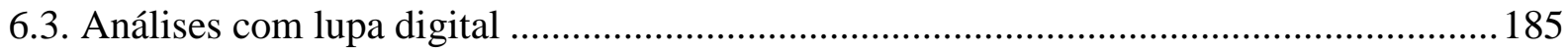

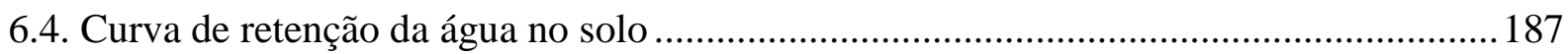

6.5. Ensaio de porosimetria por intrusão de mercúrio ......................................................... 188

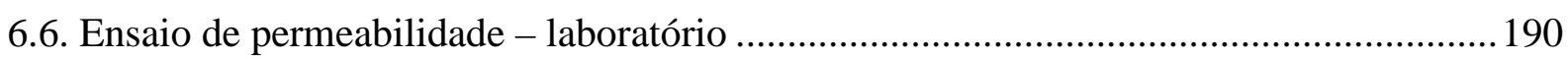

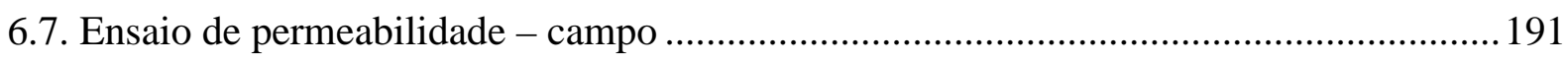

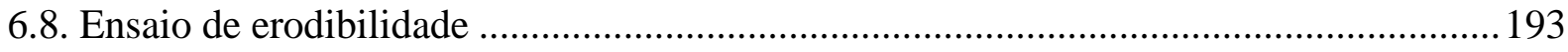

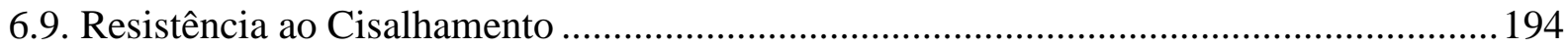

6.9.1. Ensaios adensado-drenado (CD) com solo saturado ................................................ 195

6.9.2. Ensaios para determinação da resistência do solo com teor de umidade natural (solo não saturado) 
6.9.3. Ensaios adensado-drenado (CD) com solo não saturado

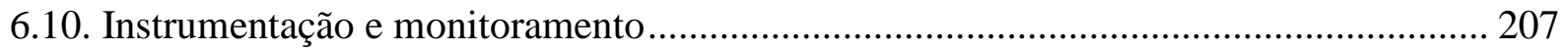

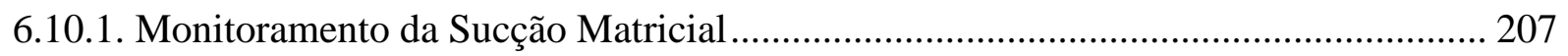

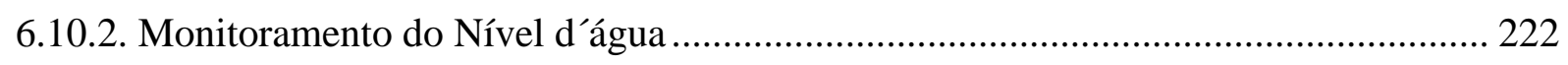

6.10.3. Monitoramento das Precipitações Pluviométricas .................................................. 222

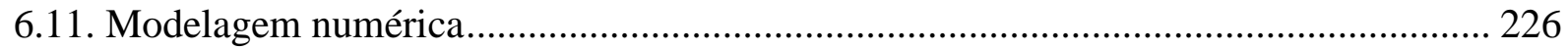

6.11.1. Análise numérica para avaliar o nível de estabilidade das seções investigadas ........ 226

6.11.2. Análise numérica para analisar a estabilidade do talude a partir da modificação na geometria das seções

6.11.3. Análise numérica da infiltração da água da chuva acoplada com análise de estabilidade de talude 234

6.11.3.1. Modelagem numérica do primeiro evento pluviométrico...................................... 236

6.11.3.2. Modelagem numérica do segundo evento pluviométrico ..................................... 243

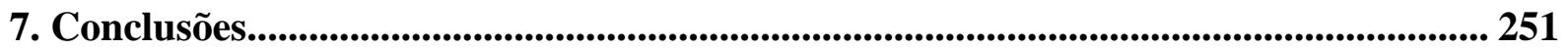

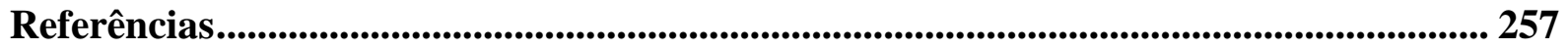

APÊNDICE A - Procedimentos utilizados no software computacional GeoStudio 2012

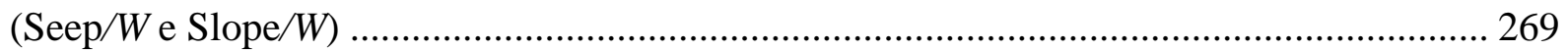

APÊNDICE B - Planta Topográfica Completa da Área Piloto ............................................ 273

APÊNDICE C - Índices físicos dos corpos de prova empregados na técnica do papel filtro 277 APÊNDICE D - Índices físicos dos corpos de prova empregados no ensaio de erodibilidade 


\section{INTRODUÇÃO}

Um grande número de pesquisas na área de estabilidade de taludes vem sendo desenvolvido nas últimas décadas ao redor do mundo, muitas delas estando concentradas no estudo de taludes em solo não saturado, especialmente em países com clima tropical ou subtropical. O processo de instabilização de um maciço terroso pode ser condicionado por fatores geológicos, hidrológicos, climáticos, antrópicos e por agentes deflagradores, merecendo grande destaque a água, que usualmente atua como principal agente deflagrador natural nesse processo.

Inúmeros pesquisadores estudam como os efeitos da infiltração da água da chuva no solo podem ser prejudiciais na estabilidade do talude terroso, colaborando para o seu processo de instabilização. No caso do talude em que o solo encontra-se na condição não saturada surge o efeito da sucção matricial, termo muito utilizado para expressar a pressão negativa da água intersticial do solo. A sucção matricial varia em função do tempo e influencia diretamente alguns parâmetros do solo como a resistência ao cisalhamento e a condutividade hidráulica não saturada. Portanto, em um talude de solo não saturado, a sucção matricial tende a diminuir ou até mesmo anular-se durante a infiltração da água da chuva no solo desse talude. Se isso ocorrer, a coesão aparente do solo sofre um decréscimo, ou mesmo se anula, acarretando na diminuição da resistência ao cisalhamento do solo e, consequemente, na redução do nível de estabilidade do talude, podendo até condicionar sua ruptura. 
Alguns autores (AU, 1998; CHO; LEE, 2001; GASMO; RAHARDJO; LEONG, 2000; GUI; WU, 2014; RAHARDJO; LEONG; REZAUR, 2002; RAHARDJO et al., 2005; RAHIMI; RAHARDJO; LEONG, 2011; TEIXEIRA, 2014; TSAPARAS et al. 2002; ZAMBRANA, 2014) buscam estabelecer uma relação entre a infiltração da água da chuva e a deflagração de escorregamentos de encostas ou de taludes na condição não saturada enquanto outros autores (CAMPOS, 1984; LUMB, 1975; NG; SHI, 1998; RAHARDJO et al., 1995; RAHARDJO et al., 2007) investigam a influência da variabilidade dos parâmetros como sucção matricial, resistência ao cisalhamento e coesão aparente na estabilidade de talude em solo não saturado. No entanto, como os ensaios laboratoriais com solo não saturado são mais complexos e o monitoramento da instrumentação de campo demanda tempo, algumas pesquisas nessa área acabam desprezando ou até mesmo simplificando seus estudos na quantificação dos efeitos da sucção.

A infiltração da água da chuva pode provocar alguns efeitos no solo não saturado tais como a diminuição na pressão negativa da água, o aumento do teor de umidade, o acréscimo do peso específico do solo, o decréscimo da sucção do solo, a redução da resistência ao cisalhamento do solo e o aumento da condutividade hidráulica do solo. Além dos efeitos mencionados anteriormente, também é importante compreender como a variação sazonal da sucção ocasiona a alteração do teor de umidade do solo em função do regime pluviométrico anual.

Diante dos fatos expostos anteriormente, nota-se a importância do estudo dos efeitos da infiltração da água no solo bem como sua contribuição na estabilidade do talude. Esse estudo pode ser realizado através de modelagens numéricas em programas computacionais específicos da área, utilizando como dados de entrada os parâmetros obtidos ou coletados na área do talude. Porém, nesse caso, é conveniente e recomendado ter um levantamento abrangente e detalhado acerca das características físico-químicas dos parâmetros do solo, do monitoramento da instrumentação de campo e da geometria das seções geológico-geotécnicas do talude; de maneira que não seja necessário fazer simplificações ou adotar valores para alguns parâmetros.

Nesse contexto, o presente trabalho tem por finalidade investigar os mecanismos instabilizadores atuantes em um talude de solo não saturado a partir de análises numéricas feitas com o uso do Seep/W e do Slope/W, ambos integrantes do software computacional GeoStudio 2012. Todos os dados de entrada empregados nas análises numéricas foram baseados nos resultados das etapas de campo e laboratório, as quais foram feitas durante todo o desenvolvimento desse trabalho. 
Os parâmetros e dados resultantes das etapas anteriores à da análise numérica correspondem à investigação geológico-geotécnica de superfície (levantamento topográfico de detalhe) e de subsuperfície (sondagem a trado e poços com coleta de amostras); aos ensaios de laboratório e campo (análise granulométrica conjunta, massa específica dos sólidos, porosimetria, erodibilidade, permeabilidade, ensaio de compressão triaxial); à instrumentação de campo e monitoramento (pluviômetro, piezômetro e tensiômetro). A análise numérica foi desenvolvida utilizando o método dos elementos finitos por meio da simulação de fluxo transiente no Seep/ $W$ e em seguida, foi analisada a estabilidade do talude a partir do uso de dois métodos da fatia no Slope/W.

A área piloto da pesquisa abrange um setor de taludes de corte localizado na SP215 Rodovia Luis Augusto de Oliveira, km 179+300 LE, município de Ribeirão Bonito, Estado de São Paulo. Na área investigada ocorrem solos residuais dos arenitos eólicos da Formação Botucatu, (Grupo São Bento, Bacia Sedimentar do Paraná) de idade jurássico-cretácea. Eles apresentam textura arenosa fina a média e com baixa percentagem de finos.

A apresentação dessa Tese de Doutorado está estruturada em 7 Capítulos, os quais encontram-se todos descritos mais detalhadamente a seguir.

O Capítulo 1 apresenta uma breve introdução acerca do tema estabilidade de talude em solo não saturado, mencionando sobre o processo de infiltração e o acréscimo no nível de estabilidade devido aos efeitos da sucção.

O Capítulo 2 expõe as hipóteses inicialmente adotadas nessa pesquisa e os objetivos propostos para realização do presente trabalho.

O Capítulo 3 apresenta a revisão bibliográfica abrangendo um breve resumo dos principais tópicos abordados neste trabalho, estando divididos em dois grandes grupos: instabilidade de talude e mecânica dos solos não saturados. No primeiro grupo é basicamente comentado sobre as características gerais e fatores condicionantes dos movimentos de massa, sistema de classificação de movimento de massa, métodos de análise de estabilidade de talude e uma revisão acerca de diversos trabalhos científicos nacionais e internacionais na área de talude em solo não saturado. No segundo grupo é comentado sobre os conceitos e aspectos gerais da mecânica dos solos não saturados, curva de retenção da água do solo, infiltração da água no solo, condutividade hidráulica dos solos e resistência ao cisalhamento do solo.

O Capítulo 4 sintetiza os materiais e métodos utilizados na pesquisa incluindo a escolha da área piloto, ensaios de laboratório, ensaios de campo, instalação da instrumentação de campo e seu monitoramento além das análises numéricas de fluxo e de estabilidade. 
O Capítulo 5 descreve a área piloto e menciona suas principais características, destacando as características geológicas, pluviométricas, hidrológicas locais.

O Capítulo 6 apresenta e discute os resultados dessa pesquisa desde os dados relativos ao levantamento de campo, caracterização do solo (análise granulométrica conjunta, massa específica dos solos, porosimetria, erodibilidade), parâmetro hidráulico (laboratório e campo), parâmetro mecânico (solo saturado e não saturado) até a análise de fluxo (permanente e transiente) e a análise de estabilidade de talude.

O Capítulo 7 expõe as conclusões acerca do trabalho, verifica as hipóteses iniciais adotadas nesse trabalho e deixa algumas sugestões para futuros trabalhos.

Após o Capítulo 7, são identificadas e listadas todas as referências bibliográficas citadas ao longo do presente trabalho. 


\section{HIPÓTESES DE TRABALHO E OBJETIVOS}

As hipóteses de trabalho que direcionaram a presente pesquisa foram:

- Eventos pluviométricos podem provocar o aumento do grau de saturação dos solos, com a consequente redução da tensão de sucção e da parcela de coesão aparente em taxas suficientes para a deflagração de deslizamentos nos taludes estudados sem a atuação de nível d’água e pressões neutras positivas;

- Variações texturais presentes nos solos do talude estudado e as consequentes anisotropias na condutividade hidráulica dos mesmos podem gerar condições favoráveis para a formação de lençóis suspensos, pressões neutras transientes e também acarretar a ruptura do talude.

Os objetivos dessa pesquisa foram definidos a partir das hipóteses de trabalho mencionadas anteriormente.

O presente trabalho tem como principal objetivo contribuir com o aprimoramento dos modelos teóricos e empíricos que relacionam a precipitação pluviométrica, o grau de saturação e o deslizamento de taludes de solos residuais arenosos.

Diante do objetivo principal deste trabalho foram estabelecidos cinco objetivos específicos, tais como:

- definir os tipos e os mecanismos de deslizamento de solo presentes na área de estudo; 
- definir os parâmetros geotécnicos e de resistência do solo em diferentes condições de saturação/de sucção;

- analisar a infiltração, a formação e a evolução em profundidade das "frentes de saturação";

- analisar a estabilidade do talude simulando diferentes condições e variáveis caracterizadas em investigações de campo e ensaios de laboratório;

- definir intensidades pluviométricas mínimas para deflagração dos deslizamentos de solo estudados e seus tempos de retorno/probabilidade de ocorrência. 


\section{REVISÃO BIBLIOGRÁFICA}

Este capítulo tem como propósito apresentar uma breve síntese relacionada aos conceitos presentes na literatura técnico-científica sobre o tema desta pesquisa. A revisão bibliográfica abrange basicamente os tópicos de instabilização de taludes e de mecânica dos solos não saturados.

\subsection{INSTABILIZAÇÃO DE TALUDES}

\subsubsection{Características gerais e fatores condicionantes dos movimentos de massa}

Os movimentos de massa basicamente se caracterizam por serem processos naturais e deslocarem um determinado volume de material, os quais podem ser acelerados devido às particularidades do meio físico ou apenas pela ação antrópica no ambiente. Guidicini e Nieble (1976) mencionam que os movimentos de massa são genericamente denominados de escorregamentos pelos estudiosos de mecânica de solos enquanto que Gerscovich (2012) relata que a literatura usualmente aborda o movimento de massa como processos associados a problemas de instabilidade de encostas

De acordo com United State Geological Survey (2004), o termo escorregamento descreve uma imensa variedade de processos que resultam em movimento descendente e externo à encosta, podendo estes processos serem basicamente diferenciados pelos tipos de materiais envolvidos e pela forma do movimento. 
De maneira geral, os taludes e as encostas sempre se apresentam em um estado de equilíbrio dinâmico na natureza, uma vez que a ocorrência de movimentos de massa está diretamente associada com este equilíbrio, tendo como principal função a adaptação do meio físico às novas condições superficiais (WICANDER; MONROE, 2009). Dessa forma, podese dizer que os fatores condicionantes de movimentos de massa na natureza são controlados por uma série de acontecimentos, tornando-se impossível identificar a atuação individual deles em um determinado talude ou encosta, visto que a maioria dos processos de escorregamento ocorre quando esses fatores agem mutuamente.

Diversos pesquisadores da área costumam atribuir características gerais aos diferentes movimentos de massa para classificar os fatores condicionantes e as causas atuantes (ABRAMSON et al., 2002; GUIDICINI; NIEBLE, 1976; USGS, 2014; VARNES, 1978). Por exemplo, Guidicini e Nieble (1976) empregam os termos agentes e causas para abordar os fatores condicionantes envolvidos no processo de instabilização de taludes e encostas, subdividindo os agentes em predisponentes e efetivos (preparatórios e imediatos) e as causas em internas, externas e intermediárias, como mostra a Tabela 3.1.

Tabela 3.1 - Agentes e causas dos escorregamentos.

\begin{tabular}{|c|c|c|c|c|c|}
\hline \multicolumn{3}{|c|}{ Agentes } & \multicolumn{3}{|c|}{ Causas } \\
\hline \multirow{2}{*}{$\begin{array}{l}\text { Predispo- } \\
\text { nentes }\end{array}$} & \multicolumn{2}{|c|}{ Efetivos } & \multirow[b]{2}{*}{ Internas } & \multirow[b]{2}{*}{ Externas } & \multirow[b]{2}{*}{ Intermediárias } \\
\hline & Preparatórios & Imediatos & & & \\
\hline $\begin{array}{l}\text { Complexo } \\
\text { geológico, } \\
\text { complexo } \\
\text { morfológico, } \\
\text { complexo } \\
\text { climatológi- } \\
\text { co, gravida- } \\
\text { de, calor } \\
\text { solar, tipo de } \\
\text { vegetação }\end{array}$ & $\begin{array}{l}\text { Pluviosidade, erosão } \\
\text { pela água e vento, } \\
\text { congelamento e } \\
\text { degelo, variação da } \\
\text { temperatura, } \\
\text { dissolução química, } \\
\text { ação de fontes e } \\
\text { manaciais, } \\
\text { oscilação do } \\
\text { freático, ação de } \\
\text { animais e antrópica }\end{array}$ & $\begin{array}{l}\text { Chuvas } \\
\text { intensas, } \\
\text { fusão do } \\
\text { gelo e neve, } \\
\text { erosão, } \\
\text { terremoto, } \\
\text { ondas, } \\
\text { vento, ação } \\
\text { do homem }\end{array}$ & $\begin{array}{l}\text { Efeito das } \\
\text { oscilações } \\
\text { térmicas, } \\
\text { redução dos } \\
\text { parâmetros de } \\
\text { resistência } \\
\text { por } \\
\text { intemperis- } \\
\text { mo }\end{array}$ & $\begin{array}{c}\text { Mudanças na } \\
\text { geometria do } \\
\text { sistema, } \\
\text { efeitos de } \\
\text { vibrações, } \\
\text { mudanças } \\
\text { naturais na } \\
\text { inclinação } \\
\text { das camadas }\end{array}$ & $\begin{array}{c}\text { Elevação do nível } \\
\text { piezométrico em } \\
\text { massas "homogêneas", } \\
\text { elevação da coluna de } \\
\text { água em } \\
\text { descontinuidades, } \\
\text { rebaixamento rápido } \\
\text { do lençol freático, } \\
\text { erosão subterrânea } \\
\text { retrogressiva (piping), } \\
\text { diminuição do efeito } \\
\text { da coesão aparente }\end{array}$ \\
\hline
\end{tabular}

Fonte: Guidicini e Nieble (1976).

Varnes (1978) também discute os principais condicionantes e mecanismos de deflagração de escorregamentos. Este autor relaciona os fatores condicionantes de movimento 
de massa e os fenômenos naturais/antrópicos com a ação, estando esta responsável pelo aumento da solicitação e pela redução da resistência (Tabela 3.2).

Tabela 3.2 - Fatores deflagradores dos movimentos de massa.

\begin{tabular}{|c|c|c|}
\hline Ação & Fatores & Fenômenos naturais/antrópicos \\
\hline \multirow{9}{*}{$\begin{array}{l}\text { Aumento da } \\
\text { solicitação }\end{array}$} & \multirow{2}{*}{$\begin{array}{l}\text { Remoção de massa (lateral } \\
\text { ou da base) }\end{array}$} & Erosão, escorregamentos \\
\hline & & Cortes \\
\hline & \multirow{4}{*}{ Sobrecarga } & Peso da água da chuva \\
\hline & & Depósito de material \\
\hline & & Peso da vegetação \\
\hline & & Construção de estruturas, aterros, etc \\
\hline & \multirow{2}{*}{ Solicitações dinâmicas } & Terremotos, ondas, etc \\
\hline & & Explosões, tráfego, sismos induzidos \\
\hline & Pressões laterais & $\begin{array}{l}\text { Água em trincas, congelamento, material } \\
\text { expansivo }\end{array}$ \\
\hline \multirow{4}{*}{$\begin{array}{l}\text { Redução da } \\
\text { resistência }\end{array}$} & $\begin{array}{c}\text { Características inerentes ao } \\
\text { material (textura, } \\
\text { geometria, estruturas, etc) }\end{array}$ & $\begin{array}{c}\text { Características geomecânicas do material, tensões } \\
\text { iniciais }\end{array}$ \\
\hline & \multirow{3}{*}{$\begin{array}{c}\text { Mudanças ou fatores } \\
\text { variáveis }\end{array}$} & Redução da coesão, ângulo de atrito \\
\hline & & Elevação do nível d’água \\
\hline & & Aumento da umidade/redução da sucção \\
\hline
\end{tabular}

O Centro de Pesquisa Geológica dos Estados Unidos (USGS, 2004) apresenta uma publicação sobre os diferentes tipos de escorregamento e os processos envolvidos em cada um deles. Nesta publicação, USGS (2004) constam as principais causas dos movimentos de massa agrupadas em três grupos (causas geológicas, causas morfológicas e causas antrópicas), as quais estão relacionadas com os fenômenos na natureza, como mostra a Tabela 3.3.

Tabela 3.3 - Principais causas dos movimentos de massa e seus fenômenos na natureza.

\begin{tabular}{cc}
\hline \multirow{2}{*}{ Causas } & Fenômenos \\
\hline \multirow{3}{*}{ Geológicas } & Materiais pouco resistentes ou sensíveis \\
\cline { 2 - 2 } & Materiais alterados \\
\cline { 2 - 2 } & Materiais fissurados \\
\cline { 2 - 2 } & Orientação desfavorável da descontinuidade (acamamento, \\
xistosidade, falhamento)
\end{tabular}


(conclusão)

Tabela 3.3 - Principais causas dos movimentos de massa e seus fenômenos na natureza.

\begin{tabular}{|c|c|}
\hline Causas & Fenômenos \\
\hline \multirow{2}{*}{ Geológicas } & Orientação desfavorável da descontinuidade (acamamento, \\
\hline & Contraste na permeabilidade ou baixa consistência dos \\
\hline \multirow{9}{*}{ Morfológicas } & Soerguimento vulcânico ou tectônico \\
\hline & Dinâmica glacial \\
\hline & Erosão fluvial, marinha ou glacial no pé da encosta ou nas \\
\hline & Erosão subterrânea (pipping) \\
\hline & Carregamento por deposição \\
\hline & Remoção da cobertura vegetal \\
\hline & Degelo \\
\hline & Intemperismo por congelamento e derretimento \\
\hline & Intemperismo por variação de volume \\
\hline \multirow{7}{*}{ Antrópicas } & Escavação da encosta ou de seu pé \\
\hline & Carregamento da encosta ou de sua crista \\
\hline & Exploração do lençol freático \\
\hline & Desmatamento \\
\hline & Irrigação \\
\hline & Mineração \\
\hline & Vibrações artificiais \\
\hline
\end{tabular}

Fonte: Traduzido e adaptado de USGS (2004).

Abramson et al. (2002) alegam que o escorregamento de talude é frequentemente causado por processos que aumentam ou diminuem a resistência ao cisalhamento da massa de solo envolvido neste processo. Estes mesmos autores também listam uma série de fatores que estão associados com o aumento da resistência ao cisalhamento (remoção de apoio, sobrecarga, efeito transiente, remoção de material subjacente que promove o apoio e aumento na pressão lateral) e a diminuição da resistência ao cisalhamento (fatores inerentes à natureza do material, mudanças causadas por intemperismo ou atividade físico-química, efeitos da poro pressão e mudanças na estrutura).

\subsubsection{Sistemas de classificação de movimentos de massa}

As classificações dos movimentos de massa envolvem uma grande variedade de materiais, processos e fatores condicionantes, resultando em diversas propostas de sistemas de classificação nacional e internacional. A maioria dos sistemas de classificação desenvolvidos 
ao longo dos anos foi baseada nas condições geológicas e climáticas regional, tendo aplicabilidade basicamente de caráter local.

$\mathrm{Na}$ literatura científica nacional e internacional constam inúmeras propostas para classificação dos movimentos de massa a partir da combinação de diferentes critérios atribuídos à este processo tais como as características associadas ao movimento (velocidade de deformação e tipo do movimento), a natureza do material (teor de umidade, textura, estrutura; geometria e quantidade de massa mobilizada), a geometria do talude e às condições ambientais (climatologia e hidrologia). De um modo geral, o desenvolvimento de sistemas de classificação de movimentos de massa tem grande importância no meio geológico-geotécnico pois permite associar e relacionar os diferentes tipos de movimento com um conjunto de características e seus fatores condicionantes.

Guidicini e Nieble (1976) citam as propostas de sistema de classificação de movimentos de massa elaboradas por Baltzer, Heim, Penck e Molitor que datam do final do século XIX. Estes mesmos autores também mencionam trabalhos do século XX, destacando alguns realizados por Terzaghi, Sharpe, Varnes, Skempton e Hutchinson.

Sharpe (1938) propôs um sistema de classificação em que considera como parâmetros a velocidade do movimento, o tipo do material (solo ou rocha) e a quantidade de água ou gelo atuante nesse processo (GUIDICINI; NIEBLE, 1976), como apresenta a Figura 3.1. O trabalho de Sharpe (1938) foi amplamente difundido e precursor para inúmeros sistemas de classificação, apresentando como principal vantagem a sua simplicidade e o seu caráter genérico na identificação dos tipos de movimentos.

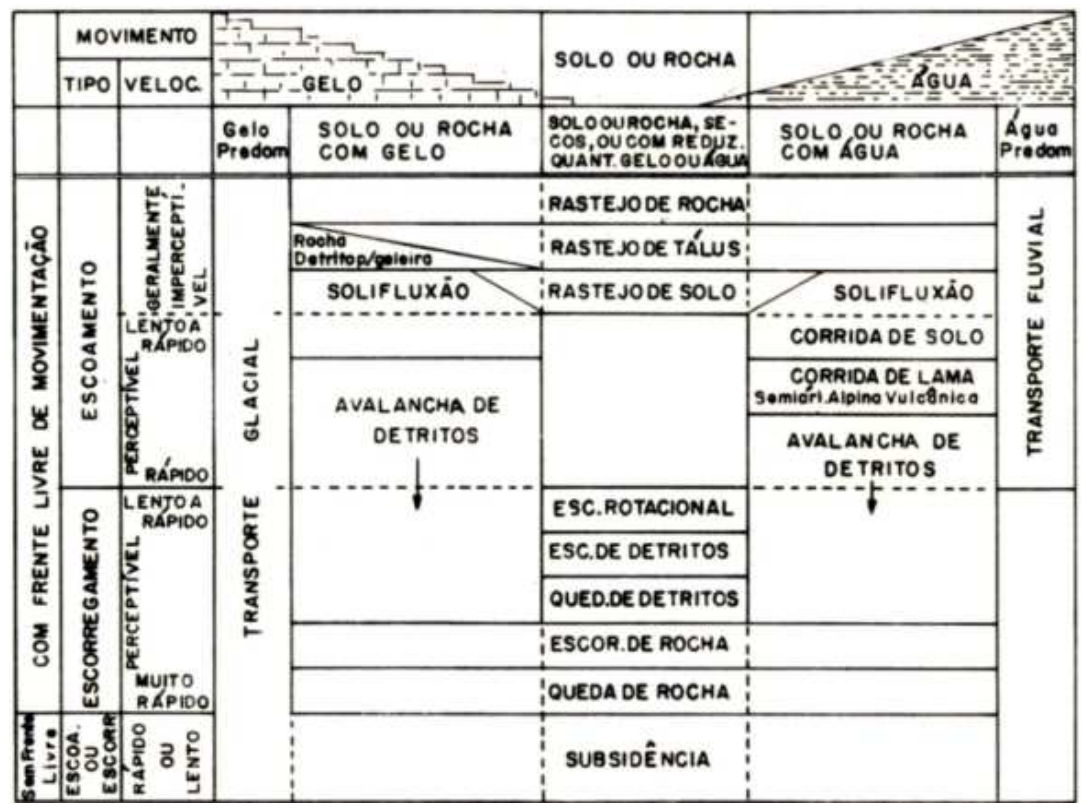

Figura 3.1 - Classificação dos movimentos de massa segundo Sharpe (1938).

Fonte: Guidicini e Nieble (1976). 
Baseado no trabalho de Sharpe (1938), Varnes (1978) elaborou um sistema de classificação bem simples para os movimentos de massa no qual utiliza apenas dois critérios para essa classificação: tipo de movimento e tipo de material mobilizado. A classificação proposta por Varnes (1978) é considerada como a classificação oficial da Associação Internacional de Geologia de Engenharia (International Association for Engineering Geology - IAEG), tornando-se modelo para muitos pesquisadores e a mais utilizada internacionalmente.

Tabela 3.4 - Classificação dos movimentos de massa segundo Varnes (1978).

\begin{tabular}{|c|c|c|c|c|}
\hline \multirow{3}{*}{\multicolumn{2}{|c|}{ Tipo de movimento }} & \multicolumn{3}{|c|}{ Tipo de material } \\
\hline & & \multirow{2}{*}{ Rocha } & \multicolumn{2}{|c|}{ Solo } \\
\hline & & & Fino & Grosseiro \\
\hline \multicolumn{2}{|c|}{ Quedas } & De rocha & De detritos & De terra \\
\hline \multicolumn{2}{|c|}{ Tombamentos } & De rocha & De detritos & De terra \\
\hline \multicolumn{2}{|c|}{ Escorregamento rotacional } & $\begin{array}{c}\text { Abatimento } \\
\text { de rocha }\end{array}$ & $\begin{array}{l}\text { Abatimento } \\
\text { de detritos }\end{array}$ & $\begin{array}{c}\text { Abatimento } \\
\text { de terra }\end{array}$ \\
\hline \multirow{2}{*}{$\begin{array}{l}\text { Escorregamento } \\
\text { translacional }\end{array}$} & Poucas unidades & $\begin{array}{l}\text { De blocos } \\
\text { rochosos }\end{array}$ & $\begin{array}{l}\text { De blocos de } \\
\text { detrito }\end{array}$ & $\begin{array}{c}\text { De blocos de } \\
\text { terra }\end{array}$ \\
\hline & Muitas unidades & De rocha & De detritos & De terra \\
\hline \multicolumn{2}{|c|}{ Expansões laterais } & De rocha & De detritos & De terra \\
\hline \multicolumn{2}{|c|}{ Corridas/escoamentos } & De rocha & De detritos & De terra \\
\hline \multicolumn{2}{|c|}{ Complexo } & \multicolumn{3}{|c|}{$\begin{array}{c}\text { combinação de dois ou mais tipos de } \\
\text { movimentos }\end{array}$} \\
\hline
\end{tabular}

Fonte: Traduzido e adaptado de Varnes (1978).

Hutchinson (1988) propôs um sistema de classificação de movimentos de massa fundamentada na morfologia da massa em movimento e em aspectos relacionados ao tipo de material, ao mecanismo de ruptura, à velocidade do movimento, às condições de pressão neutra e às características do solo. A proposta de classificação apresentada por Hutchinson (1988) foi baseada na classificação de Varnes (1978), abrangendo todos os tipos de movimentos de solo e rocha, sendo considerada uma das classificações mais complexas e completas até o momento. A classificação de Hutchinson (1988) divide o movimento de massa em alívio de tensões, rastejo, rompimento de taludes de montanha, escorregamentos, fluxo de detritos, tombamentos, quedas e movimentos complexos de talude.

Também existem algumas propostas de classificações nacionais de movimentos de massa sugeridas por pesquisadores brasileiros a partir da década de 1950 (AUGUSTO FILHO, 1992; BARATA, 1969; COSTA NUNES, 1966; CUNHA; FARAH; CERRI, 1991; 
FREIRE, 1965; GUIDICINI; NIEBLE, 1976; VARGAS; PICHLER, 1957). Dentre as inúmeras propostas nacionais, destacam-se as sugeridas por Augusto Filho (1992), Freire (1965) e Guidicini e Nieble (1976).

Freire (1965) desenvolveu um sistema de classificação pioneiro no Brasil baseado no trabalho de Sharpe (1938), em que divide os movimentos de massa em escoamentos (rastejo e corridas), escorregamentos (rotacionais e translacionais) e subsidências e desabamentos. A proposta de Freire (1965) foi fundamentada nos dados físicos dos locais, na superfície de escorregamento e materiais envolvidos, nos dados mecânicos associados ao desenvolvimento dos movimentos e no tempo de duração dos fluxos e suas causas.

Guidicini e Nieble (1976) adaptaram a proposta de Freire (1965), acrescentando mais um grupo aos tipos de movimentos de massa, estando distribuídos da seguinte maneira: escoamentos (rastejo e corridas), escorregamentos (rotacionais, translacionais, quedas de blocos e quedas de detritos), subsidências (subsidências, recalques e desabamentos) e formas de transição movimentos complexos.

Augusto Filho (1992) propôs um sistema de classificação bastante simplificada, na qual os movimentos de massa encontram-se divididos em rastejo (ou fluência), escorregamentos, quedas e corridas (ou fluxos), como indicam a Tabela 3.5. Nesta proposta, Augusto Filho (1992) busca revisar e adaptar a classificação de Varnes (1978) de acordo com os processos de escorregamentos observados no Brasil.

Tabela 3.5 - Classificação dos movimentos de massa segundo Augusto Filho (1992).

\begin{tabular}{|c|c|}
\hline Processos & Características do movimento, material e geometria \\
\hline \multirow{5}{*}{$\begin{array}{l}\text { Rastejo ou } \\
\text { fluência }\end{array}$} & Vários planos de deslocamento (interno) \\
\hline & $\begin{array}{l}\text { Velocidades muito baixas (cm/ano) a baixas e decrescentes com a } \\
\text { profundidade }\end{array}$ \\
\hline & Movimentos constantes, sazonais ou intermitentes \\
\hline & Solo, depósito, rocha alterada/fraturada \\
\hline & Geometria indefinida \\
\hline \multirow{6}{*}{ Escorregamento } & Poucos planos de deslocamento (externos) \\
\hline & Velocidades médias $(\mathrm{km} / \mathrm{h})$ a altas $(\mathrm{m} / \mathrm{s})$ \\
\hline & Pequenos a grandes volumes de material \\
\hline & Geometria e materiais variáveis \\
\hline & Planares: solos pouco espessos, solos e rochas com um plano de fraqueza \\
\hline & Circulares: solos espessos homogêneos e rochas muito fraturadas \\
\hline
\end{tabular}

Em cunha: solos e rochas com dois planos de fraqueza 
(conclusão)

Tabela 3.5 - Classificação dos movimentos de massa segundo Augusto Filho (1992).

\begin{tabular}{|c|c|}
\hline Processos & Características do movimento, material e geometria \\
\hline \multirow{8}{*}{ Queda } & Pequenos a médios volumes \\
\hline & Geometria variável: lascas, placas, blocos, etc \\
\hline & Rolamento de matacão \\
\hline & Tombamento \\
\hline & Sem planos de deslocamento \\
\hline & Movimentos tipo queda livre ou em plano inclinado \\
\hline & Velocidades muito altas (vários $\mathrm{m} / \mathrm{s}$ ) \\
\hline & Material rochoso \\
\hline \multirow{7}{*}{ Corrida } & $\begin{array}{l}\text { Muitas superfícies de deslocamento (internas e externas à massa em } \\
\text { movimentação) }\end{array}$ \\
\hline & Movimento semelhante ao de um líquido viscoso \\
\hline & Desenvolvimento ao longo das drenagens \\
\hline & Velocidades médias a altas \\
\hline & Mobilização de solo, rocha, detritos e água \\
\hline & Grandes volumes de material \\
\hline & Extenso raio de alcance, mesmo em áreas planas \\
\hline
\end{tabular}

\subsubsection{Estabilidade de talude}

Estabilidade de talude é um tema que engloba um amplo conhecimento na área de geotecnia e um complexo levantamento de dados e parâmetros do local. Fredlund (1984) cita que um estudo de análise de estabilidade de talude geralmente envolve um levantamento topográfico da superfície do talude, a investigação da sub-superfície e a coleta de amostra, realização de ensaios de laboratório para determinação dos parâmetros de resistência e a instalação de piezômetros para monitorar o nível d’água dessa maneira. O autor conclui que, após a elaboração completa desse estudo, é possível analisar a estabilidade do referido talude.

O estudo da estabilidade de talude no Brasil é regulamentado através de normatização técnica ABNT NBR 11682 (ASSOCIAÇÃO BRASILEIRA DE NORMAS TÉCNICAS, 2009), responsável por prescrever os requisitos exigíveis para o estudo e controle da estabilidade de encostas e de taludes (corte ou aterro). A referida norma técnica apresenta as condições para elaboração de estudos, projeto, execução, controle e observação de obras de estabilização (ABNT, 2009).

Existem diferentes maneiras de elaborar a análise de estabilidade de um talude, a qual 
possui a principal finalidade de aferir a possibilidade de ocorrência de escorregamento de massa de solo bem como de determinar o grau de estabilidade que se encontra o talude. Tendo o intuito de avaliar a estabilidade a partir de diferentes enfoques e técnicas, essas análises podem ser basicamente divididas em grupos de análise probabilística e de análise determinística.

O grupo de análise probabilística trata os parâmetros do solo como variáveis aleatórias e seu resultado não é um fator de segurança, mas sim, a probabilidade de ocorrer a ruptura do talude quantificada a partir da obtenção do índice de confiabilidade denominado $\beta$. Neste tipo de análise são utilizados métodos para quantificar as incertezas e a variabilidade espacial relacionadas com a ocorrência da ruptura. Abramson et al. (2002) enumeram algumas incertezas espaciais como topografia, variabilidade e estratigrafia do local, características do material da sub-superfície e origens geológicas, nível d’água e também algumas incertezas dos dados como características das rochas e dos solos in situ, propriedades geotécnicas e comportamento do solo e/ou da rocha.

De acordo com Abramson et al. (2002), os métodos de análise probabilística de estabilidade de talude mais utilizados são o Método das Séries de Taylor, o Método das Estimativas Pontuais (PEM ou Método de Rosenblueth) e Simulação Monte Carlo, recebendo grande destaque o último método por ser amplamente empregado e divulgado no meio geotécnico.

O grupo de análise determinística utiliza as características do talude (geometria e dinâmica da água no seu interior) e os parâmetros do solo (físico, hidráulico e mecânico) em modelos matemáticos específicos para cálculo do fator de segurança. Neste tipo de análise podem ser enquadrados inúmeros métodos, podendo subdividi-los nos Métodos da Análise Limite, Método da Tensão-Deformação e Método do Equilíbrio Limite. Como a proposta desta pesquisa visa analisar a estabilidade de talude por meio de análise determinística apenas com o uso do Método do Equilíbrio Limite, nesta revisão bibliográfica não será desenvolvido o assunto sobre análise probabilística.

\subsubsection{Análise determinística de estabilidade de talude}

A análise determinística de estabilidade de talude fornece um valor para o Fator de Segurança (FS), podendo este ser calculado utilizando o Método do Equilíbrio-Limite ou o Método da Tensão-Deformação.

O Fator de Segurança (FS) representa uma condição de estabilidade para um dado talude a partir do equilíbrio de forças, do equilíbrio de momento ou do equilíbrio limite (em 
termos de tensão total ou tensão efetiva). Estas relações podem implicar em diferentes valores para representação do Fator de Segurança, o qual também pode variar em função dos parâmetros geotécnicos (como a resistência ao cisalhamento) e dos métodos adotados para analisar a estabilidade do talude em estudo.

Além do Fator de Segurança poder ser determinado para uma situação específica e possuir um valor único, é possível estabelecer um limite entre a condição estável e a condição instável do talude comparando-se com o valor conhecido como unitário. Portanto, genericamente pode-se afirmar que quanto maior for o valor do Fator de Segurança menor será a possibilidade de o talude sofrer a ruptura ou vice-versa. A Tabela 3.6 classifica a condição de estabilidade de um talude em função do seu Fator de Segurança, representada por meio da terminologia Coeficiente de Segurança.

Tabela 3.6 - Condição de estabilidade do talude em função do Coeficiente de Segurança.

\begin{tabular}{cc}
\hline Coeficiente de segurança (CS) & Condição do talude \\
\hline CS $<1,0$ & $\begin{array}{c}\text { Talude instável; caso o talude venha a ser implantado (corte ou } \\
\text { aterro) nestas condições, deverá sofrer ruptura }\end{array}$ \\
\hline CS $=1,0$ & $\begin{array}{c}\text { Condição limite de estabilidade associada à iminência de } \\
\text { ruptura; também condição adotada geralmente nos cálculos de } \\
\text { retroanálise }\end{array}$ \\
\hline $\begin{array}{c}\text { CS }>1,0 \\
\text { pouco maior) }\end{array}$ & $\begin{array}{c}\text { Condição estável; quanto mais próximo de 1,0 for o CS, mais } \\
\text { precária e frágil será a condição de estabilidade do talude }\end{array}$ \\
\hline $\begin{array}{c}\text { CS }>>1,0 \\
\text { (muito maior) }\end{array}$ & $\begin{array}{c}\text { Condição estável; quanto maior for o CS, menores serão as } \\
\text { possibilidades de o talude vir a sofrer ruptura quando submetido } \\
\text { a condições críticas (percolação d'água, etc) }\end{array}$ \\
\hline
\end{tabular}

Fonte: Carvalho (1991).

A Tabela 3.7 mostra os valores mínimos recomendados pela ABNT (2009) para o Fator de Segurança levando em consideração o nível de segurança contra danos a vidas humanas e o nível de segurança contra danos materiais e ambientais estabelecidos para o projeto de estabilidade de talude.

Tabela 3.7 - Fatores de Segurança mínimos para deslizamentos.

\begin{tabular}{cccc}
\hline \multirow{2}{*}{$\begin{array}{c}\text { Nível de segurança contra danos } \\
\text { materiais e ambientais }\end{array}$} & \multicolumn{3}{c}{ Nível de segurança contra danos a vidas humanas } \\
\cline { 2 - 4 } & Alto & Médio & Baixo \\
\hline Alto & 1,5 & 1,5 & 1,4 \\
\hline Médio & 1,5 & 1,4 & 1,3 \\
\hline Baixo & 1,4 & 1,3 & 1,2 \\
\hline
\end{tabular}

Fonte: ABNT (2009). 


\subsection{Método do Equilíbrio Limite}

Diferentes métodos de análise determinística de estabilidade de talude foram propostos ao longo das últimas décadas, tendo como intenção avaliar as condições de equilíbrio da massa de solo num estado de ruptura iminente. Um desses métodos é denominado Método do Equilíbrio Limite, amplamente utilizado e divulgado por profissionais da área de geotecnia, embora receba muitas críticas por conta de suas simplificações.

Apesar do Método do Equilíbrio Limite apresentar algumas simplificações, ele incorpora e assume algumas hipóteses básicas, as quais estão destacadas abaixo:

- A superfície de ruptura é bem definida (circular, planar, cunha ou irregular);

- A massa de solo encontra-se na condição de ruptura generalizada e iminente;

- O critério de ruptura (geralmente é utilizado o critério de Mohr-Coulomb) é admitido constante ao longo de toda a superfície de ruptura;

- A superfície de ruptura corresponderá ao menor valor do fator de segurança, o qual será sempre constante ao longo de toda superfície.

Os métodos que compõem o Método do Equilíbrio Limite podem ser classificados em dois grandes grupos: o primeiro grupo em que considera a massa rompida como um corpo único (Método do Talude Infinito, Método da Espiral Logarítmica e Método Círculo Sueco) e o segundo grupo em que considera a massa rompida em cunha ou em fatias (Método de Fellenius, Método de Bishop Simplificado, Método de Janbu, Método de Morgenstern e Price, Método Corpo de Engenheiros, Método de Lowe e Karafiath, Método Spencer e Método de Sarma). Na Tabela 3.8 encontram-se reunidos os principais métodos determinísticos, os quais são classificados de acordo com o tipo do método, geometria da ruptura e dinâmica do processo.

Tabela 3.8 - Métodos determinísticos de estabilidade de talude.

\begin{tabular}{|c|c|c|c|}
\hline \multicolumn{2}{|c|}{ Métodos de análise de estabilidade } & \multirow{2}{*}{$\begin{array}{c}\text { Geometria da } \\
\text { ruptura }\end{array}$} & \multirow{2}{*}{ Dinâmica do processo } \\
\hline Tipo & Nome & & \\
\hline \multirow{8}{*}{ Equilíbrio limite } & Espiral logarítmica & \multirow{8}{*}{ Rupturas circulares } & \multirow{8}{*}{$\begin{array}{l}\text { Não condicionado por } \\
\text { estruturas reliquiares }\end{array}$} \\
\hline & Taylor & & \\
\hline & Fellenius & & \\
\hline & Bishop & & \\
\hline & Spencer & & \\
\hline & Tridimensional & & \\
\hline & Janbu & & \\
\hline & Morgenstern e Price & & \\
\hline
\end{tabular}


(conclusão)

Tabela 3.8 - Métodos determinísticos de estabilidade de talude.

\begin{tabular}{|c|c|c|c|}
\hline \multicolumn{2}{|c|}{ Métodos de análise de estabilidade } & \multirow{2}{*}{$\begin{array}{l}\text { Geometria da } \\
\text { ruptura }\end{array}$} & \multirow{2}{*}{ Dinâmica do processo } \\
\hline Tipo & Nome & & \\
\hline \multirow{3}{*}{ Tensão-deformação } & Elementos finitos & \multirow{3}{*}{ Rupturas não circulares } & \multirow{3}{*}{$\begin{array}{l}\text { Não condicionado por } \\
\text { estruturas reliquiares }\end{array}$} \\
\hline & Diferenças finitas & & \\
\hline & Multiblocos & & \\
\hline \multirow{3}{*}{ Equilíbrio limite } & Planar & 1 plano & \multirow{4}{*}{$\begin{array}{l}\text { Condicionado por } \\
\text { estruturas reliquiares }\end{array}$} \\
\hline & Biplanar, em cunha & 2 planos & \\
\hline & Multiplanar & Vários planos & \\
\hline Tensão-deformação & & $\begin{array}{l}\text { Tombamento/queda de } \\
\text { blocos }\end{array}$ & \\
\hline
\end{tabular}

Fonte: IPT ${ }^{1}$ (1990 apud AUGUSTO FILHO; VIRGILI, 1998, p. 261).

No caso dos métodos que consideram a massa rompida em fatias (conhecidos como Método das Fatias), a massa de solo analisada deve ser dividida em diversas fatias, em que (n) representa uma única fatia, como ilustra a Figura 3.2a. É importante comentar que existem algumas regras básicas para efetuar a distribuição das fatias tais como: a base da fatia deverá estar contida no mesmo material e ser considerada linear além do topo da fatia não poder apresentar descontinuidades na superfície. A Figura 3.2b ilustra o conjunto de forças ao qual uma fatia está sujeita, o qual corresponde a um sistema estaticamente indeterminado, totalizando um número de incógnitas (6n-2) superior a um número de equações (4n), como mostra a Tabela 3.9.

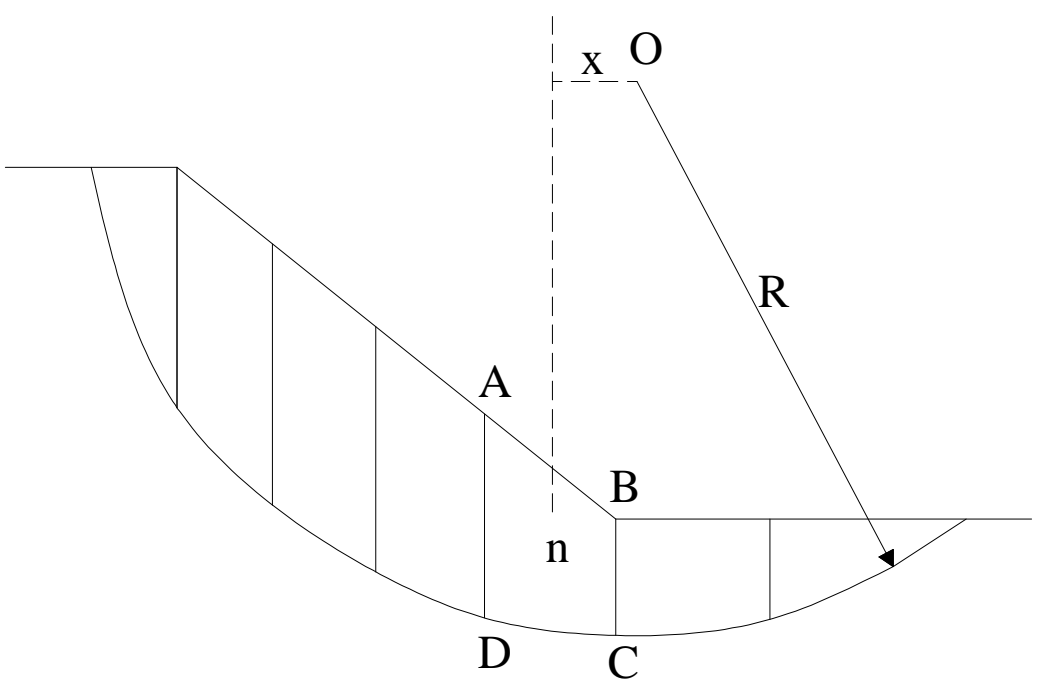

(a)

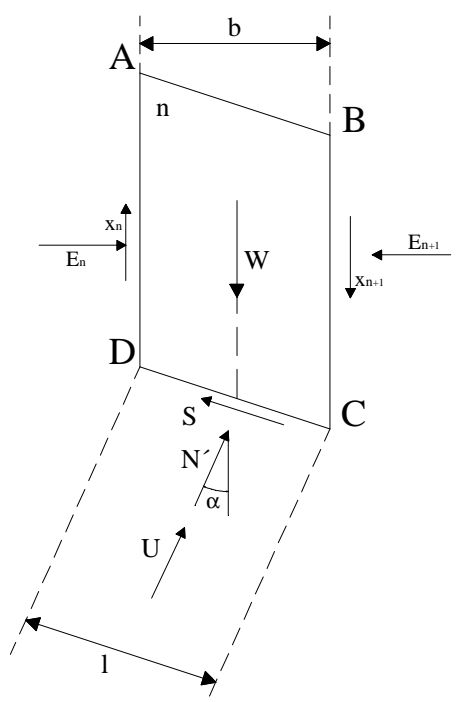

(b)

Figura 3.2 - Método das Fatias (a) divisão em fatias e (b) equilíbrio de forças.

Fonte: modificado de Gerscovich (2012). 
Tabela 3.9 - Equações e variáveis associadas ao Método das Fatias.

\begin{tabular}{cc}
\hline Equações & Condição \\
\hline $\mathrm{n}$ & Equilíbrio de momento \\
\hline $2 \mathrm{n}$ & Equilíbrio de forças \\
\hline $\mathrm{n}$ & Envoltória de resistência \\
\hline $\mathbf{4 n}$ & Total do número de equações \\
\hline Incógnitas & Fator de Segurança \\
\hline 1 & Força normal na base da fatia (N') \\
\hline $\mathrm{n}$ & Força tangencial na base da fatia (s) \\
\hline $\mathrm{n}$ & Localização de $\mathrm{N}^{\prime}$ na base da fatia \\
\hline $\mathrm{n}-1$ & Força tangencial entre fatias $(\mathrm{T})$ \\
\hline $\mathrm{n}-1$ & Força normal entre fatias $(\mathrm{E})$ \\
\hline $\mathrm{n}-1$ & Ponto de aplicação da força entre fatias $(\mathrm{T}$ e E) \\
\hline $\mathbf{6 n}-\mathbf{2}$ & Total do número de incógnitas \\
\hline
\end{tabular}

Fonte: Traduzido e adaptado de Abramson et al., (2002) e Gerscovich (2012).

O problema do número de incógnitas passa a ser estaticamente determinado a partir do momento em que são assumidas hipóteses simplificadoras, reduzindo-se o número de incógnitas e tornando-se possível a solução do problema. Com isso, as diferentes hipóteses simplificadoras originarão também diferentes métodos para cálculo do Fator de Segurança, como mostra a Tabela 3.10, em que cada método adota um equilíbrio de forças ( $\mathrm{x}$ e y) e equilíbrio de momento para uma única fatia.

Tabela 3.10 - Condições satisfeitas do equilíbrio estático pelos Métodos do Equilíbrio Limite.

\begin{tabular}{cccc}
\hline \multirow{2}{*}{ Método } & \multicolumn{2}{c}{ Equilíbrio de forças } & \multirow{2}{*}{ Equilíbrio de momento } \\
\cline { 2 - 3 } & $\mathbf{x}$ & $\mathbf{y}$ & \\
\hline Fellenius & Não & Não & Sim \\
\hline Bishop Simplificado & Sim & Não & Sim \\
\hline Janbu & Sim & Sim & Não \\
\hline Lowe e Karafiath & Sim & Sim & Não \\
\hline Corpo de Engenheiros & Sim & Sim & Não \\
\hline Spencer & Sim & Sim & Sim \\
\hline Bishop & Sim & Sim & Sim \\
\hline Janbu generalizado & Sim & Sim & Não \\
\hline Sarma & Sim & Sim & Sim \\
\hline Morgenstern-Price & Sim & Sim & Sim \\
\hline
\end{tabular}

Fonte: Traduzido de Abramson et al. (2002).

A seguir encontram-se detalhados três Métodos das Fatias: Método de Fellenius (1936), Método de Janbu (1954) e Método de Bishop Simplificado (1955). 


\subsection{Método de Fellenius (1936)}

O Método de Fellenius, também conhecido como Método Sueco ou Método Ordinário das Fatias, é um dos métodos mais antigos que utilizam o método das fatias para avaliar a estabilidade do talude (ABRAMSON et al., 2002). Este método satisfaz somente o equilíbrio de momento e assume que a superfície de ruptura é circular, sendo que a resultante das forças interlamelares de todas as fatias são paralelas à base da fatia e desprezadas. Portanto, neste método o equilíbrio de forças em cada fatia ocorrerá somente nas direções normal e tangencial à superfície de ruptura.

A Figura 3.3 ilustra as forças atuantes em uma fatia nas direções normal e tangencial à base da fatia incluindo os valores de pressão neutra, resultando no equilíbrio de forças representado pela equação (1). No caso deste método, o Fator de Segurança poderá ser determinado em termos de tensão total ou tensão efetiva, como mostra as equações (2) e (3), respectivamente.
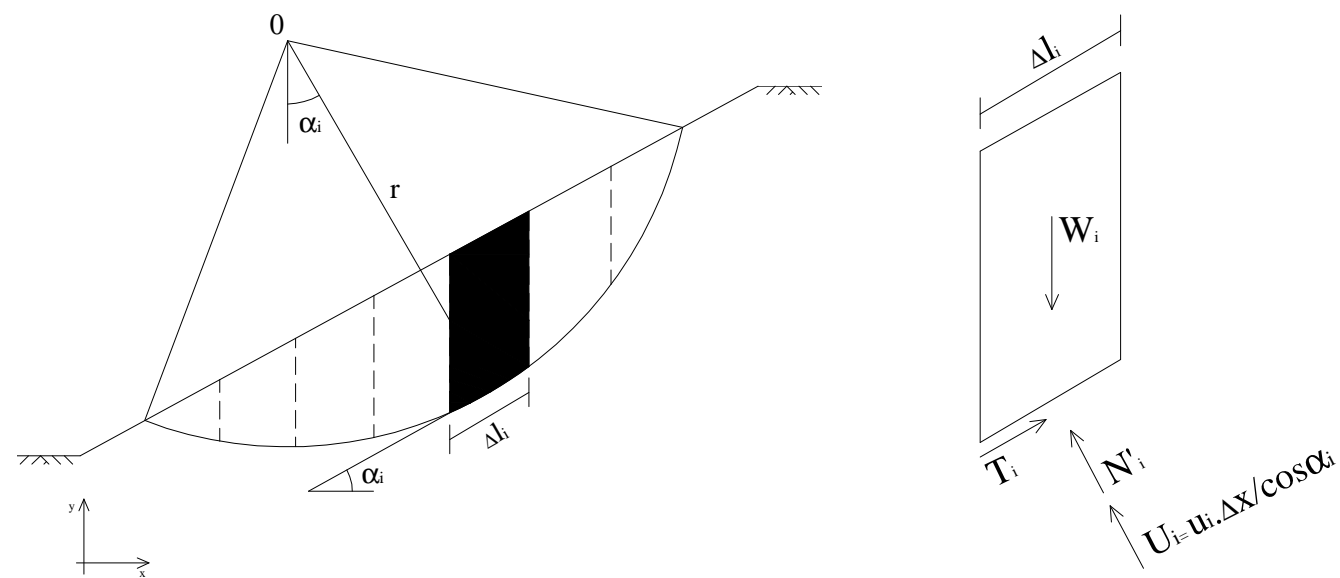

Figura 3.3 - Método de Fellenius (1936) - representação das forças atuantes em uma fatia.

$$
\begin{gathered}
W_{i} \cdot \cos \alpha_{i}-N^{\prime}{ }_{i}-U_{i}=0 \\
F S=\frac{\sum_{\mathrm{i}=1}^{\mathrm{n}}\left[{c^{\prime}}^{\prime} \cdot \Delta l_{i}+W_{i} \cdot \cos \alpha_{i} \cdot \operatorname{tg} \phi^{\prime}{ }_{i}\right]}{\sum_{\mathrm{i}=1}^{\mathrm{n}} W_{i} \cdot \operatorname{sen} \alpha_{i}} \\
F S=\frac{\sum_{\mathrm{i}=1}^{\mathrm{n}}\left[{c^{\prime}}_{i} \cdot \Delta l_{i}+\left(W_{i} \cdot \cos \alpha_{i}-u_{i} \cdot \Delta l_{i}\right) \cdot \operatorname{tg} \phi^{\prime}{ }_{i}\right]}{\sum_{\mathrm{i}=1}^{\mathrm{n}} W_{i} \cdot \operatorname{sen} \alpha_{i}}
\end{gathered}
$$


em que $W_{i}$ é o peso da fatia, em $\left[\mathrm{ML}^{-1} \mathrm{~T}^{-2}\right] ; \alpha_{i}$ é o ângulo de inclinação da fatia, em $\left[{ }^{\circ}\right] ; N_{i}^{\prime}$ é a resultante das tensões efetivas normais à base da fatia, em $\left[\mathrm{ML}^{-1} \mathrm{~T}^{-2}\right] ; U_{i}$ é a resultante da pressão neutra na base da fatia, em $\left[\mathrm{ML}^{-1} \mathrm{~T}^{-2}\right] ; F S$ é o fator de segurança, em [adimensional]; $c^{\prime}{ }_{i}$ é a coesão efetiva do solo, em $\left[\mathrm{ML}^{-1} \mathrm{~T}^{-2}\right] ; \Delta l_{i}$ é a largura ortogonal à fatia, em [L]; $u_{i}$ é a pressão neutra na base da fatia, em $\left[\mathrm{ML}^{-1} \mathrm{~T}^{-2}\right] ; \phi^{\prime}{ }_{i}$ é o ângulo de atrito efetivo, em $\left[{ }^{\circ}\right]$.

De acordo com Gerscovich (2012), este método é mais conservativo pois tende a fornecer baixos valores de fator de segurança. Esta mesma autora relata que o método gera valores de fator de segurança poucos confiáveis no caso de círculos muito profundos e valores de pressão neutra elevados. Duncan e Wright (2005) afirmam que o Método de Fellenius é menos preciso do que os outros Métodos das Fatias, sendo que a precisão deste método é menor em termos de tensão efetiva e diminui à medida que os valores de pressão neutra tornam-se maiores.

\subsection{Método de Janbu (1954)}

O Método de Janbu supõe que a superfície de ruptura é irregular e assume que o equilíbrio de forças em cada fatia ocorre nas direções horizontal e vertical, além das forças interlamelares ocorrerem na direção horizontal (Figura 3.4). No caso deste método, as resultantes das forças atuantes em uma fatia podem ser descritas por meio da equação (4), na qual também está considerada a pressão neutra.
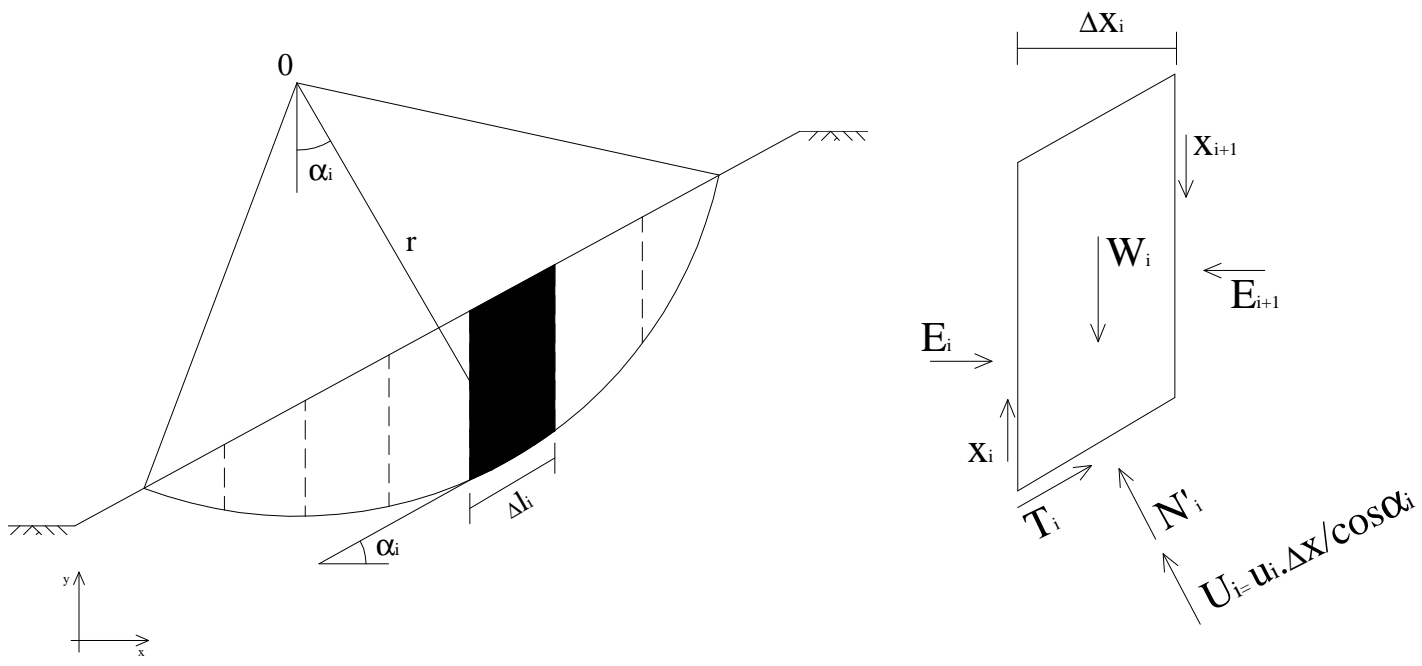

Figura 3.4 - Método de Janbu (1954) - representação das forças atuantes em uma fatia. 


$$
N^{\prime}{ }_{i} \cdot \cos \alpha_{i}+U_{i} \cdot \cos \alpha_{i}+T_{i} \cdot \operatorname{sen} \alpha_{i}-W_{i}=0
$$

em que $N^{\prime}{ }_{i}$ é a resultante das tensões efetivas normais à base da fatia, em $\left[\mathrm{ML}^{-1} \mathrm{~T}^{-2}\right] ; \alpha_{i}$ é o ângulo de inclinação da fatia, em $\left[{ }^{\circ}\right] ; U_{i}$ é a resultante da pressão neutra na base da fatia, em $\left[\mathrm{ML}^{-1} \mathrm{~T}^{-2}\right] ; T_{i}$ é a resultante das tensões tangenciais mobilizadas na base da fatia, em $\left[\mathrm{ML}^{-1} \mathrm{~T}^{-2}\right] ; W_{i}$ é o peso da fatia, em $\left[\mathrm{ML}^{-1} \mathrm{~T}^{-2}\right]$.

O Fator de Segurança pode ser determinado em termos de tensão total ou efetiva, como mostram as equações (5) e (6), respectivamente. De acordo com Duncan e Wright (2005), este método normalmente produz Fatores de Segurança muito pequenos do que aqueles obtidos por procedimentos mais rigorosos, por esse motivo, Janbu propõe aplicar um fator de correção $\left(f_{0}\right)$ ao cálculo do Fator de Segurança, que é dado em função da profundidade e comprimento da superfície de ruptura, como ilustra a Figura 3.5. Este fator de correção é multiplicado pelo Fator de Segurança.

$$
\begin{gathered}
F S=\frac{\mathrm{f}_{0}}{\sum_{\mathrm{i}=1}^{\mathrm{n}} \mathrm{W}_{\mathrm{i}} \cdot \operatorname{tg} \alpha_{i}} \cdot \sum_{\mathrm{i}=1}^{\mathrm{n}} \frac{\left[{c^{\prime}}^{\prime} \cdot \Delta x_{i}+W_{i} \cdot \operatorname{tg} \phi^{\prime}{ }_{i}\right]}{\cos ^{2} \alpha_{i} \cdot\left(1+\frac{\operatorname{tg} \alpha_{i} \cdot \operatorname{tg} \phi^{\prime}{ }_{i}}{F S_{a}}\right)} \\
F S=\frac{\mathrm{f}_{0}}{\sum_{\mathrm{i}=1}^{\mathrm{n}} \mathrm{W}_{\mathrm{i}} \cdot \operatorname{tg} \alpha_{i}} \cdot \sum_{\mathrm{i}=1}^{\mathrm{n}} \frac{\left[{c^{\prime}}_{i} \cdot \Delta x_{i}+\left(W_{i}-u_{i} \cdot \Delta x_{i}\right) \cdot \operatorname{tg} \phi_{i}^{\prime}\right]}{\cos ^{2} \alpha_{i} \cdot\left(1+\frac{\operatorname{tg} \alpha_{i} \cdot \operatorname{tg} \phi^{\prime}}{F S_{a}}\right)}
\end{gathered}
$$

em que $F S$ é o fator de segurança, em [adimensional]; $f_{0}$ é o fator de correção, [adimensional]; $c^{\prime}{ }_{i}$ é a coesão efetiva do solo, em $\left[\mathrm{ML}^{-1} \mathrm{~T}^{-2}\right] ; \Delta x_{i}$ é a largura da fatia, em [L]; $W_{i}$ é o peso da fatia, em $\left[\mathrm{ML}^{-1} \mathrm{~T}^{-2}\right] ; u_{i}$ é a pressão neutra na base da fatia, em $\left[\mathrm{ML}^{-1} \mathrm{~T}^{-2}\right] ; \phi^{\prime}{ }_{i}$ é o ângulo de atrito efetivo, em [ $\left.{ }^{\circ}\right] ; \alpha_{i}$ é o ângulo de inclinação da fatia, em $\left[{ }^{\circ}\right] ;$ $F S_{a}$ é o fator de segurança arbitrário, [adimensional].

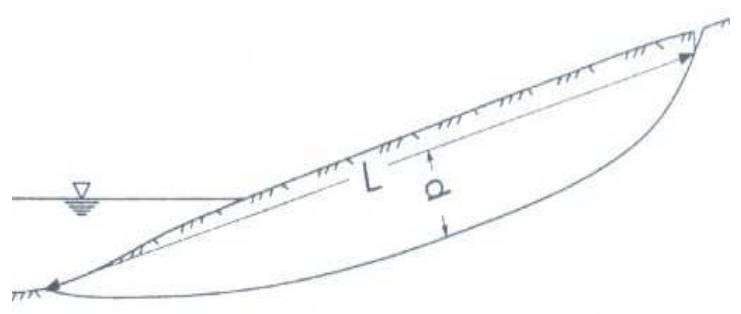

superfície de ruptura

(a) 


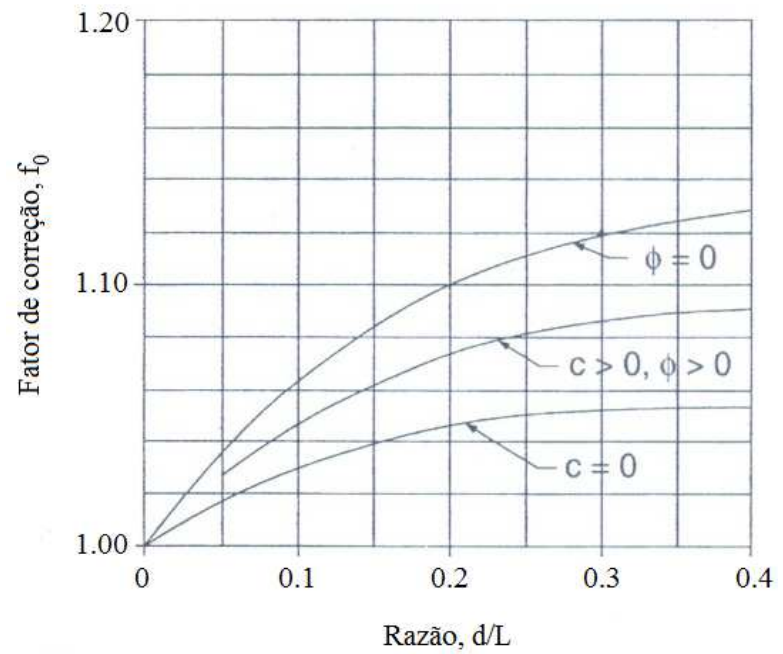

(b)

Figura 3.5 - (a), (b) Fator de correção (f $f_{0}$ ) para o Método de Janbu (1954).

Fonte: Traduzido e adaptado de Duncan e Wright (2005).

$$
F S=\frac{\mathrm{f}_{0}}{\sum_{\mathrm{i}=1}^{\mathrm{n}} \mathrm{W}_{\mathrm{i}} \cdot \operatorname{tg} \alpha_{i}} \cdot \sum_{\mathrm{i}=1}^{\mathrm{n}} \frac{\left[c^{\prime}{ }_{i} \cdot \Delta x_{i}+\left(W_{i}-u_{i} \cdot \Delta x_{i}\right) \cdot \operatorname{tg} \phi_{i}^{\prime}{ }_{i}\right]}{\cos \alpha_{i} \cdot M_{i}(\alpha)_{J}}
$$

sendo que:

$$
M_{i}(\alpha)_{J}=\cos \alpha_{i}\left(1+\frac{\operatorname{tg} \alpha_{i} \cdot \operatorname{tg}^{\prime}{ }_{i}}{F S_{a}}\right)
$$

em que $N^{\prime}{ }_{i}$ é a resultante das tensões efetivas normais à base da fatia, em $\left[\mathrm{ML}^{-1} \mathrm{~T}^{-2}\right] ; \alpha_{i}$ é o ângulo de inclinação da fatia, em $\left[{ }^{\circ}\right] ; U_{i}$ é a resultante da pressão neutra na base da fatia, em $\left[\mathrm{ML}^{-1} \mathrm{~T}^{-2}\right] ; T_{i}$ é a resultante das tensões tangenciais mobilizadas na base da fatia, em $\left[\mathrm{ML}^{-1} \mathrm{~T}^{-2}\right] ; W_{i}$ é o peso da fatia, em $\left[\mathrm{ML}^{-1} \mathrm{~T}^{-2}\right] ; F S$ é o fator de segurança, em [adimensional]; $f_{0}$ é o fator de correção, [adimensional]; $c^{\prime}{ }_{i}$ é a coesão efetiva do solo, em $\left[\mathrm{ML}^{-1} \mathrm{~T}^{-2}\right] ; \Delta x_{i}$ é a largura da fatia, em [L]; $u_{i}$ é a pressão neutra na base da fatia, em $\left[\mathrm{ML}^{-1} \mathrm{~T}^{-2}\right] ; \phi_{i}^{\prime}$ é o ângulo de atrito efetivo, em $\left[^{\circ}\right] ; M_{i}(\alpha)_{J}$ é um coeficiente, em [adimensional]; $F S_{a}$ é o fator de segurança arbitrário, [adimensional].

De acordo com Gerscovich (2012), este método foi desenvolvido com a finalidade de diminuir o esforço computacional, permitindo obter o valor de Fator de Segurança através de 
cálculos mais simples. Esta mesma autora menciona que o método é aplicado para talude homogêneo e que para talude com a superfície em formato de cunha não oferece bons resultados.

\subsection{Método de Bishop Simplificado (1955)}

O Método de Bishop Simplificado supõe que a superfície de ruptura é circular e assume que o equilíbrio de forças em cada fatia ocorre na direção vertical, além das forças interlamelares ocorrerem na direção horizontal (Figura 3.6). No caso deste método, as resultantes das forças atuantes em uma fatia podem ser descritas por meio da equação (9), na qual também está considerada a pressão neutra.
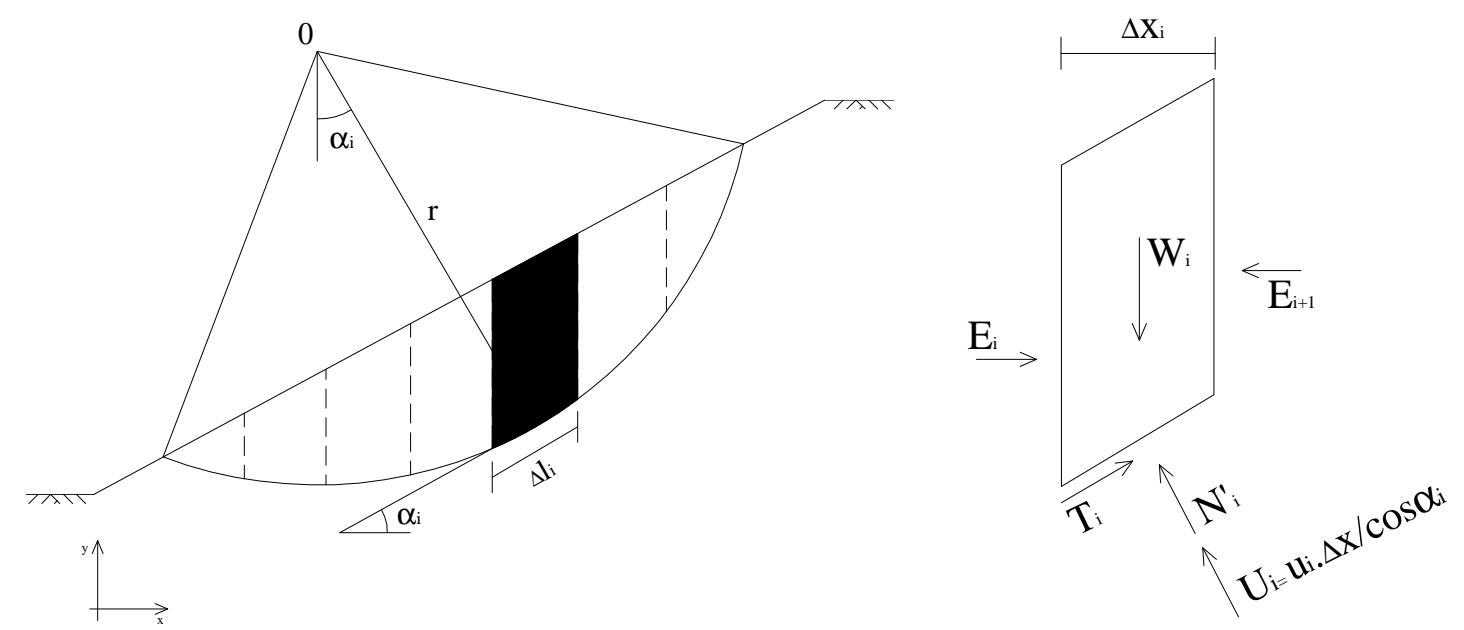

Figura 3.6 - Método de Bishop Simplificado (1955) - representação das forças atuantes em uma fatia.

$$
W_{i}-N^{\prime}{ }_{i} \cdot \cos \alpha_{i}-U_{i} \cdot \cos \alpha_{i}-T_{i} \cdot \operatorname{sen} \alpha_{i}=0
$$

em que $W_{i}$ é o peso da fatia, em $\left[\mathrm{ML}^{-1} \mathrm{~T}^{-2}\right] ; N^{\prime}{ }_{i}$ é a resultante das tensões efetivas normais à base da fatia, em $\left[\mathrm{ML}^{-1} \mathrm{~T}^{-2}\right] ; \alpha_{i}$ é o ângulo de inclinação da fatia, em [ $\left.{ }^{\circ}\right] ; U_{i}$ é a resultante da pressão neutra na base da fatia, em $\left[\mathrm{ML}^{-1} \mathrm{~T}^{-2}\right] ; T_{i}$ é a resultante das tensões tangenciais mobilizadas na base da fatia, em $\left[\mathrm{ML}^{-1} \mathrm{~T}^{-2}\right]$.

O Fator de Segurança pode ser determinado em termos de tensão total ou efetiva, como mostram as equações (10) e (11), respectivamente. Este método não fornece um fator de segurança explícito, pois é necessário que seja adotado um valor inicial para fator de segurança até a determinação do fator de segurança equivalente para aquela dada situação analisada, como pode ser constatado na equação (12). 


$$
\begin{gathered}
F S=\frac{\sum_{\mathrm{i}=1}^{\mathrm{n}}\left[c^{\prime}{ }_{i} \cdot \Delta x_{i}+W_{i} \cdot \operatorname{tg} \phi_{i}^{\prime}\right] \cdot\left[1 / M_{i}(\alpha)_{B S}\right]}{\sum_{\mathrm{i}=1}^{\mathrm{n}} W_{i} \cdot \cos \alpha_{i}} \\
F S=\frac{\sum_{\mathrm{i}=1}^{\mathrm{n}}\left[c^{\prime}{ }_{i} \cdot \Delta x_{i}+\left(W_{i}-u_{i} \cdot \Delta x_{i}\right) \cdot \operatorname{tg} \phi_{i}^{\prime}\right] \cdot\left[1 / M_{i}(\alpha)_{B S}\right]}{\sum_{\mathrm{i}=1}^{\mathrm{n}} W_{i} \cdot \cos \alpha_{i}}
\end{gathered}
$$

sendo que:

$$
M_{i}(\alpha)_{B S}=\cos \alpha_{i}\left(1+\frac{\operatorname{tg} \alpha_{i} \cdot \operatorname{tg} \phi_{i}^{\prime}}{F}\right)
$$

em que FS é o fator de segurança, em [adimensional]; $c^{\prime}{ }_{i}$ é a coesão efetiva do solo, em $\left[\mathrm{ML}^{-1} \mathrm{~T}^{-2}\right] ; \Delta x_{i}$ é a largura da fatia, em $[\mathrm{L}] ; W_{i}$ é o peso da fatia, em $\left[\mathrm{ML}^{-1} \mathrm{~T}^{-2}\right] ; \phi^{\prime}{ }_{i}$ é o ângulo de atrito efetivo, em $\left[{ }^{\circ}\right] ; M_{i}(\alpha)_{B S}$ é um coeficiente, em [adimensional]; $\alpha_{i}$ é o ângulo de inclinação da fatia, em $\left[{ }^{\circ}\right] ; F$ é o fator de segurança arbitrário, [adimensional]; $u_{i}$ é a pressão neutra na base da fatia, em $\left[\mathrm{ML}^{-1} \mathrm{~T}^{-2}\right]$.

De acordo com Duncan e Wright (2005), este método normalmente é mais preciso que o Método de Fellenius, especialmente para as análises de tensão efetiva e pressão neutra relativamente elevada. Os mesmos autores relatam que esse método fica restrito para superfície de ruptura circular.

\subsubsection{Pesquisas no tema estabilidade de talude em solo não saturado}

Neste item estão reunidas algumas pesquisas nacionais e internacionais sobre o tema de estabilidade de talude em solos não saturados, apresentando uma síntese contendo as principais características do trabalho e as considerações mais relevantes.

Sabe-se que a infiltração da água da chuva provoca uma diminuição ou completa eliminação dos efeitos da sucção matricial nos solos dos taludes localizados em regiões com clima tropical, podendo gerar o escorregamento parcial ou total do talude. Inúmeras pesquisas nacionais e internacionais foram desenvolvidas sobre este tema nas últimas décadas, as quais buscam estabelecer uma correlação entre a precipitação e o escorregamento a partir de 
diferentes métodos (VARGAS; PICHLER, 1957; MATOS, 1974; LUMB, 1975; GUIDICINI; IWASA, 1976; EYLES; CROZIER; WHEELER, 1978; CAINE, 1980; BRAND, 1985; VARGAS JR.; COSTA FILHO; CAMPOS, 1986; TATIZANA et al., 1987; WIECZOREK, 1987; WOLLE, 1988; CARVALHO, 1989; KIM; HONG; KIM, 1991; LARSEN; SIMON, 1993; CERRI, 1993; FINLAY; FELL; MAGUIRE, 1997; GUZZETTI et al., 2008; CAI; UGAI, 2004).

Além dos trabalhos que buscam uma correlação entre precipitação e escorregamento, existem outros que procuram avaliar a estabilidade de taludes devido à redução da resistência ao cisalhamento provocada pela infiltração da água da chuva, pelo avanço da "frente de saturação" e pela consequente perda da sucção matricial. A maioria destes trabalhos visa avaliar a influência da intensidade pluviométrica no perfil de sucção matricial, nos parâmetros de resistência e no grau de estabilidade do talude a partir da modelagem numérica baseada nos resultados de ensaios de laboratório, ensaios de campo e monitoramento da instrumentação de campo.

Muitos dos trabalhos internacionais publicados nesta área de concentração avaliam a estabilidade de taludes a partir de dados técnicos sobre casos históricos ou locais de estudos que estão propensos à ocorrência de escorregamentos de solo. Como exemplo, pode-se citar algumas pesquisas desenvolvidas em países como Canadá (KRAHN; FREDLUND; KLASSEN, 1989; BLATZ; FERREIRA; GRAHAM, 2004), Estados Unidos (COLLINS; ZNIDARCIC, 2004; LU; GODT, 2008), Hong Kong (LUMB, 1975), Singapura (LIM et al., 1996; GASMO; RAHARDJO; LEONG, 2000; RAHARDJO; LEONG; REZAUR, 2002; TSAPARAS et al., 2002; RAHARDJO et al., 2007), Itália (MERIGGI; DI MARCO; PAVONI, 2002), Coréia (CHO; LEE, 2001; KIM; LEE, 2013), China (ZHANG; JIAO; YANG, 2000; HAMDHAN; SHWEIGER, 2013), Indonésia (GOFAR; LEE; ASOF, 2006), Japão (TRANDAFIR et al., 2008).

Além dos trabalhos internacionais, também merecem serem destacados neste item os trabalhos nacionais que estudam os taludes e as encostas localizadas em diferentes cidades ou regiões do Brasil, como a região da Serra do Mar (WOLLE, 1980; ABRAMENTO, 1988; CARVALHO, 1989; ZAMBRANA, 2014; VICTORINO, 2015), na cidade de Viçosa (TEIXEIRA, 2014), na cidade de São Paulo (GODOIS, 2011), na cidade de Santos (FREIRE, 1995), na cidade do Rio de Janeiro (MORGENSTERN; MATOS, 1975; GERSCOVICH; DE CAMPOS; VARGAS JR., 2011), na cidade de Salvador (JESUS, 2008) e no interior do Estado de São Paulo (QUEIROZ, 1986; QUEIROZ; GAIOTO, 1989; CALLE, 2000; MATTOS, 2009; SANTOS, 2004). 
Na sequência está apresentada uma síntese e as principais conclusões de trabalhos desenvolvidos recentemente sobre análise de estabilidade de talude em solo não saturado utilizando o programa computacional GeoStudio.

$\mathrm{Ng}$ e Shi (1998) realizaram investigação numérica para verificar a estabilidade de talude em solo não saturado sujeito ao fluxo transiente. $\mathrm{O}$ talude estudado localiza-se ao norte de Hong Kong, possuindo inclinação de $28^{\circ}$ e uma berma com $10 \mathrm{~m}$ de comprimento, sendo composto por uma camada superficial de $24 \mathrm{~m}$ de colúvio e uma camada de $6 \mathrm{~m}$ de rocha. As análises de fluxo foram realizadas no Seep/W, as quais investigaram a influência da intensidade da chuva (267 mm/dia, $181 \mathrm{~mm} / \mathrm{dia}, 267 \mathrm{~mm} /$ dia e $394 \mathrm{~mm} /$ dia $)$, duração da chuva ( 0 h, 24 h, 7 dias, 15 dias e 31 dias), condutividade hidráulica saturada do solo $\left(4,8.10^{-4}\right.$ $\mathrm{m} / \mathrm{s}, 4,8.10^{-5} \mathrm{~m} / \mathrm{s}$ e $\left.4,8.10^{-6} \mathrm{~m} / \mathrm{s}\right)$ e anisotropia do solo $\left(k_{x} / k_{y}=1, k_{x} / k_{y}=2\right.$ e $\left.k_{x} / k_{y}=4\right)$. Já as análises de estabilidade do talude foram feitas a partir do método de Bishop Simplificado e os parâmetros de resistência ao cisalhamento do solo definido segundo o critério de ruptura de Mohr-Coulomb modificado.

Os resultados da influência da intensidade da chuva para as três seções críticas mostraram que as pressões neutras (positiva/negativa) e a profundidade do nível d’água variaram principalmente para as maiores intensidades de chuva, destacando-se a seção C-C, localizada na crista do talude, que apresentou uma considerável redução na pressão neutra negativa. No geral, o fator de segurança mostra que há uma tendência na sua diminuição em função do aumento da intensidade da chuva, podendo este efeito estar associado com a redução da sucção matricial devido ao acréscimo da pressão neutra. Os autores relatam que a série de análises paramétricas ilustram claramente como o fator de segurança depende da intensidade da chuva e da distribuição de pressão neutra inicial.

Os resultados da influência da duração da chuva apontaram que o fator de segurança diminui em função da sua duração. Nas análises realizadas nesse trabalho, os autores determinaram a duração da chuva crítica, que ocorre entre o terceiro e o sétimo dia, como ilustra a Figura 3.7. Observa-se que o fator de segurança diminui até atingir a duração da chuva crítica, sendo identificados trechos denominados $\Delta f_{1}$ e $\Delta f_{2}$ que representam chuva antecedente e chuva de alta intensidade (tempestade), respectivamente. Os autores sugerem que a chuva forte (tempestade) que ocorre após a chuva antecedente cuja duração tenha sido inferior ou igual ao da duração crítica, esta afeta a estabilidade do talude. Os autores também comentam que uma chuva de alta intensidade pode ser um fator de desencadeamento de deslizamento assim como a duração da chuva antecedente. 


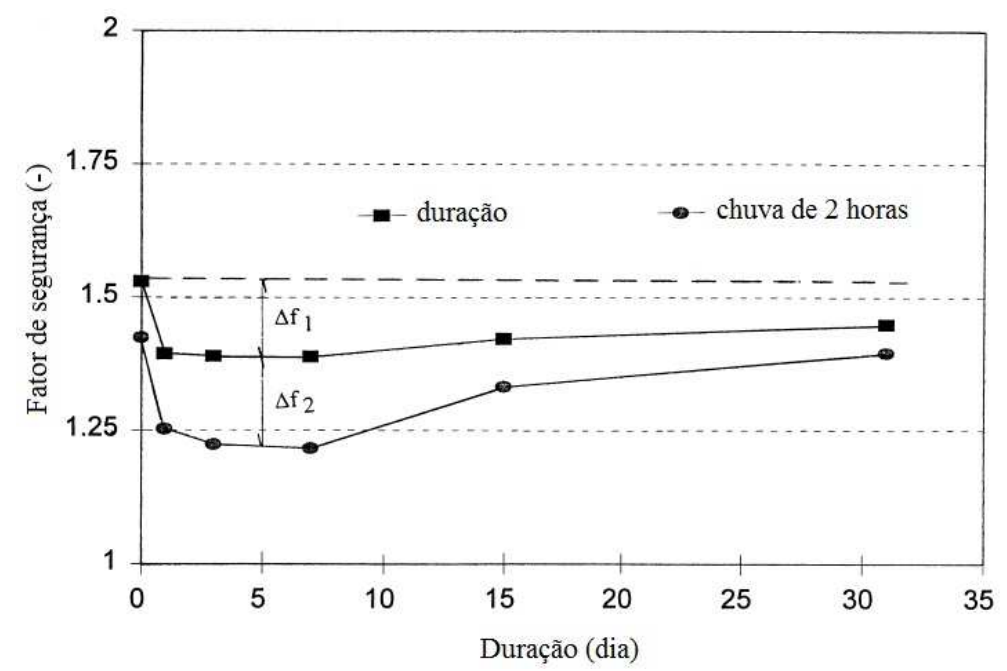

Figura 3.7 - Fator de segurança variando em função da duração da chuva.

Fonte: Traduzido e adaptado de Ng e Shi (1998).

Os resultados da influência da condutividade hidráulica saturada do solo considerado isotrópico indicaram que o fator de segurança reduz em função da diminuição da permeabilidade saturada do solo, conforme ilustra a Figura 3.8. Esta figura representa a variação do fator de segurança num talude sujeito à chuva de $267 \mathrm{~mm} /$ dia, composto por solo com diferentes permeabilidades $\left(4,8.10^{-4} \mathrm{~m} / \mathrm{s}, 4,8.10^{-5} \mathrm{~m} / \mathrm{s}\right.$ e $\left.4,8.10^{-6} \mathrm{~m} / \mathrm{s}\right)$. Os autores comentam que o fator de segurança diminui significantemente quando a permeabilidade saturada do solo é da mesma ordem de grandeza que a chuva $\left(4,8.10^{-6} \mathrm{~m} / \mathrm{s}\right.$ e $267 \mathrm{~mm} / \mathrm{dia}$, que corresponde a $3,1 \cdot 10^{-6} \mathrm{~m} / \mathrm{s}$ ).

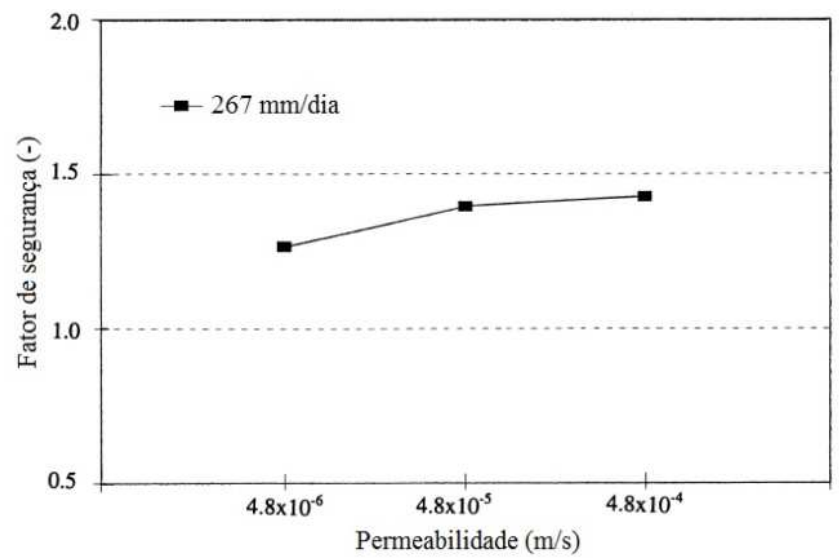

Figura 3.8 - Fator de segurança variando em função da permeabilidade do solo.

Fonte: Traduzido e adaptado de Ng e Shi (1998).

Os resultados da influência da anisotropia do solo mostraram que o talude sofre algumas alterações na distribuição de pressão neutra e tem uma significante interferência na posição do nível d’água inicial, visto que o solo tem sua permeabilidade reduzida na direção 
vertical $\left(k_{x}\right.$ igual a $4,8 \cdot 10^{-5} \mathrm{~m} / \mathrm{s}$ e $k_{y}$ igual a $4,8 \cdot 10^{-5} \mathrm{~m} / \mathrm{s}, 2,4 \cdot 10^{-5} \mathrm{~m} / \mathrm{s}$ e $\left.1,2 \cdot 10^{-5} \mathrm{~m} / \mathrm{s}\right)$. Os autores relatam que, no caso do fluxo permanente, o fator de segurança diminui à medida que a razão da anisotropia do solo aumenta e no caso do fluxo transiente, o fator de segurança diminui rapidamente quando o talude está sujeito à chuva diária de $267 \mathrm{~mm} / \mathrm{h}$, ocorrendo a ruptura do talude quando a relação de $k_{x} / k_{y}$ for igual a 4 (Figura 3.9).

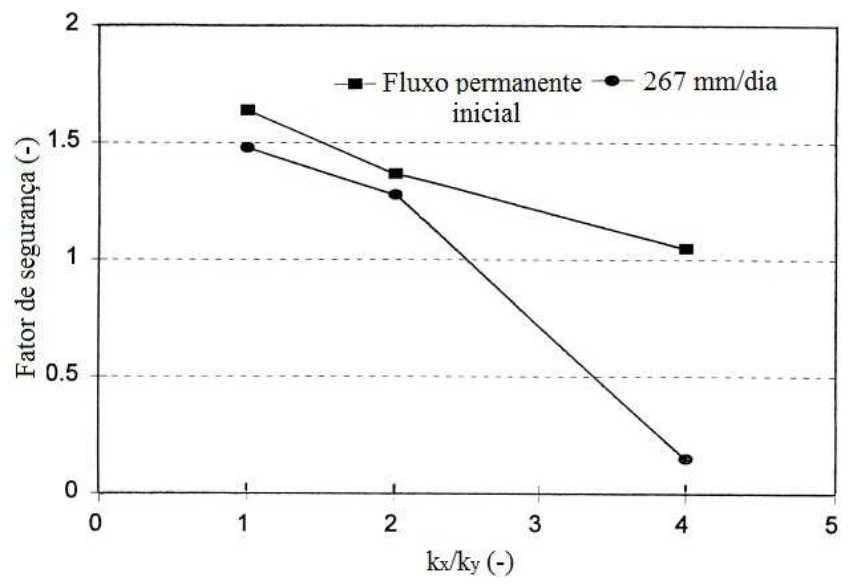

Figura 3.9 - Fator de segurança variando em função da anisotropia do solo.

Fonte: Traduzido e adaptado de Ng e Shi (1998).

Os autores concluem que a profundidade inicial do nível d’água corrobora para um efeito significante na estabilidade do talude e que as análises paramétricas mostram claramente que o fator de segurança não depende somente da intensidade da chuva, mas das condições do nível d’água antes da chuva. $\mathrm{Ng}$ e Shi (1998) também concluem que a chuva antecedente influencia na estabilidade do talude e o fator de segurança diminui até atingir uma duração crítica. Além disso, os autores comentam que o fator de segurança reduz com o aumento da permeabilidade do solo e da relação de anisotropia do solo $\left(k_{x} / k_{y}\right)$.

Gasmo, Rahardjo e Leong (2000) desenvolveram um estudo numérico para analisar os efeitos da infiltração em um talude de solo residual. Neste trabalho foi modelado um talude localizado em Singapura, com inclinação de aproximadamente $26^{\circ}$ e altura média de 6,5 metros, o qual é composto por camada de argila siltosa laranja e argila siltosa roxa (ambos da formação Jurong). Na primeira etapa do trabalho, os autores realizaram um estudo para avaliar como a taxa de infiltração varia em função da intensidade da chuva, do tempo e da localidade do talude (crista, face e pé). Nestas análises foram adotadas diferentes intensidades de chuva no fluxo permanente (de $1.10^{-8} \mathrm{~m} / \mathrm{s}$ a $1.10^{-3} \mathrm{~m} / \mathrm{s}$ ) e no fluxo transiente (de $1.10^{-7} \mathrm{~m} / \mathrm{s}$ a $1.10^{-5} \mathrm{~m} / \mathrm{s}$ ). Os resultados dessa etapa mostraram que o maior fluxo de água ocorreu na crista do talude, atingindo um valor de fluxo de $4,6.10^{-7} \mathrm{~m} / \mathrm{s}$, que corresponde à $55 \%$ do 
valor da condutividade hidráulica saturada. Já o menor fluxo de água ocorreu no pé do talude, o qual corresponde um valor de $0,5 \%$ da condutividade hidráulica saturada $\left(4,5 \cdot 10^{-9} \mathrm{~m} / \mathrm{s}\right)$.

$\mathrm{Na}$ segunda etapa do trabalho, os autores fizeram simulação numérica no Seep/W para determinar a distribuição de pressão neutra. Posteriormente, eles analisaram a estabilidade de talude usando método do equilíbrio limite no Slope/W para analisar como as variações na distribuição da pressão neutra afetam o fator de segurança. Nesta etapa foi utilizada a mesma geometria que o talude da etapa anterior e dados de instrumentação de campo presentes no trabalho de Gasmo et al. (1999). Nas análises de fluxo foram aplicados na superfície do talude valores de chuva e evaporação correspondente ao período de 21 de julho de 1996 a 10 de agosto de 1996.

Os resultados das análises de fluxo relativas a essa etapa mostraram que o modelo numérico de perfil de pressão neutra obtida no Seep/W apresenta a mesma tendência que o perfil de pressão neutra resultante em campo. Porém, os autores relatam que o modelo numérico não representa precisamente perfil de pressão neutra pelo tempo decorrido em campo e que este modelo não está hábil para descrever fielmente a infiltração no caso estudado.

Os resultados das análises de estabilidade indicaram que o fator de segurança tende a ser maior para o perfil de pressão neutra obtido pela instrumentação de campo e menor para o modelo numérico do Seep/W (Figura 3.10). No caso do modelo numérico, o fator de segurança cresceu em 34\% após 13 dias (20 de julho a 03 de agosto) e diminuiu em 27\% após $2 \mathrm{~h}$ de chuva ocorrida no dia 03 de agosto. Gasmo, Rahardjo e Leong (2000) comentam que embora o modelo numérico seja impróprio para a infiltração do caso estudado, a distribuição de pressão neutra resultante do modelo pode ser utilizada para as análises de estabilidade do talude.

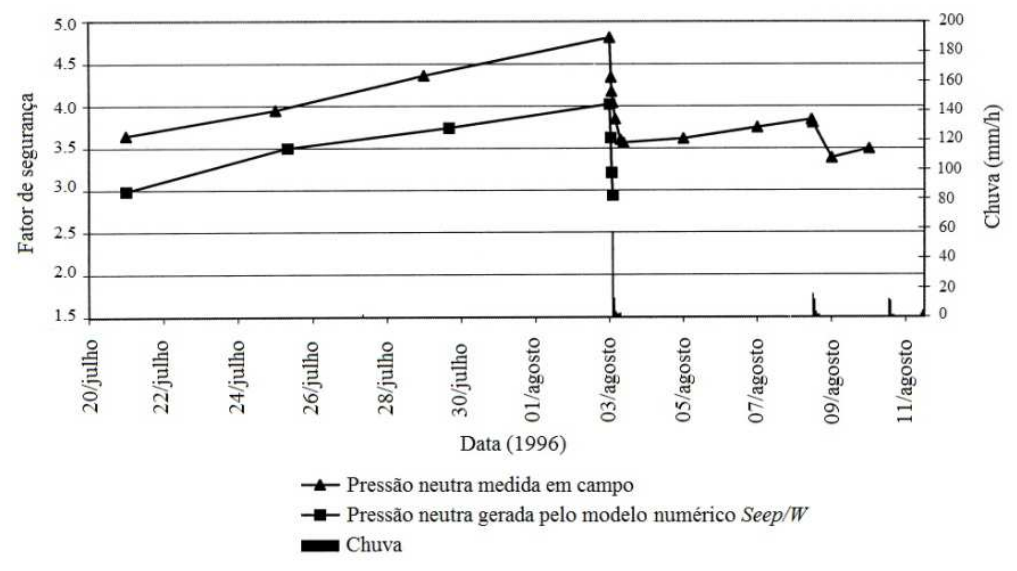

Figura 3.10 - Resultados das análises de fluxo permanente.

Fonte: Traduzido e adaptado de Gasmo, Rahardjo e Leong (2000). 
Os autores mencionam algumas limitações numéricas do modelo, relatando alguns detalhes que podem ter ocasionado essas diferenças, tais como: a representação simplificada do talude em solo residual, o modelo idealizado das camadas do talude não correspondem exatamente com as condições de campo, a permeabilidade utilizada pode não representar como ela varia com a profundidade, as especificações das condições de contorno e os parâmetros especificados no modelo precisam ser mais refinados.

Calle (2000) elabora uma análise paramétrica de um talude localizado na região Centro-Oeste Paulista com o objetivo de avaliar o efeito da chuva na estabilidade de um talude rompido. Neste trabalho foram realizados ensaios de campo, laboratório e modelagens numéricas para uma seção de talude com inclinação de aproximadamente $63,9^{\circ}$ e altura de 15,2 m. O talude estudado é composto por solo residual da Formação Serra Geral e Botucatu, o qual é classificado como areia argilosa, sendo este admitido homogêneo e seco ao longo de toda a seção. O perfil inicial de pressão neutra foi obtido a partir dos valores máximos de campo fornecidos pelos tensiômetros (entre $-50 \mathrm{kPa}$ e $-60 \mathrm{kPa}$ ), tendo sido assumido que o nível d’água localiza-se à $25 \mathrm{~m}$ abaixo da superfície da crista do talude. As análises de fluxo foram feitas no Seep/W simulando chuvas com intensidade de $20 \mathrm{~mm} / \mathrm{h}$ e de $70 \mathrm{~mm} / \mathrm{h}$ para um intervalo de 30 minutos a 30 horas. Na sequência, os resultados dessas análises foram acopladas ao Slope/W, o qual foi utilizado para verificar a estabilidade do talude a partir da determinação do fator de segurança.

As análises de estabilidade desta pesquisa mostraram que o fator de segurança é ligeiramente maior que a unidade para a superfície de ruptura delimitada em campo, no caso das análises feitas utilizando parâmetros de resistência de solo não saturado. Já para o caso das análises em que foram considerados os parâmetros de resistência do solo saturado, o fator de segurança apresentou-se bem inferior que a unidade. Diante desses resultados, o autor conclui que o talude possivelmente encontrava-se numa condição de não saturação quando ocorreu sua ruptura. $\mathrm{O}$ autor também ressalta a importância da influência da redução da sucção matricial na resistência ao cisalhamento em taludes terrosos situados nas regiões com clima tropical, que devido ao processo de infiltração da água da chuva acabam muitas vezes tornando-se instáveis.

Cho e Lee (2001) usaram métodos numéricos para estudar a instabilidade de talude em solo não saturado, acoplando análises de fluxo, deformação e estabilidade. Neste trabalho foi idealizado um talude com inclinação de $40^{\circ}$ e altura de 30 metros, composto por solo homogêneo e isotrópico. O perfil inicial de pressão neutra foi considerado hidrostático, tendo sido assumido -60 kPa para o máximo valor de pressão neutra negativa acima do nível d’água. 
A análise de fluxo transiente foi feita empregando uma chuva de intensidade $20 \mathrm{~mm} / \mathrm{h}$ para um período de 66 horas. Nestas análises numéricas foram utilizados dois valores de condutividade hidráulica saturada $\left(5.10^{-5} \mathrm{~m} / \mathrm{s}\right.$ e $\left.5.10^{-6} \mathrm{~m} / \mathrm{s}\right)$ para estudar o efeito que esse parâmetro proporciona na estabilidade do talude. Nas análises de estabilidade, o fator de segurança foi determinado para superfície crítica de escorregamento com formato circular e não circular.

Os resultados de fluxo mostraram que decorrido o tempo de 66 horas e comparando-se com a distribuição de pressão neutra inicial, o perfil de pressão neutra variou bruscamente para a condutividade hidráulica saturada de $5.10^{-5} \mathrm{~m} / \mathrm{s}$ enquanto que, para a condutividade hidráulica saturada de $5.10^{-6} \mathrm{~m} / \mathrm{s}$ o perfil de pressão neutra variou mais lentamente, inclusive apresentando uma pequena elevação do nível d’água próximo ao pé do talude (Figura 3.11).

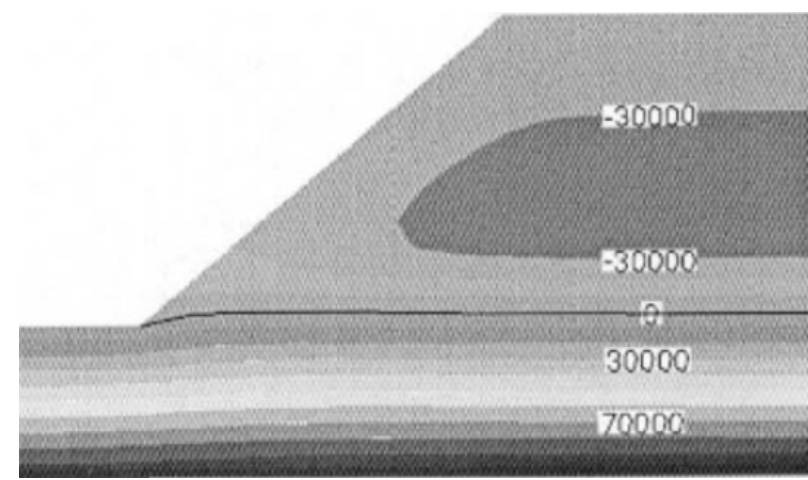

(a)

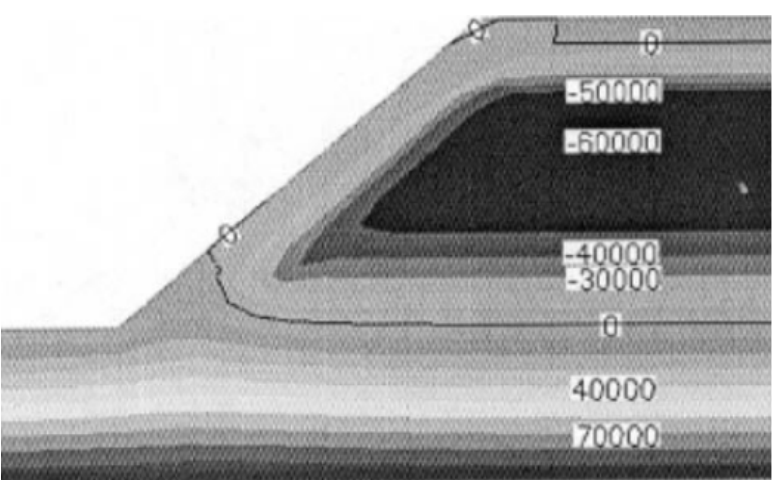

(b)

Figura 3.11 - Distribuição da pressão neutra para condutividade hidráulica saturada correspondente a (a) $5.10^{-5} \mathrm{~m} / \mathrm{s}$ e (b) $5.10^{-6} \mathrm{~m} / \mathrm{s}$.

Fonte: Cho e Lee (2001).

Já os resultados de estabilidade apontaram que o baixo valor de condutividade hidráulica saturada impede a flutuação do nível d’água, induzindo o aumento da pressão neutra e reduzindo o fator de segurança. A Figura 3.12a,b ilustra as superfícies críticas de escorregamento com formato circular para dois valores de condutividade hidráulica saturada $\left(5.10^{-5} \mathrm{~m} / \mathrm{s}\right.$ e $\left.5.10^{-6} \mathrm{~m} / \mathrm{s}\right)$, em que a variação do fator de segurança é dado em função da infiltração da água da chuva durante 66 horas. Nota-se nessas figuras que a superfície crítica de escorregamento tende a se deslocar em direção à superfície do talude conforme ocorra $\mathrm{o}$ aumento na duração da chuva. Além disso, o fator de segurança tende a reduzir significantemente quando a superfície de escorregamento está localizada próxima da superfície do talude, ou seja, quando a duração da chuva está próxima de 66 horas (Figura $3.13)$. 


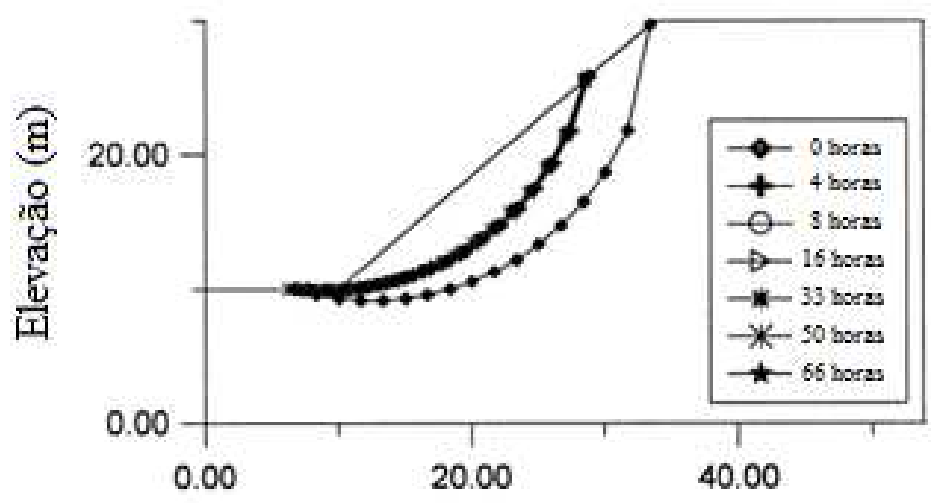

Distância (m)

(a)

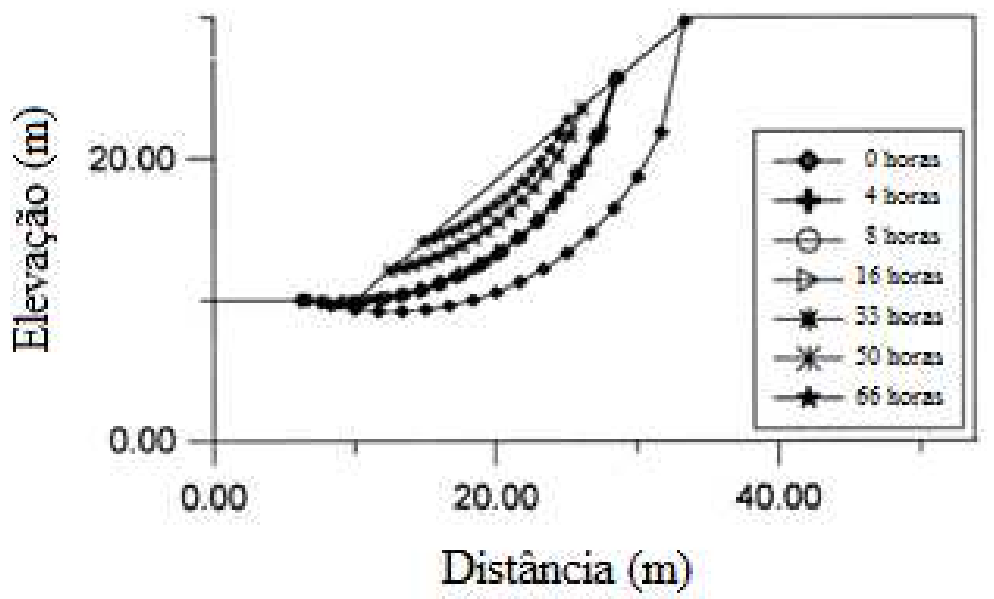

(b)

Figura 3.12 - Superfícies críticas de escorregamento em formato circular para condutividade hidráulica saturada correspondente a (a) $5.10^{-5} \mathrm{~m} / \mathrm{s}$ e (b) $5.10^{-6} \mathrm{~m} / \mathrm{s}$.

Fonte: Traduzido e adaptado de Cho e Lee (2001).

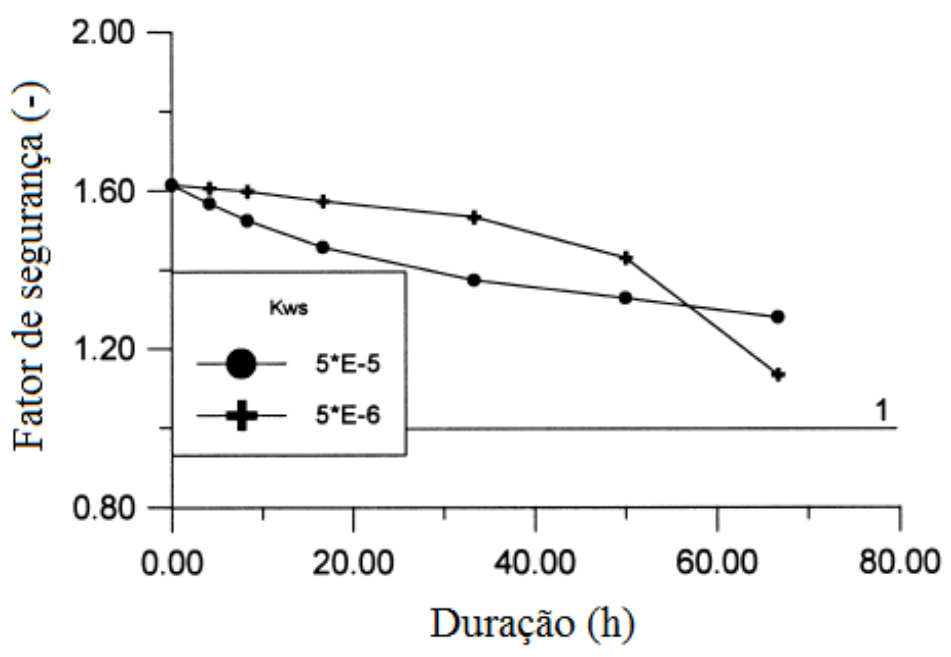

Figura 3.13 - Fator de segurança em função da infiltração da água da chuva para condutividade hidráulica saturada de $5.10^{-5} \mathrm{~m} / \mathrm{s}$ e de $5.10^{-6} \mathrm{~m} / \mathrm{s}$.

Fonte: Traduzido e adaptado de Cho e Lee (2001). 
Tsaparas et al. (2002) tentam identificar a influência de alguns parâmetros na estabilidade de um talude de solo não saturado a partir de análises paramétricas. Neste trabalho o talude estudado possui altura de $10 \mathrm{~m}$ e inclinação de $26,6^{\circ}(2 \mathrm{H}: 1 \mathrm{~V})$, localizado em Cingapura. O solo residual que compõe o talude é homogêneo e isotrópico ao longo de todo perfil, típico da formação Jurong e classificado como argila siltosa. As análises de fluxo foram realizadas no Seep/W, as quais avaliaram a distribuição da chuva antecedente (diversos cenários como $1 \mathrm{~mm} / \mathrm{h}, 5 \mathrm{~mm} / \mathrm{h}$ e $0,21 \mathrm{~mm} / \mathrm{h}$ e sem chuva antecedente), a distribuição da principal chuva (diversos cenários como $15 \mathrm{~mm} / \mathrm{h}, 30 \mathrm{~mm} / \mathrm{h}, 60 \mathrm{~mm} / \mathrm{h}$ e $120 \mathrm{~mm} / \mathrm{h}$ ), o coeficiente de permeabilidade $\left(1.10^{-4} \mathrm{~m} / \mathrm{s}, 1.10^{-5} \mathrm{~m} / \mathrm{s}, 1.10^{-6} \mathrm{~m} / \mathrm{s} \mathrm{e} 1.10^{-7} \mathrm{~m} / \mathrm{s}\right)$ e o perfil inicial de pressão neutra (valores máximos de $-25 \mathrm{kPa},-50 \mathrm{kPa},-75 \mathrm{kPa}$ ). De acordo com os autores, a instrumentação de campo desse talude aponta que os valores da pressão neutra negativa próxima à superfície são superiores à $-70 \mathrm{kPa}$ após um longo período seco. Por esse motivo foram assumidas três condições iniciais de distribuição de pressão neutra, conforme mencionado anteriormente. As análises de estabilidade de talude foram feitas usando o método de Bishop Simplificado no Slope/W a partir do acoplamento dos resultados de fluxo transiente, determinando o fator de segurança para as diversas condições de distribuição de pressão neutra.

Os resultados de fluxo mostraram que, caso o evento da chuva principal seja distribuído para um longo período, esta poderia ocasionar maior influência no desenvolvimento e na variação das pressões neutra no talude. A Figura 3.14 ilustra a distribuição de pressão neutra na crista do talude para uma chuva de $240 \mathrm{~mm}$ com diferentes durações ( 2 h, 4 h, 8 h e 16 h) no solo com condutividade hidráulica saturada de $1.10^{-4} \mathrm{~m} / \mathrm{s} \mathrm{e}$ perfil inicial de pressão neutra de $-25 \mathrm{kPa}$. Observa-se nesta figura que a duração da chuva interfere na variação da pressão neutra, ou seja, o aumento da profundidade da frente de umedecimento e da variação da pressão neutra é proporcional com o aumento da duração da chuva. Os autores comentam que, quando a razão entre a intensidade da chuva e a condutividade hidráulica saturada é muito pequena, a pressão neutra negativa pode não ser afetada pela infiltração da água, enquanto que, quando a razão entre a intensidade da chuva e a condutividade hidráulica saturada é muito grande, o acréscimo de pressão neutra pode ter pequeno impacto no início da precipitação e tornar-se um efeito importante após o término do período chuvoso. 


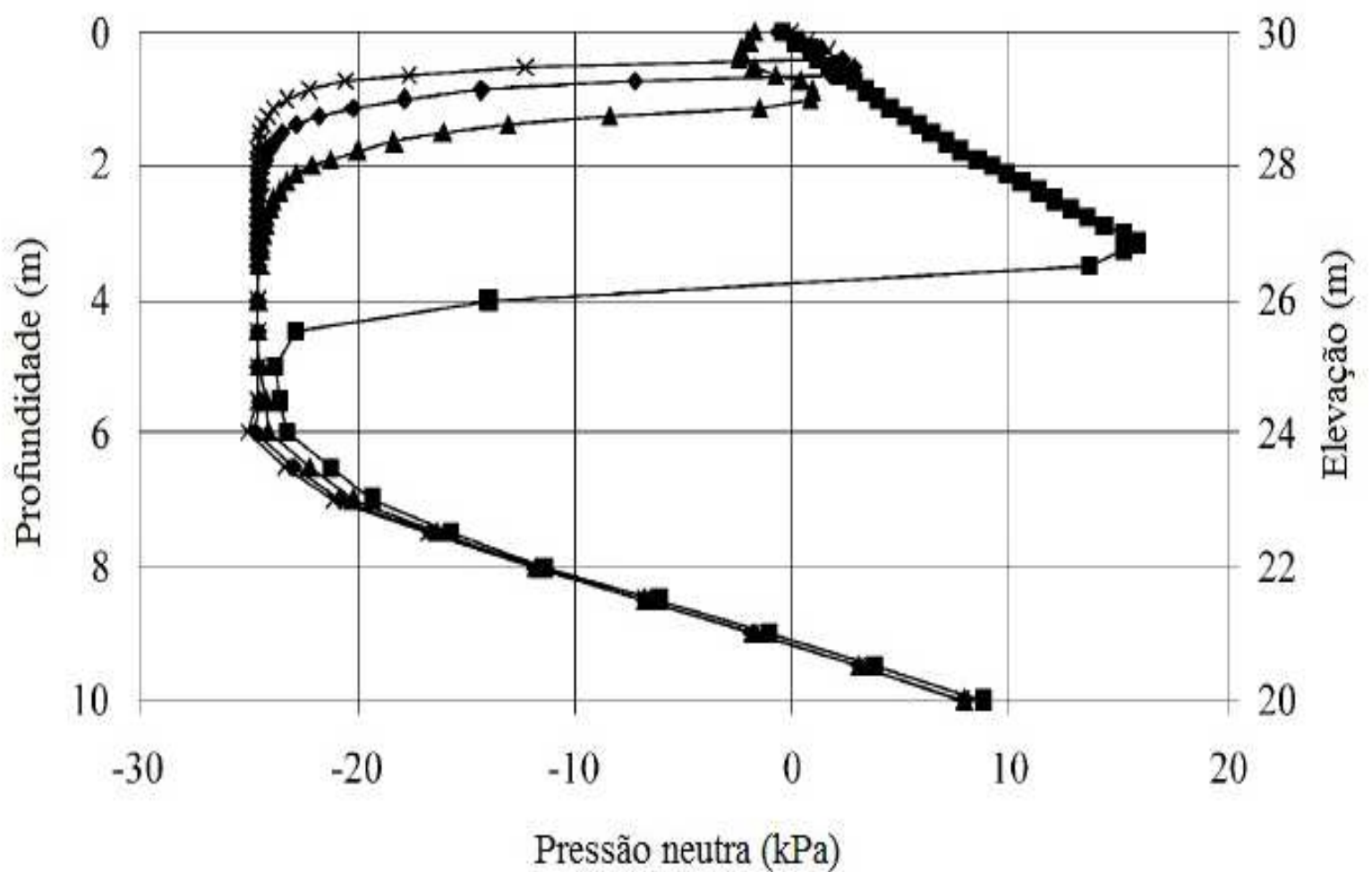

\section{$\rightarrow$ - Distribuição de $240 \mathrm{~mm}$ em 16 horas $\rightarrow$ Distribuição de $240 \mathrm{~mm}$ em 8 horas \\ $\rightarrow$ Distribuição de $240 \mathrm{~mm}$ em 4 horas * Distribuição de $240 \mathrm{~mm}$ em 2 horas}

Figura 3.14 - Distribuição da pressão neutra na crista do talude após o término da chuva para o solo com condutividade hidráulica saturada de $1.10^{-4} \mathrm{~m} / \mathrm{s}$ e perfil inicial de pressão neutra de $-25 \mathrm{kPa}$.

Fonte: Traduzido e adaptado de Tsaparas et al. (2002).

Os resultados de análise de estabilidade apontaram que os eventos pluviométricos (chuva principal e chuva antecedente) e os valores de condutividade hidráulica saturada do solo controlam o fator de segurança. A Figura 3.15 ilustra a variação do fator de segurança em função do tempo decorrido da infiltração da chuva correspondente ao cenário 3 (chuva antecedente com intensidade de $0,21 \mathrm{~mm} / \mathrm{h}$ distribuída ao longo de 120 horas e chuva principal intensidade de $60 \mathrm{~mm} / \mathrm{h}$ distribuída ao longo de 4 horas) para o perfil inicial de pressão neutra de $-25 \mathrm{kPa}$ e nível d’água localizado no pé do talude. Observa-se nesta figura uma tendência no comportamento do fator de segurança para os solos altamente permeáveis $\left(1.10^{-4} \mathrm{~m} / \mathrm{s}\right.$ e $\left.1.10^{-5} \mathrm{~m} / \mathrm{s}\right)$ e os solos moderadamente permeáveis $\left(1.10^{-6} \mathrm{~m} / \mathrm{s}\right.$ e $\left.1.10^{-7} \mathrm{~m} / \mathrm{s}\right)$. No caso dos solos altamente permeáveis, por exemplo, estes usualmente apresentaram fator de segurança igual ou inferior ao valor unitário no término da chuva principal. Já no caso dos solos moderadamente permeáveis, por exemplo, estes praticamente não apresentaram grande variação do fator de segurança nem com a chuva antecedente nem com a chuva principal. 


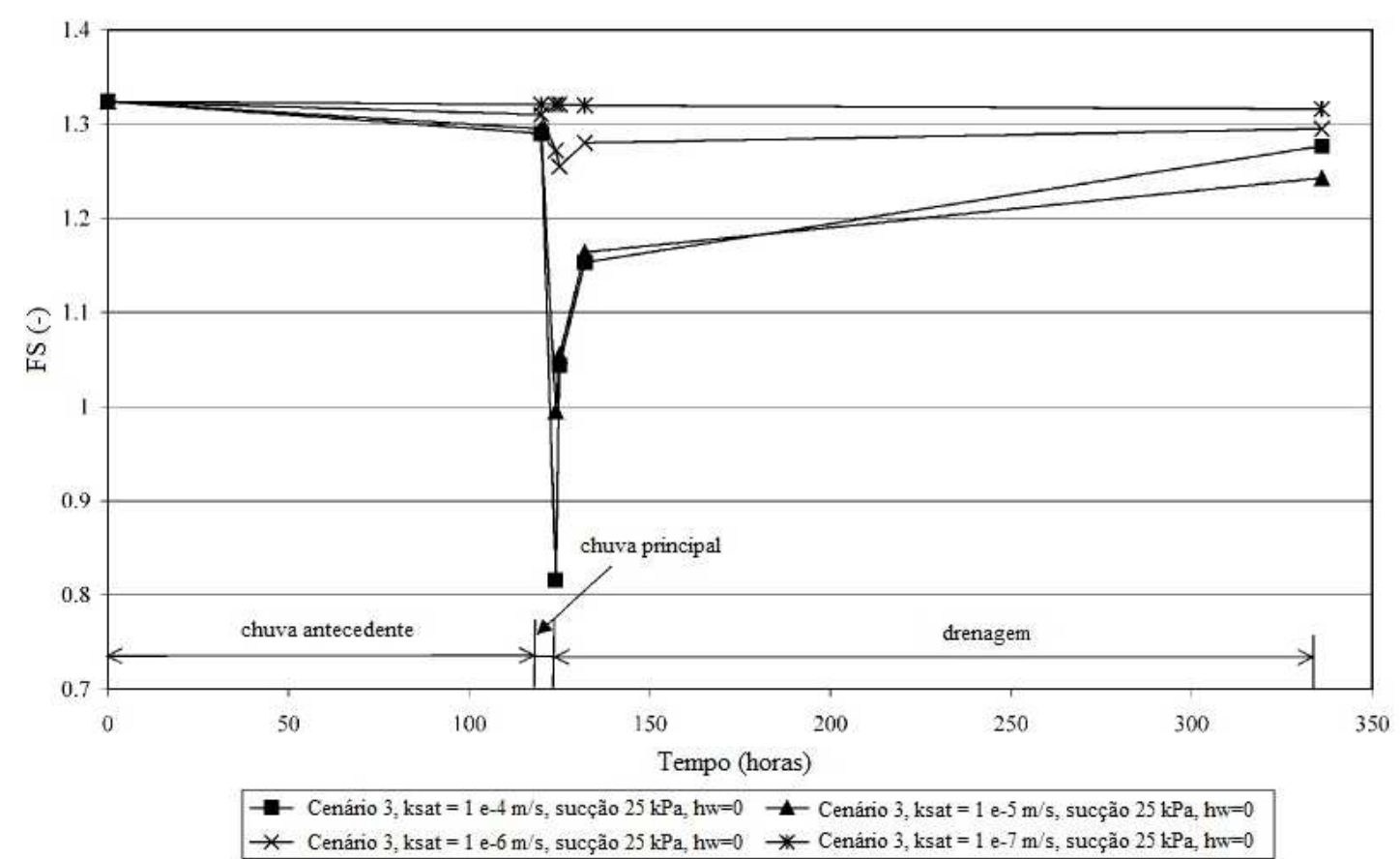

Figura 3.15 - Fator de segurança em função do tempo decorrido da infiltração da chuva correspondente ao cenário 3 para o perfil inicial de pressão neutra de $-25 \mathrm{kPa}$ e nível d’água localizado no pé do talude.

Fonte: Traduzido e adaptado de Tsaparas et al. (2002).

Rahardjo, Leong e Rezaur (2002) realizaram análises paramétricas no Seep/W para estudar os efeitos da infiltração na estabilidade de um talude em solo residual não saturado e análises de estabilidade no Slope/W para determinar a superfície crítica de ruptura e o fator de segurança a partir das análises de fluxo transiente. Neste trabalho foram utilizadas uma combinação de quatro tipos de inclinação do talude $\left(18^{\circ}, 27^{\circ}, 45^{\circ}\right.$ e $\left.63^{\circ}\right)$ e três tipos de altura $(10 \mathrm{~m}, 20 \mathrm{~m}$ e $40 \mathrm{~m})$, sendo assumido que o talude é composto por solo homogêneo e uma única camada em todo perfil, típico de Cingapura. O perfil inicial de pressão neutra foi considerado hidrostático, limitando à $-75 \mathrm{kPa}$ o máximo valor de pressão neutra negativa acima do nível d'água. Nas análises de fluxo foi aplicada uma chuva com intensidade de 80 $\mathrm{mm} / \mathrm{h}$ num período de 4 horas e posteriormente, outra chuva com intensidade de $1.10^{-9} \mathrm{~mm} / \mathrm{h}$ num período de 10 dias com a finalidade de redistribuir a água infiltrada no talude.

Os resultados das análises de fluxo mostraram que a inclinação e a altura do talude bem como a distribuição da pressão neutra influenciam na estabilidade do talude. No caso de um talude com altura de $10 \mathrm{~m}$ e $27^{\circ}$ de inclinação, os resultados indicaram que antes da chuva o fator de segurança era de 2,907 e após a chuva de $80 \mathrm{~mm} / \mathrm{h}$ num período de 4 horas, o fator de segurança passou a ser de 1,400. A Figura 3.16a ilustra os gráficos de superfície crítica de ruptura versus tempo e de fator de segurança versus tempo para um talude com inclinação de $27^{\circ}$ e altura de $10 \mathrm{~m}, 20 \mathrm{~m}$ e $40 \mathrm{~m}$. Observa-se pela Figura $3.16 \mathrm{~b}$ que independente da altura 
do talude o menor fator de segurança foi alcançado no tempo de 4 horas e a profundidade da superfície crítica de ruptura variou em função do tempo, sendo menos profunda para o período com chuva de $80 \mathrm{~mm} / \mathrm{h}$ e mais profunda para o período sem chuva.

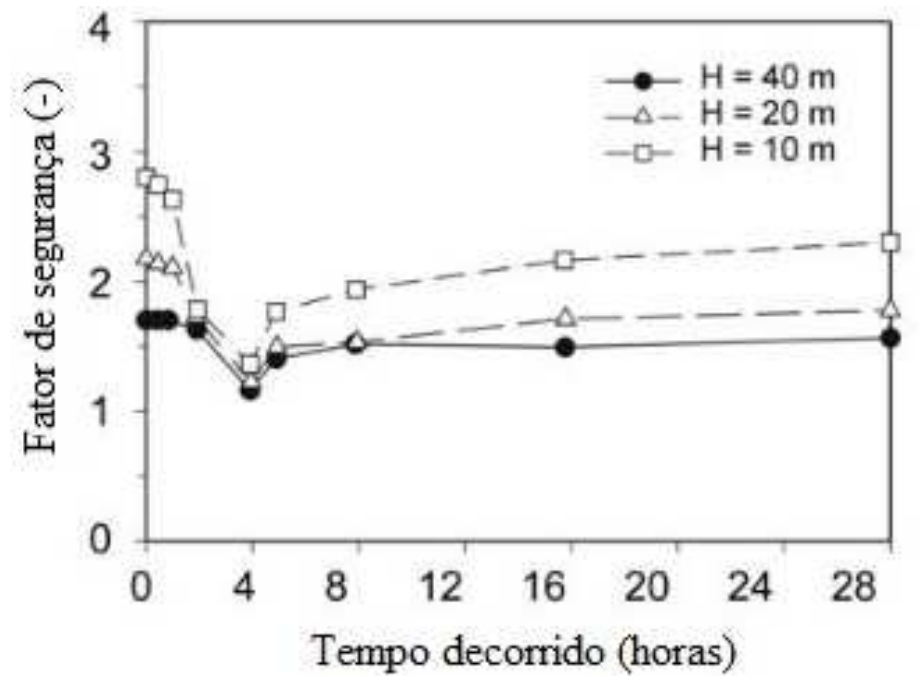

(a)

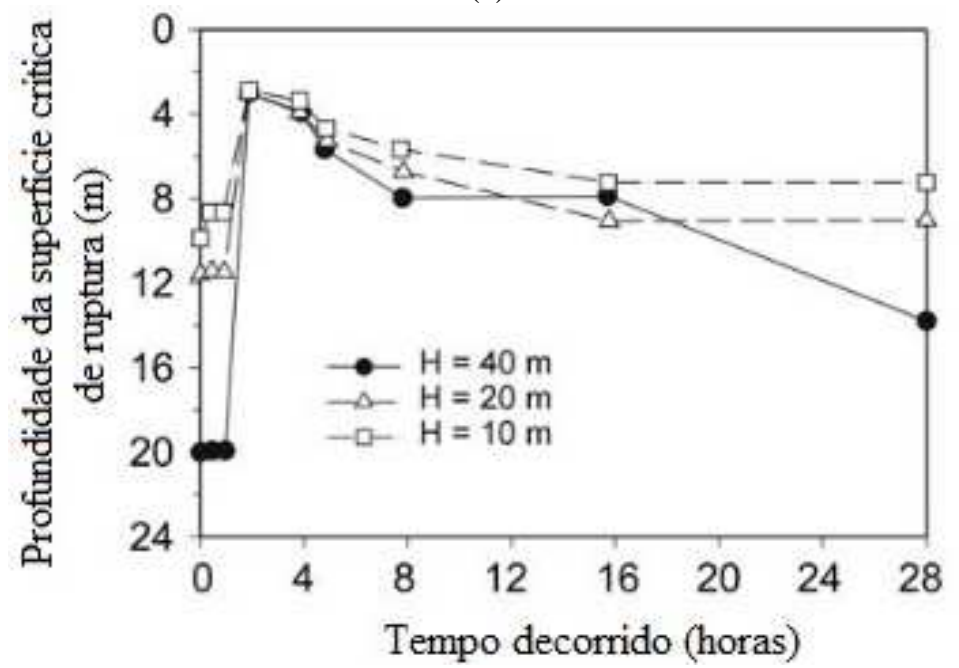

(b)

Figura 3.16 - (a) Fator de segurança em função do tempo decorrido e (b) Profundidade da superfície crítica de ruptura em função do tempo decorrido.

Fonte: Traduzido e adaptado de Rahardjo, Leong e Rezaur (2002).

Os autores também analisaram a variação do fator de segurança para diversos intervalos de tempo ( 0 h, $30 \mathrm{~min}, 1 \mathrm{~h}, 2 \mathrm{~h}$ e $4 \mathrm{~h}$ ) aplicando uma chuva com intensidade de 80 $\mathrm{mm} / \mathrm{h}$. Estas análises têm a finalidade de compreender como o fator de segurança se modifica para diferentes inclinações e alturas do talude. No caso do talude com altura fixa de $10 \mathrm{~m}$, os resultados indicam uma tendência no comportamento do fator de segurança para as diferentes inclinações, variando bem pouco e lentamente até o tempo de $1 \mathrm{~h}$ e variando mais rapidamente e bruscamente para tempo superior a $1 \mathrm{~h}$ (Figura 3.17a). Já para o caso do talude com inclinação fixa de $27^{\circ}$, os resultados também apontam uma tendência no comportamento 
do fator de segurança para as diferentes alturas, pois praticamente não ocorre variação no fator de segurança para o intervalo de $0 \mathrm{~h}$ a $1 \mathrm{~h}$ enquanto que a partir do tempo de $1 \mathrm{~h}$ ocorre uma rápida variação do fator de segurança (Figura 3.17b).

Fator de segurança para taludes com altura de $10 \mathrm{~m}$

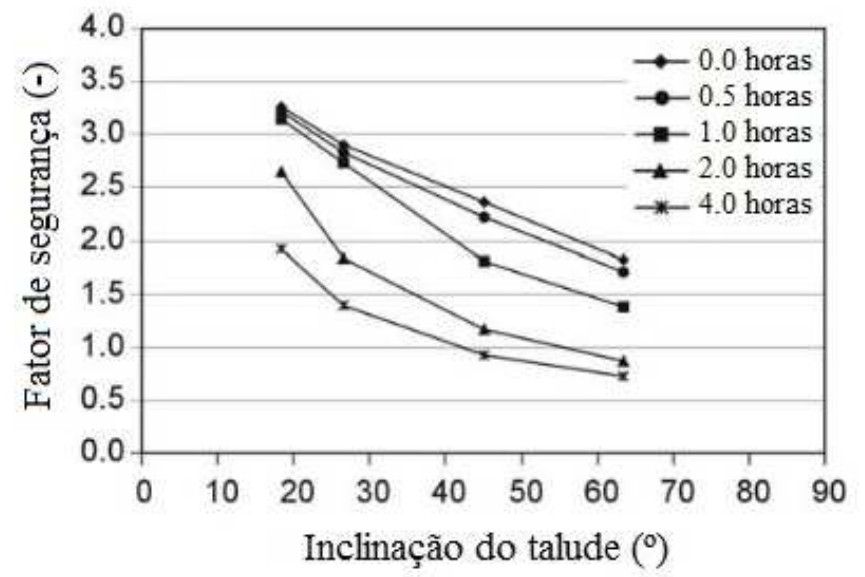

(a)

Fator de segurança para taludes com inclinação

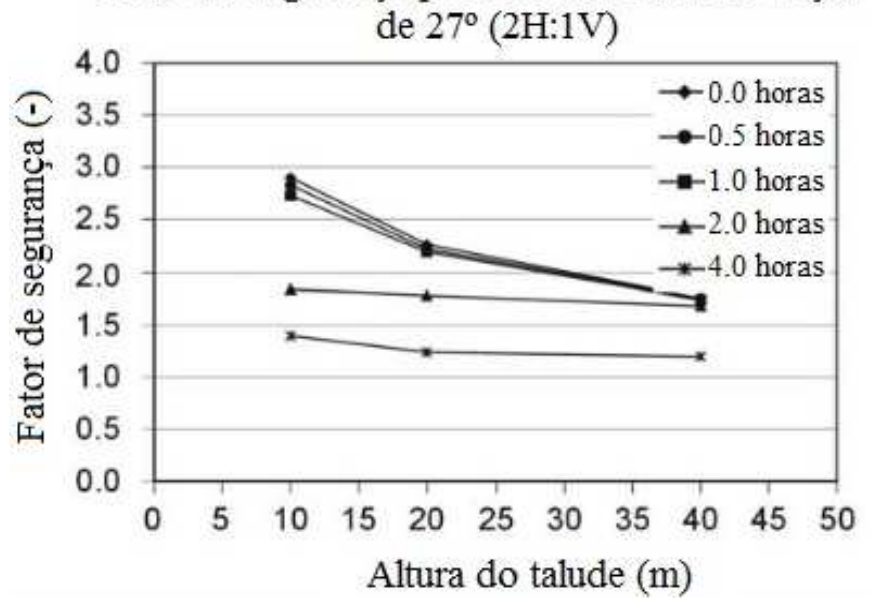

(b)

Figura 3.17 - Fator de segurança em função da (a) inclinação do talude e (b) altura do talude.

Fonte: Traduzido e adaptado de Rahardjo, Leong e Rezaur (2002).

Santos (2004) realizou um estudo paramétrico para analisar a infiltração da água da chuva e sua interferência na estabilidade de um talude em solo não saturado. O talude estudado possui $63^{\circ}$ de inclinação e $8 \mathrm{~m}$ de altura (baseado nos dados apresentado por CALLE (2000)) e está localizado na região Centro-Oeste Paulista. O solo do talude foi considerado homogêneo e isotrópico, sendo analisado o comportamento do talude para três tipos de solo (A - areia, B - silte argiloso e C - areia silto argilosa). O nível d'água foi assumido horizontal e posicionado $8 \mathrm{~m}$ abaixo da superfície do pé do talude. O perfil inicial de pressão neutra negativa foi assumido hidrostático acima do nível d'água, variando de $0 \mathrm{kPa}$ a $-50 \mathrm{kPa}$ e permanecendo constante $(-50 \mathrm{kPa})$ até alcançar a superfície do talude. As análises 
de fluxo foram feitas utilizando o método dos elementos finitos no Seep/W, sendo aplicada em toda a superfície do talude diferentes intensidade de chuva $(1 \mathrm{~mm} / \mathrm{h}, 20 \mathrm{~mm} / \mathrm{h}$ e $70 \mathrm{~mm} / \mathrm{h})$ para diversos intervalo de tempo. Também foram realizadas diversas análises paramétricas para avaliar algumas características do solo e compreender a evolução do perfil de pressão neutra no talude. Já as análises de estabilidade de talude foram baseadas nos resultados de fluxo transiente e feitas no Slope/W com o uso do método de Bishop simplificado, simulando algumas condições de distribuição de pressão neutra no talude.

Os resultados de fluxo transiente mostram que é possível distinguir quatro diferentes padrões de comportamento para o perfil de pressão neutra dos três tipos de solo (Figura 3.18), sendo eles:

- perfil tipo 1: saturação da superfície, estando bem definida a frente de umedecimento. Esse perfil poderá ocorrer nos solos arenosos (areia e areia silto argilosa) caso a precipitação seja maior que a condutividade hidráulica saturada;

- perfil tipo 2: saturação da superfície, não estando definida a frente de umedecimento. Esse perfil poderá ocorrer no solo siltoso caso a precipitação seja maior que a condutividade hidráulica saturada;

- perfil tipo 3: não há saturação da superfície, podendo a frente de umedecimento ser ou não ser uniforme. Esse perfil poderá ocorrer para os três tipos de solo caso a precipitação seja menor que a condutividade hidráulica saturada;

- perfil tipo 4: elevação do nível d’água até que ocorra o equilíbrio hidrostático com a sucção atuante em superfície. Esse perfil poderá ocorrer para os três tipos de solo caso a duração da precipitação seja suficiente para permitir a ascensão do nível d’água.

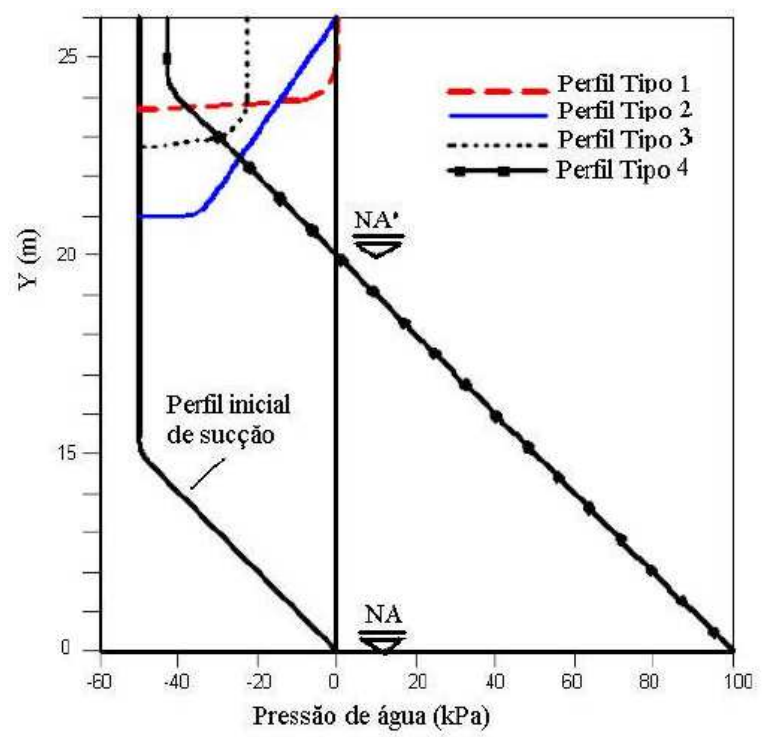

Figura 3.18 - Tipos de perfil de pressão neutra originada ao longo da precipitação.

Fonte: Santos (2004). 
Também com respeito aos resultados das análises paramétricas que foram realizadas para avaliar as características do solo determinantes no comportamento da infiltração da água da chuva no talude, o estudo mostra que as principais características correspondem à função condutividade hidráulica e à pressão de entrada de ar para as condições e hipóteses impostas aos parâmetros dos solos.

Já os resultados das análises de estabilidade de talude indicam que a diminuição no fator de segurança acontece mais lentamente para os casos de precipitação não excedente e que o fator de segurança reduz mais rapidamente para o talude composto por areia (solo A) do que o composto por silte (solo B) ou areia silto argilosa (solo C). O autor também constatou que, para as diversas situações impostas ao talude (intensidade e duração da chuva), solos que possuem alto valor de condutividade hidráulica saturada apresentam elevadas taxas de infiltração e resultam em maiores taxas de diminuição do fator de segurança (Figura 3.19), citando como exemplo o talude composto por areia (solo A).

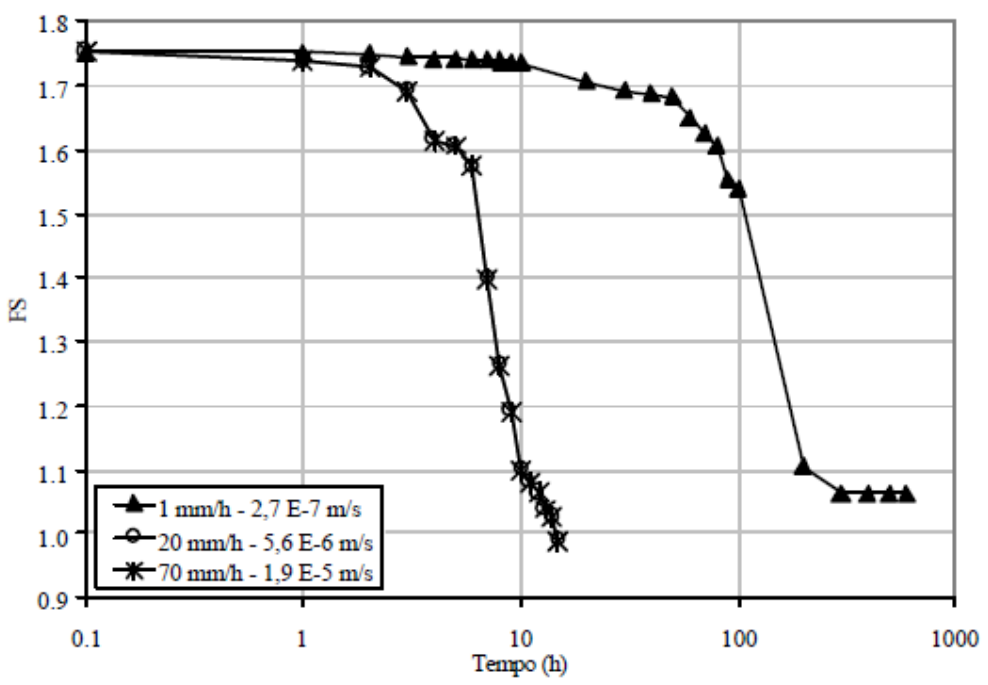

Figura 3.19 - Fator de Segurança em função do tempo para o solo A.

Fonte: Santos (2004).

Cardoso Júnior (2006) realiza um estudo experimental e numérico para avaliar a influência da infiltração da água da chuva na estabilidade de talude. O talude idealizado neste estudo possui $45^{\circ}$ de inclinação e $15 \mathrm{~m}$ de altura, sendo considerado homogêneo e analisado o comportamento do talude para quatro tipos de solo (Gnaisse, AG3, AG2, AG1). O nível d'água foi assumido horizontal e posicionado $5 \mathrm{~m}$ abaixo da superfície do pé do talude. $\mathrm{O}$ perfil inicial de pressão neutra negativa foi feita a partir da utilização do procedimento de ciclos, sendo utilizados os dados de chuva correspondente à média histórica do período de 1996 a 2005. O fluxo transiente foi feito aplicando-se a precipitação diária referente ao ano de 
2004, sendo escolhida uma situação mais crítica (ocorrida no mês de março) e uma situação mais favorável (ocorrida no mês de outubro) para retratar a sucção na crista do talude de cada tipo de solo. Posteriormente, quatro cenários foram escolhidos para configurar diferentes eventos pluviométricos (precipitação e duração) e consequentemente, analisar o processo de infiltração. As análises de estabilidade de talude foram baseadas nos resultados de fluxo transiente e feitas no Slope/ $W$ com o uso do método de Bishop Simplificado, além também de avaliar a estabilidade do talude para a condição do solo saturado.

Os resultados das escolhas da situação mais crítica e situação mais favorável mostram que a variação da sucção é condizente com a alteração climática, ou seja, para ambas as situações que o talude está sujeito podem ocorrer aumento ou diminuição da pressão neutra ao longo da sua profundidade. A Figura 3.20 ilustra os perfis correspondentes à situação mais crítica e mais favorável, nos quais observa-se que dependendo do tipo do solo desenvolvem pressões neutra entre $0 \mathrm{kPa}$ e $-35 \mathrm{kPa}$ para a situação mais crítica e pressões neutra entre $0 \mathrm{kPa}$ e $-180 \mathrm{kPa}$.

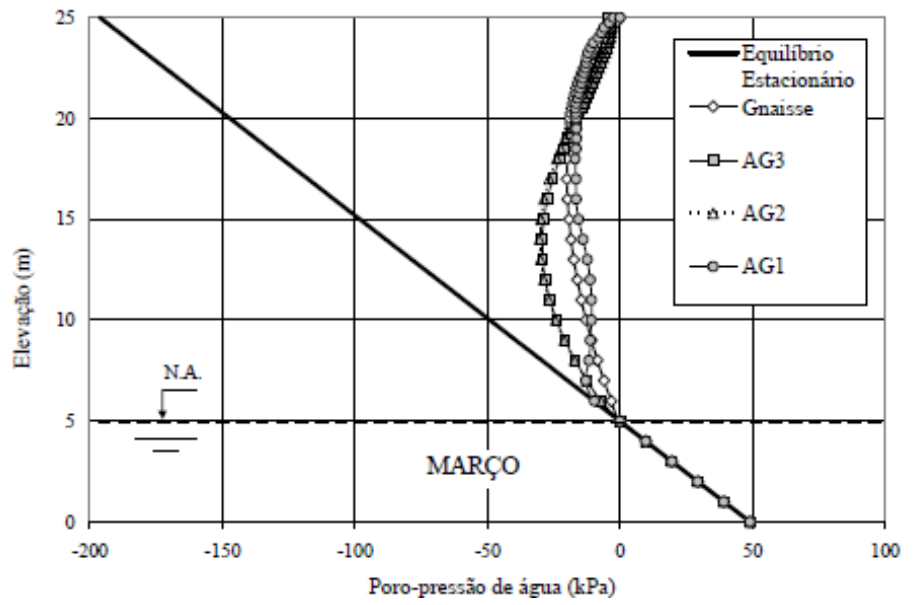

(a)

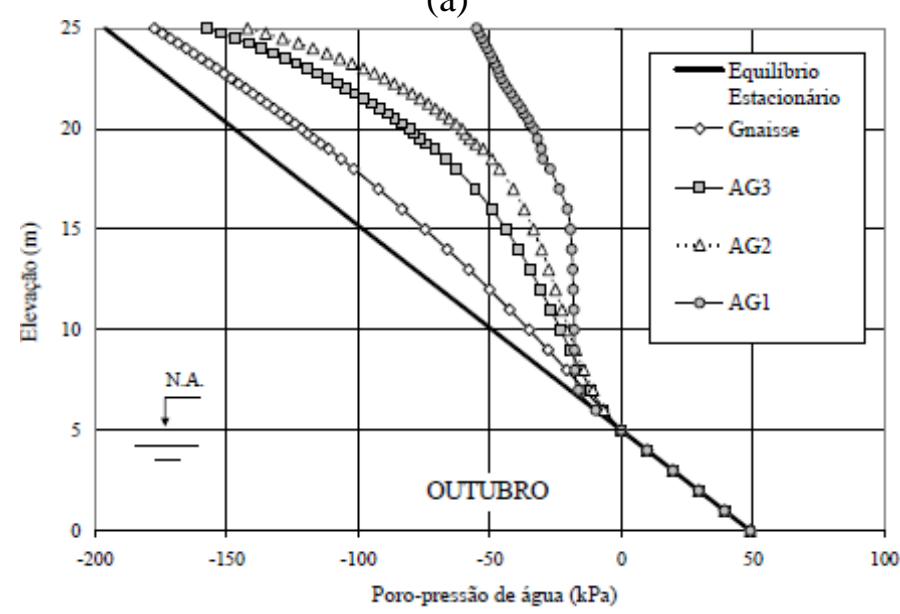

(b)

Figura 3.20 - Perfil do talude para (a) situação mais crítica e (b) situação mais favorável.

Fonte: Cardoso Júnior (2006). 
Além disso, os resultados das análises de fluxo feitas para avaliar a influência dos diferentes cenários no processo de infiltração da água mostram que geralmente o cenário 1 gerou maior variação na pressão neutra enquanto que o cenário 2 provocou menor alteração nessa mesma variável. Este resultado é decorrente da intensidade e da duração de cada evento pluviométrico estipulado para cada cenário.

Os resultados de análise de estabilidade de talude apontaram que existe uma tendência de comportamento do fator de segurança para os quatro cenários, mesmo que este tenha sido analisado para diferentes tipos de solo e para duas situações (mais crítica e mais favorável). Pode-se dizer que, no geral, o maior valor para o fator de segurança variou entre o cenário $2 \mathrm{e}$ 4 enquanto que o menor valor para o fator de segurança foi para o cenário 1. Portanto, observa-se que o fator de segurança depende do perfil inicial de sucção, da precipitação (intensidade e duração) e dos parâmetros de resistência ao cisalhamento do solo.

$\mathrm{O}$ autor conclui que a situação mais crítica produz um maior avanço da frente de umedecimento devido aos baixos valores de sucção e da condutividade hidráulica do solo estar muito próxima do valor da condutividade hidráulica saturada. Já para a situação mais favorável, o autor relata que o pequeno avanço da frente de umedecimento é reflexo dos altos valores de sucção, citando como exemplo o caso do solo AG1, em que a frente de umedecimento atinge uma profundidade de aproximadamente $0,50 \mathrm{~m}$. O autor também comenta que o tempo transcorrido entre o menor valor de fator de segurança e o término da precipitação parece estar relacionado com as características da precipitação e com as propriedades do solo.

Lee, Gofar e Rahardjo (2009) sugerem um modelo simples para uma avaliação preliminar da instabilidade de talude induzida pela chuva, a partir da integração das análises de chuva e das propriedades intrínseca do solo não saturado. O talude estudado possui $21^{\circ}$ de inclinação e $20 \mathrm{~m}$ de comprimento, tendo sido considerado nas análises quatro solos típicos da Malásia (pedregulho-areia, pedregulho siltoso, silte arenoso e silte - caolinita) e o nível d'água localizado $20 \mathrm{~m}$ abaixo da superfície do talude. O perfil inicial de pressão neutra foi considerado hidrostático e baseado nos dados de sucção em campo, limitando valores máximos de sucção de $10 \mathrm{kPa}$ para pedregulho-areia, $23 \mathrm{kPa}$ para pedregulho siltoso, $30 \mathrm{kPa}$ para silte arenoso e $50 \mathrm{kPa}$ para silte. A análise de fluxo transiente foi feita no $\mathrm{Seep} / \mathrm{W}$ variando as intensidades da chuva crítica principal, da chuva crítica antecedente e da combinação entre elas além também de alterar a duração de cada intensidade da chuva. Já a análise de estabilidade de talude foi realizada no Slope/W usando o método do equilíbrio limite - talude infinito modificado com a finalidade de desenvolver um modelo denominado 
pelos autores de PERISI ("avaliação preliminar da instabilidade de talude induzida pela chuva”) e comparar com o modelo de Rahardjo et al. (1995).

Os resultados das análises de fluxo transiente para a chuva crítica principal mostraram que a razão entre a intensidade da chuva e a permeabilidade saturada do solo (I/ $k_{S}$ ) estabelece um papel decisivo na determinação da chuva crítica principal contribuindo para o menor valor de sucção mínima. Portanto, a condição para determinar a distribuição do perfil de pressão neutra mínima e da chuva crítica principal dependerá da intensidade da chuva principal e da condutividade hidráulica saturada de cada solo. Já os resultados das análises da chuva crítica antecedente apontaram que o efeito da chuva antecedente extrema na distribuição da sucção para os quatro tipos de solo também é dominado pela razão entre a intensidade da chuva e a permeabilidade saturada do solo $\left(I / k_{s}\right)$, variando para cada tipo de solo.

Nas análises de fator de segurança, os autores compararam os resultados das análises feitas a partir do modelo de PERISI e do modelo de Rahardjo et al. (1995), considerando-se três tipos de perfis para a distribuição da pressão neutra no interior do talude e três tipos de solos diferentes. No geral, os autores verificaram que o fator de segurança é maior para a distribuição de pressão neutra inicial na condição hidrostática, enquanto que o fator de segurança sob a condição de chuva apresenta boa correlação para ambos os modelos.

Os autores concluem que a sucção desenvolvida e o fator de segurança calculado a partir do modelo PERISI mostra uma boa correlação com os resultados a partir das análises realizadas com o Seep/W e o Slope/W bem como do modelo desenvolvido por Rahardjo et al. (1995). Esses mesmo autores afirmam que o modelo PERISI pode ser utilizado para estimar a profundidade crítica da frente de umedecimento e do valor de sucção mínimo para cálculo do fator de segurança de um talude com solo homogêneo.

Zambrana (2014) realizou um estudo numérico da influência de chuvas extremas no processo de infiltração e sua contribuição na instabilidade de talude. Neste trabalho foram analisados dois taludes distintos, estando o primeiro situado na região da Serra de Cubatão e o segundo na região Serrana do Rio de Janeiro. As características geométricas, a composição dos solos, as análises numéricas e os resultados dos taludes serão apresentados e discutidos individualmente.

Para o talude estudado da região da Serra de Cubatão foram estabelecidas diferentes geometrias para realização das modelagens numéricas, utilizando perfis com três tipos de inclinações $\left(30^{\circ}, 40^{\circ}\right.$ e $\left.50^{\circ}\right)$ e altura constante de $75 \mathrm{~m}$, todos eles compostos por uma camada superficial de solo coluvionar com espessura de $1 \mathrm{~m}$, uma camada de solo saprolítico com 
espessura de $4 \mathrm{~m}$ e uma camada de rocha fraturada. O nível d'água foi considerado a uma profundidade maior que $10 \mathrm{~m}$, estando abaixo e ao longo de toda a superfície do talude. De acordo com Zambrana (2014), o nível dá água não foi identificado nas investigações in situ. O perfil inicial de pressão neutra negativa foi feita a partir da utilização do procedimento numérico denominado de ciclo, em que cada ciclo corresponde à duração de um ano e representa a precipitação diária. Neste procedimento foram utilizados os dados de chuva correspondente à média histórica do período de 1975 a 1985. O fluxo transiente foi feito aplicando-se a precipitação diária referente ao ano de 1984 a fim de analisar a influência das chuvas antecedentes. Posteriormente, foi aplicada a precipitação diária do mês de janeiro de 1985 para analisar os escorregamentos registrados neste mês. As análises de fluxo foram feitas utilizando o método dos elementos finitos no Seep/W enquanto que as análises de estabilidade de talude foram realizadas no Slope/ $W$ a partir do cálculo do fator de segurança utilizando o Método do Talude Infinito, considerando-se a variação da sucção.

Os resultados das análises transientes mostraram que as camadas mais superficiais apresentam maior variação na sucção enquanto que as sucções das camadas mais profundas se alteram em decorrência do avanço da frente umedecimento. Também ocorre uma diferença nos valores de sucção para os pontos situados na parte mais alta e na parte mais baixa do talude. Além disso, as variações bruscas de sucção para profundidade de 0,50 m em eventos com precipitação superior à $40 \mathrm{~mm}$ após 20 dias sem chuva, como ilustra a Figura 3.21 para o caso do talude com inclinação de $30^{\circ}$. Observa-se nesta figura que os valores de sucção são diferentes para o ponto A $(0,50 \mathrm{~m})$, ponto $\mathrm{B}(1,50 \mathrm{~m})$, ponto $\mathrm{C}(2,50 \mathrm{~m})$ e ponto $\mathrm{D}(3,50 \mathrm{~m})$ em função da precipitação e do tempo de redistribuição da água no solo, ocorrendo uma variação da sucção mais rápida no ponto A e mais lenta no ponto D.

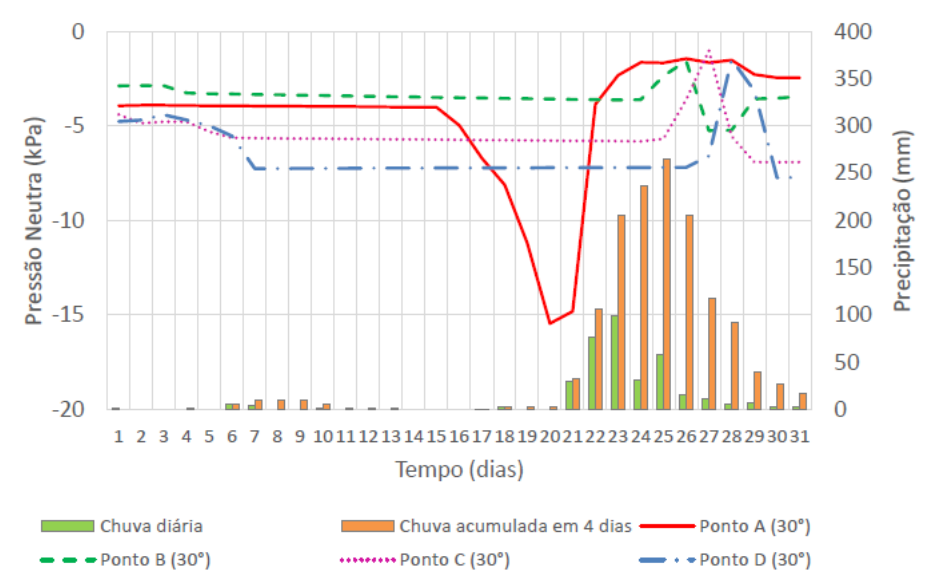

Figura 3.21 - Pressão neutra variando em função do tempo e da precipitação para diferentes profundidades no talude com $30^{\circ}$ de inclinação localizado na Serra de Cubatão.

Fonte: Zambrana (2014). 
Os resultados de análise de estabilidade de talude mostram que as precipitações ocorridas entre os dias 23 e 24 de janeiro de 1985 resultaram em valores diferentes de fator de segurança para cada inclinação do talude. No caso do talude com inclinação de $30^{\circ}$, o menor valor do fator de segurança foi de 1,40 ocorrido entre os dias 24 e 25 de janeiro. Já no caso do talude com inclinações de $40^{\circ}$ e $50^{\circ}$, a partir do dia 23 de janeiro os valores de fator de segurança foram menores que a unidade, mostrando que o talude encontra-se instável.

$\mathrm{O}$ autor concluiu que as análises de infiltração indicam que a sucção tende a diminuir ou ser eliminada ao longo dos eventos de chuva extrema. Também comenta que a inclinação do talude poderia gerar pouca interferência nas alterações da sucção e que a pluviosidade deste local provoca uma pequena alteração na faixa dos valores de sucção do talude, citando como exemplo o aumento ou a diminuição da sucção entre $1 \mathrm{kPa}$ e $3 \mathrm{kPa}$ para precipitações entre $20 \mathrm{~mm}$ e $60 \mathrm{~mm}$. O autor também relata que os escorregamentos nessas encostas são superficiais, os quais são provocados pelo avanço da frente de umedecimento durante o processo de infiltração das chuvas extremas.

Assim como o talude da região da Serra de Cubatão, para o talude da região Serrana do Rio de Janeiro também foi estabelecida diferentes geometrias para realização das modelagens numéricas, utilizando perfis com três tipos de inclinações e com três tipos de altura $\left(20^{\circ}\right.$ e $20 \mathrm{~m}, 30^{\circ}$ e $30 \mathrm{~m}, 40^{\circ}$ e $\left.50 \mathrm{~m}\right)$, todos eles formados por uma camada superficial de solo coluvionar com espessura de $2 \mathrm{~m}$ e uma camada de solo residual com espessura de 3 m. O nível d’água foi assumido horizontal e posicionado no pé da superfície do talude, e que segundo Zambrana (2014), tende a variar em função da distribuição das chuvas ao longo das estações do ano. O perfil inicial de pressão neutra negativa também foi feita a partir da utilização de ciclos, sendo utilizados os dados de chuva correspondente à média histórica do período de 2002 a 2011. O fluxo transiente foi feito aplicando-se a precipitação diária referente ao ano de 2010 a fim de analisar a influência das chuvas antecedentes. Posteriormente, foi aplicada a precipitação diária do mês de janeiro de 2011 para analisar os escorregamentos registrados neste mês. As análises de fluxo foram feitas utilizando o método dos elementos finitos no $\mathrm{Seep} / \mathrm{W}$ enquanto que as análises de estabilidade de talude foram realizadas no Slope/W a partir do cálculo do fator de segurança utilizando o Método do Talude Infinito, considerando-se a variação da sucção.

Os resultados das análises transientes mostraram que ocorre uma grande variação nos valores de sucção para os pontos mais próximos da superfície $(0,50 \mathrm{~m}$ e $1,50 \mathrm{~m})$ e uma diminuição nessa variação para os pontos mais profundos $(2,50 \mathrm{~m} \mathrm{e} 3,50 \mathrm{~m})$ devido à proximidade do nível d’água. Além disso, a ocorrência de eventos pluviométricos pontuais 
com precipitações de $10 \mathrm{~mm}$ a $20 \mathrm{~mm}$ são insuficientes para modificar os valores de sucção do talude, porém a ocorrência de eventos consecutivos de $10 \mathrm{~mm}$ a $20 \mathrm{~mm}$ resultam na redução dos valores de sucção do talude.

Os resultados de análise de estabilidade de talude mostraram que o fator de segurança reduz após a chuva de 124,6 mm do dia 12 de janeiro de 2011 para os taludes mais íngremes e menos íngremes. A Figura 3.22 ilustra como ocorreu a variação do fator de segurança entre os meses de dezembro de 2010 e de janeiro de 2011 para o talude com $20^{\circ}$ de inclinação, apresentando no dia 12 de janeiro fator de segurança próximo a 0,86 .

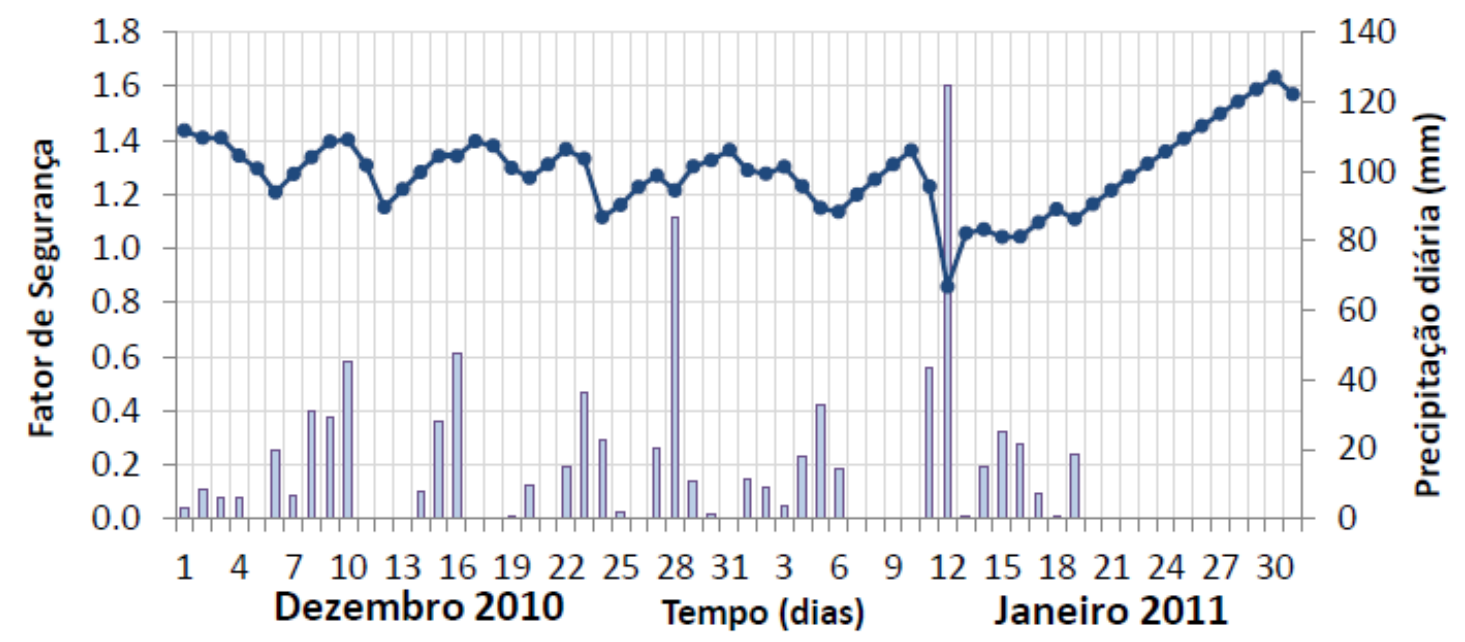

Figura 3.22 - Fator de segurança variando em função do tempo e da precipitação diária para o talude com $20^{\circ}$ de inclinação localizado na região Serrana do Rio de Janeiro.

Fonte: Zambrana (2014).

O autor concluiu que as análises de infiltração indicam que a sucção tende a diminuir ou ser eliminada ao longo dos eventos de chuva extrema. Também comenta que a inclinação do talude poderia gerar maior interferência nas alterações da sucção e que a pluviosidade deste local provoca uma variação da sucção entre $10 \mathrm{kPa}$ e $15 \mathrm{kPa}$ para precipitações inferiores a $60 \mathrm{~mm}$ e uma variação da sucção maior que $20 \mathrm{kPa}$ para precipitações superiores a $60 \mathrm{~mm}$. O autor também relata que os escorregamentos nessas encostas são mais profundos, os quais são provocados pelo rápido aumento do nível d’água durante o processo de infiltração das chuvas extremas.

\subsection{CONCEITOS E ASPECTOS GERAIS DA MECÂNICA DOS SOLOS NÃO SATURADOS}

Em 1925 a Mecânica dos Solos despontou como ciência a partir da publicação do trabalho sobre adensamento de solos desenvolvido por Karl Terzaghi, reconhecido 
mundialmente como fundador da Mecânica dos Solos. No ano de 1936 aconteceu na Universidade de Harvard a $1^{\mathrm{a}}$ Conferência Internacional de Mecânica dos Solos e Engenharia de Fundações (ISSMFE), a partir desse evento, promovendo um fórum para estabelecimento de princípios e equações relevantes para a Mecânica dos Solos (FREDLUND; RAHARDJO, 1993).

A Mecânica dos Solos pode ser definida como a ciência que estuda o comportamento dos solos através de teorias fundamentadas em bases físicas, modelos reológicos e observações de campo (BUENO; VILAR, 1979). Com o objetivo de aprofundar o conhecimento nessa ciência, a clássica Mecânica dos Solos pode ser agrupada em solos saturados e os solos não saturados. Essa subdivisão, que está baseada no critério do conteúdo de água, permite estudar o comportamento e as características peculiares relacionadas ao solo. Neste contexto, destaca-se a importância do estudo sobre o comportamento do solo não saturado, que concentra um dos tópicos desta pesquisa.

Os solos não saturados localizam-se em inúmeras áreas do planeta Terra e normalmente são predominantes em regiões áridas e semi-áridas devido aos aspectos climáticos característicos da região como a elevada taxa de evaporação e a baixa taxa de precipitação anual. Lu e Likos (2004) relatam que os mecanismos ambientais naturais como a precipitação, evaporação e evapotranspiração influenciam na profundidade e na extensão da zona não saturada, também denominada por muitos pesquisadores de zona vadosa. No caso do Brasil, por exemplo, país em que predomina o clima tropical e o clima temperado, é comum encontrar solo na condição não saturada em grande parte de sua extensão territorial. Por esse motivo, nas últimas décadas, diversos estudiosos e profissionais brasileiros da área de Geotecnia buscam ampliar o desenvolvimento de pesquisas relacionadas à Mecânica dos Solos não Saturados e a solucionar problemas de âmbito geotécnico considerando a questão da não saturação do solo.

Um elemento de solo não saturado é comumente representado como um sistema trifásico, constituído por uma fase sólida (grãos e partículas minerais), uma fase líquida (normalmente água) e uma fase gasosa (gases). Entretanto, Fredlund e Rahardjo (1993) sugerem acrescentar uma fase adicional ao sistema, denominada de membrana contráctil, resultante da interface entre o ar e a água presente no sistema. Esses pesquisadores relatam que quando a fase ar é contínua, a membrana contráctil interage com as partículas de solo e influenciam no comportamento mecânico do solo. A Figura 3.23 ilustra um elemento de solo não saturado incluindo nele a membrana-contráctil. 


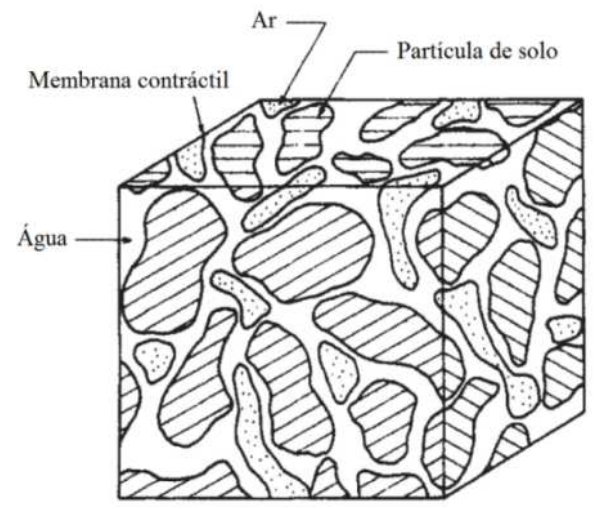

Figura 3.23 - Elemento de um solo não saturado.

Fonte: Traduzido de Fredlund e Rahardjo (1993).

A massa e o volume presentes em cada fase de um elemento de solo não saturado podem ser representados esquematicamente por um diagrama de fases. A Figura 3.24a ilustra um diagrama tetrafásico rigoroso para um solo não saturado, nele, a espessura da camada de membrana contráctil pode ser considerada da ordem de algumas camadas moleculares. A subdivisão física da membrana contráctil é desnecessária quando pretende-se estabelecer uma relação de massa-volume, podendo esta ser considerada pertencente à fase líquida do sistema. Desse modo, a Figura 3.24b ilustra um diagrama trifásico simplificado para um solo não saturado, o qual desconsidera a fase da membrana contráctil (FREDLUND; RAHARDJO, 1993).

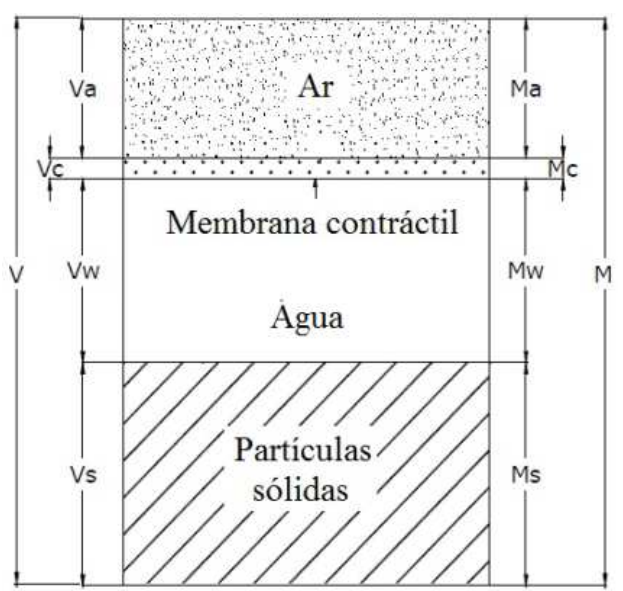

(a)

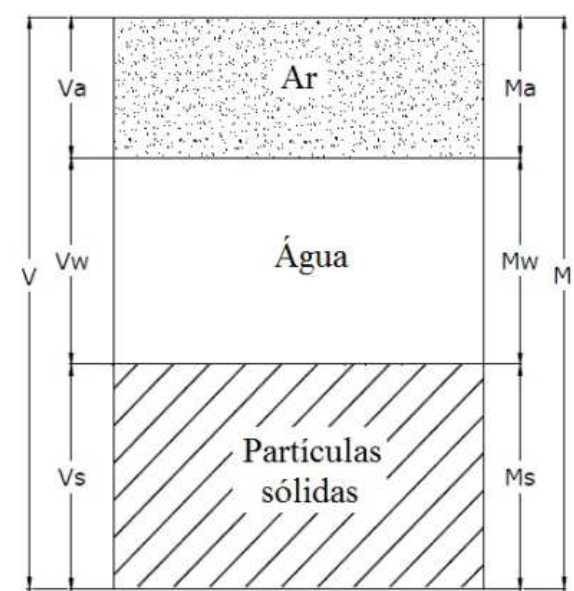

(b)

Figura 3.24 - Diagramas de fases, rigoroso e simplificado para um solo não saturado (a) sistema tetrafásico rigoroso e (b) sistema trifásico simplificado.

Fonte: Traduzido de Fredlund e Rahardjo (1993).

É extremamente importante conhecer o conteúdo de água presente no solo não saturado, que pode ser calculado em termos de massa ou volume. O teor de umidade 
gravimétrica $(w)$ expressa o conteúdo de água em termos de massa, representado pela relação entre a massa de água $\left(M_{w}\right)$ e a massa dos sólidos $\left(M_{S}\right)$. Já o teor de umidade volumétrico $(\theta)$ determina o conteúdo de água em termos de volume, representado pela relação entre o volume de água $\left(V_{w}\right)$ e o volume total $(V)$.

A partir dessas duas relações é possível fazer uma correlação desses índices físicos, que resulta na equação (13), apresentada a seguir:

$$
\theta=w \cdot \frac{\rho_{d}}{\rho_{w}}
$$

em que $\theta$ é o teor de umidade volumétrica, em $\left[\mathrm{L}^{3} \mathrm{~L}^{-3}\right] ; w$ é o teor de umidade gravimétrica, em $\left[\mathrm{MM}^{-1}\right] ; \rho_{d}$ é a massa específica seca do solo, em $\left[\mathrm{ML}^{-3}\right] ; \rho_{w}$ é a massa específica da água, em $\left[\mathrm{ML}^{-3}\right]$.

\subsection{POTENCIAL DA ÁGUA NO SOLO}

Assim como qualquer corpo na natureza, a água presente nos poros do solo pode ser caracterizada por um estado de energia, determinado por diferentes formas e quantidades de energia (HILLEL, 1980).

O estado de energia da água nos poros do solo não saturado pode ser determinado a partir da soma das energias cinética e potencial. Como o movimento da água no solo ocorre muito lentamente e a energia cinética equivale ao quadrado da velocidade, na maioria dos casos esta energia pode ser desprezada. Por outro lado, a energia potencial, que é uma função da posição ou condição interna da água no ponto em consideração, equivale a energia total da água no solo (HILLEL, 1980; REICHARDT, 1985).

De acordo com Vilar (2009), o potencial total da água no solo representa o trabalho útil que deve ser realizado em uma quantidade infinitesimal de água pura, de maneira que seja conduzida, reversível e isotermicamente, de um dado reservatório em uma determinada cota sujeita à pressão atmosférica até a água no solo, na cota de interesse (Figura 3.25). Em outras palavras, Reichardt (1985) define que o potencial total da água no solo representa a somatória dos trabalhos realizados quando a unidade de massa (volume ou peso) de água em estado padrão é levada isotérmica, isobárica e reversivelmente para o estado considerado no solo. Portanto, pode-se dizer que o potencial total da água no solo define seu estado de energia no ponto considerado. 


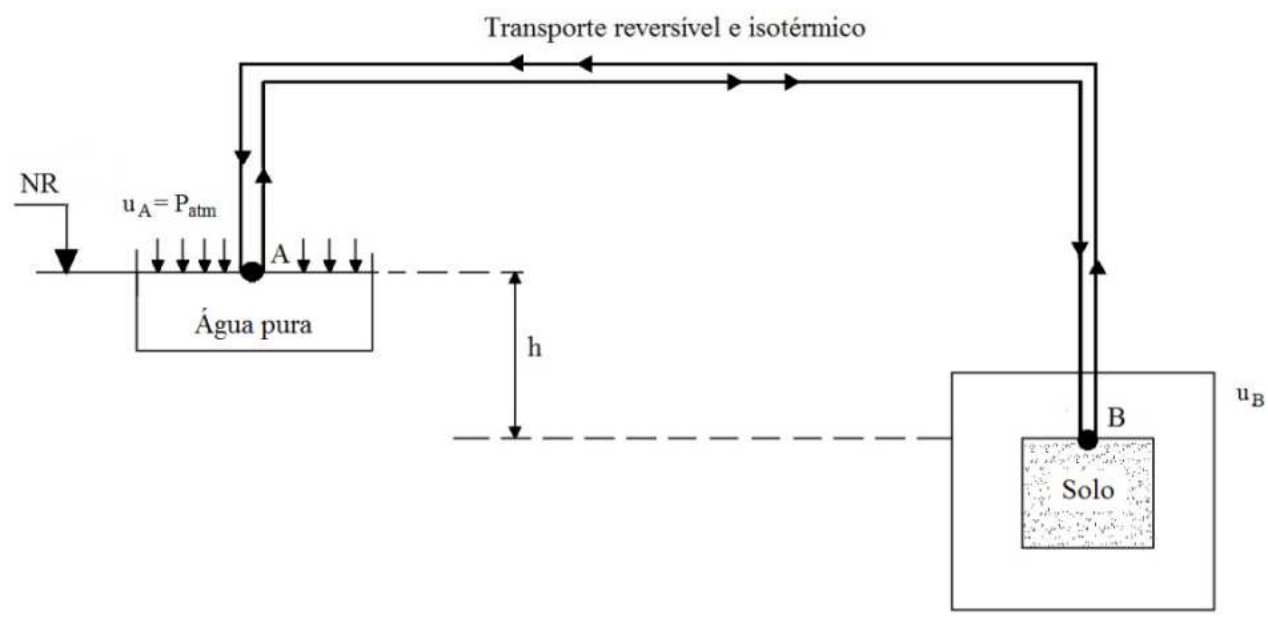

Figura 3.25 - Esquema da definição de potencial total da água no solo. Fonte: Vilar (2009).

Sabe-se que a tendência da água no solo é de se mover do ponto com maior energia potencial para o ponto com menor energia potencial, ou seja, a água assume um estado de menor energia. Portanto, conhecendo a energia potencial da água em diferentes pontos do solo é possível determinar a tendência do fluxo da água dentro do solo e seu respectivo estado de energia.

A água presente nos poros do solo está sujeita a uma série de campos de força, os quais resultam da atração da matriz do solo (representada pelas partículas sólidas) por água, da presença de solutos, da ação da pressão de gás externo e da ação da gravidade (HILLEL, 1980). Desse modo, o potencial total da água no solo não saturado é composto pelo somatório de diversos potenciais, estando aqui reunidos os principais deles: osmótico, gravitacional, matricial e pneumático, representado pela equação (14). Existem outros tipos de potenciais que podem compor o potencial total (como por exemplo, o potencial de consolidação e o potencial térmico), porém, por não terem muita importância no comportamento geotécnico dos solos não saturados, eles podem ser desprezados (VILAR, 2009). O potencial da água no solo pode ser quantitativamente representado por algumas grandezas físicas, neste caso, as três grandezas mais utilizadas nessa representação é dada em termos de energia por unidade de massa, energia por unidade de volume e energia por unidade de peso - carga hidráulica.

$$
\phi_{t}=\phi_{o s}+\phi_{g}+\phi_{p n}+\phi_{m}
$$

em que $\phi_{t}$ é o potencial total da água no solo, em [L]; $\phi_{o s}$ é o potencial osmótico, em [L]; $\phi_{g}$ é o potencial gravitacional, em [L]; $\phi_{p n}$ é o potencial pneumático, em [L]; $\phi_{m}$ é o potencial matricial, em [L]. 
Potencial osmótico: equivale a presença de sais minerais e substâncias orgânicas dissolvidas na solução da água do solo. O potencial osmótico torna-se importante no potencial total quando a concentração salina é significante (REICHARDT, 1985).

$\mathrm{Na}$ Figura 3.25, o potencial osmótico corresponderá ao potencial total $\left(\phi_{t}\right)$ quando a água pura do reservatório padrão e a solução de água no solo encontrar-se na mesma cota $(h=0)$, com a mesma pressão $\left(u_{B}=u_{A}=P_{a t m}\right)$ e não apresentar efeitos da matriz do solo (VILAR, 2009).

Potencial gravitacional: corresponde a própria energia potencial do campo gravitacional, e pelo fato desse campo gravitacional estar sempre presente, esse potencial sempre existirá (REICHARDT, 1985). O potencial gravitacional é independente das condições de pressão e química da água do solo e dependente somente da elevação relativa ou nível de referência (HILLEL, 1980).

$\mathrm{Na}$ Figura 3.25, o potencial gravitacional representa a diferença de cotas existente entre a água pura do reservatório padrão e a água do solo, podendo ser igual ao potencial total $\left(\phi_{t}\right)$ se a água pura do reservatório padrão e a água no solo possuir a mesma composição, estiver na mesma pressão $\left(u_{B}=u_{A}=P_{a t m}\right)$ e não apresentar efeitos da matriz do solo (VILAR, 2009).

Potencial pneumático: resultante da atuação de pressão externa de gás diferente da pressão atmosférica. Reichardt (1985) relata que o potencial pneumático só será considerado para representar pressões positivas (maiores que a pressão atmosférica) pois, as pressões negativas serão representadas a partir do potencial matricial. Na Figura 3.25, este potencial corresponderá ao potencial total $\left(\phi_{t}\right)$ se a água pura do reservatório padrão e a água no solo tiver a mesma composição, encontrar-se na mesma cota $(h=0)$ e não apresentar efeitos da matriz do solo pois este encontra-se na condição saturada (VILAR, 2009).

Potencial matricial: decorrente da ação das forças de capilaridade e adsorção causada pela interação entre a água e as partículas sólidas (REICHARDT, 1985). As forças de capilaridade retêm a água nos espaços existentes entre as partículas sólidas enquanto que as forças de adsorção atraem a água para a superfície de cada partícula sólida, formando uma película ao seu redor. A Figura 3.26 ilustra a atuação desses dois mecanismos de interação água-solo. 


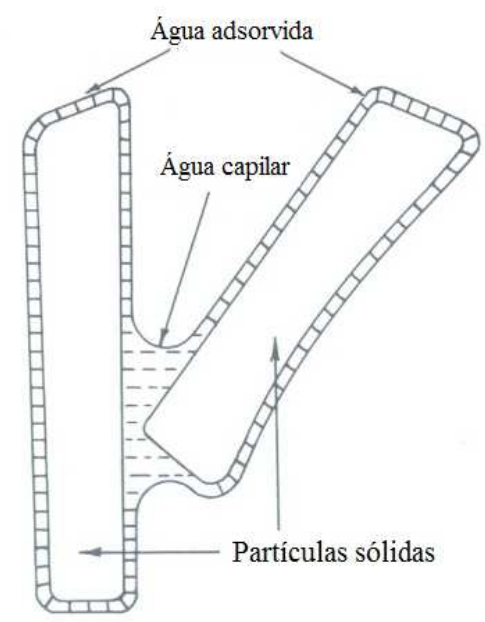

Figura 3.26 - Potencial matricial - forças de capilaridade e adsorção.

Fonte: Traduzido e adaptado de Hillel (1980).

Na Figura 3.25, o potencial matricial equivalerá ao potencial total $\left(\phi_{t}\right)$ quando a água pura do reservatório padrão e a água no solo possuir a mesma composição, encontrar-se na mesma pressão $\left(u_{B}=u_{A}=P_{a t m}\right)$ e tiver a mesma cota $(h=0)$ (VILAR, 2009).

\subsection{SUCÇÃO}

De acordo com Vilar (2009), a sucção total do solo pode ser definida como a pressão manométrica negativa, em relação à pressão externa de gás sobre a água do solo, que deve ser aplicada a um reservatório de água pura de modo que se mantenha o equilíbrio, através de uma membrana semi-permeável, entre a água do reservatório padrão e a água do solo. A Figura 3.27 esquematiza essa definição, onde a água pura e o ar encontram-se sob uma determinada pressão $\left(u_{w}\right)$ e $\left(u_{a}\right)$, respectivamente. Uma membrana semi-permeável separa o reservatório de água pura e do solo, permitindo somente o fluxo de água e impedindo a transferência de solutos presentes na água intersticial do solo para a água pura. Desse modo, a diferença entre a pressão de ar e a pressão da água $\left(u_{a}-u_{w}\right)$ representa a sucção, podendo esta ser interpretada como a avidez que o solo não saturado tem por água.

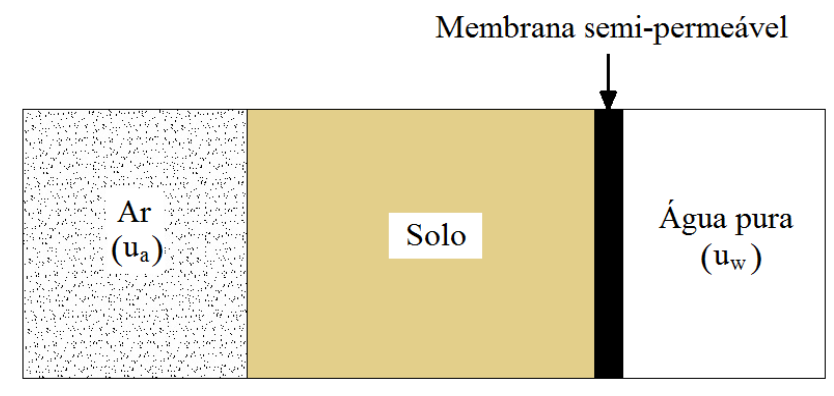

Figura 3.27 - Esquema da definição de sucção.

Fonte: Vilar (2009). 
Hillel (1971) faz um comentário sobre a utilização do termo sucção, o qual foi adotado com o intuito de evitar o uso do sinal negativo como forma de representar a pressão negativa da água. Desse modo, a sucção total do solo será correspondente ao potencial total da água, porém, expressa em valores positivos. Neste contexto, assumindo-se que os potenciais pneumático e gravitacional sejam desprezados por não interferirem no equilíbrio do sistema, pode-se afirmar que o potencial total da água no solo é dado pelos potenciais matricial e osmótico. Portanto, a sucção total do solo pode ser dividida em duas componentes, sucção matricial e sucção osmótica. A Figura 3.28 esquematiza conceitualmente a sucção total, osmótica e matricial.

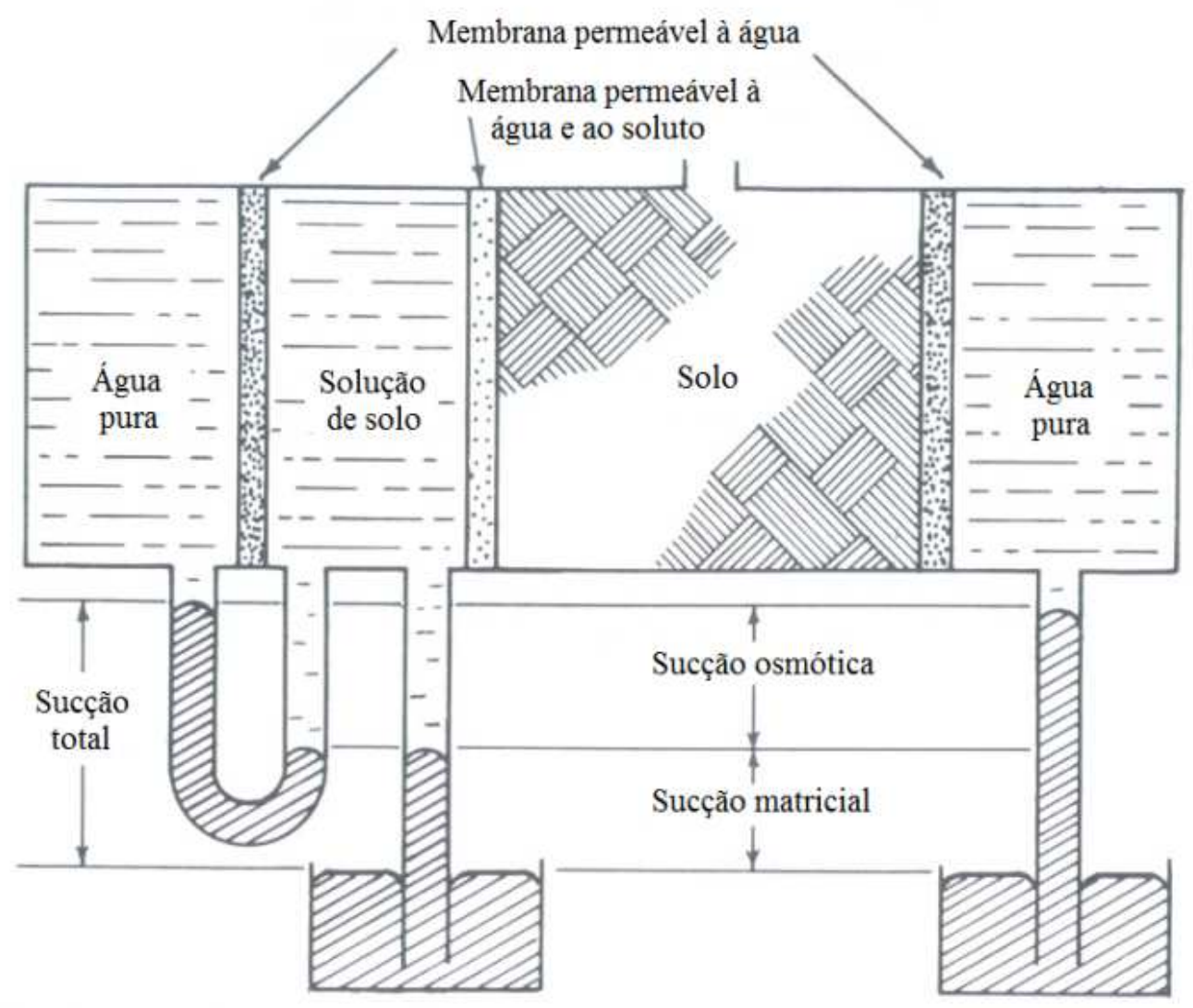

Figura 3.28 - Esquema ilustrando a definição de sucção total, matricial e osmótica. Fonte: Traduzido e adaptado de Hillel (1980).

$\mathrm{Na}$ Figura 3.28, a sucção total é medida a partir da elevação do mercúrio do reservatório de água pura, que está interligado ao solo através de uma membrana permeável à água, também denominada de membrana semi-permeável pois permite o fluxo de água pura e impede a passagem de solutos. A sucção matricial é medida a partir da elevação do mercúrio do reservatório de solutos, que está interligado ao solo através de uma membrana permeável, a qual permite passagem de água pura e soluto. A sucção osmótica é medida pela elevação do 
mercúrio do reservatório de água pura com o reservatório de água com igual solução do solo a partir de uma membrana permeável à água.

Algumas técnicas de ensaio foram desenvolvidas e aprimoradas nas últimas décadas, permitindo dessa maneira, obter a medida da sucção total, matricial e/ou osmótica em campo ou em laboratório. A maioria das técnicas disponíveis apresentam algum tipo de limitação, tais como a variação da faixa de medida da sucção (muito pequena ou grande), o tempo do ensaio (curto ou longo), o tipo de sucção medida (total, matricial ou osmótica), os valores de sucção são obtidos direta ou indiretamente, dentre outros. A

Tabela 3.11 apresenta as principais técnicas de ensaio, estando nela reunidas a técnica de ensaio, a faixa de medida (fornecida em $\mathrm{kPa}$ ) e as observações pertinentes de cada técnica.

Tabela 3.11 - Técnicas de ensaio para medida de sucção.

\begin{tabular}{|c|c|c|}
\hline $\begin{array}{l}\text { Técnica de ensaio } \\
\text { (tipo de sucção) }\end{array}$ & $\begin{array}{c}\text { Faixa de medida } \\
\qquad(\mathrm{kPa})\end{array}$ & Observações \\
\hline $\begin{array}{c}\text { Funil de pedra porosa } \\
\text { (matricial) }\end{array}$ & 0 a 90 & $\begin{array}{l}\text { Sucção é aplicada diretamente à amostra; } \\
\text { Bom para baixas sucções onde a precisão das } \\
\text { panelas é limitada; }\end{array}$ \\
\hline $\begin{array}{c}\text { Papel filtro } \\
\text { (matricial/total) }\end{array}$ & Todos os valores & $\begin{array}{l}>\text { Depende do contato com o solo (garantir o } \\
\text { contato parece ser problemático); } \\
>\text { Calibração; fungos; } \\
>\text { Pesagem; }\end{array}$ \\
\hline $\begin{array}{c}\text { Placa de pressão } \\
\text { (matricial) }\end{array}$ & 0 a 1500 & $\begin{array}{l}\text { Emprega a técnica de translação de eixos; } \\
\text { Depende da capacidade da pedra porosa (pressão } \\
\text { de entrada de ar); }\end{array}$ \\
\hline $\begin{array}{l}\text { Psicrômetros } \\
\text { (osmótica/total) }\end{array}$ & 100 a 8000 & $\begin{array}{l}\text { Depende de rigoroso controle de temperatura, } \\
\text { principalmente nas baixas sucções; mais } \\
\text { recomendado para laboratório; } \\
\text { Sucção osmótica: mede sucção de extrato da } \\
\text { solução do solo (confiabilidade precária); }\end{array}$ \\
\hline $\begin{array}{c}\text { Tensiômetro } \\
\text { (matricial) }\end{array}$ & 0 a 70 & $\begin{array}{l}\text { Tempo de resposta: condutância da pedra porosa; } \\
\text { sensibilidade do elemento de medida; } \\
\text { Tensiômetros osmóticos; } \\
\text { Tensiômetros de alta capacidade (medem } \\
\text { pressões abaixo de }-1 \text { atm): tiram partido da } \\
\text { elevada resistência à tração da água; }\end{array}$ \\
\hline
\end{tabular}

Fonte: Vilar (2009).

\subsection{CURVA DE RETENÇÃO DA ÁGUA DO SOLO}

A curva de retenção da água do solo, também chamada de curva característica, é a representação gráfica da relação entre a sucção e o conteúdo de água do solo. Neste gráfico, a sucção (total, osmótica, matricial) é representada no eixo das abscissas em escala linear ou 
logarítmica e o conteúdo de água do solo (teor de umidade gravimétrico, teor de umidade volumétrico ou grau de saturação) é representado no eixo das ordenadas em escala linear.

A curva de retenção da água do solo tem sido repetidamente utilizada como uma informação chave para resolver análises de fluxo, resistência ao cisalhamento e problemas de variação volumétrica envolvendo solo não saturado (FREDLUND, 2002). A determinação da curva de retenção é muito utilizada nas ciências que estudam o solo tais como Agricultura, Engenharia Ambiental e Engenharia Geotécnica; apresentando a relação entre a sucção e o conteúdo de água do solo a partir da trajetória de secagem e da trajetória de umedecimento

A Figura 3.29 ilustra os principais elementos componentes da curva de retenção da água do solo para um solo tipicamente siltoso. Nesta figura, a pressão de entrada de ar do solo corresponde ao momento em que inicia a entrada de ar nos maiores poros do solo. O conteúdo de água residual equivale a água presente nos menores poros do solo, sendo que este, normalmente corresponde à valores altos de sucção. $O$ teor de umidade volumétrico representado por $\theta_{s}$ e $\theta^{\prime}{ }_{s}$ correspondem ao teor de umidade volumétrica de saturação para as trajetórias de secagem e de umedecimento, respectivamente. A diferença entre o teor de umidade volumétrico de saturação das trajetórias de secagem e de umedecimento equivale ao conteúdo de ar residual (FREDLUND; XING, 1994).

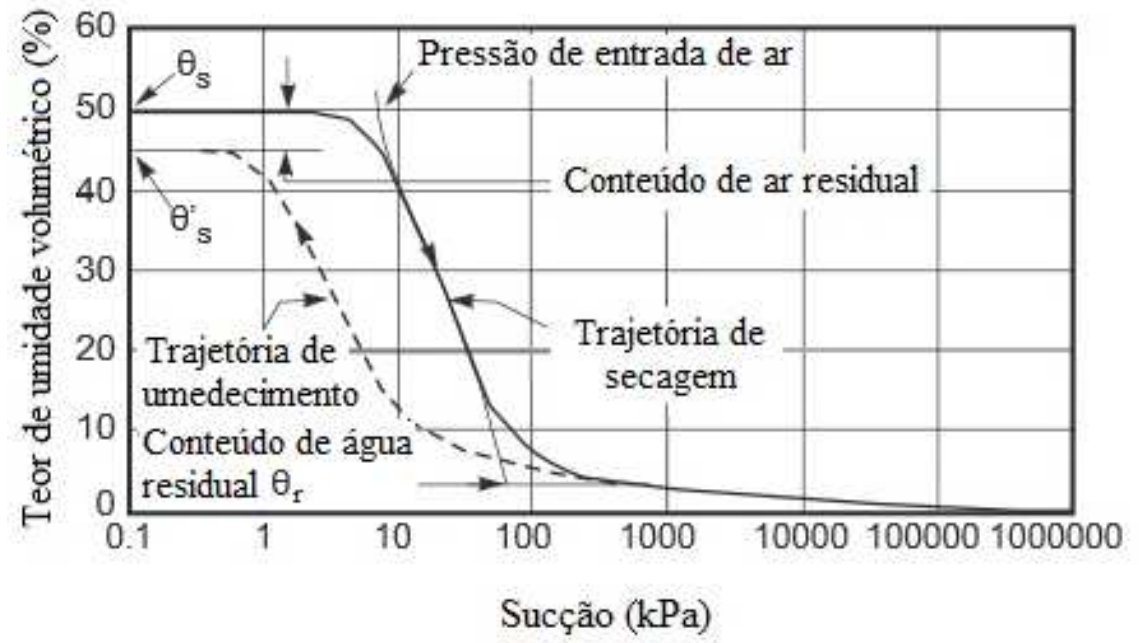

Figura 3.29 - Elementos da curva retenção de água do solo para um solo tipicamente siltoso.

Fonte: Traduzido e adaptado de Fredlund e Xing (1994).

Nota-se que na Figura 3.29 ocorre uma diferença entre as curvas determinadas a partir das trajetórias de secagem e de umedecimento, sendo este fenômeno denominado de histerese. A umidade do solo na condição de equilíbrio a uma dada sucção é maior na trajetória de secagem e menor na trajetória de umedecimento (REICHARDT, 1985). Algumas causas podem ser atribuídas ao efeito de histerese tais como a geometria irregular dos poros 
individuais do solo resultante da ação da capilaridade, os efeitos do ângulo de atrito soloágua, as bolhas de ar oclusas nos macroporos e os fenômenos de expansão/contração que resultam na variação de volume (HILLEL, 1980; REICHARDT, 1985).

Hillel (1980) aponta que a quantidade de água mantida relativamente em valores baixos de sucção matricial (na faixa de 0 a $100 \mathrm{kPa}$ de sucção) depende primariamente dos efeitos de capilaridade e da distribuição dos tamanhos dos poros, e, portanto, é fortemente afetado pela estrutura do solo. De outro lado, a quantidade de água retida em valores altos de sucção matricial é devido ao aumento da adsorção, sendo este fenômeno menos influenciado pela estrutura do solo e mais influenciado pela textura e tensão superficial das partículas do solo.

A Figura 3.30 ilustra o comportamento do efeito da textura do solo na curva de retenção, em que, o solo arenoso por apresentar poros relativamente grande, faz com que a maioria deles estejam vazios para um valor baixo de sucção, desse modo, restando apenas uma pequena quantidade de água para valores altos de sucção. Enquanto que o solo argiloso, por apresentar uma distribuição mais uniforme dos poros, causa uma diminuição gradual da quantidade de água conforme ocorra o aumento da sucção. Nota-se que na Figura 3.30, o conteúdo de água está representado no eixo das abscissas e a sucção está representada no eixo das ordenadas.

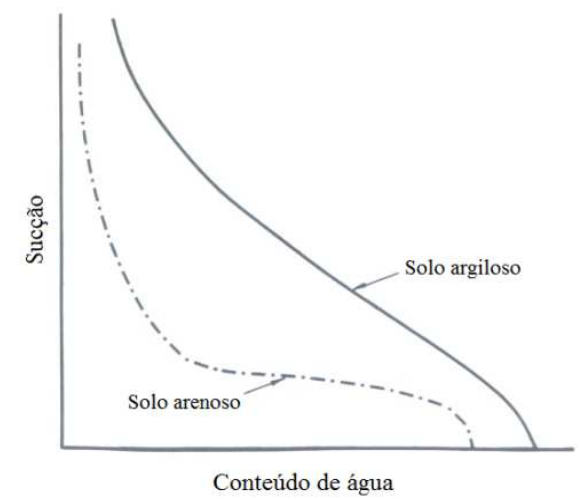

Figura 3.30 - Efeito da textura do solo na curva de retenção da água do solo.

Fonte: Traduzido e adaptado de Hillel (1980).

A curva de retenção da água do solo pode basicamente apresentar o formato de "S", denominada de curva modal, e o formato duplo "S", conhecida por curva bimodal. A distribuição do tamanho dos poros do solo é um dos fatores que, assim como a estrutura e a mineralogia das partículas, influenciam no formato dessa curva. A Figura 3.31 representa as curvas de retenção da água no solo para ilustrar o comportamento de três tipos de solos tipicamente argiloso, siltoso e arenoso. 


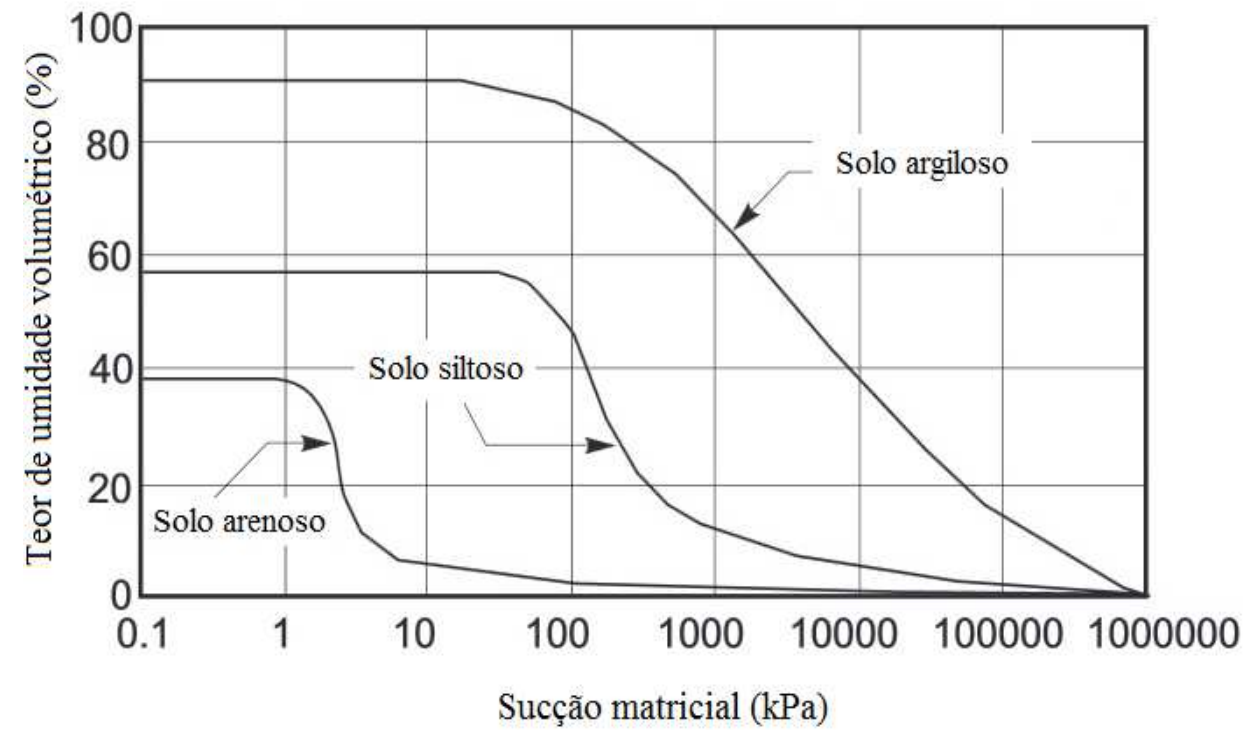

Figura 3.31 - Curva de retenção da água no solo para um solo argiloso, siltoso e arenoso.

Fonte: Traduzido e adaptado de Fredlund e Xing (1994).

Existem diversas técnicas experimentais propostas para determinar alguns pontos da curva de retenção da água do solo (item 3.4) e inúmeras equações matemáticas que permitem calcular os parâmetros de ajuste e definir o traçado da curva de retenção. Destacam-se as equações de Fredlund e Xing (1994) e Van Genuchten (1980) dentre as equações matemáticas amplamente utilizadas no meio geotécnico por conta de proporcionar um bom ajuste para a maioria dos solos. A Tabela 3.12 apresenta algumas dessas equações matemáticas propostas, os autores das equações e os parâmetros utilizados no ajuste da curva.

Tabela 3.12 - Equações matemáticas da curva de retenção da água do solo.

\section{Equação}

Origem

Parâmetros

$\theta$ é o teor de umidade volumétrica a ser calculado; $\theta_{r}$ é o teor de umidade volumétrica residual; $\theta_{s}$ é o teor de

$$
\theta=\theta_{r}+\left(\theta_{s}-\theta_{r}\right) \cdot \frac{1}{1+\left(q_{G} \cdot \psi\right)^{n}}
$$

Gardner umidade volumétrica de saturação; $\mathrm{q}_{\mathrm{G}}$ é o parâmetro de ajuste relacionado a $\psi_{b}$ (pressão de entrada de ar); $\psi$ é a sucção; n é o parâmetro relacionado à inclinação do ponto de inflexão.

$\theta$ é o teor de umidade volumétrica a ser calculado; $\theta_{r}$ é o teor de umidade

$$
\theta=\theta_{r}+\left(\theta_{s}-\theta_{r}\right) \cdot\left(\frac{\psi_{\mathrm{b}}}{\psi}\right)^{\lambda} \quad \text { Corey }
$$
volumétrica residual; $\theta_{S}$ é o teor de umidade volumétrica de saturação; $\psi_{b}$ é a pressão de entrada de ar; $\psi$ é a sucção; $\lambda$ é o índice de distribuição de poros.

(continua) 
(conclusão)

Tabela 3.12 - Equações matemáticas da curva de retenção da água do solo.

\begin{tabular}{ccc}
\hline Equação & Origem & Parâmetros \\
\hline$\theta=\theta_{r}+\left(\theta_{s}-\theta_{r}\right) \cdot\left[\frac{1}{1+\left(\alpha_{1} \cdot \psi\right)^{\mathrm{n}_{1}}}\right]^{\mathrm{m}_{1}}$ & $\begin{array}{c}\text { Van } \\
\text { Genuchten } \\
(1980)\end{array}$ & $\begin{array}{c}\theta \text { é o teor de umidade volumétrica a } \\
\text { ser calculado; } \theta_{r} \text { é o teor de umidade } \\
\text { volumétrica residual; } \theta_{s} \text { é o teor de } \\
\text { umidade volumétrica de saturação; } \\
\psi \text { é a sucção; } \alpha_{1}, m_{1}, n_{1} \text { são os } \\
\text { parâmetros de ajuste }\left(m_{1}=1-1 / n_{1}\right)\end{array}$ \\
\hline$\left.\theta=\theta_{r} \cdot \theta_{s}+\left(\theta_{s}-\theta_{r}\right) \cdot \theta_{s}\left\{\frac{1}{\ln \left[e+\left(\frac{\psi}{a_{2}}\right)^{n_{2}}\right]}\right\}^{m_{2}}\right\}$ & $\begin{array}{c}\text { Fredlund e teor de umidade volumétrica a } \\
\text { ser calculado; } \theta_{r} \text { é o teor de umidade } \\
\text { volumétrica residual; } \theta_{s} \text { é o teor de } \\
\text { umidade volumétrica de saturação; } \\
\psi \text { é a sucção; } a_{2}, m_{2}, n_{2} \text { são os } \\
\text { parâmetros de ajuste. }\end{array}$ \\
\hline
\end{tabular}

Fonte: Traduzido e adaptado de Leong e Rahardjo (1997).

\subsection{MOVIMENTO DA ÁGUA NO SOLO}

O movimento da água no solo pode ser descrito através de equações de fluxo, podendo estas serem utilizadas para descreverem duas situações distintas. Na primeira situação, a equação é utilizada para expressar as características do fluxo em que não varia com o tempo porém, varia com a posição, sendo esta chamada de equação para fluxo em regime estacionário ou regime permanente. Na segunda situação, a equação é usada para expressar as características do fluxo em que varia em função do tempo e da posição, sendo esta chamada de equação para fluxo em regime transiente.

Portanto, este item tem a finalidade de apresentar como parte integrante da revisão bibliográfica uma síntese das equações que regem o fluxo em regime estacionário e transiente juntamente com as equações da continuidade e de Richards. Também serão descritos conceitos relacionados com o processo de infiltração da água no solo e mencionados alguns modelos matemáticos propostos para a descrição desse processo.

\subsubsection{Equação de Darcy}

A equação geral do fluxo em meio saturado foi obtida em 1856, pelo engenheiro hidráulico Henry Darcy, a partir de ensaios de infiltração vertical de água feitos em filtros (colunas) de material poroso homogêneo sob condições de saturação. Este arranjo experimental permitiu que Darcy concluísse que o vazão do fluxo $(Q)$ é diretamente proporcional à área da seção transversal do filtro $(A)$ e a diferença entre o potencial total da água $\left(-\Delta \phi=H_{1}-H_{2}=\phi_{1}-\phi_{2}\right)$, enquanto que é inversamente proporcional ao 
comprimento do filtro $(L)$ (LIBARDI, 2005). A equação (15) representa as três conclusões obtidas por Darcy:

$$
Q \propto A \frac{\phi_{1}-\phi_{2}}{L}
$$

Desta maneira, substituindo-se o símbolo de proporcionalidade $(\alpha)$ por uma constante de proporcionalidade $\left(k_{s}\right)$, tem-se a famosa equação de Darcy (16). Esta constante é conhecida como coeficiente de condutividade hidráulica saturada porque neste arranjo experimental Darcy utilizou a água como líquido. Libardi (2012) descreve que esta propriedade do meio poroso traduz a rapidez com que determinado líquido atravessa esse meio.

$$
Q=k_{s} \cdot A \cdot \frac{\phi_{1}-\phi_{2}}{L}
$$

em que $Q$ é a vazão do fluxo, em $\left[\mathrm{L}^{3} \mathrm{~T}^{-1}\right] ; k_{s}$ é a condutividade hidráulica saturada do meio poroso, em $\left[\mathrm{LT}^{-1}\right] ; A$ é a área da seção transversal do filtro, em $\left[\mathrm{L}^{2}\right] ; \phi_{1}$ é o potencial total da água no ponto 1 , em [L]; $\phi_{2}$ é o potencial total da água no ponto 2 , em [L]; $L$ é o comprimento do filtro, em [L].

A equação de Darcy pode ser representada pela equação (17), resultante da divisão da equação (16) pela área da seção transversal do filtro $(A)$. Nesta equação (17), a densidade de fluxo equivale à um vetor, cujo módulo corresponde à relação entre vazão de fluxo pela área e com sentido e direção igual ao gradiente de potencial total da água. Vale ressaltar que o sinal negativo na equação abaixo indica apenas que o sentido do fluxo é inverso do gradiente, ou seja, no sentido em que ocorre diminuição do potencial da água.

$$
\begin{gathered}
q=-k_{s} \cdot \nabla \phi_{t} \\
\nabla \phi_{t}=\frac{\partial \phi_{t}}{\partial x}+\frac{\partial \phi_{t}}{\partial y}+\frac{\partial \phi_{t}}{\partial z}
\end{gathered}
$$

em que $q$ é a densidade de fluxo, em $\left[\mathrm{LT}^{-1}\right] ; k_{S}$ é a condutividade hidráulica saturada do meio poroso, em $\left[\mathrm{LT}^{-1}\right] ; \nabla \phi_{\mathrm{t}}$ é o gradiente de potencial total da água no solo, em [adimensional]. 


\subsubsection{Equação de Darcy-Buckingham}

Em 1907, o engenheiro Buckingham percebeu a necessidade de aprimorar a equação de Darcy para o fluxo de água em meio poroso não saturado, visto que ela retrata apenas uma particularidade de fluxo, o qual ocorre em meio poroso saturado. Esta nova equação denominada de equação de Darcy-Buckingham pode ser expressa como:

$$
q=-k(\theta) \cdot \nabla \phi_{m}(\theta)
$$

sendo:

$$
\nabla \phi_{m}(\theta)=\frac{\partial \phi_{m}(\theta)}{\partial x}+\frac{\partial \phi_{m}(\theta)}{\partial y}+\frac{\partial \phi_{m}(\theta)}{\partial z}
$$

em que $q$ é a densidade de fluxo, em $\left[\mathrm{LT}^{-1}\right] ; k(\theta)$ é a condutividade hidráulica não saturada em função do teor de umidade volumétrico do solo, em $\left[\mathrm{LT}^{-1}\right] ; \nabla \phi_{\mathrm{m}}$ é o gradiente de potencial matricial total da água no solo, em [adimensional].

A equação (19) somente é válida para o movimento da água na direção horizontal ou quando o efeito da gravidade, isto é, do potencial gravitacional seja desprezível. Libardi (2005) relata que Richards ${ }^{2}$ (1928 apud LIBARDI, 2005) acrescentou o potencial gravitacional na equação de Darcy-Buckingham, resultando na equação (22):

$$
q=-k(\theta) \cdot \nabla \phi_{t}
$$

sendo:

$$
\nabla \phi_{t}(\theta)=\frac{\partial\left[\phi_{g}+\phi_{m}(\theta)\right]}{\partial x}+\frac{\partial\left[\phi_{g}+\phi_{m}(\theta)\right]}{\partial y}+\frac{\partial\left[\phi_{g}+\phi_{m}(\theta)\right]}{\partial z}
$$

em que $q$ é a densidade de fluxo, em $\left[\mathrm{LT}^{-1}\right] ; k(\theta)$ é a condutividade hidráulica não saturada em função do teor de umidade volumétrico do solo, em $\left[\mathrm{LT}^{-1}\right] ; \nabla \phi_{\mathrm{t}}$ é o gradiente de potencial total da água no solo, em [adimensional].

\subsubsection{Equação da Continuidade}

A equação da Continuidade nada mais é do que uma equação de conservação de massa, a qual estabelece por meio de formulações matemáticas que não pode existir nem a criação e nem a destruição de massa (LIBARDI, 2012). Esta equação relaciona o volume de 
entrada e o volume de saída de água em um dado elemento de solo, permitindo descrever uma situação de fluxo transiente e determinar para qualquer ponto no interior de um perfil de solo a umidade em função do tempo e da posição (REICHARDT, 1985).

A Figura 3.32 ilustra um elemento de solo de volume $(\Delta V)$ em torno de um ponto $\mathrm{M}$, situado no perfil do solo, com dimensões de $\Delta x, \Delta y$ e $\Delta z$. Neste elemento, a densidade de fluxo de água (q) pode ser decomposta nas três direções ortogonais à $x, \mathrm{y}$ e z; resultando em $q_{x}, q_{y} e q_{z}$

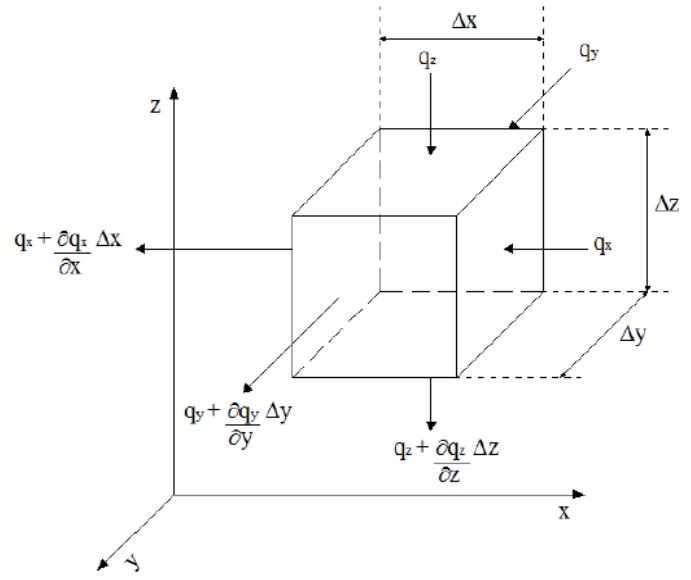

Figura 3.32 - Elemento de volume de solo em torno de um ponto $\mathrm{M}$.

Fonte: Fernandes (2011) adaptado de Reichardt (1985).

No caso da face representada por $\Delta \mathrm{y} . \Delta \mathrm{z}$ neste elemento de solo, a densidade de fluxo ocorre na direção ortogonal à face e é representada pelo vetor $\mathrm{q}_{\mathrm{x}}$. Considerando-se que ao longo da direção x pode ocorrer uma variação no fluxo equivalente a $\partial \mathrm{q}_{\mathrm{x}} / \partial \mathrm{x}$, pode-se dizer que o fluxo de água $\left(\mathrm{q}_{\mathrm{x}}^{\prime}\right)$ que sairá desse elemento é igual a:

$$
q^{\prime}{ }_{x}=q_{x}+\left(\frac{\partial q_{x}}{\partial x}\right) \cdot \Delta \mathrm{x}
$$

A partir das equações de densidade de fluxo de entrada e de saída, também pode-se representar o volume de entrada de água $\left(V_{w_{x}}\right)$ e de saída de água $\left(V^{\prime}{ }_{w_{x}}\right)$ por unidade de tempo, de acordo com as equações (24) e (25). A variação de volume de água na direção $x$ é dada pela diferença entre o volume de entrada e saída (equação 26), resultando na equação (27).

$$
V_{w_{x}}=q_{x} \cdot \Delta \mathrm{y} \cdot \Delta \mathrm{z}
$$




$$
\begin{gathered}
V_{w_{x}}^{\prime}=\left[q_{x}+\left(\frac{\partial q_{x}}{\partial x}\right) \cdot \Delta \mathrm{x}\right] \cdot \Delta \mathrm{y} \cdot \Delta \mathrm{z} \\
\frac{\partial V_{w_{x}}}{\partial t}=q_{x} \cdot \Delta \mathrm{y} \cdot \Delta \mathrm{z}-\left[q_{x}+\left(\frac{\partial q_{x}}{\partial x}\right) \cdot \Delta \mathrm{x}\right] \cdot \Delta \mathrm{y} \cdot \Delta \mathrm{z} \\
\frac{\partial V_{w_{x}}}{\partial t}=-\left(\frac{\partial q_{x}}{\partial x}\right) \cdot \Delta \mathrm{x} \cdot \Delta \mathrm{y} \cdot \Delta \mathrm{z}
\end{gathered}
$$

Empregando-se o mesmo raciocínio utilizado na equação (27), tem-se que o volume de água para as demais direções y e z será igual a $\partial V_{w_{y}} / \partial t$ e $\partial V_{w_{z}} / \partial t$, respectivamente. Logo, a variação de volume total no elemento corresponderá à soma das variações nas três direções, como mostra equação (28):

$$
\frac{\partial V_{w}}{\partial t}=-\left(\frac{\partial q_{x}}{\partial x}+\frac{\partial q_{y}}{\partial y}+\frac{\partial q_{z}}{\partial z}\right) \cdot \Delta \mathrm{x} \cdot \Delta \mathrm{y} \cdot \Delta \mathrm{z}
$$

Como o teor de umidade volumétrico $(\theta)$ é a relação entre o volume de água $\left(V_{w}\right)$ e o volume total $(V=\Delta \mathrm{x} . \Delta \mathrm{y} . \Delta \mathrm{z})$ (equação 29), a equação da continuidade pode ser simplificada e representada por (30):

$$
\begin{gathered}
\frac{\partial \theta}{\partial t}=-\left(\frac{\partial q_{x}}{\partial x}+\frac{\partial q_{y}}{\partial y}+\frac{\partial q_{z}}{\partial z}\right) \\
\frac{\partial \theta}{\partial t}=-\nabla q
\end{gathered}
$$

\subsubsection{Equação de Richards}

A equação de Richards é resultante da combinação da equação da Continuidade com a equação de Darcy-Buckingham, utilizada para descrever o fluxo em solo não saturado. Nesta equação, Richards (1931) propõe relacionar a condutividade hidráulica não saturada do solo e o potencial matricial por meio da substituição da equação (21) de Darcy-Buckingham na equação (30) da Continuidade, dado por: 


$$
\begin{gathered}
\frac{\partial \theta}{\partial t}=\nabla\left[k(\theta) \cdot \nabla \phi_{t}\right] \\
\frac{\partial \theta}{\partial t}=\frac{\partial}{\partial x}\left[k(\theta) \cdot \frac{\partial \phi_{t}}{\partial x}\right]+\frac{\partial}{\partial y}\left[k(\theta) \cdot \frac{\partial \phi_{t}}{\partial y}\right]+\frac{\partial}{\partial z}\left[k(\theta) \cdot \frac{\partial \phi_{t}}{\partial z}\right]
\end{gathered}
$$

\subsubsection{Infiltração: termos e conceitos}

O termo infiltração pode ser definido como sendo o fenômeno de entrada na superfície do solo da água proveniente da chuva, neve derretida ou irrigação Maidment ${ }^{3}$ (1993 apud FORMIGA et al., 2012). Este fenômeno proporciona o umedecimento gradativo das camadas superiores do perfil de solo, alterando o teor de umidade ao longo da profundidade conforme ocorra a entrada da água no solo (BRANDÃO et al., 2009).

Gerscovich (2012) relata que a partir do momento que uma determinada quantidade de água atinge à superfície de um solo não saturado, imediatamente é iniciado o processo de infiltração, que é essencialmente vertical e movido pela ação das forças de capilaridade e gravitacional. Libardi (2012) menciona que durante uma chuva, parte da água pode infiltrar e movimentar-se no interior do solo e parte pode escoar superficialmente, dependendo da declividade do terreno. Outro fator que é determinante na quantidade de água a ser infiltrada no solo é a condição de umidade inicial do solo.

A distribuição da água com a profundidade em um perfil de solo uniforme, submetido a uma pequena carga hidráulica na superfície do solo, pode ser representada esquematicamente como mostra a Figura 3.33. Este perfil de umedecimento pode ser dividido em quatro zonas: saturação, transição, transmissão e umedecimento. A zona de saturação situa-se logo abaixo da superfície do solo e presume-se que o solo esteja saturado. A zona de transição é uma região onde ocorre um rápido decréscimo do teor de umidade e encontra-se logo abaixo da zona de saturação. A zona de transmissão é caracterizada por ser uma região que apresenta pequena variação no teor de umidade, mantendo-se basicamente uniforme ao longo do tempo, e pelo aumento da espessura dessa camada de acordo com a disponibilidade da quantidade de água na superfície. A zona de umedecimento é marcada pela acentuada variação do teor de umidade do solo, limitando visivelmente o solo seco do solo úmido a partir da frente de molhamento, também denominado de frente de umedecimento
(BRANDÃO
et
al.,
2009 ;
LIBARDI,
2012). 


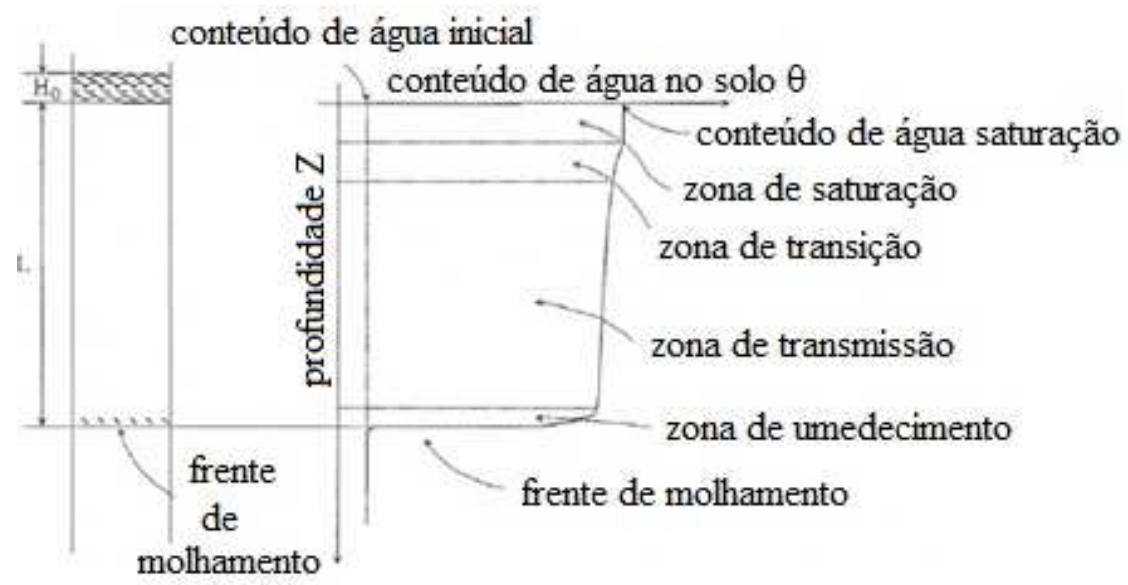

Figura 3.33 - Perfil de umedecimento do solo durante a infiltração.

Fonte: Modificado e adaptado de Libardi (2012).

O processo de infiltração da água no solo depende de fatores que estão associados às propriedades do solo como porosidade, composição textural, estrutura do solo, teor de umidade, presença de matéria orgânica e de fatores que estão relacionados ao local como tipo de cobertura superficial, topografia do terreno, condições da superfície, temperatura, precipitação diária.

Diversos modelos matemáticos foram propostos para descrever o processo de infiltração da água no solo, podendo estes serem agrupados em duas classes principais: empíricos e teóricos (também denominados de conceituais). Basicamente, a diferença entre essas classes consta na origem das equações pois os modelos empíricos foram desenvolvidos para as características e as condições de contorno do solo estudado e os modelos teóricos foram fundamentados em teorias e equações do escoamento da água em meios porosos (equações de Darcy e de Richards). Dentre os modelos existentes, destacam-se os modelos empíricos de Kostiakov, Kostiakov-Lewis, Horton e os modelos teóricos de Green-Ampt e Philip. Maiores detalhes desses modelos podem ser consultados em outras literaturas científicas (BRANDÃO et al., 2009; FORMIGA et al., 2012; LIBARDI, 1995; LIBARDI, 2012; SILVA, 2015).

Alguns termos como infiltração acumulada, taxa de infiltração, capacidade de infiltração e escoamento superficial estão relacionados com a dinâmica da infiltração da água no solo. O conhecimento e o domínio do conceito de cada um desses termos é de grande importância para a compreensão de como ocorre esse processo na natureza.

Infiltração acumulada (I): definida como o volume de água infiltrada em uma determinada unidade de área do solo, sendo expressa em $[L]$ e normalmente utilizadas as unidades $\mathrm{mm}$ e cm. 
Taxa de infiltracão $(\boldsymbol{i}):$ corresponde a relação entre a infiltração acumulada e o tempo de duração, sendo expressa em [LT ${ }^{-1}$ ] e usualmente utilizadas as unidades $\mathrm{mm} / \mathrm{h}$ e $\mathrm{cm} / \mathrm{min}$. Gerscovich (2012) cita que a taxa de infiltração depende da capacidade de infiltração, da condutividade hidráulica e da intensidade da chuva. Além disso, pode-se dizer que a taxa de infiltração também varia de acordo com o teor de umidade inicial do solo, pois um solo seco absorve maior quantidade de água que um solo úmido.

Capacidade de infiltracão $(\boldsymbol{C})$ : equivale a taxa máxima de água que um solo pode absorver água através da sua superfície durante um determinado tempo. A capacidade de infiltração do solo decresce com o tempo e tende a diminuir até alcançar um valor constante. Esta capacidade também varia de acordo com o teor de umidade do solo, isto é, o solo seco terá maior capacidade de infiltração e o solo saturado terá menor capacidade de infiltração.

Escoamento superficial $(\boldsymbol{E S})$ : ocorre quando intensidade da chuva ultrapassa a capacidade de infiltração do solo, formando-se uma lâmina de água na superfície do solo, resultante do excesso de volume de água.

\subsubsection{Condutividade hidráulica dos solos}

A condutividade hidráulica do solo é uma propriedade que expressa a facilidade com que a água percola através de seus poros. Hillel (1980) menciona em seu trabalho que a condutividade hidráulica não é apenas uma propriedade exclusiva do solo pois esta depende da característica do solo como porosidade, distribuição do tamanho dos poros, geometria dos poros e da característica do líquido como densidade e viscosidade.

A equação de Darcy (apresentada no item 3.6.1) foi a primeira equação desenvolvida para quantificar o movimento da água no solo saturado a partir do parâmetro denominado de condutividade hidráulica saturada $\left(k_{S}\right)$. No caso do solo não saturado em que os vazios do solo encontram-se preenchidos por água e ar, a variação do parâmetro chamado de condutividade hidráulica não saturada ocorre em função do teor de umidade do solo, sendo ele usualmente representado por $k(\theta), k\left(\phi_{m}\right)$ ou $k(\psi)$. Os valores da condutividade hidráulica saturada e não saturada dependem da composição textural do solo, apresentando uma faixa de variação da condutividade hidráulica saturada na ordem de $10^{-2} \mathrm{~cm} / \mathrm{s}$ a $10^{-3} \mathrm{~cm} / \mathrm{s}$ para solo arenoso e na ordem de $10^{-4} \mathrm{~cm} / \mathrm{s}$ a $10^{-7} \mathrm{~cm} / \mathrm{s}$ para solo argiloso (HILLEL, 1980).

Existem os métodos de medida direta que permitem determinar a condutividade hidráulica (saturada ou não saturada) utilizando apenas técnicas de laboratório ou de campo e ainda os métodos de medida indireta que possibilitam relacionar outras propriedades do solo 
com a condutividade hidráulica (saturada ou não saturada) a partir do desenvolvimento de equações matemáticas empíricas. Dentre os métodos de medida direta destacam-se o permeâmetro de parede rígida e flexível (laboratório), permeâmetro Guelph (campo), infiltrômetro de disco (campo), infiltrômetro do duplo anel (campo) e os métodos de medida indireta destacam-se as equações empíricas de Gardner (1958) e Van Genuchten (1980). A Tabela 3.13 apresenta as equações mais utilizadas, os autores das equações e os parâmetros utilizados na obtenção da condutividade hidráulica não saturada.

Tabela 3.13 - Equações empíricas para obtenção da condutividade hidráulica não saturada.

\section{Equação}

$$
k\left(S_{r}\right)=k_{s} \cdot\left[\frac{\left(S_{r}-S_{r u}\right)}{\left(1-S_{r u}\right)}\right]^{3}
$$

$$
k\left(S_{r}\right)=k_{s^{\cdot}} \cdot\left[\frac{\left(S_{r}-S_{r u}\right)}{\left(1-S_{r u}\right)}\right]^{4}
$$

Corey

$k(\psi)=k_{s} \cdot \exp ^{(-\alpha . \psi)} \quad$ Gardner

$$
\begin{gathered}
k(\psi)=k_{s} \text { para } \psi \leq \psi_{b} \\
k(\psi)=k_{s} \cdot\left(\frac{\psi}{\psi_{b}}\right)^{-\lambda} \quad \text { para } \psi \geq \psi_{b}
\end{gathered}
$$

Brooks e

Corey (1964)
$k\left(S_{r}\right)$ é a condutividade hidráulica não saturada; $k_{s}$ é a condutividade hidráulica saturada; $S_{r}$ é o grau de saturação; $S_{r u}$ é o grau de saturação residual.

$k\left(S_{r}\right)$ é a condutividade hidráulica não saturada; $k_{s}$ é a condutividade hidráulica saturada; $S_{r}$ é o grau de saturação; $S_{r u}$ é o grau de saturação residual.

$k(\psi)$ é a condutividade hidráulica não saturada; $k_{s}$ é a condutividade hidráulica saturada; $\alpha$ é o parâmetro que depende da porosidade e textura do solo; $\psi$ é a sucção.

$k(\psi)$ é a condutividade hidráulica não saturada; $k_{s}$ é a condutividade hidráulica saturada; $\psi$ é a sucção; $\psi_{b}$ é a sucção de entrada de ar; $\lambda$ é o índice de distribuição de poros.

$k(\theta)$ é a condutividade hidráulica não saturada; $k_{s}$ é a condutividade hidráulica

$$
k(\theta)=\mathrm{k}_{\mathrm{s}} \cdot\left[\frac{\left(\theta-\theta_{\mathrm{r}}\right)}{\left(\theta_{\mathrm{s}}-\theta_{\mathrm{r}}\right)}\right]^{1 / 2} \cdot\left\{1-\left[1-\left(\frac{\theta-\theta_{\mathrm{r}}}{\theta_{\mathrm{s}}-\theta_{\mathrm{r}}}\right)^{\frac{1}{\mathrm{~m}}}\right]^{\mathrm{m}}\right\}^{2} \quad \begin{gathered}
\text { Van } \\
\text { Genuchten }
\end{gathered}
$$

saturada; $\theta$ é o teor de umidade volumétrica a ser calculado; $\theta_{r}$ é o teor de umidade volumétrica residual; $\theta_{s}$ é o teor de umidade; $m_{1}, n_{1}$ são os parâmetros de ajuste $\left(m_{1}=1-1 / n_{1}\right)$. 


\subsection{RESISTÊNCIA AO CISALHAMENTO DO SOLO}

O termo denominado de resistência ao cisalhamento é amplamente utilizado por engenheiros geotécnicos para caracterizar o comportamento mecânico dos solos. Esse termo designa uma das propriedades mais importantes do solo, estando este descrito pela variável de estado de tensão denominada de tensão efetiva. Vilar (2009) menciona que a determinação dos parâmetros de resistência ao cisalhamento do solo é complexa e indispensável para a solução de problemas geotécnicos gerados pela ruptura de solos, destacando a utilização desses parâmetros na análise de estabilidade de talude, empuxos de terra, dimensionamento de pavimento e capacidade de carga de fundações.

A resistência ao cisalhamento do solo pode ser definida como a máxima resistência interna por unidade de área que o solo é capaz de sustentar ao longo de um plano de ruptura sobre um carregamento de tensão interno ou externo (LU; LIKOS, 2004). No caso do solo saturado, a resistência ao cisalhamento pode ser descrita por meio do critério de ruptura Mohr-Coulomb e do conceito das tensões efetivas formulado por Karl Terzaghi, como mostra a equação (33) e ilustra a Figura 3.34.

$$
\tau=c^{\prime}+\left(\sigma-u_{w}\right) \cdot \operatorname{tg} \phi^{\prime}
$$

em que $\tau$ é a resistência ao cisalhamento, em $\left[\mathrm{ML}^{-1} \mathrm{~T}^{-2}\right] ; c^{\prime}$ é a coesão efetiva do solo, em $\left[\mathrm{ML}^{-1} \mathrm{~T}^{-2}\right] ; \sigma$ é a tensão total, em $\left[\mathrm{ML}^{-1} \mathrm{~T}^{-2}\right] ; u_{w}$ é a pressão neutra, em $\left[\mathrm{ML}^{-1} \mathrm{~T}^{-2}\right] ; \phi^{\prime}$ é o ângulo de atrito interno efetivo do solo, em $\left[{ }^{\circ}\right]$.

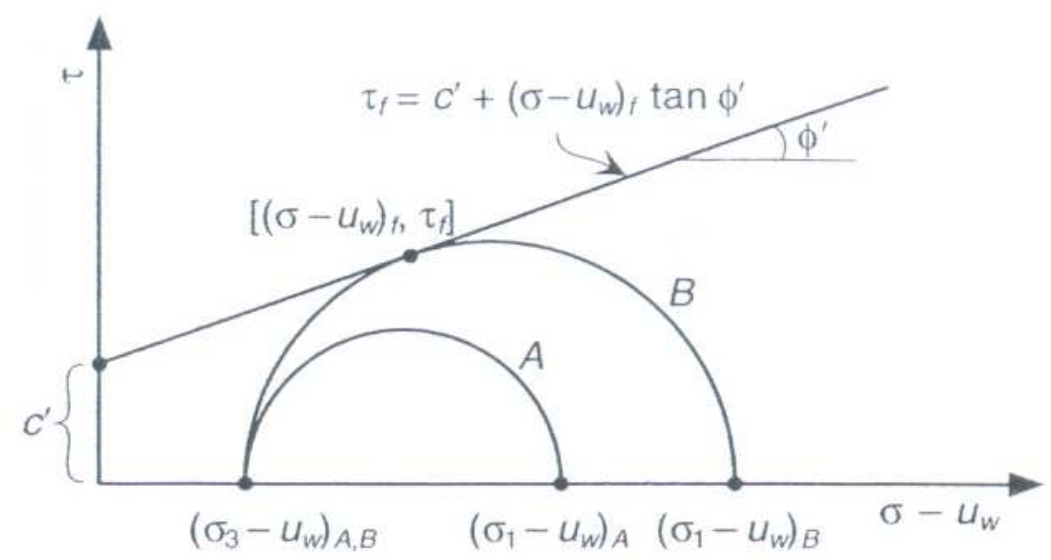

Figura 3.34 - Critério de ruptura Mohr-Coulomb para solo saturado. Fonte: Adaptado de Lu e Likos (2004).

Na Figura 3.34, a reta que tangencia o círculo B é definida como sendo a envoltória de resistência, expressa a partir de uma equação de primeiro grau (como mostra a equação (33), 
que relaciona resistência ao cisalhamento com tensão efetiva, dada em função do ângulo de atrito $(\phi)$ e da coesão $(c)$. O ângulo de atrito é resultante do contato entre as partículas sólidas do solo enquanto que a coesão corresponde à atração química entre as partículas, sendo uma característica típica de solos com muito finos.

Neste sentido, os próximos sub-itens pretendem apresentar uma síntese de conceitos associados à resistência ao cisalhamento dos solos tais como estado de tensão e variáveis de estado de tensão do solo, envoltória de resistência ao cisalhamento e métodos de previsão de resistência ao cisalhamento, apresentando todos sub-itens com enfoque na abordagem e aplicação aos solos não saturados.

\subsubsection{Tensão efetiva, estado de tensão e variáveis de estado de tensão do solo}

Variáveis de estado podem ser definidas como aquelas variáveis necessárias para descrever inteiramente o estado do sistema em que se processa o fenômeno de interesse, podendo ser utilizadas diversas variáveis na caracterização desse fenômeno. Por esse motivo, o uso do conceito de tensão efetiva para os solos saturados estabelece uma única variável de estado de tensão, responsável por traduzir o comportamento resistente e deformacional do solo (VILAR, 2009).

O princípio da tensão efetiva para solos saturados foi estabelecido por Karl Terzaghi em 1936 por meio da elaboração de uma equação matemática, a qual define que parte da tensão atua nos contatos entre as partículas sólidas e parte age na água dos vazios do solo, como expressa a equação (34):

$$
\sigma^{\prime}=\sigma-u_{w}
$$

em que $\sigma^{\prime}$ é a tensão efetiva do solo, em $\left[\mathrm{ML}^{-1} \mathrm{~T}^{-2}\right] ; \sigma$ é a tensão total do solo, em $\left[\mathrm{ML}^{-1} \mathrm{~T}^{-2}\right]$; $u_{w}$ é a pressão neutra, em $\left[\mathrm{ML}^{-1} \mathrm{~T}^{-2}\right]$.

Embora a formulação de Terzaghi tenha sido bem sucedida para o solo saturado, a utilização desse conceito mostrou-se inadequada para descrição do comportamento do solo não saturado. Essa complexidade encontra-se associado ao fato do solo não saturado ser constituído por um sistema multifásico (três ou quatro fases) pois o uso de uma única variável de estado de tensão seria insuficiente para representá-lo. Por esse motivo, inúmeros pesquisadores procuraram inserir outras variáveis de estado de tensão a fim de descrever o comportamento dos solos não saturados através de equações matemáticas fundamentadas no conceito de tensão efetiva e no estabelecimento de novas variáveis de estado de tensão. De 
maneira geral, as equações sugeridas por esses pesquisadores incorporam propriedades do solo, buscando representar o comportamento do solo não saturado a partir de uma única relação (FREDLUND; RAHARDJO, 1993). A Tabela 3.14 reúne algumas das equações de tensão efetiva para solo não saturado disponíveis na literatura científica, seguida dos seus autores e dos parâmetros utilizados em cada uma dessas equações.

Tabela 3.14 - Equações de tensão efetiva para solo não saturado.

\begin{tabular}{|c|c|c|}
\hline Equação & Origem & Parâmetros \\
\hline$\sigma^{\prime}=\sigma-\beta^{\prime} \cdot u_{w}$ & $\begin{array}{l}\text { Croney et al. } \\
\quad(1958)\end{array}$ & $\begin{array}{c}\sigma^{\prime} \text { é a tensão efetiva; } \sigma \text { é a tensão total; } \\
\beta^{\prime} \text { é o fator de ligação (que é uma } \\
\text { medida do número de ligações sob } \\
\text { tensão); } u_{w} \text { é a pressão da água. }\end{array}$ \\
\hline$\sigma^{\prime}=\left(\sigma-u_{a}\right)+\chi \cdot\left(u_{a}-u_{w}\right)$ & Bishop (1959) & $\begin{array}{c}\sigma^{\prime} \text { é a tensão efetiva; } \sigma \text { é a tensão total; } \\
\mathrm{u}_{\mathrm{a}} \text { é a pressão de ar; } \chi \text { é o parâmetro } \\
\text { relacionado com o grau de } \\
\text { saturação; } \mathrm{u}_{\mathrm{w}} \text { é a pressão da água. }\end{array}$ \\
\hline$\sigma^{\prime}=\sigma-\psi_{\mathrm{A}} \cdot \mathrm{p}_{\mathrm{A}}^{\prime \prime}$ & $\begin{array}{l}\text { Aitchison } \\
\text { (1961) }\end{array}$ & $\begin{array}{c}\sigma^{\prime} \text { é a tensão efetiva; } \sigma \text { é a tensão } \\
\text { total; } \Psi_{\mathrm{A}} \text { é um parâmetro que varia de } \\
0 \text { a } 1 ; \mathrm{p}^{\prime \prime}{ }_{\mathrm{A}} \text { é a deficiência de pressão da } \\
\text { água. }\end{array}$ \\
\hline$\sigma^{\prime}=\left(\sigma \cdot a_{m}\right)+\left(u_{a} \cdot a_{a}\right)+\left(u_{w} \cdot a_{w}\right)+R_{L}+A_{L}$ & $\begin{array}{l}\text { Lambe } \\
\text { (1960) }\end{array}$ & $\begin{array}{l}\sigma^{\prime} \text { é a tensão efetiva; } \sigma \text { é a tensão } \\
\text { total; } \mathrm{a}_{\mathrm{m}} \text { é a área de contato ocupada } \\
\text { pelos sólidos; } \mathrm{u}_{\mathrm{a}} \text { é a pressão de ar; } \mathrm{a}_{\mathrm{a}} \text { é } \\
\text { parte da área total ocupada pelo ar; } \mathrm{u}_{\mathrm{w}} \text { é } \\
\text { a pressão da água; } \mathrm{a}_{\mathrm{w}} \text { é parte da área } \\
\text { total ocupada pelo água; } \mathrm{R}_{\mathrm{L}} \text { é a } \\
\text { resultante das forças de repulsão; } \mathrm{A}_{\mathrm{L}} \text { é a } \\
\text { resultante das forças de atração elétrica. }\end{array}$ \\
\hline$\sigma^{\prime}=\sigma-\beta \cdot p_{J}^{\prime \prime}$ & $\begin{array}{l}\text { Jennings } \\
(1961)\end{array}$ & $\begin{array}{c}\sigma^{\prime} \text { é a tensão efetiva; } \sigma \text { é a tensão total; } \beta \\
\text { é um fator estático do mesmo tipo da } \\
\text { área de contato, medido } \\
\text { experimentalmente; } \mathrm{p}_{\mathrm{J}}^{\prime \prime} \text { é a pressão da } \\
\text { água tomada como valor positivo. }\end{array}$ \\
\hline$\sigma^{\prime}=\sigma-u_{a}+\chi_{m 1} \cdot\left(h_{m}+u_{a}\right)+\chi_{s 1} \cdot\left(h_{s}+u_{a}\right)$ & $\begin{array}{l}\text { Richards } \\
\text { (1966) }\end{array}$ & $\begin{array}{l}\sigma^{\prime} \text { é a tensão efetiva; } \sigma \text { é a tensão } \\
\text { total; } \mathrm{u}_{\mathrm{a}} \text { é a pressão de ar; } \chi_{\mathrm{m} 1} \text { é o } \\
\text { parâmetro de tensão efetiva para a } \\
\text { sucção matricial; } \mathrm{h}_{\mathrm{m}} \text { é a sucção } \\
\text { matricial; } \chi_{\mathrm{s} 1} \text { é o parâmetro de tensão } \\
\text { efetiva para a solução de soluto; } \mathrm{h}_{\mathrm{s}} \text { é a } \\
\text { solução de soluto. }\end{array}$ \\
\hline$\sigma^{\prime}=\sigma+\chi_{\mathrm{m} 2} \cdot \mathrm{p}_{\mathrm{m}}^{\prime \prime}+\chi_{\mathrm{s} 2} \cdot \mathrm{p}_{\mathrm{s}}^{\prime \prime}$ & $\begin{array}{l}\text { Aitchison } \\
\text { (1973) }\end{array}$ & $\begin{array}{c}\sigma^{\prime} \text { é a tensão efetiva; } \sigma \text { é a tensão } \\
\text { total; } \mathrm{u}_{\mathrm{a}} \text { é a pressão de ar; } \chi_{\mathrm{m} 2} \text { é um } \\
\text { parâmetro que varia de } 0 \text { a } 1 \\
\text { (dependendo da trajetória de tensões); } \\
\mathrm{p}^{\prime \prime}{ }_{\mathrm{m}} \text { é a sucção matricial; } \chi_{\mathrm{s} 2} \text { é um } \\
\text { parâmetro que varia de } 0 \text { a } 1 \\
\text { (dependendo da trajetória de tensões); } \\
\mathrm{p}^{\prime \prime}{ }_{\mathrm{s}} \text { é a sucção de soluto. }\end{array}$ \\
\hline
\end{tabular}


Em virtude das inúmeras dificuldades encontradas por esses pesquisadores, Fredlund e Morgenstern (1977) propuseram uma nova combinação de variáveis de estado de tensão, considerando o solo um sistema tetrafásico: partículas sólidas, ar, água e membrana contráctil. Estes pesquisadores sugeriram separar as relações entre as fases e apresentam três possíveis combinações possíveis de variáveis de estado de tensão, como mostra a Tabela 3.15.

Tabela 3.15 - Combinações possíveis das variáveis de estado de tensão para um solo não saturado

\begin{tabular}{cc}
\hline Fase de referência & Variáveis de estado de tensão \\
\hline $\operatorname{Ar}\left(\mathrm{u}_{\mathrm{a}}\right)$ & $\left(\sigma-\mathrm{u}_{\mathrm{a}}\right) \mathrm{e}\left(\mathrm{u}_{\mathrm{a}}-\mathrm{u}_{\mathrm{w}}\right)$ \\
\hline Água $\left(\mathrm{u}_{\mathrm{w}}\right)$ & $\left(\sigma-\mathrm{u}_{\mathrm{w}}\right) \mathrm{e}\left(\mathrm{u}_{\mathrm{a}}-\mathrm{u}_{\mathrm{w}}\right)$ \\
\hline Tensão total $(\sigma)$ & $\left(\sigma-\mathrm{u}_{\mathrm{a}}\right) \mathrm{e}\left(\sigma-\mathrm{u}_{\mathrm{w}}\right)$ \\
\hline
\end{tabular}

Fonte: Fredlund e Rahardjo (1993).

De acordo com Fredlund e Rahardjo (1993), a combinação de $\left(\sigma-\mathrm{u}_{\mathrm{a}}\right)$ e $\left(\mathrm{u}_{\mathrm{a}}-\mathrm{u}_{\mathrm{w}}\right)$ parece ser mais preferido para utilização em práticas de engenharia porque os efeitos da variação na tensão total podem ser avaliadas separadamente dos efeitos gerados pela variação na pressão da água. Além disso, a pressão de ar corresponde à pressão atmosférica (igual a zero) na maioria dos problemas da prática de engenharia.

\subsubsection{Envoltória de resistência ao cisalhamento para um solo não saturado}

A resistência ao cisalhamento do solo não saturado pode ser representada tendo como base as equações de tensão efetiva mostradas na Tabela 3.14. Neste caso, pode-se citar como exemplo a equação formulada por Bishop et al. (1960), em que a equação de tensão efetiva do solo não saturado proposta por Bishop (1959) é substituída na equação (33) adotada como critério de ruptura de Mohr-Coulomb para solo saturado. A equação de Bishop et al. (1960) pode ser expressa pela equação (35):

$$
\tau=c^{\prime}+\left(\sigma-u_{a}\right) \cdot \operatorname{tg} \phi^{\prime}+\chi \cdot\left(u_{a}-u_{w}\right) \cdot \operatorname{tg} \phi^{\prime}
$$

em que $\tau$ é a resistência ao cisalhamento, em $\left[\mathrm{ML}^{-1} \mathrm{~T}^{-2}\right] ; c^{\prime}$ é a coesão efetiva do solo, em $\left[\mathrm{ML}^{-1} \mathrm{~T}^{-2}\right] ;\left(\sigma-u_{a}\right)$ é a tensão normal líquida, em $\left[\mathrm{ML}^{-1} \mathrm{~T}^{-2}\right] ; \phi^{\prime}$ é o ângulo de atrito interno efetivo do solo referente a variação da tensão normal líquida, em $\left[{ }^{\circ}\right]$; $\chi$ é um parâmetro dependente do grau de saturação, em [adimensional]; $\left(u_{a}-u_{w}\right)$ é a sucção matricial, em $\left[\mathrm{ML}^{-1} \mathrm{~T}^{-2}\right]$. 
Outra maneira de representar a resistência ao cisalhamento de um solo não saturado é através da combinação de duas variáveis de estado de tensão, que segundo Fredlund e Rahardjo (1993), as variáveis representadas por $\left(\sigma-\mathrm{u}_{\mathrm{a}}\right)$ e $\left(\mathrm{u}_{\mathrm{a}}-\mathrm{u}_{\mathrm{w}}\right)$ tem sido apontadas como a combinação mais vantajosa na aplicação à engenharia. Diante disso, Fredlund, Morgenstern e Widger (1978) formularam uma extensão do critério Mohr-Coulomb para descrever a resistência ao cisalhamento do solo não saturado, assumindo a superfície de ruptura como sendo planar. A equação (36) expressa a relação entre essa variáveis, em que os primeiros dois termos descrevem o critério Mohr-Coulomb convencional para resistência do solo saturado e o terceiro termo representa o acréscimo na resistência do solo devido ao aumento proporcionado pela sucção matricial do solo não saturado (LU; LIKOS, 2004).

$$
\tau=c^{\prime}+\left(\sigma-u_{a}\right) \cdot \operatorname{tg} \phi^{\prime}+\left(u_{a}-u_{w}\right) \cdot \operatorname{tg} \phi^{b}
$$

em que $\tau$ é a resistência ao cisalhamento, em $\left[\mathrm{ML}^{-1} \mathrm{~T}^{-2}\right] ; c^{\prime}$ é a coesão efetiva do solo, em $\left[\mathrm{ML}^{-1} \mathrm{~T}^{-2}\right] ;\left(\sigma-u_{a}\right)$ é a tensão normal líquida, em $\left[\mathrm{ML}^{-1} \mathrm{~T}^{-2}\right] ; \phi^{\prime}$ é o ângulo de atrito interno efetivo do solo referente a variação da tensão normal líquida, em $\left[^{\circ}\right] ;\left(u_{a}-u_{w}\right)$ é a sucção matricial, em $\left[\mathrm{ML}^{-1} \mathrm{~T}^{-2}\right] ; \phi^{b}$ é o ângulo de atrito interno efetivo do solo referente a variação da sucção matricial, em $\left[{ }^{\circ}\right]$.

A Figura 3.35 ilustra a representação tridimensional da envoltória de resistência ao cisalhamento de um solo não saturado para a equação proposta por Fredlund, Morgenstern e Widger (1978). Nesta figura, os eixos no plano horizontal representam as variáveis de estado de tensão (tensão normal líquida e sucção matricial) e a ordenada representa a tensão de cisalhamento. $\mathrm{O}$ valor do ângulo $\phi^{\prime}$ é dado em função da tensão normal líquida enquanto o valor do ângulo $\phi^{b}$ é dado em função da sucção matricial, mantendo-se sempre um valor constante na envoltória. A coesão inicial $c^{\prime}$ tende a ter um acréscimo linear com o aumento do valor da sucção matricial e a superfície planar que representa a envoltória de ruptura está destacada pela cor vemelho. Nesta mesma figura, nota-se que a resistência ao cisalhamento é denominada por Fredlund e Rahardjo (1993) de tensão de cisalhamento. 


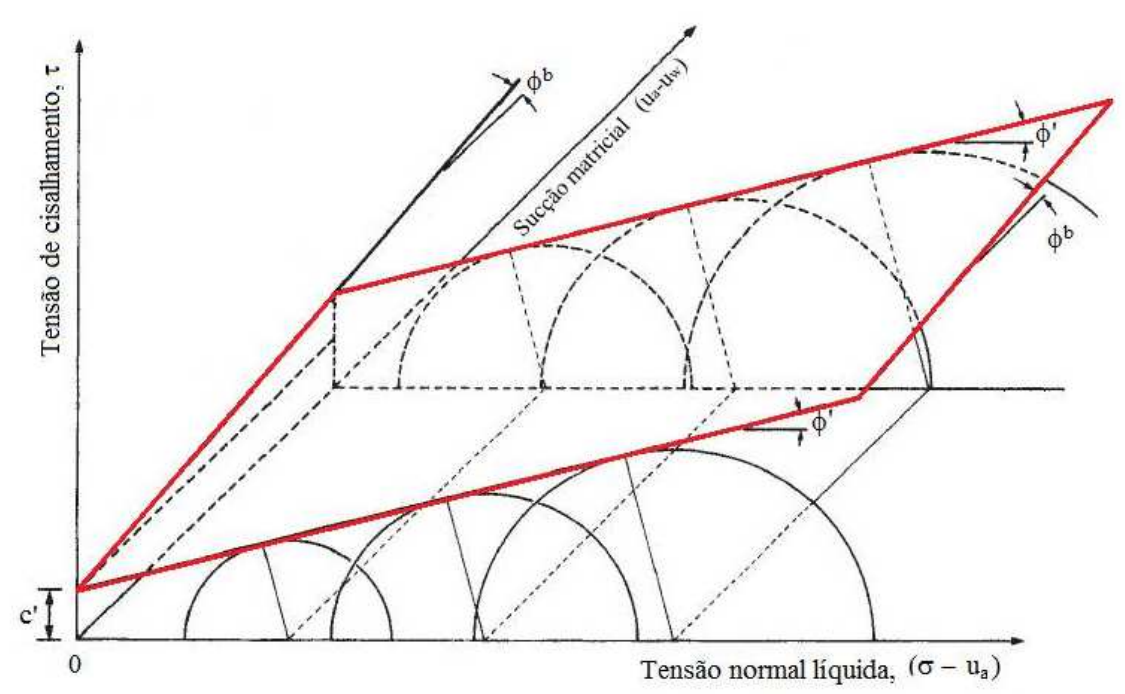

Figura 3.35 - Envoltória de ruptura de um solo não saturado para as variáveis de estado de tensão $\left(\sigma-u_{a}\right)$ e

$$
\left(u_{a}-u_{w}\right) \text {. }
$$

Fonte: Traduzido e adaptado de Fredlund e Rahardjo (1993).

Fredlund e Rahardjo (1993) mostram que o acréscimo na coesão é dado em função do aumento na sucção matricial, podendo ser avaliada a contribuição da coesão aparente para cada sucção matricial, como mostram a equação (37) e a Figura 3.36.

$$
c=c^{\prime}+\left(u_{a}-u_{w}\right) \cdot \operatorname{tg} \phi^{b}
$$

em que $c$ é a coesão aparente total do solo, em $\left[\mathrm{ML}^{-1} \mathrm{~T}^{-2}\right] ; c^{\prime}$ é a coesão efetiva do solo, em $\left[\mathrm{ML}^{-1} \mathrm{~T}^{-2}\right] ;\left(u_{a}-u_{w}\right)$ é a sucção matricial, em $\left[\mathrm{ML}^{-1} \mathrm{~T}^{-2}\right] ; \phi^{b}$ é o ângulo de atrito interno efetivo do solo referente a variação da sucção matricial, em [ $\left.{ }^{\circ}\right]$.

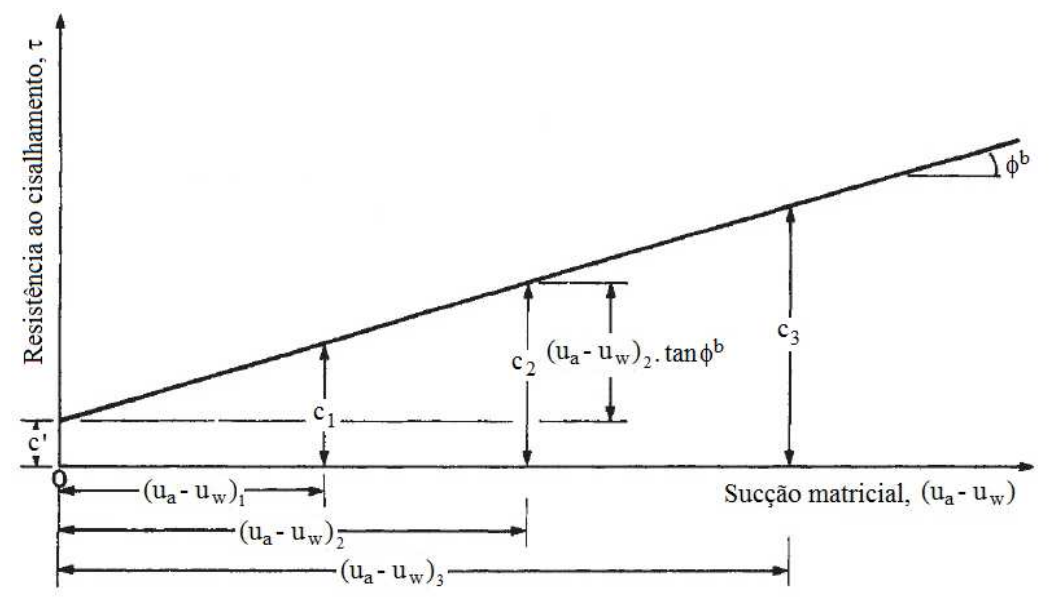

Figura 3.36 - Linhas de contorno da envoltória de ruptura representada pela resistência ao cisalhamento versus sucção matricial.

Fonte: Traduzido e adaptado de Fredlund e Rahardjo (1993). 
Embora as equações propostas por Bishop et al. (1960) e Fredlund, Morgenstern e Widger (1978) sejam conceitualmente diferentes, fazendo-se uma rápida comparação das duas equações representadas por (35) e (36) é possível obter uma relação entre elas, expressa pela equação (38). Como o parâmetro $\chi$ é obtido experimentalmente e varia de acordo com as condições do solo, o uso do ângulo $\phi^{b}$ torna-se mais prático na determinação da resistência ao cisalhamento do solo não saturado, fazendo com que a equação de Fredlund, Morgenstern e Widger (1978) seja mais atrativa e utilizada.

$$
\operatorname{tg} \phi^{b}=\chi \cdot \operatorname{tg} \phi^{\prime}
$$

em que $\phi^{b}$ é o ângulo de atrito interno efetivo do solo referente a variação da sucção matricial, em [ ${ }^{\circ}$ ]; $\chi$ é um parâmetro dependente do grau de saturação, em [adimensional]; $\phi^{\prime}$ é o ângulo de atrito interno efetivo do solo referente a variação da tensão normal líquida.

Apesar da sucção apresentar uma influência na parcela da coesão total e revelar uma linearidade na definição da envoltória de resistência com os dados analisados por Fredlund, Morgenstern e Widger (1978), muitos pesquisadores (ABRAMENTO; PINTO, 1993; ESCARIO; SÁEZ, 1986; ROHM; VILAR, 1995; SATIJA, 1978) apresentam os resultados experimentais para outros tipos de solos mostrando que o ângulo $\phi^{b}$ varia a partir de um certo valor de sucção.

Escario e Sáez (1986) apresentam resultados de ensaios de cisalhamento direto com sucção controlada realizados para uma areia argilosa de Madri e uma argila de Guadalix de La Sierra. A Figura 3.37a, b ilustra o gráfico de resistência ao cisalhamento versus sucção para areia argilosa e para a argila, observando-se claramente que para esses dois tipos de solos a envoltória de resistência apresenta uma curvatura e comportamento não linear para baixos valores de sucção, mostrando que o ângulo $\phi^{b}$ não é constante com a sucção. Já a Figura 3.38a e b ilustra o gráfico de resistência ao cisalhamento versus tensão normal líquida para areia argilosa e para a argila, nota-se que há uma tendência de divergência entre as retas com o aumento das cargas, embora Fredlund, Morgenstern e Widger (1978) afirmasse que $\phi^{\prime}$ seria constante e as retas das envoltórias seriam paralelas para diferentes valores de sucção. Diante desses resultados, Escario e Sáez (1986) concluem que o parâmetro $\chi$ da proposta de Bishop et al. (1960) é mais realista, embora seja difícil determiná-lo. Estes pesquisadores acrescentam que os efeitos da sucção na resistência ao cisalhamento provavelmente dependem do histórico de tensão e capilaridade do solo, assim como outros fatores. 


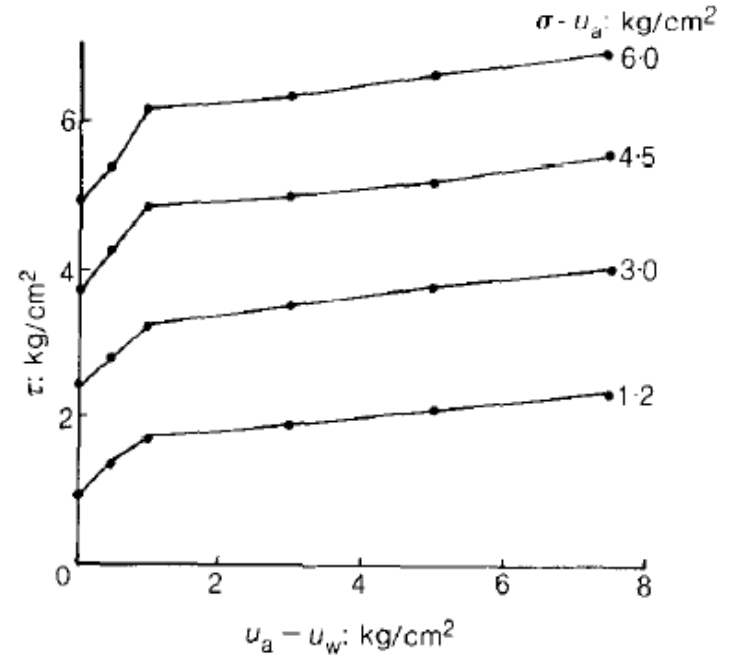

(a)

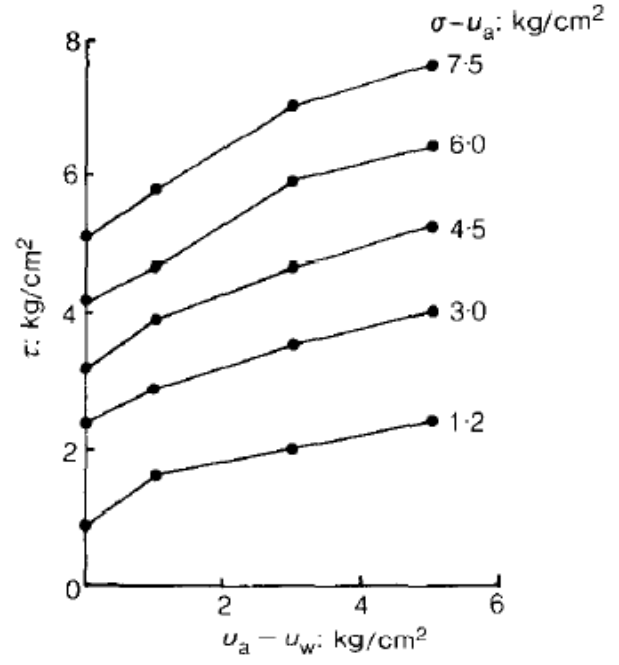

(b)

Figura 3.37 - Resistência ao cisalhamento versus sucção (a) areia argilosa de Madri e (b) argila de Guadalix de La Sierra.

Fonte: Escario e Sáez (1986).

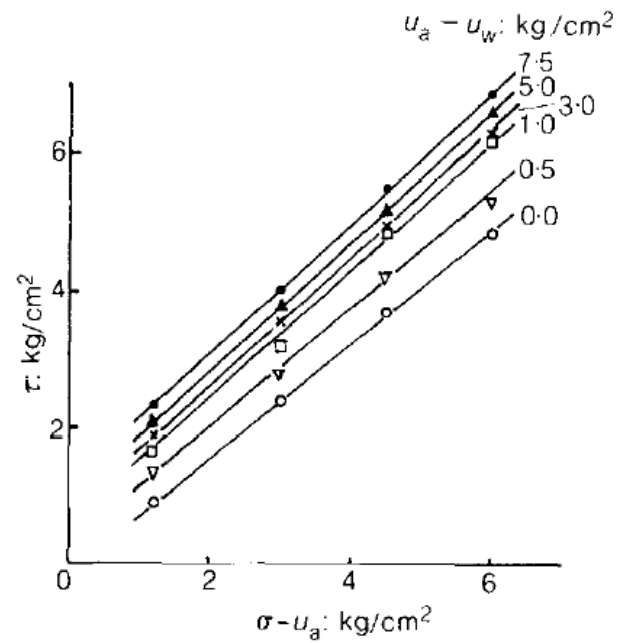

(a)

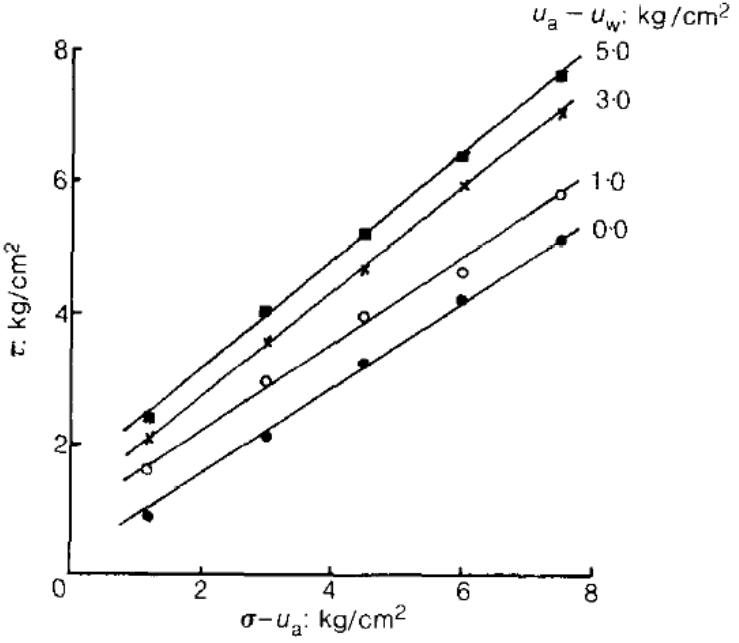

(b)

Figura 3.38 - Resistência ao cisalhamento versus tensão normal líquida (a) areia argilosa de Madri e (b) argila de Guadalix de La Sierra.

Fonte: Escario e Sáez (1986).

Abramento e Pinto (1993) fizeram ensaios de compressão triaxial drenado com sucção controlada para uma areia argilosa-siltosa da Serra do Mar do Estado de São Paulo. Os pesquisadores observaram a partir do gráfico de resistência ao cisalhamento versus sucção (Figura 3.39) que a relação não é linear para a faixa de tensões estudada, evidenciando que a equação de Fredlund, Morgenstern e Widger (1978) não fornece bom ajuste para este tipo de solo. Abramento e Pinto (1993) concluem que a forma da equação da resistência ao 
cisalhamento dependerá do solo estudado, da faixa de tensões atingida e do histórico de tensões a que o solo tenha sido submetido.

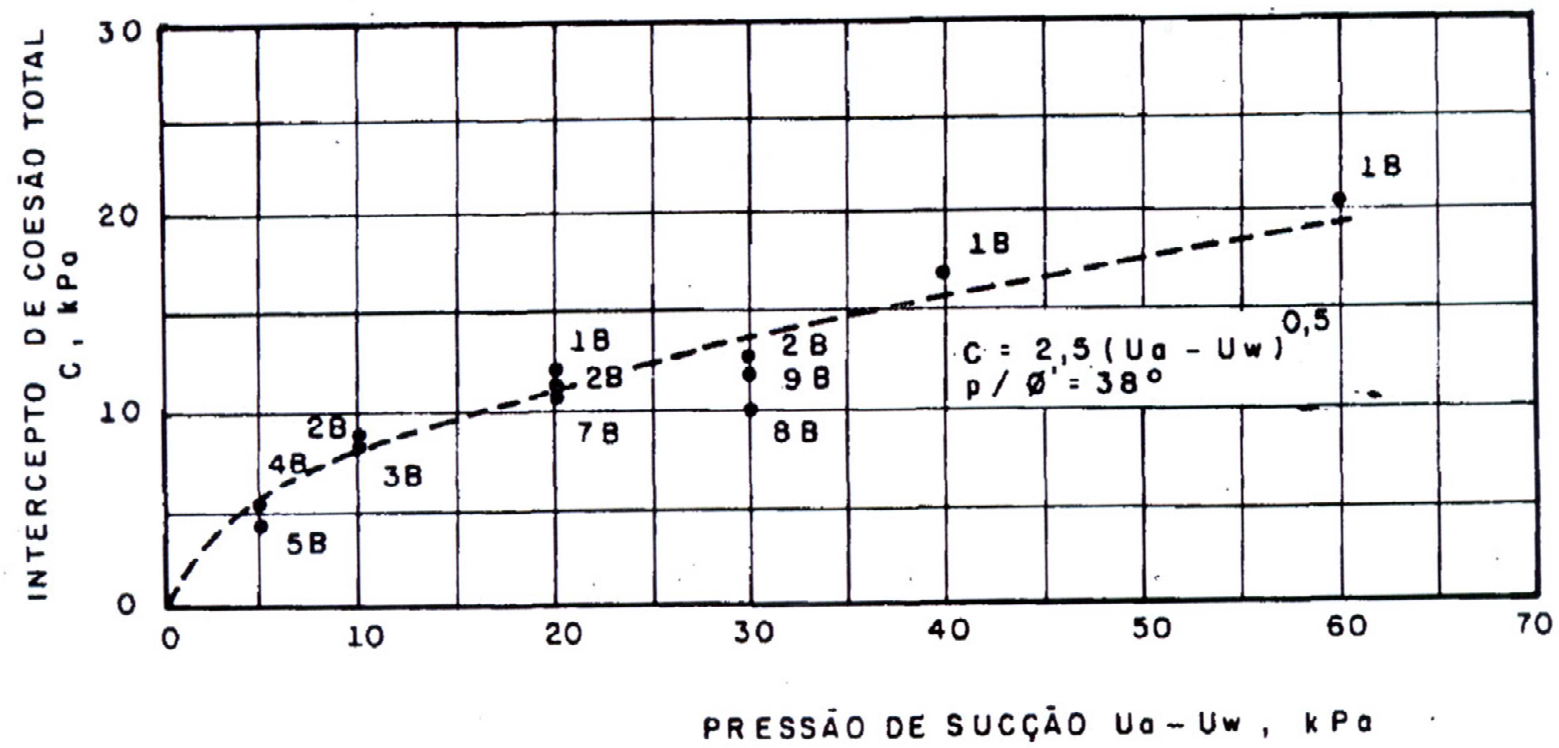

Figura 3.39 - Resistência ao cisalhamento versus sucção para uma areia argilosa-siltosa.

Fonte: Abramento e Pinto (1993).

Rohm e Vilar (1995) realizaram ensaios de compressão triaxial em um solo arenoso laterítico e notaram comportamento semelhante ao obtido por Escario e Saez (1986). Os pesquisadores mostram que os ângulos $\phi^{\prime}$ e $\phi^{b}$ tendem aumentar com a sucção e as retas das envoltórias não se mantêm paralelas, observando que a resistência ao cisalhamento torna-se praticamente constante a partir de um certo valor de sucção.

Diante do fato da equação proposta por Fredlund, Morgenstern e Widger (1978) apresentar uma não linearidade na envoltória de resistência ao cisalhamento, Fredlund, Morgenstern e Widger (1987) decidiram retratar uma justificativa teórica para a limitação dessa equação, propondo sua reformulação. Esses pesquisadores mostram que o ângulo $\phi^{b}$ equivale ao ângulo $\phi^{\prime}$ para o primeiro trecho da envoltória de resistência, pois todo o poro do solo continua preenchido por água, tendendo o solo ter um aumento na sua resistência segundo uma relação linear e em função da sua sucção matricial. Em contrapartida, o segundo trecho da envoltória de resistência inicia com a atuação da pressão de entrada de ar e consequentemente da drenagem da água dos poros do solo, ilustrado pela curva de retenção da água no solo. Neste segundo trecho o valor do ângulo $\phi^{b}$ torna-se inferior ao valor de $\phi^{\prime}$, tendendo o solo a ter um aumento na sua resistência segundo uma relação não linear e em função da sua sucção matricial. A Figura 3.40 ilustra a curva de retenção da água no solo e uma envoltória de resistência não linear típica em relação ao eixo de sucção. 


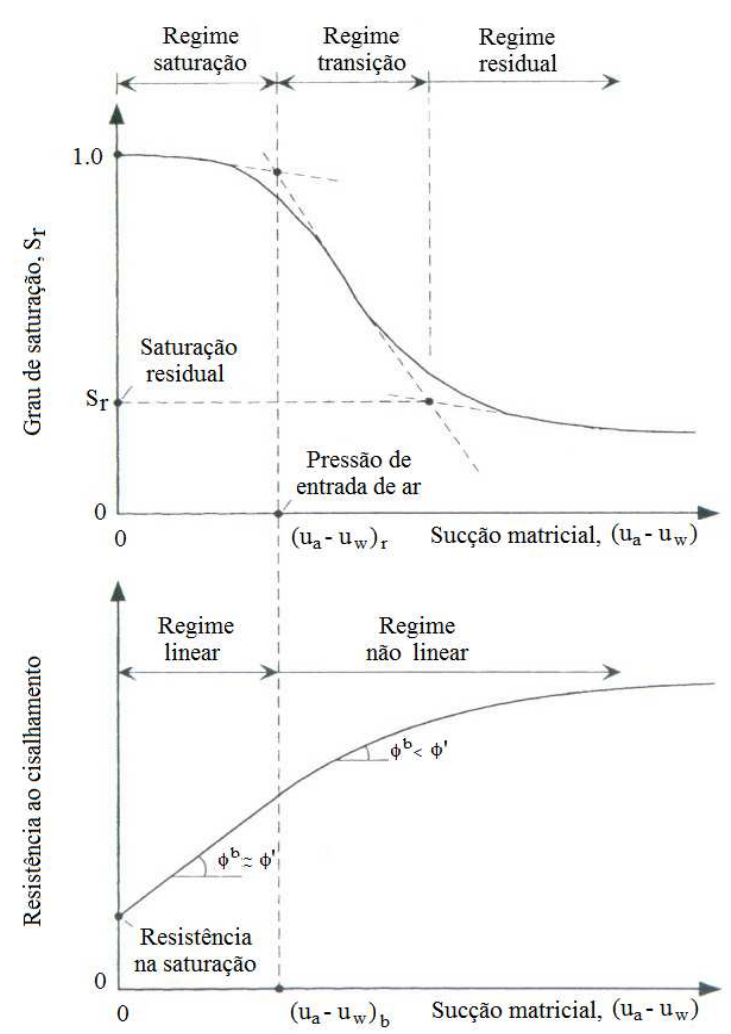

Figura 3.40 - Curva de retenção da água no solo e a representação da envoltória de resistência não linear.

Fonte: Traduzido e adaptado de Lu e Likos (2004).

\subsubsection{Métodos de previsão da resistência ao cisalhamento do solo não saturado}

Os métodos de previsão da resistência ao cisalhamento do solo não saturado foram desenvolvidos com o intuito de simplificar e facilitar a determinação dos parâmetro de resistência do solo. Essa simplificação deve-se principalmente ao fato de estar associado com as dificuldades de experimentação, o tempo necessário para a realização dos ensaios e os equipamentos envolvidos em todo esse processo.

Esses métodos estimam os parâmetros de resistência usando equações empíricas, sendo estas normalmente baseadas nos parâmetros de ajuste da curva de retenção da água no solo e nos parâmetros efetivos de resistência do solo na condição saturada.

\subsubsection{Método de Vanapalli et al. (1996)}

Vanapalli et al. (1996) propõem que a contribuição da sucção na resistência de um solo não saturado é dado em função do que os pesquisadores denominam de área de água normalizada $\left(a_{w}\right)$, que representa a relação entre a área total de água para a condição saturada e a área de água correspondente à qualquer grau de saturação, isto é, condição de não saturação. A equação (39) apresenta essa relação, sendo que o valor de $a_{w}$ deve variar entre 1 (para solo saturado) e 0 (para solo completamente seco). 


$$
a_{w}=\frac{A_{d w}}{A_{t w}}
$$

em que $a_{w}$ é a área de água normalizada, em [adimensional]; $A_{d w}$ é a área total de água para a condição saturada, em [ $\left[\mathrm{L}^{2}\right] ; A_{t w}$ é a área de água correspondente à qualquer grau de saturação, em $\left[\mathrm{L}^{2}\right]$.

O valor da área de água normalizada pode ser aproximada de acordo com o teor de umidade volumétrica do solo (equação (40) e o incremento de resistência que a parcela da sucção proporciona ao solo pode ser calculado pela equação (41).

$$
\begin{gathered}
a_{w}=\left(\frac{\theta-\theta_{\mathrm{r}}}{\theta_{\mathrm{s}}-\theta_{\mathrm{r}}}\right)^{\kappa} \\
\tau_{\left(\mathrm{u}_{\mathrm{a}}-\mathrm{u}_{\mathrm{w}}\right)}=\left(\mathrm{u}_{\mathrm{a}}-\mathrm{u}_{\mathrm{w}}\right) \cdot\left[\left(\frac{\theta-\theta_{\mathrm{r}}}{\theta_{\mathrm{s}}-\theta_{\mathrm{r}}}\right)^{\kappa} \cdot \operatorname{tg} \phi^{\prime}\right]
\end{gathered}
$$

em que $\tau_{\left(\mathrm{u}_{\mathrm{a}}-\mathrm{u}_{\mathrm{w}}\right)}$ é a resistência ao cisalhamento proporcionada pela sucção, em $\left[\mathrm{ML}^{-1} \mathrm{~T}^{-2}\right]$; $\left(u_{a}-u_{w}\right)$ é a sucção matricial, em $\left[\mathrm{ML}^{-1} \mathrm{~T}^{-2}\right] ; \theta$ é o teor de umidade volumétrica a ser calculado, em $\left[\mathrm{L}^{3} \mathrm{~L}^{-3}\right] ; \theta_{r}$ é o teor de umidade volumétrica residual, em $\left[\mathrm{L}^{3} \mathrm{~L}^{-3}\right] ; \theta_{s}$ é o teor de umidade, em $\left[\mathrm{L}^{3} \mathrm{~L}^{-3}\right]$; $\kappa$ é um parâmetro de forma, relacionado ao índice de plasticidade do solo, em [adimensional]; $\phi^{\prime}$ é o ângulo de atrito interno efetivo do solo, em $\left[^{\circ}\right]$.

Com o uso da equação proposta por Fredlund, Morgenstern e Widger (1978), a resistência ao cisalhamento do solo não saturado finalmente pode ser calculada, substituindose (41) em (36). Esta equação foi estabelecida por Vanapalli et al. (1996) a partir dos parâmetros da curva de retenção da água no solo e dos parâmetros efetivos de resistência do solo saturado.

$$
\tau=c^{\prime}+\left(\sigma-u_{a}\right) \cdot \operatorname{tg} \phi^{\prime}+\left(\mathrm{u}_{\mathrm{a}}-\mathrm{u}_{\mathrm{w}}\right) \cdot\left[\left(\frac{\theta-\theta_{\mathrm{r}}}{\theta_{\mathrm{s}}-\theta_{\mathrm{r}}}\right)^{\kappa} \cdot \operatorname{tg} \phi^{\prime}\right]
$$

em que $\tau$ é a resistência ao cisalhamento, em $\left[\mathrm{ML}^{-1} \mathrm{~T}^{-2}\right] ; c^{\prime}$ é a coesão efetiva do solo, em $\left[\mathrm{ML}^{-1} \mathrm{~T}^{-2}\right] ;\left(\sigma-u_{a}\right)$ é a tensão normal líquida, em $\left[\mathrm{ML}^{-1} \mathrm{~T}^{-2}\right] ; \phi^{\prime}$ é o ângulo de atrito interno efetivo do solo, em $\left[{ }^{\circ}\right] ;\left(u_{a}-u_{w}\right)$ é a sucção matricial, em $\left[\mathrm{ML}^{-1} \mathrm{~T}^{-2}\right] ; \theta$ é o teor de umidade 
volumétrica a ser calculado, em $\left[\mathrm{L}^{3} \mathrm{~L}^{-3}\right] ; \theta_{r}$ é o teor de umidade volumétrica residual, em $\left[\mathrm{L}^{3} \mathrm{~L}^{-3}\right] ; \theta_{S}$ é o teor de umidade, em $\left[\mathrm{L}^{3} \mathrm{~L}^{-3}\right] ; \kappa$ é um parâmetro de forma, relacionado ao índice de plasticidade do solo, em [adimensional].

\subsubsection{Método de Vilar (2007)}

Vilar (2007) desenvolveu um método empírico por meio de uma função hiperbólica, que acrescenta a contribuição da parcela sucção no cálculo da resistência ao cisalhamento do solo (equação (43)). Os parâmetros do método denominados $a$ e $b$ são obtidos por meio dos parâmetros efetivos de resistência do solo $\left(c^{\prime}\right.$ e $\left.\phi^{\prime}\right)$ e da máxima coesão efetiva para o solo com teor de umidade residual $\left(c_{r}\right)$, como expressam as equações (44) e (45). Esse método também sugere uma alternativa para o cálculo da coesão em amostras de solo que apresentem teor de umidade diferente do residual, cuja sucção desta amostra esteja num intervalo limite de interesse. Desse modo, o parâmetro $b$ deve ser calculado pela equação (46).

$$
\begin{gathered}
c=c^{\prime}+\frac{\left(u_{a}-u_{w}\right)}{a_{v}+b_{v} \cdot\left(u_{a}-u_{w}\right)} \\
a_{v}=\frac{1}{\operatorname{tg} \phi^{\prime}} \\
b_{v}=\frac{1}{c_{r}-c^{\prime}} \\
b_{v}=\frac{1}{c_{m}-c^{\prime}}-\frac{1}{\left(u_{a}-u_{w}\right)_{m} \cdot \operatorname{tg} \phi^{\prime}}
\end{gathered}
$$

em que $c$ é a coesão efetiva total do solo, em $\left[\mathrm{ML}^{-1} \mathrm{~T}^{-2}\right] ; c^{\prime}$ é a coesão efetiva do solo saturado, em $\left[\mathrm{ML}^{-1} \mathrm{~T}^{-2}\right] ;\left(u_{a}-u_{w}\right)$ é a sucção matricial, em $\left[\mathrm{ML}^{-1} \mathrm{~T}^{-2}\right] ; a_{v}, b_{v}$ são parâmetros de ajuste, em [adimensional, $\mathrm{M}^{-1} \mathrm{~L}^{1} \mathrm{~T}^{2}$ ]; $\phi^{\prime}$ é o ângulo de atrito interno efetivo do solo, em [ ${ }^{\circ}$; $c_{r}$ é a coesão efetiva do solo com teor de umidade residual, em $\left[\mathrm{ML}^{-1} \mathrm{~T}^{-2}\right] ; c_{m}$ é a coesão efetiva do solo que corresponde à sucção de interesse, em $\left[\mathrm{ML}^{-1} \mathrm{~T}^{-2}\right] ;\left(u_{a}-u_{w}\right)_{m}$ é a sucção matricial de interesse, em $\left[\mathrm{ML}^{-1} \mathrm{~T}^{-2}\right]$. 


\section{MATERIAIS E MÉTODOS}

Neste capítulo encontram-se descritas as etapas de trabalho desta pesquisa, representadas esquematicamente por meio de um fluxograma. Adicionalmente, estão detalhados nos próximos itens todos os equipamentos, instrumentação e procedimentos de ensaio correspondente a cada atividade desenvolvida.

\subsection{MÉTODOS E ETAPAS DA PESQUISA}

A Figura 4.1 ilustra a estrutura geral desta pesquisa na forma esquemática de um fluxograma das etapas de trabalho. Nesta figura os itens estão organizados de acordo com as atividades desenvolvidas, enquadradas basicamente em 12 etapas, descritas a seguir:

Etapa 1 - Planejamento

Etapa 2 - Revisão bibliográfica

Etapa 3 - Definição da área de estudo

Etapa 4 - Levantamentos de superfície

Etapa 5 - Sondagem a trado manual

Etapa 6 - Amostragem indeformada de solo

Etapa 7 - Ensaios de caracterização

Etapa 8 - Instrumentação

Etapa 9 - Monitoramento

Etapa 10 - Integração e análise dos resultados 
Etapa 11 - Elaboração da tese

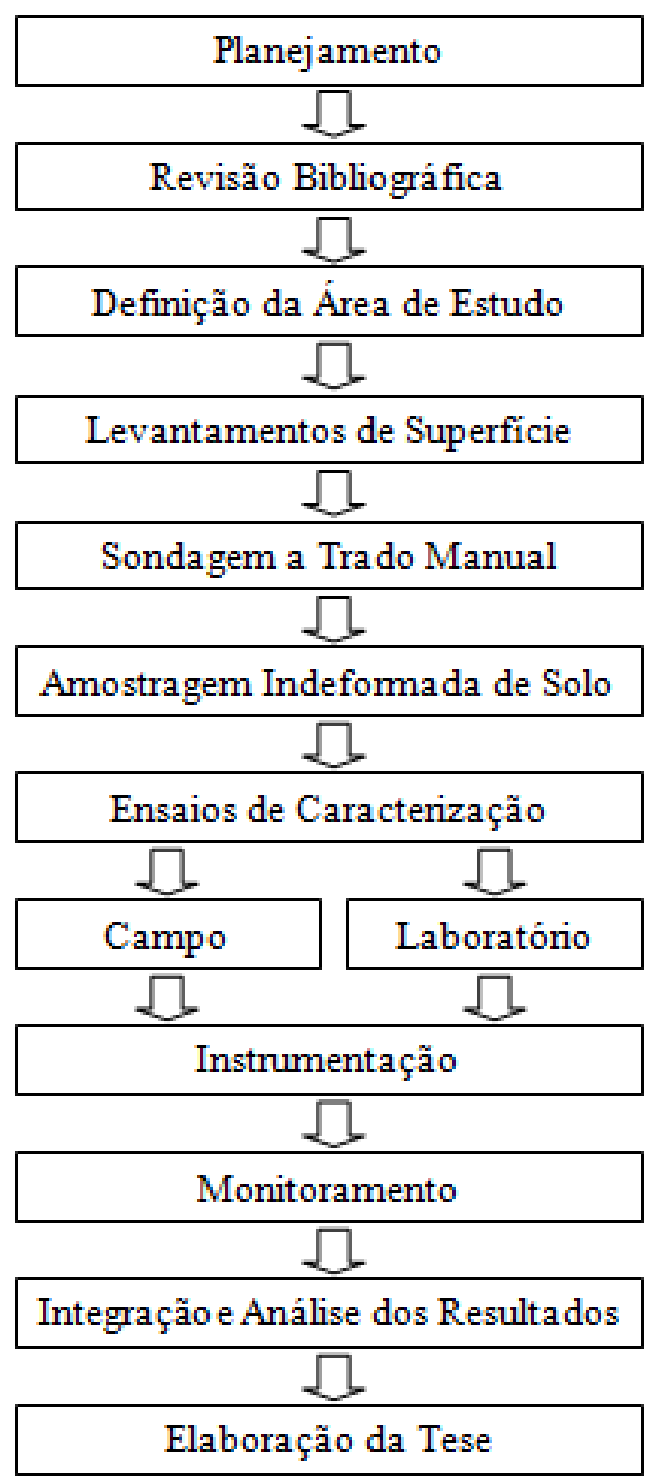

Figura 4.1 - Fluxograma esquemático das etapas de trabalho.

Os itens seguintes abordam mais detalhadamente cada uma das etapas presentes nesse trabalho.

\subsection{ETAPA 1 - PLANEJAMENTO}

A etapa de planejamento reúne as atividades iniciais realizadas para preparação desta pesquisa, envolvendo a definição do tema de trabalho, a escolha da área de estudo (área piloto), os objetivos e as hipóteses de trabalho (ambos discutidos anteriormente).

Tendo em vista que nesta pesquisa foi utilizada uma ferramenta computacional para integração dos parâmetros nas análises de estabilidade de talude, nesta etapa foi escolhido o 
software GeoStudio 2012 para cumprir esta função. Optou-se pelo uso deste software devido ao amplo número de ferramentas disponíveis e em particular, pelo Departamento de Geotecnia da Escola de Engenharia de São Carlos disponibilizar licença de uso.

\subsection{ETAPA 2 - REVISÃO BIBLIOGRÁFICA}

A revisão bibliográfica foi feita de maneira sistemática durante a elaboração deste trabalho, pesquisando trabalhos nacionais e internacionais desenvolvidos a respeito do tema estabilidade de talude. Este levantamento bibliográfico foi realizado no banco de dados de universidades brasileiras e estrangeiras, em anais de congresso e simpósio, em revistas científicas e em livros técnicos.

Buscou-se abranger na revisão bibliográfica apresentada no Capítulo 3 (Revisão Bibliográfica) uma síntese dos assuntos centrais desta pesquisa como fundamentos da mecânica dos solos não saturados, resistência ao cisalhamento de solos não saturados, conceitos de estabilidade de talude, métodos de análise de estabilidade de talude e pesquisas relacionadas ao tema de estabilidade de talude em solo não saturado.

\subsection{ETAPA 3 - DEFINIÇÃO DA ÁREA DE ESTUDO}

Um levantamento preliminar dos taludes localizados na faixa de domínio da SP 215 Rodovia Luiz Augusto de Oliveira realizado entre os municípios paulista de São Carlos, Ribeirão Bonito e Dourado indicou áreas com grandes potenciais para esta pesquisa. Vistorias de campo foram realizadas conjuntamente com o levantamento preliminar tendo como objetivo a identificação táctil-visual do solo.

Os critérios para seleção da área de estudo, que nesta pesquisa foi denominada de área piloto, seguem listados abaixo:

- talude constituído por um único tipo de solo (talude homogêneo);

- composição textural do solo, predominando a fração de areia (solo arenoso);

- extensão e topografia do talude;

- inclinação usualmente uniforme ao longo de sua extensão;

- existência de cobertura vegetal, tipicamente por gramíneas.

Portanto, a área piloto escolhida para conduzir esta pesquisa e que se enquadrou em todos os critérios mencionados anteriormente foi a área localizada próxima ao município de Ribeirão Bonito, no km179+300 LE da SP 215 - Rodovia Luiz Augusto de Oliveira. Como a área piloto está situada na faixa de domínio da rodovia sob concessão do Departamento de 
Estradas de Rodagem do Estado de São Paulo (DER/SP), foi necessário solicitar uma autorização junto a Divisão Regional 4 localizada no município de Araraquara.

\subsection{ETAPA 4 - LEVANTAMENTOS DE SUPERFÍCIE}

Os levantamentos de superfície foram divididos em dois estágios, vistoria de campo e levantamento topográfico de detalhe. A vistoria de campo teve a finalidade de caracterizar e identificar na área piloto algumas feições erosivas, surgências de água, trincas e/ou degraus de abatimento, tipo de cobertura vegetal, interferências antrópicas e obras de estabilização. O segundo estágio que corresponde ao levantamento topográfico de detalhe foi realizado a fim ter características do talude como a geometria, a inclinação de qualquer seção topográfica e as curvas de nível da área piloto.

Nesse levantamento topográfico de detalhe foi utilizada uma Estação Total da marca Leica modelo TC-403 (Figura 4.2a), tendo sido realizada esse etapa no $2^{\circ}$ semestre de 2013. A equipe de topografia foi composta por três pessoas, sendo um operador responsável por manusear a Estação Total (Figura 4.2b) e dois auxiliares tendo como função de segurar e locar o prisma refletor (Figura 4.3a). Este levantamento topográfico foi executado em dois dias, resultando em 547 pontos distribuídos para uma área de aproximadamente $3230 \mathrm{~m}^{2}$ (Figura 4.3b).

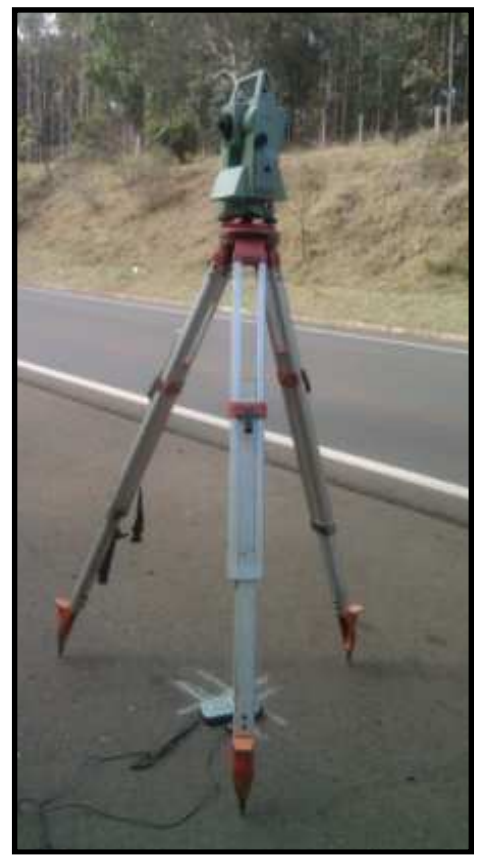

(a)

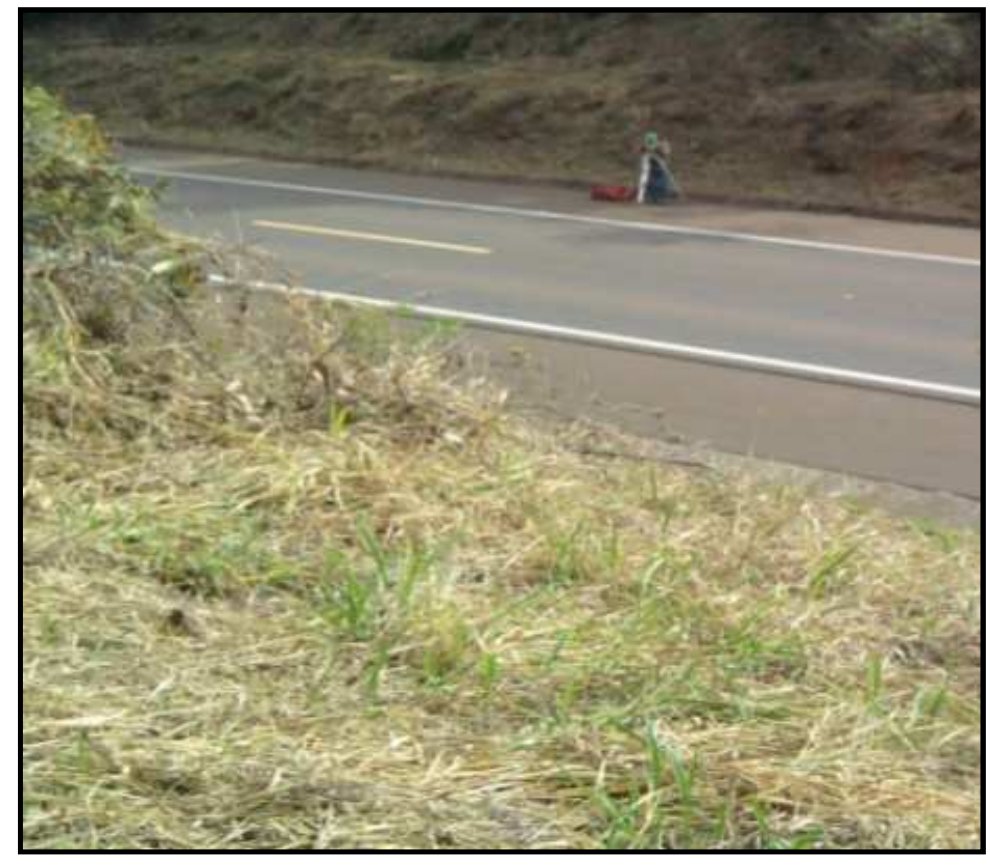

(b)

Figura 4.2 - Levantamento topográfico de detalhe (a) detalhe do equipamento Estação Total e (b) operador responsável por manusear a estação Total. 


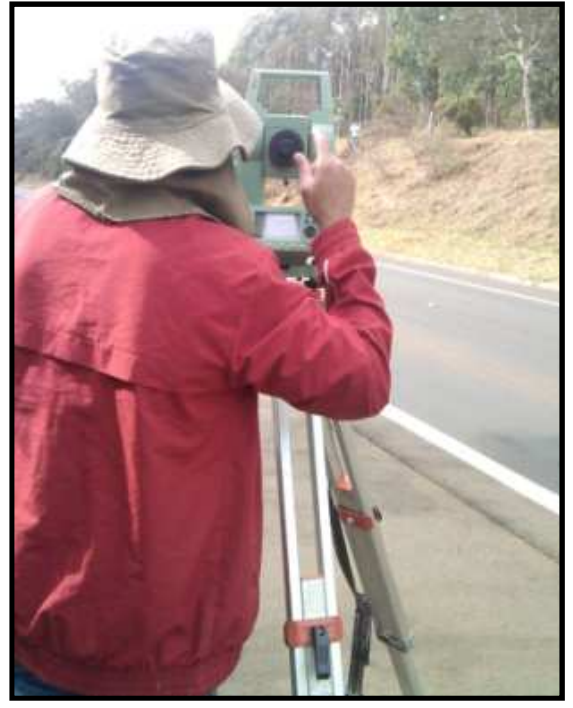

(a)

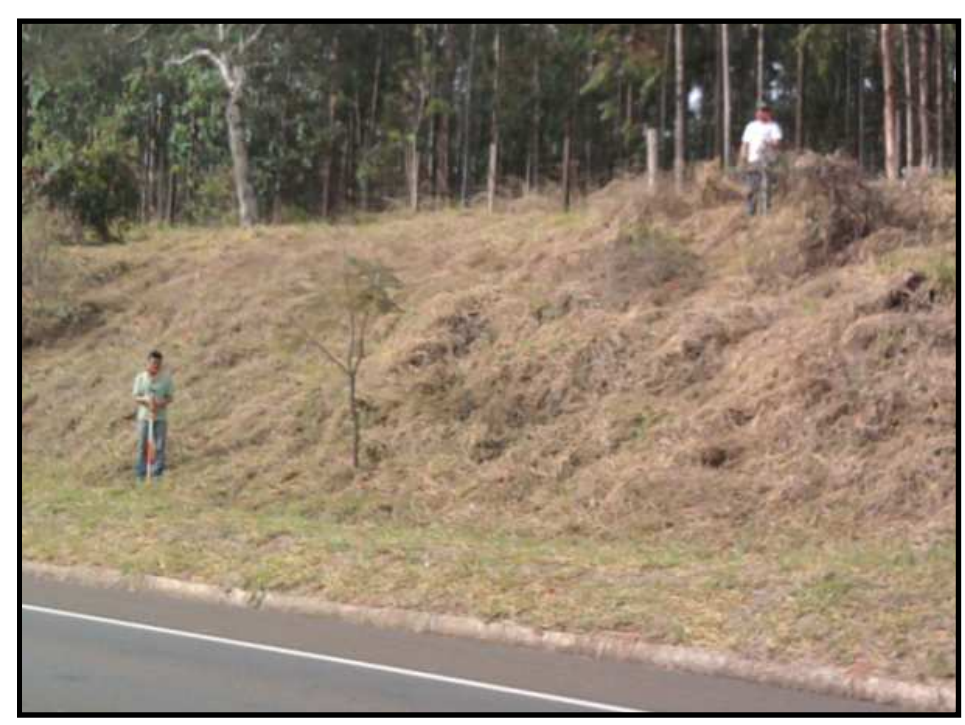

(b)

Figura 4.3 - Levantamento topográfico de detalhe (a) vista do operador mirando a Estação Total no prisma refletor e (b) auxiliares locando o prisma refletor na área piloto.

A transferência dos dados armazenados no dispositivo de memória da Estação Total foi feita para o software Sistema Posição, que por meio deste, foram processados cálculos, desenhos e memorial descritivo. Posteriormente, os dados processados foram manipulados no software AutoCad de acordo com as marcações desejadas das curvas de nível. Nesta pesquisa, as curvas de nível foram geradas para cada 0,50 metros de eqüidistância vertical.

\subsection{ETAPA 5 - SONDAGEM A TRADO MANUAL}

O método de investigação de subsuperfície escolhido para esta pesquisa foi a sondagem a trado manual. Optou-se por este método de investigação devido ao tipo de escorregamento observado na região da área piloto durante a etapa de vistoria de campo e pela sondagem a trado apresentar inúmeras vantagens, como baixo custo de operação, facilidade de manuseio e transporte do equipamento, fornecimento das espessuras das camadas de solo, identificação do nível d’água e coleta de amostra deformada do solo ao longo da profundidade investigada.

Nesta pesquisa foi utilizado um trado tipo cavadeira de 4" de diâmetro $(10,20 \mathrm{~cm}$ de diâmetro) e hastes de ferro com 1,00 m de comprimento e 3/4" de diâmetro (1,90 cm de diâmetro), como mostra a Figura 4.4a. A equipe de sondagem foi composta por três operadores, todos responsáveis em manusear a cruzeta e coletar amostra deformada de solo. Os furos de sondagem foram proporcionalmente distribuídos na área piloto, totalizando 3 furos na crista e outros 3 furos no pé. Devido ao fato das rupturas na região da área piloto 
ocorrerem em baixas profundidades, cada furo de sondagem foi feito com 5,00 metros de profundidade abaixo da cota do nível do terreno. Amostras deformadas de solo foram coletadas a cada 0,50 metros de profundidade durante a abertura dos furos de sondagem (Figura 4.4b, c, d, e), sendo estas armazenadas em sacos plásticos contendo aproximadamente $2,0 \mathrm{~kg}$ de solo e estando devidamente identificado o número do furo de sondagem e a profundidade de coleta.

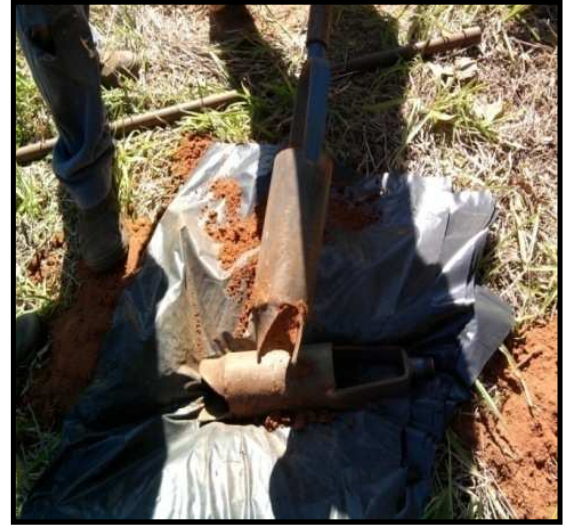

(a)

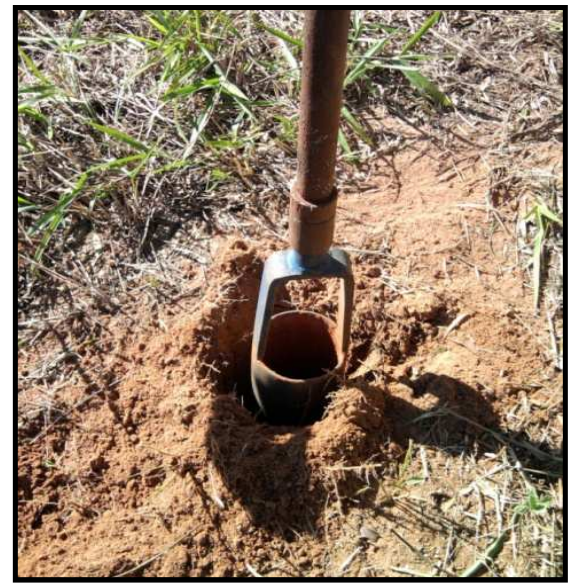

(c)

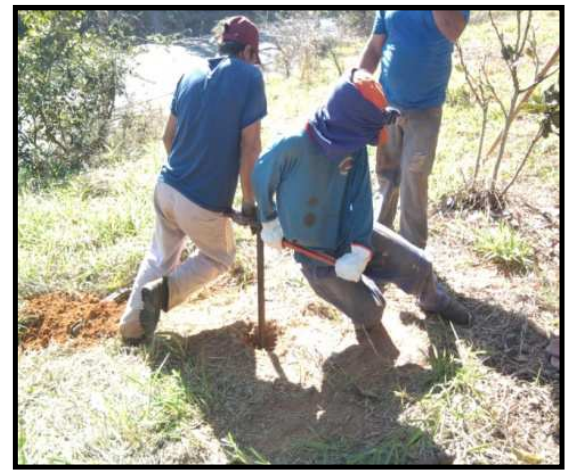

(e)

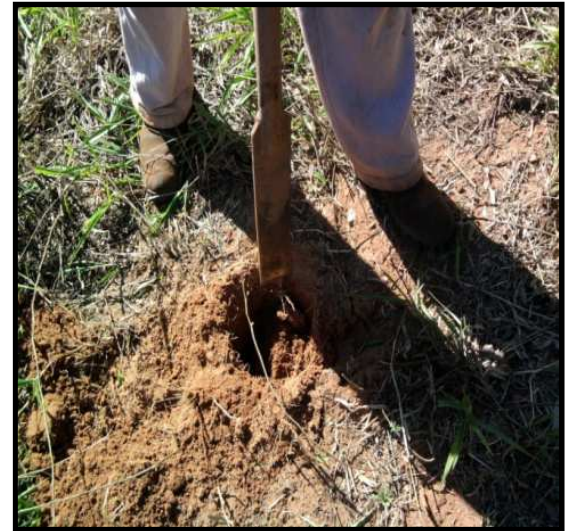

(b)

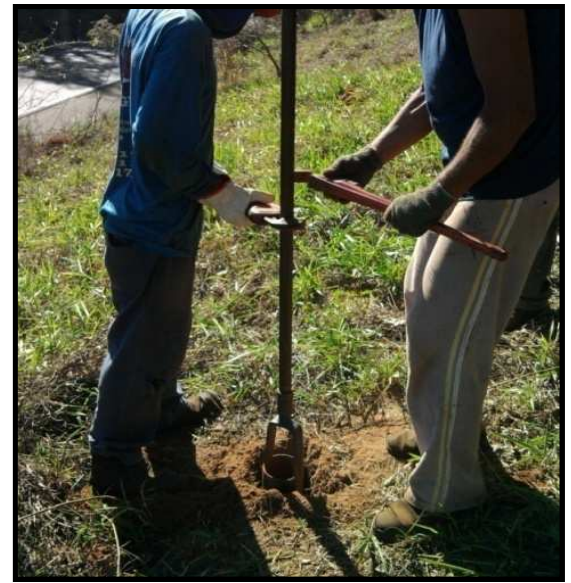

(d)

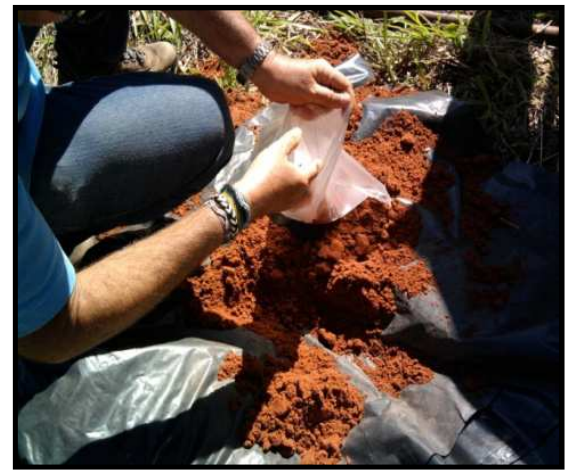

(f)

Figura 4.4 - Sondagem a trado manual (a) detalhe do trado tipo cavadeira, (b) preparo do pré-furo, (c) inserção do trado e da haste no pré-furo, (d) detalhe dos operadores com chave de grifo, (e) equipe manuseando o equipamento, (f) coleta de amostra deformada de solo. 
A Tabela 4.1 identifica as amostras deformadas de solo coletadas nos furos de sondagem a trado manual (profundidade e número do furo de sondagem), onde as letras $\mathrm{P}$ e $\mathrm{C}$ significam Pé e Crista respectivamente, as quais foram utilizadas para designar a porção do talude em que foi realizado cada furo de sondagem. Dessa maneira, observa-se na Tabela 4.1 que foram retiradas um total de 59 amostras deformadas de solo correspondentes aos seis furos de sondagem.

Tabela 4.1 - Identificação das amostras deformadas de solo coletadas nos furos de sondagem.

\begin{tabular}{|c|c|c|c|c|c|c|}
\hline \multirow{2}{*}{ Profundidade (m) } & \multicolumn{6}{|c|}{ Furo de Sondagem } \\
\hline & ST1 & ST2 & ST3 & ST4 & ST5 & ST6 \\
\hline $0,00-0,50$ & $\mathrm{P} 1-1$ & $\mathrm{C} 2-1$ & P3-1 & C4-1 & P5-1 & C6-1 \\
\hline $0,50-1,00$ & $P 1-2$ & C2-2 & \multirow{2}{*}{ P3-2 } & C4-2 & P5-2 & C6-2 \\
\hline $1,00-1,20$ & \multirow{2}{*}{$\mathrm{P} 1-3$} & \multirow{2}{*}{ C2-3 } & & \multirow{2}{*}{ C4-3 } & \multirow{2}{*}{ P5-3 } & \multirow{2}{*}{ C6-3 } \\
\hline $1,20-1,50$ & & & \multirow{2}{*}{ P3-3 } & & & \\
\hline $1,50-2,00$ & $\mathrm{P} 1-4$ & $\mathrm{C} 2-4$ & & C4-4 & P5-4 & C6-4 \\
\hline $2,00-2,50$ & $P 1-5$ & $\mathrm{C} 2-5$ & P3-4 & C4-5 & P5-5 & C6-5 \\
\hline $2,50-3,00$ & $P 1-6$ & C2-6 & P3-5 & C4-6 & $P 5-6$ & C6-6 \\
\hline $3,00-3,50$ & P1-7 & $\mathrm{C} 2-7$ & P3-6 & C4-7 & P5-7 & C6-7 \\
\hline $3,50-4,00$ & $\mathrm{P} 1-8$ & $\mathrm{C} 2-8$ & P3-7 & C4-8 & P5-8 & C6-8 \\
\hline $4,00-4,50$ & P1-9 & C2-9 & P3-8 & C4-9 & P5-9 & C6-9 \\
\hline $4,50-5,00$ & P1-10 & C2-10 & P3-9 & C4-10 & P5-10 & C6-10 \\
\hline
\end{tabular}

\subsection{ETAPA 6 - AMOSTRAGEM INDEFORMADA DE SOLO}

A amostragem indeformada de solo foi feita a partir da abertura de trincheira no pé e na crista de uma seção geológico-geotécnica da área piloto (Figura 4.5a). Nesse procedimento foram utilizadas caixas metálicas cúbicas de paredes removíveis nas dimensões de 0,25 $\mathrm{m} \mathrm{x}$ $0,25 \mathrm{~m} \times 0,25 \mathrm{~m}$ para retirada de seis blocos de amostra indeformada (Figura 4.5b). 


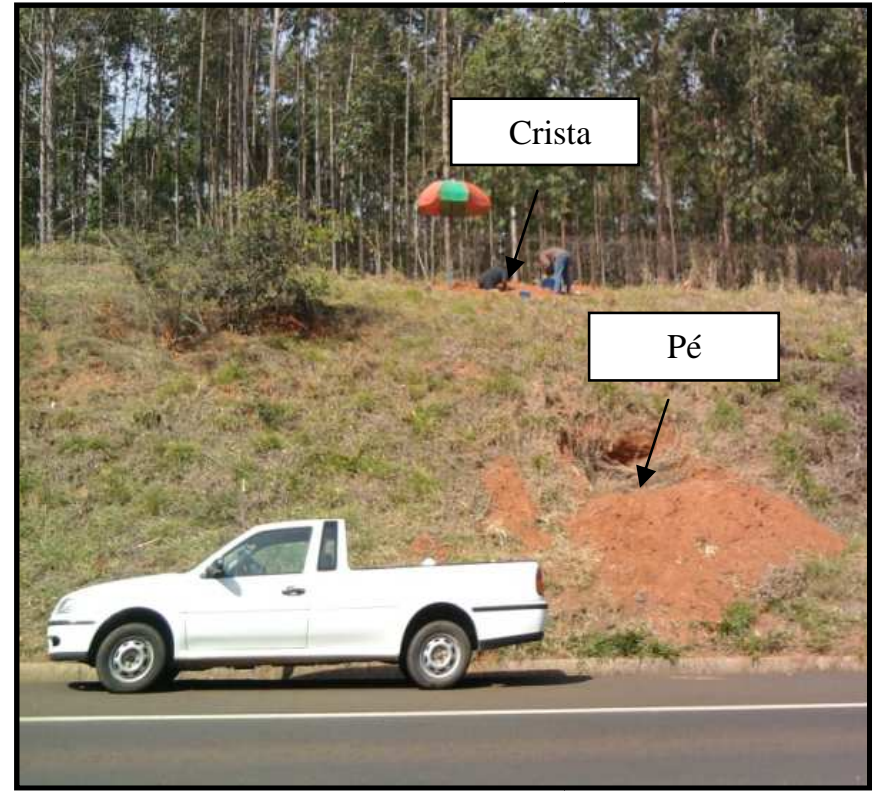

(a)

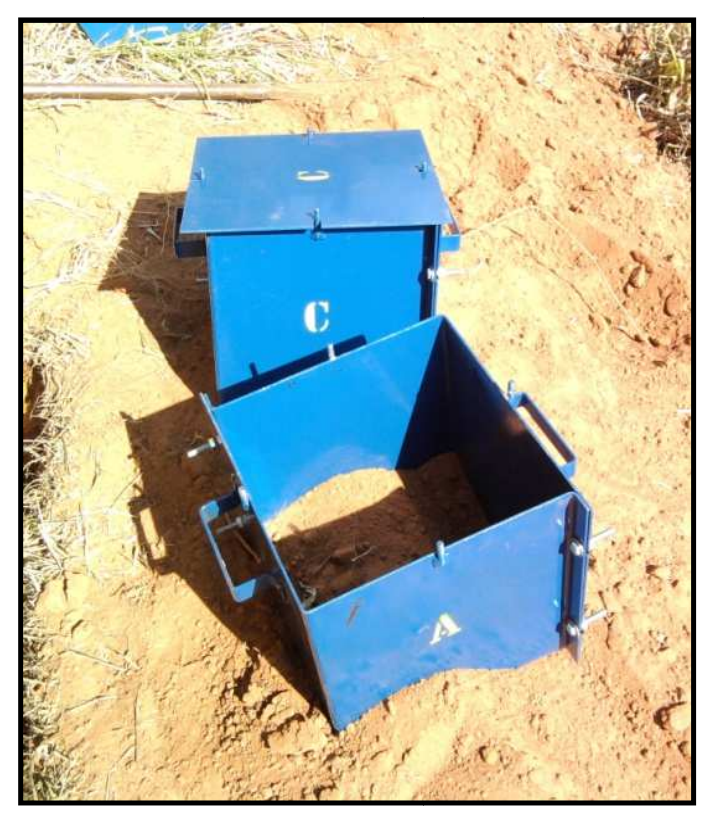

(b)

Figura 4.5 - Amostragem indeformada (a) retirada no pé e na crista do talude e (b) detalhe da caixa metálica.

No pé da seção foram extraídos três blocos, sendo dois deles retirados em agosto de 2013 na profundidade de 0,80 metros (AP-1) e 1,20 metros (AP-2) e o terceiro retirado em janeiro de 2015 na profundidade de 0,80 metros (AP-3), como mostra a Figura 4.6.

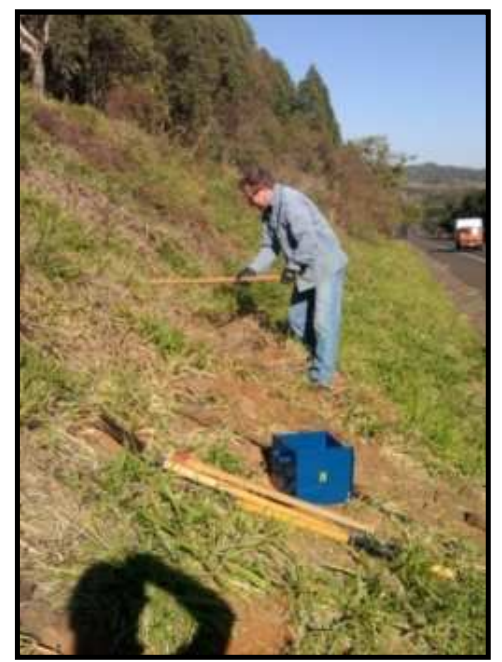

(a)

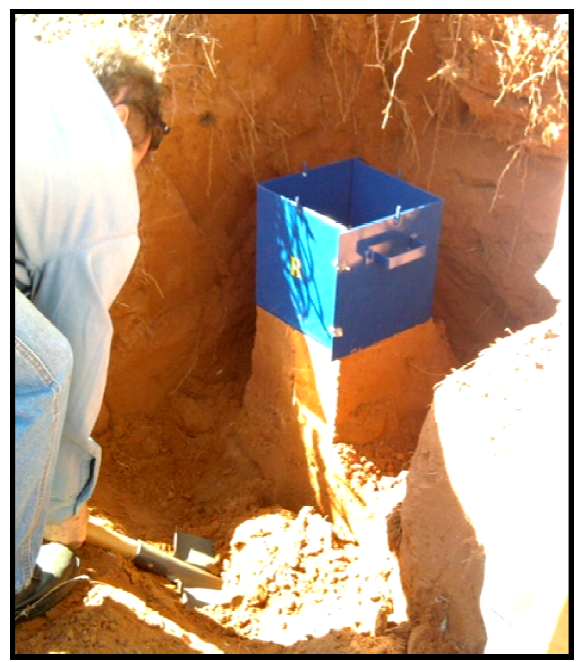

(b)

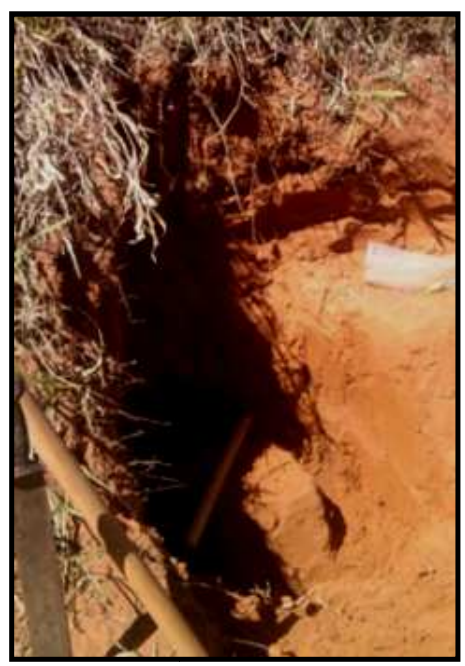

(c)

Figura 4.6 - Coleta de bloco de amostra indeformada - (a) pé do talude, (b) retirada da amostra AP-1, profundidade 0,80 metros e (c) retirada da amostra AP-2, profundidade 1,20 metros.

$\mathrm{Na}$ crista da seção foram retirados três blocos, sendo dois deles retirados em agosto de 2013 na profundidade de 0,80 metros (AC-1 e AC-2) e o terceiro retirado em janeiro de 2015 na profundidade de 0,80 metros (AC-3), como mostra a Figura 4.7. 


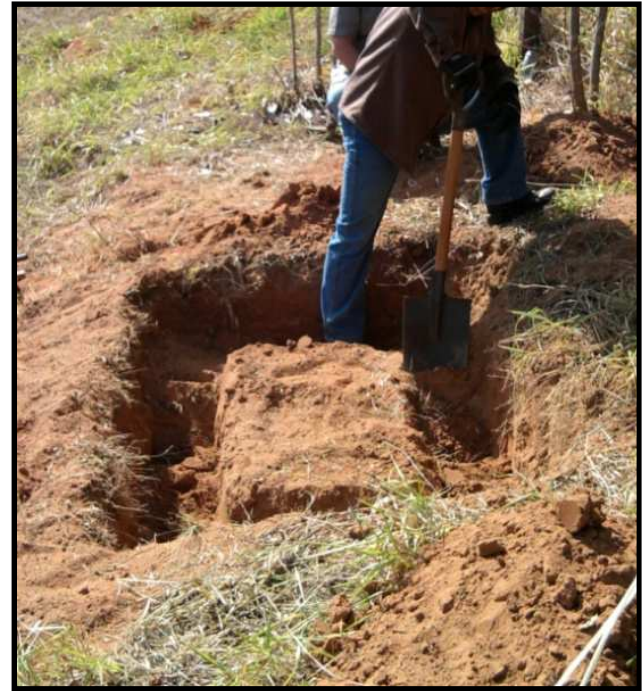

(a)

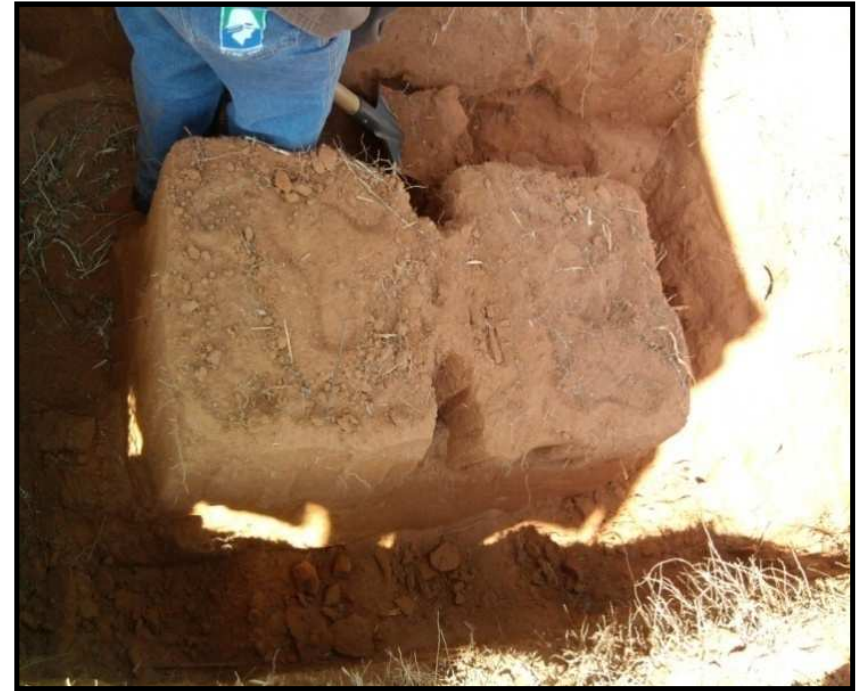

(b)

Figura 4.7 - Coleta de bloco de amostra indeformada - (a) topo do talude e (b) retirada das amostras AC-1 e AC-2, ambas na profundidade 0,80 metros.

A Tabela 4.2 identifica através de uma sigla cada uma das seis amostras indeformadas de solo coletadas em duas trincheiras abertas no talude. Observa-se que as amostras retiradas no pé do talude foram identificadas como AP enquanto que as da crista como AC.

Tabela 4.2 - Identificação das amostra indeformadas de solo coletadas no talude.

\begin{tabular}{ccc}
\hline & \multicolumn{2}{c}{ Amostra Indeformada de Solo } \\
\cline { 2 - 3 } Profundidade $(\mathbf{m})$ & Pé & Crista \\
\hline 0,80 & AP-1, AP-3 & AC-1, AC-2, AC-3 \\
\hline 1,20 & AP-2 & - \\
\hline
\end{tabular}

Alguns cuidados complementares foram tomados durante o transporte dos blocos de amostra pois a área piloto dista cerca de $30 \mathrm{~km}$ do município de São Carlos. Após estes blocos serem descarregados no Departamento de Geotecnia da Escola de Engenharia de São Carlos (EESC), os mesmos foram parafinados e armazenados na câmara úmida deste Departamento.

\subsection{ETAPA 7 - ENSAIOS DE CARACTERIZAÇÃO}

Nos próximos itens estão descritos os ensaios de caracterização realizados nesta pesquisa, tanto ensaios de campo quanto ensaios de laboratório. 


\subsubsection{Massa específica dos sólidos}

O ensaio de massa específica dos sólidos $\left(\rho_{s}\right)$ foi feito para uma única amostra deformada de solo identificada como P3-1 (profundidade 0,00-0,50 m), que corresponde ao furo de sondagem 3. Este ensaio seguiu as orientações contidas na Norma Brasileira (NBR 6508/1984) da massa específica dos sólidos (ABNT, 1984). Os testes de identificação táctilvisual feito no campo mostraram uma certa tendência do material apresentar-se homogêneo ao longo do perfil de sondagem. Por esse motivo, o valor da massa específica dos sólidos foi adotado único para todas as amostras de solo e para todos os ensaios que utilizam esse índice físico do solo.

\subsubsection{Análise granulométrica conjunta}

O ensaio de análise granulométrica conjunta foi feito para as amostras deformadas de solo dos furos de sondagem 3 e 4 de uma seção topográfica da área piloto, totalizando 19 amostras (P3-1 a P3-9 e C4-1 a C4-10). Todos os ensaios seguiram procedimentos constantes na Norma Brasileira (NBR 7181/1998) de análise granulométrica conjunta (ABNT, 1988), estando a Figura 4.8 ilustrando 5 ensaios de sedimentação.

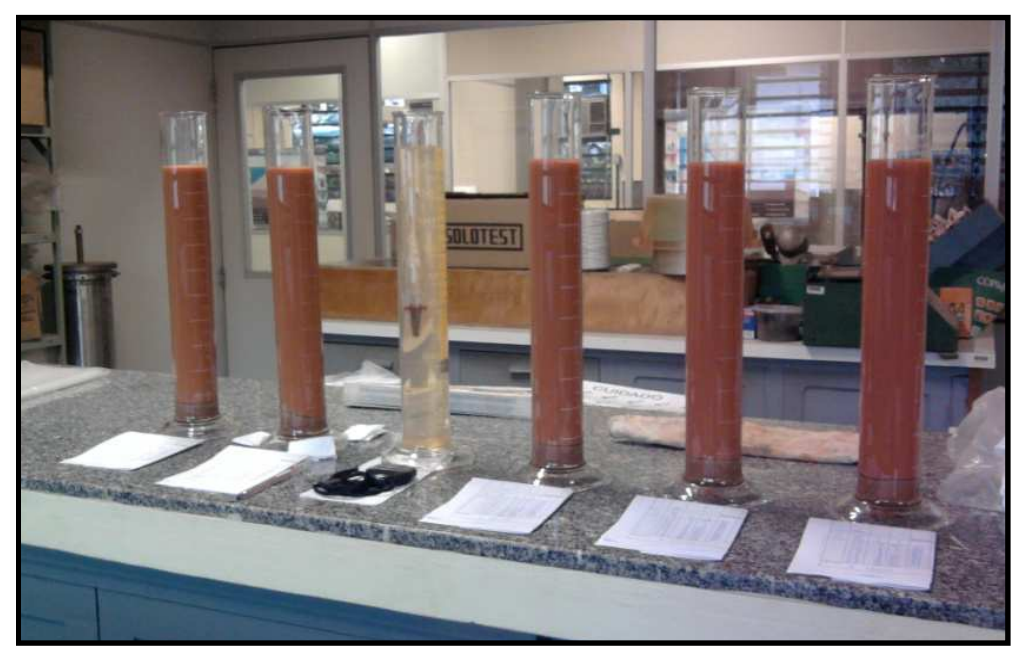

Figura 4.8 - Análise granulométrica conjunta - sedimentação.

\subsubsection{Análise com lupa digital}

A análise com lupa digital foi feita com o equipamento Olympus MIC-D para analisar a fração de areia fina e areia média de uma pequena porção de amostra indeformada de solo do pé do talude (AP-2). Nessas análises foi possível identificar a forma e o grau de alteração dos grãos de areia do solo, além de indicar o grau de intemperismo do solo.

As amostras de solo utilizadas foram peneiradas e separadas em duas frações: areia média $(0,20 \mathrm{~mm}$ a $0,60 \mathrm{~mm})$ e areia fina $(0,06 \mathrm{~mm}$ a $0,20 \mathrm{~mm})$, com o uso de peneira \#30 e 
\#100 respectivamente. As amostras de solo foram preparadas no Laboratório de Geotecnia e as imagens digitais foram obtidas no Departamento de Geotecnia da EESC/USP.

\subsubsection{Ensaios para determinação da curva de retenção da água no solo (SWRC)}

A curva de retenção da água no solo foi obtida com o uso das técnicas do Papel Filtro e do Funil de Placa Porosa, a primeira empregada na obtenção de pontos experimentais sem restrição no intervalo de valores de sucção e a segunda utilizada para a determinação de valores pequenos de sucção (até $13 \mathrm{kPa}$ ). A técnica do Funil de Placa Porosa foi utilizada somente na trajetória de secagem enquanto que a técnica do Papel Filtro foi empregada em ambas. Todos os pontos experimentais foram empregados no ajuste das trajetórias de umedecimento e secagem com o uso do software Grapher e do modelo de Van Genuchten (1980). Os próximos itens descrevem detalhadamente os procedimentos de ensaio das duas técnicas.

\subsubsection{Técnica do Funil de Placa Porosa}

A técnica do Funil de Placa Porosa, também denominada de Funil de Haines, consiste em impor a amostra de solo (apoiada sobre uma placa porosa) valores de sucção matricial a partir da diferença de cotas entre a amostra de solo e o reservatório de água, atuando em ambas a pressão atmosférica $\left(\mathrm{P}_{\mathrm{atm}}\right)$. A Figura 4.9 ilustra o esquema desse equipamento, que é basicamente composto por uma placa porosa de alta pressão de entrada de ar colada no interior de um funil, um tubo flexível e um reservatório de água, estando todos elementos interligados. O equipamento instalado no laboratório de Geotecnia da EESC permite impor o valor máximo de sucção matricial de $13 \mathrm{kPa}$, sendo utilizado nesta pesquisa sucção de $1 \mathrm{kPa}$ e $2 \mathrm{kPa}$, que equivalem as alturas de $0,10 \mathrm{~m}$ e $0,20 \mathrm{~m}$, respectivamente.

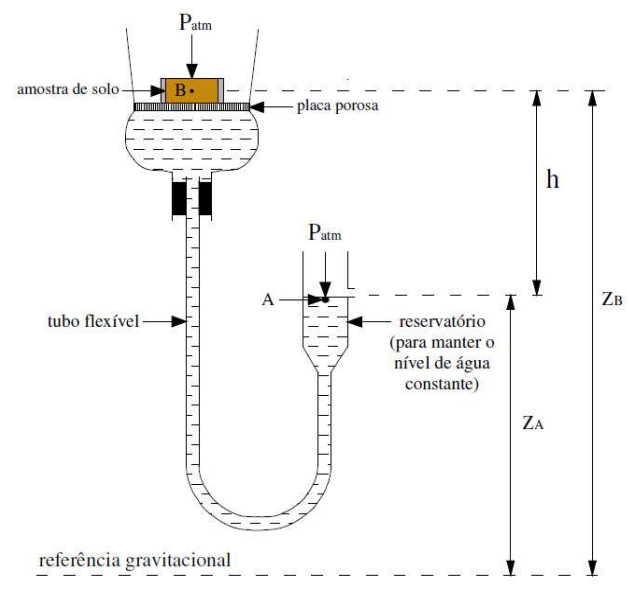

Figura 4.9 - Esquema do equipamento - Técnica do Funil de Placa Porosa.

Fonte: Fernandes (2011). 
Baseado no esquema do equipamento ilustrado na Figura 4.10, o cálculo da sucção matricial é feita com o uso equação (47), apresentada a seguir:

$$
u_{a}-u_{w}=\rho_{w} \cdot g \cdot\left(z_{a}-z_{b}\right)
$$

em que $u_{a}$ é a pressão do ar, em $\left[\mathrm{ML}^{-1} \mathrm{~T}^{-2}\right] ; u_{w}$ é a pressão da água, em $\left[\mathrm{ML}^{-1} \mathrm{~T}^{-2}\right] ; \rho_{w}$ é a massa específica da água, em $\left[\mathrm{ML}^{-3}\right]$; g é a aceleração da gravidade, em $\left[\mathrm{MT}^{-2}\right] ; z_{b}$ é a altura da amostra do solo no interior do funil, em [L]; $z_{a}$ é a altura do reservatório de água, em [L].

Os corpos de prova utilizados foram moldados do bloco de amostra indeformada do pé do talude (AP-1) em anéis de PVC com dimensão média de 5,0 cm de diâmetro e 1,0 cm de altura. Cada corpo de prova foi posto para saturar em uma placa porosa comum por um período mínimo de 24 horas. Antes de transferí-lo para o equipamento, a altura do reservatório de água foi regulada de maneira que esta correspondesse à sucção imposta na amostra de solo (Figura 4.10a). A seguir, o corpo de prova foi colocado sobre a placa porosa de $100 \mathrm{kPa}$ no interior do funil (Figura 4.10b), permitindo a drenagem da água presente no solo através do reservatório. O término do ensaio ocorreu a partir do momento em que cessou o fluxo de água do sistema solo - reservatório de água. Em seguida, foi determinado o teor de umidade gravimétrico do solo.

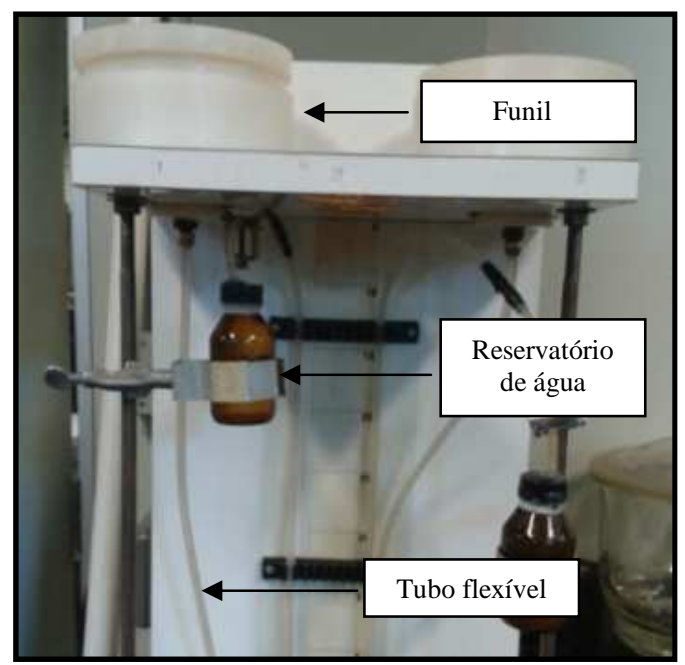

(a)

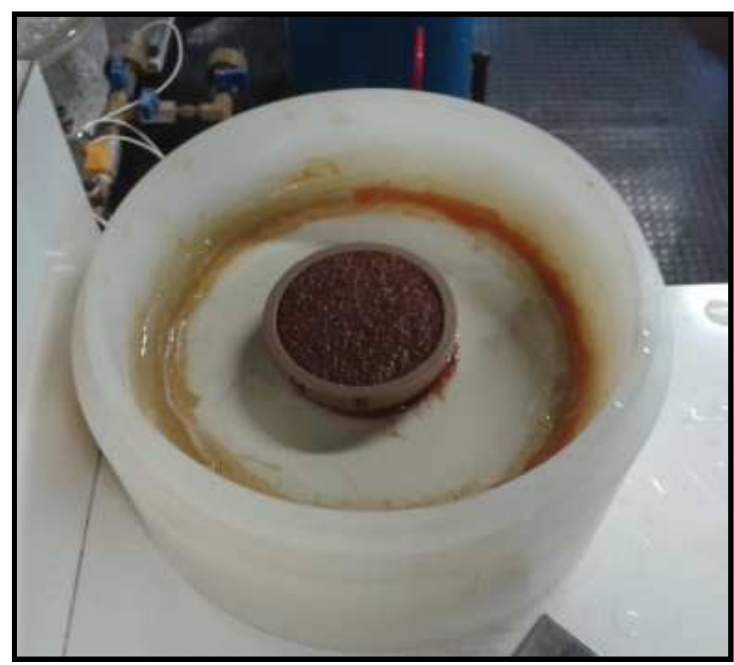

(b)

Figura 4.10 - Técnica do Funil de Placa Porosa (a) composição do equipamento e (b) da amostra do corpo de prova no interior do funil.

\subsubsection{Técnica do Papel Filtro}

A técnica do Papel Filtro consiste na medida da sucção a partir do equilíbrio entre o teor de umidade presente na amostra de solo e o papel filtro. Esta técnica de ensaio é muito 
difundida e utilizada no meio técnico por ser relativamente simples e de baixo custo. $\mathrm{O}$ uso desta técnica possibilita medir a sucção total ou matricial por meio das trajetórias de umedecimento ou secagem. A Figura 4.11 ilustra as duas configurações de ensaio com o papel filtro onde em (a) permite o fluxo de vapor pois não ocorre o contato do papel filtro com a amostra de solo, determinando a sucção total e em (b) o contato entre o papel filtro e a amostra de solo permite o fluxo capilar, dessa forma, determinando a sucção matricial para esta configuração de ensaio.

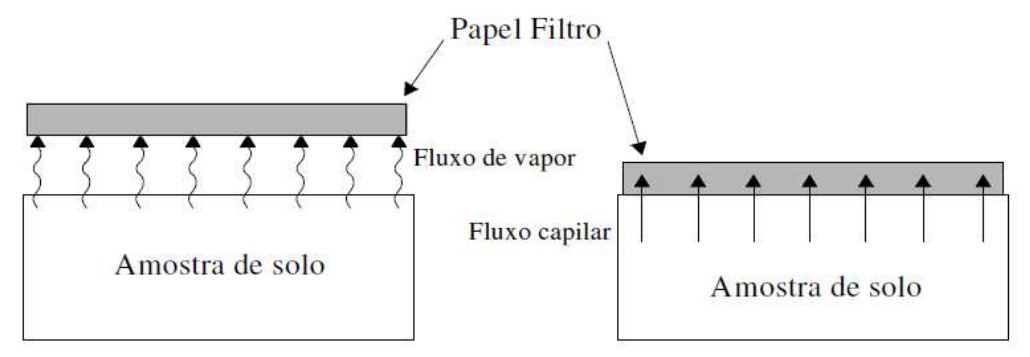

(a)

(b)

Figura 4.11 - Configuração de ensaio para determinação da (a) sucção total e (b) sucção matricial. Fonte: Fernandes (2011).

Nesta pesquisa foi empregado o papel filtro Whatman $n^{\circ} 42$ para determinação da sucção matricial do solo feita por meio das equações de correlações propostas por Chandler, Crilly e Montgomerysmith (1992):

$$
\begin{gathered}
w_{\text {papel }} \leq 47 \% \rightarrow \psi_{\text {papel }}=10^{\left(4,84-0,0622 . w_{\text {papel }}\right)} \\
w_{\text {papel }}>47 \% \rightarrow \psi_{\text {papel }}=10^{\left(6,05-2,48 . \log w_{\text {papel }}\right)}
\end{gathered}
$$

em que $\psi_{\text {papel }}$ é a sucção do papel filtro, em $\left[\mathrm{ML}^{-1} \mathrm{~T}^{-2}\right] ; w_{\text {papel }}$ é o teor de umidade gravimétrica do papel filtro, em $\left[\mathrm{MM}^{-1}\right]$.

O ajuste da curva de retenção foi feito segundo a equação empírica de Van Genuchten (1980), representada pela equação (50), a partir do teor de umidade gravimétrico:

$$
w=w_{r}+\left(w_{s}-w_{r}\right) \cdot\left\{\frac{1}{\left[1+\left(\alpha_{1} \cdot \psi\right)^{n_{1}}\right]^{m_{1}}}\right\}
$$

em que $w$ é o teor de umidade gravimétrico desejado, em $\left[\mathrm{MM}^{-1}\right] ; w_{r}$ é o teor de umidade gravimétrico residual, em $\left[\mathrm{MM}^{-1}\right] ; w_{S}$ é o teor de umidade gravimétrico de saturação, em 
$\left[\mathrm{MM}^{-1}\right] ; \psi$ é a sucção, em $\left[\mathrm{ML}^{-1} \mathrm{~T}^{-2}\right] ; \alpha_{1}, m_{1}, n_{1}$ são parâmetros de forma da curva de retenção, em $\left[\mathrm{M}^{-1} \mathrm{LT}^{2}\right.$, adimensional, adimensional $]$.

Os corpos de prova foram moldados do bloco de amostra indeformada do pé do talude (AP-1) em anéis de PVC com dimensão média de 5,0 cm de diâmetro e 1,0 cm de altura; totalizando vinte e oito corpos de prova. Os procedimentos para determinação dos pontos experimentais para a trajetória de secagem e de umedecimento encontram-se descritos a seguir.

\subsubsection{Trajetória de Secagem}

A trajetória de secagem consiste basicamente em retirar água do corpo de prova saturado até que este atinja a umidade desejada, feito por meio de controle da massa do solo. A determinação da trajetória de secagem foi feita utilizando dezessete corpos de prova, cujas características de moldagem foram descritas anteriormente (item 4.8.6). A Figura 4.12a ilustra como foi feita essa moldagem na amostra indeformada do pé do talude. Todos os corpos de prova foram saturados em um recipiente contendo água destilada e uma placa porosa comum por um período mínimo de 24 horas (Figura 4.12b).

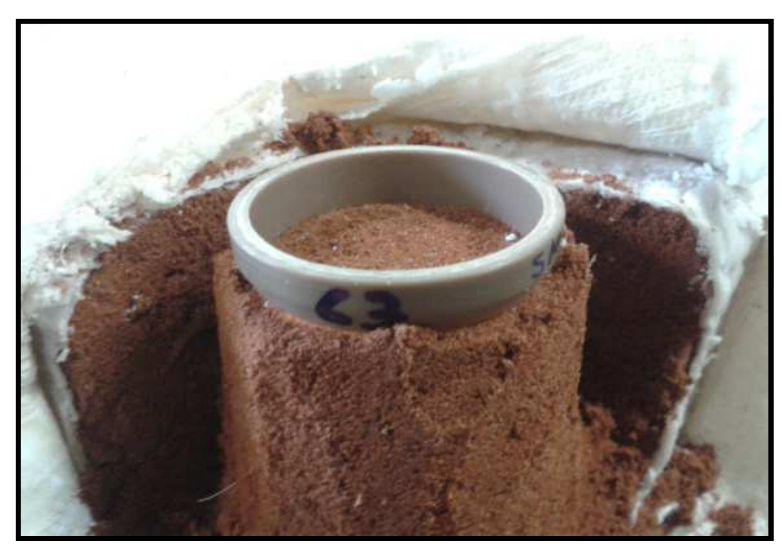

(a)

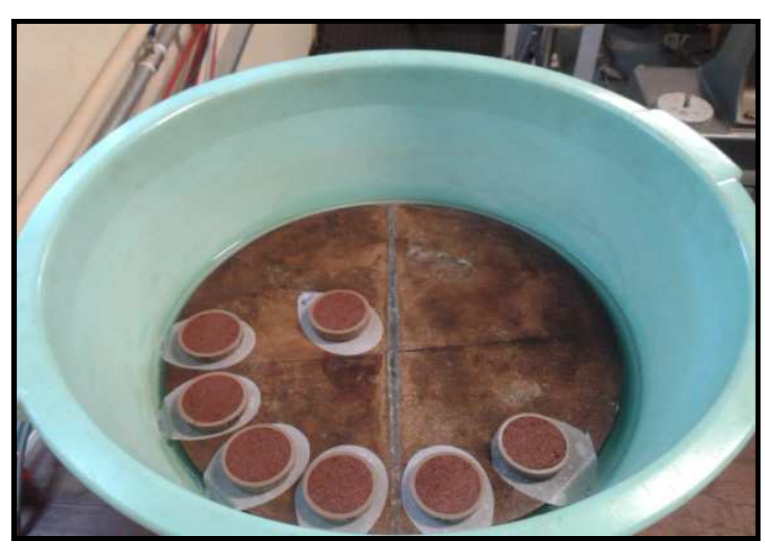

(b)

Figura 4.12 - Trajetória de secagem (a) moldagem do corpo de prova e (b) saturação dos corpos de prova.

Após a saturação, esses corpos de prova foram deixados secar ao ar livre (temperatura ambiente, como ilustra a Figura 4.13a) até os mesmos atingirem uma massa pré-estabelecida. A massa do conjunto, formada pelo anel e amostra de solo, foi controlada mediante pesagem periódica na balança eletrônica com precisão de 0,0001 g (Figura 4.13b). Portanto, a partir do momento em que a amostra de solo atingiu a massa pré-estabelecida, esta foi preparada e embalada com papel filtro. No caso desses ensaios, cada uma das faces da amostra de solo foi colocada em contato direto com o papel filtro (Figura 4.13c), sendo utilizado um disco de 
PVC para assegurar o contato entre eles. Dessa maneira, cada conjunto composto por anel, amostra de solo, papel filtro e disco de PVC foi envolvido por plástico filme, lacrado com fita adesiva e identificado com uma etiqueta. Por fim, os conjuntos foram armazenados no interior de uma caixa de isopor (Figura 4.13d).

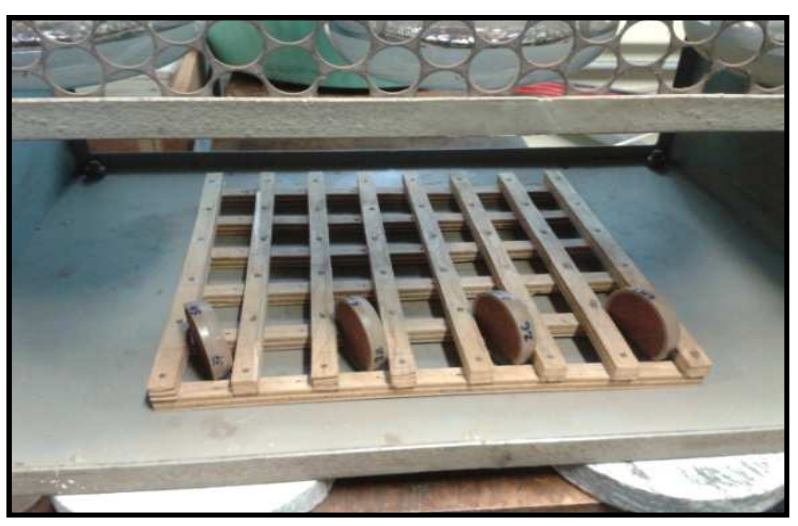

(a)

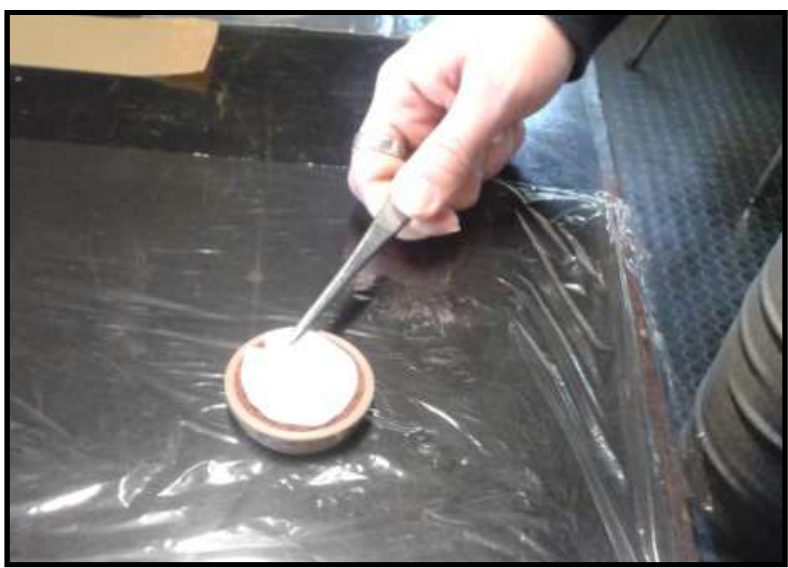

(c)

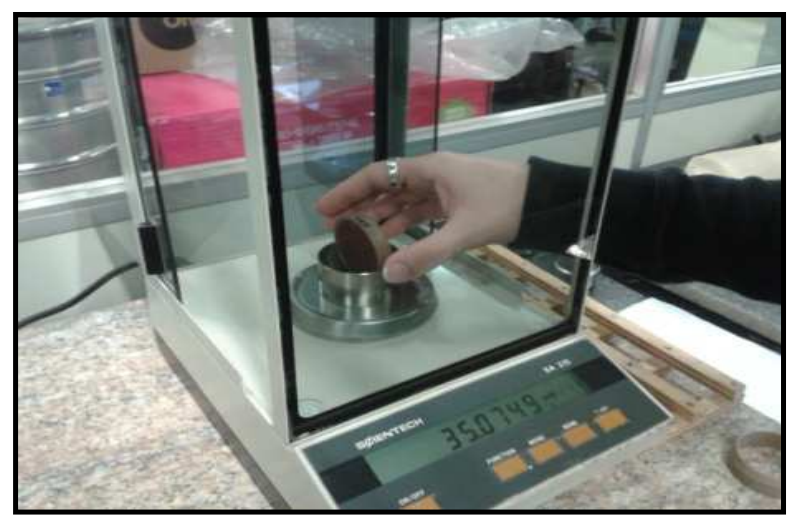

(b)

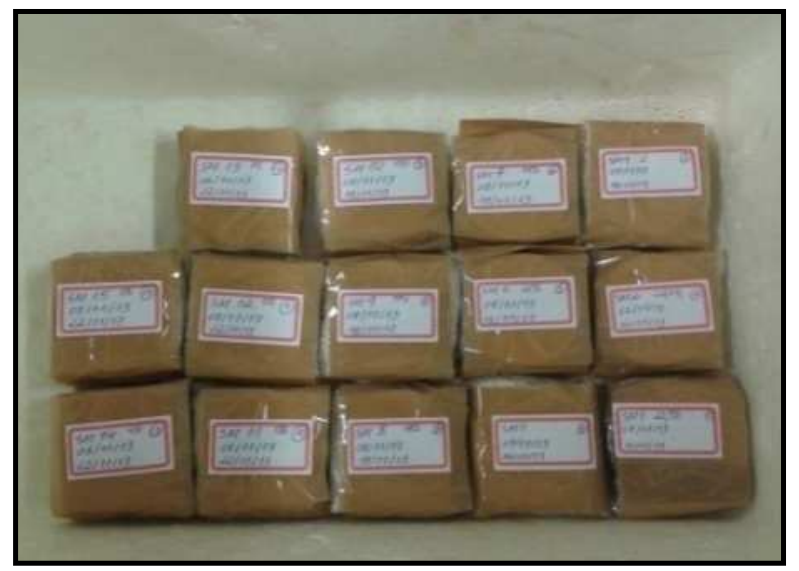

(d)

Figura 4.13 - Trajetória de secagem (a) secagem dos corpos de prova, (b) controle da massa, (c) embalagem dos corpos de prova com papel filtro e (d) armazenamento do conjunto.

O período de armazenamento variou em função do teor de umidade da amostra de solo e do tempo necessário para ocorrer o equilíbrio do fluxo de água entre o papel filtro e a amostra de solo. Nesta pesquisa, os tempos de equilíbrio foram de sete dias para as amostras de solo mais úmidas e de vinte e um dias para as amostras de solo mais secas.

Transcorrido o tempo de equilíbrio, os conjuntos foram desembalados cuidadosamente um a um. Os papéis filtro colocados no topo e na base da amostra de solo foram removidos e pesados individualmente na balança eletrônica com precisão de 0,0001 g. Imediatamente a esse procedimento, o teor de umidade gravimétrico foi determinado com uso de três cápsulas metálicas. Em seguida, os papéis filtro foram deixados em uma estufa com temperatura 
máxima de $100{ }^{\circ} \mathrm{C}$ por um período máximo de 4 horas. Esses papéis filtro foram novamente pesados na mesma balança eletrônica.

Os pontos experimentais foram determinados a partir do cálculo da sucção matricial usando as equações (48) e (49) proposta por Chandler, Crilly e Montgomerysmith (1992) e da média do teor de umidade gravimétrica.

\subsubsection{Trajetória de umedecimento}

A trajetória de umedecimento consiste basicamente em adicionar água ao corpo de prova seco ao ar livre até que este atinja a umidade desejada, feito por meio de controle da massa do solo. A determinação da trajetória de secagem foi feita utilizando onze corpos de prova, cujas características de moldagem foram descritas anteriormente (item 4.8.6).

Os corpos de prova foram deixados secar ao ar livre (temperatura ambiente) por um período de sete dias (Figura 4.14a). Após a conclusão da secagem, esses corpos de prova foram umedecidos até que os mesmos atingissem uma massa pré-estabelecida. O processo de umedecimento da amostra de solo foi feito a partir do gotejamento de água destilada por meio de uma bureta de $50 \mathrm{ml}$ (Figura 4.14b).

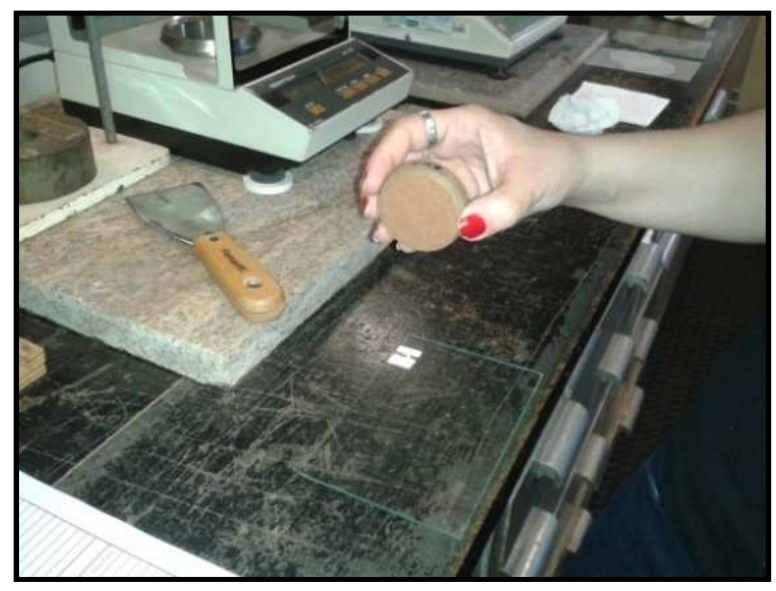

(a)

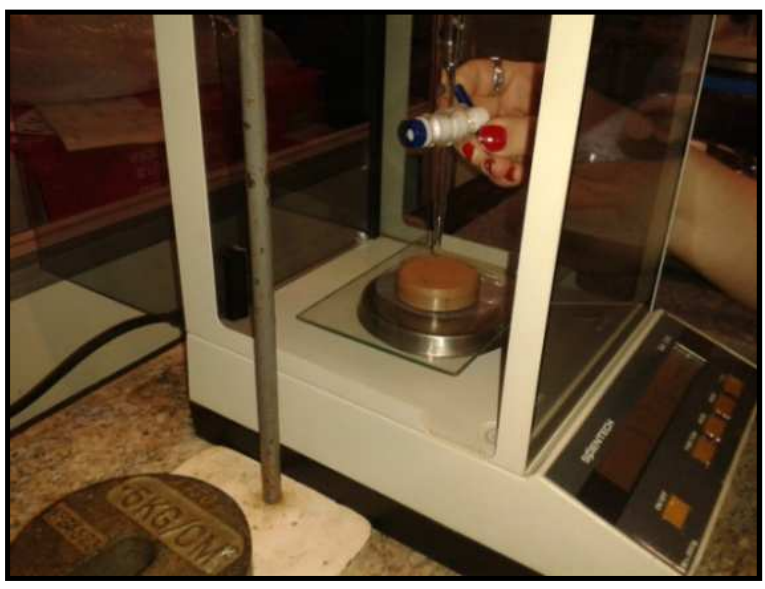

(b)

Figura 4.14 - Trajetória de umedecimento (a) corpo de prova seco ao ar livre e (b) montagem do procedimento de umedecimento da amostra de solo.

A massa do conjunto, formada pelo anel e amostra de solo, foi controlada com o uso de uma balança eletrônica com precisão de 0,0001 g (Figura 4.15a). Portanto, a partir do momento em que a amostra de solo atingiu a massa pré-estabelecida, esta foi preparada e embalada com papel filtro. Os procedimentos para embalagem do conjunto, manuseio do papel filtro, período de armazenamento, pesagem dos papéis filtro e cálculo da sucção 
matricial foram semelhantes aos descritos na trajetória de secagem, apresentados no item 4.8.6.1.

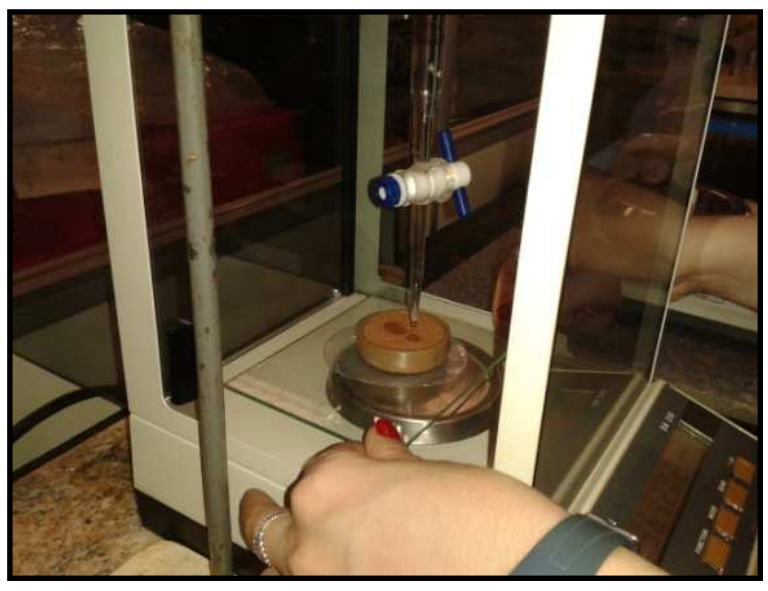

(a)

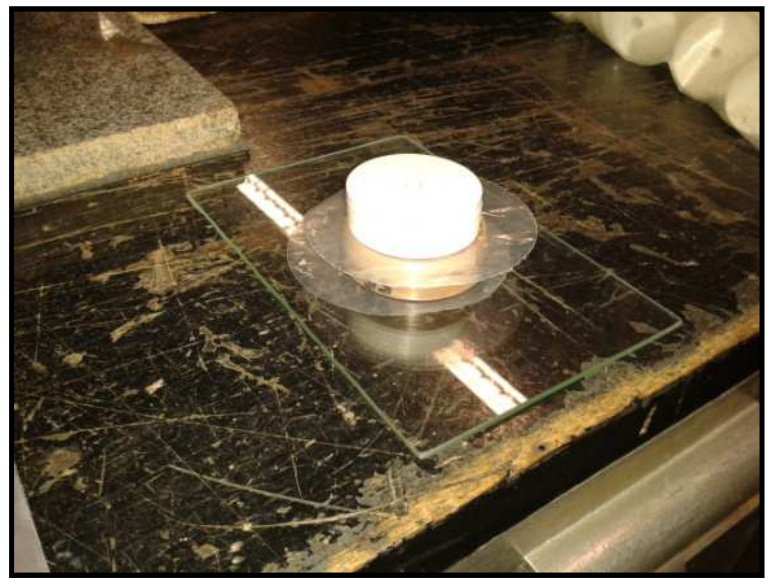

(b)

Figura 4.15 - Trajetória de umedecimento (a) processo de gotejamento e (b) equilíbrio da água na amostra de solo antes de embalar com papel filtro.

\subsubsection{Porosimetria por intrusão de mercúrio}

A porosimetria por intrusão de mercúrio é uma técnica de ensaio que consiste em aplicar uma pressão externa em um fluido não-molhante (mercúrio), forçando este fluido penetrar nos poros de um determinado material.

Esta técnica mede o volume de mercúrio injetado nos poros em função da pressão aplicada, permitindo determinar a distribuição dos diâmetros dos poros. Durante a realização do ensaio, o volume do mercúrio é medido conforme ocorra o aumento gradativo da sua pressão.

Os ensaios de porosimetria por intrusão de mercúrio foram feitos para seis corpos de prova moldados da amostra indeformada do pé do talude (AP-1), tendo cada um deles formato cilíndrico e dimensões médias de 2,0 cm de altura e 1,0 cm de diâmetro (Figura 4.16a). Os corpos de prova foram deixados secar ao ar livre e em temperatura ambiente durante cinco dias e posteriormente levados no Grupo de Crescimento de Cristais e Materiais Cerâmicos situado no Instituto de Física de São Carlos da Universidade de São Paulo, no município de São Carlos. O modelo do porosímetro utilizado foi o "PoreSizer 9320 - Micromeritics Instrument Corporation " com capacidade máxima de aplicação de 30000 psi de pressão (Figura 4.16b). 


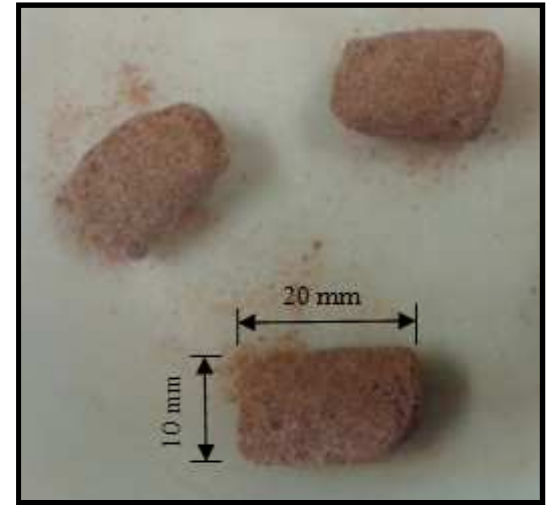

(a)

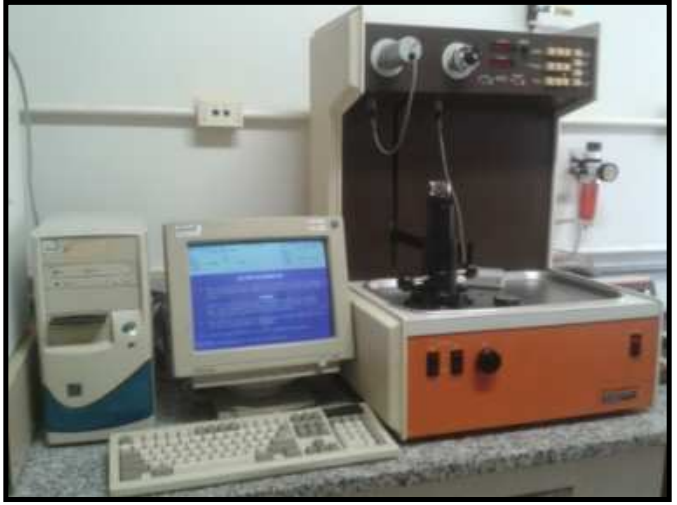

(b)

Figura 4.16 - Ensaio de porosimetria por intrusão de mercúrio (a) corpos de prova e (b) porosímetro.

\subsubsection{Ensaio de permeabilidade - laboratório}

Os ensaios de permeabilidade em laboratório foram feitos com a finalidade de determinar a condutividade hidráulica saturada e verificar a ocorrência da anisotropia. Para estes ensaios foram moldados dois corpos de prova cilíndricos do bloco da amostra indeformada do pé do talude (AP-1), com dimensão média de $5,0 \mathrm{~cm}$ de diâmetro e $12,5 \mathrm{~cm}$ de altura (Figura 4.17a, b). A verificação da anisotropia foi feita moldando corpos de prova em diferentes direções, ou seja, o primeiro corpo de prova foi moldado ortogonal ao pé do talude (direção vertical em relação ao bloco de amostra) e o segundo corpo de prova foi moldado paralelo ao pé do talude (direção horizontal em relação ao bloco de amostra).

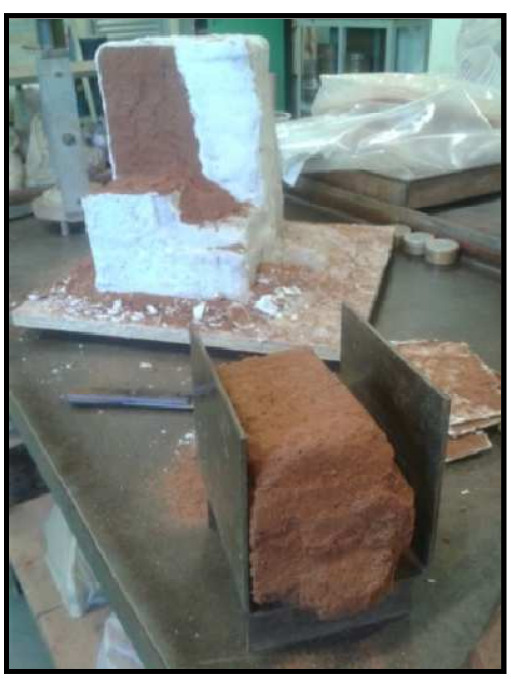

(a)

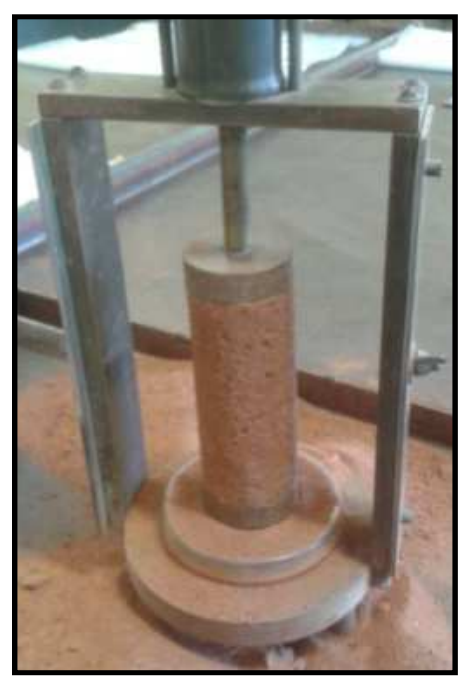

(b)

Figura 4.17 - Ensaio de permeabilidade em laboratório (a) moldagem do corpo de prova e (b) corpo de prova talhado e preparado para a montagem do ensaio.

A montagem do ensaio foi feita em permeâmetros de parede rígida nas dimensões de $7,0 \mathrm{~cm}$ de diâmetro e $16,0 \mathrm{~cm}$ de altura, alternando camadas de pedregulho, parafina e 
bentonita para vedar o corpo de prova no interior do permeâmetro. Cada permeâmetro foi conectado no painel de permeabilidade e a saturação do corpo de prova assim como a percolação foi medida por meio de fluxo descendente (Figura 4.18c).

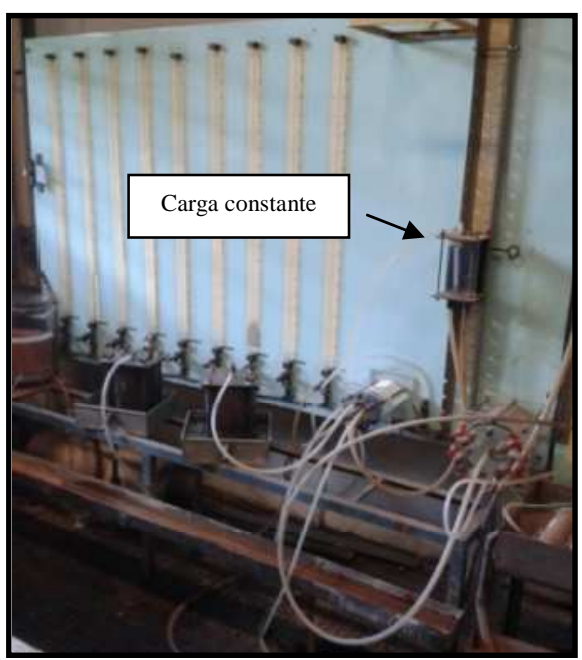

Figura 4.18 - Ensaio de permeabilidade em laboratório - permeâmetro conectado no painel de permeabilidade.

Nesta pesquisa foi utilizado o ensaio de permeabilidade a carga constante nos dois corpos de prova devido à quantidade de água percolada no solo em um curto intervalo de tempo. Estes ensaios seguiram as instruções contidas na Norma Técnica (NBR13292/1995) de ensaios de permeabilidade a carga constante (ABNT, 1995b). Em cada leitura foram medidos quatro itens: altura de carga, temperatura da água, volume de água percolado no corpo de prova e tempo decorrido para acumulação desse volume. A condutividade hidráulica saturada foi calculada utilizando-se a lei de Darcy, representada pela seguinte expressão:

$$
k_{s}=\frac{q_{c p} \cdot L_{c p}}{A_{c p} \cdot h_{c p}}
$$

em que $k_{s}$ é a condutividade hidráulica saturada do solo, em $\left[\mathrm{LT}^{-1}\right] ; q_{c p}$ é a vazão, em $\left[\mathrm{L}^{3} \mathrm{~T}^{-1}\right]$; $L_{c p}$ é a altura do corpo de prova do solo, em [L]; $A_{c p}$ é a área transversal do corpo de prova do solo, em $\left[\mathrm{L}^{2}\right] ; h_{c p}$ é a carga hidráulica, em [L].

\subsubsection{Ensaio de permeabilidade - campo}

Os ensaios de permeabilidade em campo foram feitos utilizando o permeâmetro Guelph em diversos locais e profundidades da área piloto.

O permeâmetro Guelph é basicamente composto por um tripé, um tubo de suporte, dois reservatórios de acrílico, um tubo de ar e um tubo graduado. O tubo de suporte fica 
apoiado no tripé e conectado nos reservatórios de acrílico, interno e externo, responsáveis em fornecer os valores de infiltração acumulada da água no solo em função do tempo. O tubo graduado está acoplado na tampa do reservatório externo e tem a função de regular o indicador do nível da altura de carga que o tubo de ar manterá constante na ponteira do permeâmetro. A Figura 4.19 ilustra esquematicamente o permeâmetro Guelph.

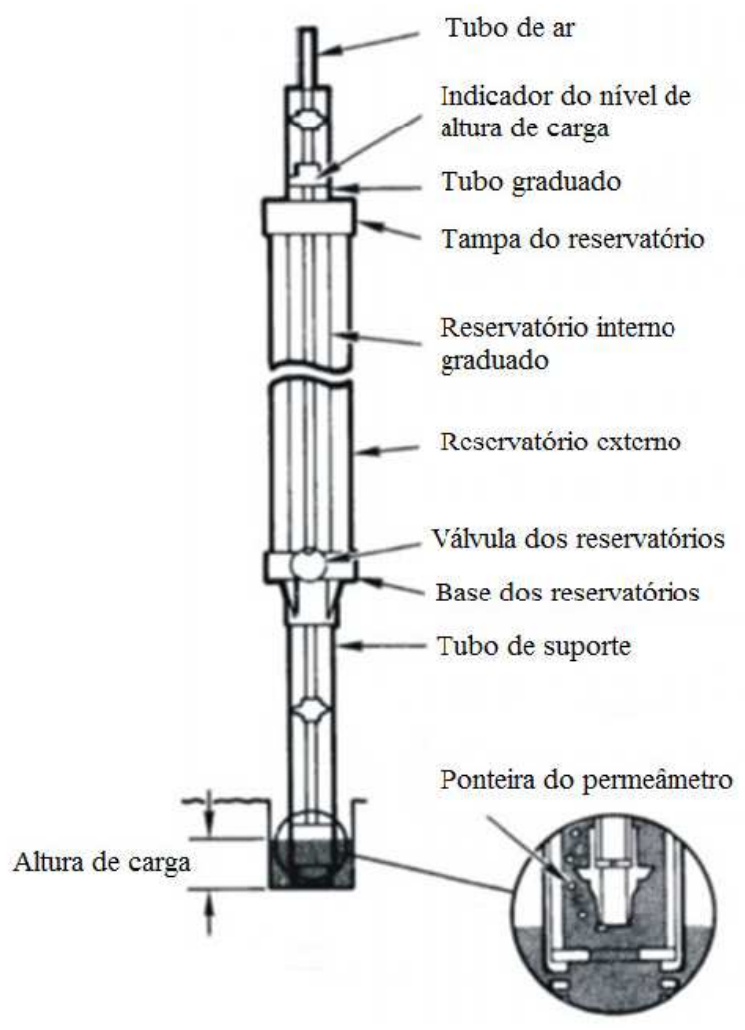

Figura 4.19 - Esquema do permeâmetro Guelph.

Fonte: Fernandes (2011).

O permeâmetro Guelph opera sob o princípio do tubo de Mariotte e os resultados são interpretados baseados na equação de Richards (1931) e no modelo teórico desenvolvido por Reynolds e Elrick (1985). Este ensaio possibilita determinar a condutividade hidráulica não saturada por meio de dois métodos: com uma altura de carga ou duas alturas de carga.

Nesta pesquisa foi utilizado o método das duas alturas de carga. Este método de ensaio determina duas medidas de vazão para duas alturas de carga diferentes. A condutividade hidráulica saturada de campo e o potencial matricial de fluxo foram determinados com as equações (52) e (53):

$$
Q_{1}=\left(\frac{2 \cdot \pi \cdot H_{1}^{2}}{C_{1}}+\pi \cdot a_{p g}^{2}\right) \cdot k_{f s}+\left(\frac{2 \cdot \pi \cdot H_{1}}{C_{1}}\right) \cdot \phi_{G m}
$$




$$
Q_{2}=\left(\frac{2 \cdot \pi \cdot H_{2}{ }^{2}}{C_{2}}+\pi \cdot a_{p g}^{2}\right) \cdot k_{f s}+\left(\frac{2 \cdot \pi \cdot H_{2}}{C_{2}}\right) \cdot \phi_{G m}
$$

em que $Q_{1}$ e $Q_{2}$ correspondem à vazão em regime permanente para alturas de cargas $H_{1}$ e $H_{2}$, em $\left[\mathrm{L}^{3} \mathrm{~T}^{-1}\right] ; H_{1}$ e $H_{2}$ correspondem à altura de carga, em [L]; $C_{1}$ e $C_{2}$ são os parâmetros que correspondem ao fator de forma e dependem da relação do tipo de solo e $H / a_{p g}$, em [adimensional]; $a_{p g}$ é o raio do furo no solo, em [L]; $k_{f s}$ é a condutividade hidráulica saturada de campo, em $\left[\mathrm{LT}^{-1}\right] ; \phi_{G m}$ é o potencial matricial de fluxo, em $\left[\mathrm{L}^{2} \mathrm{~T}^{-1}\right]$.

$\mathrm{O}$ valor do fator de forma $\left(C_{1} e C_{2}\right)$ das equações (52) e (53) foi determinado a partir da estimativa do parâmetro $\alpha$ sugerido por Elrick et al. (1989), como mostra a Tabela 4.3. A relação entre a altura de carga e o raio do furo $\left(H / a_{p g}\right)$ com a estimativa do parâmetro $\alpha_{p g}$ fornece o valor do fator de forma por meio da Figura 4.20.

Tabela 4.3 - Estimativa do parâmetro $\alpha_{\mathrm{pg}}$.

\begin{tabular}{cl}
\hline $\boldsymbol{\alpha}_{\boldsymbol{p g}}\left(\mathbf{c m}^{-\mathbf{1}}\right)$ & \multicolumn{1}{c}{ Tipo de Solo } \\
\hline 0,01 & Argilas compactas (aterro, liners, sedimentos lacustres e marinhos); \\
\hline 0,04 & Solos de textura fina, principalmente sem macro-poros e fissuras; \\
\hline 0,12 & Argilas até areias finas com alto a moderada quantidade de macro-poros e fissuras; \\
\hline 0,36 & Areias grossas - inclui solos com macroporosidade e fissuras evidentes. \\
\hline
\end{tabular}

Fonte: Traduzido e adaptado Soilmoisture Equipment Corp., (2008).

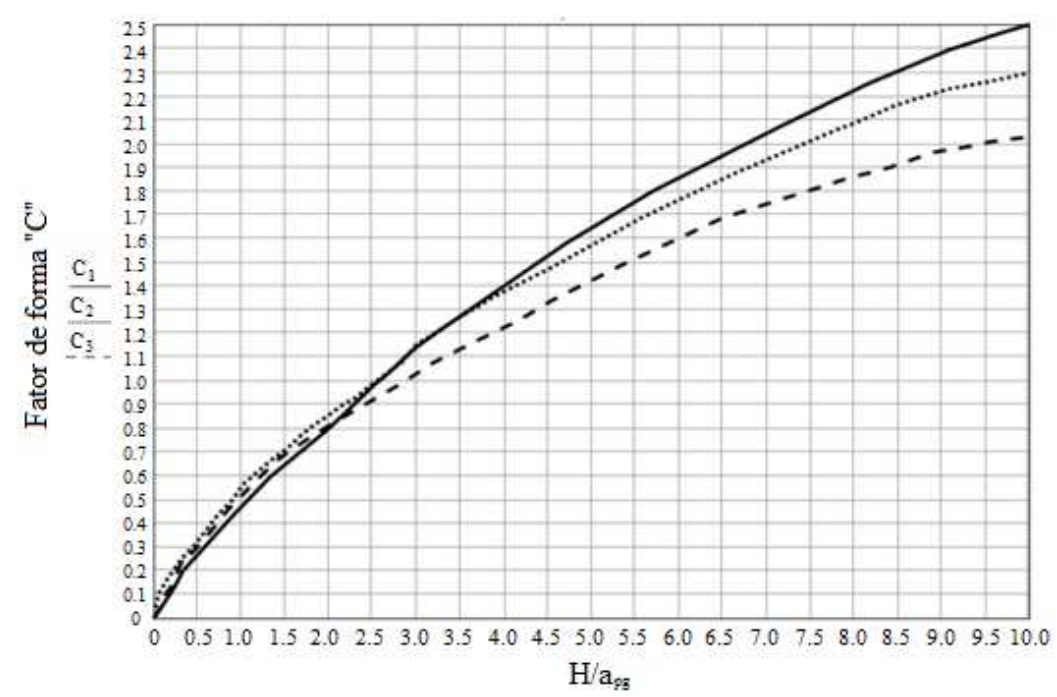

Figura 4.20 - Fator de forma "C": $C_{1}$ para valores de $\alpha \geq 0,12 \mathrm{~cm}^{-1} ; C_{2}$ para valores de $\alpha=0,04 \mathrm{~cm}^{-1}$; $\mathrm{e} \mathrm{C}_{3}$ para valores de $\alpha=0,01 \mathrm{~cm}^{-1}$.

Fonte: Soilmoisture Equipment Corp. (2008). 
O parâmetro $\alpha_{p g}$ pode ser calculado através da relação entre a condutividade hidráulica saturada de campo e o potencial matricial de fluxo, como mostra a equação (54):

$$
\alpha_{p g}=\frac{k_{f s}}{\phi_{G m}}
$$

em que $\alpha_{p g}$ é o parâmetro que depende da porosidade e textura do solo, em $\left[\mathrm{L}^{-1}\right] ; k_{f s}$ é a condutividade hidráulica saturada de campo, em $\left[\mathrm{LT}^{-1}\right] ; \phi_{G m}$ é o potencial matricial de fluxo, em $\left[\mathrm{L}^{2} \mathrm{~T}^{-1}\right]$.

Vale ressaltar que este permeâmetro só aplica carga hidráulica positiva no solo, portanto, mede somente a condutividade hidráulica saturada de campo. A função condutividade hidráulica não saturada pode ser determinada usando a equação empírica de Gardner (1958) e os parâmetros obtidos de $k_{f s}$ e $\alpha_{p g}$, como mostra a equação (55):

$$
k(\phi)=k_{f s} \cdot e^{\left(\alpha_{p g} \cdot \phi\right)}
$$

em que $k(\phi)$ é a condutividade hidráulica não saturada, em $\left[\mathrm{LT}^{-1}\right] ; k_{f s}$ é a condutividade hidráulica saturada de campo, em $\left[\mathrm{LT}^{-1}\right] ; \alpha_{p g}$ é o parâmetro que depende da porosidade e textura do solo, em $\left[\mathrm{L}^{-1}\right] ; \phi$ é o potencial, em $[\mathrm{L}]$.

$\mathrm{Na}$ execução dos ensaios foram adotados os procedimentos descritos adiante. Um furo foi feito na superfície do solo com o uso de um trado cavadeira. Na sequência, o trado reto foi inserido no seu interior para nivelar a base e regularizar sua parede. Em seguida, o trado escova foi utilizado para deixar a parede do furo áspera. Todos os ensaios desta pesquisa foram feitos com altura de carga de $5,0 \mathrm{~cm}$ e $10,0 \mathrm{~cm}$; e os furos com 6,0 cm de diâmetro e profundidade de $0,45 \mathrm{~m} ; 0,48 \mathrm{~m} ; 0,60 \mathrm{~m}$ e $0,82 \mathrm{~m}$.

O permeâmetro Guelph foi cuidadosamente montado e os reservatórios de acrílico (interno e externo) foram preenchidos com água. A remoção de bolhas de ar foi feita com uma bomba à vácuo, aplicando $20 \mathrm{kPa}$ no interior desses reservatórios. A ponteira do permeâmetro foi posicionada na base do furo e a água do reservatório foi nivelada. O indicador de altura de carga foi posicionado no tubo graduado para $5,0 \mathrm{~cm}$ e imediatamente iniciado o ensaio.

As leituras de infiltração acumulada e tempo acumulado foram anotadas em uma planilha de ensaio. O ensaio foi encerrado e definido estabilizado quando a variação das 
últimas três leituras do nível d'água foram semelhantes para o mesmo intervalo de tempo. Após o término desse ensaio, os reservatórios de água foram recarregados e o indicador de altura de carga foi posicionado para $10,0 \mathrm{~cm}$. Novamente iniciou-se o ensaio, adotando os critérios descritos anteriormente para encerramento do ensaio.

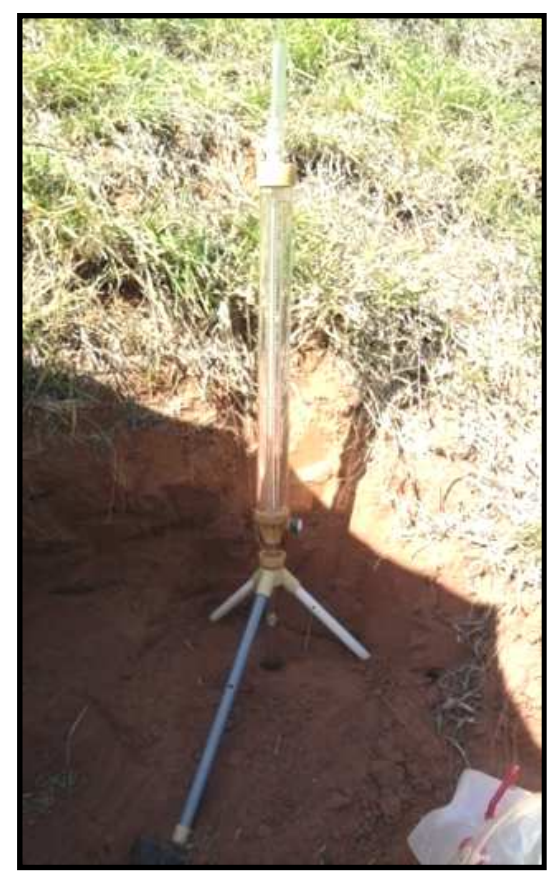

Figura 4.21 - Ensaio de permeabilidade em campo - permeâmetro Guelph.

\subsubsection{Ensaio de erodibilidade}

No ensaio de erodibilidade foi adotada a proposta de Nogami e Villibor (1979) e de Pejon (1992) para caracterizar o solo quanto a problemática erosiva a partir da determinação do índice de erodibilidade.

A metodologia proposta consiste basicamente na realização de dois ensaios laboratoriais, são eles: o ensaio de absorção de água e o ensaio de perda de massa por imersão. Os corpos de prova foram moldados em anéis de PVC a partir da amostra indeformada do pé do talude (AP-1), nas dimensões de 2,50 cm de altura e 5,00 cm de diâmetro, e deixados secar ao ar livre durante sete dias. Abaixo estão descritos como foram realizados os dois ensaios.

\subsubsection{Ensaio de absorção de água}

O equipamento utilizado neste ensaio é composto por um recipiente cilíndrico (diâmetro semelhante ao anel de PVC), uma placa porosa comum e um tubo de vidro horizontal graduado interligado próximo à base do recipiente cilíndrico (Figura 4.22a). O conjunto formado pelo recipiente cilíndrico e a placa porosa comum deve ser mantido 
nivelado com o tubo de vidro e sempre estar preenchido com água, de forma que a placa porosa comum permaneça sempre saturada (Figura 4.22b).

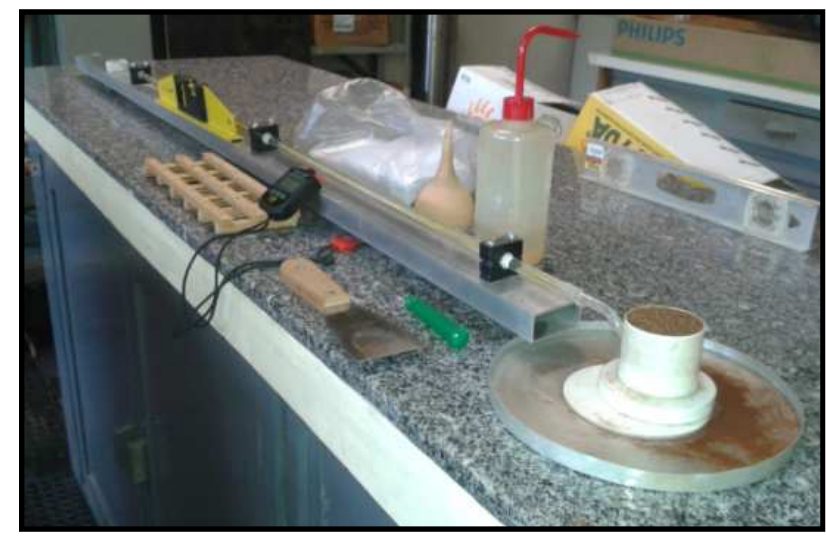

(a)

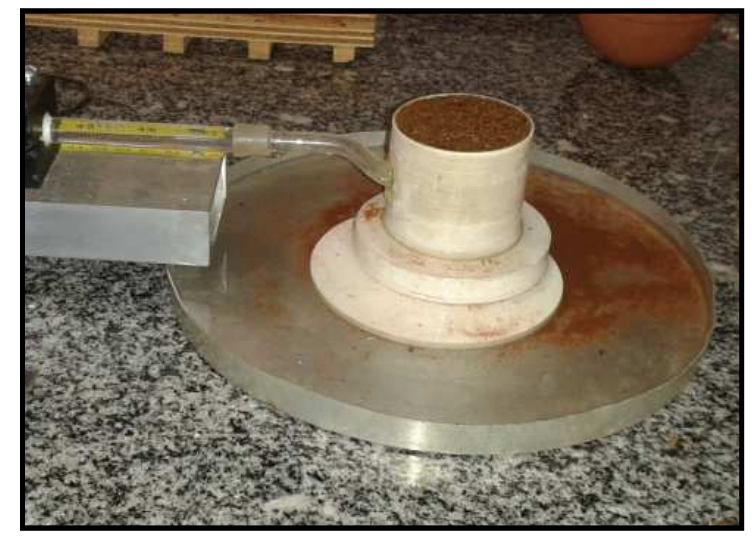

(b)

Figura 4.22 - Ensaio de absorção de água (a) equipamentos utilizados e (b) detalhe do suporte com a placa porosa comum.

Cada corpo de prova foi levado na balança digital com resolução 0,0001 g antes de iniciar o ensaio sendo sua massa inicial anotada na folha de ensaio. Em seguida, o corpo de prova foi posto sobre a placa porosa saturada e, imediatamente, acionado o cronômetro. Durante o ensaio foram feitas leituras de volume de água em função do intervalo de tempo. $\mathrm{O}$ ensaio foi encerrado quando a água absorvida pela amostra de solo atingiu o topo do corpo de prova e tornou-se visível.

O cálculo do índice de absorção de água (S) foi feito a partir do gráfico de volume de água absorvida por unidade de área da base do corpo de prova (q) versus raiz quadrada do tempo $(\sqrt{t})$, em que a distribuição dos pontos acontece ao longo de uma linha reta e o índice de absorção é dado pelo valor do coeficiente angular, segundo a equação (56):

$$
S=\frac{q_{e}}{\sqrt{t}}
$$

em que $S$ é o índice de absorção de água, em $\left[\mathrm{LT}^{-1 / 2}\right] ; q_{e}$ é o volume de água absorvida por unidade de área da base do corpo de prova, em $\left[\mathrm{L}^{3} \mathrm{~L}^{-2}\right] ; \sqrt{t}$ é a raiz do tempo, em $\left[\mathrm{T}^{1 / 2}\right]$.

\subsubsection{Ensaio de perda de massa por imersão}

Após o encerramento do ensaio de absorção de água, o corpo de prova foi imediatamente amarrado a outro recipiente cilíndrico de PVC e submergido em um tanque com água. O topo da amostra foi sempre mantido na posição vertical no interior do tanque e o 
conjunto assentado sobre um suporte, permitindo que um recipiente de vidro colete o material de solo desprendido da amostra (Figura 4.23a e b). Este conjunto foi armazenado no tanque com água por um período de 24 horas sendo que, o material desprendido da amostra foi levado para secar em estufa (temperatura em torno de $100^{\circ} \mathrm{C}$ ) e pesado após um dia.

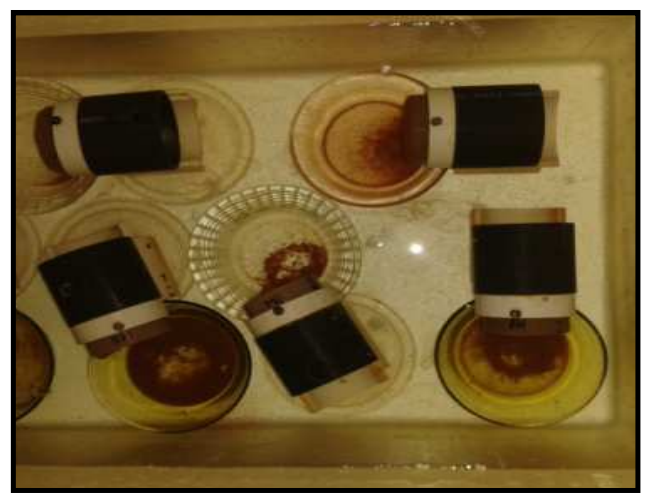

(a)

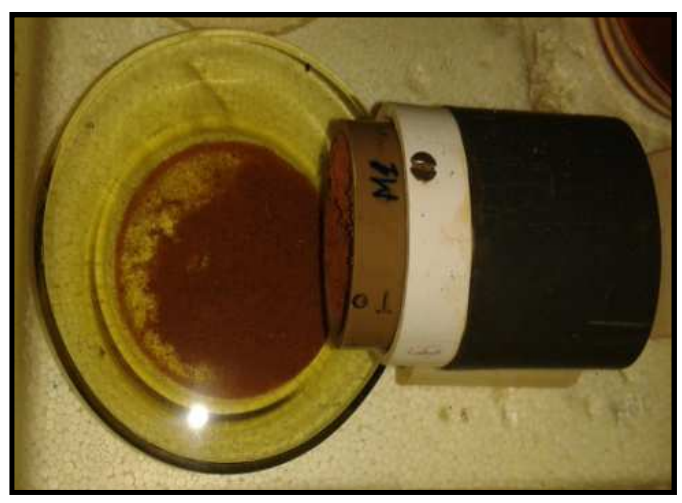

(b)

Figura 4.23 - Ensaio de perda de massa por imersão (a) submersão dos corpos de prova no tanque com água e (b) detalhe de um corpo de prova submerso.

O índice de perda de massa por imersão (P) é a razão entre a massa seca desprendida de solo e a massa seca inicial de solo, e foi calculado com o uso da equação (57).

$$
P=\frac{m_{i}-m_{f}}{m_{i}} .100
$$

em que $P$ é o índice de perda de massa por imersão, em [\%]; $m_{i}$ é a massa seca inicial de solo, em $[\mathrm{M}] ; m_{f}$ é a massa seca final de solo, em [M].

O índice de erodibilidade é dado pela relação entre os índices de absorção de água e perda de massa por imersão, podendo ser calculado com as propostas de Nogami e Villibor (1979) e Pejon (1992), como mostram as equações (58) e (59), respectivamente:

$$
\begin{aligned}
& E_{52}=52 \cdot \frac{S}{P} \\
& E_{40}=40 \cdot \frac{S}{P}
\end{aligned}
$$

em que $E_{52}$ é o índice de erodibilidade segundo Nogami e Villibor (1979); $S$ é o índice de absorção de água, em $\left[\mathrm{LT}^{-1 / 2}\right] ; P$ é o índice de perda de massa por imersão, em $\left[\mathrm{MM}^{-1}\right]$ e $E_{40}$ é o índice de erodibilidade segundo Pejon (1992). 


\subsubsection{Ensaios de Resistência ao Cisalhamento}

A resistência ao cisalhamento do solo foi determinada a partir dos ensaios de compressão triaxial realizados em amostras indeformadas de solo para a condição saturada e para a condição não saturada. Os ensaios feitos para determinação da resistência do solo saturado foram do tipo adensado-drenado (CD) utilizando corpos de prova moldados do bloco de amostra indeformada do pé e da crista do talude. Já os ensaios para determinação da resistência do solo com teor de umidade natural foram feitos utilizando corpos de prova moldados da amostra indeformada do pé e da crista além dos ensaios do tipo adensadodrenado (CD) utilizando corpos de prova moldados do bloco de amostra indeformada da crista do talude.

A configuração do equipamento para realização do ensaio de compressão triaxial sempre esteve condicionada com o tipo de ensaio e a condição de saturação do solo. Pode-se descrever que este equipamento é basicamente composto por uma prensa mecânica da marca Wykeham Farrance com capacidade de $50 \mathrm{kN}$, um microcomputador, um sistema de aquisição digital de dados, dois tipos de sistemas de aplicação de pressão (interface mercúrio/água e atuador de pressão) e uma câmara triaxial da marca Wykeham Farrance. A Figura 4.25 apresenta a prensa mecânica da marca Wykeham Farrance utilizada nos ensaios de compressão triaxial.

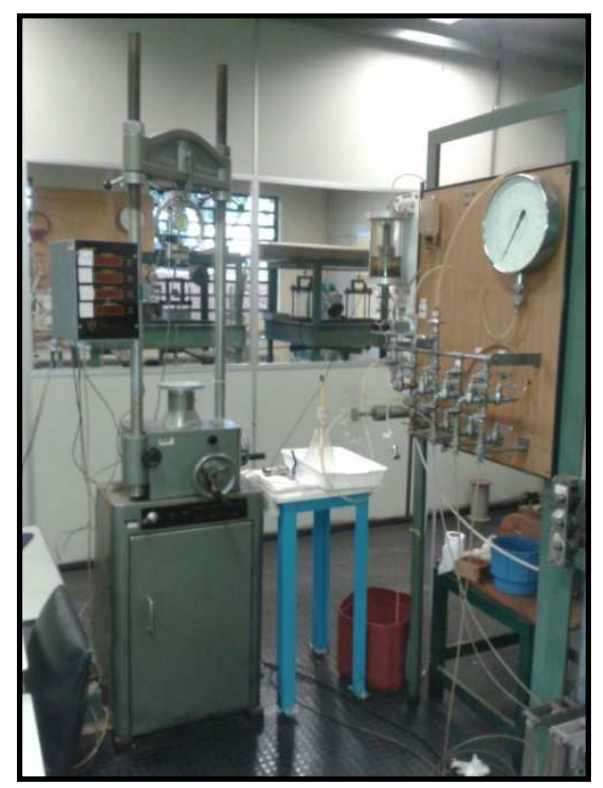

Figura 4.24 - Prensa mecânica utilizada nos ensaios de compressão triaxial.

O sistema de aquisição digital de dados é composto por quatro canais capazes de monitorar e medir dados como a força (canal 1 - transdutor), pressão neutra (canal 2 transdutor de pressão), variação volumétrica (canal 3 - variador de volume) e deslocamento 
(canal 4 - transdutor de deslocamento), como mostra a Figura 4.25. Todos os canais foram previamente calibrados através do cálculo da constante de cada canal.

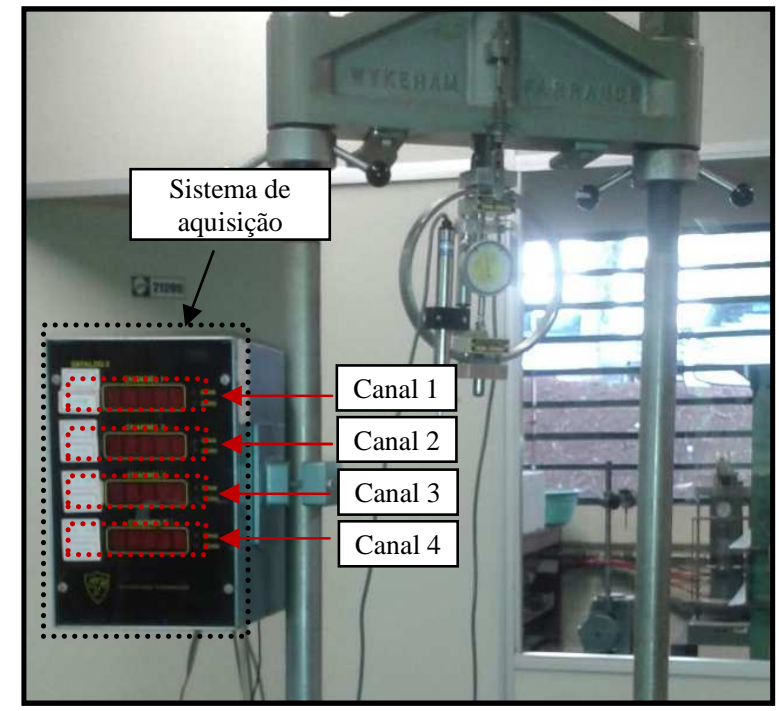

Figura 4.25 - Sistema de aquisição de dados - canal 1 ao 4.

No caso específico dos ensaios com o solo não saturado, três pedestais de base foram adaptados para abrigar placas porosa de alta pressão de entrada de ar (cada uma delas com capacidade de $50 \mathrm{kPa}, 100 \mathrm{kPa}$ e $300 \mathrm{kPa}$ ) e um sistema de aplicação de pressão (ar comprimido) foi adicionado na configuração do equipamento (Figura 4.26).

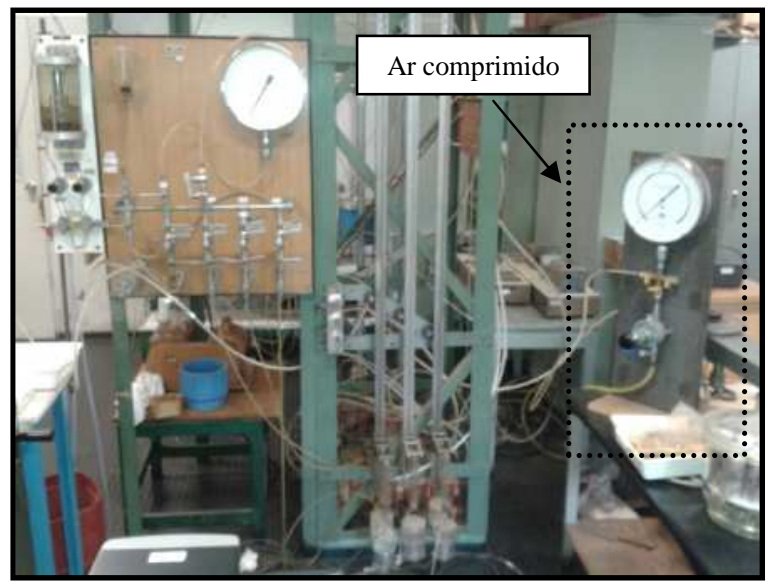

Figura 4.26 - Sistema de aplicação de pressão - ar comprimido.

\subsubsection{Ensaios adensado-drenado (CD) - solo saturado}

A realização dos ensaios adensado-drenado (CD) foi feito a partir da execução de uma série de etapas, dentre elas destacando-se os detalhes envolvidos na moldagem do corpo de prova, na montagem do corpo de prova na câmara triaxial, na saturação do corpo de prova por contra-pressão, na etapa de adensamento e na etapa de cisalhamento. Todas as etapas encontram-se descritas abaixo, obedecendo a sequência do ensaio. 
Os corpos de prova utilizados neste tipo de ensaio foram moldados da amostra indeformada do pé do talude (AP-1 e AP-2) e da crista do talude (AC-1) nas dimensões de 5,0 $\mathrm{cm}$ de diâmetro e 10,0 cm de altura, sempre obedecendo a relação entre o diâmetro $(D)$ e a altura $(H=2,0$ a 2,5 .D) do corpo de prova. Após a moldagem do corpo de prova, cada um foi preparado no aparato da câmara triaxial seguindo os procedimentos descritos a seguir.

a-) eliminação das bolhas de ar oclusas no interior de duas placas porosa comum (sendo uma delas utilizada na base e outra no topo do corpo de prova) a partir do aquecendo de um pequeno volume de água destilada deaerada em um recipiente metálico, seguido da submersão dessas duas placas por curto tempo.

b-) montagem do corpo de prova na câmara triaxial obedecendo a sequência: pedestal da base, placa porosa comum, papel filtro comum, corpo de prova, papel filtro comum, placa porosa comum e cabeçote.

c-) verificação de furos na membrana de látex antes de inseri-la no corpo de prova, de maneira que esta impeça a passagem de água da câmara para o interior do corpo de prova;

d-) fixação da membrana de látex na base do pedestal com o uso de o-rings e elásticos de borracha e no topo do cabeçote com auxílio de elásticos de borracha.

e-) fechamento da câmara triaxial seguida pelo seu preenchimento com água destilada.

A saturação do corpo de prova foi feita por meio de um sistema de aplicação de pressão na câmara triaxial utilizando a interface mercúrio/água para imposição da pressão confinante $\left(\sigma_{3}\right)$ e o atuador de pressão para imposição da contra-pressão. Essas pressões (confinante e contra-pressão) foram sempre elevadas em incremento de $50 \mathrm{kPa}$ e mantidas uma diferença constante entre a pressão confinante e a contra-pressão de $10 \mathrm{kPa}$ para cada estágio de saturação. O corpo de prova foi considerado saturado quando este atingiu valor superior ou igual a 0,95 para o parâmetro B de Skempton, determinado a partir da medição do acréscimo de pressão neutra ocasionada pela aplicação de um incremento de $50 \mathrm{kPa}$ na pressão confinante.

A etapa de adensamento foi feita através de carregamento isotrópico com tensões confinantes de $50 \mathrm{kPa}, 100 \mathrm{kPa}$ e $150 \mathrm{kPa}$ em cada série de corpos de prova, sendo permitida a drenagem da água do corpo de prova ao longo de toda a etapa de adensamento. A variação volumétrica de cada corpo de prova foi controlada a partir do registro dos valores de fluxo de água pelo sistema de aquisição digital de dados (canal 2) em função do tempo. Esta etapa do ensaio foi considerada encerrada quando o corpo de prova atingiu a estabilização da variação volumétrica em função do tempo. 
As velocidades de cisalhamento utilizadas em cada corpo de prova neste tipo de ensaio foram calculadas com os dados do adensamento e seguindo as recomendações proposta por Head (1998). A estimativa do tempo $t_{100}$ foi feita pelo gráfico de adensamento (variação volumétrica versus raiz quadrada do tempo), o qual corresponde ao valor médio de tempo dos ensaios em aproximadamente 0,7 minutos. Portanto, o tempo correspondente à ruptura do corpo de prova $\left(t_{f}\right)$ foi calculado pela equação (60) proposta por Head (1998) e a velocidade máxima de cisalhamento estabelecida para o solo estudado em cada ensaio foi determinada pela equação (61).

$$
\begin{gathered}
t_{f}=8,5 \cdot t_{100} \\
v_{\text {máx }}=\frac{\varepsilon \cdot H}{100 \cdot t_{f}}
\end{gathered}
$$

em que $t_{f}$ é o tempo correspondente à ruptura do corpo de prova, em $[\mathrm{T}] ; t_{100}$ é o tempo correspondente à $100 \%$ do adensamento, em [T]; v máx é a velocidade máxima de cisalhamento, em $\left[\mathrm{LT}^{-1}\right] ; \varepsilon$ é a deformação axial assumida do corpo de prova na ruptura, em [\%]; $H$ é a altura inicial do corpo de prova, em [L].

No caso do solo estudado, assumiu-se que a ruptura ocorre com uma taxa de deformação axial de 5\% resultando numa velocidade máxima de 1,200 mm/min. Portanto, em todos os ensaios do tipo adensado-drenado (CD) foi utilizada uma velocidade de cisalhamento de 0,076 mm/ $\mathrm{min}$, que é inferior à recomendada por Head (1998).

Os resultados dos ensaios adensado-drenado (CD) com solo saturado foram utilizados na determinação de duas envoltórias de resistência (amostra indeformada do pé e da crista do talude), estando cada uma delas composta por uma série com três corpos de prova.

\subsubsection{Ensaio de compressão triaxial para determinação da resistência do solo com teor de umidade natural (solo não saturado)}

A realização dos ensaios de compressão triaxial para determinação da resistência do solo com teor de umidade natural (solo não saturado) foi feito a partir da execução de uma série de etapas, dentre elas destacando-se os detalhes envolvidos na moldagem do corpo de prova, a montagem do corpo de prova na câmara triaxial, a etapa de adensamento e a etapa de cisalhamento. Todas as etapas encontram-se descritas abaixo, obedecendo a sequência do ensaio. 
Os corpos de prova utilizados neste tipo de ensaio foram moldados da amostra indeformada do pé do talude (AP-2) e da crista do talude (AC-1) nas dimensões de 5,0 cm de diâmetro e $10,0 \mathrm{~cm}$ de altura, obedecendo a relação entre o diâmetro $(D)$ e a altura $(H=$ 2,0 a 2,5 . D ) do corpo de prova. Após a moldagem do corpo de prova, cada um foi preparado no aparato da câmara triaxial seguindo os procedimentos descritos abaixo.

a-) secagem de duas pedras porosa comum na estufa.

b-) montagem do corpo de prova na câmara triaxial obedecendo a sequência: pedestal da base, placa porosa comum seca, papel filtro comum, corpo de prova, papel filtro comum, placa porosa comum seca e cabeçote.

c-) verificação de furos na membrana de látex antes de inseri-la no corpo de prova, de maneira que esta impeça a passagem de água da câmara para o interior do corpo de prova;

d-) fixação da membrana de látex na base do pedestal com o uso de o-rings e elásticos de borracha e no topo do cabeçote com auxílio de elásticos de borracha.

e-) fechamento da câmara triaxial seguida pelo seu preenchimento com água destilada.

A etapa de adensamento foi feita através de carregamento isotrópico com tensões confinantes de $50 \mathrm{kPa}, 100 \mathrm{kPa}$ e $150 \mathrm{kPa}$ em cada série de corpos de prova, sendo permitida a drenagem do corpo de prova ao longo de toda a etapa de adensamento, já que nesses ensaios os corpos de prova não foram saturados. A variação volumétrica de cada corpo de prova foi controlada a partir dos registros feitos pelo sistema de aquisição digital de dados (canal 2) em função do tempo. Esta etapa do ensaio foi considerada encerrada quando o corpo de prova atingiu a estabilização da variação volumétrica em função do tempo.

A etapa de cisalhamento foi feita através da aplicação de uma velocidade de cisalhamento de $0,076 \mathrm{~mm} / \mathrm{min}$ (igual ao ensaio $\mathrm{CD}$ com solo saturado), não sendo permitida qualquer tipo de drenagem durante essa etapa. Após o encerramento do ensaio, o corpo de prova foi dividido em duas porções (base e topo) para determinação da sucção matricial utilizando a técnica do papel filtro.

Os resultados dos ensaios para determinação da resistência do solo com teor de umidade residual (solo saturado) foram utilizados na determinação de duas envoltórias de resistência (amostra indeformada do pé e da crista do talude), estando cada uma delas composta por uma série com três corpos de prova.

\subsubsection{Ensaios adensado-drenado (CD) - solo não saturado}

A realização dos ensaios adensado- drenado (CD) com solo não saturado foi feito a partir da execução de uma série de etapas, dentre elas destacando-se os detalhes envolvidos na 
configuração do equipamento, na adaptação do pedestal de base e na saturação da placa porosa de alta pressão de entrada de ar, na moldagem do corpo de prova, na montagem do corpo de prova na câmara triaxial, na saturação do corpo de prova, na desaturação do corpo de prova, na etapa de adensamento e na etapa de cisalhamento. Todas as etapas encontram-se descritas abaixo, obedecendo a sequência do ensaio.

Um sistema de pressão (ar comprimido) foi adicionado à configuração do equipamento inicial, de maneira que permitisse impor ao corpo de prova o valor desejado de sucção matricial.

O pedestal de base foi adaptado para a realização dos ensaios com solo não saturado, de maneira que ficasse incrustada uma placa porosa de alta pressão de entrada de ar em cada pedestal. Nesses ensaios foram utilizados três pedestais, cada um contendo uma placa porosa com capacidade de $50 \mathrm{kPa}, 100 \mathrm{kPa}$ e $300 \mathrm{kPa}$.

Dois detalhes importantes que devem ser realizados antes da montagem dos corpos de prova na câmara triaxial é a saturação da placa porosa de alta pressão de entrada de ar e a verificação de vazamento na placa porosa. Nesta pesquisa, a saturação da placa porosa foi feita por meio da aplicação de pressão na câmara triaxial (pressão inferior à capacidade de cada placa porosa), a qual foi preenchida por uma lâmina de água destilada deaerada superior à ela, permitindo a drenagem da água percolada na placa para uma bureta e medindo o volume de água em função do tempo. A placa porosa foi considerada saturada a partir do momento que o valor de sua condutividade hidráulica foi próxima ao valor sugerido pelo manual do fabricante. A verificação de vazamento na placa porosa também foi feita por meio da aplicação de pressão na câmara triaxial (pressão inferior à capacidade de cada placa porosa), porém observando-se a ocorrência de bolhas de ar num dispositivo conectado à drenagem da câmara.

Após estarem concluídas a nova configuração do equipamento e os testes com os pedestais de base, foi dado início a moldagem dos corpos de prova. Os corpos de prova utilizados neste tipo de ensaio foram moldados da amostra indeformada da crista do talude (AC-1) nas dimensões de 5,0 cm de diâmetro e 10,0 cm de altura, obedecendo a relação entre o diâmetro $(D)$ e a altura $(H=2,0$ a 2,5 . $D)$ do corpo de prova. Após a moldagem do corpo de prova, cada um foi preparado no aparato da câmara triaxial seguindo os procedimentos descritos abaixo:

a-) montagem do corpo de prova na câmara triaxial obedecendo a sequência: pedestal da base contendo uma placa porosa de alta pressão de entrada de ar, corpo de prova, papel filtro, placa porosa comum e cabeçote. 
b-) verificação de furos na membrana de látex antes de inseri-la no corpo de prova, de maneira que esta impeça a passagem de água da câmara para o interior do corpo de prova;

c-) fixação da membrana de látex na base do pedestal com o uso de o-rings e elásticos de borracha e no topo do cabeçote com auxílio de elásticos de borracha.

d-) fechamento da câmara triaxial seguida pelo seu preenchimento com água destilada.

Nos ensaios com solo não saturado, a saturação do corpo de prova foi feita através de uma bureta graduada instalada na saída de uma das duas torneiras da base da câmara. Feito isso, o volume de água necessário para saturação do corpo de prova foi calculado através da relação de índices físicos do solo e controlado pela bureta graduada. Após a saturação do corpo de prova, um período de 24 horas foi aguardado para equalizar o teor de umidade no interior do solo. Transcorrido esse período, foi iniciada o processo de desaturação do corpo de prova.

A desaturação do corpo de prova também foi feita com o uso de uma bureta graduada instalada na saída de uma das duas torneiras da base da câmara. Assim como na saturação, o volume de água a ser retirado do corpo de prova foi calculado por meio da relação de índices físicos e do ajuste da curva de retenção da água do solo, sendo esse volume também controlado pela bureta graduada. Após a desaturação do corpo de prova, um período de 24 horas foi aguardado para equalizar o teor de umidade no interior do solo.

A etapa de adensamento foi feita através de carregamento isotrópico com tensões confinantes líquida $\left(\sigma-u_{a}\right)$ de $50 \mathrm{kPa}, 100 \mathrm{kPa}$ e $150 \mathrm{kPa}$ e sucção matricial $\left(u_{a}-u_{w}\right)$ de $30 \mathrm{kPa}$. A pressão do ar $\left(u_{a}\right)$ na base do corpo de prova, a pressão da água $\left(u_{w}\right)$ no topo do corpo de prova e a tensão confinante $\left(\sigma_{3}\right)$ foram mantidas constantes durante toda a etapa de adensamento. Assim como nos ensaios adensado-drenado com solo saturado, a variação volumétrica de cada corpo de prova de solo não saturado foi controlada a partir do registro dos valores de fluxo de água pelo sistema de aquisição digital de dados (canal 2) em função do tempo. Esta etapa do ensaio foi considerada encerrada quando o corpo de prova atingiu a estabilização da variação volumétrica em função do tempo.

A etapa de cisalhamento foi feita mantendo sempre constantes a pressão do ar $\left(u_{a}\right)$ na base do corpo de prova, a pressão da água $\left(u_{w}\right)$ no topo do corpo de prova e a tensão confinante $\left(\sigma_{3}\right)$. Observa-se que a velocidade de cisalhamento do solo não saturado não é determinado como no solo saturado, isso se deve ao fato da velocidade de cisalhamento poder interferir na diferença de tensões principais ao longo do ensaio e consequentemente, influenciar na obtenção dos parâmetros de resistência do solo. Essa velocidade escolhida foi baseada nas taxas de deformação utilizadas por Calle (2000) em ensaios CD para uma areia 
argilosa (velocidade de 0,004 $\mathrm{mm} / \mathrm{min}$ ) e por Reis (2004) em ensaios CD para uma areia siltosa/areia argilosa (velocidade de $0,006 \mathrm{~mm} / \mathrm{min}$ ). Portanto, como o solo estudado nesta pesquisa possui uma porcentagem significativa de areia (em torno de $85 \%$ ), a velocidade de cisalhamento escolhida foi $0,012 \mathrm{~mm} / \mathrm{min}$ para a realização deste ensaio. Após o término do ensaio, o corpo de prova foi dividido em duas porções (base e topo) para determinação da sucção matricial utilizando a técnica do papel filtro.

Os resultados do ensaio adensado-drenado (CD) com solo não saturado foram utilizados na determinação de uma envoltória de resistência (amostra indeformada da crista), estando composta por uma série com três corpos de prova.

\subsubsection{Envoltória de resistência}

A envoltória de resistência do solo foi estabelecida por meio dos valores de tensão na ruptura de cada corpo de prova, os quais foram obtidos através das curvas denominadas tensão-deformação tanto para o solo saturado quanto para o solo não saturado. As curvas tensão-deformação representam como a deformação do solo varia em função do aumento da tensão desviatória, a qual foi produzida pelo deslocamento ascendente da base da câmara a uma velocidade constante. Essas curvas apresentam diferentes comportamentos, os quais dependem do tipo do ensaio, das características do solo e da representação dos valores de tensão no eixo das ordenadas.

Nesta pesquisa, as curvas tensão-deformação foram representadas no eixo das ordenadas através da diferença de tensões principais $\left(\sigma_{1}-\sigma_{3}\right)$ para os ensaios adensadodrenado $(\mathrm{CD})$ do solo saturado, os ensaios adensado-drenado com solo não saturado e os ensaios para determinação da resistência do solo com teor de umidade natural.

A partir dos resultados das curvas tensão-deformação foram estabelecidos os critérios de ruptura para cada ensaio e na sequência, definidas as envoltórias de resistência e os parâmetros de resistência do solo (denominados de coesão e ângulo de atrito). Nesta pesquisa, o critério de ruptura adotado para todos os ensaios (solo saturado e solo não saturado) foi o máximo valor de tensão $\left(\sigma_{1}-\sigma_{3}\right)_{\text {máximo }}$ fornecido pela curva tensão-deformação.

No caso dos ensaios adensado-drenado com solo saturado e dos ensaios para determinação da resistência do solo com teor de umidade natural, os parâmetros de resistência (ângulo de atrito e coesão) foram determinados a partir do critério de ruptura Mohr-Coulomb, como mostra a equação (33). Além disso, também foi utilizado um método para previsão da resistência ao cisalhamento (VILAR, 2007), utilizando as equações apresentadas no item 3.7.3.2 sobre este método. 
No caso dos ensaios adensado-drenado com solo não saturado, os parâmetros de resistência (ângulo de atrito interno do solo referente à variação da tensão normal líquida, ângulo de atrito interno do solo referente a variação da sucção matricial e coesão) foram determinados a partir da equação sugerida por Fredlund, Morgenstern e Widger (1978), como mostra a equação (36).

\subsection{ETAPA 8 - INSTRUMENTAÇÃO}

A instrumentação de campo da área piloto foi feita por meio da instalação de equipamentos em diferentes localidades do talude, tendo como principal objetivo a coleta e a reprodução de dados na forma de parâmetros indicadores de formação de nível d’água transiente, variação da sucção matricial do solo ao longo da profundidade e registro de chuvas. A escolha dos equipamentos e a profundidade de instalação são decorrentes das observações feitas nos taludes situados próximos da área piloto, as quais apontam a predominância de rupturas rasas.

\subsubsection{Tensiômetro}

O tensiômetro é um equipamento de campo constituído por um tubo plástico de comprimento variável, uma tampa, uma placa porosa (cerâmica ou porcelana) e um manômetro de pressão (ou vacuômetro) com uma escala graduada de 0 a $100 \mathrm{kPa}$. A Figura 4.27 ilustra os componentes de um tensiômetro comum.

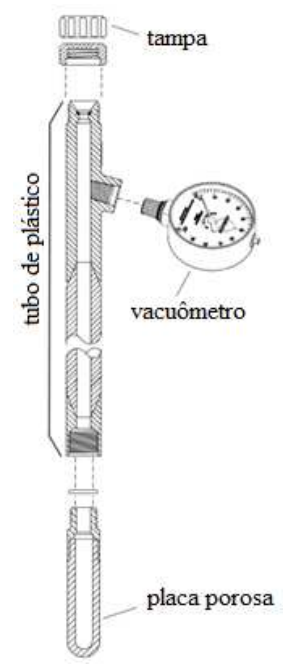

Figura 4.27 - Tensiômetro comum.

Fonte: Traduzido e adaptado de Soilmoisture Equipment Corp. (2011).

O funcionamento do tensiômetro é bem simples e o valor da sucção matricial é dado pelo equilíbrio entre a água presente no solo (o qual está em contato com a placa porosa do 
tensiômetro) e a água contida no sistema interno desse equipamento, que também dependerá do teor de umidade do solo. Como a água contida no interior do tensiômetro não sofre ação da gravidade e não está livre, o solo necessita exercer uma pressão para retirar água do sistema. Essa pressão indica o valor do vácuo criado no interior do sistema e consequentemente, o valor da sucção matricial.

Nesta pesquisa foram instalados seis conjuntos de tensiômetros, estando estes distribuídos ao longo do pé, da face e da crista de duas seções típicas da área piloto com inclinação de $27^{\circ}$ e $37^{\circ}$. Cada conjunto foi composto por três tensiômetros (comprimento de $0,45 \mathrm{~m} ; 0,90 \mathrm{~m} \mathrm{e} 1,50 \mathrm{~m}$ ), todos eles instalados em diferentes profundidades, como mostra a Tabela 4.4.

Tabela 4.4 - Profundidade de instalação dos tensiômetros nas duas seções do talude.

\begin{tabular}{|c|c|c|c|c|}
\hline Seção & Local & Tensiômetro & $\begin{array}{c}\text { Comprimento do } \\
\text { tensiômetro }(\mathbf{m})\end{array}$ & $\begin{array}{l}\text { Profundidade de instalação } \\
\text { do tensiômetro }(\mathrm{m})\end{array}$ \\
\hline \multirow{9}{*}{$\mathrm{i} 27^{\circ}$} & \multirow{3}{*}{ Pé } & $\mathrm{A} 1$ & 0,45 & 0,40 \\
\hline & & $\mathrm{A} 2$ & 0,90 & 0,81 \\
\hline & & A3 & 1,50 & 1,46 \\
\hline & \multirow{3}{*}{ Face } & A4 & 0,45 & 0,37 \\
\hline & & A5 & 0,90 & 0,83 \\
\hline & & A6 & 1,50 & 1,35 \\
\hline & \multirow{3}{*}{ Crista } & A7 & 1,50 & 1,40 \\
\hline & & A8 & 0,90 & 0,79 \\
\hline & & A9 & 0,45 & 0,40 \\
\hline \multirow{9}{*}{ i $37^{\circ}$} & \multirow{3}{*}{ Pé } & B1 & 0,45 & 0,32 \\
\hline & & B2 & 0,90 & 0,74 \\
\hline & & B3 & 1,50 & 1,43 \\
\hline & \multirow{3}{*}{ Face } & B4 & 0,45 & 0,41 \\
\hline & & B5 & 0,90 & 0,84 \\
\hline & & B6 & 1,50 & 1,42 \\
\hline & \multirow{3}{*}{ Crista } & B7 & 0,45 & 0,35 \\
\hline & & B8 & 0,90 & 0,80 \\
\hline & & B9 & 1,50 & 1,36 \\
\hline
\end{tabular}


Embora os tensiômetros sejam conhecidos por sua simplicidade, para que eles apresentem um desempenho satisfatório em campo é imprescindível uma série de cuidados especiais nos procedimentos de preparo e instalação. Deste modo, o preparo dos tensiômetros ocorreu no laboratório do Departamento de Geotecnia por meio da saturação da placa porosa, estando na sequência abaixo descrito resumidamente quais foram os procedimentos adotados em cada etapa.

As placas porosas foram inseridas uma a uma no interior de um recipiente com água destilada, ficando armazenadas neste local por um período de quatro dias. Os componentes do tensiômetro foram encaixados um a um e o tubo plástico preenchido com água destilada e deairada. A placa porosa foi mantida mergulhada no recipiente e com o uso de uma pequena bomba de vácuo foi aplicada uma pressão negativa afim de cessar a ascensão de bolhas de ar. O tubo plástico foi tampado e o tensiômetro foi pendurado para secar ao ar livre. Quando o vacuômetro registrou a leitura de $50 \mathrm{kPa}$, o tensiômetro foi mergulhado no recipiente com água destilada sendo computado o tempo para atingir $0 \mathrm{kPa}$. A partir do momento em que a placa porosa teve um tempo de resposta adequado, o tensiômetro estava pronto para ser instalado em campo.

A instalação dos tensiômetros foi feita em furos de trado espiral com diâmetro de 1" equivalente à 2,54 cm (Figura 4.28a) e em diferentes profundidades (como indicado na Tabela 4.4). O visor do vacuômetro foi conferido se registrava $0 \mathrm{kPa}$ (Figura 4.28b). Uma pasta composta por água e solo do local foi introduzida em pequena quantidade no fundo do furo para garantir o contato da placa porosa do tensiômetro com o solo do local (Figura 4.29a). Imediatamente o tensiômetro foi inserido no furo (Figura 4.29b).

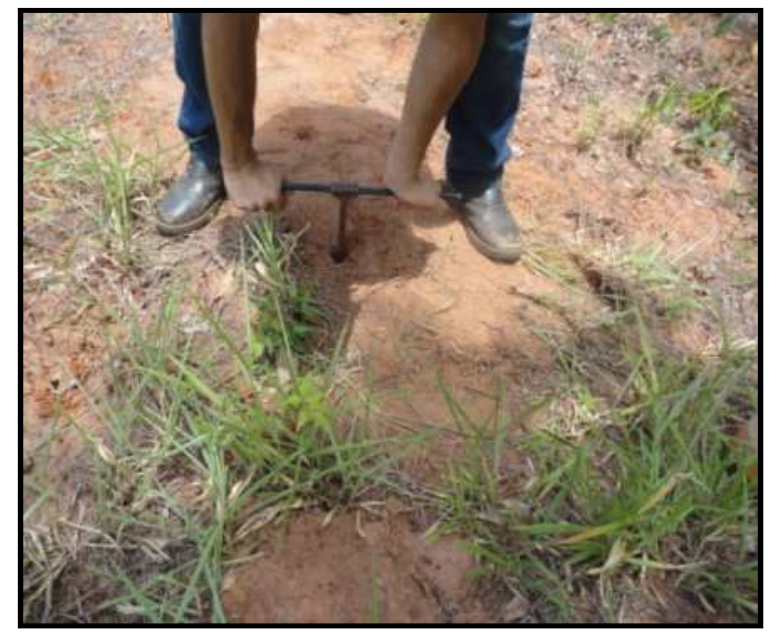

(a)

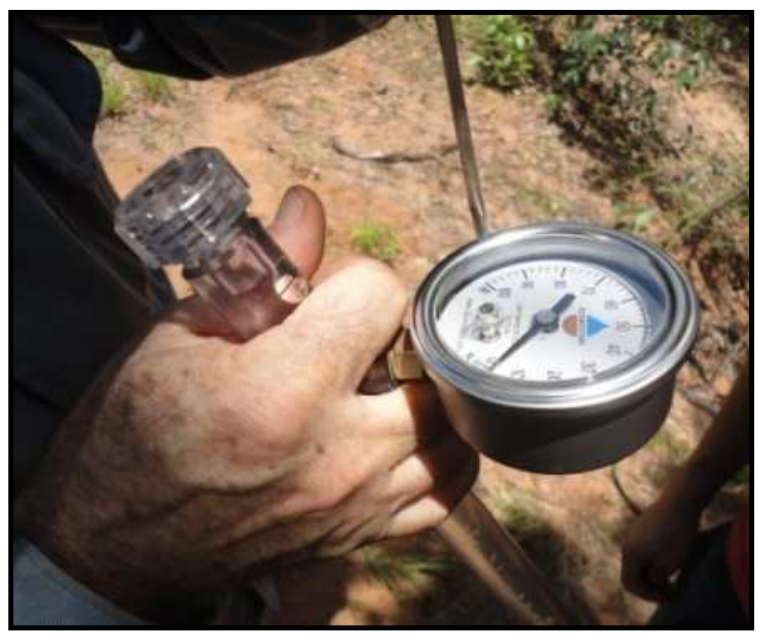

(b)

Figura 4.28 - Etapas da instalação dos tensiômetros (a) perfuração com trado espiral e (b) visor do vacuômetro registrando $0 \mathrm{kPa}$. 


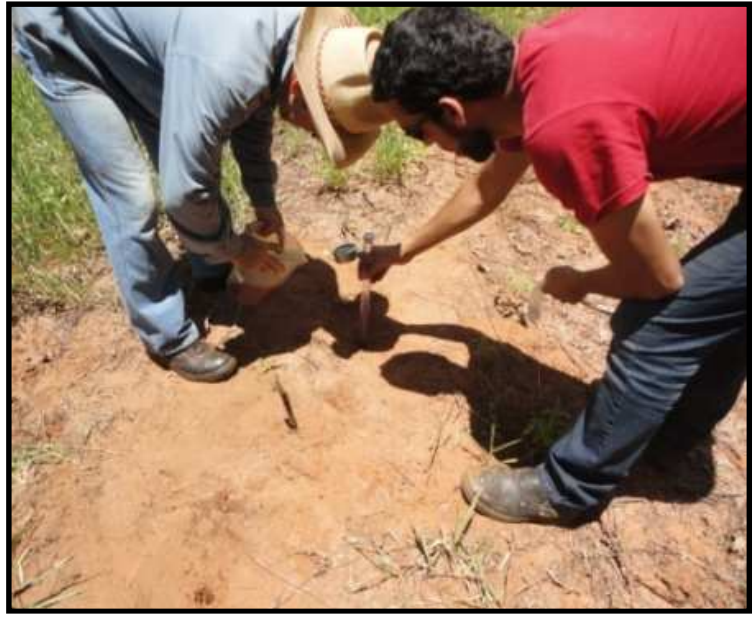

(a)

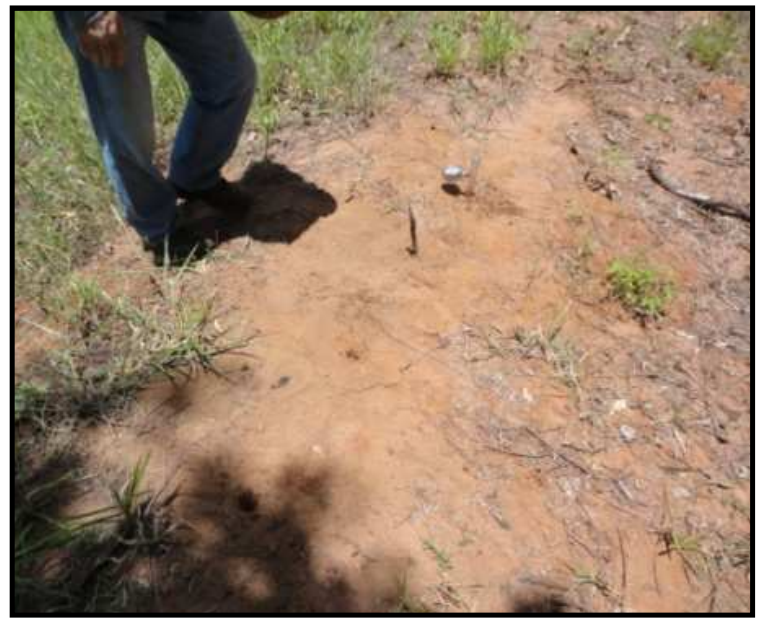

(b)

Figura 4.29 - Etapas da instalação dos tensiômetros (a) introdução da pasta e do tensiômetro no furo e (b) tensiômetro instalado.

O cálculo da sucção matricial foi feita a partir da leitura no vacuômetro do tensiômetro e corrigida em função do comprimento deste equipamento, de acordo com equação (62):

$$
\psi_{m}=S_{t}-\gamma_{w} \cdot h_{t}
$$

em que $\psi_{m}$ é a sucção matricial, em $\left[\mathrm{ML}^{-1} \mathrm{~T}^{-2}\right] ; S_{t}$ é a leitura no vacuômetro do tensiômetro, em $\left[\mathrm{ML}^{-1} \mathrm{~T}^{-2}\right] ; \gamma_{w}$ é o peso específico da água, em $\left[\mathrm{ML}^{-2} \mathrm{~T}^{-2}\right] ; h_{t}$ é o comprimento medido entre o meio da placa porosa e o vacuômetro, em [L].

\subsubsection{Medidor de nível d’água de máxima}

O medidor de nível d’água de máxima é composto basicamente por um tubo de PVC, uma mangueira de borracha e rolhas de silicone. Este equipamento foi desenvolvido pelo Instituto de Pesquisas Tecnológicas, também sendo denominado como piezômetro de máxima, e que segundo Guidicini, Wolle e Moruzzi (1976) pode ter funcionamento mecânico ou elétrico.

A escolha desse equipamento foi feita baseado no seu baixo custo de confecção, simples manuseio, capacidade de armazenamento da variação do nível d’água no interior do equipamento e principalmente decorrente do fato das rupturas na região da área piloto serem rasas (pouco profundas). Nesta pesquisa foram instalados dois medidores de nível d’água de máxima próximos aos tensiômetros do pé e da crista do talude na seção topográfica com inclinação de $27^{\circ}$, os quais foram denominados de $\mathrm{M}_{\mathrm{pé}}$ e $\mathrm{M}_{\text {crista. }}$. 
A confecção da mangueira do equipamento foi feita no laboratório do Departamento de Geotecnia da Escola de Engenharia de São Carlos, dividindo-a em segmentos de 0,10 m e utilizando uma rolha de silicone para delimitá-los, como mostra o esquema da Figura 4.30a. $\mathrm{Na}$ parte superior de cada segmento foi feito um furo para passagem da água, de modo que este possa registrar a variação do nível d'água (Figura 4.30b).

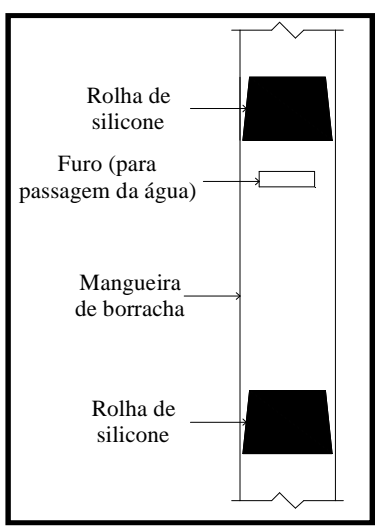

(a)

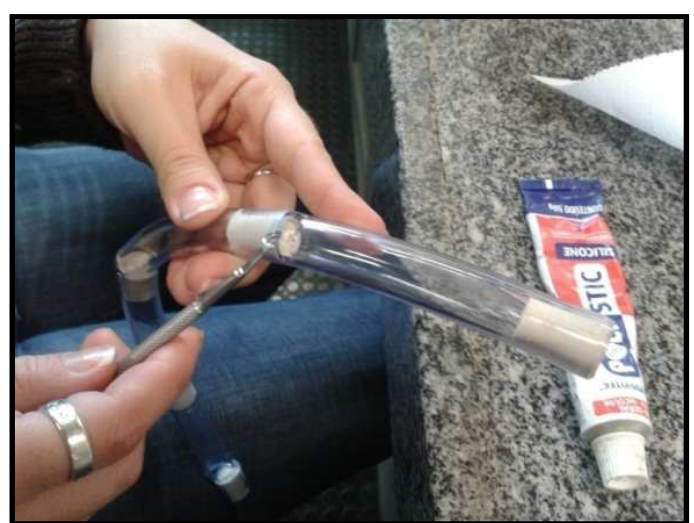

(b)

Figura 4.30 - Mangueira do medidor de nível d'água de máxima (a) esquema ilustrativo (desenho sem escala) e (b) confecção da magueira.

A instalação do medidor de nível d'água foi feita em furos de trado concha com diâmetro de 2" equivalente à 5,08 cm e profundidade de 2,00 m (Figura 4.31a). O fundo do furo foi revestido com uma fina camada de areia fina e na parte inferior do tubo de PVC foi fixada uma manta geotextil (Figura 4.31b). O tubo de PVC foi inserido no furo e em seguida, a mangueira confeccionada em laboratório foi posta no seu interior e amarrada no cap rosqueável deste tubo (Figura 4.32a, b).

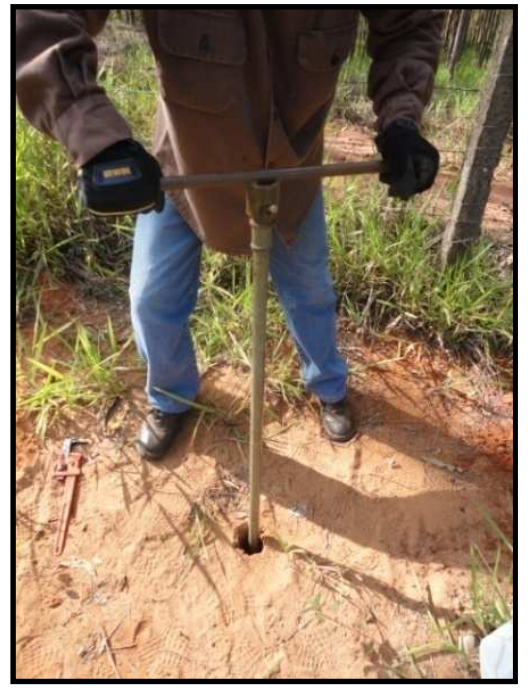

(a)

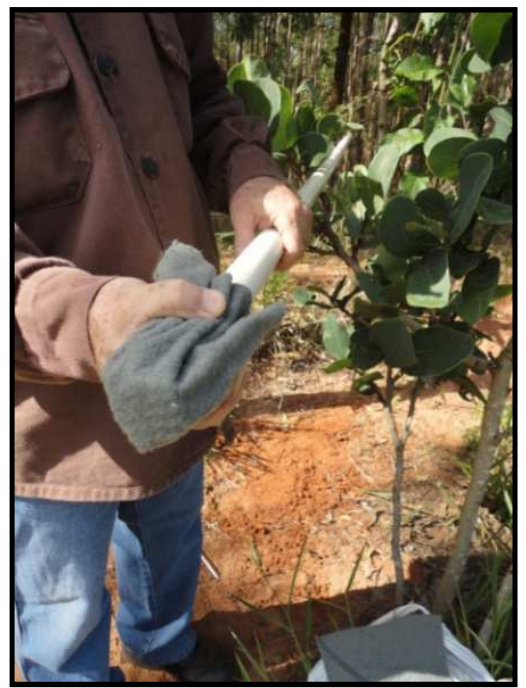

(b)

Figura 4.31 - Instalação do equipamento na área piloto (a) perfuração com trado concha e (b) fixação da manta geotextil no tubo de PVC. 


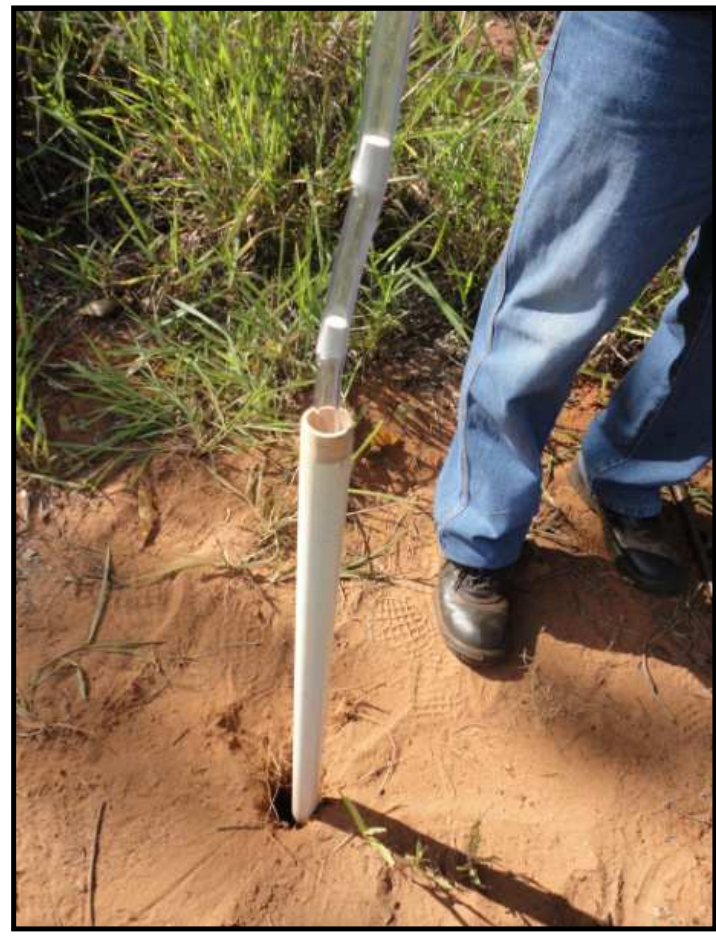

(a)

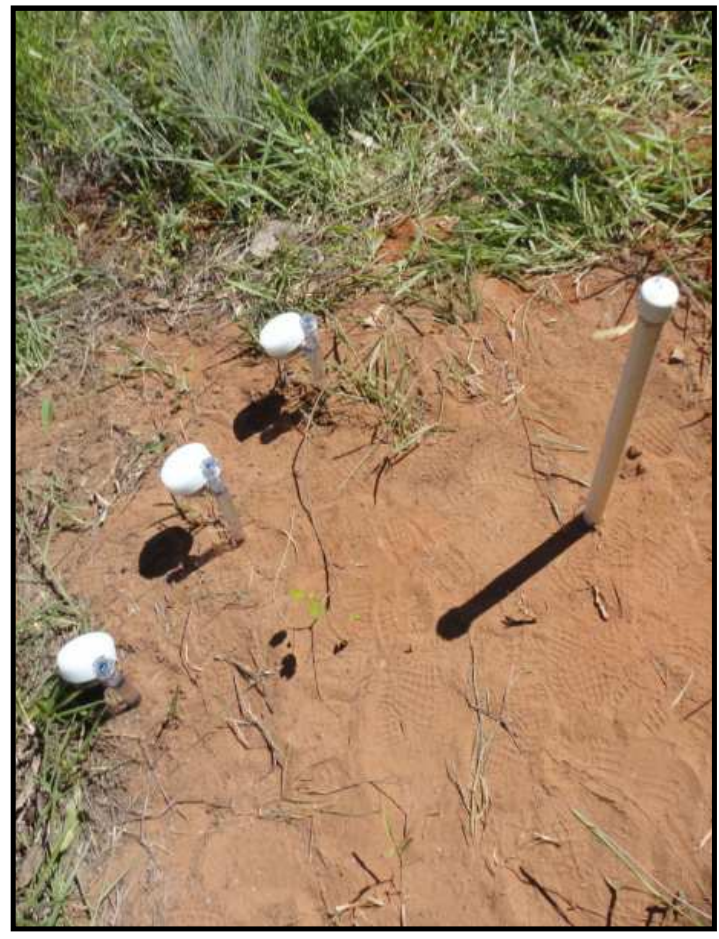

(b)

Figura 4.32 - Instalação do equipamento na área piloto (a) colocação da mangueira e (b) após instalação, próximos aos tensiômetros.

\subsubsection{Pluviômetro}

O pluviômetro escolhido para monitoramento da chuva nesta pesquisa foi o pluviômetro Ville de Paris, mais utilizado e difundido no Brasil. Este equipamento apresenta algumas vantagens como baixo custo de fabricação, fácil instalação e manuseio.

O pluviômetro Ville de Paris é um recipiente metálico (aço inoxidável), provido de uma superfície horizontal aberta com um ralo na extremidade superior, capaz de captar e armazenar determinado volume de água. Este equipamento possui uma área de superfície de captação de $400 \mathrm{~cm}^{2}$ e capacidade de armazenamento de $150 \mathrm{~mm}$, com precisão de leitura de $0,2 \mathrm{~mm}$. O volume de chuva acumulado é medido com uma proveta graduada, a qual deve ser inserida na parte inferior desse equipamento.

O local escolhido para instalação do pluviômetro foi uma região descampada e próxima da área piloto, uma vez que o talude se localiza na faixa de domínio do DER (evitar danos e roubo do equipamento) e ao lado de uma plantação de eucalipto (sofrer influência da vegetação na captação da água da chuva).

A Figura 4.33 indica a localização do pluviômetro e a distância entre a área piloto e o pluviômetro, que dista em torno de $460 \mathrm{~m}$. 


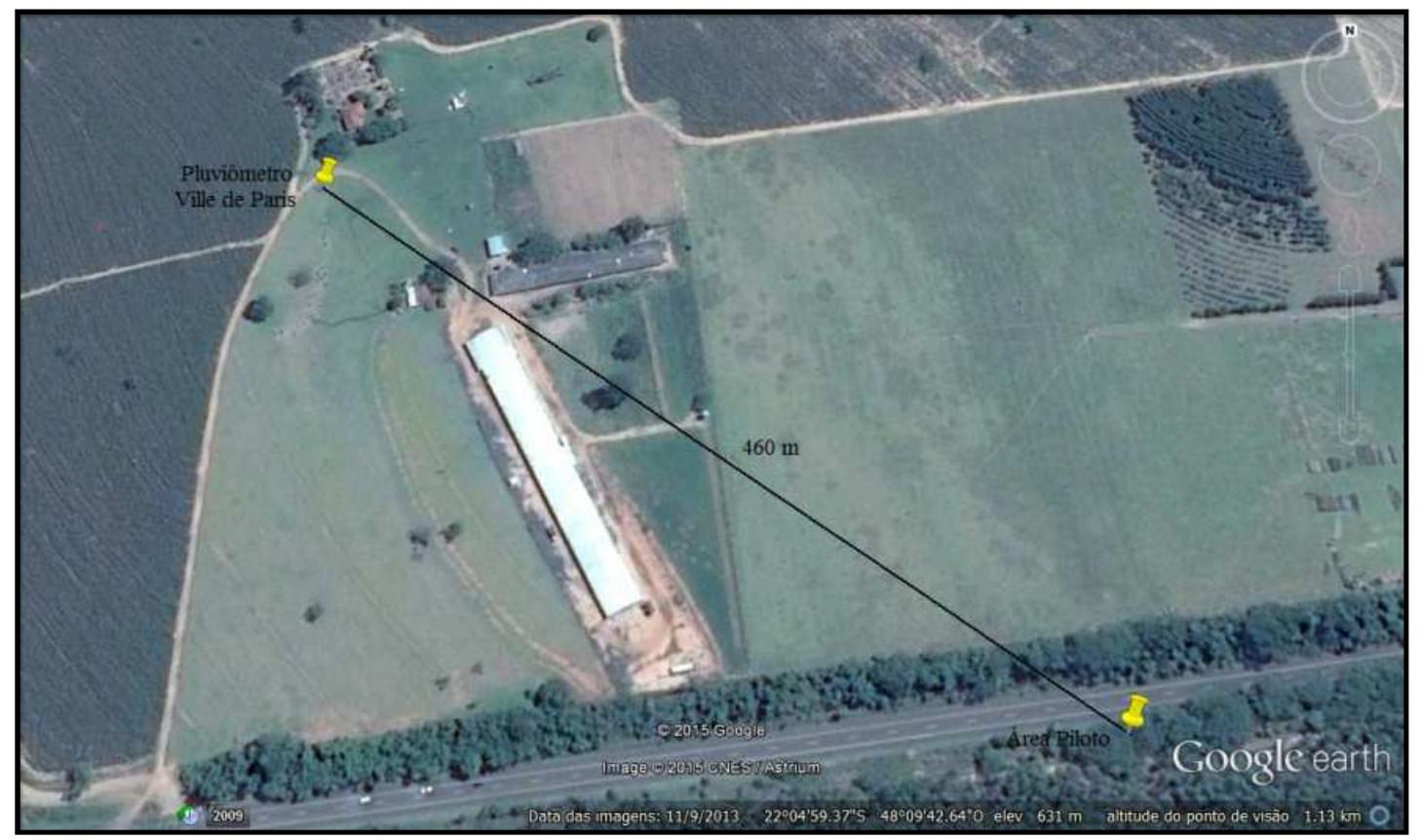

Figura 4.33 - Localização do pluviômetro Ville de Paris.

Fonte: Google Earth (2015).

O pluviômetro foi fixado em um mourão de madeira e a distância entre o bocal da área de captação e a superfície do solo foi de 1,50 m. A Figura 4.34a mostra o pluviômetro instalado em campo enquanto que a Figura 4.34 b mostra como é feita a coleta da água da chuva na proveta.

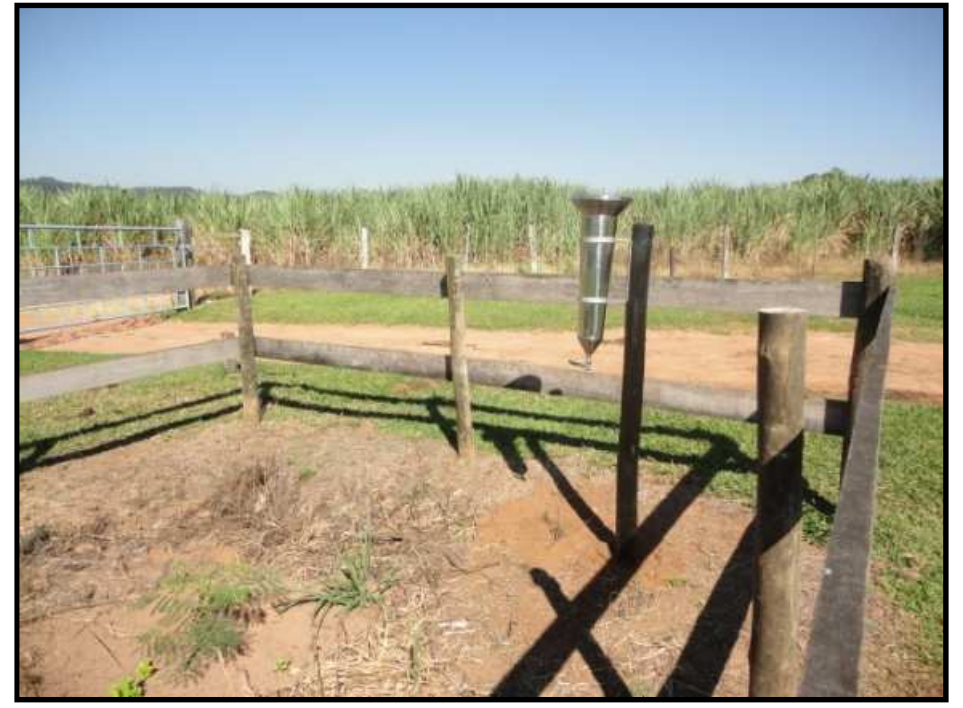

(a)

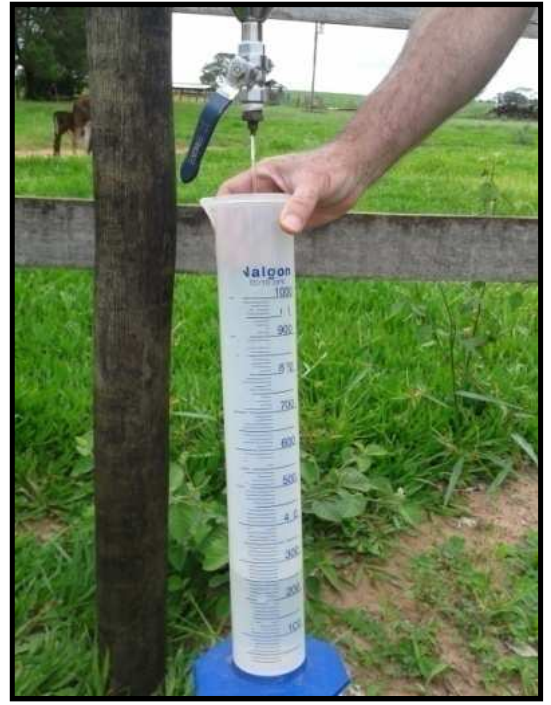

(b)

Figura 4.34 - Pluviômetro Ville de Paris (a) medida da chuva na proveta e (b) equipamento instalado em campo.

O cálculo da altura diária de chuva foi feita a partir do volume de água acumulado medido na proveta graduada e da área da superfície de captação, como mostra a equação (63): 


$$
P_{p v p}=10 \cdot \frac{V_{p v p}}{A_{p v p}}
$$

em que $P_{p v p}$ é a altura diária de chuva, em [L]; $V_{p v p}$ é o volume de água acumulado recolhido na proveta graduada, em $\left[\mathrm{L}^{3}\right] ; A_{p v p}$ é a área da superfície de captação, em $\left[\mathrm{L}^{2}\right]$.

Nesta pesquisa, o volume de água foi medido em mililitros e a área da captação em centímetros quadrado. Posteriormente, as unidades de medida do volume de água foram transformadas de mililitros para centímetro cúbico. Logo, o cálculo da altura diária de chuva foi feito primeiramente em centímetros, o qual foi posteriormente transformado em milímetros, que é a unidade de medida mais utilizada para sua representação.

Além dos dados hidrológicos medidos pelo pluviômetro Ville de Paris, também foram utilizados os dados hidrológicos de dois equipamentos localizados próximos da área piloto, tendo o intuito de comparar e analisar a representatividade das medidas fornecidas por esses equipamentos.

No caso do primeiro equipamento, este encontra-se instalado no município de São Carlos, cujas coordenadas geográficas corresponde à 4752'00" longitude Oeste e $21^{\circ} 58^{\prime} 00^{\prime \prime}$ latitude Sul, altitude de $856,0 \mathrm{~m}$ e distante de aproximadamente $33,2 \mathrm{~km}$ da área piloto (medidas obtidas no GOOGLE EARTH, 2016). Este equipamento está identificado como OMM83726 na rede de estações meteorológicas convencionais pertencentes ao INMET (Instituto Nacional de Meteorologia), sendo denominado nessa pesquisa de pluviômetro INMET. Os dados de precipitação pluviométrica utilizados desse equipamento foram obtidos no banco de dados do BDMEP (Banco de Dados Meteorológicos para Ensino e Pesquisa), consultado em Instituto Nacional de Meteorologia (2016).

Já no caso do segundo equipamento, este encontra-se instalado no município de Ribeirão Bonito (Figura 4.35a), cujas coordenadas geográficas corresponde à 48 10'44" longitude Oeste e $22^{\circ} 04^{\prime} 29^{\prime \prime}$ latitude Sul, altitude de 486,0 m e distante de aproximadamente 1,8 km da área piloto, como mostra a Figura 4.35b (medidas obtidas no GOOGLE EARTH, 2016). Este equipamento está identificado como 02248110 na rede de estações convencionais pertencentes à ANA (Agência Nacional de Água), sendo denominado nessa pesquisa de pluviômetro ANA. Os dados de precipitação pluviométrica utilizados desse equipamento foram obtidos no banco de dados do Hidroweb (Sistema de informações hidrológicas), consultado em Agência Nacional das Águas (2016). 


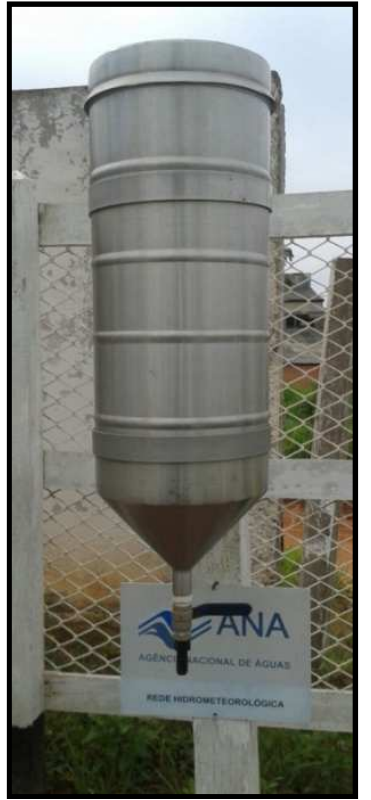

(a)

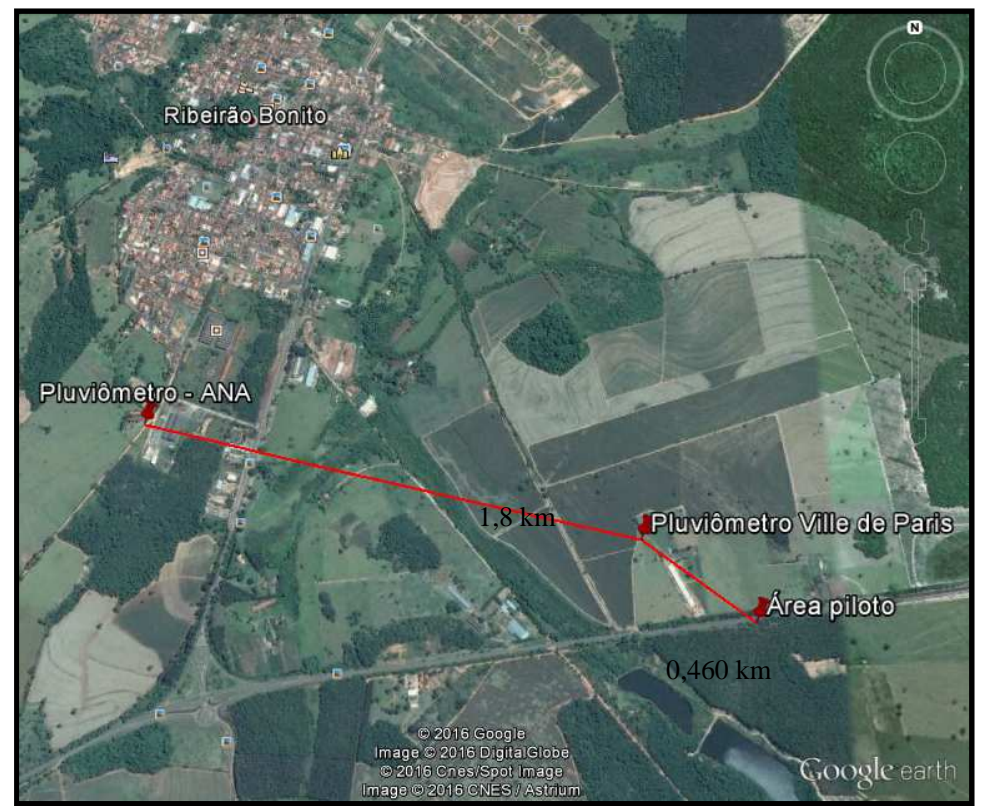

(b)

Figura 4.35 - (a) Pluviômetro utilizado para medição da precipitação diária pela Agência Nacional de Águas (b) distância entre o Pluviômetro Ville de Paris e o Pluviômetro ANA.

Fonte: Google Earth (2016).

\subsection{ETAPA 9 - MONITORAMENTO}

O monitoramento da área piloto foi realizada por meio de um pluviômetro, dois medidores de nível d’água de máxima e dezoito tensiômetros. O período de monitoramento foi de dezembro de 2013 a dezembro de 2015. As leituras dos tensiômetros e dos medidores de nível d'água foram feitas sempre no mesmo dia, geralmente num intervalo de quatro dias. O número de leituras foi intensificado durante a estação chuvosa (outubro a março) ou quando houvesse a ocorrência de eventos pluviométricos intensos no município de São Carlos, o qual está localizado próximo à área piloto.

Cabe ressaltar que, durante o monitoramento da sucção matricial nos meses de dezembro de 2013 a fevereiro de 2014, o conjunto de tensiômetros localizados no pé da seção geológico-geotécnica com inclinação $37^{\circ}$ não acusava leituras. Acredita-se que o fato desses tensiômetros não registrarem leituras neste período é decorrente do mau contato entre a placa porosa do tensiômetro e o solo local. Por esse motivo, optou-se em reinstalá-los no mesmo local, porém alargando o diâmetro do furo de instalação do tensiômetro com uso de um trado espiral de 2" equivalente a $5,08 \mathrm{~cm}$.

O tensiômetro com comprimento de $0,90 \mathrm{~m}$ do conjunto localizado na crista da seção geológico-geotécnica com inclinação $27^{\circ}$ precisou ser reinstalado no mês de março de 2015 . Essa reinstalação foi necessária por conta de um formigueiro gerar um buraco próximo à 
lateral desse tensiômetro, podendo criar um caminho preferencial para infiltração da água da chuva (Figura 4.36a). A Figura 4.36b, c ilustra o conjunto desses tensiômetros antes e depois da reinstalação, respectivamente, apresentando a distância após esse procedimento.

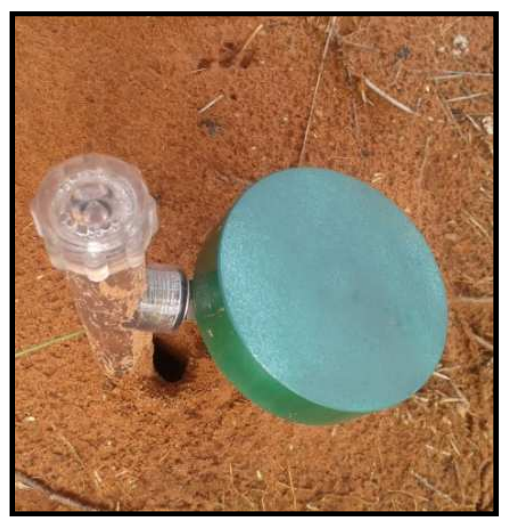

(a)

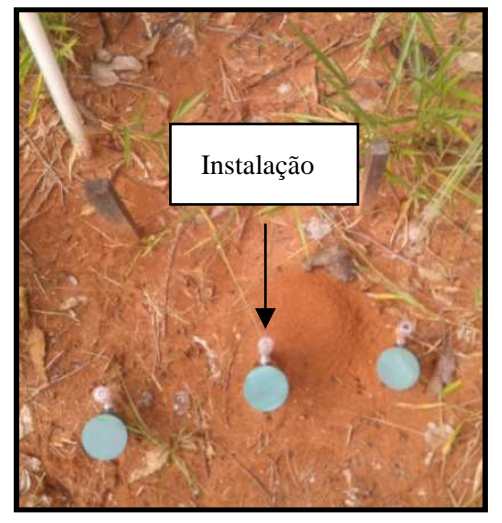

(b)

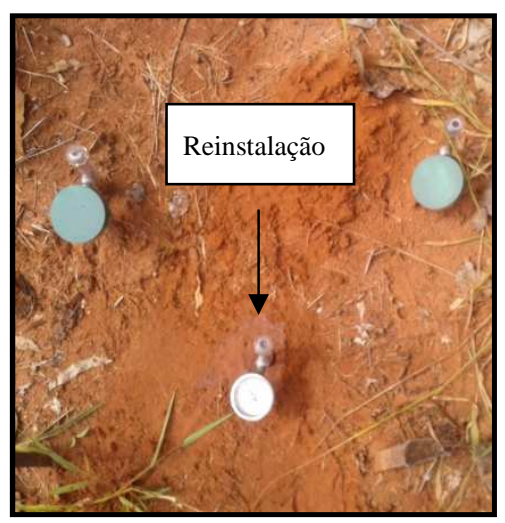

(c)

Figura 4.36 - Conjunto de tensiômetros da crista da seção geológico-geotécnica com inclinação de $27^{\circ}$ (a) tensiômetro com comprimento de $0,90 \mathrm{~m}$ afetado por um formigueiro, (b) conjunto de tensiômetros instalados em dezembro de 2013 e (c) conjunto de tensiômetros após reinstalação do equipamento.

O tubo de plástico do tensiômetro com comprimento de $0,45 \mathrm{~m}$ do conjunto localizado no pé da seção geológico-geotécnica com inclinação $37^{\circ}$ precisou ser substituído no mês de janeiro de 2015. Esse tubo foi danificado por operários durante a manutenção da vegetação na faixa de domínio, ocorrido no final do mês de dezembro de 2014. Antes da reinstalação do tensiômetro foi preciso saturar a placa porosa devido ao tempo do equipamento estar sujeito a pressão atmosférica e a possível entrada de ar na placa porosa. O tensiômetro foi instalado no mesmo local, sendo as leituras retomadas a partir do final do mês de janeiro de 2015. A Figura $4.37 \mathrm{a}$ mostra o tensiômetro danificado enquanto que a Figura $4.37 \mathrm{~b}$ ilustra o tensiômetro após a substituição.

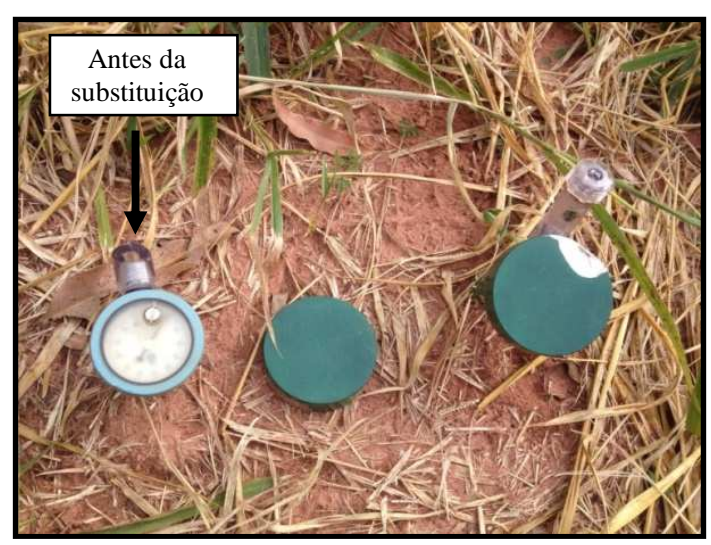

(a)

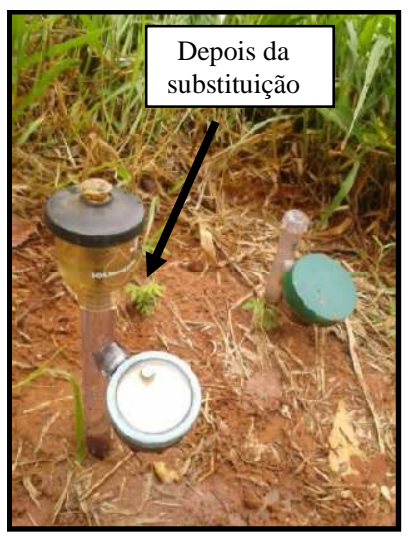

(b)

Figura 4.37 - Conjunto de tensiômetros localizados no pé da seção geológico-geotécnica com inclinação $37^{\circ}$ (a) antes da substituição - tubo do tensiômetro danificado e (b) depois da substituição - tensiômetro substituído. 
As medidas das precipitações pluviométricas foram feitas por um morador do local onde foi instalado o pluviômetro. Este morador foi treinado para coletar e medir diariamente o volume de água armazenado no pluviômetro.

Como mencionado anteriormente, os dados de precipitação pluviométrica medido pelo pluviômetro Ville de Paris foram avaliados e comparados com os dados de outras duas Estações Convencionais localizada nas proximidades da área piloto. Essas Estações Convencionais pertencem à Agência Nacional de Águas (ANA) e ao Instituto Nacional de Meteorologia (INMET).

\subsection{ETAPA 10 - INTEGRAÇÃO E ANÁLISE DOS RESULTADOS}

A avaliação dos mecanismos de ruptura foi feita tanto para a condição saturada como para a condição não saturada do talude. Esta etapa de integração e análise dos resultados dependeu da configuração do talude e se baseou nas seções geológico-geotécnicas de detalhe, nos parâmetros determinados a partir dos ensaios de laboratório, de campo e pelos dados resultantes do monitoramento fornecido pela instrumentação de campo.

A análise da estabilidade do talude foi realizada utilizando os métodos determinísticos de Bishop Simplificado (1955) e Janbu (1954) a partir do software computacional Slope/W do pacote GeoStudio 2012 disponível no Departamento de Geotecnia da ESSC/USP. Neste programa foram simuladas diferentes condições monitoradas na área piloto, principalmente, no que se refere às condições de saturação/tensão de sucção e parâmetros de resistência avaliando seus reflexos nos valores do fator de segurança e nas superfícies de ruptura críticas resultantes dessas análises.

Mais do que analisar valores absolutos de fatores de segurança, planejou-se investigar a variação destes fatores de segurança frente às diferentes condições geotécnicas simuladas, buscando-se incorporar os conceitos de variabilidade e de confiabilidade nas análises de estabilidade determinísticas realizadas.

Com base nestas modelagens e análise da infiltração no solo da área piloto caracterizada pelas investigações de campo e de laboratório, pretendeu-se estabelecer valores mínimos de intensidade pluviométrica para propiciarem a formação e evolução das "frentes de saturação" até as profundidades críticas para deflagração dos deslizamentos de solo identificados na área piloto.

Ainda tentou-se estabelecer os tempos de retorno e as probabilidades pluviométricas considerando-se o regime pluviométrico da área estudada. 


\subsubsection{Estabilidade de talude em solo não saturado}

Taludes naturais e artificiais situados em áreas de clima tropical e sub-tropical tendem a permanecer estáveis por décadas. Porém, dependendo da variação do índice pluviométrico ao longo das estações chuvosas de cada ano, estes taludes poderão se tornar instáveis e em consequência, romperem totalmente ou parcialmente.

Os métodos tradicionais de análise de estabilidade de talude usualmente consideram a hipótese que o solo encontra-se na condição saturada, sendo que a pressão neutra positiva varia em função da profundidade do nível d’água. Por outro lado, a análise da estabilidade de talude em solo não saturado é bem mais complexa, envolve o conhecimento de características da área do talude (climática, geométricas, física, dentre outras) e o estudo de diversos parâmetros mecânicos e hidráulicos do solo. Dessa maneira, destaca-se a importância da realização de estudos para avaliar a influência do processo de infiltração da água da chuva e do fluxo da água na distribuição da pressão neutra negativa no solo não saturado, permitindo posteriormente analisar com maior precisão a estabilidade do talude.

Por esse motivo, as análises desta pesquisa foram feitas a partir de duas etapas de modelagem numérica no software computacional GeoStudio 2012 com o intuito de avaliar o fluxo de água e analisar a estabilidade do talude. Inicialmente, na primeira etapa foi avaliado como ocorre o processo de infiltração da água da chuva no interior do talude e a influência que esse processo gera na distribuição da pressão neutra negativa e no avanço da frente de umedecimento. Após isso, na segunda etapa foi analisada a estabilidade do talude através de métodos disponibilizados pelo software e verificada a variação do fator de segurança em função dos diferentes índices pluviométricos através do acoplamento hidro-mecânico das condições de pressão neutra quantificada pela infiltração da água da chuva e da resistência ao cisalhamento do solo não saturado.

Os próximos sub-itens descrevem detalhadamente o passo a passo das análises realizadas ao longo das etapas bem como as ferramentas computacionais, as condições de contorno e os parâmetros utilizados em cada uma delas.

\subsubsection{Análises paramétricas da infiltração da água no solo}

As análises paramétricas da infiltração da água no solo não saturado foram feitas através da modelagem numérica do fluxo da água no solo com o uso do pacote $S e e p / W$. As ferramentas numéricas disponíveis no Seep/W permitem analisar o fluxo de água no solo não saturado tanto para o regime estacionário (também conhecido como regime permanente) quanto para o regime transiente, utilizando o método dos elementos finitos. 
Embora ao longo desse trabalho tenham sido desenvolvidas inúmeras atividades de campo e de laboratório para obtenção de dados e parâmetros experimentais, na realização das análises paramétricas de infiltração foram necessárias algumas simplificações na modelagem numérica do problema real em questão, tais como a desconsideração da taxa de evapotranspiração, dos efeitos de histerese (relacionadas à trajetória de secagem e de umedecimento da curva de retenção da água no solo) e das oscilações na temperatura do solo e da água durante as análises numéricas.

Ressalta-se ainda que, nas modelagens numéricas de fluxo de água ficou estabelecida a condição de não ocorrer o desenvolvimento de pressão neutra positiva na superfície do talude caso o valor da precipitação pluviométrica superasse ao da condutividade hidráulica saturada do solo, ou seja, os valores de pressão neutra sempre foram iguais ou menores que 0 $\mathrm{kPa}$. Além disso, também foi impedido o empoçamento da água da chuva na superfície do talude, isto é, a água que não for infiltrada será instantaneamente escoada superficialmente.

\subsubsection{Geometria das seções geológico-geotécnicas}

A geometria das seções geológico-geotécnicas do talude de referência utilizadas nas análises paramétricas de infiltração da água da chuva e análise de estabilidade foram estabelecidas de acordo com o levantamento topográfico da área piloto (item 4.5) e com a localização dos tensiômetros na crista, na face e no pé do talude (item 4.9.1).

Portanto, nesta pesquisa foram modeladas seções com diferentes características geométricas, tais como inclinação de $27,0^{\circ}$ e $37,0^{\circ}$; altura de $6,2 \mathrm{~m}$ e $6,1 \mathrm{~m}$ e comprimento de $18,70 \mathrm{~m}$ e $20,50 \mathrm{~m}$ estando cada seção limitada em sua porção inferior por uma linha horizontal situada 5 metros abaixo do pé do talude devida à máxima profundidade investigada na etapa de sondagem a trado manual (item 4.6). Nestas seções também foram locados 18 pontos de referência (A1 ao A9 para talude com inclinação de $27^{\circ}$ e B1 ao B9 para talude com inclinação de $37^{\circ}$ ) para ilustrar os resultados das variações de pressão neutra no interior do talude. Esses pontos foram escolhidos de acordo com a profundidade de instalação dos tensiômetros para cada seção do talude, os quais foram instalados entre as profundidades de $0,32 \mathrm{~m}$ a $1,46 \mathrm{~m}$.

A Figura 4.38a,b ilustra as duas seções geológico-geotécnicas do talude e a Tabela 4.5 apresenta as coordenadas dos pontos de referência (distância e elevação) referentes a cada seção. 


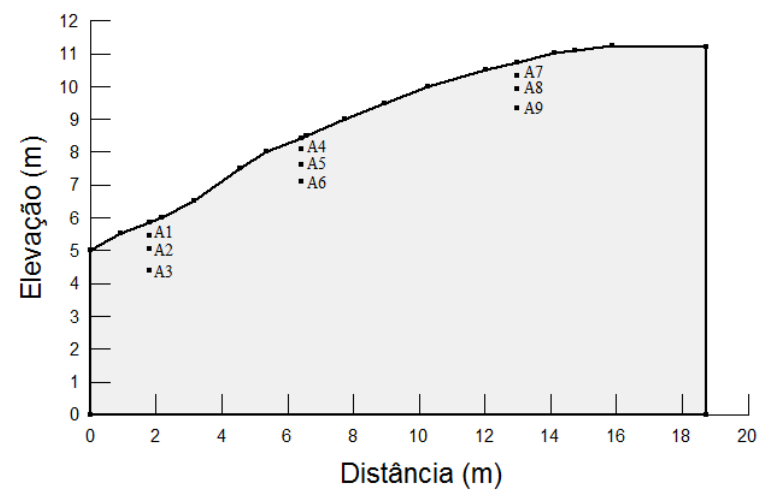

(a)

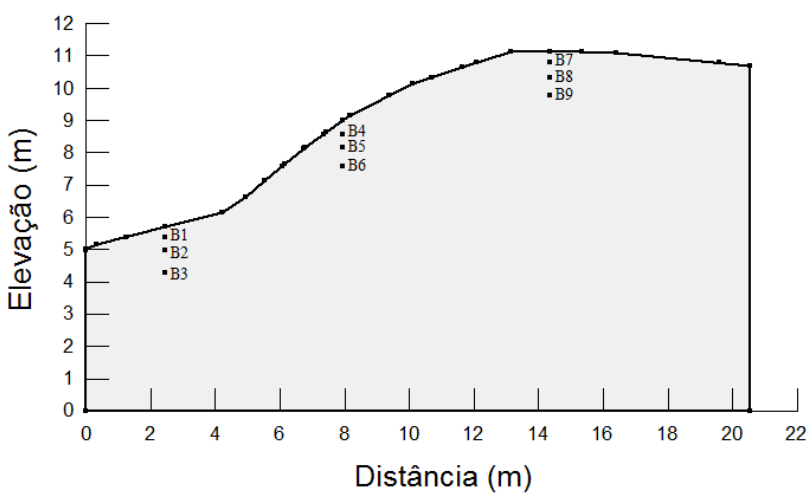

(b)

Figura 4.38 - Seção topográfica com inclinação de (a) $27^{\circ}$ e (b) $37^{\circ}$.

Tabela 4.5 - Pontos de referência dos tensiômetros para as duas seções geológico-geotécnicas.

\begin{tabular}{|c|c|c|c|c|}
\hline Seção & Local & Tensiômetro & Distância (m) & Elevação (m) \\
\hline \multirow{9}{*}{$\mathrm{i} 27^{\circ}$} & \multirow{3}{*}{ Pé } & A1 & 1,79 & 5,44 \\
\hline & & $\mathrm{A} 2$ & 1,79 & 5,03 \\
\hline & & A3 & 1,79 & 4,38 \\
\hline & \multirow{3}{*}{ Face } & A4 & 6,40 & 8,07 \\
\hline & & A5 & 6,40 & 7,61 \\
\hline & & A6 & 6,40 & 7,09 \\
\hline & \multirow{3}{*}{ Crista } & A7 & 12,97 & 10,33 \\
\hline & & A8 & 12,97 & 9,94 \\
\hline & & A9 & 12,97 & 9,33 \\
\hline \multirow{9}{*}{ i37음 } & \multirow{3}{*}{ Pé } & B1 & 2,46 & 5,37 \\
\hline & & B2 & 2,46 & 4,95 \\
\hline & & B3 & 2,46 & 4,26 \\
\hline & \multirow{3}{*}{ Face } & B4 & 7,93 & 8,58 \\
\hline & & B5 & 7,93 & 8,15 \\
\hline & & $\mathrm{B} 6$ & 7,93 & 7,57 \\
\hline & \multirow{3}{*}{ Crista } & B7 & 14,35 & 10,79 \\
\hline & & B8 & 14,35 & 10,34 \\
\hline & & B9 & 14,35 & 9,78 \\
\hline
\end{tabular}

Vale ressaltar que nas análises paramétricas de infiltração de água realizadas no Seep/ $W$, todas as seções foram configuradas como sendo bidimensionais e idênticas às seções utilizadas no Slope/W, permitindo o acoplamento hidro-mecânico e a integração dos 
resultados. Após a configuração da geometria de cada seção foram atribuídas informações quanto a distribuição da malha de elementos finitos, os parâmetros hidráulicos do solo e as condições de contorno impostas em cada seção, como descrito nos próximos sub-itens.

\subsubsection{Discretização da malha de elementos finitos}

A discretização da malha de elementos finitos foi definida a partir da verificação dos valores de pressão neutra resultantes das modelagens numéricas para fluxo permanente e transiente. Essas verificações foram feitas através da escolha do tipo dos elementos (triangulares ou quadriláteros) e suas dimensões, as quais apontaram que a distribuição da malha de elementos finitos e as condições de contorno influenciavam nos valores resultantes de pressão neutra.

Algumas distribuições de malha foram experimentadas até que fosse definida a melhor malha para representar as duas seções do talude. Devido a geometria da superfície do talude ser bastante irregular, na discretização dessa malha foi necessário empregar uma combinação entre elementos triangulares (três nós) e quadriláteros (quatro nós) nas dimensões de 0,50 m, $0,20 \mathrm{~m}$ e $0,15 \mathrm{~m}$. Dentre as três malhas escolhidas e verificadas, aquela que melhor se ajustou aos resultados de pressão neutra e consumiu menor tempo no processo iterativo foi a malha composta por elementos com dimensões de $0,20 \mathrm{~m}$. Por esse motivo, nesta pesquisa foi utilizada uma malha mista (elementos triangulares e quadriláteros) com dimensões de $0,20 \mathrm{~m}$ para ambas seções, como ilustra a Figura 4.39 e Figura 4.40 para as duas seções geológicogeotécnicas.

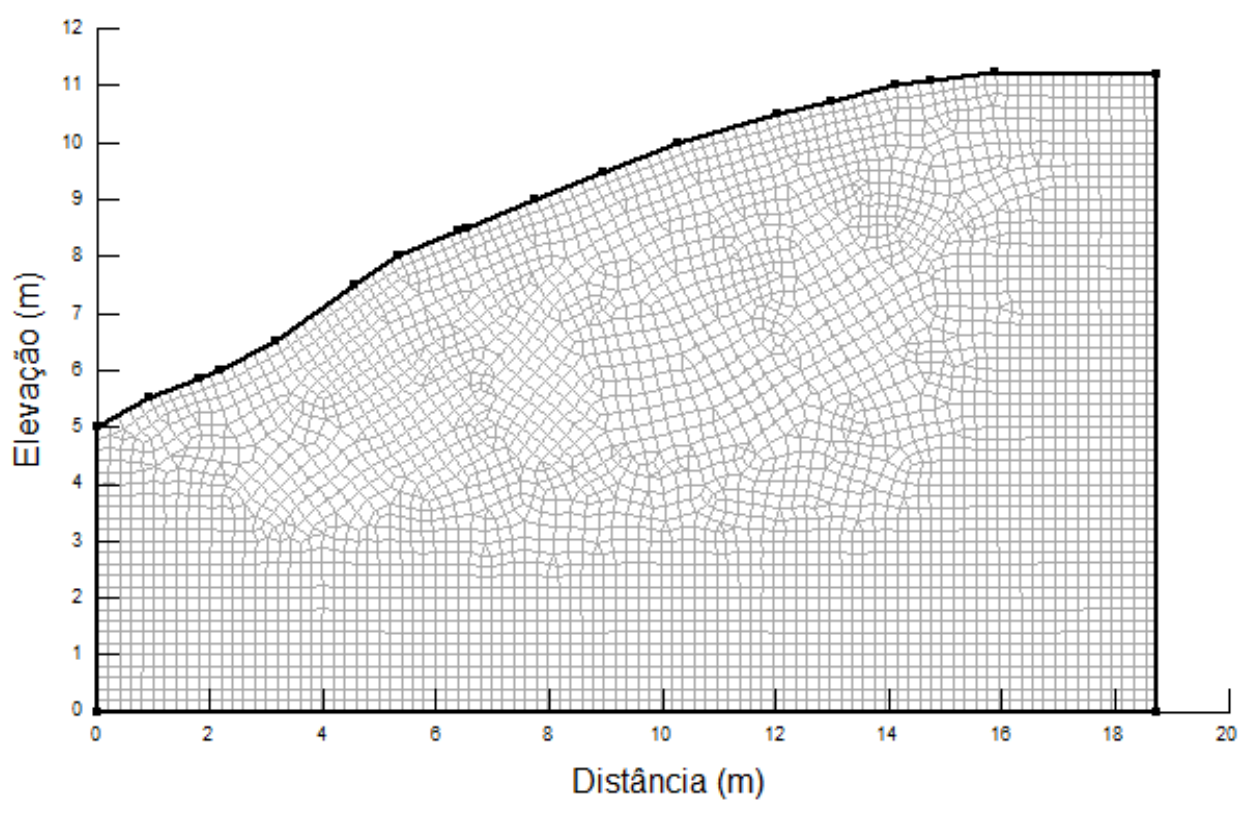

Figura 4.39 - Malha de elementos finitos para seção topográfica com inclinação de $27^{\circ}$. 


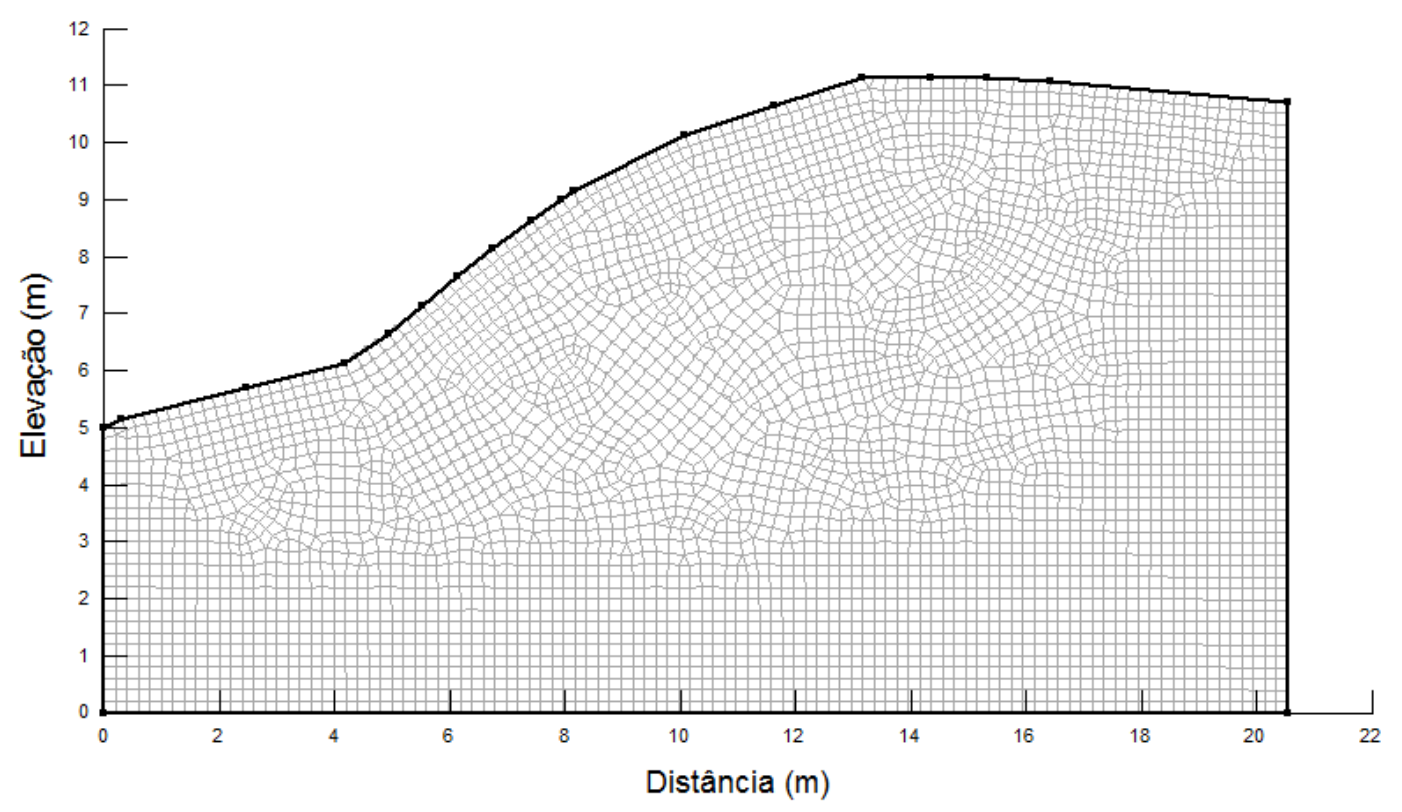

Figura 4.40 - Malha de elementos finitos para seção topográfica com inclinação de $37^{\circ}$.

\subsubsection{Parâmetros hidráulicos do solo}

Os parâmetros hidráulicos do solo empregados nas modelagens numéricas no Seep/W correspondem à curva de retenção da água do solo e à função condutividade hidráulica. Conforme observado nas investigações da subsuperfície em campo (item 4.6) e nos resultados dos ensaios de análise granulométrica conjunta (item 4.8.2) e permeabilidade (item 4.8.8) em laboratório, as seções do talude de referência foram consideradas compostas por um único tipo de solo, o qual é homogêneo e isotrópico.

A curva de retenção da água do solo utilizada em todas as modelagens numéricas de infiltração de água corresponde ao ajuste obtido a partir da equação de Van Genuchten (1980) para a trajetória de secagem, sendo desconsiderado o efeito de histerese. De acordo com Tsaparas et al. (2002), não é possível considerar o efeito de histerese nas análises com o Seep/W, visto que o programa não permite utilizar duas curvas de retenção da água do solo (trajetórias de secagem e umedecimento), tornando-se uma limitação do software computacional.

Assim como a curva de retenção, a função condutividade hidráulica empregada nas análises paramétricas equivale aos valores de condutividade hidráulica não saturada em função da sucção matricial obtidos a partir do ajuste dos resultados do permeâmetro Guelph utilizando a equação de Gardner (1958). Os valores de condutividade hidráulica saturada resultantes dos ensaios com o permeâmetro Guelph e de permeabilidade em laboratório foram comparados entre si, de maneira que fosse escolhido um valor próximo aos dois ensaios. 


\subsubsection{Condições de contorno - análises de fluxo}

As condições de contorno utilizadas nas análises de fluxo foram feitas para a obtenção do perfil inicial de pressão neutra (fluxo permanente) e do perfil de pressão neutra durante um dado evento pluviométrico (fluxo transiente). Para isso, foram utilizadas ferramentas computacionais contidas no Seep/W para configurar essas condições de fluxo.

$\mathrm{Na}$ análise de fluxo permanente foi utilizada uma condição de contorno, o qual é denominado de gradiente unitário (unit gradient). Essa condição foi imposta ao longo de toda a base da seção do talude devido ao nível d’água não ter sido encontrado nas investigações/monitoramento de campo e do Manual do Usuário (GEOSLOPE INTERNATIONAL LTD, 2015a) recomendar o uso dessa condição de contorno para representar situações em que o nível d'água encontra-se profundo.

Nesta pesquisa optou-se em obter o perfil inicial de pressão neutra em função dos valores medidos nos tensiômetros. Para isso, foram experimentadas e analisadas diferentes condições de contorno para o fluxo permanente em três modelos (denominados de 1, 2 e 3 ) utilizando a geometria e os dados de tensiometria da seção geológico-geotécnica com inclinação de $37^{\circ}$. Abaixo encontram-se descritos os critérios utilizados em cada modelo.

- Modelo 1: traçado de uma linha horizontal à superfície do pé do talude em função da profundidade de instalação do tensiômetro do pé da seção (tensiômetro identificado como B3). Toda a linha horizontal representará o valor da pressão neutra negativa medida naquele tensiômetro (Figura 4.41). Observa-se que esta condição de contorno foi empregada em alguns trabalhos científicos (CHO; LEE, 2001; SANTOS, 2004; TSAPARAS et al., 2002).

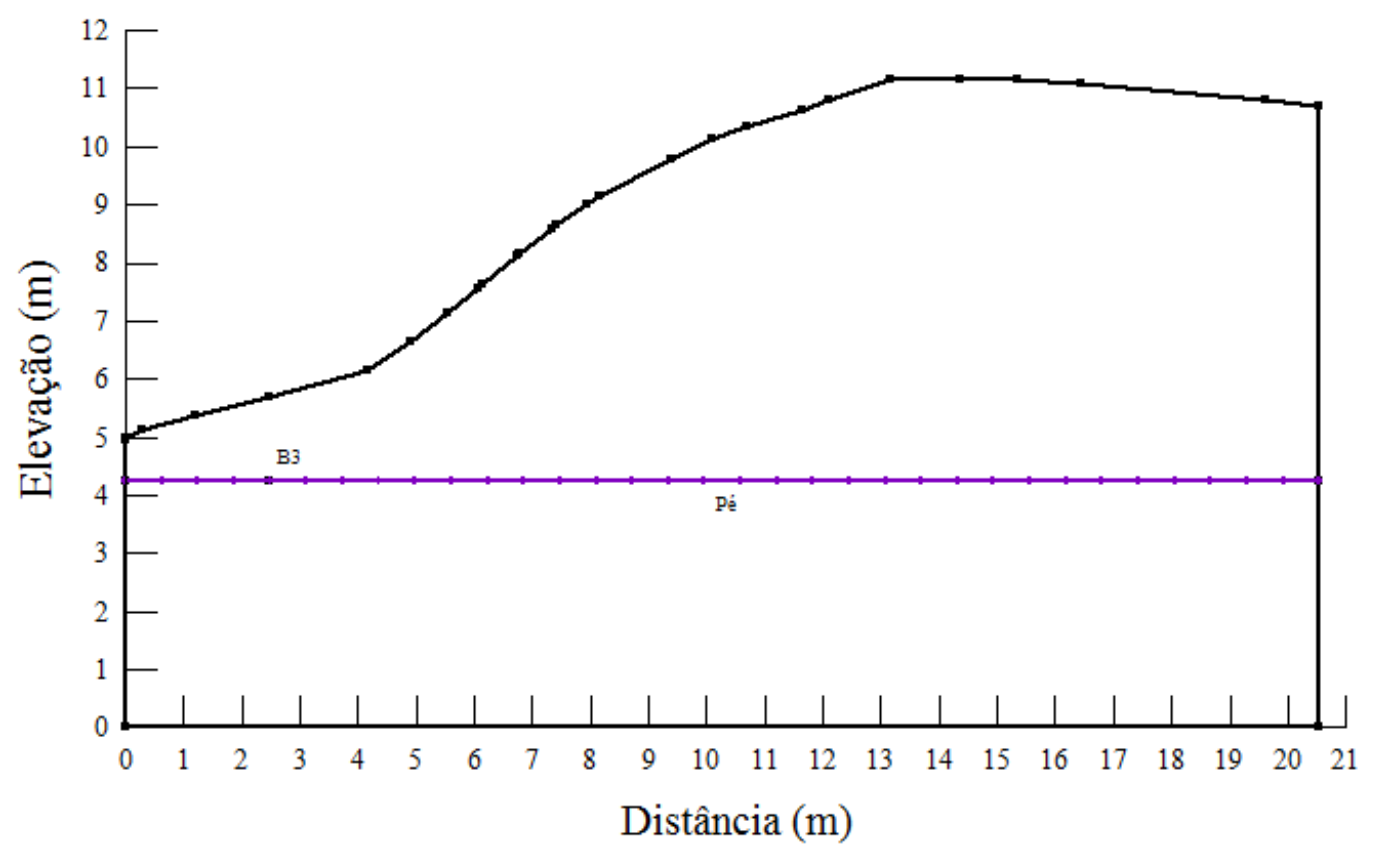

Figura 4.41 - Condição de contorno do fluxo permanente utilizada no Modelo 1. 
- Modelo 2: traçado de uma linha horizontal à superfície do pé do talude em função da profundidade de instalação do tensiômetro do pé da seção (tensiômetro identificado como B3). A linha horizontal estará segmentada em três trechos, sendo que cada trecho corresponderá aos valores medidos de pressão neutra negativa no tensiômetro com comprimento de 1,50 m do pé, na face e na crista desta seção. Como existe uma diferença de cota entre a linha horizontal e os tensiômetros da face e da crista, o valor de pressão neutra foi corrigido sendo assumido que o solo estava mais úmido na superfície e mais seco no interior do talude (Figura 4.42).

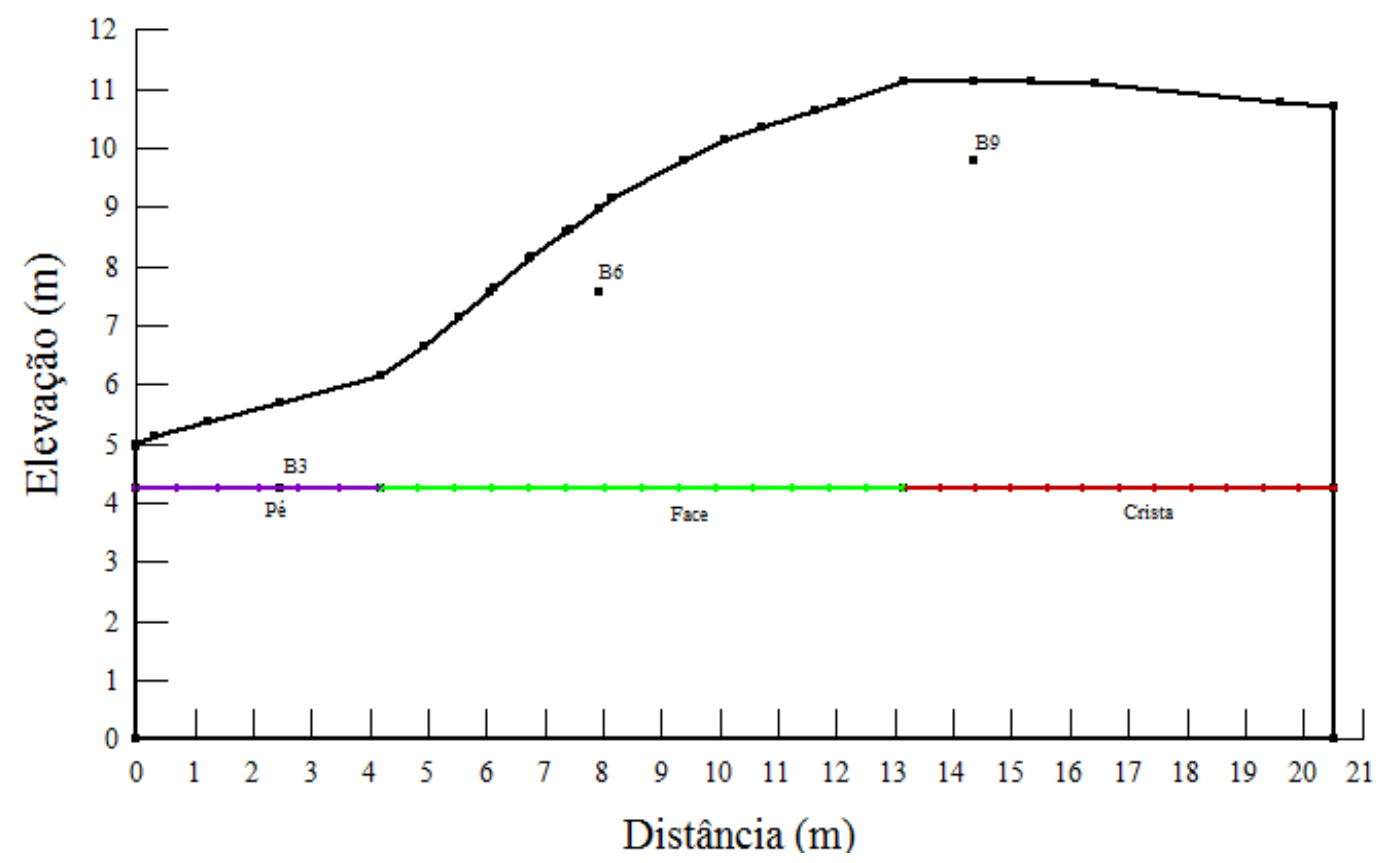

Figura 4.42 - Condição de contorno do fluxo permanente utilizada no Modelo 2.

- Modelo 3: traçado de uma linha horizontal no pé, na face e na crista do talude em função da profundidade de instalação dos tensiômetros com comprimento de $1,50 \mathrm{~m}$ (tensiômetros identificados como B3, B6 e B9). Cada linha horizontal terá um único trecho, sendo que o término de um trecho corresponderá ao início do outro trecho. Por exemplo, o término da linha horizontal da crista corresponderá ao início da linha horizontal da face. Cada linha representará o valor de pressão neutra negativa medida no tensiômetro daquela porção (Figura 4.43). 


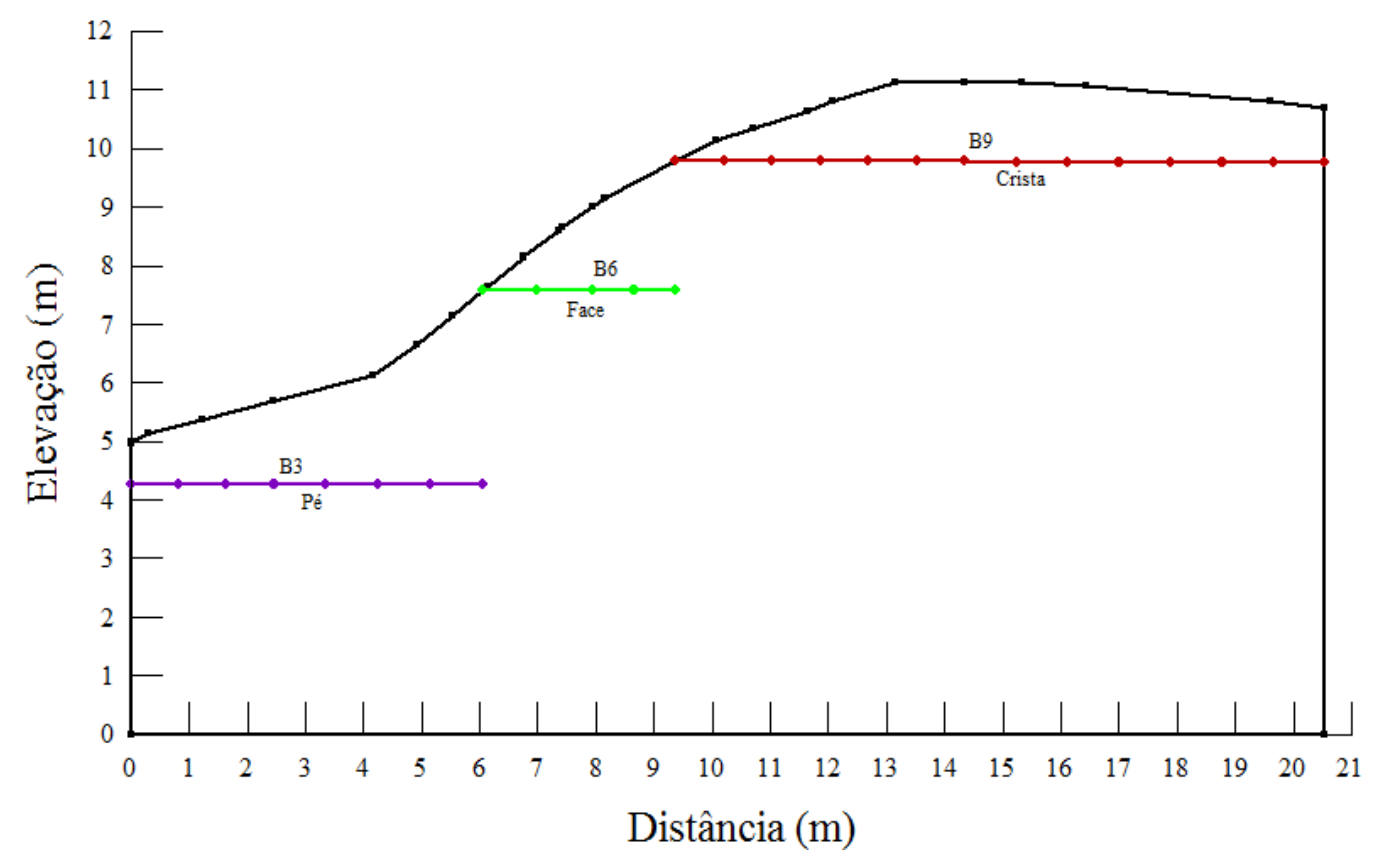

Figura 4.43 - Condição de contorno do fluxo permanente utilizada no Modelo 3.

$\mathrm{Na}$ análise de fluxo transiente foi utilizada uma condição de contorno denominada de unidade de fluxo (unit flux), sendo esta aplicada ao longo de toda a superfície da seção do talude a fim de simular a precipitação pluviométrica diária medida no pluviômetro Ville de Paris. Os valores de fluxo transiente foram aplicados em função das medidas de precipitação e dos eventos pluviométricos escolhidos tendo o intuito de verificar como ocorrerá a distribuição de pressão neutra ao longo do perfil da seção e comparar com os valores medidos nos tensiômetros.

\subsubsection{Análises de estabilidade de talude}

As análises de estabilidade de talude foram feitas com o uso do pacote Slope/W utilizando os métodos de Bishop Simplificado (1955) e Janbu (1954). As ferramentas numéricas disponíveis no Slope/ $W$ permitem analisar a estabilidade do talude para as condições de solo saturado e solo não saturado. Como mencionado anteriormente, as geometrias das seções geológico-geotécnicas utilizadas no Slope/W foram iguais as do Seep/W, sendo que as análises de estabilidade foram realizadas a partir do acoplamento hidromecânico.

Além disso, algumas seções foram modeladas com diferentes alturas sendo mantida constante a inclinação da seção $\left(27^{\circ}\right.$ e $\left.37^{\circ}\right)$, como mostra a Figura 4.44 e outras seções com diferentes inclinações sendo mantida constante a altura da seção $(5,4 \mathrm{~m}$ e 5,0 m), como mostra Figura 4.45 . 


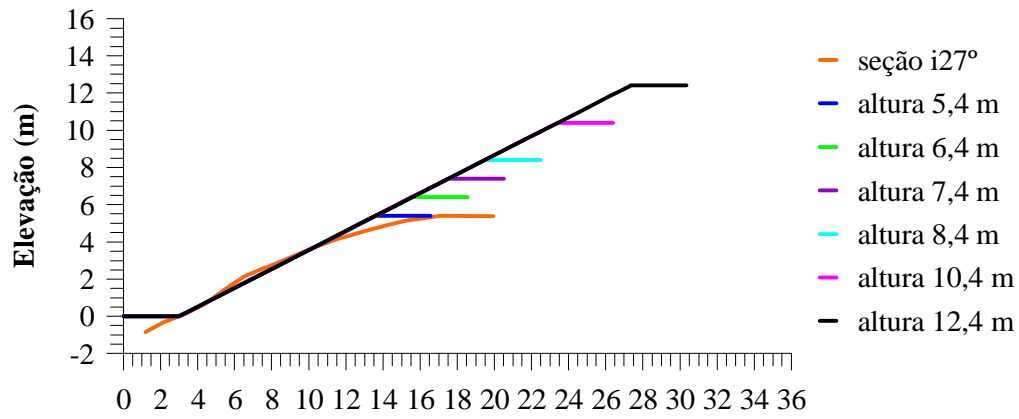

Distância (m)

(a)

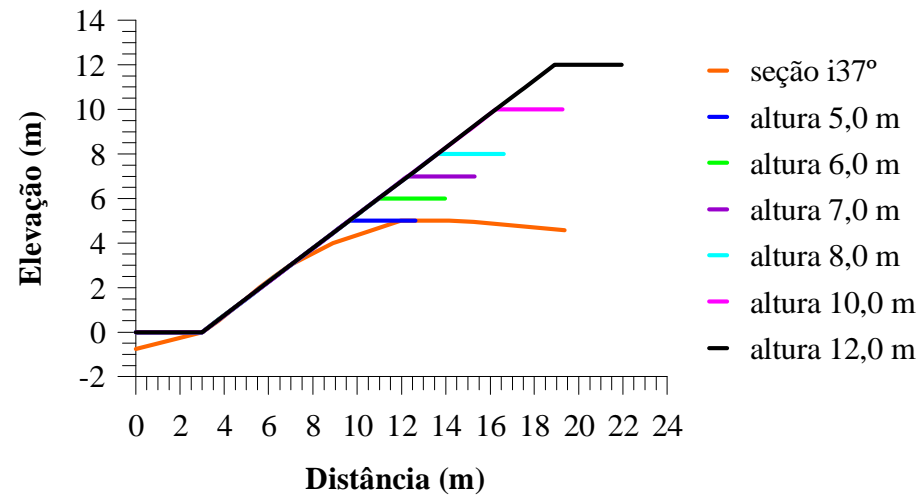

(b)

Figura 4.44 - Modelagem numérica de seções com diferentes alturas baseada na (a) seção i27º (b) seção i $37^{\circ}$.

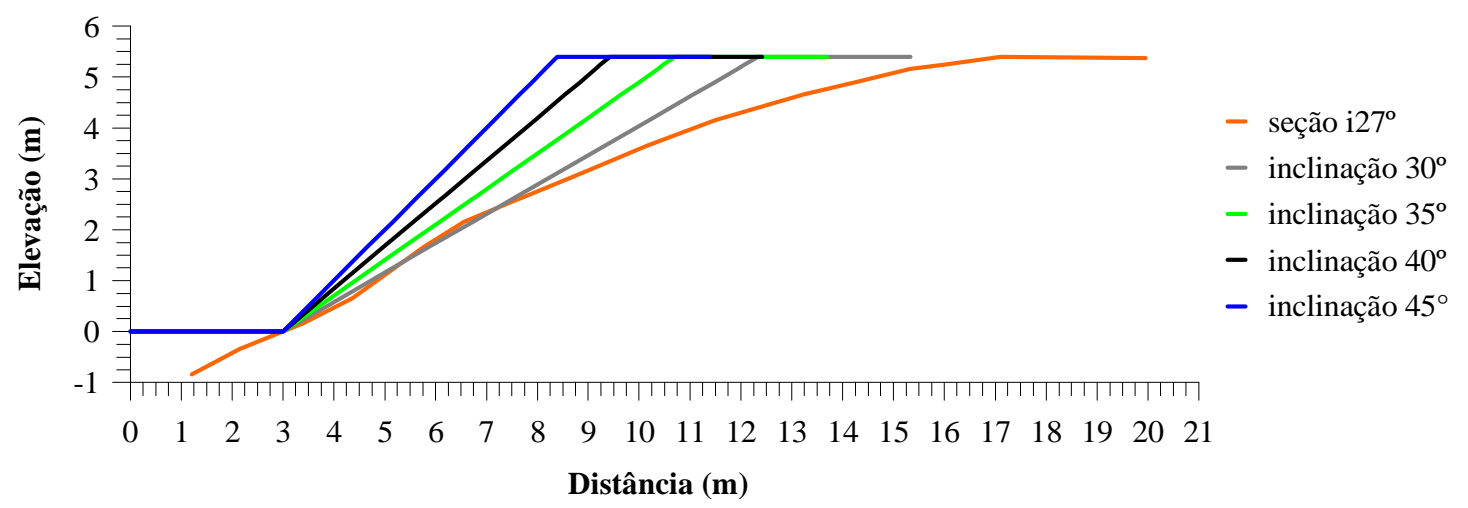

(a)

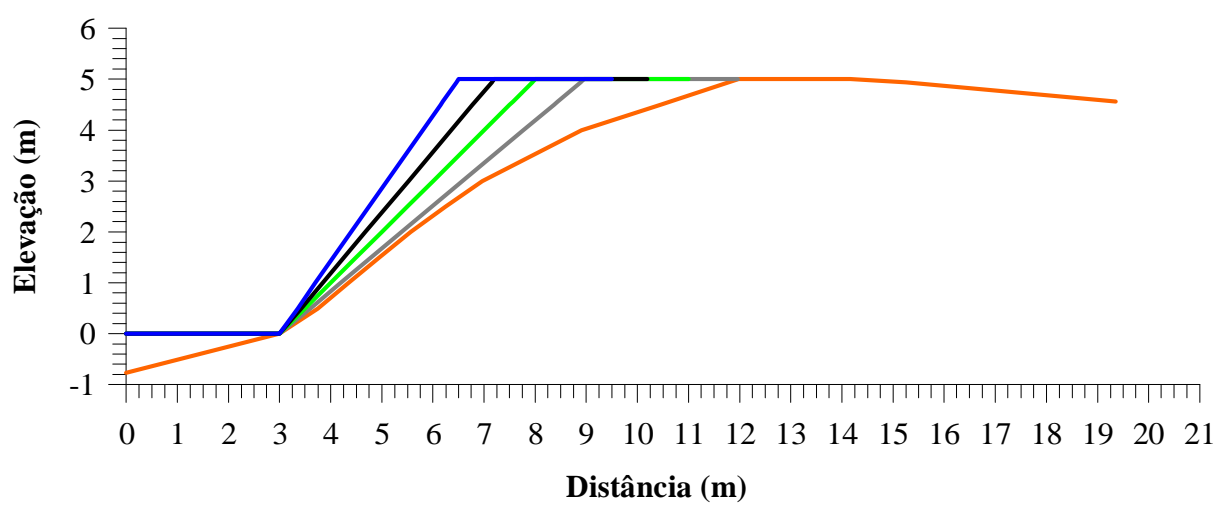

- seção i37

- inclinação $40^{\circ}$

- inclinação $45^{\circ}$

- inclinação $50^{\circ}$

- inclinação $55^{\circ}$

(b)

Figura 4.45 - Modelagem numérica de seções com diferentes inclinações baseada na (a) seção i27º (b) seção i3 $37^{\circ}$. 
A variação da inclinação e da altura da seção do talude tem como finalidade determinar o fator de segurança além de analisar a influência da geometria e dos parâmetros de resistência na estabilidade do talude.

\subsubsection{Parâmetros mecânicos do solo}

Os parâmetros mecânicos do solo empregados nas modelagens numéricas no Slope/W correspondem ao peso específico, à coesão efetiva, ao ângulo de atrito efetivo e ao ângulo de atrito do solo referente à variação da sucção matricial.

Nesta pesquisa foram utilizados os dados de ajustes das envoltórias de resistência referentes ao ensaio CD com solo saturado, ensaio CD com solo não saturado e ensaio para determinação da resistência do solo com teor de umidade natural. Além disso, também foram determinados os índices físicos dos corpos de prova para escolha do valor do peso específico do solo adotado nas análises numéricas. No caso particular do peso específico do solo, este foi considerado constante em todas as análises de estabilidade, isto é, o peso específico devido ao acréscimo ou decréscimo de água no solo não foi computado.

Além disso, a configuração dos parâmetros mecânicos do solo para todas as análises numéricas foram feitas baseadas no critério de ruptura de Mohr-Coulomb, tanto para condição saturada como para condição não saturada.

\subsubsection{Definição da superfície de ruptura}

De acordo com o manual do usuário Geoslope International Ltd.(2015b), existem muitas maneiras diferentes para estabelecimento da forma e da posição da tentativa da superfície de ruptura.

A delimitação da superfície de ruptura pode ser estabelecida a partir de diferentes configurações, tais como: definição do grid e do raio da superfície de ruptura, definição da linha de entrada e de saída pela qual passará a superfície de ruptura, especificação de dois blocos (grid) ou ainda, a especificação de uma série de pontos. Nesta pesquisa, optou-se em delimitar a superfície de ruptura a partir da definição do grid e do raio, ou seja, configurar o posicionamento dos possíveis centros de rotação a partir da delimitação da malha denominada de grid assim como configurar as linhas em que o raio da superfície de ruptura irá tangenciar a partir da delimitação da malha denominada de raio.

A Figura 4.46 ilustra a delimitação da superfície de ruptura utilizando a configuração do grid e do raio, na qual se observa que o raio foi traçado paralelo à face da seção do talude para uma profundidade 3,0 m. Essa profundidade foi escolhida devido ao tipo de ruptura 
ocorrido em outros taludes na mesma região da área piloto (ruptura rasa), os quais apresentam mesma formação geológica. Vale ressaltar que a delimitação do grid e do raio foi empregado em todas as análises de estabilidade de talude.

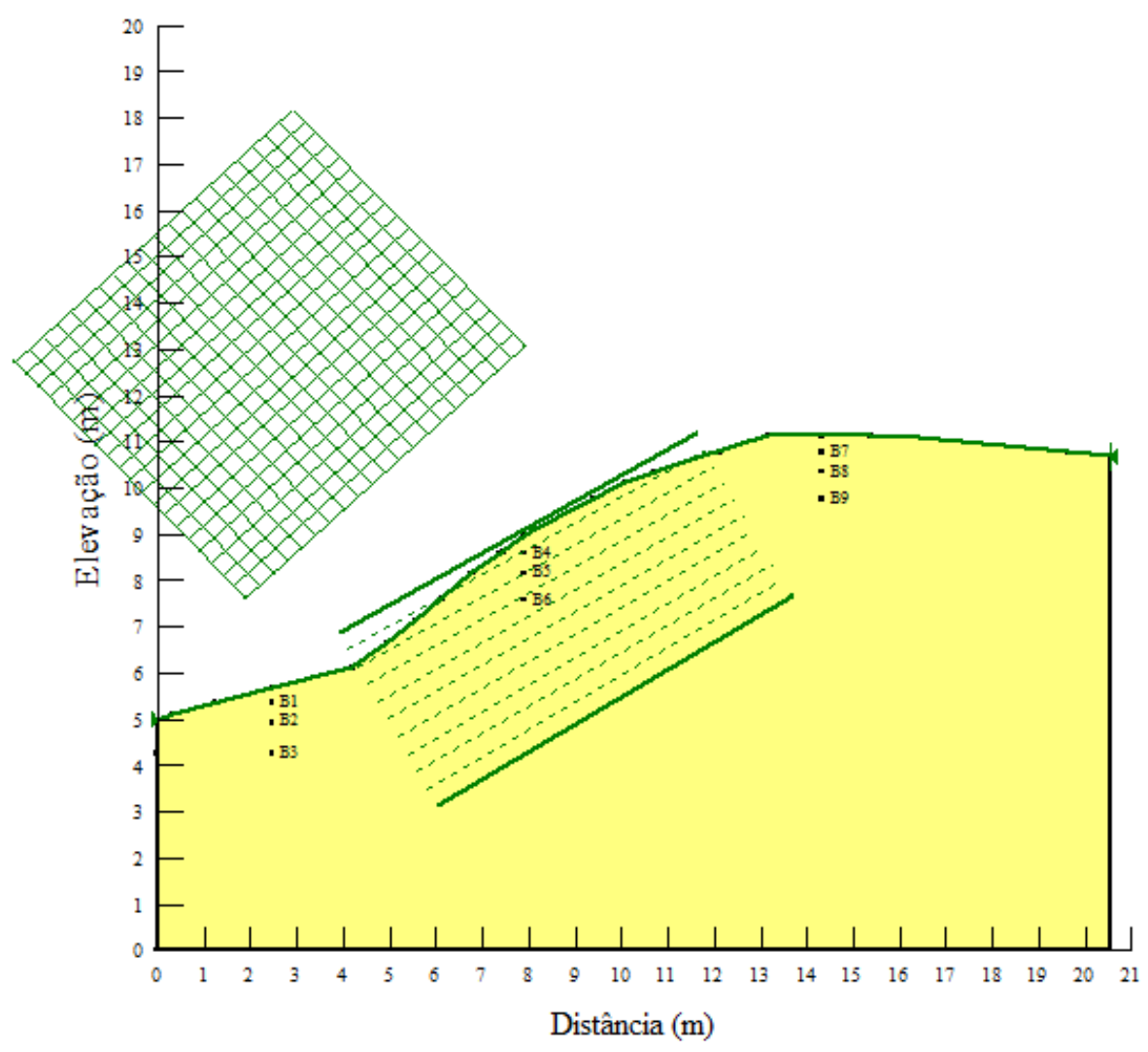

Figura 4.46 - Delimitação da superfície de ruptura a partir do posicionamento dos possíveis centros de rotação e das linhas que estabelecem o raio da superfície de ruptura - seção geológico-geotécnica com inclinação de $37^{\circ}$.

O Apêndice A apresenta um resumo dos procedimentos utilizados no software computacional GeoStudio versão 2012 para as análises de infiltração da água da chuva e de estabilidade de talude.

\subsection{ETAPA 11 - ELABORAÇÃO DA TESE}

A elaboração da tese foi feita de acordo com o desenvolvimento desse trabalho. Nesta etapa do trabalho foram elaboradas as conclusões do presente estudo, sendo também verificadas as hipóteses iniciais de trabalho, as quais foram baseadas na integração dos dados e análise dos resultados realizada no item 4.11. 


\section{5. ÁREA PILOTO}

Este capítulo descreve as características gerais da área piloto visando uma melhor identificação acerca da sua localização, das características gerais, aspectos climáticos, aspectos hidrológicos e aspectos hidrogeológicos.

\subsection{LOCALIZAÇÃO}

A área piloto localiza-se na porção central do Estado de São Paulo, no município de Ribeirão Bonito. O município abrange uma área de 471,5 km² com altitude média de 585,2 m acima do nível do mar e situa-se nas coordenadas geográficas $48^{\circ} 10^{\prime} 34^{\prime \prime}$ de Longitude Oeste e $22^{\circ} 04^{\prime} 00 "$ de Latitude Sul (Figura 5.1).

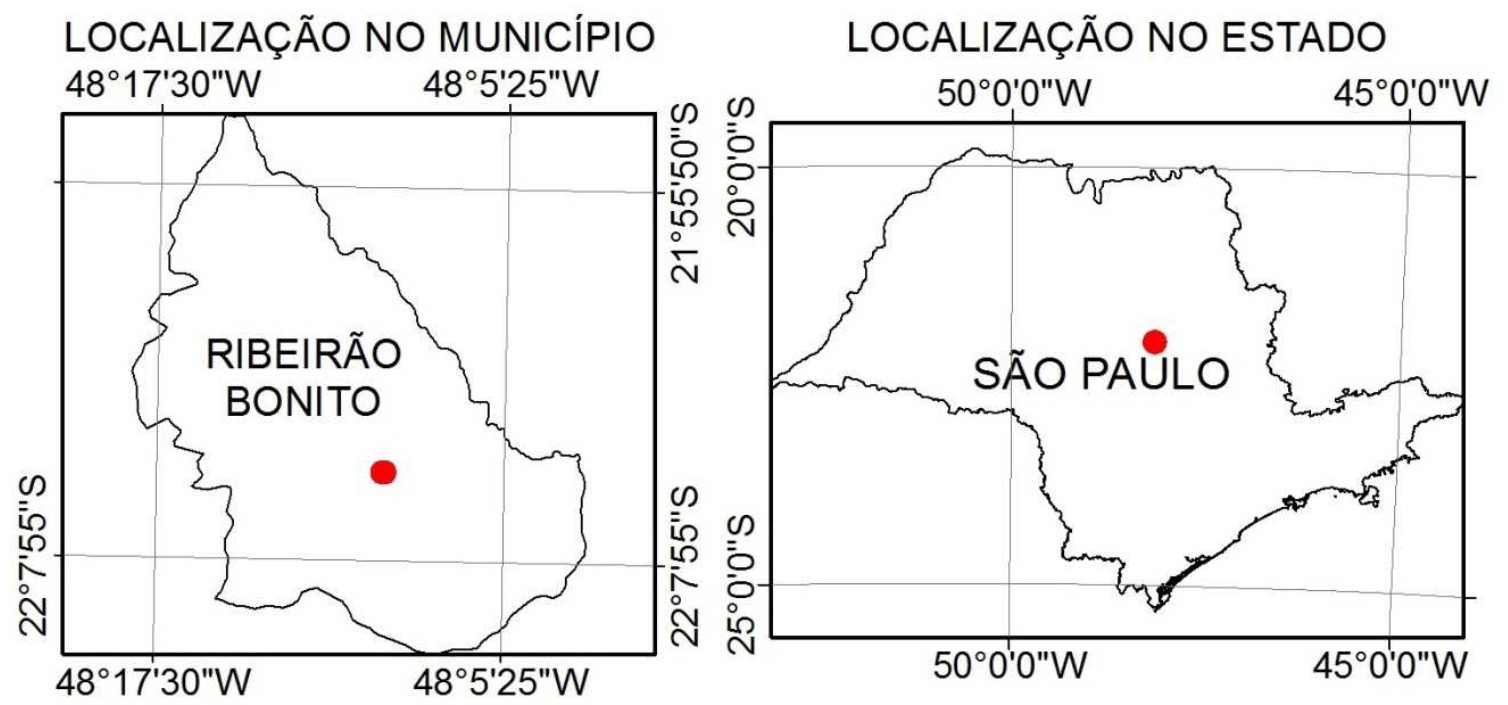

Figura 5.1 - Localização do município de Ribeirão Bonito. 
Este município limita-se ao Norte com o município de Araraquara (45,3 km); ao Sul com o município de Brotas (35,4 km); a Oeste com os municípios de Dourado (19,8 km), Boa Esperança do Sul (39,9 km) e Trabiju (16,6 km); e a Leste com os municípios de São Carlos $(45,9 \mathrm{~km})$ e Ibaté $(63,1 \mathrm{~km})$.

A área piloto abrange um setor de taludes de corte, situado na faixa de domínio da Rodovia Luis Augusto de Oliveira (SP-215) no km 179+300 LE e dista 2,5 km da Igreja Matriz de Ribeirão Bonito (Figura 5.2). A carta topográfica da área piloto corresponde à folha SF- 2 - Z - B - III - 2, Ribeirão Bonito, escala 1:50000, projeção Universal Transversa de Mercator (UTM), Instituto Brasileiro de Geografia e Estatística (IBGE, 1971).

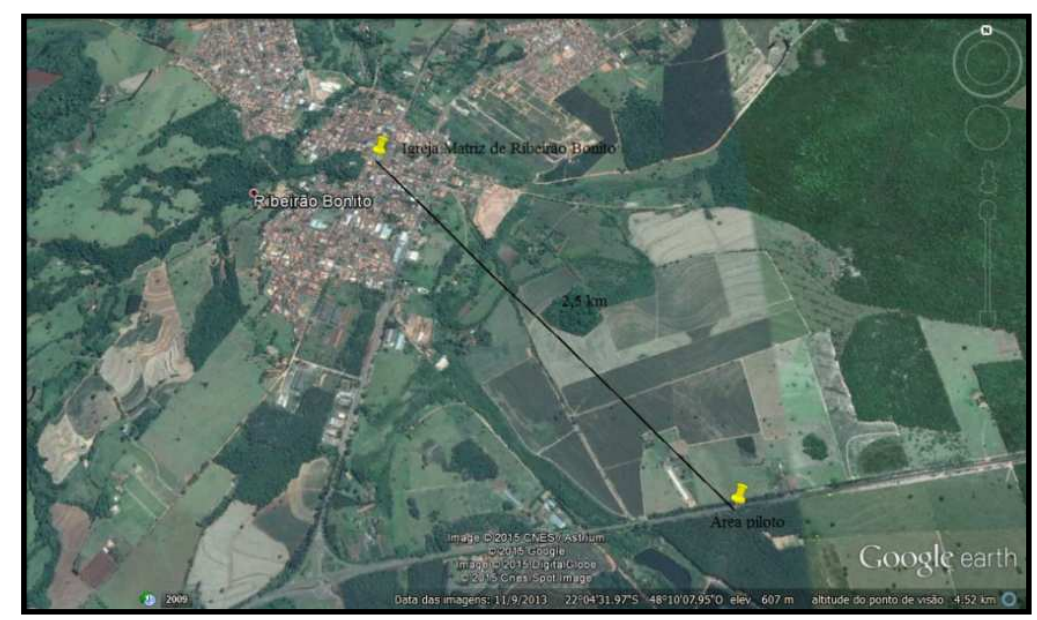

Figura 5.2 - Distância entre a área piloto e a cidade de Ribeirão Bonito.

Fonte: Google Earth (2015).

\subsection{CARACTERÍSTICAS GERAIS DA ÁREA PILOTO}

A área piloto corresponde a um talude de corte, o qual apresenta ao longo de toda sua extensão cobertura vegetal de gramíneas, presença de poucos arbustos, inexistência de nível d’água na superfície e nenhum indício de movimentação ou cicatrizes de deslizamentos. Em alguns trechos da crista é possível observar a presença de pequenas feições erosivas.

$\mathrm{Na}$ área piloto ocorrem solos residuais dos arenitos eólicos da Formação Botucatu (Grupo São Bento, Bacia Sedimentar do Paraná) de idade jurrásico-cretácea. Eles apresentam textura arenosa fina a média com baixa percentagem de finos, de coloração vermelha, rósea ou amarelo-clara.

A área piloto contempla um talude que possui altura média de 7,0 metros e extensão de aproximadamente 250,0 metros, apresentando ao longo de sua extensão diferentes inclinações. O ponto mais baixo encontra-se próximo à cota de $619,0 \mathrm{~m}$ e o ponto mais alto situa-se próximo à cota de $634,0 \mathrm{~m}$. A porção do talude localizada próximo à cota de $634,0 \mathrm{~m}$ 
possui uma pequena berma e concentra a maior quantidade de arbustos da área piloto enquanto que a porção localizada próximo à cota 619,0 m apresenta uma pequena feição erosiva na face do talude e cobertura vegetal de gramíneas.

A Figura 5.3 mostra algumas imagens a área piloto, dando enfoque para a porção do talude em que ocorreram as coletas de amostra indeformada e demais ensaios.

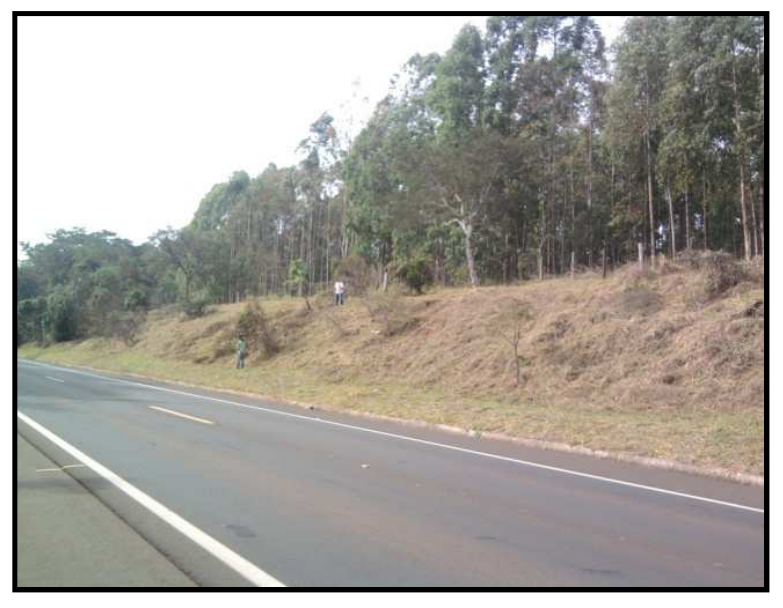

(a)

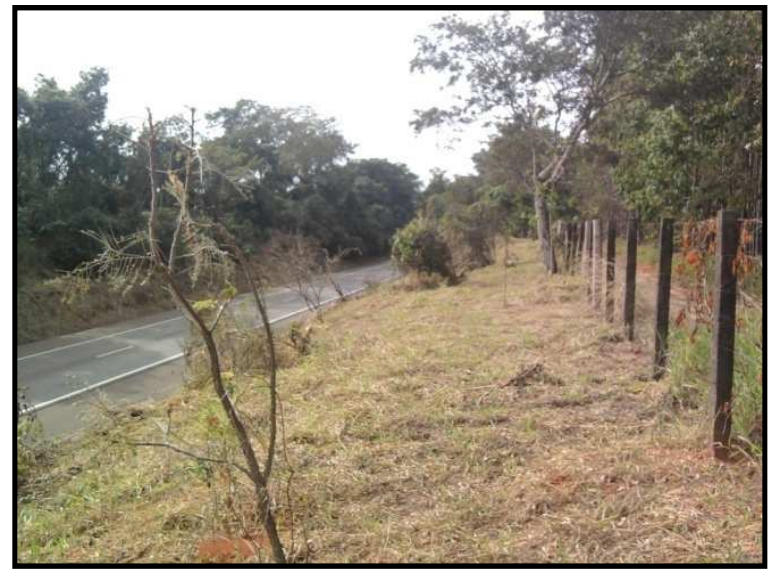

(c)

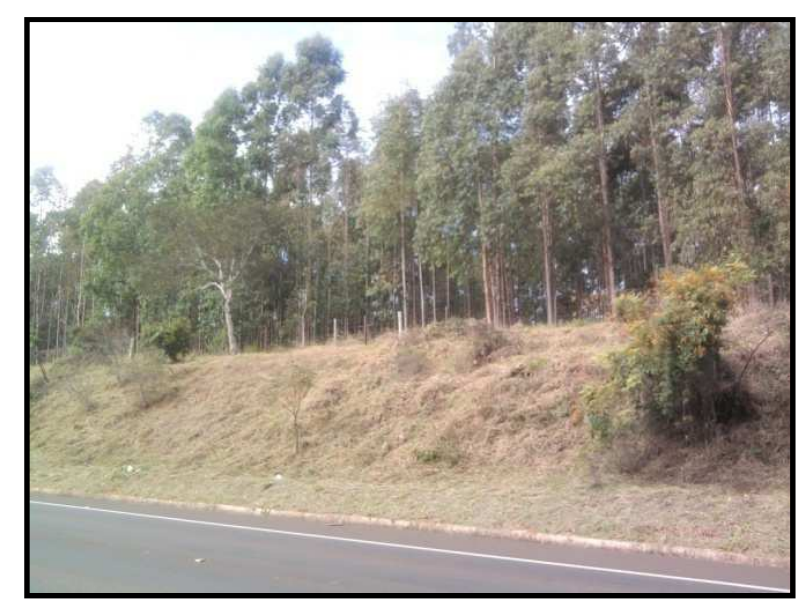

(b)

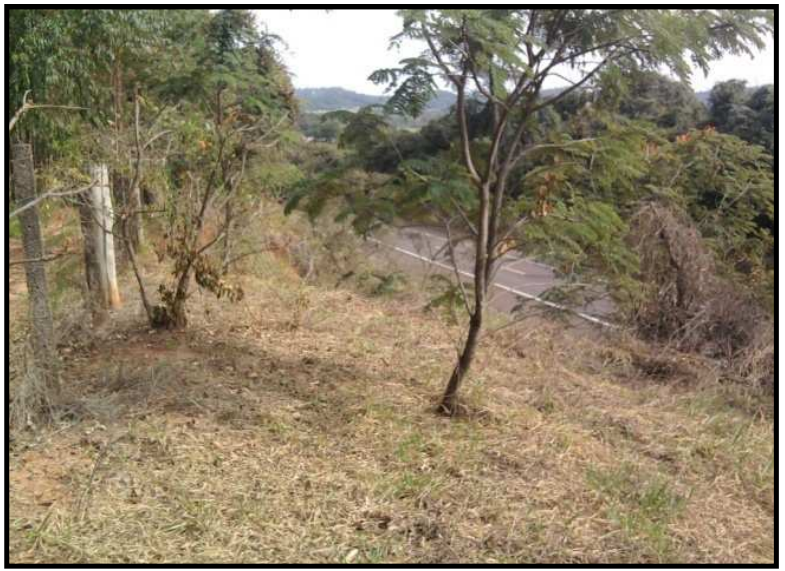

(d)

Figura 5.3 - Área piloto (a) visão geral da topografia do talude (b) inclinação típica do talude (c) crista do talude - rodovia sentido São Carlos e (d) crista do talude - rodovia sentido Ribeirão Bonito.

\subsection{ASPECTOS CLIMÁTICOS}

De acordo com a classificação de W. Koppen, o clima característico da área piloto é do tipo Aw (Clima Tropical, com inverno seco) caracterizado por verão chuvoso e inverno seco. A média térmica anual corresponde a temperatura mínima de $13^{\circ} \mathrm{C}$ e a temperatura máxima de $30^{\circ} \mathrm{C}$, conforme informações baseadas em uma série de dados de 30 anos consultada em Climatempo (2015).

Os dados pluviométricos para o município de Ribeirão Bonito apontam que as estações do ano são bem definidas, apresentando um período chuvoso (durante as estações da 
primavera e verão) e um período seco (durante as estações do outono e inverno). Segundo a série de dados de 30 anos consultada em Climatempo (2015), a precipitação média anual corresponde a $1438 \mathrm{~mm}$, como mostra a Figura 5.4. Portanto, a partir dessa figura pode-se dizer que a precipitação média do período chuvoso é de $1113,0 \mathrm{~mm}$ e do período seco é de $325,0 \mathrm{~mm}$.

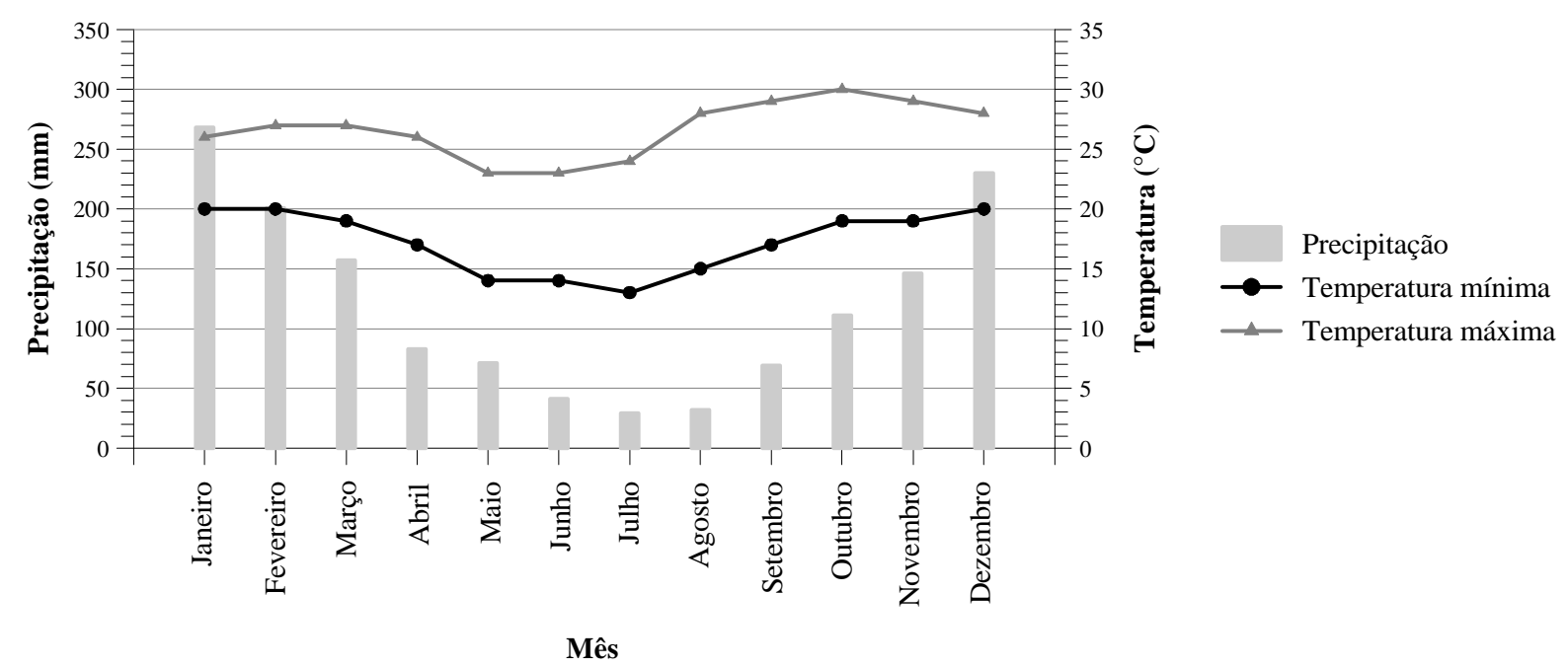

Figura 5.4 - Precipitação média mensal do município de Ribeirão Bonito.

Fonte: Climatempo (2015).

\subsection{ASPECTOS HIDROLÓGICOS}

O Plano Estadual de Recursos Hídricos foi implantando pelo Governo do Estado de São Paulo através da Lei Estadual n 9.304, de 27 de setembro de 1994, com a finalidade de planejar o aproveitamento e o controle dos recursos hídricos presentes no Estado de São Paulo, dividindo-o em 22 Unidades de Gerenciamento de Recursos Hídricos (UGRHI), conforme mostra a Figura 5.5.

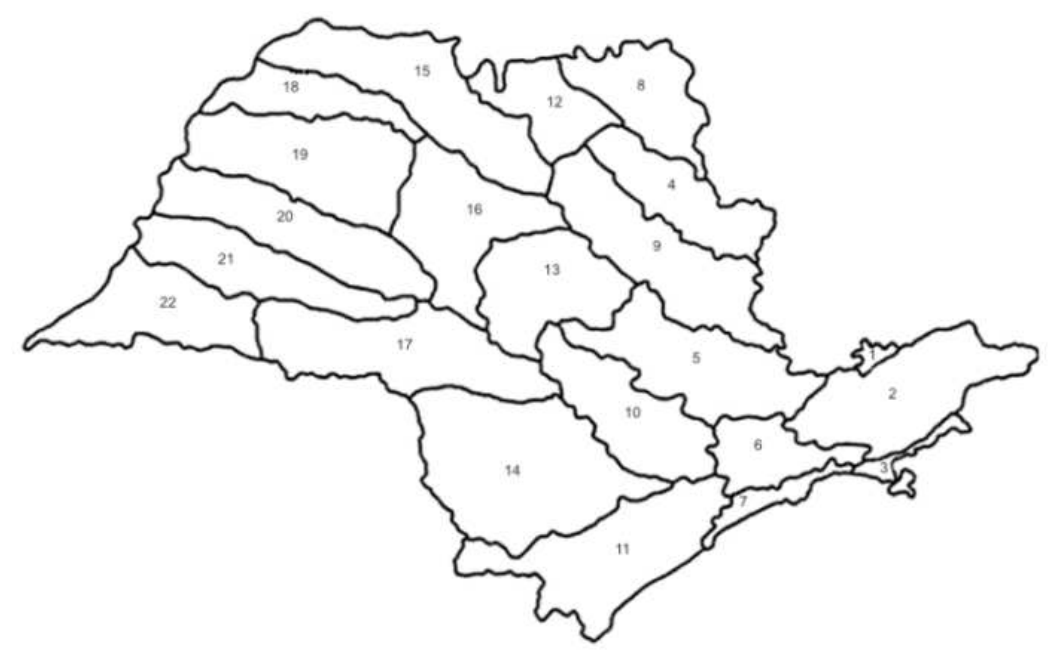

Figura 5.5 - Distribuição das UGRHI no Estado de São Paulo.

Fonte: Adaptado de Instituto de Pesquisa Tecnológica - IPT (2000). 
De acordo com a distribuição das UGRHI mostrada na Figura 5.5, o município de Ribeirão Bonito situa-se na Bacia Hidrográfica do Tietê-Jacaré, denominada de Unidade de Gerenciamento de Recursos Hídricos 13 (UGRHI-13) ou do Tietê-Jacaré (UGRHI-TJ). Segundo informações apresentadas em IPT (2000), a UGRHI do Tietê-Jacaré integra 34 municípios, possui uma área total de $15.808 \mathrm{~km}^{2}$ e subdivide-se em 9 sub-bacias, tendo como principais rios Tietê, Jacaré-Guaçu e Jacaré-Pepira. A Figura 5.6 apresenta um mapa com a distribuição das sub-bacias da UGRHI do Tietê-Jacaré, destacando o município de Ribeirão Bonito (número 29), que engloba quatro sub-bacias: Baixo Jacaré-Guaçu (87,74 km²), Médio Jacaré-Guaçu (195,54km²), Alto Jacaré-Guaçu (83,42 km²) e Alto Jacaré-Pepira (101,41 km²).

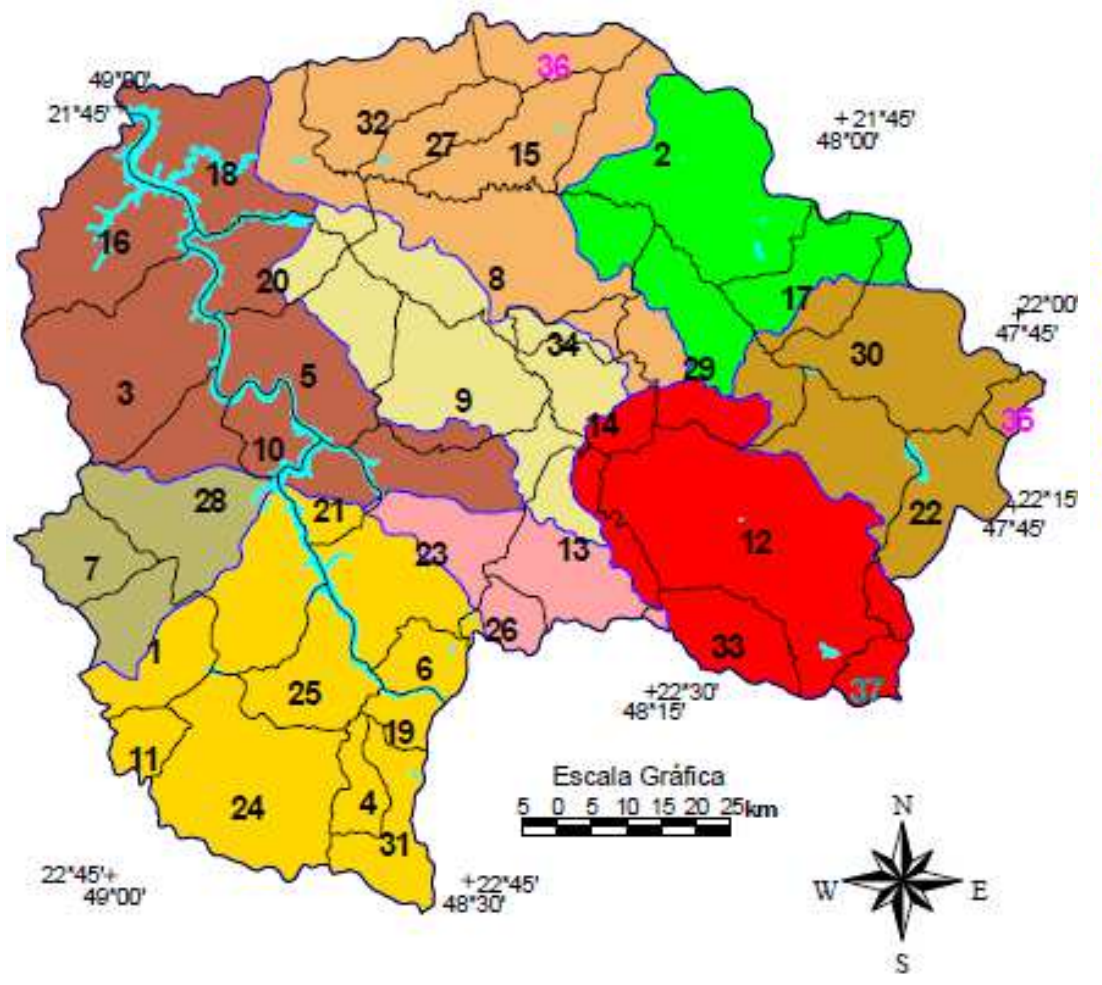

\section{LEGENDA}

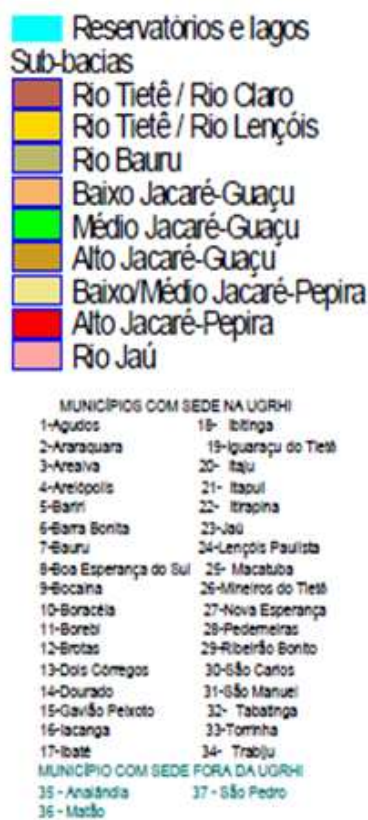

Figura 5.6 - Sub-bacias da UGRHI do Tietê-Jacaré.

Fonte: Adaptado de IPT (2000).

\subsection{ASPECTOS HIDROLGEOLÓGICOS}

O município de Ribeirão Bonito localiza-se na Bacia Sedimentar do Paraná e pertence a uma região de recarga do Aquífero Guarani. De acordo com Sistema Integrado de Gerenciamento de Recursos Hídricos do Estado de São Paulo (SIGRH, 2014), todo o município de Ribeirão Bonito integra o sistema do Aquífero Guarani, estando 90\% da área do município sobre o afloramento deste aqüífero. A Figura 5.7 ilustra o mapa com a distribuição 
dos três sistemas de aquíferos presentes na UGRHI do Tietê-Jacaré incluindo o município de Ribeirão Bonito.

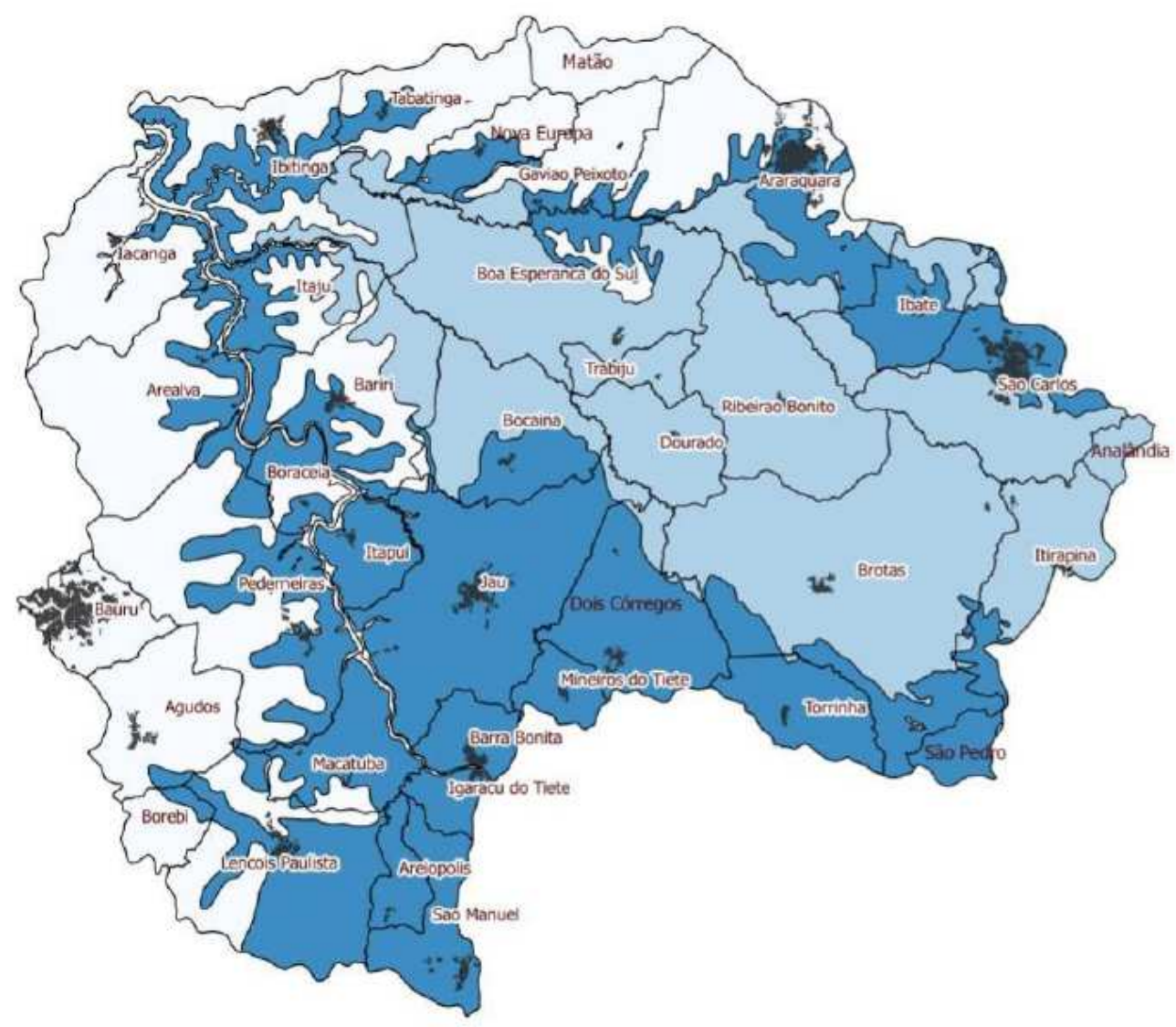

Legenda

AreaUrbanizada

Aquiferos

$\square$ Bauru

Guarani

Serra Geral

Figura 5.7 - Distribuição dos três sistemas de aquíferos presentes na UGRHI 13.

Fonte: Adaptado de SIGRH (2014).

O aquífero Guarani é constituído em sua base por arenitos da Formação Pirambóia e em seu topo por arenitos da Formação Botucatu. A Formação Pirambóia, de idade Triássica, é constituída por arenitos de granulação média a fina, de origem fluvio-lacustrino e eólico. A Formação Botucatu, de idade Jurássico-Cretáceo, é composto predominantemente por arenitos quartzosos de granulação média a fina, possui coloração avermelhada, rósea ou amarelo-claro, grãos de alta esfericidade e bem selecionados.

O município de Ribeirão Bonito apresenta uma grande área de afloramento do Aquífero Guarani, que devido a formação geológica (Formação Pirambóia e Botucatu) ocorre a zona de recarga natural. A espessura do aquífero é de aproximadamente $100 \mathrm{~m}$ para a área aflorante. 


\section{RESULTADOS E ANÁLISES}

Neste capítulo são apresentados e discutidos os resultados das etapas dessa pesquisa, incluindo os ensaios de laboratório, os ensaios de campo, o monitoramento da instrumentação de campo além das análises numéricas (infiltração de água e estabilidade de talude), conforme descritos e apresentados no Capítulo 4 Materiais e Métodos.

\subsection{LEVANTAMENTO TOPOGRÁFICO}

A planta topográfica apresentada na Figura 6.1 mostra o resultado do levantamento topográfico de detalhe para um trecho da área piloto, variando de 622,0 m a 630,0 m a cota das curvas de nível. Nesta figura é possível identificar as curvas de nível, as delimitações ao redor do talude (pista, acostamento, canaleta de drenagem e cerca), os pontos de locação da instrumentação (tensiômetros - A1 ao A9, B1 ao B9 - e medidores de nível d'água de máxima $-\mathrm{M}_{\text {pé }}$ e $\mathrm{M}_{\text {crista }}$ ), as áreas de retirada dos blocos de amostra indeformada (AP e AC) bem como os locais de realização da sondagem a trado (ST3 ao ST6), estando todos devidamente representados na legenda da planta topográfica. Nesse trabalho, as curvas de nível foram determinadas a partir da triangulação dos pontos levantados, sendo geradas a cada 0,50 m (curvas mestras e curvas auxiliares) e variando da cota 619,0 m à cota 634,0 m. O Apêndice B apresenta o levantamento topográfico de detalhe completo para todo o trecho da área piloto. 


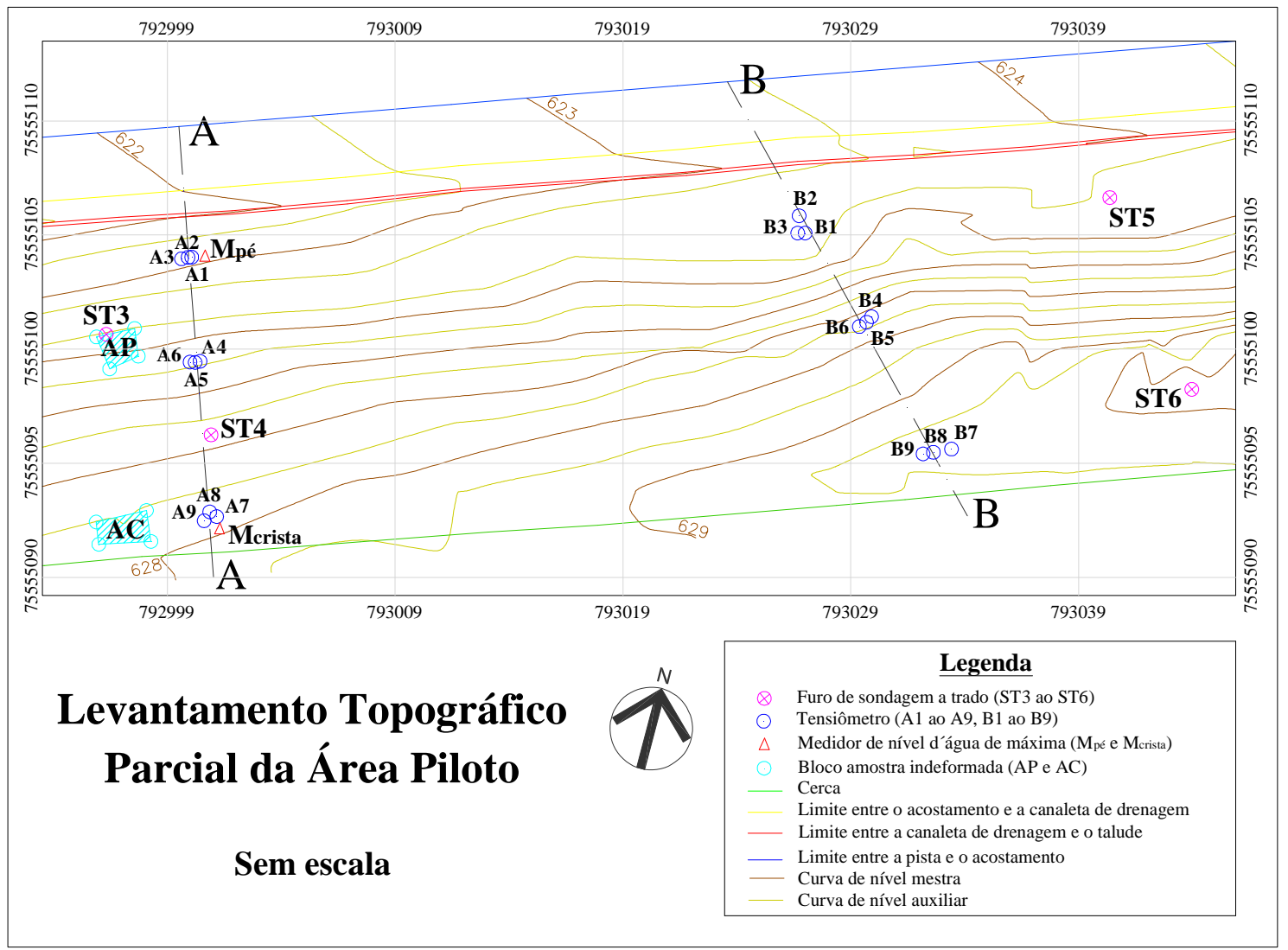

Figura 6.1 - Levantamento topográfico parcial da área piloto (sem escala).

O levantamento topográfico de detalhe indica que o talude apresenta uma altura média de 7,0 m e comprimento de aproximadamente $225,0 \mathrm{~m}$. Nesse trabalho optou-se em dividir o talude em duas porções, isto é, o talude foi dividido em uma porção que apresentava berma e outra porção que não apresenta berma. Consequentemente, em função da porção do talude que não continha a berma, observou-se a presença de um trecho com inclinações mais suaves e outro trecho com inclinações mais íngremes, as quais foram determinantes para estabelecer e definir as duas seções geológico-geotécnicas representativas desses trechos do talude.

A primeira seção geológico-geotécnica possui inclinação de $27^{\circ}$ e altura de $5,4 \mathrm{~m}$ enquanto que a segunda seção geológico-geotécnica apresenta inclinação de $37^{\circ}$ e altura de 5,0 m, como ilustram a Figura 6.2 e Figura 6.3, respectivamente. As duas seções foram definidas pelos cortes A-A' e B-B' (apresentados na planta topográfica parcial da área piloto através da Figura 6.1) e determinadas a partir dos valores das curvas de nível apresentadas na planta topográfica e dos locais escolhidos para instalação da instrumentação. A partir desse item, a seção geológico-geotécnica com inclinação de $27^{\circ}$ será identificada como Seção A-A' enquanto que a seção geológico-geotécnica com inclinação de $37^{\circ}$ será identificada de Seção B-B'. 


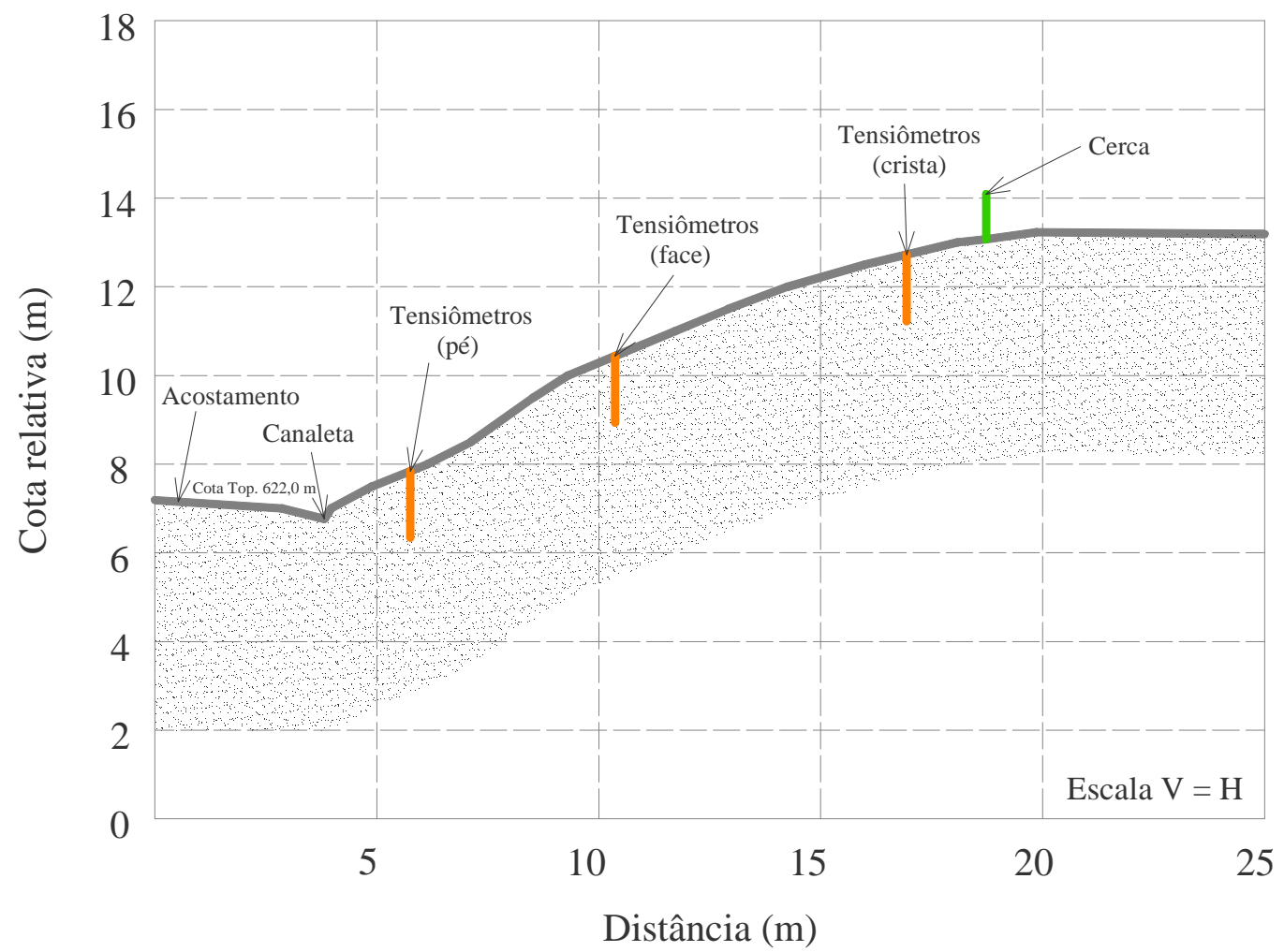

Figura 6.2 - Seção geológico-geotécnica com inclinação de $27^{\circ}$ também identificada como Seção A-A' (desenho sem escala).

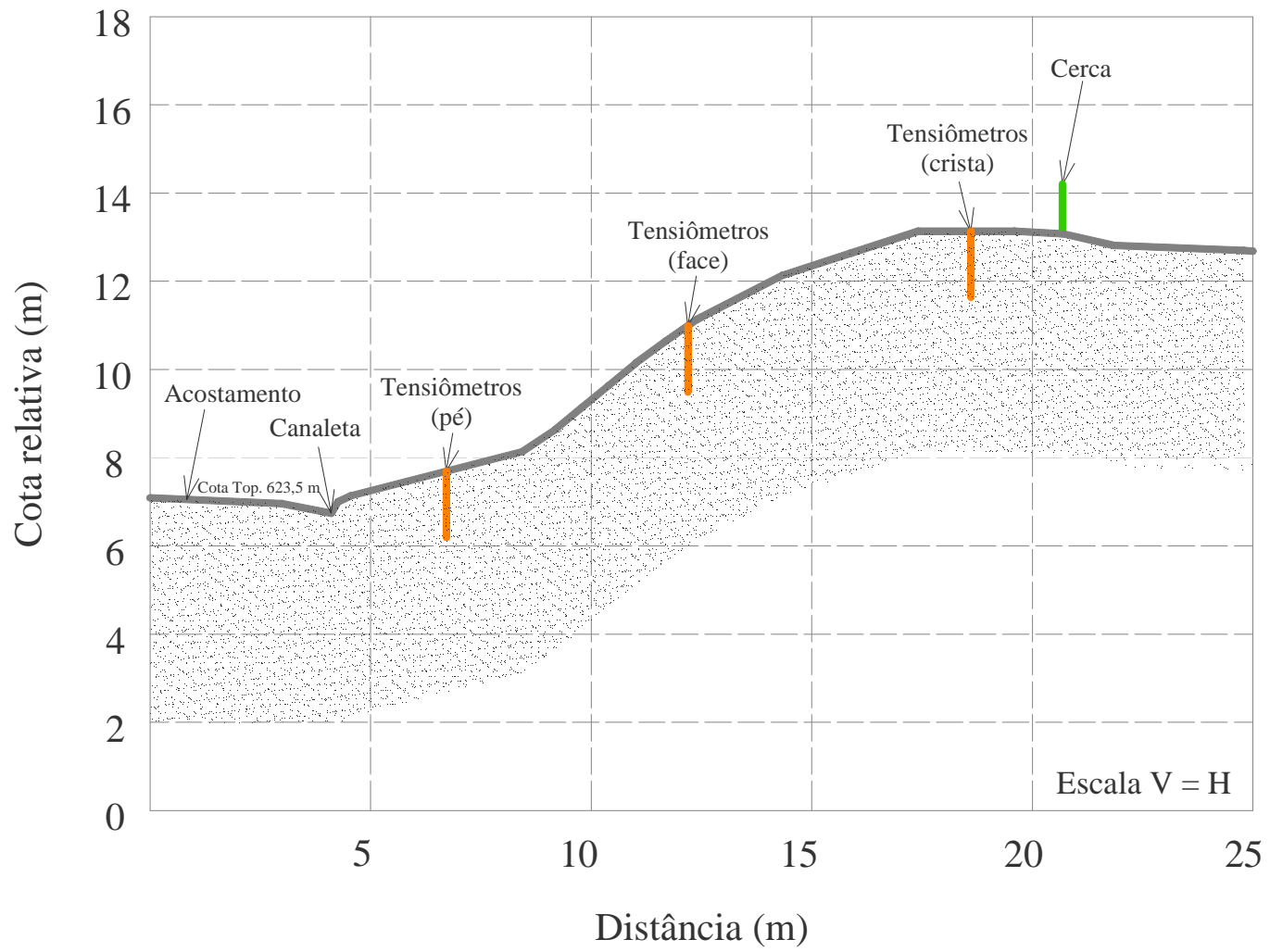

Figura 6.3 - Seção geológico-geotécnica com inclinação de $37^{\circ}$ também identificada como Seção B-B' (desenho sem escala). 


\subsection{SONDAGEM A TRADO MANUAL}

A caracterização do solo coletado nas sondagens a trado manual foi feita para dois furos de sondagem (ST3 e ST4), ambos situados no pé e na crista da Seção A-A'. Verificouse a partir dos testes de identificação táctil-visual in situ que o material se apresentava uniforme e homogêneo ao longo da profundidade dos demais furos de sondagem.

A Tabela 6.1 e a Tabela 6.2 apresenta os resultados dos ensaios de análise granulométrica conjunta (com defloculante) feita em 19 amostras deformadas de solo coletas em diferentes profundidades e localidade do talude (P3-1 a P3-9 e C4-1 a C4-10). Nessas tabelas constam identificadas a profundidade investigada, a composição textural do solo (pedregulho, areia, silte e argila) e a respectiva classificação correspondente ao solo dos furos localizados no pé e na crista de acordo com os critérios estabelecidos pela ABNT (1995a). Observa-se que a variação da textura do solo é muito pequena, predominando na composição do solo desse talude a fração de areia fina e areia média em toda a profundidade investigada.

Tabela 6.1 - Composição textural do solo coletado do furo de sondagem (ST3) da Seção A-A'.

\begin{tabular}{|c|c|c|c|c|c|c|c|}
\hline \multirow{2}{*}{$\begin{array}{l}\text { Profundi- } \\
\text { dade } \\
\text { (m) }\end{array}$} & \multirow{2}{*}{$\begin{array}{l}\text { Pedre- } \\
\text { gulho } \\
(\%)\end{array}$} & \multicolumn{3}{|c|}{ Areia } & \multirow{2}{*}{$\begin{array}{l}\text { Silte } \\
(\%)\end{array}$} & \multirow{2}{*}{$\begin{array}{c}\text { Argila } \\
(\%)\end{array}$} & \multirow[b]{2}{*}{ Classificação do solo } \\
\hline & & $\begin{array}{c}\text { Grossa } \\
(\%)\end{array}$ & $\begin{array}{l}\text { Média } \\
(\%)\end{array}$ & $\begin{array}{c}\text { Fina } \\
(\%)\end{array}$ & & & \\
\hline $0,00-0,50$ & 0,4 & 4,5 & 35,1 & 44,0 & 2,5 & 13,5 & $\begin{array}{c}\text { Areia fina a média pouco argilosa } \\
\text { marrom avermelhado }\end{array}$ \\
\hline $0,50-1,20$ & 0,7 & 4,8 & 35,5 & 42,0 & 3,7 & 13,3 & $\begin{array}{c}\text { Areia fina a média pouco argilosa } \\
\text { marrom avermelhado }\end{array}$ \\
\hline $1,20-2,00$ & 2,7 & 4,2 & 35,1 & 42,0 & 3,4 & 12,6 & $\begin{array}{c}\text { Areia fina a média pouco argilosa } \\
\text { marrom avermelhado }\end{array}$ \\
\hline $2,00-2,50$ & 7,3 & 6,2 & 24,6 & 29,8 & 11,6 & 20,5 & $\begin{array}{l}\text { Areia fina a média argilosa } \\
\text { marrom avermelhado }\end{array}$ \\
\hline $2,50-3,00$ & 0,7 & 3,5 & 46,8 & 35,0 & 3,6 & 10,4 & $\begin{array}{c}\text { Areia média a fina pouco argilosa } \\
\text { marrom avermelhado }\end{array}$ \\
\hline $3,00-3,50$ & 0,0 & 1,9 & 47,1 & 38,0 & 3,7 & 9,3 & $\begin{array}{c}\text { Areia média a fina pouco argilosa } \\
\text { marrom avermelhado }\end{array}$ \\
\hline $3,50-4,00$ & 0,8 & 1,4 & 52,8 & 36,0 & 1,7 & 7,3 & $\begin{array}{c}\text { Areia média a fina pouco argilosa } \\
\text { marrom avermelhado }\end{array}$ \\
\hline $4,00-4,50$ & 0,0 & 2,1 & 40,9 & 46,0 & 2,1 & 8,9 & $\begin{array}{c}\text { Areia fina a média pouco argilosa } \\
\text { marrom avermelhado }\end{array}$ \\
\hline $4,50-5,00$ & 0,0 & 2,9 & 27,1 & 57,5 & 4,5 & 8,0 & $\begin{array}{c}\text { Areia fina a média pouco argilosa } \\
\text { marrom avermelhado }\end{array}$ \\
\hline
\end{tabular}


Tabela 6.2 - Composição textural do solo coletado do furo de sondagem (ST4) da Seção B-B'.

\begin{tabular}{|c|c|c|c|c|c|c|c|}
\hline \multirow{2}{*}{$\begin{array}{l}\text { Profundi- } \\
\text { dade } \\
\text { (m) }\end{array}$} & \multirow{2}{*}{$\begin{array}{l}\text { Pedre- } \\
\text { gulho } \\
(\%)\end{array}$} & \multicolumn{3}{|c|}{ Areia } & \multirow{2}{*}{$\begin{array}{l}\text { Silte } \\
(\%)\end{array}$} & \multirow{2}{*}{$\begin{array}{c}\text { Argila } \\
(\%)\end{array}$} & \multirow[b]{2}{*}{ Classificação do solo } \\
\hline & & $\begin{array}{c}\text { Grossa } \\
(\%)\end{array}$ & $\begin{array}{l}\text { Média } \\
(\%)\end{array}$ & $\begin{array}{l}\text { Fina } \\
(\%)\end{array}$ & & & \\
\hline $0,00-0,50$ & 0,3 & 4,7 & 40,0 & 40,6 & 3,9 & 10,5 & $\begin{array}{c}\text { Areia fina a média pouco argilosa } \\
\text { marrom avermelhado }\end{array}$ \\
\hline $0,50-1,00$ & 0,3 & 4,2 & 40,5 & 41,5 & 2,8 & 10,7 & $\begin{array}{c}\text { Areia fina a média pouco argilosa } \\
\text { marrom avermelhado }\end{array}$ \\
\hline $1,00-1,50$ & 0,4 & 4,2 & 38,9 & 40,7 & 4,0 & 11,8 & $\begin{array}{c}\text { Areia fina a média pouco argilosa } \\
\text { marrom avermelhado }\end{array}$ \\
\hline $1,50-2,00$ & 0,3 & 4,3 & 38,4 & 42,3 & 2,4 & 12,3 & $\begin{array}{c}\text { Areia fina a média pouco argilosa } \\
\text { marrom avermelhado }\end{array}$ \\
\hline $2,00-2,50$ & 0,4 & 4,3 & 38,3 & 40,5 & 4,3 & 12,2 & $\begin{array}{c}\text { Areia fina a média pouco argilosa } \\
\text { marrom avermelhado }\end{array}$ \\
\hline $2,50-3,00$ & 0,1 & 4,0 & 38,9 & 42,2 & 3,6 & 11,2 & $\begin{array}{l}\text { Areia fina a média pouco argilosa } \\
\text { marrom avermelhado }\end{array}$ \\
\hline $3,00-3,50$ & 0,4 & 4,4 & 37,2 & 43,5 & 2,3 & 12,2 & $\begin{array}{c}\text { Areia fina a média pouco argilosa } \\
\text { marrom avermelhado }\end{array}$ \\
\hline $3,50-4,00$ & 0,5 & 4,2 & 35,8 & 45,0 & 1,9 & 12,6 & $\begin{array}{l}\text { Areia fina a média pouco argilosa } \\
\text { marrom avermelhado }\end{array}$ \\
\hline $4,00-4,50$ & 0,3 & 4,3 & 35,4 & 45,0 & 2,5 & 12,5 & $\begin{array}{c}\text { Areia fina a média pouco argilosa } \\
\text { marrom avermelhado }\end{array}$ \\
\hline $4,50-5,00$ & 0,4 & 4,7 & 36,9 & 43,3 & 2,6 & 12,1 & $\begin{array}{c}\text { Areia fina a média pouco argilosa } \\
\text { marrom avermelhado }\end{array}$ \\
\hline
\end{tabular}

A determinação da massa específica dos sólidos foi feita somente para uma amostra de solo (amostra P3-1) por conta da composição textural se manter praticamente homogênea ao longo da profundidade investigada. Sendo assim, a massa específica dos sólidos foi calculada para a amostra deformada coletada do furo de sondagem denominado de ST3, pertencente à Seção A-A' enquanto que, para as demais amostras (deformada e indeformada) ficou estabelecido o valor de $2,654 \mathrm{~g} / \mathrm{cm}^{3}$.

\subsection{Análises com lupa digital}

As amostras do solo na fração areia fina e média foram analisadas em lupa digital Olympus MIC-D. Observou-se a estrutura e a presença de feições típicas dos solos oriundos da alteração do arenito eólico da Formação Botucatu (Grupo São Bento, Bacia Sedimentar do Paraná) de idade jurássico-cretácea.

Os grãos de areia apresentam-se bem arredondados e bem selecionados, características típicas do ambiente sedimentar eólico de dunas (Figura 6.4 e Figura 6.5). As cores avermelhadas são indicativas de laterização, sendo visível a presença de grãos menores de 
areia formando agregados cimentados com óxidos e hidróxidos (Figura 6.4b, destaque 1 e Figura 6.5).

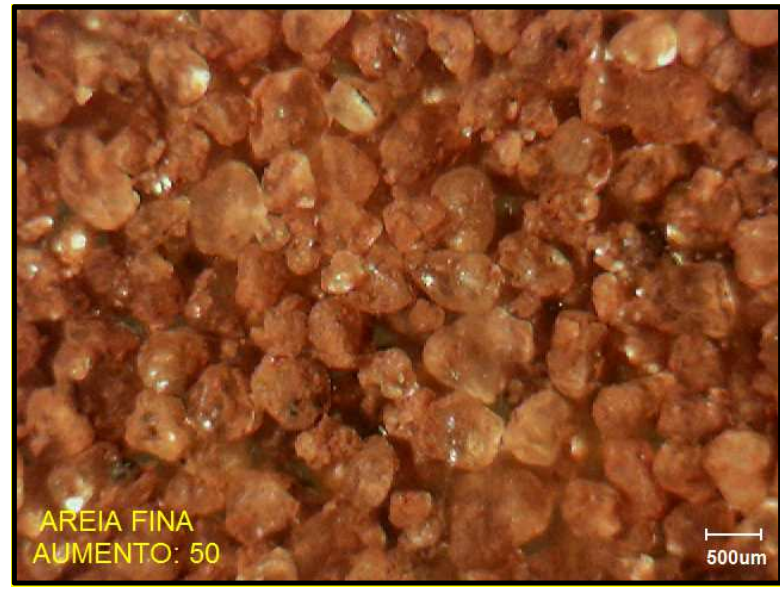

(a)

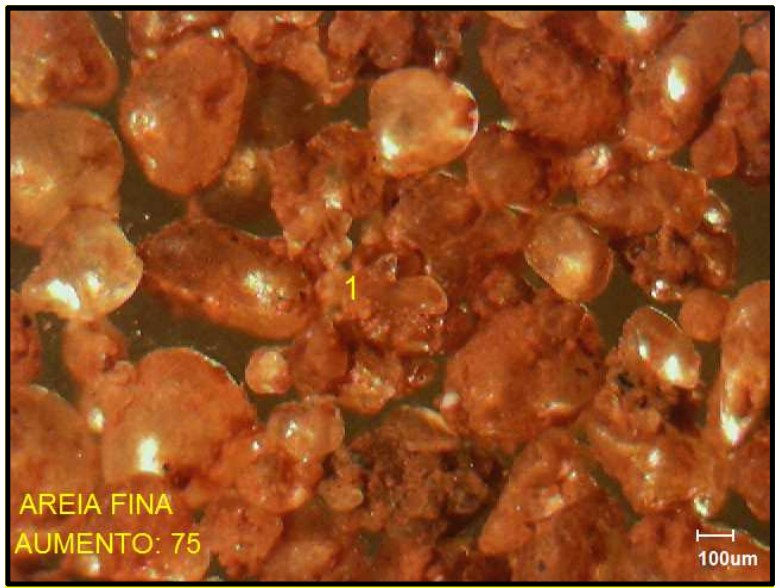

(b)

Figura 6.4 - Fotos obtidas com a lupa digital - fração areia fina - solo residual da Formação Botucatu (a) aumento 50 e (b) aumento 75 .

Também são identificados grãos de areia facetados, feição que também é típica do ambiente sedimentar eólico, devido ao transporte dos grãos maiores por saltação (Figura 6.5b, destaque 1).

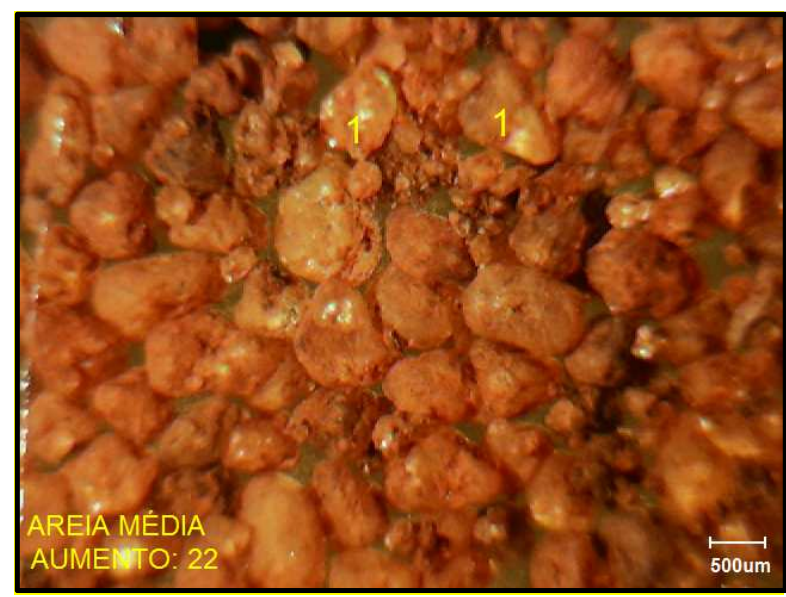

(a)

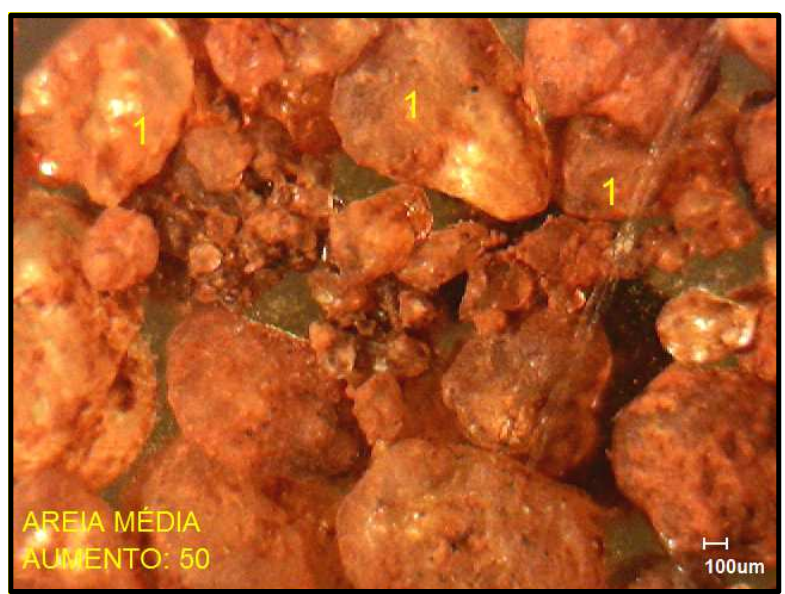

(b)

Figura 6.5 - Fotos obtidas com a lupa digital - fração areia média - solo residual da Formação Botucatu () aumento 22 e (b) aumento 50 .

Esta laterização marcante identificada na fração areia deve ocorrer mais intensamente nas frações silte e argila, que resulta num efeito semelhante ao ensaio de granulometria sem defloculante. Ou seja, o solo in situ tem comportamento característico não coesivo, confirmado pelos baixos valores de coesão efetiva obtidos nos ensaios de compressão triaxial. 


\subsection{CURVA DE RETENÇÃO DA ÁGUA NO SOLO}

A curva de retenção da água no solo foi obtida para as trajetórias de secagem e de umedecimento a partir dos pontos experimentais resultantes do uso das técnicas do Funil de Placa Porosa e do Papel Filtro.

Os pontos experimentais foram ajustados por meio da equação de Van Genuchten (1980) representada pela equação (50), obtendo-se o traçado da curva de retenção da água no solo. A Figura 6.6 ilustra a curva de retenção da água no solo por meio da relação entre a sucção matricial $\left(\psi_{m}\right)$ versus o teor de umidade gravimétrico $(w)$ e a Tabela 6.3 reúne os parâmetros de ajuste de cada curva assim como seus respectivos coeficientes de determinação $\left(\mathrm{r}^{2}\right)$ obtidos desse ajuste. Além disso, encontra-se disponível no Apêndice $\mathrm{C}$ as características de todos os corpos de prova (Tabela 0.1 e Tabela 0.2 ).

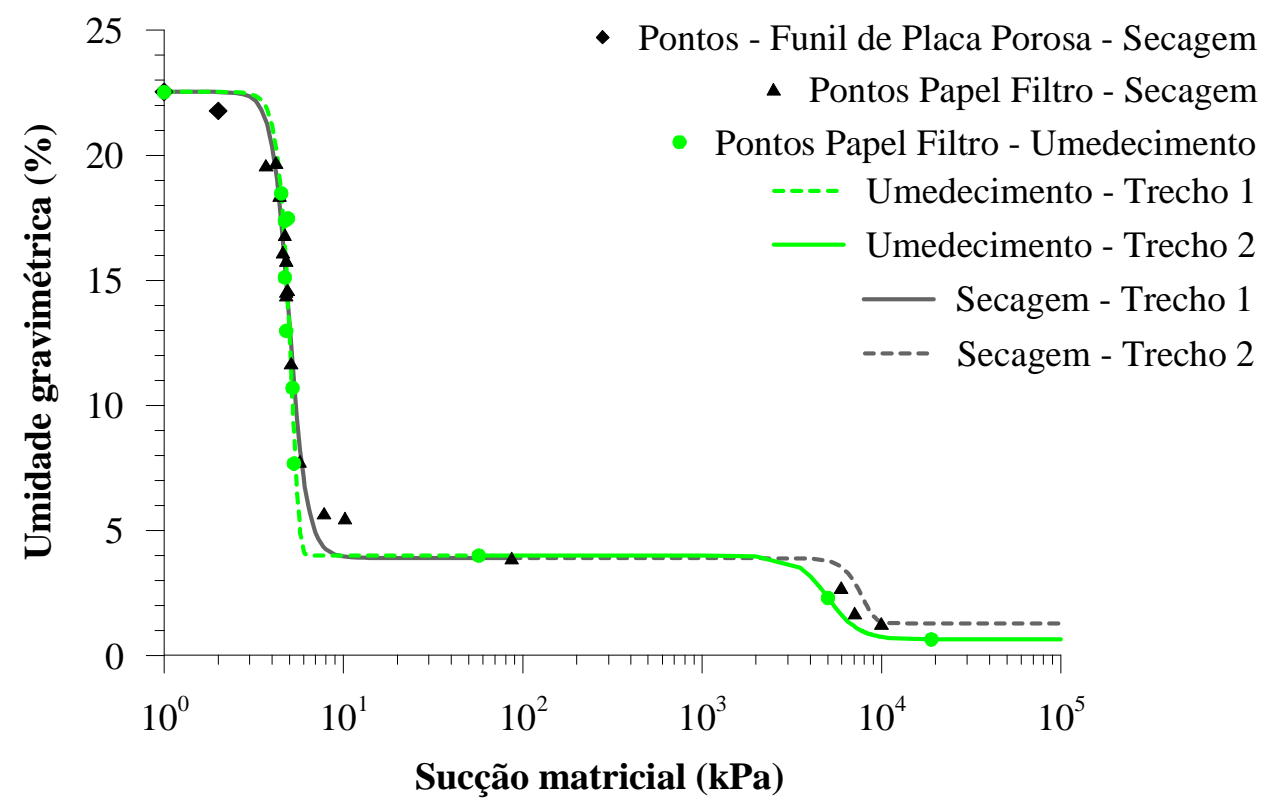

Figura 6.6 - Sucção matricial versus teor de umidade gravimétrico.

Tabela 6.3 - Curva de retenção da água no solo - parâmetros de ajuste.

\begin{tabular}{ccccccc}
\hline Trecho & $\boldsymbol{w}_{\boldsymbol{s}}$ & $\boldsymbol{w}_{\boldsymbol{r}}$ & $\boldsymbol{\alpha}_{\mathbf{1}}$ & $\boldsymbol{m}_{\mathbf{1}}$ & $\boldsymbol{n}_{\mathbf{1}}$ & $\boldsymbol{r}^{\mathbf{2}}$ \\
\hline T1 - secagem & $\mathbf{( \% )}$ & $\mathbf{( \% )}$ & $\left(\mathbf{k P a}^{-\mathbf{1}}\right)$ & $\mathbf{( - )}$ & $\mathbf{( - )}$ & $(-)$ \\
\hline T2 - secagem & 3,90 & 1,29 & 0,0001 & 5,5471 & 7,0133 & 1,000 \\
\hline T1 - umedecimento & 22,53 & 4,00 & 0,1387 & 33,0893 & 10,3698 & 0,921 \\
\hline T2 - umedecimento & 4,00 & 0,65 & 0,0002 & 0,9967 & 5,0000 & 0,999 \\
\hline
\end{tabular}


Nota-se na Figura 6.6 que ambas as curvas possuem dois picos bem definidos, correspondente às sucções em torno de $3 \mathrm{kPa}$ e de $5000 \mathrm{kPa}$. Isso indica que o solo possui comportamento bimodal, isto é, presença de micro e macroporo. Em razão desse comportamento, o ajuste da curva de retenção foi feito em dois trechos, de maneira que a umidade gravimétrica residual do primeiro trecho equivalesse à umidade gravimétrica de saturação para o segundo trecho. Esse critério de ajuste para solos com comportamento bimodal também foi utilizado nos trabalhos de Rodrigues (2007), Freitas Neto (2008), Menezes (2010) e Georgetti (2010).

A partir dos teores de umidade gravimétrica inferiores a 10\%, também é possível observar na Figura 6.6 um leve efeito do fenômeno denominado como histerese, o qual é identificado e visualizado a partir da diferença entre as trajetórias de secagem e de umedecimento.

Em geral, as curvas de retenção resultantes desses ajustes traduzem o comportamento típico de solos arenosos. Os valores correspondentes à pressão de entrada de ar são muito baixos visto que o diâmetro das partículas do solo influencia diretamente na capacidade do solo reter água nos poros, decorrente da ação da capilaridade. Isto significa dizer que, quanto maior for o diâmetro dessas partículas menor será a capacidade em reter água, ou vice-versa.

\subsection{ENSAIO DE POROSIMETRIA POR INTRUSÃO DE MERCÚRIO}

O ensaio de porosimetria foi feito com a finalidade de conhecer a distribuição do tamanho dos poros no solo, já que esta distribuição dos poros está diretamente associada com o processo de infiltração da água no solo. A identificação do tamanho dos poros é importantíssimo para compreender a movimentação da água no interior do solo e para auxiliar no estudo do comportamento físico-hídrico do solo.

Observando a Figura 6.7, que mostra a relação entre o volume acumulado de poros e o diâmetro dos poros, é possível visualizar que com o aumento do volume acumulado de poros há uma tendência em diminuir o diâmetro dos poros. O grande volume acumulado de poros nas amostras de solo no início dos ensaios indica uma concentração de poros grandes, uma vez que esse volume acumulado torna-se quase constante para poros com diâmetros menores que $10 \mu \mathrm{m}$, apresentando uma leve alteração nesse volume a partir dos poros com diâmetros inferiores a 0,015 $\mu \mathrm{m}$. Este resultado do ensaio de porosimetria pode ser caracterizado e correspondente ao comportamento de um solo tipicamente arenoso, que como representado pela curva de retenção da água do solo no item 6.4, aponta a ocorrência de uma rápida 
drenagem da água para pressão de entrada de ar de $3 \mathrm{kPa}$, indicando a presença de macroporos no solo.

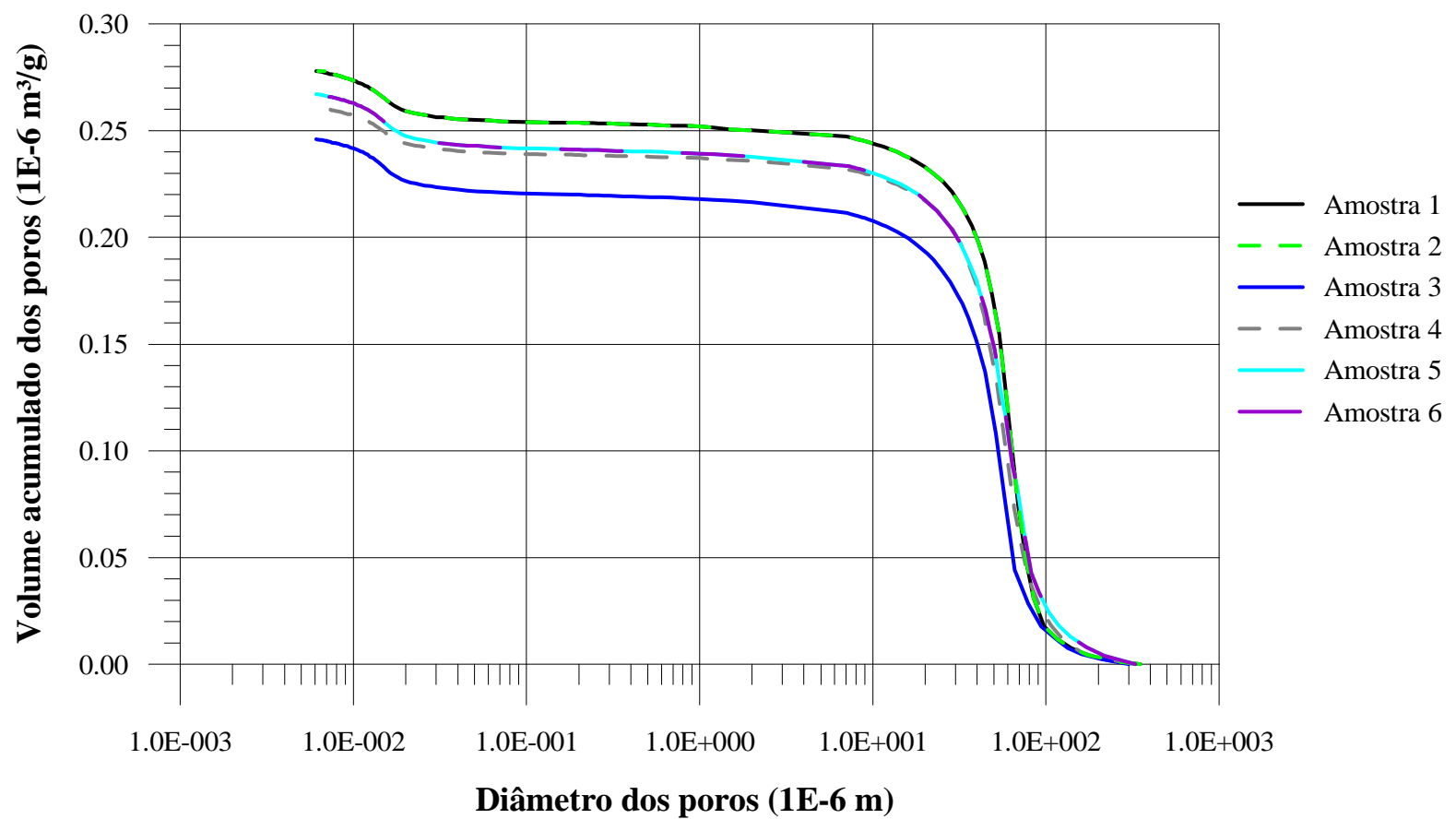

Figura 6.7 - Diâmetro dos poros versus volume acumulado de mercúrio.

A Figura 6.8 ilustra a relação diâmetro dos poros versus log intrusão diferencial de mercúrio, apresentando como ocorre a distribuição do tamanho dos poros do solo. É possível distinguir nitidamente nesta figura dois picos de diâmetro de poros, indicando que as amostras de solo apresentam com maior freqüência diâmetros da ordem de $60 \mu \mathrm{m}$ e de 0,015 $\mu \mathrm{m}$.

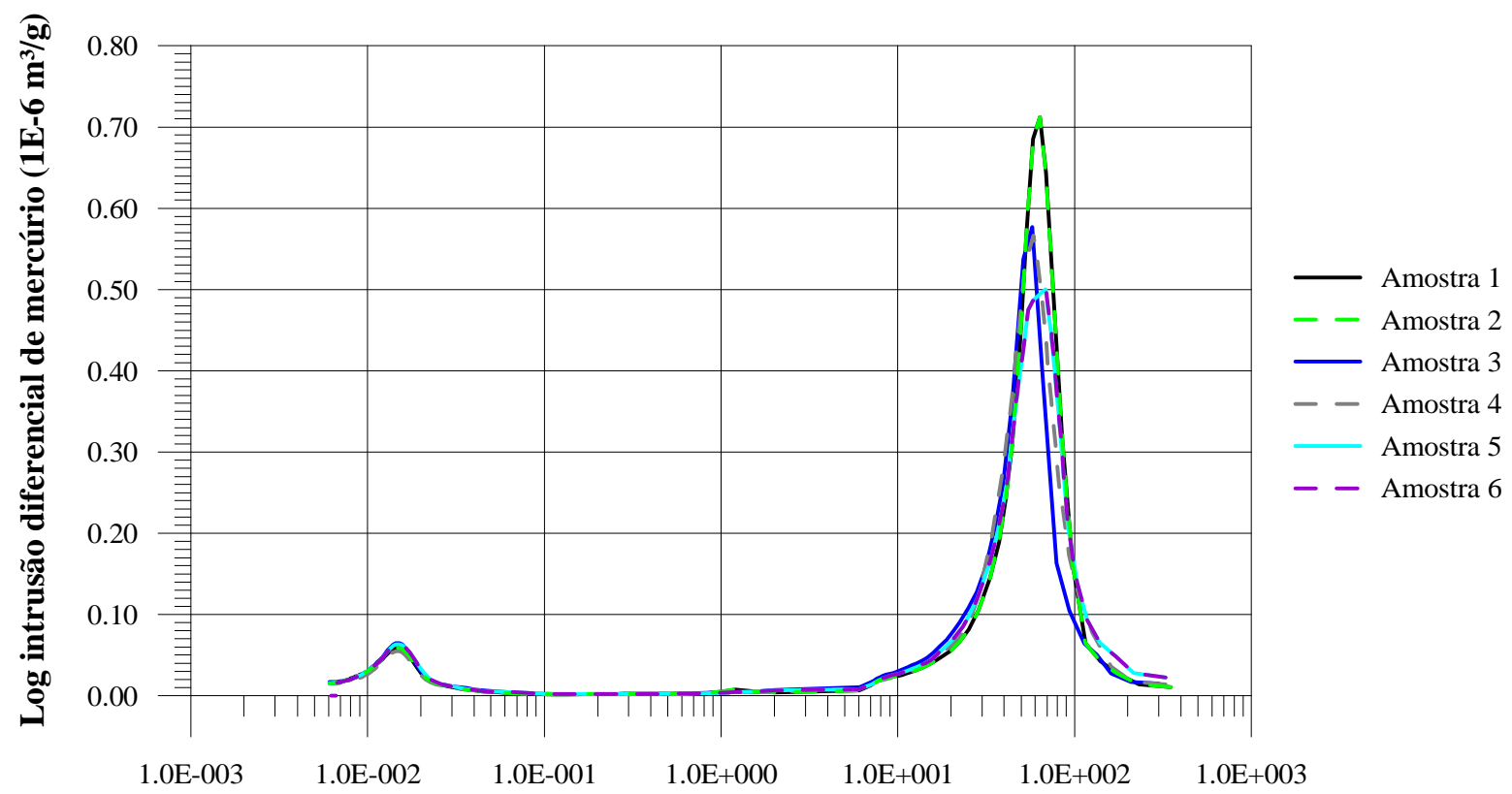

Diâmetro dos poros (1E-6 m)

Figura 6.8 - Diâmetro dos poros versus log intrusão diferencial. 
Existem inúmeras classificações para os tamanhos dos poros disponíveis na literatura científica, porém, não tendo sido definido um limite padrão de diâmetro dos poros e estabelecida uma terminologia para sua classificação. Algumas classificações são mais simplificadas, limitando o diâmetro dos poros em dois grupos (macroporos e microporos), como por exemplo, Richards (1965) fixa o valor de 0,05 $\mathrm{mm}$ e Kiehl (1979) estabelece o valor de 0,06 $\mathrm{mm}$ para separação desses poros. Outras classificações incluem um terceiro grupo intermediário de poros, denominada de mesoporo, a qual limita os macroporos dos microporos. Como exemplo de classificação de três grupos de poros, cita-se a proposta sugerida por Luxmoore (1981), em que os microporos apresentam diâmetro inferior a 0,01 $\mathrm{mm}$, os mesoporos apresentam diâmetro entre $0,01 \mathrm{~mm}$ e $1,0 \mathrm{~mm}$ e os macroporos possuem diâmetro superior a $1,0 \mathrm{~mm}$.

Nesta pesquisa, adotou-se a classificação de Luxmoore (1981), em que os poros com $60 \mu \mathrm{m}$ correspondem a mesoporos e os poros com $0,015 \mu \mathrm{m}$ equivalem a microporos.

\subsection{ENSAIO DE PERMEABILIDADE - LABORATÓRIO}

A determinação da condutividade hidráulica saturada em laboratório foi feita a partir de ensaios a carga constante, utilizando diferentes alturas de carga na amostra saturada de solo. O volume de água foi medido para diversos intervalos de tempo e o valor da condutividade hidráulica saturada foi calculado com o uso da equação (51).

A Tabela 6.4 apresenta as características dos corpos de prova (altura - $H$, diâmetro - $D$, massa $-M$, volume $-V$, teor de umidade gravimétrico de moldagem - $w_{\text {mold }}$ ), os valores dos índices físicos (massa específica - $\rho$, massa específica seca - $\rho_{d}$, índice de vazios - $e$, porosidade - $\eta$ e grau de saturação $-S_{r}$ ) e os resultados de condutividade hidráulica saturada $\left(k_{s}\right)$ obtido em laboratório.

Tabela 6.4 - Ensaio de permeabilidade em laboratório - características, índices físicos e condutividade hidráulica saturada dos corpos de prova.

\begin{tabular}{|c|c|c|c|c|c|c|c|c|c|c|c|}
\hline \multirow[b]{2}{*}{$\begin{array}{c}\text { Corpo de } \\
\text { prova }\end{array}$} & \multicolumn{5}{|c|}{ Características } & \multicolumn{5}{|c|}{ Índices físicos } & \multirow{2}{*}{$\begin{array}{c}\boldsymbol{k}_{\boldsymbol{s}} \\
(\mathrm{cm} / \mathrm{s})\end{array}$} \\
\hline & $\begin{array}{c}\boldsymbol{H} \\
(\mathbf{c m})\end{array}$ & $\begin{array}{c}D \\
(\mathbf{c m})\end{array}$ & $\begin{array}{l}M \\
(\mathrm{~g})\end{array}$ & $\begin{array}{c}V \\
\left(\mathbf{c m}^{3}\right)\end{array}$ & $\begin{array}{c}\boldsymbol{w}_{\text {mold }} \\
(\%)\end{array}$ & $\begin{array}{c}\rho \\
\left(\mathrm{g} / \mathrm{cm}^{3}\right)\end{array}$ & $\begin{array}{c}\rho_{d} \\
\left(\mathrm{~g} / \mathrm{cm}^{3}\right)\end{array}$ & $\begin{array}{r}\boldsymbol{e} \\
(-)\end{array}$ & $\begin{array}{c}\eta \\
(\%)\end{array}$ & $\begin{array}{c}S_{r} \\
(\%)\end{array}$ & \\
\hline Horizontal & 12,37 & 5,09 & 379,60 & 251,7 & 2,02 & 1,508 & 1,478 & 0,80 & 44,3 & 6,7 & $1,5 \cdot 10^{-2}$ \\
\hline Vertical & 11,39 & 4,99 & 341,18 & 222,7 & 2,22 & 1,532 & 1,498 & 0,77 & 59,8 & 7,6 & $1,6.10^{-2}$ \\
\hline
\end{tabular}


Já a Tabela 6.5 reúne os resultados dos valores médios de condutividade hidráulica saturada bem como o teor de umidade e o grau de saturação após o encerramento dos ensaios de permeabilidade. Importante comentar que os dois ensaios de permeabilidade foram executados durante um ano para verificar a ocorrência de uma possível diminuição na condutividade hidráulica saturada do solo e carreamento das partículas de areia fina do solo. Portanto, embora o solo seja basicamente composto por partículas de areia, observou-se que o valor desse parâmetro hidráulico foi alterado em cerca de uma ordem de grandeza ao longo do ensaio para os dois corpos de prova (de $1,5 \cdot 10^{-2} \mathrm{~cm} / \mathrm{s}$ para $5,2 \cdot 10^{-3} \mathrm{~cm} / \mathrm{s}$ ou de 1,6.10 $10^{-2} \mathrm{~cm} / \mathrm{s}$ para $4,2 \cdot 10^{-3} \mathrm{~cm} / \mathrm{s}$ ).

Tabela 6.5 - Ensaio de permeabilidade em laboratório - condutividade hidráulica saturada dos corpos de prova alguns índices físicos após o ensaio.

\begin{tabular}{ccccc}
\hline \multirow{2}{*}{ Corpo de prova } & Condutividade hidráulica saturada & \multicolumn{2}{c}{ Índices físicos } \\
\cline { 2 - 5 } & $\begin{array}{c}\boldsymbol{k}_{\boldsymbol{s}} \\
(\mathbf{c m} / \mathbf{s})\end{array}$ & $\begin{array}{c}\boldsymbol{w} \\
(\mathbf{\%})\end{array}$ & $\begin{array}{c}\boldsymbol{S}_{\boldsymbol{r}} \\
(\boldsymbol{\%})\end{array}$ \\
\hline Horizontal & $\mathbf{5 , 2 . 1 0 ^ { - 3 }}$ & 24,3 & 54,2 \\
\hline Vertical & $\mathbf{4 , 2 . 1 0 ^ { - 3 }}$ & 22,5 & 53,2 \\
\hline
\end{tabular}

Calle (2000) realizou ensaio de permeabilidade com carga variável para uma amostra indeformada de solo, obtendo valor de condutividade hidráulica saturada de $4,4.10^{-4} \mathrm{~cm} / \mathrm{s}$ para uma areia argilo siltosa. Fernandes (2011) estudou a permeabilidade de um solo classificado como areia argilosa obtendo valores de $1,1.10^{-2} \mathrm{~cm} / \mathrm{s}$ a $1,2.10^{-4} \mathrm{~cm} / \mathrm{s}$ para corpos de prova moldados dos blocos de amostra indeformada.

\subsection{ENSAIO DE PERMEABILIDADE - CAMPO}

Os ensaios com o permeâmetro Guelph foram realizados próximo ao local de instalação da instrumentação de campo e dos furos de sondagem a trado manual. Em todos os ensaios foi empregado o método das duas alturas de carga $(5,0 \mathrm{~cm}$ e 10,0 cm), de acordo com os procedimentos descritos no item 4.8.9.

A Tabela 6.6 reúne os detalhes (local e profundidade) e os parâmetros resultantes de cada ensaio (condutividade hidráulica saturada de campo - $k_{f s}$, potencial matricial de fluxo $\phi_{G m}$ e o parâmetro - $\alpha_{p g}$ ). Estes três parâmetros foram determinados por meio das equações (52), (53) e (54); respectivamente. 
Tabela 6.6 - Condutividade hidráulica saturada de campo - permeâmetro Guelph.

\begin{tabular}{cccccc}
\hline Ensaio & $\begin{array}{c}\text { Local/Próximo ao } \\
\text { furo de sondagem }\end{array}$ & $\begin{array}{c}\text { Profundidade } \\
(\mathbf{m})\end{array}$ & $\begin{array}{c}\boldsymbol{k}_{f s} \\
(\mathbf{c m} / \mathbf{s})\end{array}$ & $\begin{array}{c}\boldsymbol{\phi}_{G m} \\
\left(\mathbf{c m}^{2} / \mathbf{s}\right)\end{array}$ & $\begin{array}{c}\boldsymbol{\alpha}_{\boldsymbol{g g}} \\
\left(\mathbf{c m}^{-1}\right)\end{array}$ \\
\hline 1 & Pé - ST5 & 0,48 & $1,2 \cdot 10^{-3}$ & $1,7 \cdot 10^{-2}$ & $7,1 \cdot 10^{-2}$ \\
\hline 2 & Crista - ST6 & 0,45 & $1,7 \cdot 10^{-3}$ & $1,3 \cdot 10^{-2}$ & $1,3 \cdot 10^{-2}$ \\
\hline 3 & Crista - ST6 & 0,60 & $5,3 \cdot 10^{-3}$ & $5,6 \cdot 10^{-2}$ & $9,4 \cdot 10^{-2}$ \\
\hline 4 & Crista-ST4 & 0,82 & $1,4 \cdot 10^{-3}$ & $1,1 \cdot 10^{-2}$ & $1,3 \cdot 10^{-2}$ \\
\hline 5 & Crista-ST4 & 0,45 & $3,7 \cdot 10^{-3}$ & $2,0 \cdot 10^{-2}$ & $1,9 \cdot 10^{-1}$ \\
\hline 6 & Pé-ST5 & 0,45 & $4,4 \cdot 10^{-3}$ & $1,0 \cdot 10^{-2}$ & $4,3 \cdot 10^{-2}$ \\
\hline 7 & Pé-ST5 & 0,45 & $1,1 \cdot 10^{-2}$ & $3,3 \cdot 10^{-2}$ & $3,4 \cdot 10^{-1}$ \\
\hline
\end{tabular}

Como o permeâmetro Guelph não permite determinar a condutividade hidráulica não saturada em campo, esta foi estimada por meio de uma equação empírica e dos parâmetros resultantes dos ensaios $\left(k_{f s}\right.$ e $\left.\alpha_{p g}\right)$. Para isso, foi utilizada a equação empírica de Gardner (1958) representada pela equação (55), para obtenção da função condutividade hidráulica não saturada.

A Tabela 6.7 reúne a função condutividade hidráulica saturada não saturada correspondente a cada ensaio enquanto que a Figura 6.9 ilustra a condutividade hidráulica não saturada em função dos valores de sucção para o intervalo de $1 \mathrm{kPa}$ a $80 \mathrm{kPa}$.

Tabela 6.7 - Função condutividade hidráulica não saturada - permeâmetro Guelph.

\begin{tabular}{cc}
\hline Ensaio & $\begin{array}{c}\boldsymbol{k}(\boldsymbol{\phi}) \\
(\mathbf{c m} / \mathbf{s})\end{array}$ \\
\hline 1 & $k(\phi)=1,2 \cdot 10^{-3} \cdot e^{(0,071 \cdot \phi)}$ \\
\hline 2 & $k(\phi)=1,7 \cdot 10^{-3} \cdot e^{(0,013 \cdot \phi)}$ \\
\hline 3 & $k(\phi)=5,3 \cdot 10^{-3} \cdot e^{(0,094 \cdot \phi)}$ \\
\hline 4 & $k(\phi)=1,4 \cdot 10^{-3} \cdot e^{(0,013 \cdot \phi)}$ \\
\hline 6 & $k(\phi)=3,7 \cdot 10^{-3} \cdot e^{(0,19 \cdot \phi)}$ \\
\hline 7 & $k(\phi)=4,4 \cdot 10^{-3} \cdot e^{(0,043 \cdot \phi)}$ \\
\hline & $k(\phi)=1,1 \cdot 10^{-2} \cdot e^{(0,34 . \phi)}$ \\
\hline
\end{tabular}




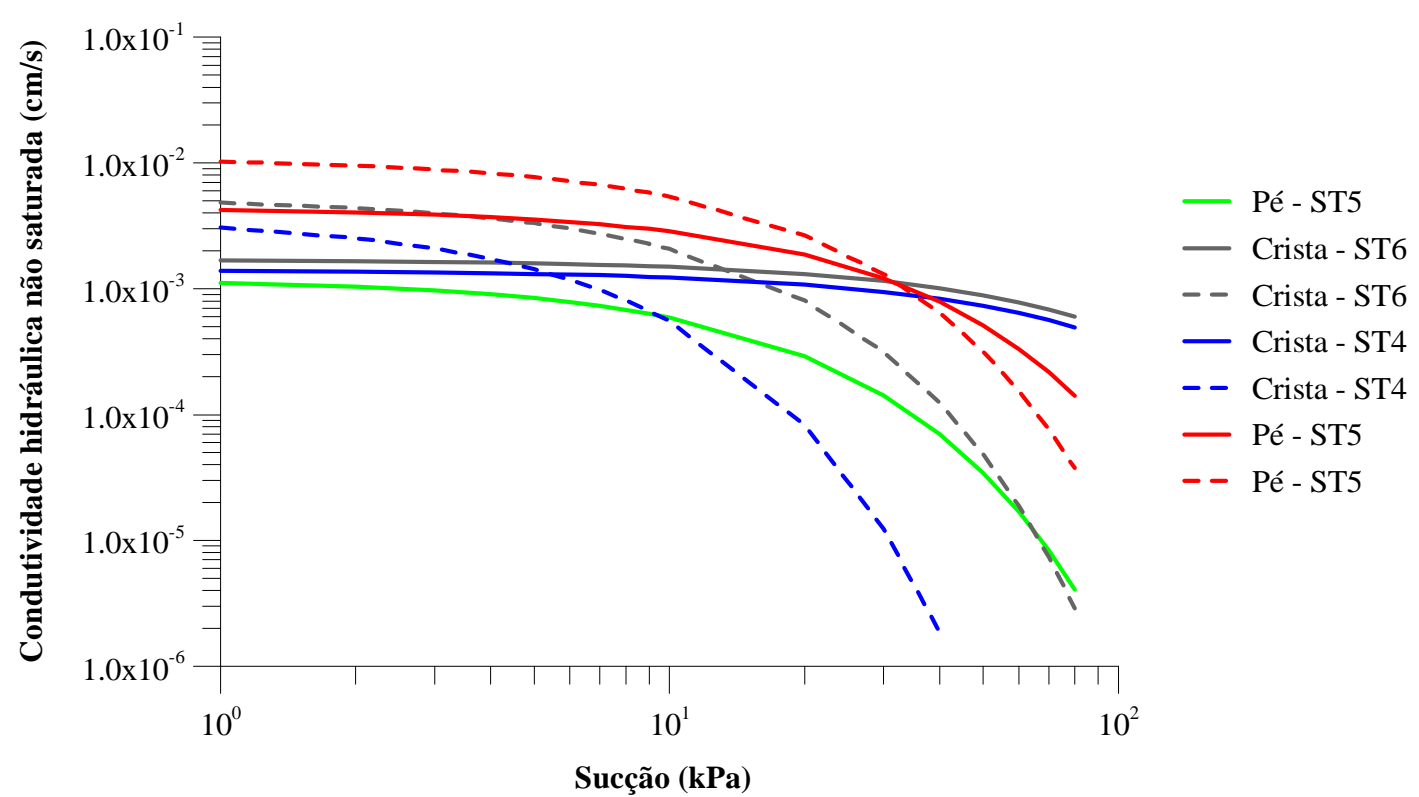

Figura 6.9 - Condutividade hidráulica não saturada em função da sucção - permeâmetro Guelph.

Nota-se que para o intervalo de sucção apresentado na Figura 6.9, os valores de condutividade hidráulica não saturada diminuíram de uma a três ordens de grandeza, variando de $1,1 \cdot 10^{-2} \mathrm{~cm} / \mathrm{s}$ para sucção $0 \mathrm{kPa}$ (ou seja, para o solo saturado) a $1,9.10^{-6} \mathrm{~cm} / \mathrm{s}$ para sucção de $40 \mathrm{kPa}$. Além disso, é possível observar que os valores de condutividade hidráulica de laboratório e de campo são valores próximos, na ordem de $10^{-2} \mathrm{~cm} / \mathrm{s}$ e $10^{-3} \mathrm{~cm} / \mathrm{s}$.

Calle (2000) também realizou ensaio com o permeâmetro Guelph em campo, obtendo valores de condutividade hidráulica saturada de campo de $1,6 \cdot 10^{-4} \mathrm{~cm} / \mathrm{s}$ e $1,5 \cdot 10^{-4} \mathrm{~cm} / \mathrm{s}$. Fernandes (2011) também utilizou o permêametro Guelph para determinação da condutividade hidráulica saturada de campo, obtendo valores de $1,7.10^{-4} \mathrm{~cm} / \mathrm{s}$ e 9,1 $10^{-4} \mathrm{~cm} / \mathrm{s}$ desse parâmetro hidráulico.

\subsection{ENSAIO DE ERODIBILIDADE}

O índice de erodibilidade foi determinado a partir do índice de absorção de água e do índice de perda de massa por imersão utilizando as equações propostas por Nogami e Villibor (1979) e Pejon (1992). A Tabela 6.8 apresenta as características dos corpos de prova, o índice de absorção calculado graficamente com uso da equação (56), o índice de perda de massa por imersão determinado a partir da equação (57) e o índice de erodibilidade usando a equação (58) para a proposta de Nogami e Villibor (1979) e a equação (59) para a proposta de Pejon (1992). Além disso, encontram-se disponíveis no Apêndice D os índices físicos de todos os corpos de prova utilizados neste ensaio (Tabela 0.3). 
Tabela 6.8 - Ensaio de erodibilidade - características dos corpos de prova, índice de absorção de água, índice de perda de massa por imersão e índice de erodibilidade.

\begin{tabular}{ccccccccc}
\hline \multirow{2}{*}{$\begin{array}{c}\text { Corpo de } \\
\text { prova }\end{array}$} & $\boldsymbol{H}$ & $\boldsymbol{D}$ & $\mathbf{M}$ & $\boldsymbol{w}_{\text {mold }}$ & $\boldsymbol{S}$ & $\boldsymbol{P}$ & $\boldsymbol{E}_{\mathbf{5 2}}$ & $\boldsymbol{E}_{\mathbf{4 0}}$ \\
\cline { 2 - 9 } & $(\mathbf{c m})$ & $(\mathbf{c m})$ & $(\mathbf{g})$ & $(\boldsymbol{\%})$ & $\left(\mathbf{c m} / \mathbf{s}^{\mathbf{1 / 2}}\right)$ & $(\boldsymbol{\%})$ & & \\
\hline M1 & 2,27 & 4,39 & 51,59 & 3,53 & 0,92 & 20,57 & 2,33 & 1,79 \\
\hline M2 & 2,27 & 4,48 & 52,97 & 3,75 & 0,97 & 7,22 & 6,98 & 5,37 \\
\hline M3 & 2,27 & 4,37 & 51,15 & 3,53 & 0,93 & 1,30 & 37,09 & 28,53 \\
\hline M4 & 2,31 & 4,38 & 51,02 & 3,53 & 0,93 & 19,11 & 2,53 & 1,95 \\
\hline M5 & 2,30 & 4,38 & 51,23 & 3,53 & 0,73 & 24,15 & 1,57 & 1,21 \\
\hline M6 & 2,28 & 4,38 & 57,14 & 3,75 & 1,68 & 16,42 & 5,33 & 4,10 \\
\hline
\end{tabular}

Observando-se os valores constantes na Tabela 6.8, conclui-se que nenhuma das amostras de solo apresentam comportamento erodível pois, para o solo ser erodível, o índice de erodibilidade (E) tem que ser menor que $1(\mathrm{E}<1)$. Nota-se na Tabela 6.8, que o corpo de prova denominado M5 é o que possui menor índice de erodibilidade enquanto que o corpo de prova denominado M3 é o que possui maior índice de erodibilidade. Os valores do índice de erodibilidade comprovam o comportamento não erodível do material observado em campo, que no caso de todas as amostras, apresentam baixo índice de erobilidade.

Pode-se afirmar que os valores do índice de erodibilidade são parcialmente concordantes com o comportamento observado em campo. Apesar da característica arenosa e pouco coesiva dos solos (baixas percentagens das frações de silte e argila), observa-se a ocorrência moderada de sulcos erosivos e poucas ravinas nos trechos sem cobertura vegetal.

Estes processos parecem ser mais condicionados pela concentração de fluxo localizada do que por uma alta erodibilidade natural do solo. Talvez, este comportamento pouco erodível destes solos, apesar das suas texturas amplamente arenosas, possa ser explicado pelas elevadas condutividades hidráulicas destes solos, facilitando a infiltração e não a desagregação e carreamento das partículas pelo escoamento superficial.

\subsection{RESISTÊNCIA AO CISALHAMENTO}

A seguir estão apresentados os parâmetros de resistência ao cisalhamento dos ensaios adensado-drenado com solo saturado, ensaio para determinação da resistência do solo com teor de umidade natural e ensaios adensado-drenado com solo saturado não saturado. 


\subsubsection{Ensaios adensado-drenado (CD) com solo saturado}

Os ensaios de compressão triaxial do tipo adensado-drenado (CD) com solo saturado foram realizados com tensões confinantes de $50 \mathrm{kPa}, 100 \mathrm{kPa}$ e $150 \mathrm{kPa}$, como mencionado no item 4.8.11.1. A Figura 6.10a, b ilustra as curvas de variação volumétrica em função da raiz do tempo na etapa de adensamento para as tensões confinantes de $50 \mathrm{kPa}, 100 \mathrm{kPa}$ e 150 $\mathrm{kPa}$ dos corpos de prova moldados do bloco de amostra indeformada do pé e da crista do talude, respectivamente. Observa-se nessas figuras que ocorre uma rápida variação volumétrica para um curto intervalo de tempo, tendendo a estabilizar transcorrido esse intervalo. Além disso, nota-se que a variação volumétrica do corpo de prova tende aumentar conforme ocorra o aumento nos valores de tensão confinante. Ressalta-se que as medidas das variações volumétricas não estão associadas somente com o adensamento do corpo de prova, mas sim com as variações de todo conjunto formado pela câmara triaxial e o equipamento.

\section{Raiz do tempo (min)}

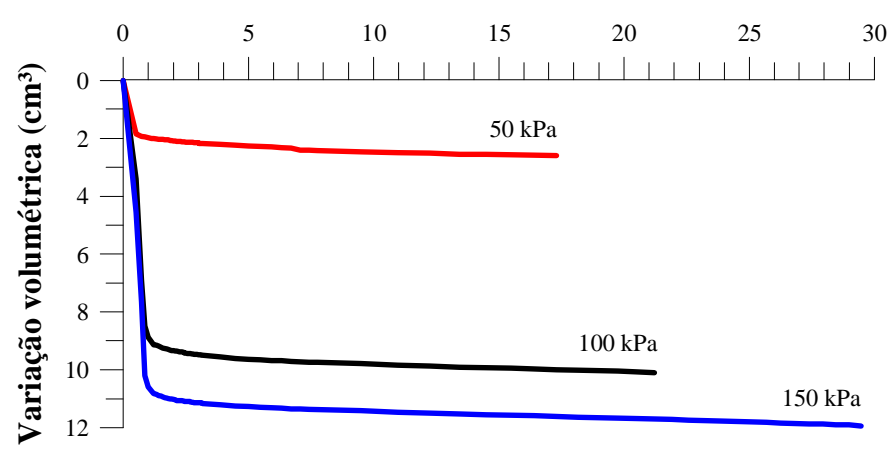

(a)

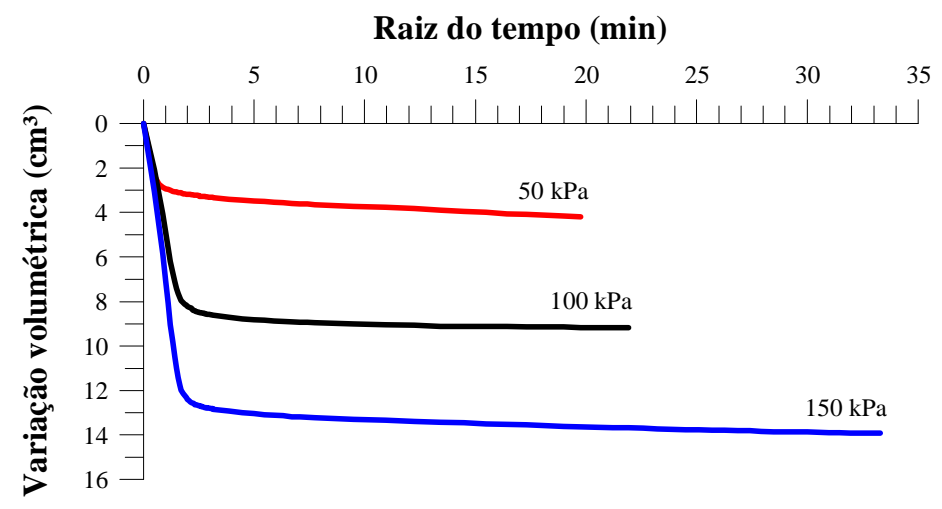

(b)

Figura 6.10 - Variação volumétrica versus raiz do tempo para o ensaio adensado-drenado com solo saturado utilizando (a) amostra indeformada do pé do talude e (b) amostra indeformada da crista do talude.

A Figura 6.11a,b representa as curvas tensão versus deformação para as tensões confinantes de $50 \mathrm{kPa}, 100 \mathrm{kPa}$ e $150 \mathrm{kPa}$ dos corpos de prova moldados do bloco de amostra indeformada do pé e da crista do talude, respectivamente. Observa-se que não ocorre um pico 
nas curvas da Figura 6.11 e que o aumento no incremento de tensão provoca um aumento gradual na deformação dos corpos de prova até atingir um valor de aproximadamente $20 \%$, momento em que a esta se estabiliza. Verifica-se que o corpo da amostra indeformada da crista do talude com tensão confinante de $50 \mathrm{kPa}$ não apresenta variação na deformação e no incremento de tensão, fato que pode estar associado aos pequenos ajustes necessários no equipamento no início da etapa de cisalhamento do corpo de prova.

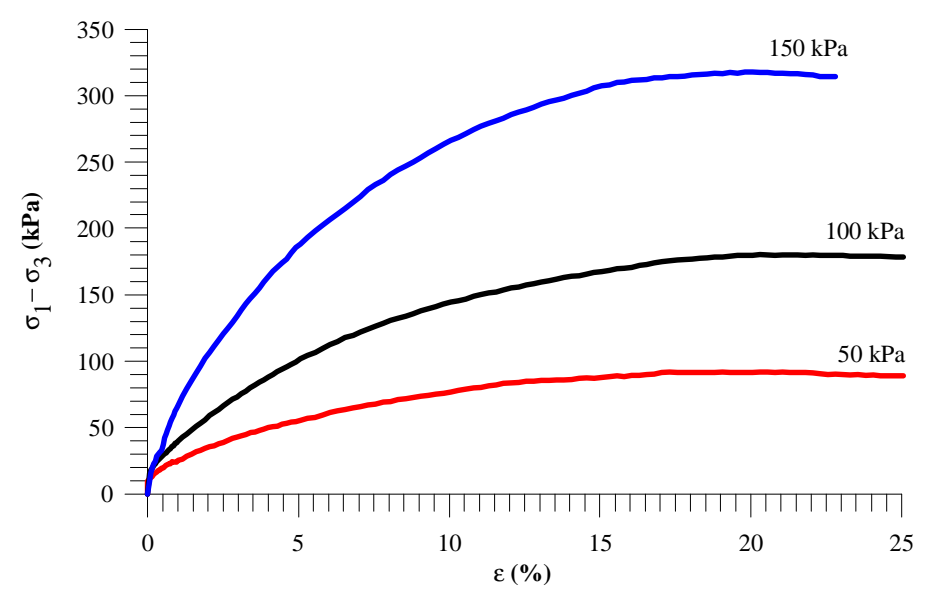

(a)

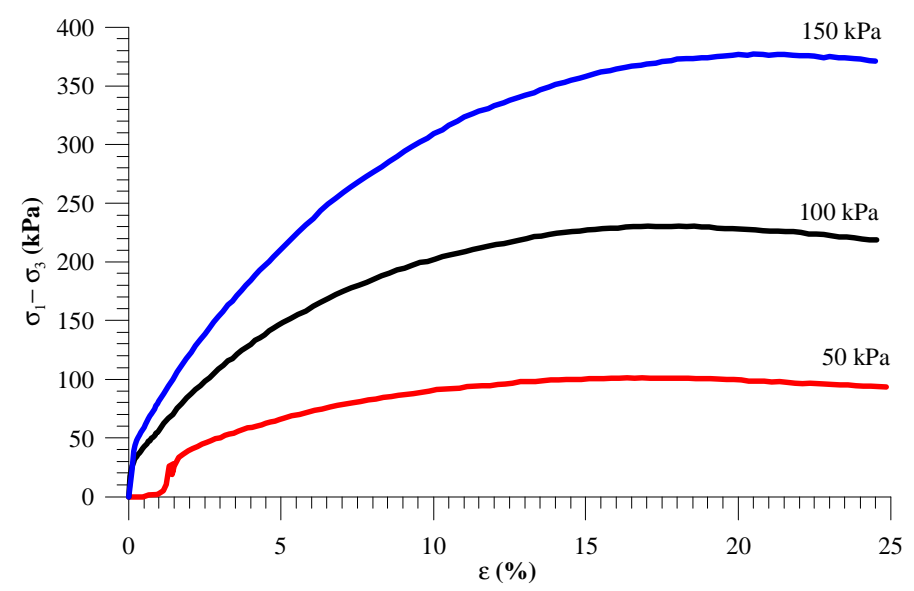

(b)

Figura 6.11 - Curva tensão versus deformação do ensaio adensado-drenado com solo saturado utilizando (a) amostra indeformada do pé do talude e (b) amostra indeformada da crista do talude.

A Tabela 6.9 reúne as características e os índices físicos dos corpos de prova utilizados no ensaio adensado-drenado com solo saturado. Observa-se nessa tabela que as dimensões dos corpos de prova (altura e diâmetro) são iguais, isso se deve ao fato de que em todas as moldagens dos corpos de prova foram utilizadas o mesmo molde. Além disso, verifica-se nessa tabela que ocorre uma pequena variação na massa desses corpos de prova, porém, essa discrepância quase não proporciona alterações nos valores dos seus índices 
físicos embora os blocos de amostra indeformada tivessem diferentes teores de umidade gravimétrica.

Tabela 6.9 - Características e índices físicos dos corpos de prova - ensaio adensado-drenado com solo saturado.

\begin{tabular}{|c|c|c|c|c|c|c|c|c|c|c|c|}
\hline \multirow{2}{*}{$\begin{array}{l}\text { Corpo } \\
\text { de } \\
\text { prova }\end{array}$} & \multirow{2}{*}{$\begin{array}{c}\text { Tensão } \\
\text { confi- } \\
\text { nante } \\
\text { (kPa) }\end{array}$} & \multicolumn{5}{|c|}{ Características } & \multicolumn{5}{|c|}{ Índices físicos } \\
\hline & & $\begin{array}{c}\boldsymbol{H} \\
(\mathbf{c m})\end{array}$ & $\begin{array}{c}D \\
(\mathbf{c m})\end{array}$ & $\begin{array}{c}V \\
\left(\mathbf{c m}^{3}\right)\end{array}$ & $\begin{array}{l}M \\
(\mathrm{~g})\end{array}$ & $\begin{array}{c}w_{\text {mold }} \\
(\%)\end{array}$ & $\begin{array}{c}\rho \\
\left(\mathrm{g} / \mathrm{cm}^{3}\right)\end{array}$ & $\begin{array}{c}\rho_{d} \\
\left(\mathrm{~g} / \mathrm{cm}^{3}\right)\end{array}$ & $\begin{array}{r}\boldsymbol{e} \\
(-)\end{array}$ & $\begin{array}{c}\eta \\
(\%)\end{array}$ & $\begin{array}{r}S_{r} \\
(\%)\end{array}$ \\
\hline \multirow{3}{*}{ Pé } & 50 & 10,03 & 4,97 & 194,5 & 296,3 & 2,49 & 1,524 & 1,487 & 0,79 & 44,0 & 8,4 \\
\hline & 100 & 10,03 & 4,97 & 194,5 & 296,6 & 2,78 & 1,525 & 1,484 & 0,79 & 44,1 & 9,4 \\
\hline & 150 & 10,03 & 4,97 & 194,5 & 308,7 & 5,71 & 1,588 & 1,502 & 0,77 & 43,4 & 19,8 \\
\hline \multirow{3}{*}{ Crista } & 50 & 10,03 & 4,97 & 194,5 & 309,1 & 3,74 & 1,590 & 1,533 & 0,73 & 42,3 & 13,6 \\
\hline & 100 & 10,03 & 4,97 & 194,5 & 304,3 & 3,85 & 1,565 & 1,507 & 0,76 & 43,2 & 13,4 \\
\hline & 150 & 10,03 & 4,97 & 194,5 & 303,6 & 3,18 & 1,562 & 1,514 & 0,75 & 43,0 & 11,2 \\
\hline
\end{tabular}

A Figura 6.12 e a Figura 6.13 apresentam as envoltórias de resistência MohrCoulomb, as quais foram determinadas por meio da trajetória de tensões para os corpos de prova do bloco de amostra indeformada do pé e da crista, respectivamente. Essas envoltórias representam a resistência em termos de tensão efetiva e o critério adotado para a máxima diferença de tensão foi quando a curva tensão-deformação atingiu seu maior valor, ou seja, $\left(\sigma_{1}-\sigma_{3}\right)_{\max }$. A Tabela 6.10 reúne os parâmetros de ajuste de envoltória de resistência em termos de tensões efetivas para as amostras do pé e da crista do talude.

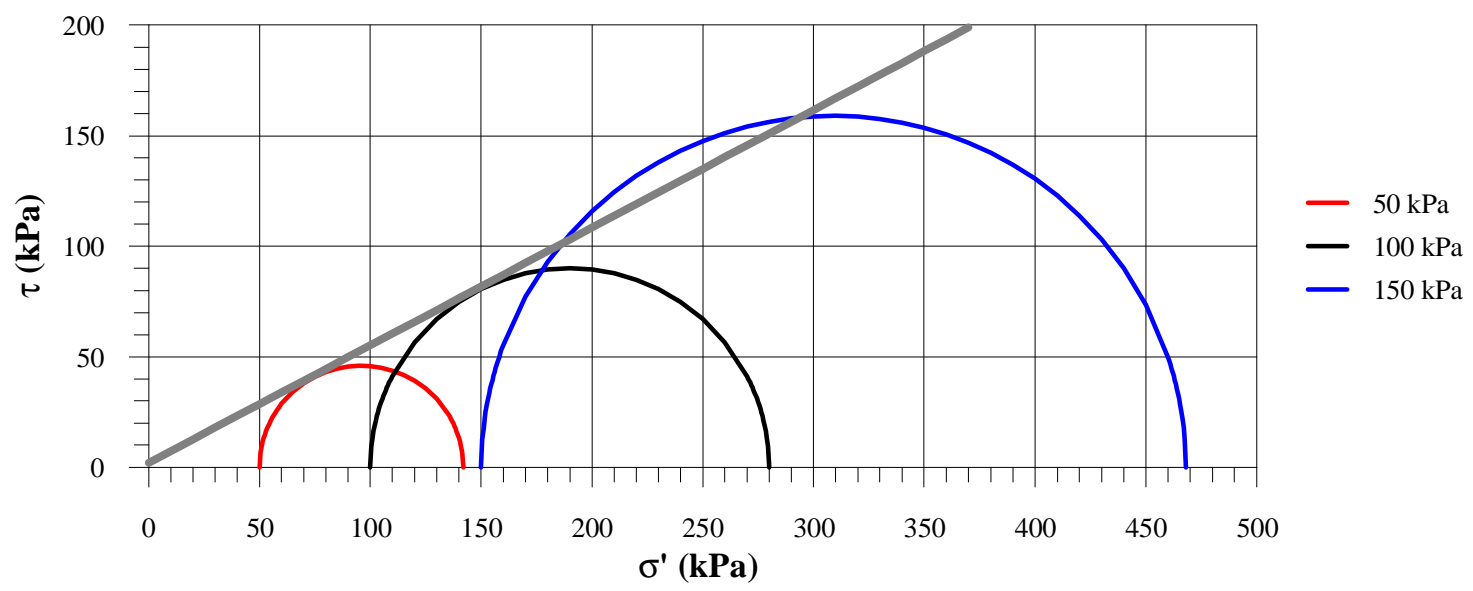

Figura 6.12 - Envoltória de resistência em termos de tensão efetiva do ensaio adensado-drenado com solo saturado - amostra indeformada do pé do talude. 


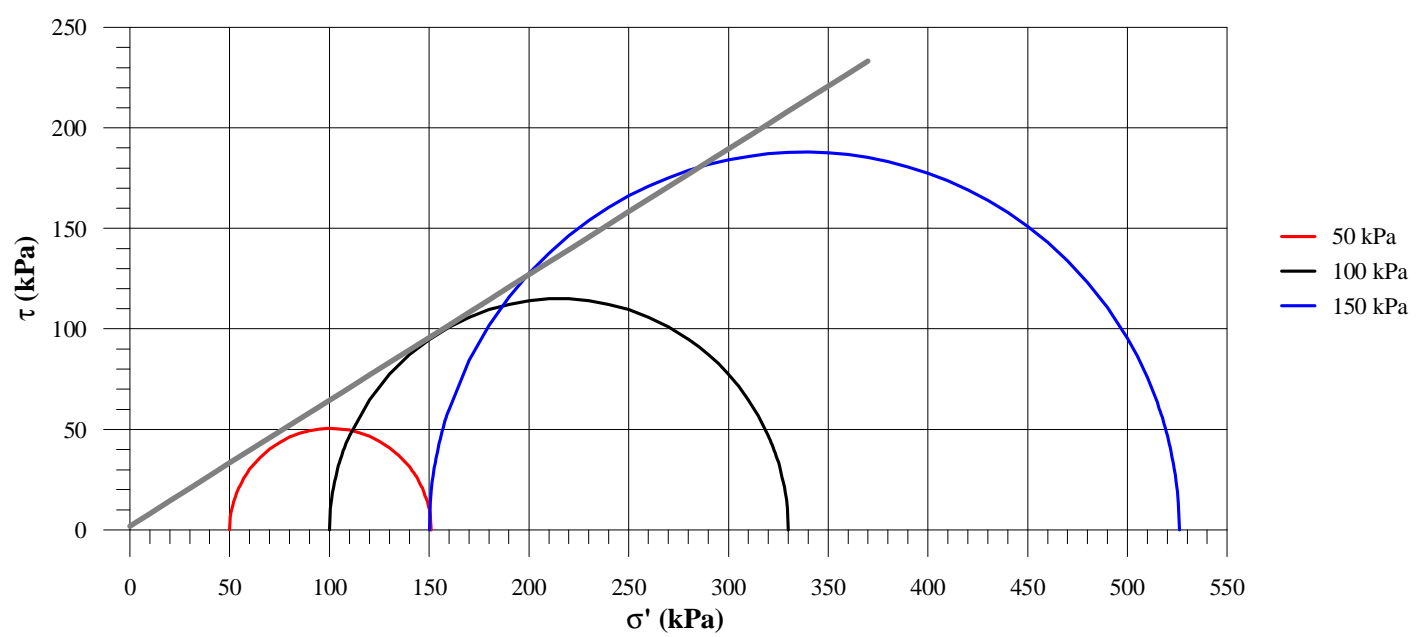

Figura 6.13 - Envoltória de resistência em termos de tensão efetiva do ensaio adensado-drenado com solo saturado - amostra indeformada da crista do talude.

Tabela 6.10 - Parâmetros efetivos de ajuste - ensaio adensado-drenado com solo saturado.

\begin{tabular}{|c|c|c|c|}
\hline Corpos de prova & $\begin{array}{c}c^{\prime} \\
(\mathbf{k P a})\end{array}$ & $\begin{array}{l}\phi^{\prime} \\
\left({ }^{\circ}\right)\end{array}$ & Envoltória de resistência \\
\hline Pé & 2,0 & 28,0 & $\tau=2+\sigma^{\prime} \cdot \operatorname{tg} 28^{\circ}$ \\
\hline Crista & 2,0 & 32,0 & $\tau=2+\sigma^{\prime} \cdot \operatorname{tg} 32^{\circ}$ \\
\hline
\end{tabular}

A Figura 6.14 apresenta a imagem do corpo de prova da amostra indeformada do pé do talude, no qual foi aplicada uma tensão confinante de $150 \mathrm{kPa}$, após seu cisalhamento. Observa-se que mesmo tendo sido retirada a membrana de látex, o corpo de prova permaneceu íntegro no pedestal de base, porém não foi possível identificar nitidamente e visualmente seu plano de ruptura.

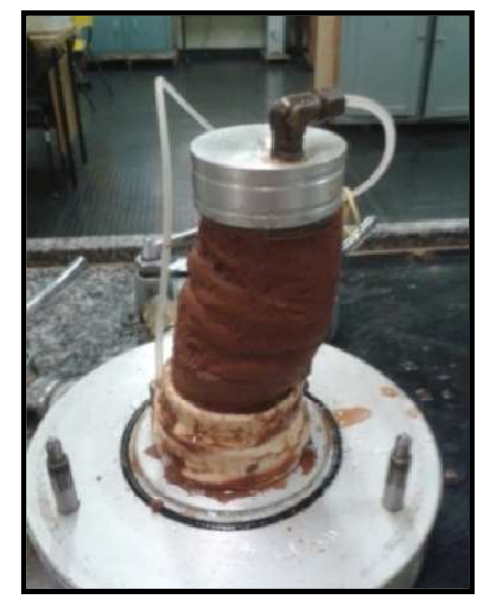

Figura 6.14 - Corpo de prova moldado do bloco de amostra indeformada do pé do talude, após o encerramento do cisalhamento utilizando tensão confinante de $150 \mathrm{kPa}$ no ensaio CD com solo saturado. 


\subsubsection{Ensaios para determinação da resistência do solo com teor de umidade natural (solo não saturado)}

Os ensaios de compressão triaxial com solo não saturado foram realizados com tensões confinantes de $50 \mathrm{kPa}, 100 \mathrm{kPa}$ e $150 \mathrm{kPa}$ para solo com teor de umidade natural. A Figura 6.15a, b ilustra as curvas de variação volumétrica em função da raiz do tempo na etapa de adensamento para as tensões confinantes de $50 \mathrm{kPa}, 100 \mathrm{kPa}$ e $150 \mathrm{kPa}$ dos corpos de prova moldados do bloco de amostra indeformada do pé e da crista do talude, respectivamente. Observa-se nessas figuras que há uma alteração na variação volumétrica dos corpos de prova independente do valor de tensão confinante utilizada, sendo maiores nos corpos de prova sujeitos às tensões confinantes de $50 \mathrm{kPa}$ (amostra indeformada do pé e da crista do talude).

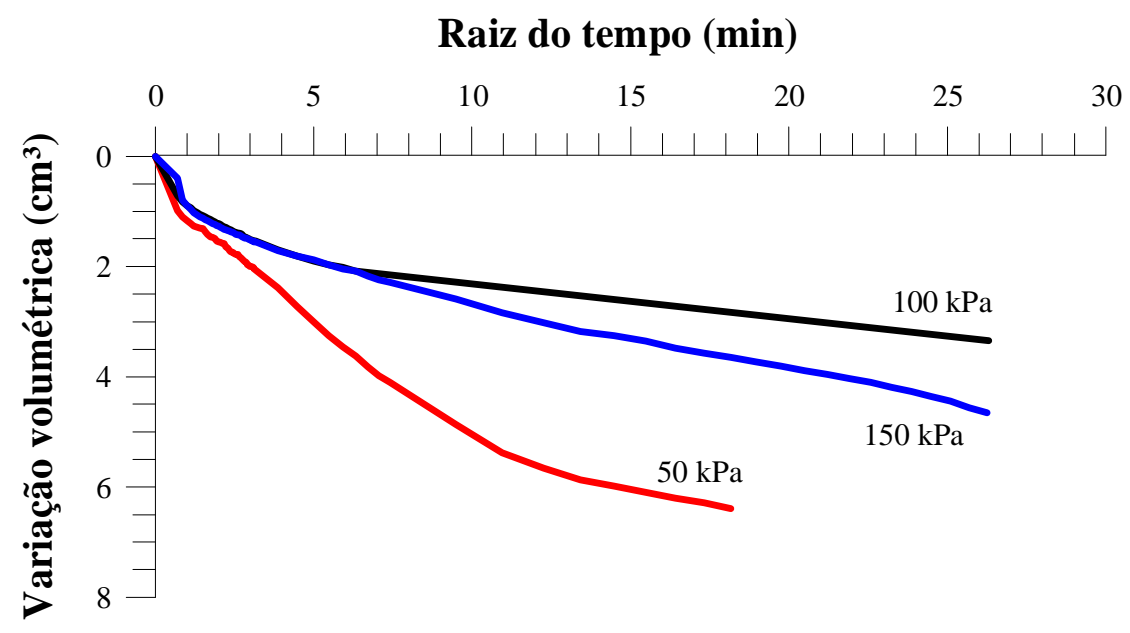

(a)

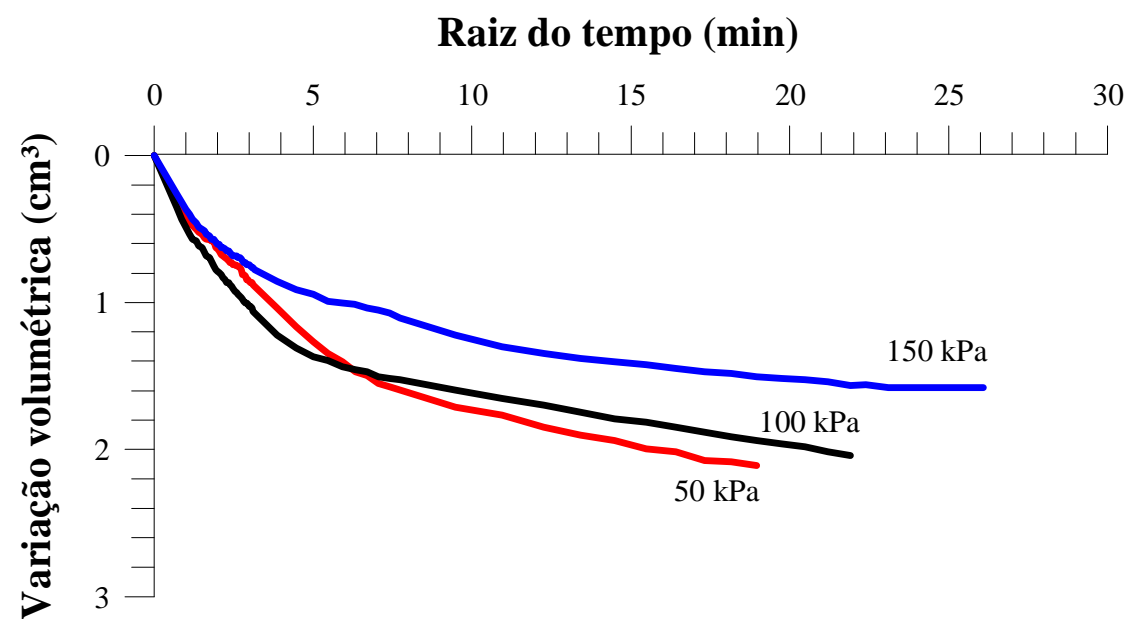

(b)

Figura 6.15 - Variação volumétrica versus raiz do tempo do ensaio com solo no teor de umidade natural utilizando (a) amostra indeformada do pé do talude e (b) amostra indeformada da crista do talude.

A Figura 6.16a,b representa as curvas tensão versus deformação para as tensões 
confinantes de $50 \mathrm{kPa}, 100 \mathrm{kPa}$ e $150 \mathrm{kPa}$ dos corpos de prova moldados do bloco de amostra indeformada do pé e da crista, respectivamente. Nota-se que o formato da curva do corpo de prova da amostra indeformada do pé do talude no qual é aplicada uma tensão confinante de $150 \mathrm{kPa}$ não apresenta comportamento similar aos demais, os quais tendem possuir um pico bem sutil.

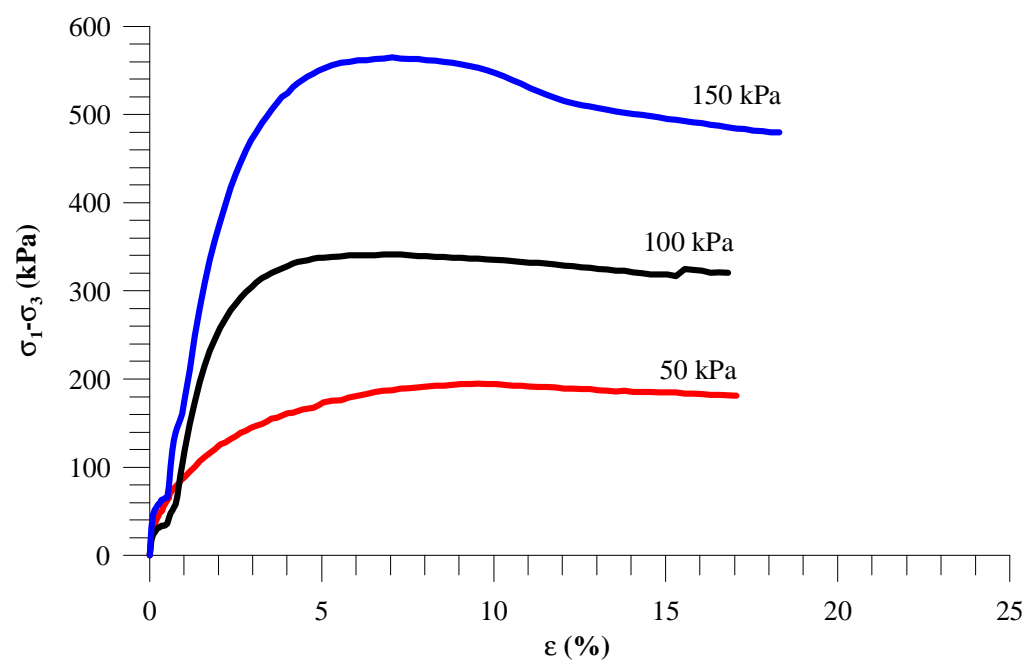

(a)

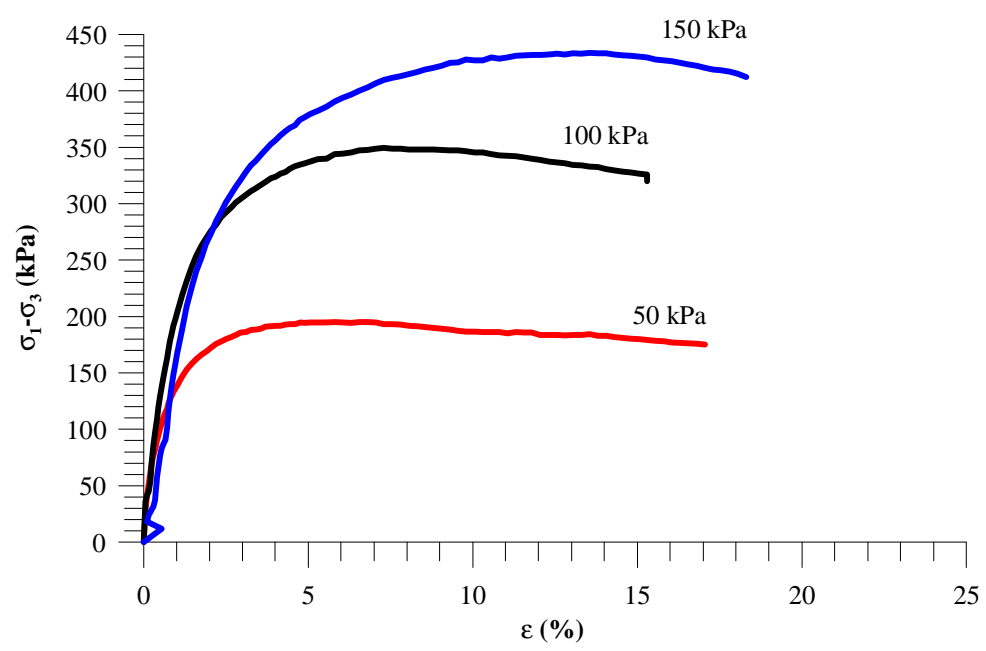

(b)

Figura 6.16 - Curva tensão versus deformação do ensaio com solo no teor de umidade natural utilizando (a) amostra indeformada do pé do talude e (b) amostra indeformada da crista do talude.

A Tabela 6.11 reúne as características e os índices físicos dos corpos de prova utilizados no ensaio para determinação da resistência do solo com teor de umidade natural. Os índices físicos desses corpos de prova apresentam uma pequena faixa de variação, assim como registrado para os corpos de prova dos outros ensaios. Observa-se maior variação na massa do corpo de prova moldado da amostra indeformada do pé do talude sujeito a tensão 
confinante de $150 \mathrm{kPa}$, o qual variou em torno de $7 \%$ se comparado com os demais corpos de prova.

Tabela 6.11 - Características e índices físicos dos corpos de prova - ensaio para determinação da resistência do solo com teor de umidade natural.

\begin{tabular}{|c|c|c|c|c|c|c|c|c|c|c|c|}
\hline \multirow{2}{*}{$\begin{array}{c}\text { Corpo } \\
\text { de } \\
\text { prova }\end{array}$} & \multirow{2}{*}{$\begin{array}{c}\text { Tensão } \\
\text { confi- } \\
\text { nante } \\
(\mathbf{k P a})\end{array}$} & \multicolumn{5}{|c|}{ Características } & \multicolumn{5}{|c|}{ Índices físicos } \\
\hline & & $\begin{array}{c}\boldsymbol{H} \\
(\mathbf{c m})\end{array}$ & $\begin{array}{c}D \\
(\mathrm{~cm})\end{array}$ & $\begin{array}{c}V \\
\left(\mathbf{c m}^{3}\right)\end{array}$ & $\begin{array}{l}M \\
(\mathrm{~g})\end{array}$ & $\begin{array}{c}\boldsymbol{w}_{\text {mold }} \\
(\%)\end{array}$ & $\begin{array}{c}\rho \\
\left(\mathrm{g} / \mathrm{cm}^{3}\right)\end{array}$ & $\begin{array}{c}\rho_{d} \\
\left(\mathrm{~g} / \mathrm{cm}^{3}\right)\end{array}$ & $\begin{array}{r}e \\
(-)\end{array}$ & $\begin{array}{c}\eta \\
(\%)\end{array}$ & $\begin{array}{r}S_{r} \\
(\%)\end{array}$ \\
\hline \multirow{3}{*}{ Pé } & 50 & 10,03 & 4,97 & 194,5 & 298,06 & 2,83 & 1,533 & 1,490 & 0,781 & 43,8 & 9,6 \\
\hline & 100 & 10,03 & 4,97 & 194,5 & 302,04 & 2,50 & 1,533 & 1,515 & 0,752 & 42,9 & 8,8 \\
\hline & 150 & 10,03 & 4,97 & 194,5 & 321,71 & 1,82 & 1,654 & 1,626 & 0,632 & 38,7 & 7,6 \\
\hline \multirow{3}{*}{ Crista } & 50 & 10,03 & 4,97 & 194,5 & 293,59 & 2,27 & 1,509 & 1,476 & 0,798 & 44,4 & 7,6 \\
\hline & 100 & 10,03 & 4,97 & 194,5 & 298,58 & 1,85 & 1,535 & 1,507 & 0,761 & 43,2 & 6,5 \\
\hline & 150 & 10,03 & 4,97 & 194,5 & 295,92 & 1,92 & 1,521 & 1,493 & 0,778 & 43,8 & 6,6 \\
\hline
\end{tabular}

A Tabela 6.12 apresenta o valor da sucção matricial medida após o encerramento do ensaio com o uso da Técnica do Papel Filtro bem como o valor do teor de umidade gravimétrico de cada corpo de prova.

Tabela 6.12 - Sucção e teor de umidade gravimétrico dos corpos de prova após o encerramento do ensaio para determinação da resistência do solo com teor de umidade natural.

\begin{tabular}{|c|c|c|c|}
\hline Corpo de prova & $\begin{array}{c}\text { Tensão confinante } \\
(\mathbf{k P a})\end{array}$ & $\begin{array}{c}\text { Sucção calculada } \\
(\mathbf{k P a})\end{array}$ & $\begin{array}{c}w \\
(\%)\end{array}$ \\
\hline \multirow{3}{*}{ Pé } & 50 & 20017 & 3,00 \\
\hline & 100 & 20167 & 2,62 \\
\hline & 150 & 19742 & 2,82 \\
\hline \multirow{3}{*}{ Crista } & 50 & 20943 & 1,99 \\
\hline & 100 & 20384 & 2,20 \\
\hline & 150 & 13394 & 1,51 \\
\hline
\end{tabular}


A Figura 6.17 e a Figura 6.18 apresentam as envoltórias de resistência Mohr-Coulomb para os corpos de prova do bloco de amostra indeformada do pé e da crista do talude, respectivamente. Essas envoltórias representam a resistência do solo em termos de tensão efetiva e o critério adotado para a máxima diferença de tensão foi quando a curva tensãodeformação atingiu seu maior valor, ou seja, $\left(\sigma_{1}-\sigma_{3}\right)_{\max }$.

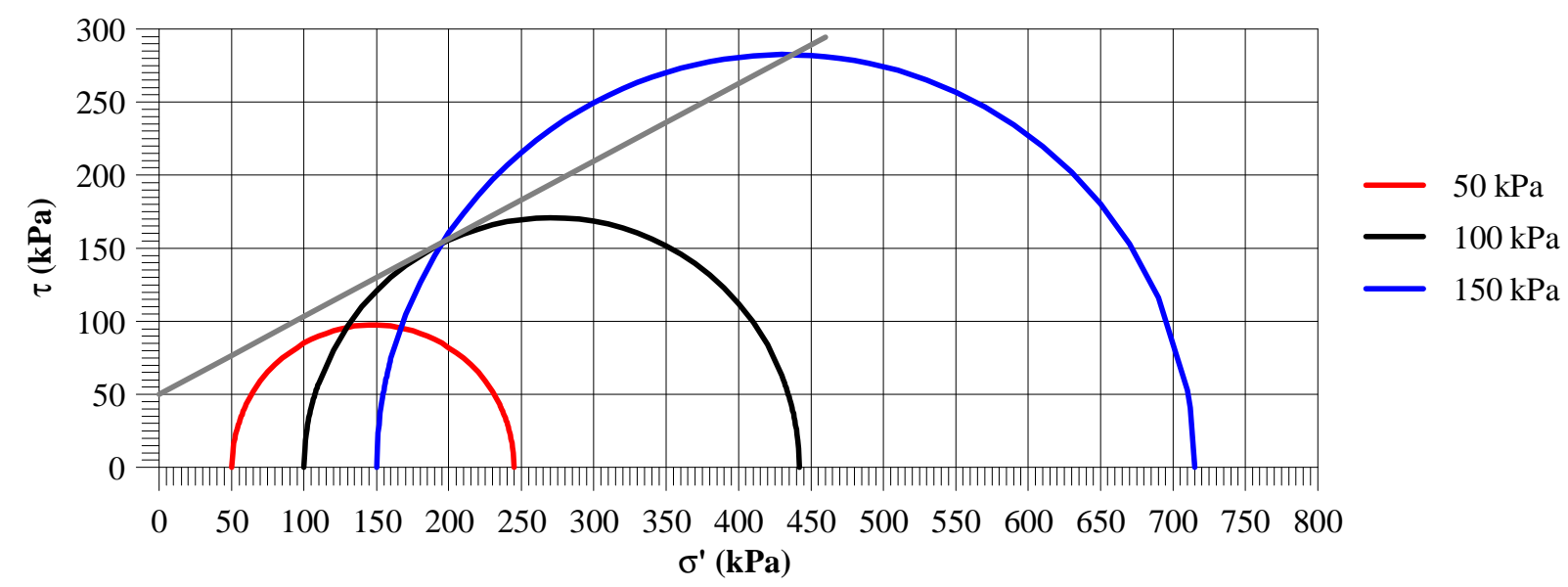

Figura 6.17 - Envoltória de resistência em termos de tensão efetiva do ensaio para determinação da resistência do solo com teor de umidade natural - amostra indeformada do pé do talude.

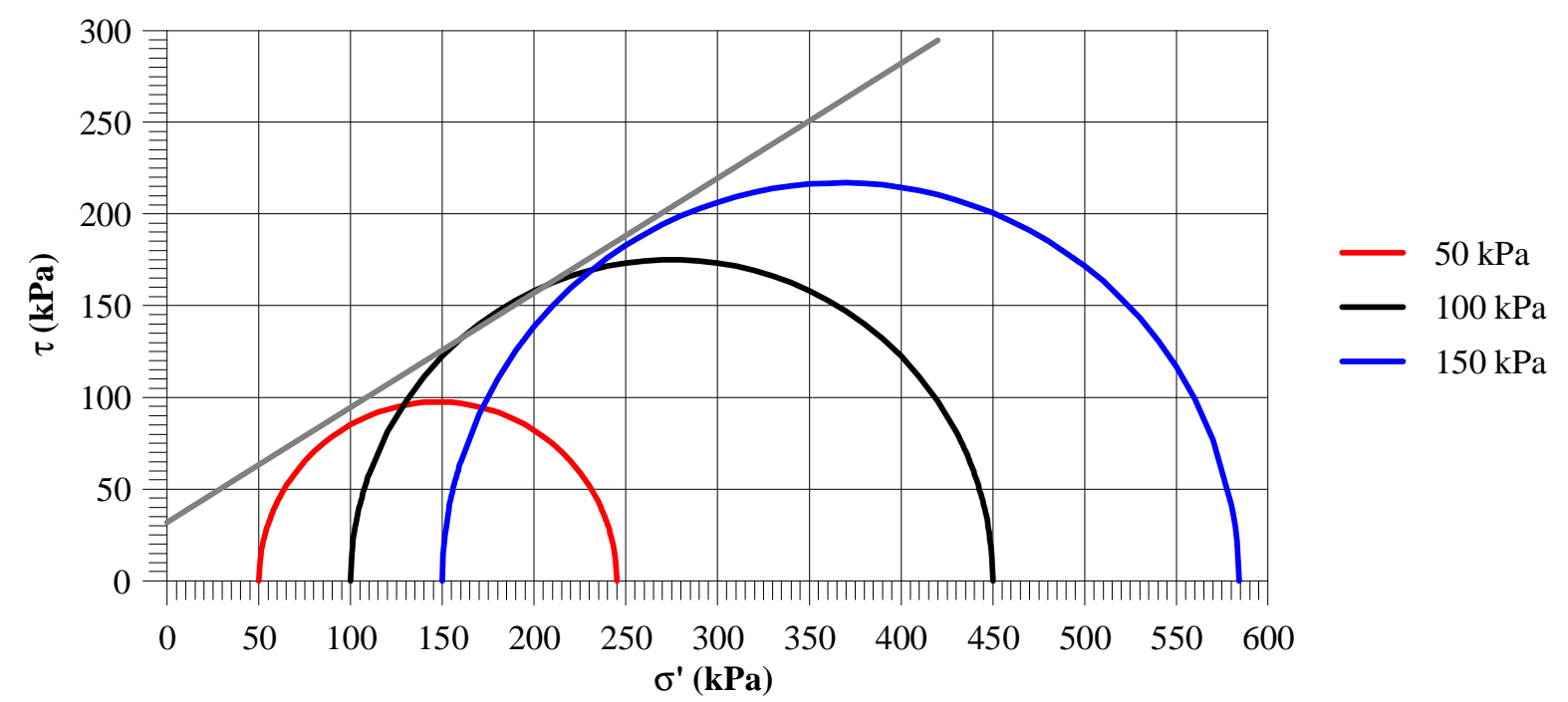

Figura 6.18 - Envoltória de resistência em termos de tensão efetiva do ensaio para determinação da resistência do solo com teor de umidade natural - amostra indeformada da crista do talude.

A Tabela 6.13 reúne os parâmetros de ajuste definidos a partir da envoltória de resistência em termos de tensões efetivas para as amostras do pé e da crista do talude além dos parâmetros de ajuste calculados utilizando o método de Vilar (2007) para previsão da resistência do solo não saturado (item 3.7.3.2). 
Tabela 6.13 - Parâmetros efetivos de ajuste e previsão da resistência ao cisalhamento do solo não saturado utilizando método de Vilar (2007) - ensaio determinação da resistência do solo com teor de umidade natural.

\begin{tabular}{|c|c|c|c|c|c|c|}
\hline Corpos de prova & $\begin{array}{c}c^{\prime} \\
(\mathbf{k P a})\end{array}$ & $\begin{array}{l}\phi^{\prime} \\
\left(^{\circ}\right)\end{array}$ & $\begin{array}{c}c_{m} \\
(\mathbf{k P a})\end{array}$ & $\begin{array}{l}a_{v} \\
(-)\end{array}$ & $\begin{array}{c}\boldsymbol{b}_{v} \\
\left(\mathbf{k P a}^{-1}\right)\end{array}$ & $\begin{array}{c}\left(\boldsymbol{u}_{\boldsymbol{a}}-\boldsymbol{u}_{w}\right)_{m} \\
(\mathbf{k P a})\end{array}$ \\
\hline Pé & 2,0 & 28,0 & 50,0 & 1,881 & 0,0207 & 19975 \\
\hline Crista & 2,0 & 32,0 & 32,0 & 1,600 & 0,0332 & 18240 \\
\hline
\end{tabular}

A Figura 6.19 ilustra as curvas de previsão da resistência ao cisalhamento utilizando os dados de ajustes calculados por meio do método de Vilar (2007) para as amostras indeformadas do pé e da crista do talude. Nota-se na Figura 6.19 que a coesão aparente é inferior a $50 \mathrm{kPa}$, isso se deve ao fato do intervalo de sucção adotado para representação gráfica da variação da coesão em função da sucção matricial (0 a 500 kPa).

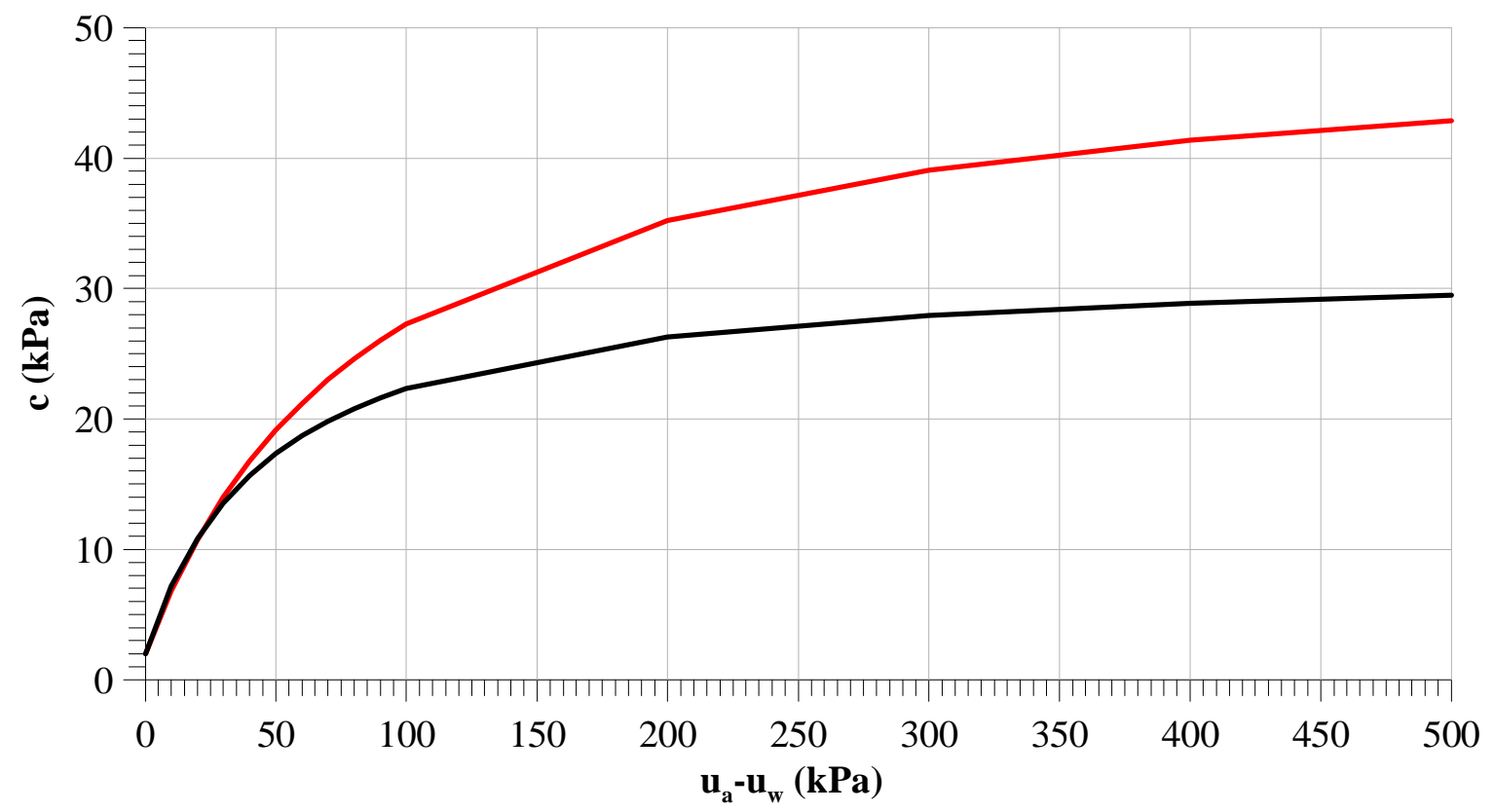

— Ajuste utilizando o método de Vilar (2007) - amostra indeformada do pé do talude

— Ajuste utilizando o método de Vilar (2007) - amostra indeformada da crista do talude

Figura 6.19 - Previsão de resistência ao cisalhamento do solo não saturado a partir do método de Vilar (2007) para amostra indeformada do pé e da crista do talude.

Já a Figura 6.20 apresenta o corpo de prova da amostra indeformada do pé do talude após seu cisalhamento, no qual foi aplicado uma tensão confinante de $100 \mathrm{kPa}$. Embora o corpo de prova esteja bem frágil após o encerramento do ensaio de compressão triaxial e a remoção da membrana de látex, é possível observar um provável plano de ruptura. 


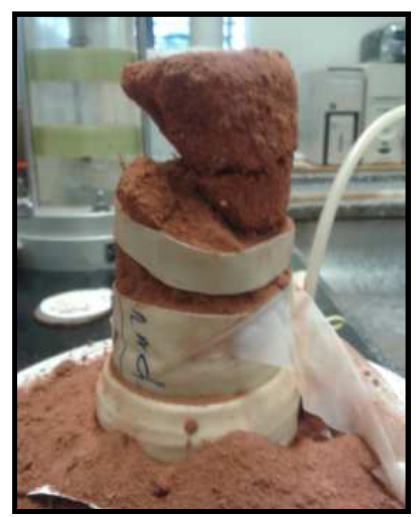

Figura 6.20 - Corpo de prova moldado do bloco de amostra indeformada da crista do talude após o cisalhamento utilizando tensão confinante de $100 \mathrm{kPa}$.

\subsubsection{Ensaios adensado-drenado (CD) com solo não saturado}

Os ensaios de compressão triaxial do tipo adensado-drenado (CD) com solo não saturado foram realizados com tensões confinantes líquida de $50 \mathrm{kPa}, 100 \mathrm{kPa}$ e $150 \mathrm{kPa}$ para sucção de $30 \mathrm{kPa}$. Cada corpo de prova foi saturado e desaturado seguindo as instruções comentadas no item 4.8.11.3, até que o mesmo atingisse o teor de umidade necessário para realização do ensaio propriamente dito.

A Figura 6.21 representa a curva de variação volumétrica em função da raiz do tempo na etapa de adensamento para a tensão confinantes líquida de $50 \mathrm{kPa}, 100 \mathrm{kPa}$ e $150 \mathrm{kPa}$ dos corpos de prova moldados do bloco de amostra indeformada da crista do talude. Observa-se que a curva do corpo de prova sujeito a uma tensão confinante líquida de $150 \mathrm{kPa}$ foi superior do que para as demais tensões, apresentando comportamento diferente das curvas obtidas nos ensaios adensado-drenado. Mais uma vez ressalta-se que as medidas das variações volumétricas não estão associadas somente com o adensamento do corpo de prova, mas sim com as variações de todo conjunto formado pela câmara triaxial e o equipamento.

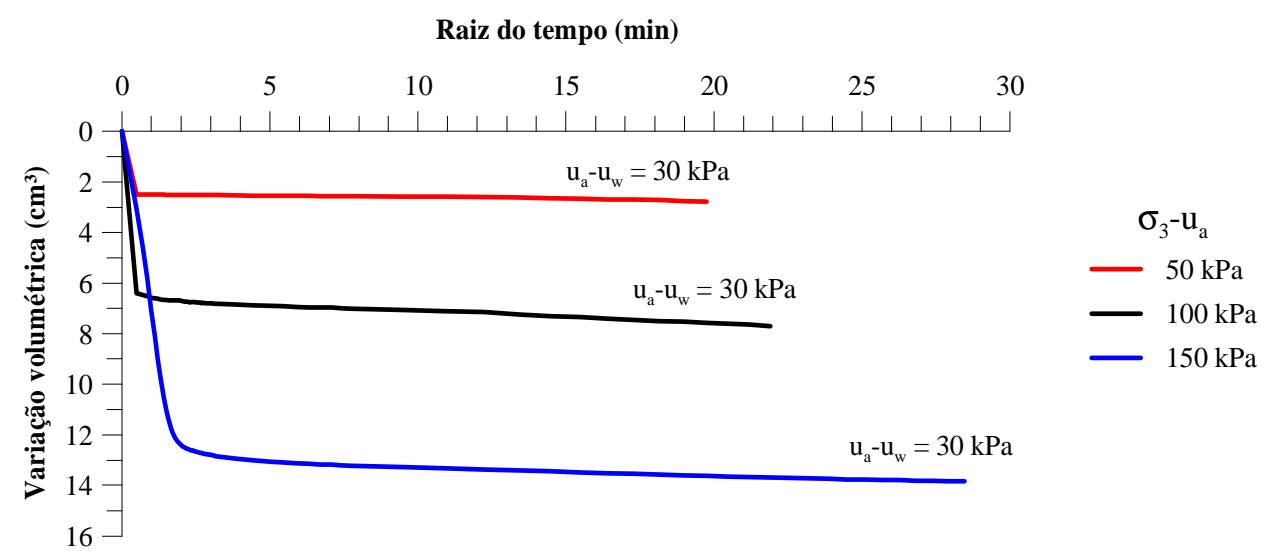

Figura 6.21 - Variação volumétrica versus raiz do tempo para o ensaio adensado-drenado com solo não saturado ( sucção de $30 \mathrm{kPa}$ ) utilizando amostra indeformada da crista do talude. 
A Figura 6.22 representa as curvas tensão versus deformação, sendo a tensão representada pela diferença de tensões $\left(\sigma_{1}-\sigma_{3}\right)$. Constata-se a partir da Figura 6.22 que o comportamento das curvas tensão-deformação do solo não saturado é semelhante às curvas apresentadas nos ensaios adensado-drenado com solo saturado. Também nota-se que a diferença de tensão aumenta em função do aumento dos valores de tensão líquida confinante. Já a Figura 6.23 representa como a relação da diferença de tensão e sucção varia conforme ocorra a deformação do corpo de prova, na qual observa-se que a relação se mantém sempre constante, garantindo que a sucção permanece inalterada ao longo de todo o ensaio.

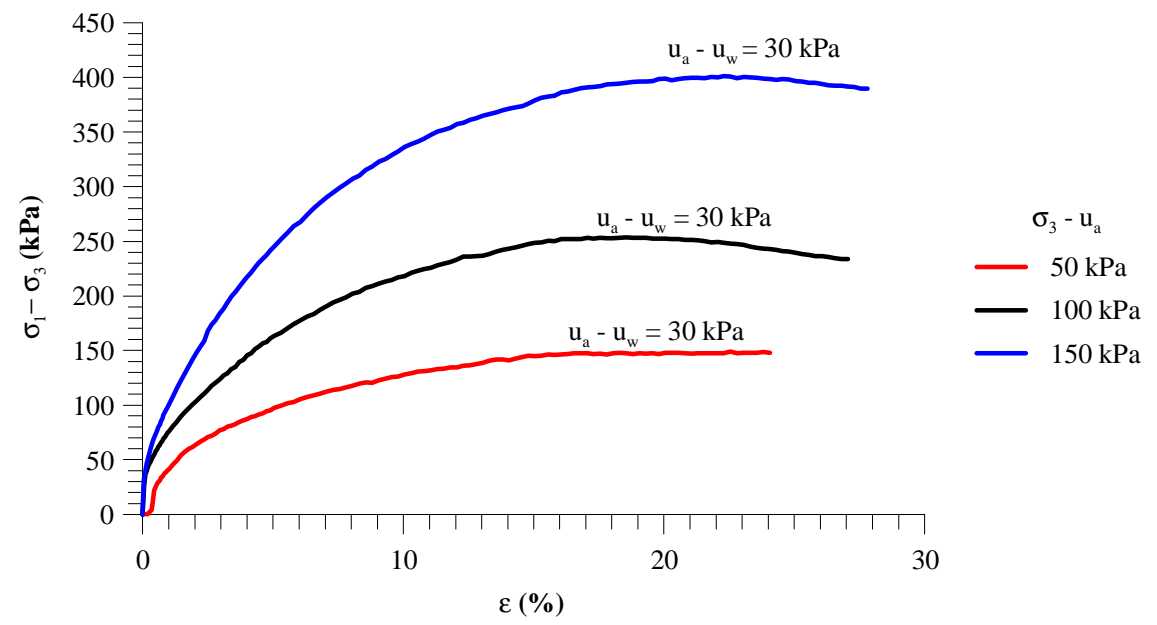

Figura 6.22 - Curvas tensão versus deformação do ensaio adensado-drenado com solo não saturado (sucção de $30 \mathrm{kPa})$ para amostra indeformada da crista do talude.

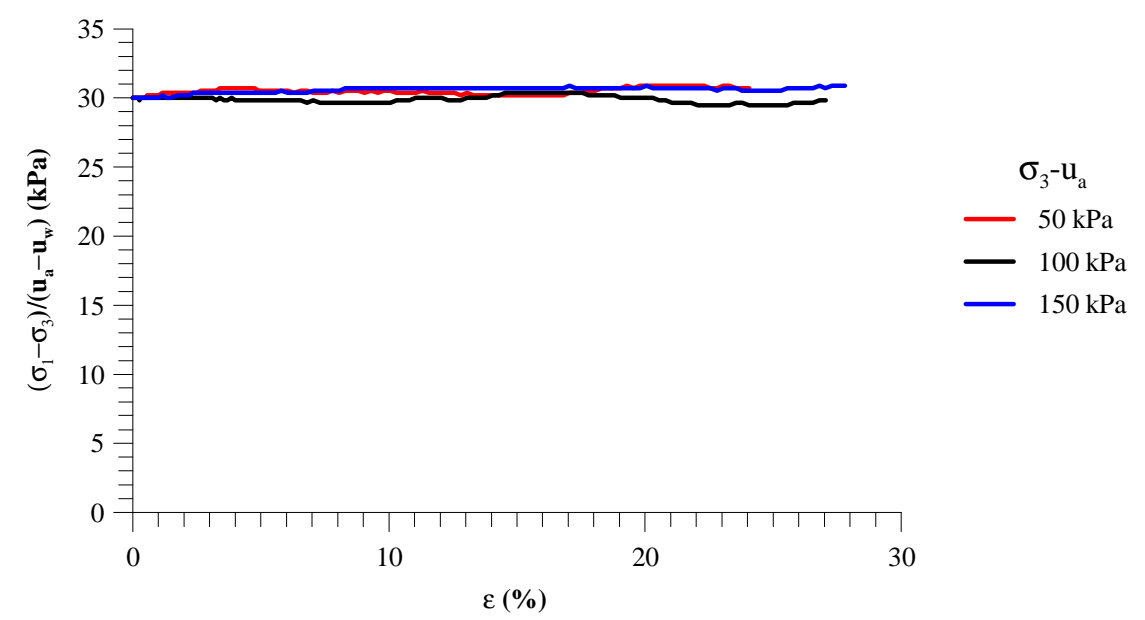

Figura 6.23 - Relação entre $\left(\sigma_{1}-\sigma_{3}\right) /\left(u_{a}-u_{w}\right)$ versus deformação do ensaio adensado-drenado com solo não saturado (sucção de $30 \mathrm{kPa}$ ) para amostra indeformada da crista do talude.

A Tabela 6.14 reúne as características e os índices físicos dos corpos de prova utilizados no ensaio adensado-drenado com solo não saturado. Observa-se que ocorre uma pequena variação na massa desses corpos de prova, porém, essa discrepância praticamente não afeta nos valores dos seus índices físicos. 
Tabela 6.14 - Características e índices físicos dos corpos de prova - ensaio adensado-drenado com solo não saturado (sucção de $30 \mathrm{kPa}$ ).

\begin{tabular}{|c|c|c|c|c|c|c|c|c|c|c|c|}
\hline \multirow{2}{*}{$\begin{array}{c}\text { Corpo } \\
\text { de prova }\end{array}$} & \multirow{2}{*}{$\begin{array}{c}\text { Tensão } \\
\text { confinante } \\
\text { líquida } \\
\text { (kPa) }\end{array}$} & \multicolumn{5}{|c|}{ Características } & \multicolumn{5}{|c|}{ Índices físicos } \\
\hline & & $\begin{array}{c}H \\
(\mathbf{c m})\end{array}$ & $\begin{array}{c}D \\
(\mathbf{c m})\end{array}$ & $\begin{array}{c}V \\
\left(\mathbf{c m}^{3}\right)\end{array}$ & $\begin{array}{l}M \\
(\mathbf{g})\end{array}$ & $\begin{array}{c}w_{\text {mold }} \\
(\%)\end{array}$ & $\begin{array}{c}\rho \\
\left(\mathrm{g} / \mathrm{cm}^{3}\right)\end{array}$ & $\begin{array}{c}\rho_{d} \\
\left(\mathrm{~g} / \mathrm{cm}^{3}\right)\end{array}$ & $\begin{array}{r}e \\
(-)\end{array}$ & $\begin{array}{c}\eta \\
(\%)\end{array}$ & $\begin{array}{c}S_{r} \\
(\%)\end{array}$ \\
\hline \multirow{3}{*}{ Crista } & 50 & 10,01 & 4,98 & 195,0 & 313,3 & 6,51 & 1,607 & 1,490 & 0,78 & 43,8 & 22,2 \\
\hline & 100 & 10,36 & 4,99 & 202,6 & 320,7 & 6,51 & 1,583 & 1,515 & 0,75 & 42,9 & 23,0 \\
\hline & 150 & 9,99 & 4,95 & 192,3 & 313,6 & 5,67 & 1,631 & 1,626 & 0,63 & 38,7 & 23,9 \\
\hline
\end{tabular}

A Figura 6.24 apresenta a envoltória de resistência Mohr-Coulomb do ensaio adensado-drenado com solo não saturado (sucção de $30 \mathrm{kPa}$ ), a qual foi determinada com o uso da equação (36) proposta por Fredlund, Morgenster e Widger (1978), enquanto que a Tabela 6.15 mostra os parâmetros resultantes desse ajuste.

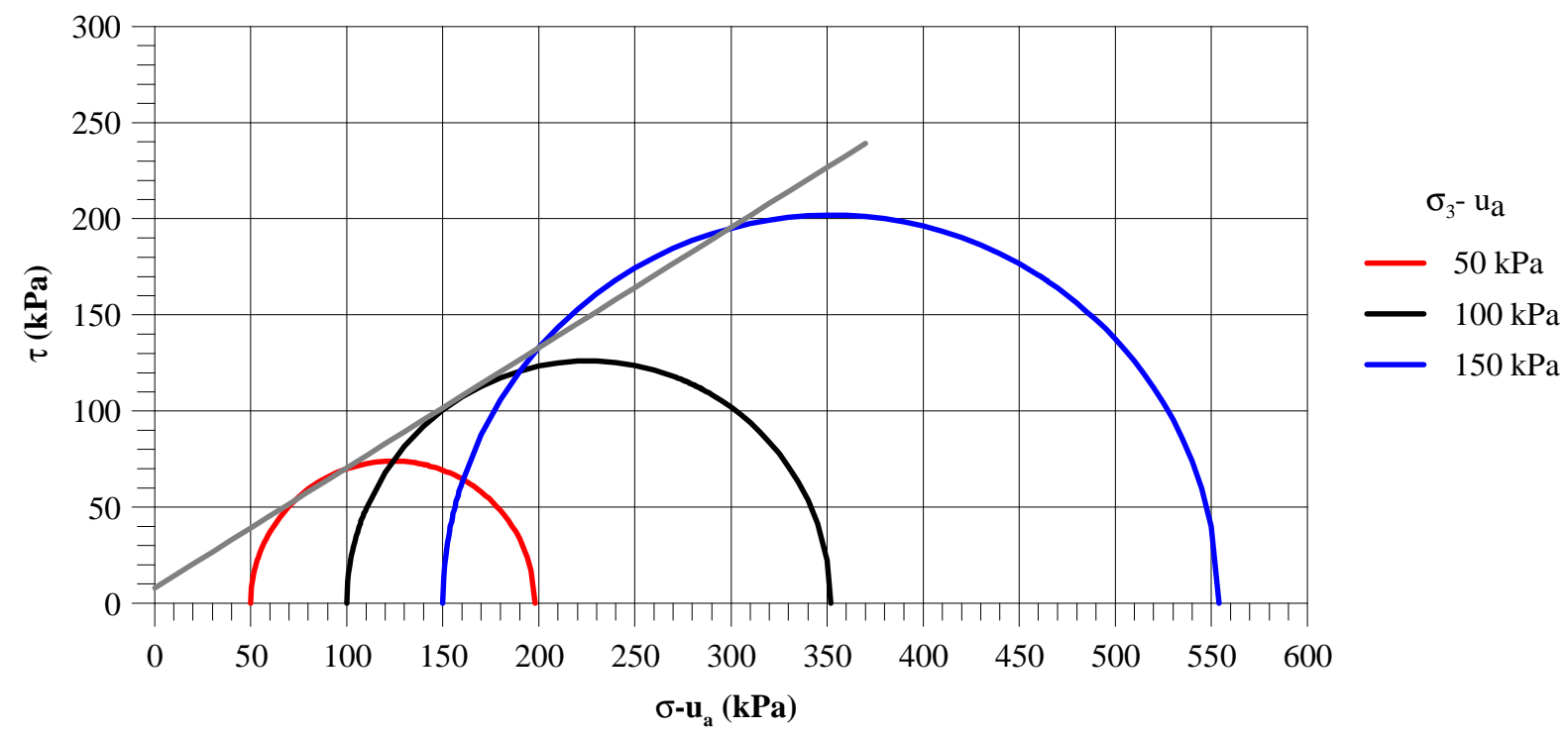

Figura 6.24 - Envoltória de resistência em termos de tensão efetiva do ensaio adensado-drenado com solo não saturado (sucção de $30 \mathrm{kPa}$ ) - amostra indeformada da crista do talude.

Tabela 6.15 - Parâmetros efetivos de ajuste - ensaio adensado-drenado com solo não saturado (sucção de 30 $\mathrm{kPa})$.

\begin{tabular}{ccccc}
\hline Corpos de prova & $\boldsymbol{c}^{\prime}$ & $\boldsymbol{\phi}^{\prime}$ & $\boldsymbol{\phi}^{\boldsymbol{b}}$ & Envoltória de resistência \\
& $(\mathbf{k P a})$ & $\left(^{\circ}\right)$ & $\left(^{\circ}\right)$ & \\
\hline Crista & 2,0 & 32,0 & 11,3 & $\tau=2+\left(\sigma-u_{a}\right) \cdot \operatorname{tg} 32^{\circ}+\left(u_{a}-u_{w}\right) \cdot \operatorname{tg} 11,3^{\circ}$ \\
\hline
\end{tabular}


A Figura 6.25a,b ilustra os corpos de prova após a etapa de cisalhamento e conclusão de cada ensaio, nos quais foram aplicados tensão confinante líquida de $50 \mathrm{kPa}$ e $150 \mathrm{kPa}$, respectivamente. Já a Tabela 6.16 reúne os valores referentes ao teor de umidade gravimétrico de cada corpo de prova, em que a média dos teores de umidade gravimétrica $(5,59 \%)$ corresponde à sucção matricial de aproximadamente $6 \mathrm{kPa}$ na curva de retenção da água no solo, podendo ser um indicativo de que o corpo de prova não estava com a sucção matricial de $30 \mathrm{kPa}$ durante a realização desse ensaio.

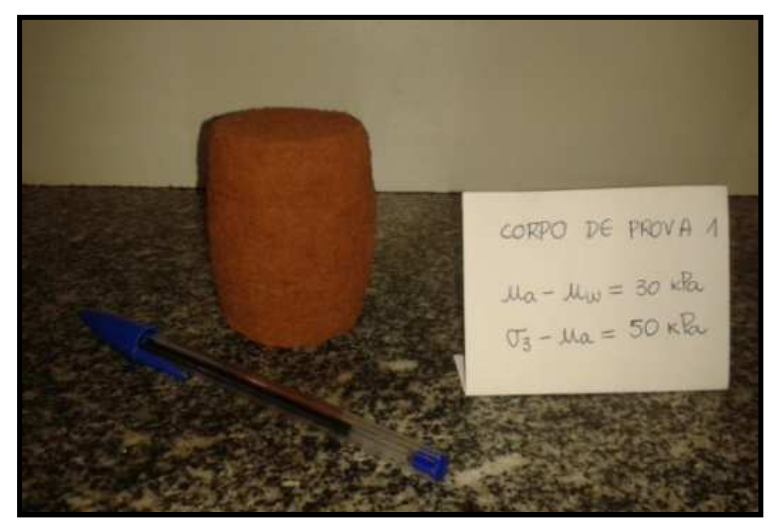

(a)

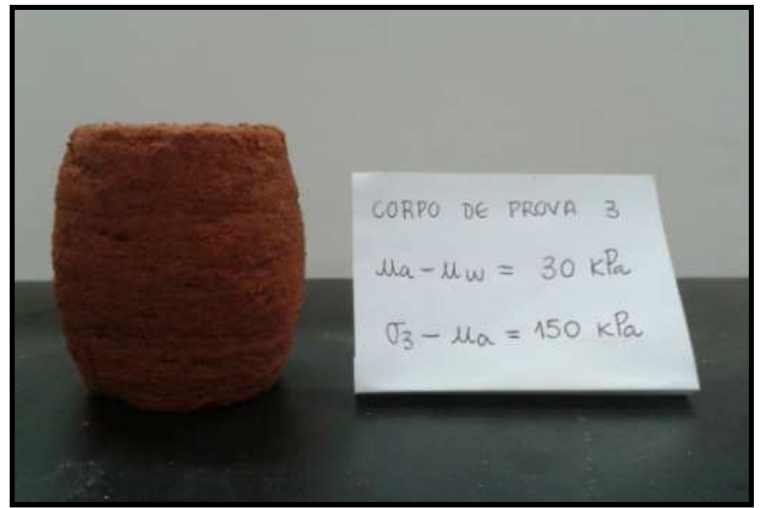

(b)

Figura 6.25 - Corpos de prova após o encerramento do ensaio adensado-drenado com solo não saturado utilizando sucção inicial de $30 \mathrm{kPa}$ e tensão confinante líquida de (a) $50 \mathrm{kPa}$ e (b) $150 \mathrm{kPa}$.

Tabela 6.16 - Teor de umidade gravimétrico dos corpos de prova após o encerramento do ensaio adensadodrenado com solo não saturado.

\begin{tabular}{cccc}
\hline $\begin{array}{c}\text { Corpo de } \\
\text { prova }\end{array}$ & $\left(\boldsymbol{\sigma}_{\mathbf{3}}-\boldsymbol{u}_{\boldsymbol{a}}\right)$ & Sucção empregada & $\boldsymbol{w}$ \\
& $(\mathbf{k P a})$ & $(\mathbf{k P a})$ & $(\boldsymbol{\%})$ \\
\hline Crista & 50 & 30 & 5,14 \\
\cline { 2 - 4 } & 100 & 30 & 5,98 \\
\hline
\end{tabular}

\subsection{INSTRUMENTAÇÃO E MONITORAMENTO}

\subsubsection{Monitoramento da Sucção Matricial}

A sucção matricial foi medida em campo com o uso de dezoito tensiômetros, tendo sido monitorados no período de 24 de dezembro de 2013 a 31 de dezembro de 2015. A Figura 6.26 a Figura 6.31 apresenta o monitoramento da sucção matricial correspondente aos nove tensiômetros instalados na Seção A-A' 


\section{(в}

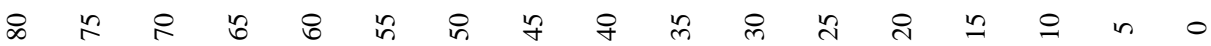

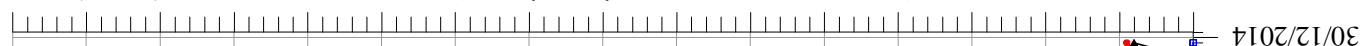

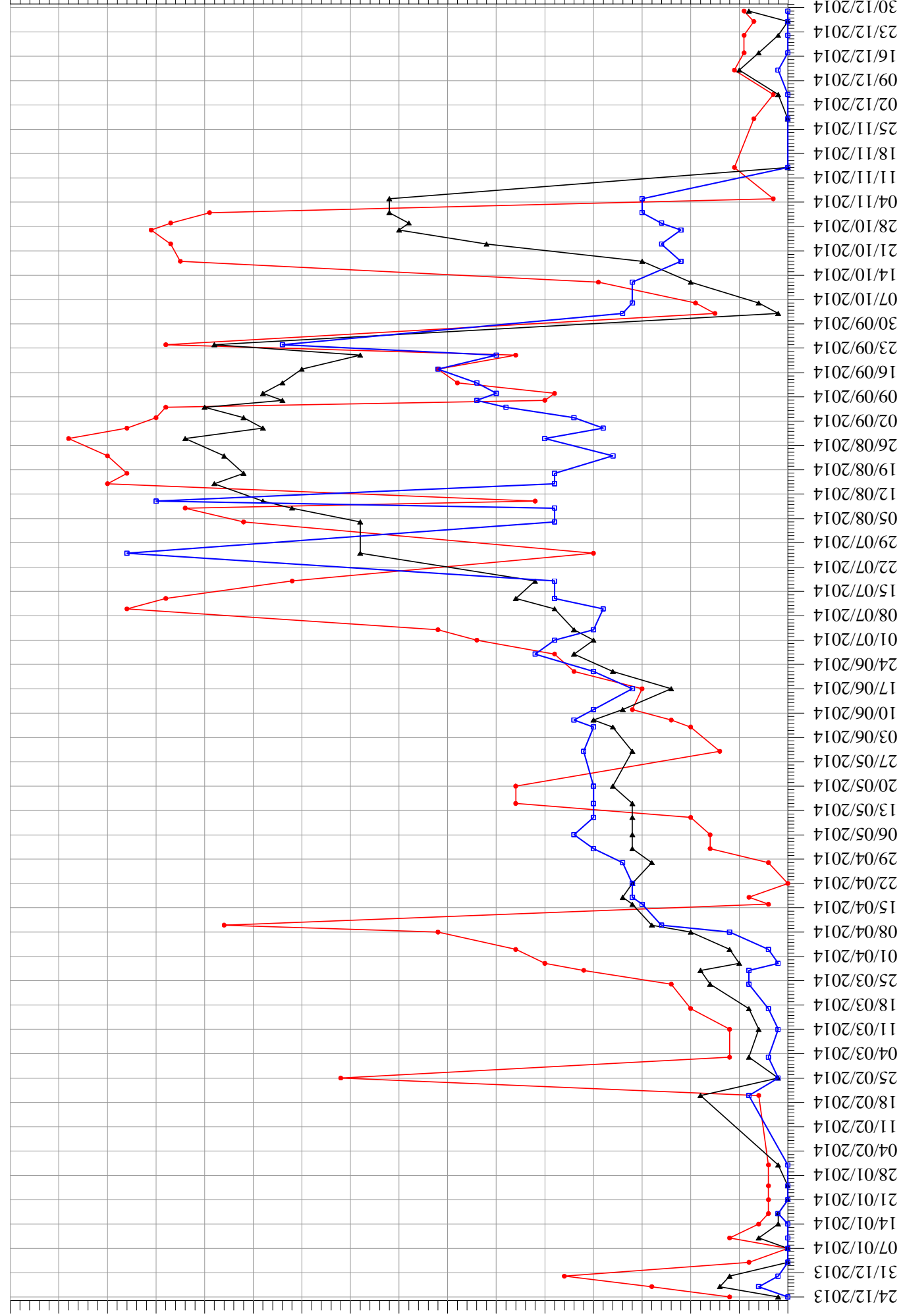

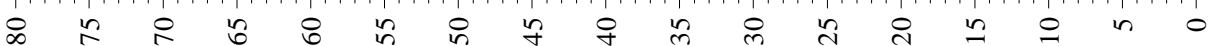

(

Figura 6.26 - Leituras de sucção matricial realizadas no pé da Seção A-A’ (período de 24/12/2013 a 31/12/2014). 
(в

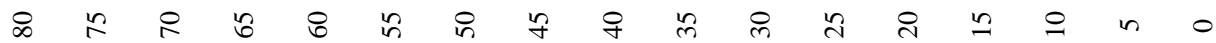

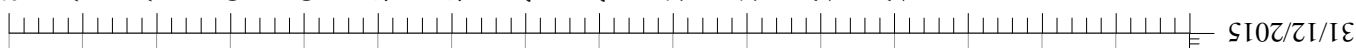

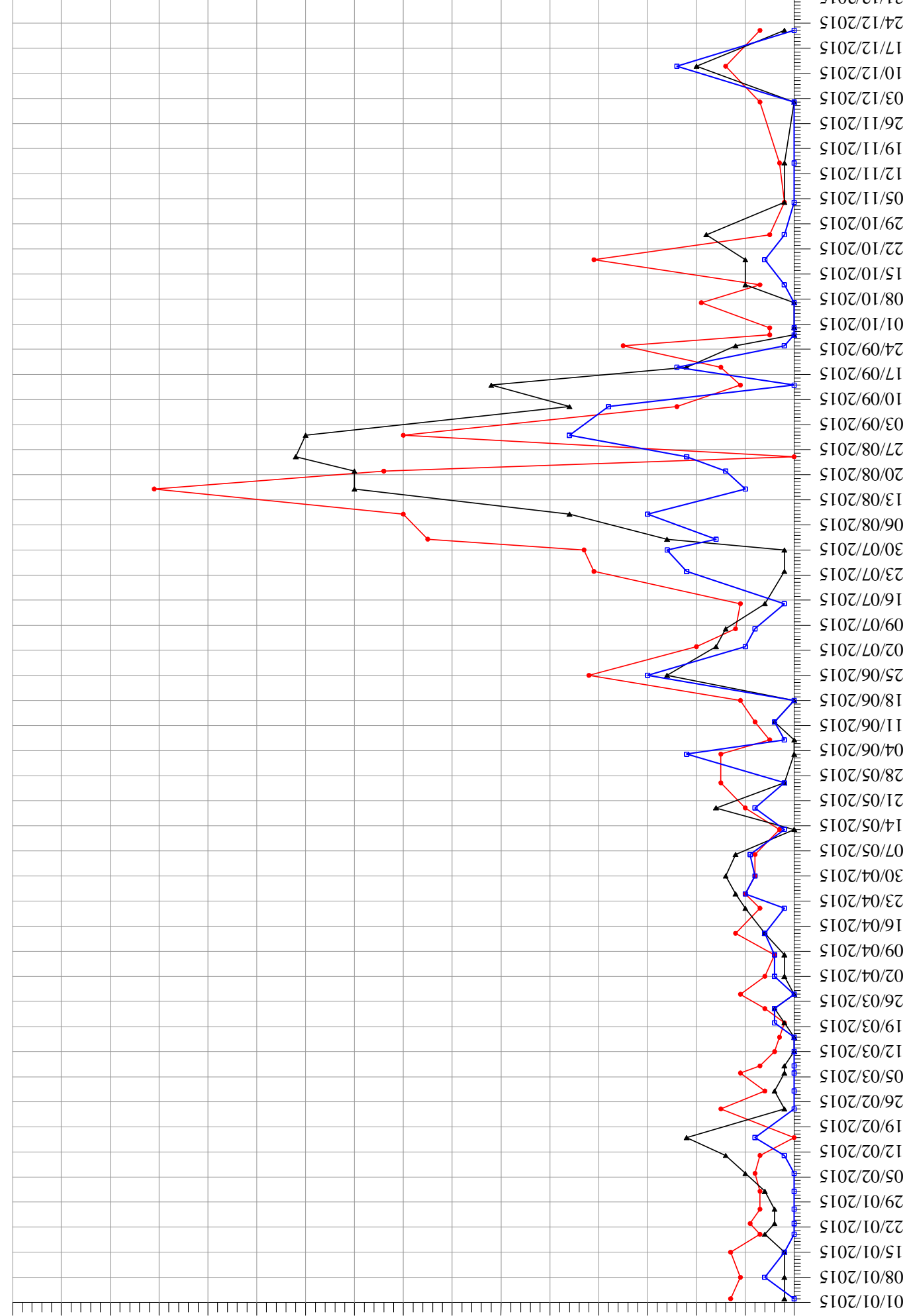

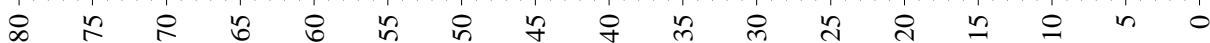

(в

Figura 6.27 - Leituras de sucção matricial realizadas no pé da Seção A-A' (período de 01/01/2015 a $31 / 12 / 2015)$. 


\section{(}

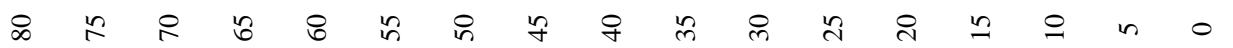

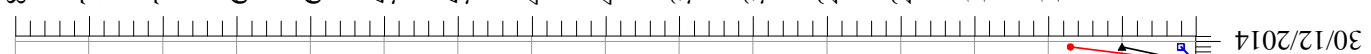

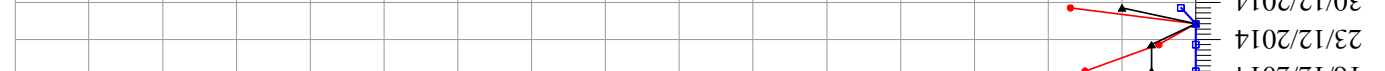
(2) toz/ZI/9I $\downarrow[0 Z / 2 L / 60$ $\operatorname{tI0Z/ZI/Z0}$ $\downarrow I 0 Z / I I / S Z$ $t \mathrm{I} 0 z / \mathrm{I} / \mathrm{d} \mathrm{I}$ $t \mathrm{I} 0 \mathrm{Z} / \mathrm{I} \mathrm{I} / \mathrm{I}$ tI0Z/L I/t0 $+[0 z / 0 t / 8 z$ $\downarrow t 0 z / 0 \mathrm{~L} / \mathrm{I} Z$ $+\mathrm{L} 0 \mathrm{z} / 0 \mathrm{~L} / \mathrm{t} \mathrm{I}$ tIOZ/OLI/LO $+50 z / 60 / 0 \mathcal{E}$ $\downarrow I 0 z / 60 / \varepsilon z$ $+\mathrm{L} 0 z / 60 / 9 \mathrm{I}$ $\downarrow I 0 z / 60 / 60$ $+10 z / 60 / z 0$ $-t 10 z / 80 / 9 z$ tI0z/80/6I tI0Z/80/ZI $+50 z / 80 / s 0$ $-t I 0 z / L 0 / 6 z$ $\downarrow I 0 Z / L 0 / Z z$ $-t I 0 Z / L 0 / S I$ - tI0Z/L0/80 $+I 0 Z / L O / L 0$ $-t[0 z / 90 / t z$ $+\mathrm{I}=\mathrm{C} / 90 / \mathrm{LI}$ - tI0Z/90/0I $-t$ LOZ/90/E0 $\downarrow I 0 Z / S 0 / L Z$ $-t 10 z / s 0 / 0 z$ FIOZ/S0/EI $-\downarrow I 0 z / \varsigma 0 / 90$ $+10 z / t 0 / 6 z$ $+10 z / t 0 / z z$ $-t I 0 Z / t 0 / \varsigma I$ - $t$ I0Z/t0/80 $+\mathrm{L} 0 z / t 0 / \mathrm{L} 0$ $+50 z / \varepsilon 0 / s z$ t $t 0 z / \varepsilon 0 / 8 \mathrm{I}$ $+\mathrm{I} 0 z / \varepsilon 0 / \mathrm{II}$ $-t I 0 z / \varepsilon 0 / t 0$ $+10 z / z 0 / \varsigma z$ $-t \mathrm{I0z/Z0/8 \textrm {I }}$ - tI0Z/Z0/I I $+50 z / z 0 / t 0$ $+10 z / L 0 / 8 z$ $+10 z / L 0 / I z$ $\downarrow \mathrm{I} 0 \mathrm{Z} / \mathrm{I} 0 / \mathrm{t} \mathrm{I}$ $\rightarrow I 0 Z / L 0 / L 0$ - $\varepsilon I 0 z / z L / I \varepsilon$ $\varepsilon I 0 z / z I / t z$

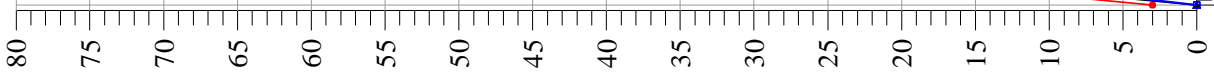

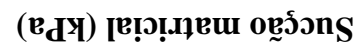

Figura 6.28 - Leituras de sucção matricial realizadas na face da Seção A-A’ (período de 24/12/2013 a $31 / 12 / 2014)$. 
(в

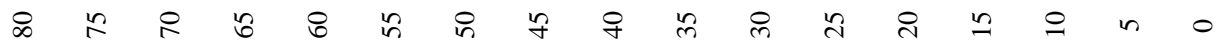

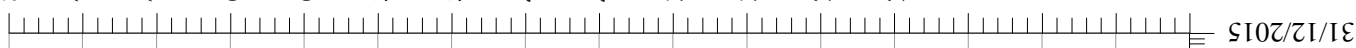

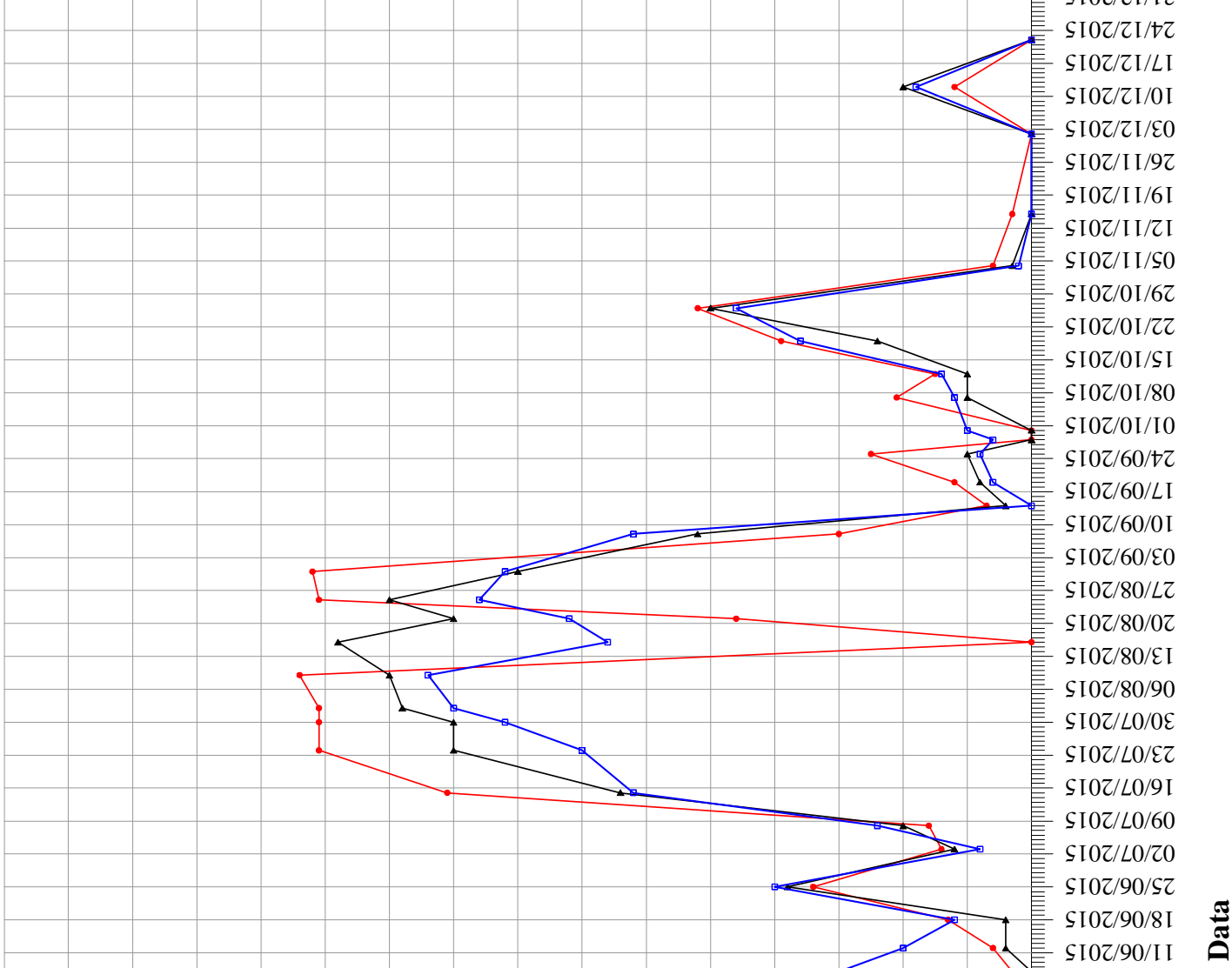

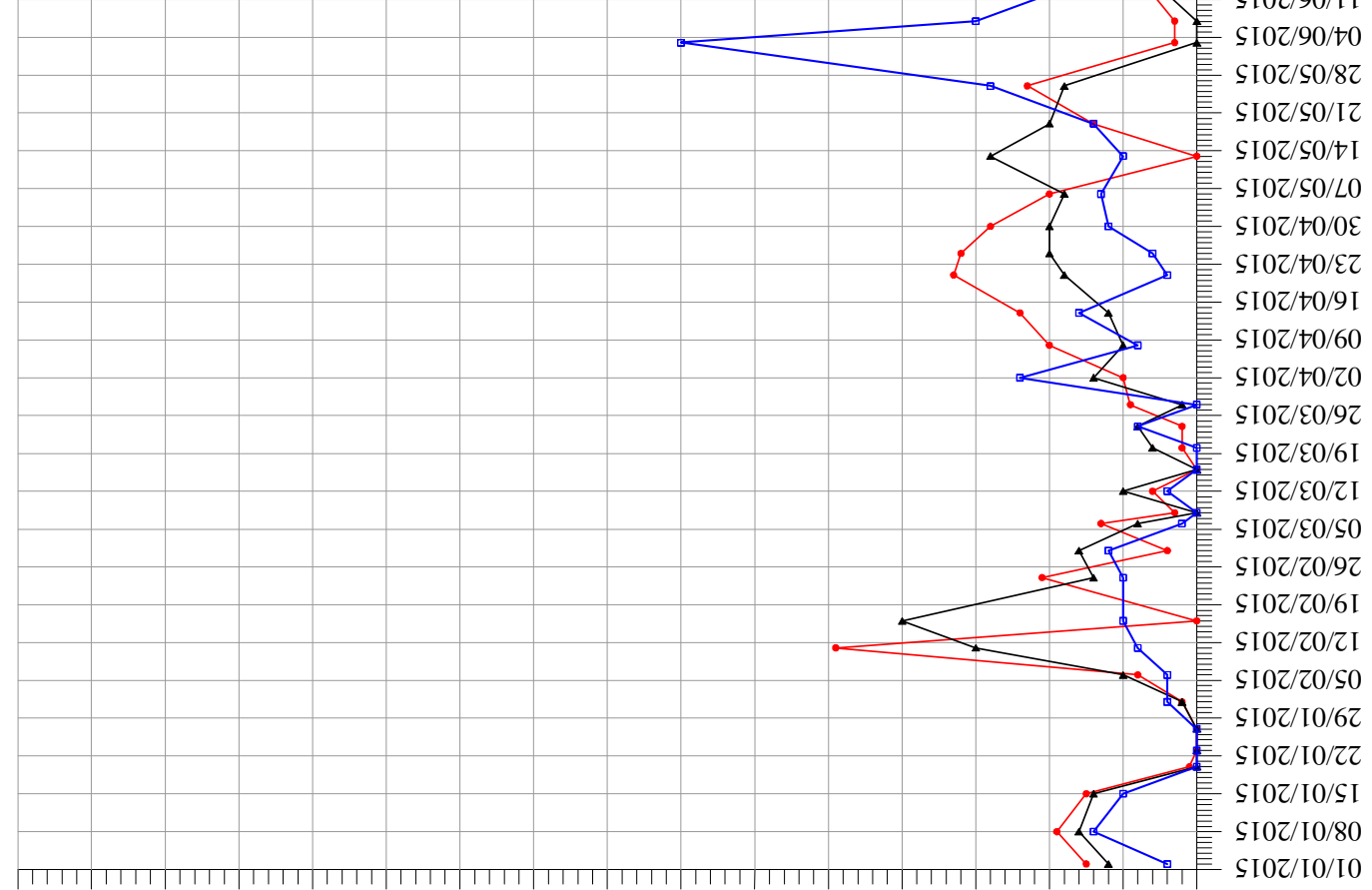

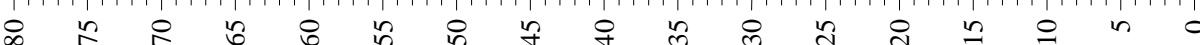

(в

Figura 6.29 - Leituras de sucção matricial realizadas na face da Seção A-A' (período de 01/01/2015 a $31 / 12 / 2015)$. 


\section{(}

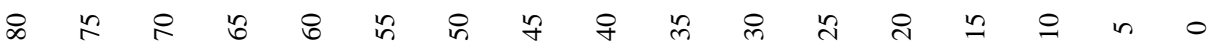

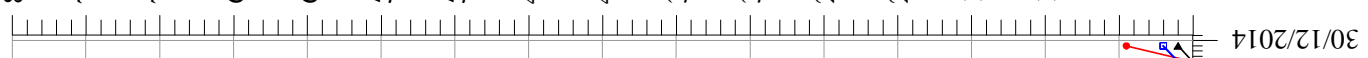
(1) †I0Z/ZI/EZ $\downarrow I 0 Z / 2 I / 9 \mathrm{I}$ $+50 Z / 2 L / 60$ $+I 0 Z / Z I / Z 0$

$\downarrow I 0 Z / \mathrm{I} / \mathrm{SZ}$

t I0Z/I I/8 I $t \mathrm{I} 0 \mathrm{Z} / \mathrm{I} / \mathrm{I} \mathrm{I}$ tI0Z/L I/t0 $t 50 z / 01 / 8 z$ $+\mathrm{I} 0 \mathrm{z} / 0 \mathrm{I} / \mathrm{Iz}$ $t[0 z / 0 \mathrm{I} / \mathrm{t} \mathrm{I}$ $\downarrow L 0 Z / 0 L / L 0$ $\downarrow$ I0Z/60/0ع $+\mathrm{I} 0 z / 60 / \varepsilon z$ $+\mathrm{L} 0 \mathrm{Z} / 60 / 9 \mathrm{I}$ †I0Z/60/60 $+\mathrm{I} 0 z / 60 / 20$ t $\mathrm{L} 0 \mathrm{z} / 80 / 9 \mathrm{Z}$ $\downarrow \mathrm{I} 0 z / 80 / 6 \mathrm{I}$ tI0Z/80/ZI $\downarrow I 0 Z / 80 / S_{0}$ $+I 0 z / L 0 / 6 z$ $+I 0 Z / L 0 / Z z$ $\downarrow I 0 Z / L O / S I$ $\downarrow[0 Z / L 0 / 80$ $\downarrow I 0 Z / L 0 / L 0$ $\downarrow t 0 z / 90 / t z$ $+\mathrm{I} 0 Z / 90 / \angle \mathrm{L}$ $\downarrow$ IOZ/90/0I $\downarrow I 0 Z / 90 / \varepsilon 0$ $\downarrow I 0 Z / S O / L Z$ $+\mathrm{I} 0 z / S 0 / 0 z$ $\downarrow I 0 Z / S 0 / \varepsilon I$ $\downarrow I 0 z / \varsigma 0 / 90$ $+10 z / t 0 / 6 z$ $+10 z / t 0 / 2 z$ $\downarrow I 0 z / t 0 / S I$ $\downarrow t 0 z / t 0 / 80$ $\downarrow \mathrm{LOZ} / \mathrm{t} 0 / \mathrm{L} 0$ $\downarrow I 0 Z / E 0 / S Z$ $\downarrow$ I0Z/E0/8I †I0Z/EO/I I $\downarrow I 0 Z / E 0 / t 0$ $\downarrow \mathrm{LOZ/Z0/SZ}$ $\downarrow I 0 Z / 20 / 8 \mathrm{I}$ $\downarrow I 0 Z / Z 0 / \mathrm{I} \mathrm{I}$ $\downarrow$ L $02 / 20 / t 0$ $+10 z / \mathrm{I} 0 / 8 z$ $+\mathrm{I} 0 \mathrm{Z} / \mathrm{I} 0 / \mathrm{IZ}$ $\downarrow \mathrm{L} 0 \mathrm{Z} / \mathrm{L} 0 / \mathrm{t} \mathrm{I}$ $\downarrow I 0 Z / L 0 / L 0$ $\varepsilon I 0 Z / 2 I / I \varepsilon$ $\varepsilon I 0 Z / Z I / \hbar Z$

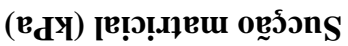

Figura 6.30 - Leituras de sucção matricial realizadas na crista da Seção A-A’ (período de 24/12/2013 a 31/12/2014). 
(в

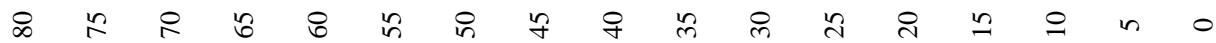

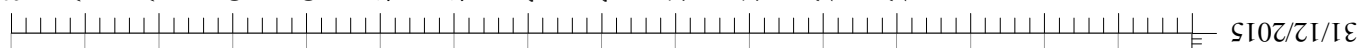

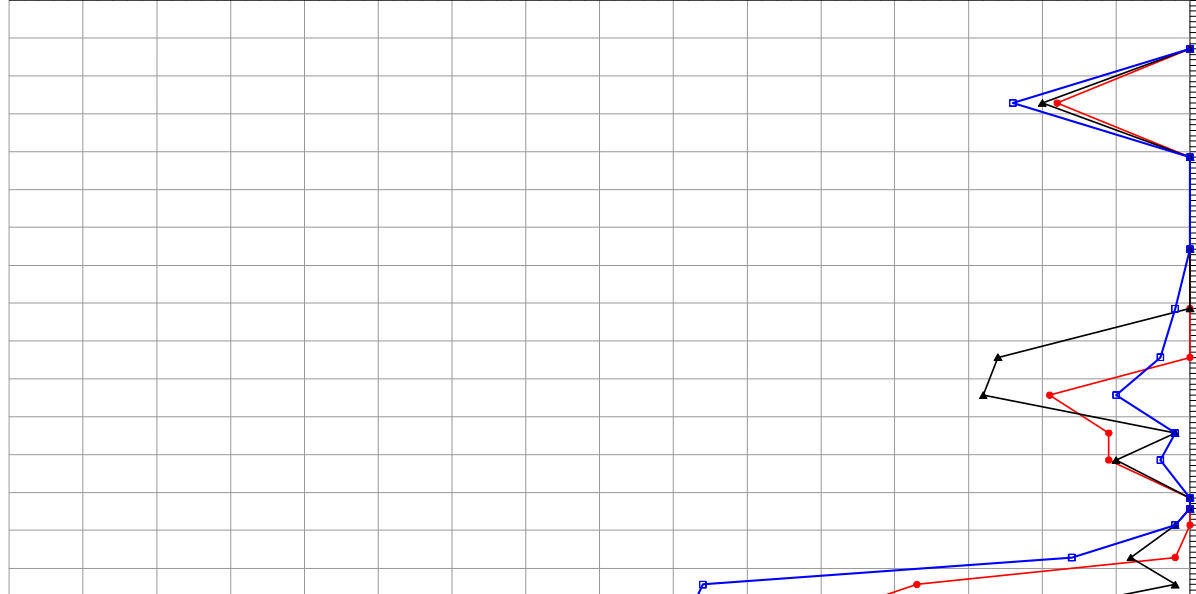
SIOZ/ZI/tZ SIOZ/ZI/LI - sI0z/ZI/0I SI0Z/ZI/EO SI0Z/L I/9Z SI0Z/I I/6I SI0Z/It/ZI

SI0Z/L L ISO sI0z/0I/6z sI0Z/0I/ZZ SI0Z/0I/SI $\varsigma L$ LI/0L/80 - SI0Z/0I/LO $\varsigma L 0 z / 60 / t z$ SI0Z/60/LI ৎIOZ/60/0I SI0Z/60/E0 SI0Z/80/LZ SI0Z/80/0Z $\varsigma I 0 Z / 80 / \mathcal{E} \mathrm{I}$ SI0Z/80/90 SIOZ/LO/OE SIOZ/LO/EZ - SI0Z/LO/9I EIOZ/LO/60 SIOZ/LO/Z0 SI0Z/90/sZ SI0Z/90/8 I SI0Z/90/L I - sI0Z/90/t0 - $I 0 Z / \varsigma 0 / 8 Z$ SI0Z/ऽ0/IZ sI0Z/s0/t I SIOZ/ऽO/LO sI0Z/t0/0ع sI0Z/t0/EZ SI0Z/t0/9I sI0Z/t0/60 - sI0z/t0/z0 sI0Z/E0/9Z sI0Z/E0/6I SI0Z/E0/ZI sI0Z/E0/s0 SI0Z/Z0/9Z SI0Z/Z0/6I sI0Z/Z0/ZI sI0Z/Z0/s0 SI0Z/L0/6Z SI0Z/L0/Zz SIOZ/IO/SI - SI0Z/L0/80

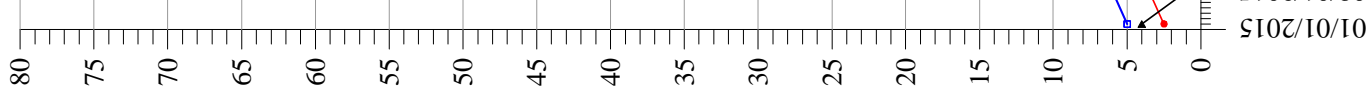

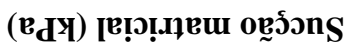

Figura 6.31 - Leituras de sucção matricial realizadas na crista da Seção A-A’ (período de 01/01/2015 a 31/12/2015). 
Como apresentado anteriormente na Figura 6.26 a Figura 6.31, estas representam as leituras nos tensiômetros realizadas no período de monitoramento e que correspondem aos valores de sucção matricial dos nove tensiômetros localizados em três porções (pé, face e crista) da Seção A-A'. Em cada uma dessas figuras constam identificados os comprimentos de cada equipamento, a porção da seção geológico-geotécnica em que eles estão localizados e o período do monitoramento em campo. Além disso, o período de monitoramento encontra-se fracionado em dois trechos para cada porção desta seção (de 24/12/2013 a 31/12/2014 e de 01/01/2015 a 31/12/2015) e os períodos em que não apresentam registros de leituras é devido ao fato dos problemas mencionados no item 4.10.

A faixa de variação dos valores de sucção matricial foi de $0 \mathrm{kPa}$ a $74 \mathrm{kPa}$ para os tensiômetros localizados no pé, na face e na crista da Seção A-A'. O maior valor de sucção matricial registrado na seção investigada foi de $74 \mathrm{kPa}$ em 28 de agosto de 2014, que corresponde ao tensiômetro com comprimento de $0,45 \mathrm{~m}$ instalado no pé desta seção. Já nos demais foram registrados valores de sucção matricial de até $70 \mathrm{kPa}$ e $64 \mathrm{kPa}$, que correspondem aos equipamentos localizados na crista e na face, respectivamente. Constata-se que a maioria desses valores máximos de sucção matricial ocorreu no mês de agosto de 2014 .

De maneira geral, nota-se uma tendência nas leituras dos tensiômetros nas estações chuvosa e seca, isto é, entre os meses de abril a setembro os tensiômetros registraram valores de sucção matricial na ordem de $74 \mathrm{kPa}$ enquanto que nos meses de outubro a março os mesmos equipamentos registraram valores de sucção matricial na ordem de $0 \mathrm{kPa}$. Além disso, certifica-se que a faixa de variação de sucção aumenta de acordo com a profundidade de instalação do equipamento, ou seja, a faixa de variação é mais ampla para os tensiômetros com comprimento de 1,50 m do que para os tensiômetros com comprimento de 0,45 m.

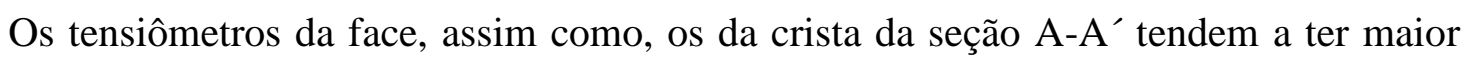
dispersão dos valores de sucção matricial e apresentarem altas leituras da sucção matricial. Este comportamento está associado com o escoamento superficial de grande parte da água precipitada na crista desta seção que, consequentemente, será infiltrada ou até mesmo ficará acumulada na região do pé do talude.

A Figura 6.32 a Figura 6.37 apresenta o monitoramento da sucção matricial correspondente aos nove tensiômetros instalados na Seção B-B'. 


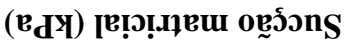

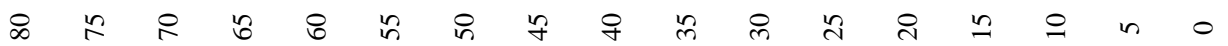

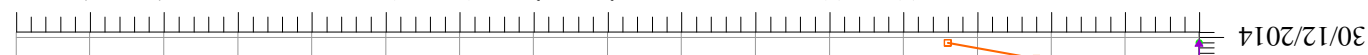

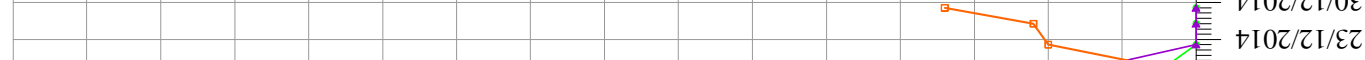

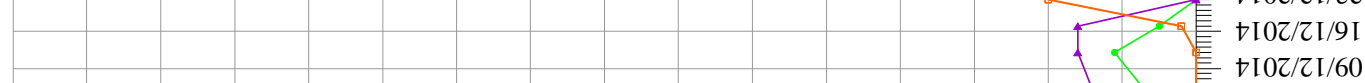

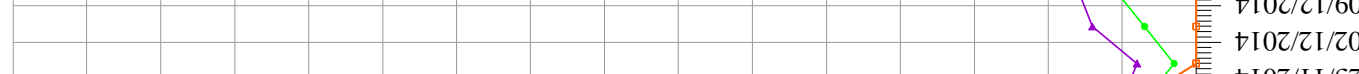

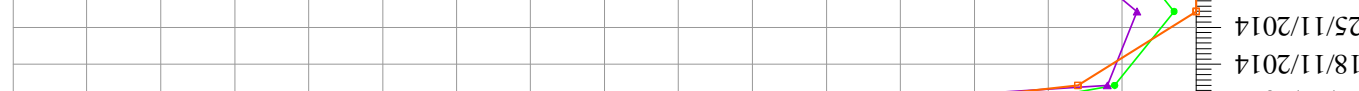

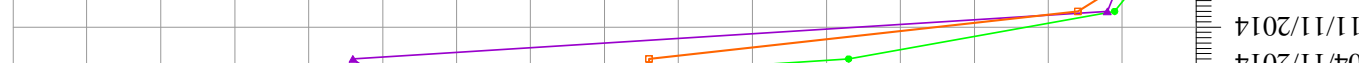
(2)

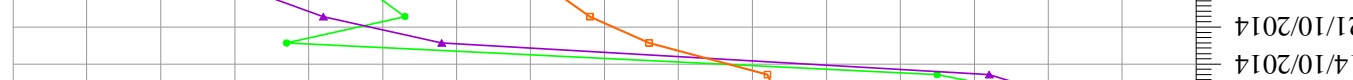

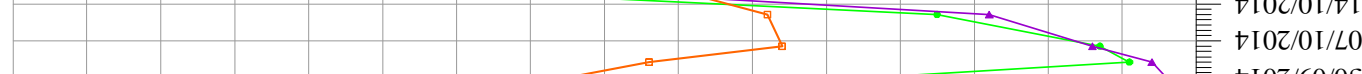

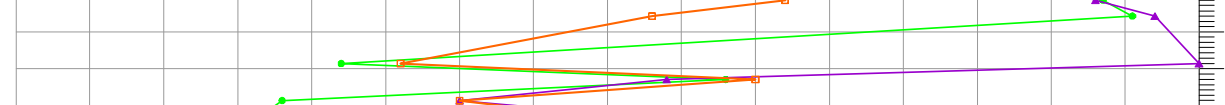
$\downarrow t 0 z / 60 / 0 \varepsilon$ $\downarrow$ t $0 Z / 60 / \varepsilon z$ $\downarrow$ I0Z/60/9I

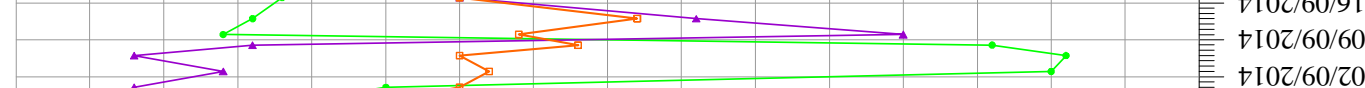

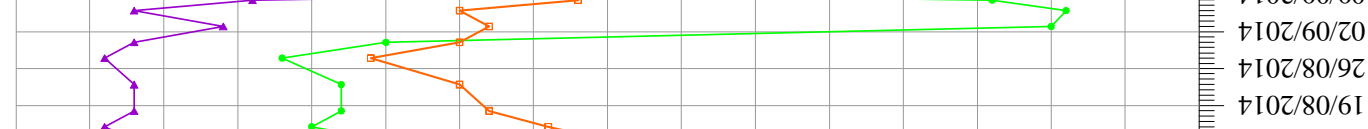

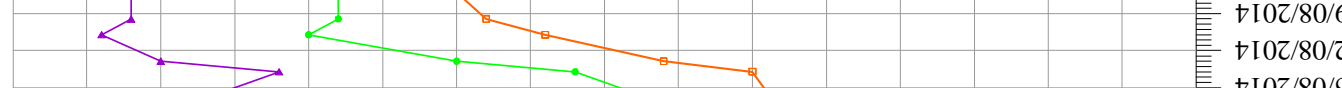
P $+10 z / L 0 / 2 z$ $\downarrow I 0 Z / L 0 / S \mathrm{I}$ $\downarrow t 0 Z / L 0 / 80$ $\downarrow I 0 Z / L 0 / L 0$ $\downarrow t 0 z / 90 / t z$ $\downarrow I 0 Z / 90 / L I$ $\downarrow$ I0Z/90/0I $\downarrow$ I0Z/90/E0 $+I 0 Z / S 0 / L Z$ $\downarrow I 0 Z / S 0 / 0 z$ $\downarrow t 0 z / \varsigma_{0} / \mathcal{E} \mathrm{I}$ $\downarrow$ I0Z/S0/90 $-t 50 z / t 0 / 6 z$ $+10 z / t 0 / z z$ $\downarrow I 0 Z / t 0 / \varsigma I$ $t 50 z / t 0 / 80$ $\downarrow I 0 z / t 0 / \mathrm{L} 0$ $+[0 z / \varepsilon 0 / s z$ $\downarrow$ I0Z/E0/8 I $\downarrow \mathrm{I} 0 z / \varepsilon 0 / \mathrm{II}$ $\downarrow I 0 Z / \mathcal{E} 0 / t 0$ $\downarrow I 0 Z / z 0 / s z$ $\downarrow t 0 z / 20 / 8 \mathrm{I}$ $t$ I0z/z0/I I $+10 z / 20 / t 0$ $\downarrow I 0 z / L 0 / 8 z$ $\rightarrow \mathrm{IOZ} / \mathrm{I} 0 / \mathrm{IZ}$ $t \mathrm{IOZ} / \mathrm{I} 0 / \mathrm{t} \mathrm{I}$ $\downarrow I 0 Z / I 0 / L 0$ $\varepsilon I 0 Z / Z I / I \varepsilon$

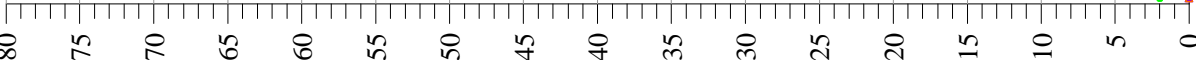
$\varepsilon \mathrm{I} 0 z / 2 \mathrm{I} / \mathrm{t} z$

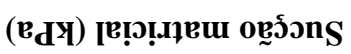

Figura 6.32 - Leituras de sucção matricial realizadas no pé da Seção B-B’' (período de 24/12/2013 a 31/12/2014). 


\section{(घ}

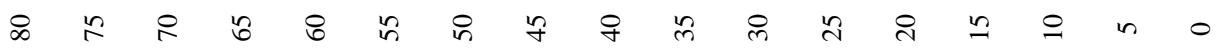

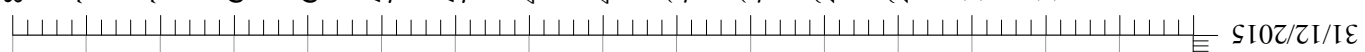

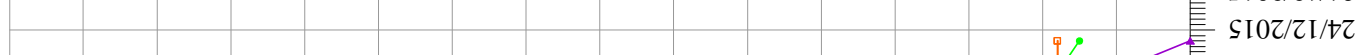

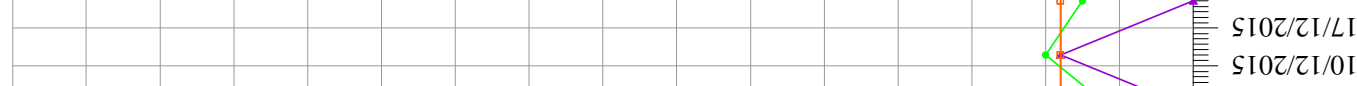

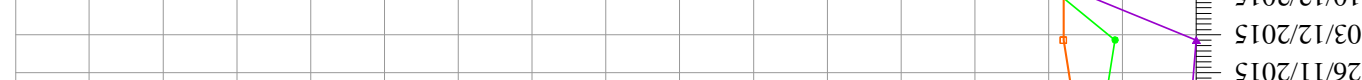

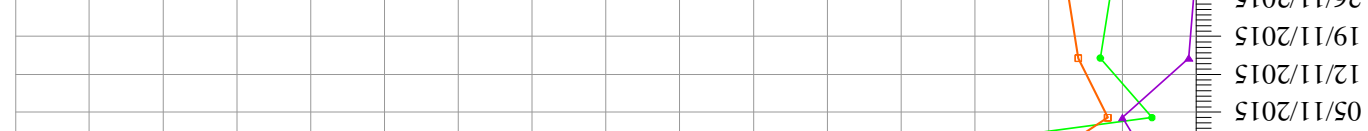

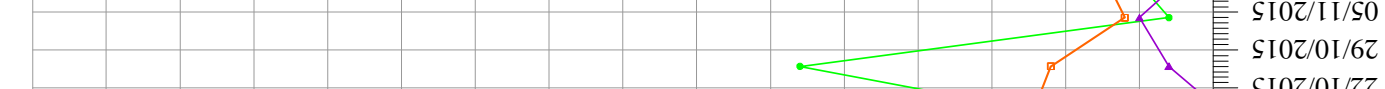

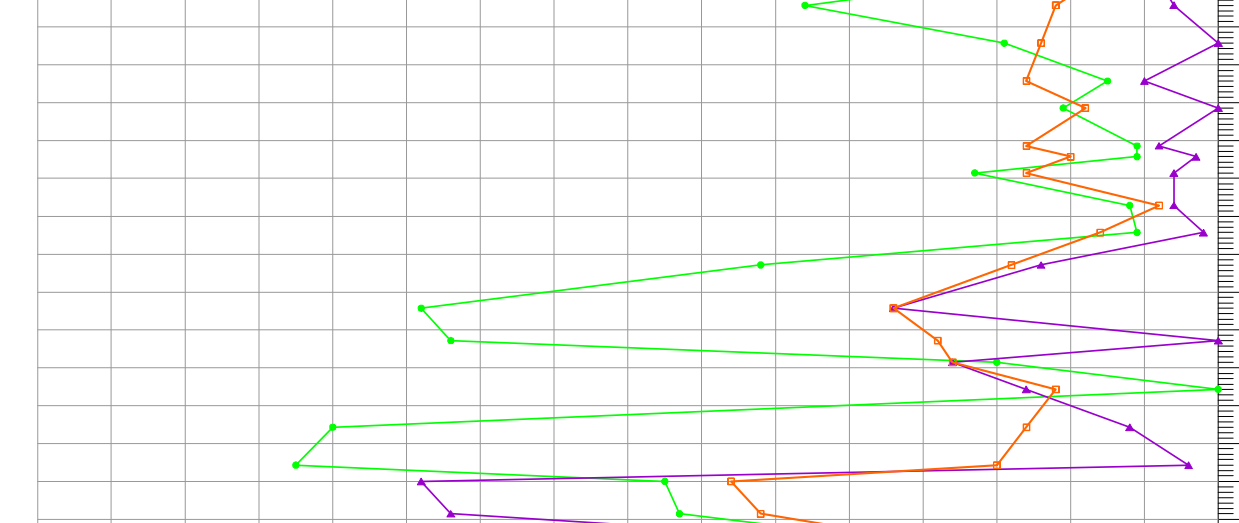
SI0Z/0I/ZZ SI0Z/0L/S I SI0Z/0I/80 SI0Z/0I/I0 sI $02 / 60 / t z$ SI0Z/60/LI SI0Z/60/0I SI0Z/60/E0 SI0Z/80/LZ SI0Z/80/0Z SIOZ/80/E I SI0Z/80/90 SIOZ/LO/OE SIOZ/LO/EZ SI0Z/LO/9I SIOZ/LO/60 SIOZ/LO/Z0 SI0Z/90/SZ SI0Z/90/8I sI0Z/90/I I sI0Z/90/t0 sLOZ/S0/8Z sI0Z/S0/IZ $\varsigma_{I} 0 Z / \varsigma_{0} / \mathrm{tI}$ SIOZ/SO/L0 sI0Z/t0/0E sI0Z/t0/EZ sLoz/t0/9I sI 2 Z/t0/60 - $s$ I0Z/t0/Z0 sL0z/E0/9z sI0z/E0/6I sI0Z/E0/ZI sLOz/E0/s0 sI0z/Z0/9z sI0z/Z0/6I SI0Z/Z0/ZI - sI0Z/Z0/s0 SI0Z/I0/6Z SI0Z/I0/ZZ SIOZ/I0/SI SI0Z/I0/80 sloz/IO/IO

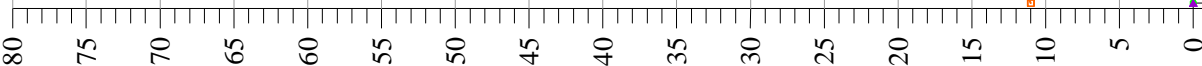
SIOZ/LO/LO

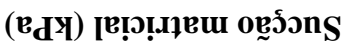

Figura 6.33 - Leituras de sucção matricial realizadas no pé da Seção B-B' (período de 01/01/2015 a 31/12/2015). 


\section{(}

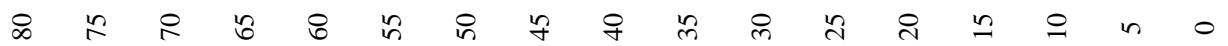

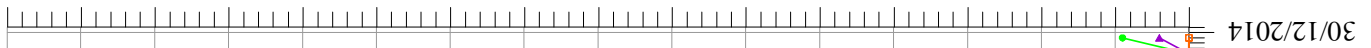

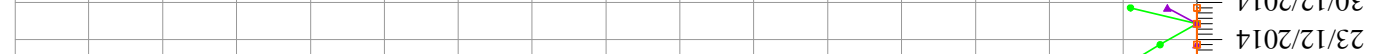

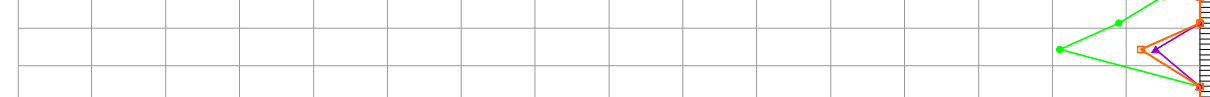
$\downarrow I 0 Z / Z I / 9 \mathrm{I}$ $+\mathrm{I} 0 \mathrm{Z} / \mathrm{I} \mathrm{L} / 60$ $+\mathrm{I} 0 z / \tau \mathrm{I} / \mathrm{Z} 0$ $+\mathrm{I} 0 Z / \mathrm{I} / \mathrm{L} / \mathrm{CZ}$

tI0Z/L I/8I $+\mathrm{IOZ} / \mathrm{I} / \mathrm{I} \mathrm{I}$

$\downarrow \mathrm{I} 0 \mathrm{Z} / \mathrm{I} \mathrm{L} / \mathrm{t} 0$

$+\mathrm{L} 0 \mathrm{z} / 0 \mathrm{~L} / \mathrm{8z}$

$+\mathrm{I} 0 z / 0 \mathrm{~L} / \mathrm{I} Z$

$+\mathrm{I} 0 \mathrm{C} / \mathrm{L} \mathrm{I} / \mathrm{t} \mathrm{I}$

$\downarrow \mathrm{I} 0 \mathrm{Z} / 0 \mathrm{~L} / \mathrm{LO}$

$\downarrow \mathrm{I} 0 \mathrm{Z} / 60 / 0 \varepsilon$

$\downarrow T$ I0Z/60/EZ

$+\mathrm{T} 0 \mathrm{Z} / 60 / 9 \mathrm{I}$

$+10 z / 60 / 60$

$+\mathrm{I} 0 z / 60 / 20$

$\downarrow I 0 Z / 80 / 9 z$

$-t 50 z / 80 / 6 \mathrm{I}$

$-t I 0 Z / 80 / Z I$

$\downarrow \mathrm{I} 0 Z / 80 / \varsigma_{0}$

$\downarrow I 0 Z / L 0 / 6 Z$

$+\mathrm{I} 0 z / L 0 / 2 z$

$\downarrow I 0 Z / L 0 / S I$

$\downarrow I 0 Z / L 0 / 80$

$\downarrow I 0 Z / L 0 / \mathrm{I} 0$

$\downarrow I 0 Z / 90 / t z$

$\downarrow t 0 Z / 90 / L I$

$+\mathrm{I} 0 Z / 90 / 0 \mathrm{I}$

$+\mathrm{I0Z/90/ \varepsilon 0}$

$+I 0 Z / S 0 / L Z$

$-\oplus \mathrm{I} 0 z / s_{0} / 0 z$

$-t I 0 z / S 0 / \varepsilon I$

$\downarrow I 0 z / \varsigma 0 / 90$

$+t 0 z / t 0 / 6 z$

$\downarrow I 0 z / t 0 / z z$

$\downarrow \mathrm{I} 0 \mathrm{Z} / \mathrm{t} 0 / \mathrm{S} \mathrm{I}$

$-t 50 Z / t 0 / 80$

$\rightarrow I 0 z / t 0 / L 0$

$\rightarrow$ IOZ/EO/SZ

$+\mathrm{I} 0 \mathrm{Z} / \mathrm{E} 0 / 8 \mathrm{I}$

$\downarrow$ I0Z/E0/L I

$\downarrow t 0 Z / \varepsilon 0 / t 0$

$+\mathrm{I} 0 z / z 0 / \varsigma z$

$+\mathrm{I0z/z0/8 \textrm {I }}$

tIOZ/Z0/I I

$+50 z / z 0 / t 0$

$t$ I0z/L0/8z

$\rightarrow I 0 z / L 0 / I Z$

$\downarrow \mathrm{IOZ} / \mathrm{L} 0 / \mathrm{tI}$

$\downarrow I 0 z / L 0 / L 0$

$\varepsilon I 0 Z / Z I / I \varepsilon$

$\varepsilon I 0 z / \tau I / t z$

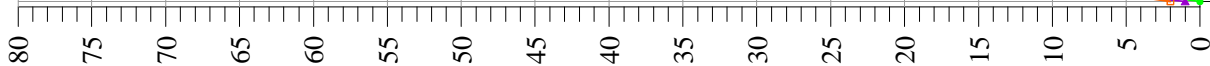

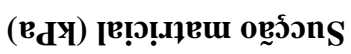

Figura 6.34 - Leituras de sucção matricial realizadas na face da Seção B-B' (período de 24/12/2013 a $31 / 12 / 2014)$. 


\section{(}

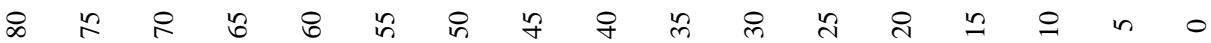

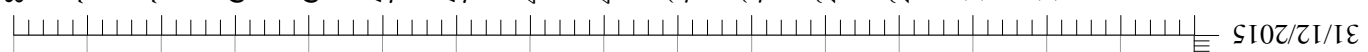

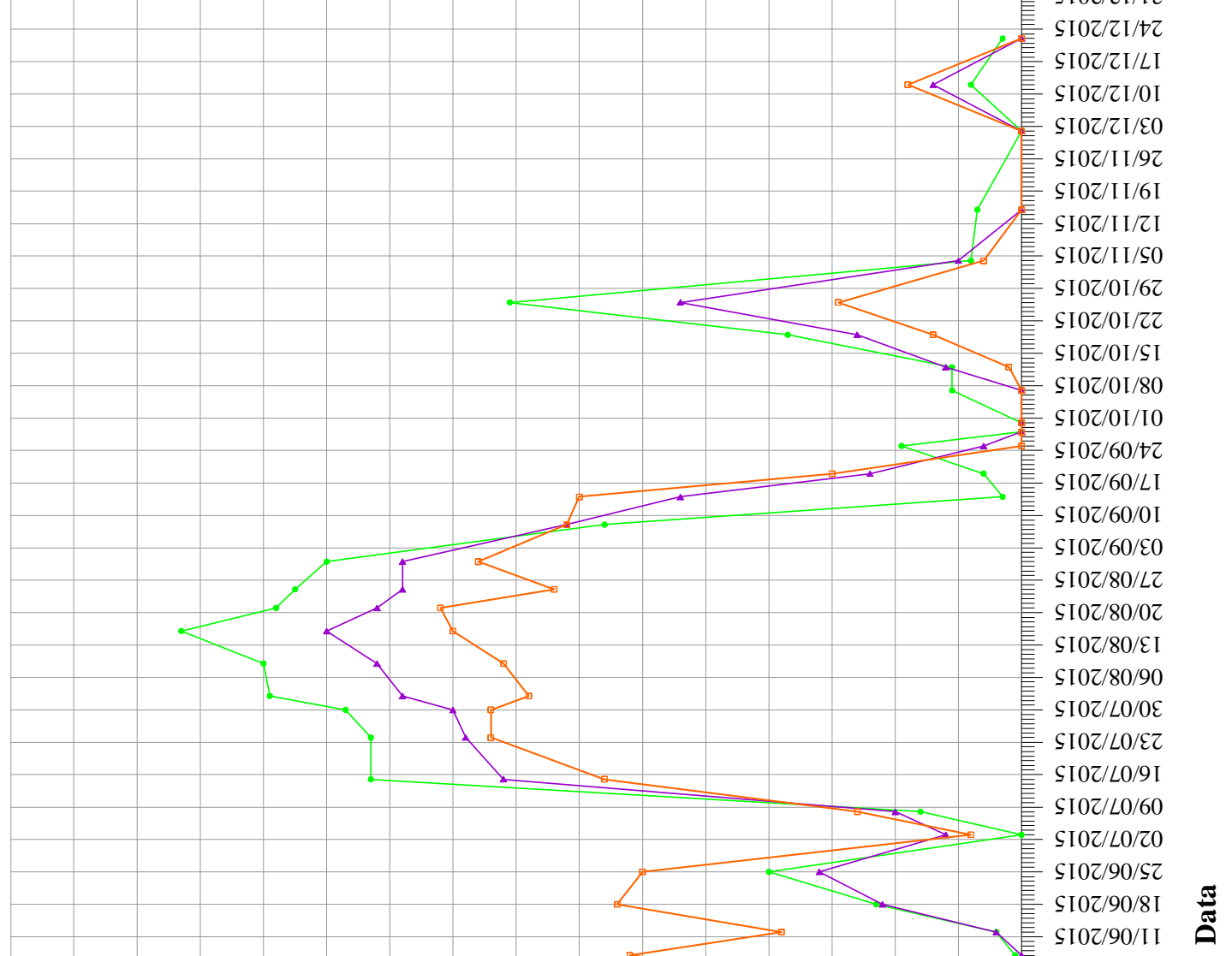

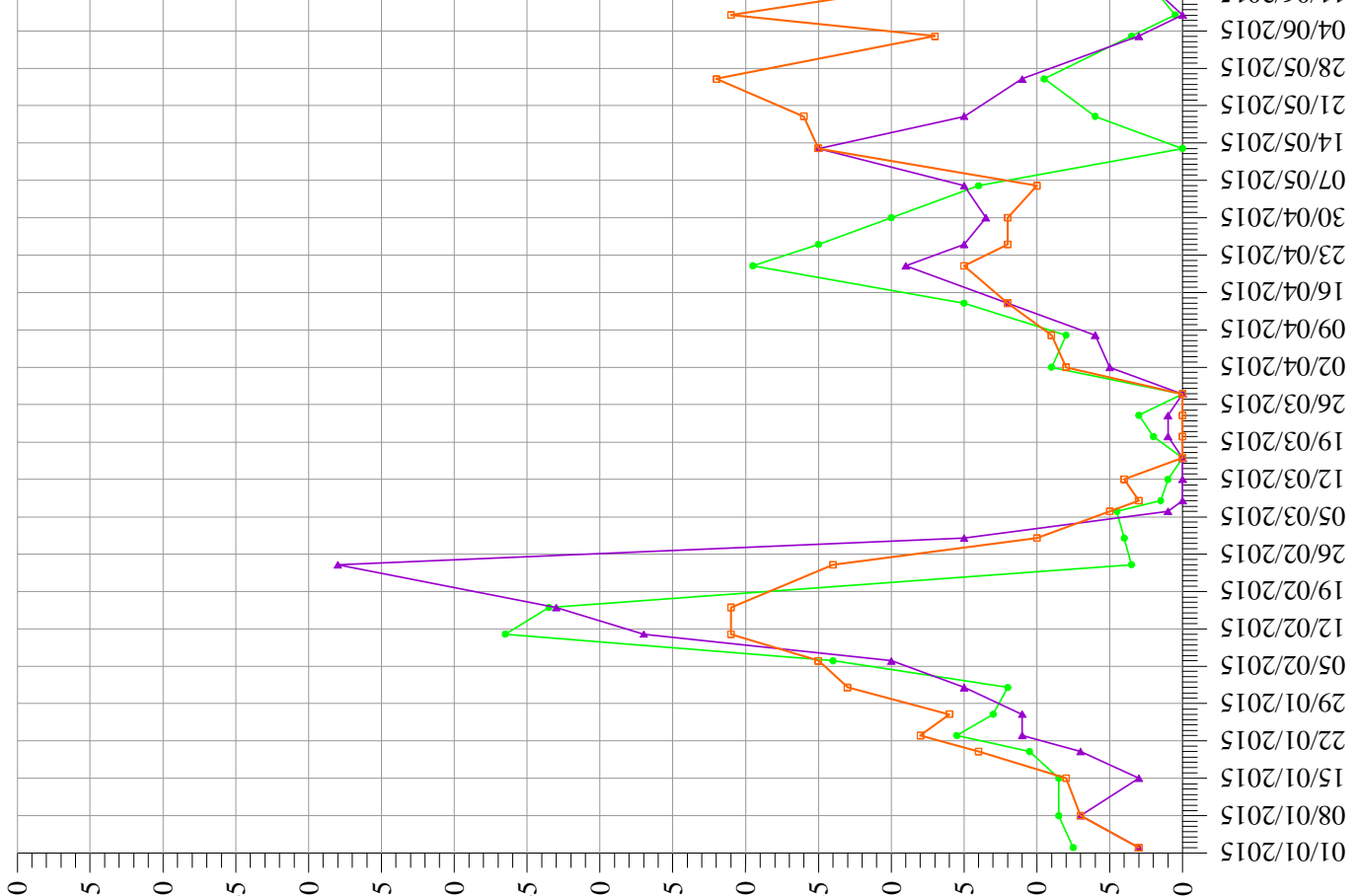

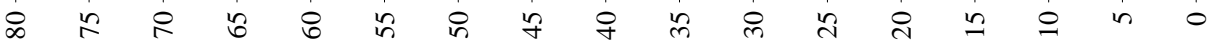

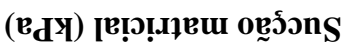

Figura 6.35 - Leituras de sucção matricial realizadas na face da Seção B-B’ (período de 01/01/2015 a 31/12/2015). 


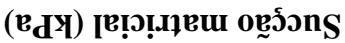

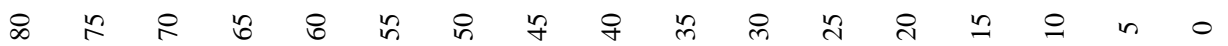

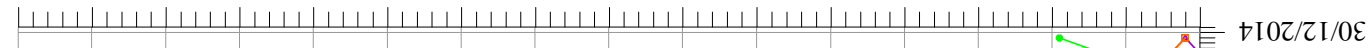

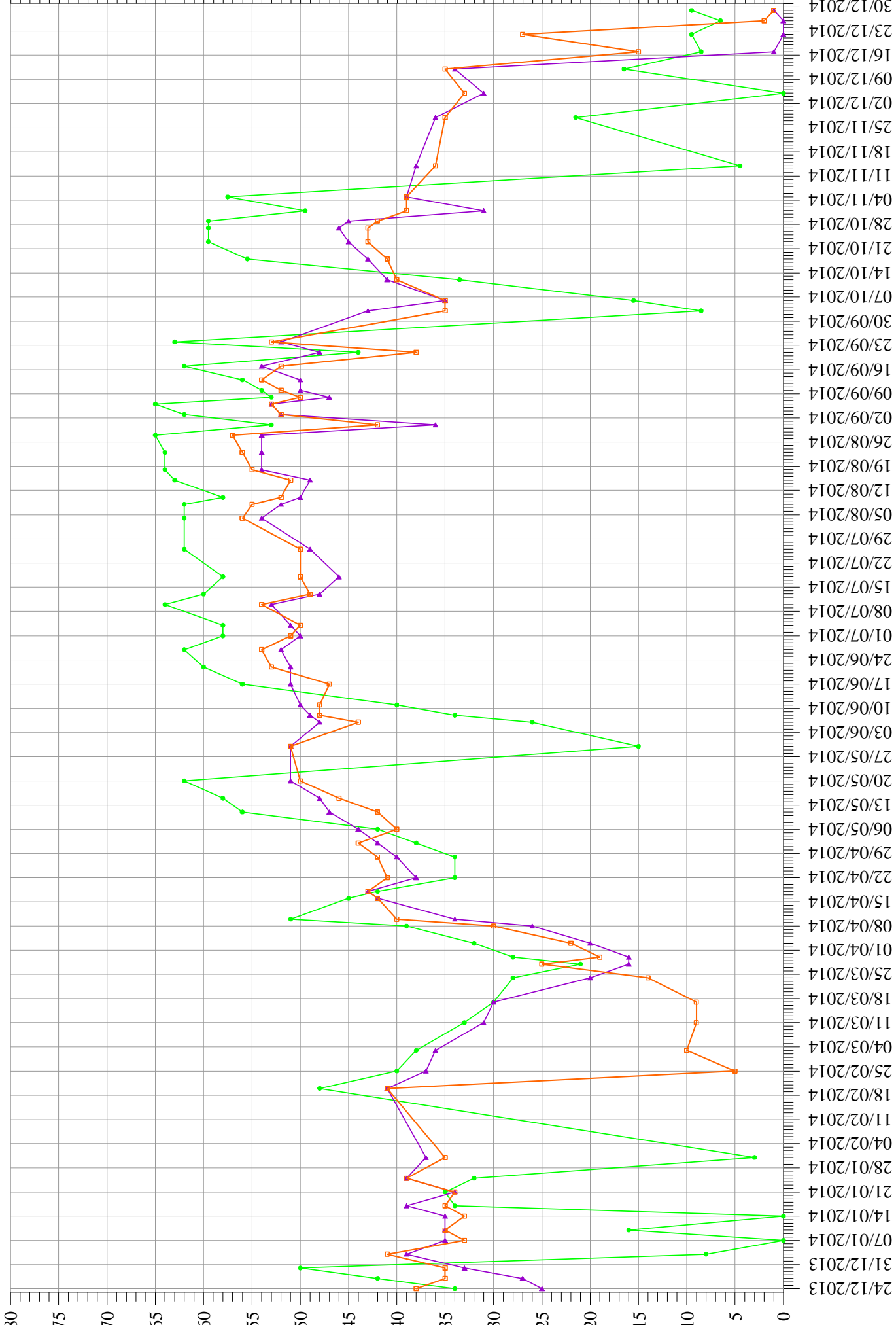

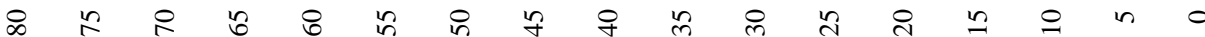

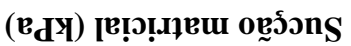

Figura 6.36 - Leituras de sucção matricial realizadas na crista da Seção B-B' (período de 24/12/2013 a $31 / 12 / 2014)$. 


\section{(}

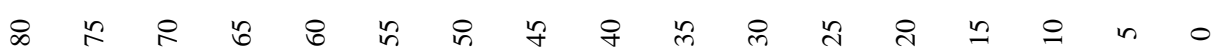

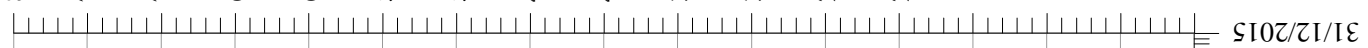

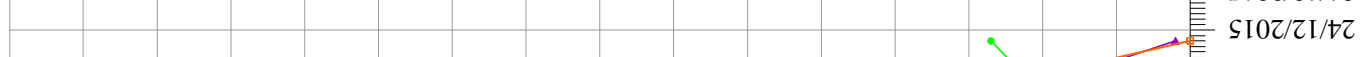

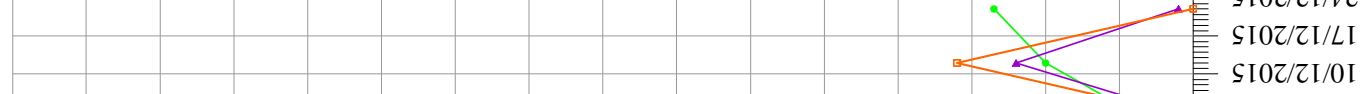

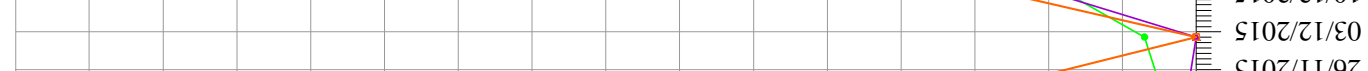
\begin{tabular}{|l|l|l|l|l|l|}
\hline & 0 \\
\hline
\end{tabular} SIOZ/II/6I SIOZ/II/ZI SIOZ/II/SO SI0Z/0I/6Z sI0Z/0I/ZZ SI0Z/0I/SI SI0Z/0I/80 SI0Z/0I/I0 sL0z/60/tz SI0Z/60/LI ऽI0Z/60/0I SI0Z/60/E0 SI0Z/80/LZ SI0Z/80/0Z SI0Z/80/E I - SI0Z/80/90 SIOZ/LO/OE SIOZ/LO/EZ SI0Z/LO/9I SIOZ/LO/60 SIOZ/LO/Z0 - sI0Z/90/sZ SI0Z/90/8I sI0Z/90/I I sI0Z/90/t0 sI0Z/S0/8Z SIOZ/S0/IZ - $s$ I0Z/S0/t I SIOZ/SO/LO sIOZ/t0/0E - SI0Z/t0/EZ sLoz/t0/9I - $10 Z / t 0 / 60$ - SI0Z/t0/Z0 - sLOZ/E0/9Z sI0z/E0/6I SIOZ/E0/ZI

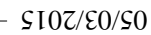
- sI0Z/Z0/9Z sI0z/z0/6I sI0Z/Z0/ZI - sI0Z/Z0/S0 SIOZ/I0/6Z - SI0Z/I0/ZZ SIOZ/I0/SI SIOZ/I0/80 SI0Z/I0/I0

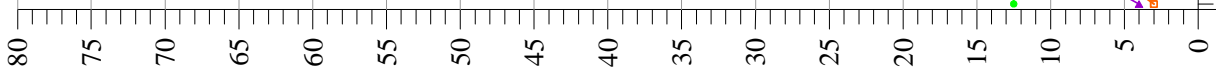

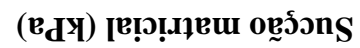

Figura 6.37 - Leituras de sucção matricial realizadas na crista da Seção B-B' (período de 01/01/2015 a 31/12/2015). 
Como apresentado anteriormente na Figura 6.32 a Figura 6.37, estas representam as leituras nos tensiômetros realizadas no período de monitoramento e que correspondem aos valores de sucção matricial dos nove tensiômetros localizados em três porções (pé, face e crista) da Seção B-B'. Em cada uma dessas figuras constam identificados os comprimentos de cada equipamento, a porção da seção geológico-geotécnica em que eles estão localizados e o período do monitoramento em campo. Além disso, o período de monitoramento encontra-se fracionado em dois trechos para cada porção desta seção (de 24/12/2013 a 31/12/2014 e de 01/01/2015 a 31/12/2015) e os períodos em que não apresentam registros de leituras é devido ao fato dos problemas mencionados no item 4.10.

A faixa de variação dos valores de sucção matricial foi de $0 \mathrm{kPa}$ a $74 \mathrm{kPa}$ para os tensiômetros localizados no pé, na face e na crista da Seção B-B'. O maior valor de sucção matricial registrado na seção investigada foi de $74 \mathrm{kPa}$ em 15 de agosto de 2014 e 28 de agosto de 2014, que corresponde ao tensiômetro com comprimento de 0,90 m instalado no pé desta seção. Já nos demais foram registrados valores de sucção matricial de até 67 kPa e 65 $\mathrm{kPa}$, que correspondem aos tensiômetros com comprimento de $0,45 \mathrm{~m}$ localizados na crista e na face, respectivamente. Constata-se que a maioria desses valores máximos de sucção matricial ocorreu no mês de agosto de 2014.

Assim como ocorre na Seção A-A' nota-se que para esta outra seção existe uma tendência nas leituras dos tensiômetros nas estações chuvosa e seca, isto é, entre os meses de abril a setembro os tensiômetros registraram valores de sucção matricial na ordem de $74 \mathrm{kPa}$ enquanto que nos meses de outubro a março os mesmos equipamentos registraram valores de sucção matricial na ordem de $0 \mathrm{kPa}$. Além disso, certifica-se que a faixa de variação de sucção aumenta de acordo com a profundidade de instalação do equipamento, ou seja, a faixa de variação é mais ampla para os tensiômetros com comprimento de 1,50 $\mathrm{m}$ do que para os tensiômetros com comprimento de $0,45 \mathrm{~m}$.

Os tensiômetros da face, assim como, os da crista da seção B-B’ tendem a ter maior dispersão dos valores de sucção matricial e apresentarem altas leituras da sucção matricial. Este comportamento está associado com o escoamento superficial de grande parte da água precipitada na crista desta seção que, consequentemente, será infiltrada ou até mesmo ficará acumulada na região do pé do talude.

Apesar dos tensiômetros desta seção estarem localizados em diferentes profundidades e distribuídos em três porções da seção do talude, percebe-se que os valores de sucção matricial tendem a serem maiores nos tensiômetros da crista, intermediários nos tensiômetros da face e menores nos tensiômetros do pé. Embora a faixa de variação seja maior durante a 
estação seca, esse comportamento também foi observado na estação chuvosa, porém apresentando uma menor dispersão nesses valores.

Portanto, analisando-se e comparando-se os resultados do monitoramento dos dezoito tensiômetros, constata-se que os valores de sucção matricial tendem a serem maiores para os tensiômetros localizados na crista da Seção B-B' e menores para os tensiômetros situados no pé da Seção A-A'. Uma explicação desse comportamento pode estar relacionada com a topografia da área piloto e a cota de cada seção, a qual propicia a movimentação da água do ponto mais alto para o ponto mais baixo.

Outra observação importante e que merece destaque é que os valores de sucção matricial relativos a esse período de monitoramento mantiveram-se compatíveis na estação chuvosa e na estação seca, permanecendo com a distribuição semelhante ao longo das seções monitoradas.

É importante mencionar que o tempo de resposta e a sensibilidade dos tensiômetros podem influenciar nas variações das leituras da sucção seja por causa da variação da temperatura ao longo do dia ou até mesmo por causa da ocorrência de um determinado evento pluviométrico, porém essas variações não foram consideradas nessa pesquisa.

\subsubsection{Monitoramento do Nível d’água}

O medidor de nível d’água de máxima não registrou nenhuma alteração do nível d’água na profundidade investigada durante o período de monitoramento ( 24 de dezembro de 2013 a 31 de dezembro de 2015).

Portanto, pode-se concluir que até o presente momento não houve formação de nível d’água transiente e confirma-se a hipótese da não atuação de pressões neutras positivas nos mecanismos de ruptura do talude investigado.

\subsubsection{Monitoramento das Precipitações Pluviométricas}

As precipitações pluviométricas diárias foram medidas com o uso do pluviômetro Ville de Paris e monitoradas no período de 24 de dezembro de 2013 a 31 de dezembro de 2015, conforme mencionado no item 4.10. A Figura 6.38 e Figura 6.39 apresentam os valores dessas precipitações, nas quais também estão incluídas os valores das precipitações pluviométricas do pluviômetro INMET e do pluviômetro ANA. 


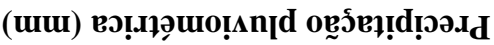

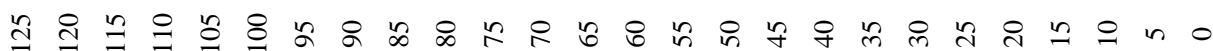

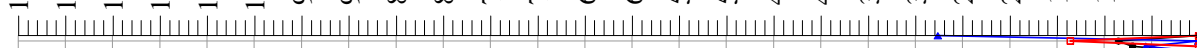

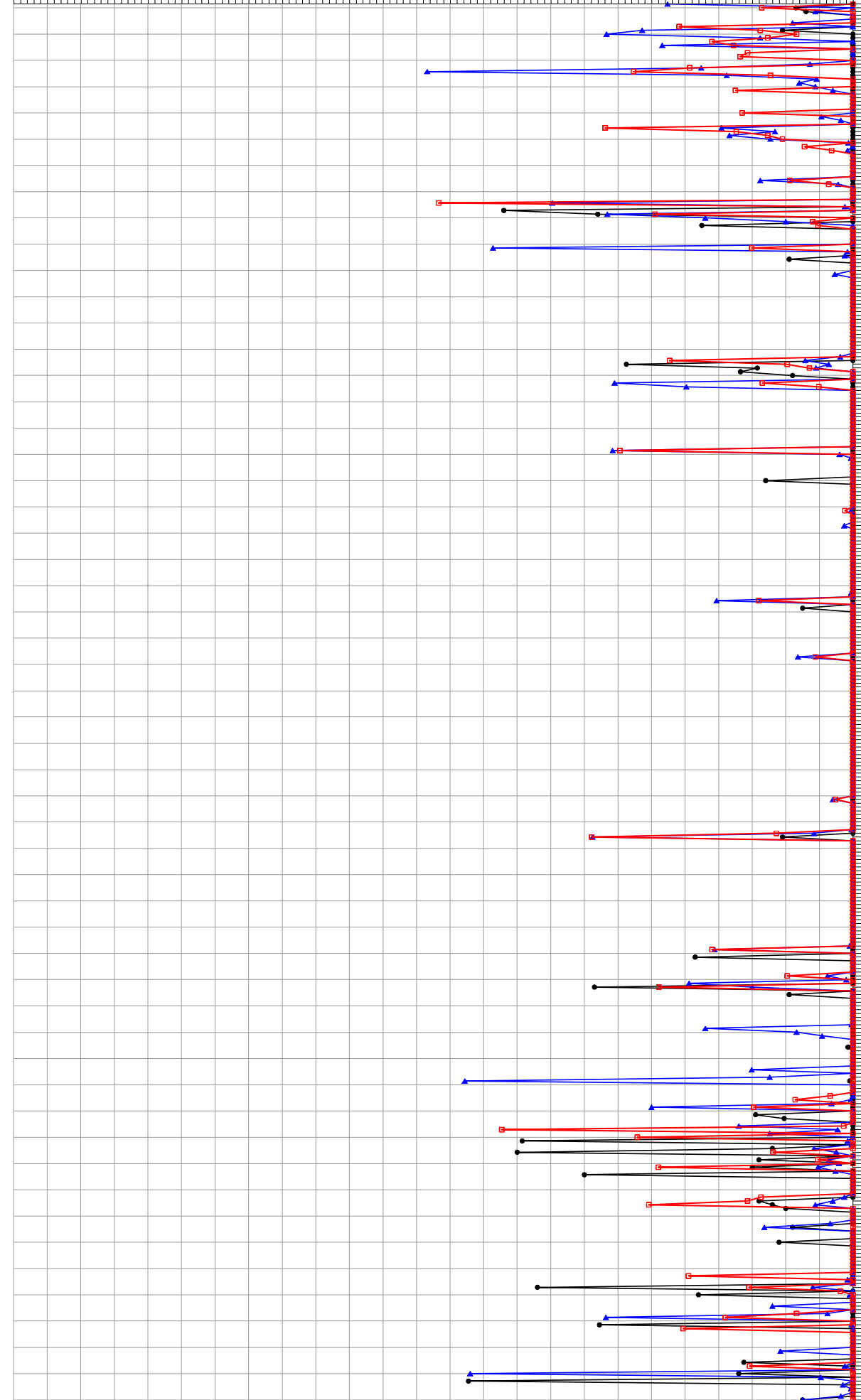

$\downarrow I 0 Z / Z I / 0 \mathcal{E}$ $t I 0 Z / Z I / \varepsilon Z$ $+I 0 Z / Z I / 9 \mathrm{I}$

$\nabla I 0 Z / Z I / 60$ $t I 0 Z / Z I / Z 0$ $\downarrow t 0 Z / \mathrm{I} I / \mathrm{SZ}$ $t \mathrm{I} 0 \mathrm{Z} / \mathrm{I} \mathrm{L} / \mathrm{8I}$ tI0Z/I I/I I

$t \mathrm{I} 0 \mathrm{Z} / \mathrm{I} \mathrm{I} / \mathrm{t} 0$ $t \mathrm{~L} 0 \mathrm{Z} / \mathrm{OL} / \mathrm{Rz}$ $t \mathrm{I} 0 \mathrm{Z} / \mathrm{0L} / \mathrm{I} Z$ $t \mathrm{I} 0 \mathrm{Z} / 0 \mathrm{~L} / \mathrm{t} \mathrm{I}$ $\downarrow t 0 z / 0 L / L 0$ tI0z/60/0ع $\downarrow[0 Z / 60 / \varepsilon z$ $\downarrow t 0 z / 60 / 9 \mathrm{I}$ tI0Z/60/60 $\downarrow 50 z / 60 / 20$ $\downarrow t 0 z / 80 / 9 z$ †I0Z/80/6I $\downarrow I 0 Z / 80 / Z I$ $\downarrow I 0 Z / 80 / s 0$ $\downarrow I 0 Z / L 0 / 6 z$ $\downarrow I 0 Z / L 0 / z z$ $\downarrow \mathrm{I} 0 Z / L 0 / S \mathrm{I}$ $\downarrow t 0 Z / L 0 / 80$ $\downarrow I 0 Z / L 0 / I 0$ $t I 0 z / 90 / t z$ $\downarrow I 0 Z / 90 / L I$ tI0Z/90/0 I $\downarrow[0 Z / 90 / \varepsilon 0$ $\downarrow I 0 Z / S 0 / L Z$ $\downarrow \mathrm{I} 0 z / \varsigma_{0} / 0 z$ $\downarrow I 0 Z / \varsigma^{\circ} / \varepsilon \mathrm{E}$ † I0Z/ऽ0/90 $+50 z / t 0 / 6 z$ $\downarrow I 0 z / t 0 / z z$ $\downarrow \mathrm{I} 0 Z / \mathrm{t} 0 / \mathrm{SI}$ $\downarrow t 0 z / t 0 / 80$ $\downarrow t 0 Z / t 0 / I 0$ $\downarrow I 0 z / \varepsilon 0 / s Z$ $\downarrow I 0 Z / \varepsilon 0 / 8 \mathrm{I}$ †I0Z/EO/ I I $\downarrow I 0 Z / E 0 / t 0$ $\downarrow I 0 z / 20 / s z$ $\downarrow I 0 Z / Z 0 / 8 \mathrm{I}$ $\downarrow$ I0Z/Z0/I I $\downarrow L 0 z / z 0 / t 0$ $\downarrow I 0 Z / I 0 / 8 z$ $\downarrow I 0 Z / I 0 / I Z$ $\downarrow \mathrm{I} 0 \mathrm{Z} / \mathrm{I} 0 / \mathrm{t} \mathrm{I}$ $\downarrow I 0 Z / I 0 / L 0$ $\varepsilon I 0 Z / Z I / I \varepsilon$

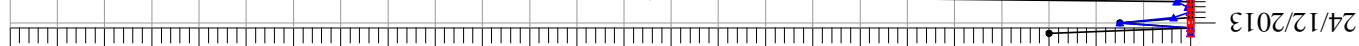

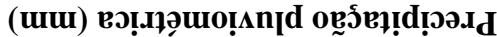

Figura 6.38 - Precipitação pluviométrica diária do Pluviômetro Ville de Paris, Pluviômetro INMET e Pluviômetro ANA (período de 24/12/2013 a 31/12/2014). 


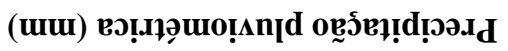

$\cong$ 그응

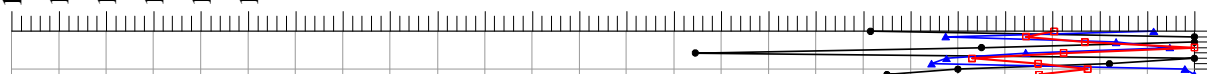
SI0Z/ZI/LE sLoz/zL/tzz (1) SI0Z/ZI/LI SI0Z/ZI/0I ৎI0Z/ZI/EO SI0Z/I I/9Z SI0Z/I L/6 I SI0Z/I I/ZI SI0Z/I I/S0 S $\mathrm{L} 0 \mathrm{Z} / 0 \mathrm{I} / 6 \mathrm{Z}$ SI0Z/0I/ZZ SI0Z/0I/SI SI0Z/0I/80 SL0Z/0I/LO ৎI0Z/60/tz SI0Z/60/LI SI0Z/60/0I ৎI0Z/60/E0 SLOZ/80/LZ SI0Z/80/0Z SI0Z/80/E I SI0Z/80/90 SIOZ/LO/OE SIOZ/LO/EZ SI0Z/LO/9I SIOZ/L0/60 SIOZ/LO/Z0 SI0Z/90/SZ SI0Z/90/8 I SLOZ/90/L I ৎLOZ/90/t0 ऽI $0 z / \varsigma_{0} / 8 Z$ SI0Z/S0/IZ $\varsigma \mathrm{I} 0 Z / \varsigma_{0} / \mathrm{t} \mathrm{I}$ ऽIOZ/SO/LO ৎI $0 z / t 0 / 0 \mathcal{E}$ SIOZ/t $0 / \varepsilon z$ ৎI0Z/t0/9I ৎI $0 Z / t 0 / 60$ S L $0 z / t 0 / 20$ ऽ $10 Z / \varepsilon 0 / 9 Z$ ऽI0Z/E0/6I SI0Z/E0/Z I SIOZ/EO/SO s $0 Z / Z 0 / 9 z$ ৎI0Z/Z0/6I SI0Z/Z0/ZI SI0Z/Z0/SO SI0Z/I0/6Z SI0Z/I0/ZZ SI0Z/I0/SI SI0Z/I0/80

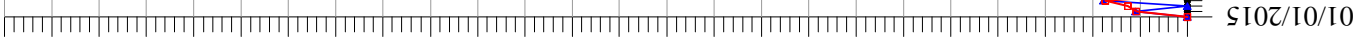

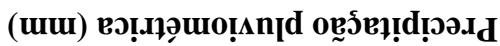

Figura 6.39 - Precipitação pluviométrica diária do Pluviômetro Ville de Paris, Pluviômetro INMET e Pluviômetro ANA (período de 01/01/2015 a 31/12/2015). 
Os valores de precipitação medidas pelo pluviômetro Ville de Paris instalado próximo à área piloto indicam que as leituras oscilaram de $0,5 \mathrm{~mm}$ a 93,1 mm, sendo o pico ocorrido no dia 01 de dezembro de 2015. Já para o pluviômetro INMET as leituras variaram de $0,1 \mathrm{~mm}$ a 72,6 mm, tendo seu pico registrado em 28 de março de 2015 enquanto que para o pluviômetro ANA as leituras variaram de 1,2 $\mathrm{mm}$ a $121,3 \mathrm{~mm}$, tendo seu pico registrado em 04 de dezembro de 2015.

No ano de 2014, o pluviômetro Ville de Paris totalizou 807,3 $\mathrm{mm}$ de precipitação anual enquanto que no ano de 2015 totalizou 1479,3 mm. Verificando-se a distribuição das precipitações para as estações chuvosa e seca do ano, essas totalizaram 534,3 mm e 273,0 mm para o ano de 2014 e de 1091,2 mm e 338,1 mm para o ano de 2015, respectivamente. Como mencionado no item 5.3 e mostrado na Figura 5.4, a precipitação média anual para a cidade de Ribeirão Bonito corresponde à 1438,0 mm, os quais encontram-se distribuídos 1113,0 mm na estação chuvosa e 325,0 mm na estação seca. Portanto, observa-se que as precipitações do ano de 2015 indicam valores muito próximos aos da precipitação média anual, inclusive considerando a distribuição das precipitações para ambas as estações (chuvosa e seca), tornando-se o ano de 2015 mais próximo da série de dados de 30 anos apresentados por Climatempo (2015).

As estações chuvosa e seca mantiveram-se semelhantes em termos de precipitação e duração ao observado para os dois anos de monitoramento, incluindo o mesmo tipo de comportamento para o pluviômetro INMET e o pluviômetro ANA. Verifica-se que a partir do início do mês de setembro ocorre um aumento da frequiência das chuvas, podendo caracterizar um período de transição entre as estações seca e chuvosa enquanto que a partir do final do mês de março ocorre uma diminuição da freqüência das chuvas, podendo caracterizar um período de transição entre as estações chuvosa e seca.

Comparando-se os valores resultantes do pluviômetro Ville de Paris com os demais, observa-se que ocorre maior dispersão com os valores do pluviômetro INMET, isso pode ser justificado pelo fato desse equipamento situar $33,2 \mathrm{~km}$ de distância da área piloto. Em contrapartida, os valores resultantes do pluviômetro ANA indicaram menor dispersão entre seus valores, mesmo esses equipamentos estando distantes de $1,8 \mathrm{~km}$. Portanto, mesmo tendo uma pequena distância entre o pluviômetro Ville de Paris e os demais pluviômetros, os dados de precipitação pluviométrica apresentam uma certa dispersão. Essa comparação foi utilizada somente para avaliar os dados coletados na área piloto e analisar sua representatividade. A diferença de valores de precipitação pluviométrica pode estar associada com a imprecisão nas leituras da proveta e com a influência da evaporação nos dias mais quentes, por exemplo. 


\subsection{MODELAGEM NUMÉRICA}

A modelagem numérica foi dividida em três etapas, sendo que a primeira etapa contempla as análises numéricas para avaliar o nível de estabilidade das seções investigadas a partir dos parâmetros de resistência do solo, a segunda etapa engloba as análises numéricas para analisar a estabilidade do talude a partir da modificação na geometria das seções (altura e inclinação) enquanto que a terceira etapa contempla as análises numéricas da infiltração da água da chuva acoplada com a análise da estabilidade de talude realizadas para as seções investigadas.

\subsubsection{Análise numérica para avaliar o nível de estabilidade das seções investigadas}

Nesta etapa dos estudos foi utilizada a rotina Slope/W do programa GeoStudio versão 2012, calculando os Fatores de Segurança (FS) a partir dos métodos determinísticos de Bishop Simplificado e de Janbu. As análises numéricas de estabilidade foram realizadas considerando as duas geometrias levantadas nas seções monitoradas em campo (Figura 6.40).

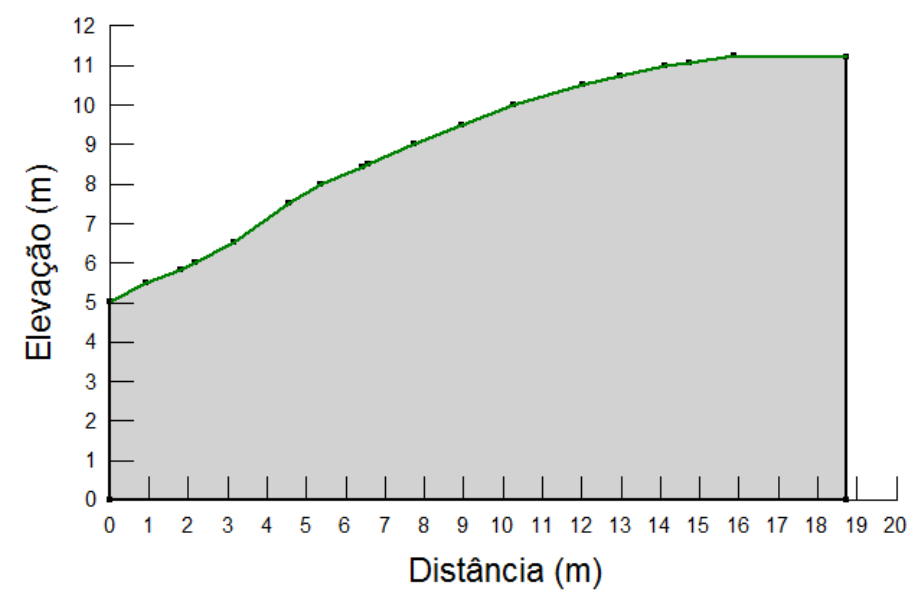

(a)

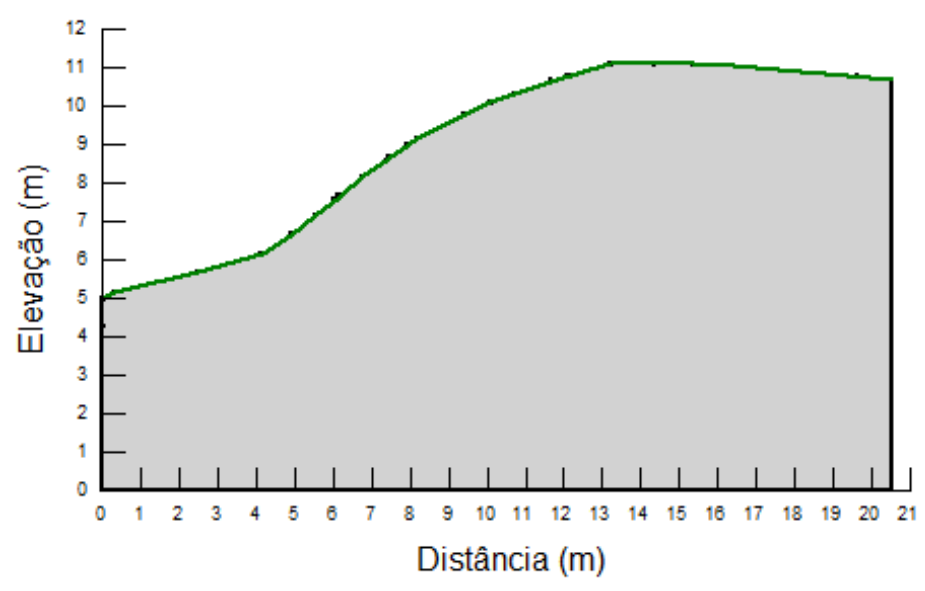

(b)

Figura 6.40 - Geometria das duas seções monitoradas em campo (a) seção A-A' e (b) seção B-B'. 
Os parâmetros mecânicos do solo utilizados nas análises correspondem aos dados resultantes dos ensaios de compressão triaxial, como mostra a Tabela 6.17. Observa-se nesta tabela que o valor do peso específico do solo corresponde a um único valor (como mencionado no item 4.11.2.7) e que os valores de coesão efetiva de $32 \mathrm{kPa}, 8 \mathrm{kPa}$ e $2 \mathrm{kPa}$ correspondem à sucção de $18240 \mathrm{kPa}, 30 \mathrm{kPa}$ e $0 \mathrm{kPa}$, respectivamente. Os outros valores de coesão efetiva $(1,5 \mathrm{kPa}$ a $0 \mathrm{kPa}$ ) foram adotados com o intuito de avaliar o nível de estabilidade de talude.

Tabela 6.17 - Parâmetros mecânicos do solo utilizados nas modelagens numéricas - nível de estabilidade.

\section{Parâmetro mecânico do solo}

Ângulo de atrito efetivo

Coesão efetiva

Peso específico

\section{Valores dos parâmetros}

\begin{tabular}{cc}
\hline Coesão efetiva & $32 \mathrm{kPa}, 8 \mathrm{KPa}, 2 \mathrm{kPa}, 1,5 \mathrm{kPa}, 1,0 \mathrm{kPa}, 0,5 \mathrm{kPa}$ e $0 \mathrm{kPa}$ \\
\hline Peso específico & $15,24 \mathrm{kN} / \mathrm{m}^{3}$ \\
\hline
\end{tabular}

Conforme mencionado e apresentado no item 4.11.2.7, as configurações consideradas na delimitação das superfícies de ruptura críticas (menores valores de FS) foram: Grid e Raio ("grid and radius"), ausência de pressão neutra e fenda de tração.

A Figura 6.41 ilustra os resultados das análises de estabilidade para a Seção A-A' e Seção B-B', tendo sido utilizadas em ambas as seções o método de Bishop Simplificado e três valores de coesão efetiva ( $2 \mathrm{kPa}, 8 \mathrm{kPa}$ e $12 \mathrm{kPa})$.

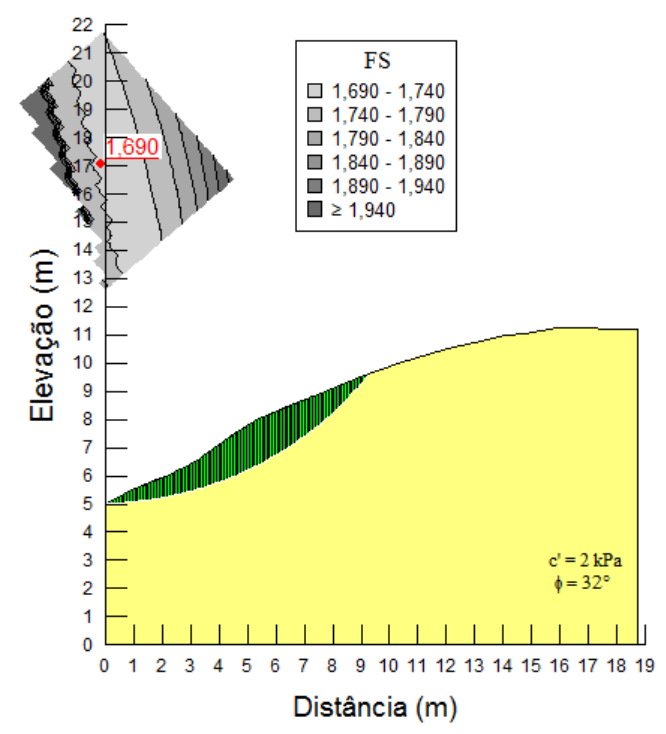

(a)

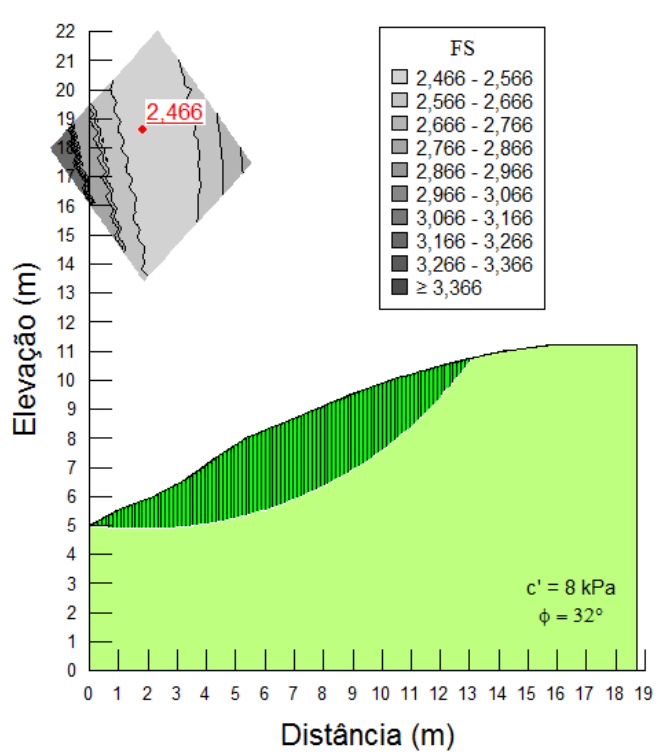

(b) 


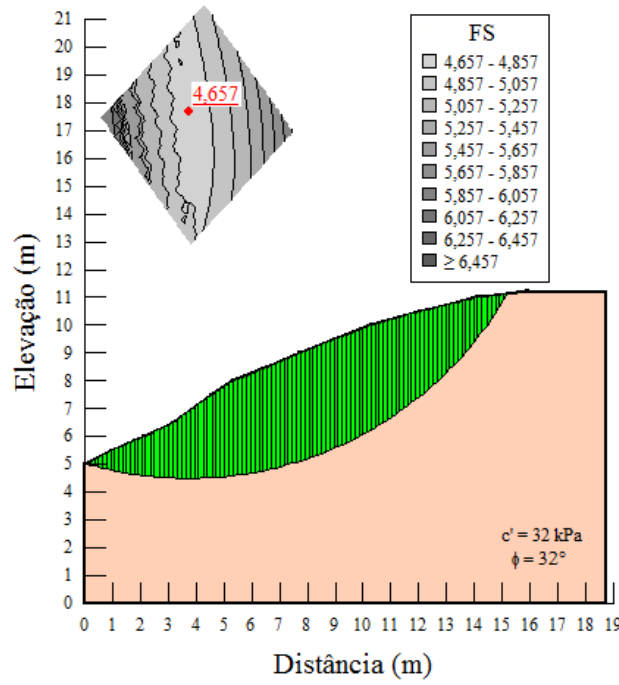

(c)

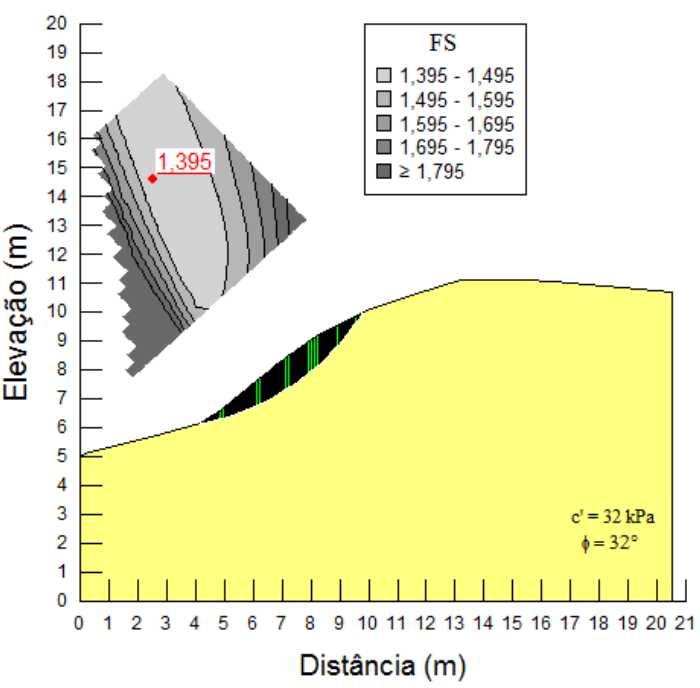

(d)

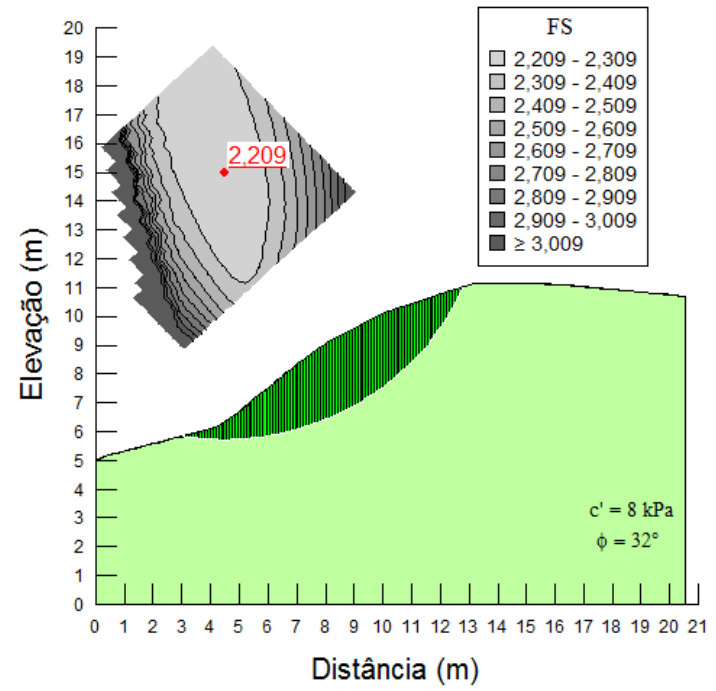

(e)

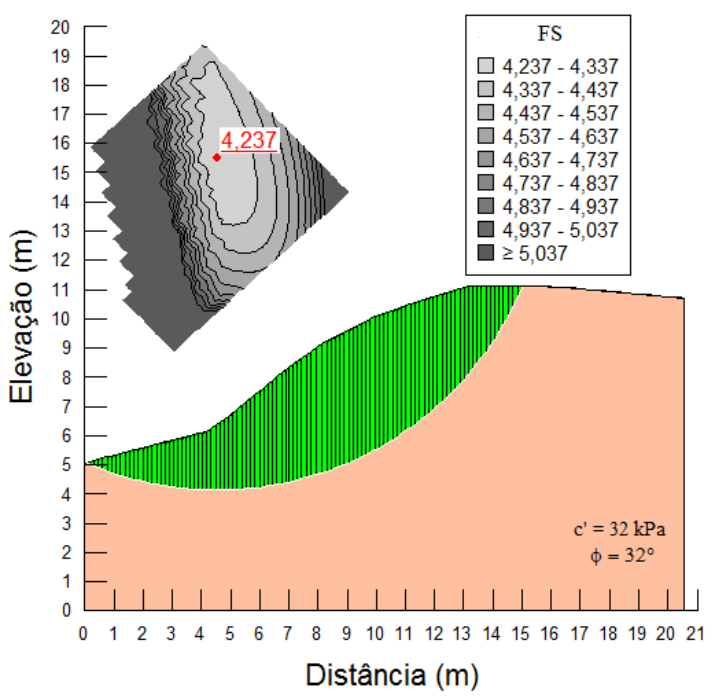

(f)

Figura 6.41 - Resultado gráfico das análises de estabilidade de talude na Seção A-A' para - (a) coesão 2 kPa, (b) coesão $8 \mathrm{kPa}$, (c) coesão $32 \mathrm{kPa}$ e na Seção B-B' para - (d) coesão $2 \mathrm{kPa}$, (e) coesão 8 kPa e (f) coesão 32 kPa. 
Na seção A-A', verifica-se que a diminuição da coesão de $32 \mathrm{kPa}$ para $2 \mathrm{kPa}$ ocasiona a redução da ordem de 64\% no FS crítico (menor valor). Apesar desta redução significativa, o talude ainda permanece $69 \%$ acima da condição de ruptura (FS mínimo $=1,690)$ nesta seção. Observa-se também que as profundidades das superfícies de ruptura críticas (associadas aos FS mínimos obtidos, áreas verdes da Figura 6.41 tendem a diminuir com a redução da coesão, ficando da ordem de 1,0 a 1,5 m, para o menor FS obtido $(1,690)$.

Na seção B-B', verifica-se que a diminuição da coesão de $32 \mathrm{kPa}$ para $2 \mathrm{kPa}$ ocasiona a redução de cerca de $67 \%$ no FS crítico. Neste caso, o talude fica apenas $40 \%$ acima da condição de ruptura (FS mínimo $=1,395)$. Observa-se também que as profundidades das superfícies de ruptura críticas (associadas aos FS mínimos obtidos, áreas verdes da Figura 6.41) tem comportamento semelhante ao observado na seção A-A', ficando da ordem de 1,0 a 1,5 m, para o menor FS obtido (1,395).

Estes resultados confirmam que a redução nos valores de sucção e a consequente redução da parcela de coesão aparente do solo produzem significativas reduções nos FS dos taludes investigados, mesmo na condição de não atuação de pressões neutras ou lençol freático. Também fica evidenciada a influência da geometria nos valores de FS, sendo que as alturas das duas seções são semelhantes (em torno de 5,0 m), porém a seção A-A' possui inclinação média de $27^{\circ}$ e a seção B-B' uma inclinação média de $37^{\circ}$.

As profundidades das superfícies de ruptura críticas (menor FS) obtidas nas análises de estabilidade em ambas as seções do talude são compatíveis com as observadas nos levantamentos de campo.

Os resultados das análises de estabilidade com as mesmas condições de contorno e utilizando o método de Janbu foram semelhantes aos obtidos pelo método Bishop Simplificado apresentados acima. Verificou-se uma tendência geral dos valores de FS obtidos com o método Janbu serem ligeiramente inferiores ao método Bishop Simplificado (cerca de $10 \%$ inferior). Esta diferença está associada à forma que cada um dos métodos considera as interações entre as lamelas de solo no cálculo do FS.

Considerando-se a importância da parcela de coesão aparente associada à sucção na estabilidade do talude de solo investigado, expressa pelos fatores de segurança determinísticos, também foram elaborados gráficos correlacionando estes dois parâmetros (Figura 6.42a). Observa-se que valores de coesão inferiores a $0,5 \mathrm{kPa}$ seriam suficientes para levar a ruptura taludes com a geometria semelhante ao observada na seção B-B', enquanto que mesmo para valores nulos de coesão, taludes com a geometria observada na seção A-A' 
ficam um pouco acima da condição de ruptura, como mostra o detalhe na Figura 6.42b para o intervalo de coesão entre 0 e $2 \mathrm{kPa}$.

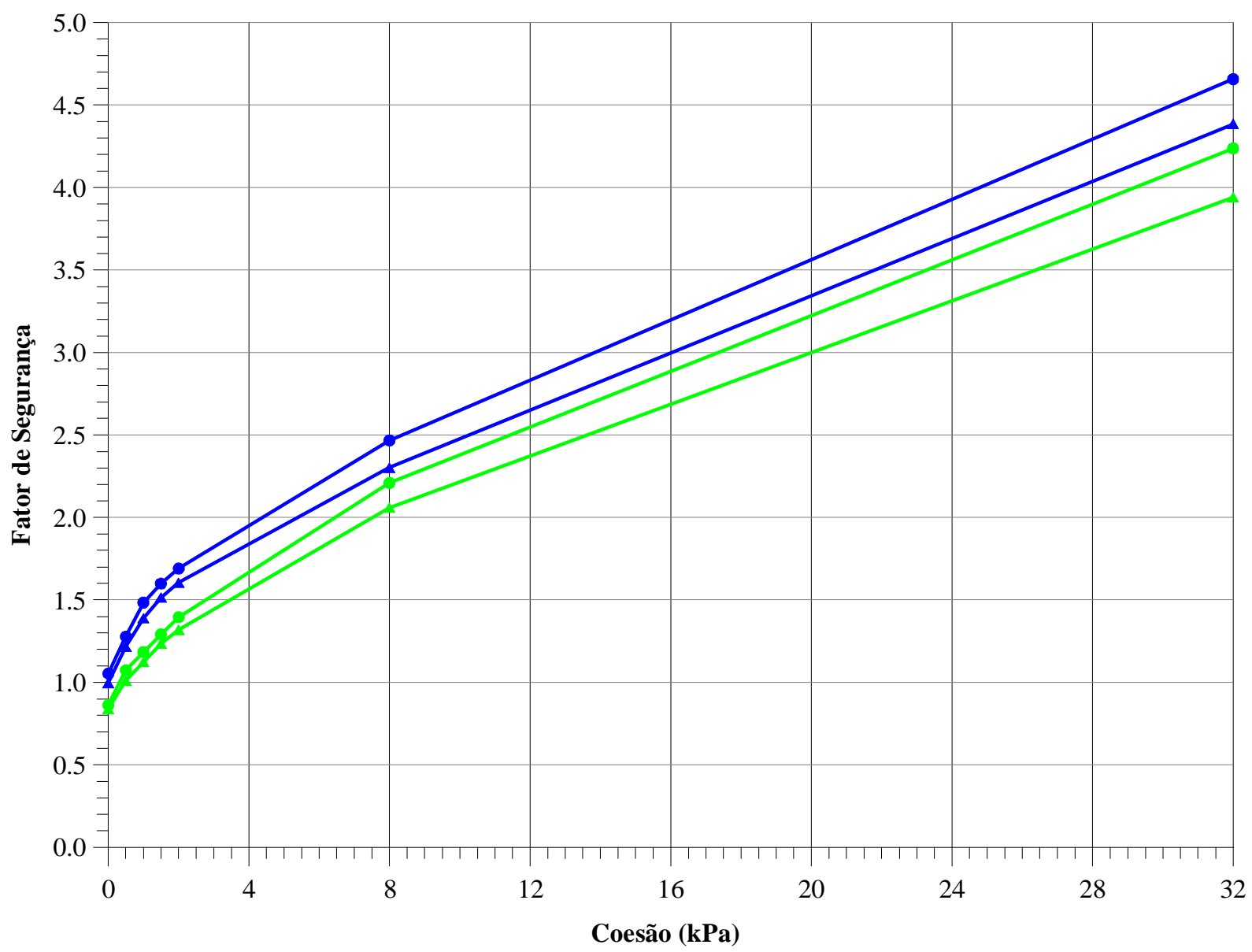

(a)

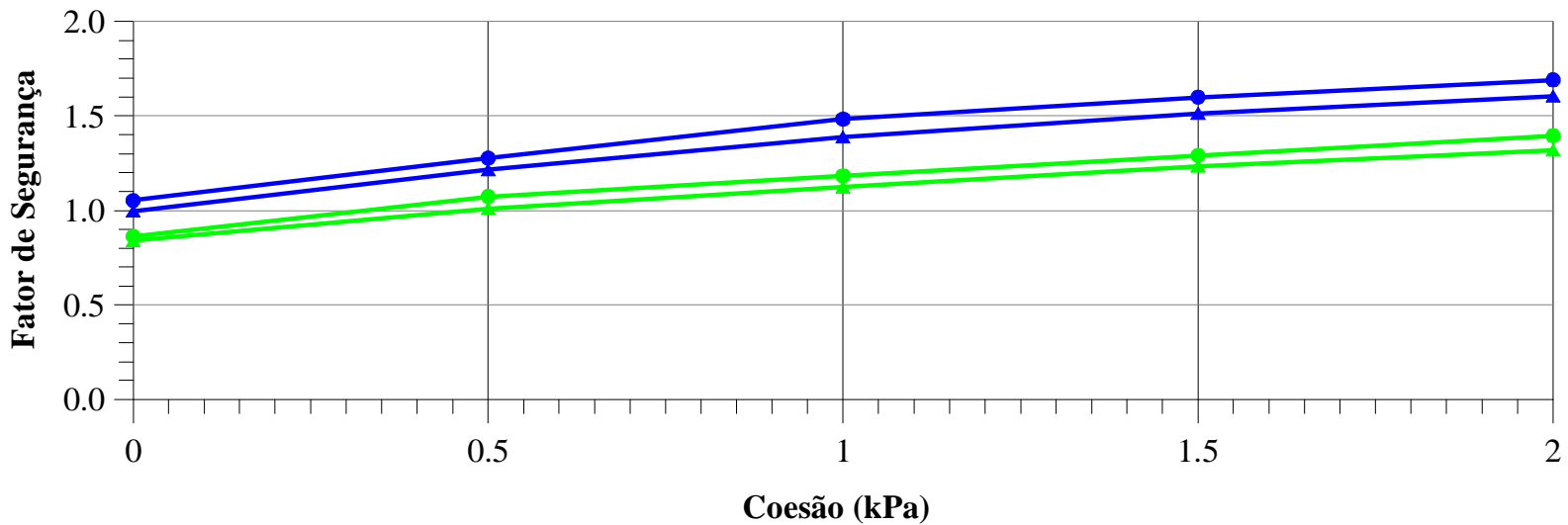

- Seção A-A' - Bishop Simplificado

$\rightarrow$ Seção A-A' - Janbu

-- Seção B-B' - Bishop Simplificado

$\_$Seção B-B' - Janbu

(b)

Figura 6.42 - (a) Fator de Segurança versus coesão - Seção A-A' e Seção B-B' - utilizando o método de Bishop Simplificado e o método de Janbu e (b) detalhe do gráfico para o intervalo de coesão entre $0 \mathrm{kPa}$ e $8 \mathrm{kPa}$. 


\subsubsection{Análise numérica para analisar a estabilidade do talude a partir da modificação na geometria das seções}

Nesta etapa dos estudos também foi utilizada a rotina Slope/W do programa GeoStudio versão 2012, sendo calculado os Fatores de Segurança (FS) a partir do método determinístico de Bishop Simplificado. As análises numéricas de estabilidade foram realizadas considerando as alterações na geometria do talude baseada na geometria da Seção A-A' e da Seção B-B', em que algumas seções foram traçadas com alturas diferentes e outras seções foram traçadas com inclinações diferentes, conforme ilustrado na Figura 4.44 e Figura 4.45 do item 4.11.2.5. As configurações consideradas na delimitação das superfícies de ruptura críticas (menores FS) foram: Grid e Raio ("grid and radius"), ausência de pressão neutra e fenda de tração, conforme mencionado e apresentado no item 4.11.2.7.

Os parâmetros mecânicos do solo utilizados nas análises correspondem aos dados resultantes dos ensaios de compressão triaxial, como mostra a Tabela 6.18. Observa-se nesta tabela que o valor de peso específico do solo corresponde a um único valor (como mencionado no item 4.11.2.7) e que os valores de coesão de $32 \mathrm{kPa}, 8 \mathrm{kPa}$ e $2 \mathrm{kPa}$ correspondem à sucção de $18240 \mathrm{kPa}, 30 \mathrm{kPa}$ e $0 \mathrm{kPa}$, respectivamente.

Tabela 6.18 - Parâmetros mecânicos do solo utilizados nas modelagens numéricas - modificação geometria.

\begin{tabular}{cc}
\hline Parâmetro mecânico do solo & Valores dos parâmetros \\
\hline Ângulo de atrito efetivo & $32,0^{\circ}$ \\
\hline Coesão efetiva & $32 \mathrm{kPa}, 8 \mathrm{KPa}, 2 \mathrm{kPa}$ \\
\hline Peso específico & $15,24 \mathrm{kN} / \mathrm{m}^{3}$ \\
\hline
\end{tabular}

No caso da Seção A-A', a modificação nas alturas das seções mostraram que os Fatores de Segurança tendem a diminuir quando ocorre o acréscimo na altura da seção e redução da coesão, como mostra a Figura 6.43. Apesar da redução do FS ser gradual, a sua faixa de dispersão é menor para a coesão de $2 \mathrm{kPa}$ (FS variando entre 1,684 e 1,483) e maior para a coesão de $32 \mathrm{kPa}$ (FS variando entre 4,578 e 3,952). Embora tenha limitado a profundidade da superfície de ruptura crítica em 3,0 m, observa-se que as profundidades dessas superfícies variaram para as diferentes alturas das seções e valores de coesão do solo, permanecendo usualmente entre $2,0 \mathrm{~m} \mathrm{e} \mathrm{3,0} \mathrm{m.}$ 


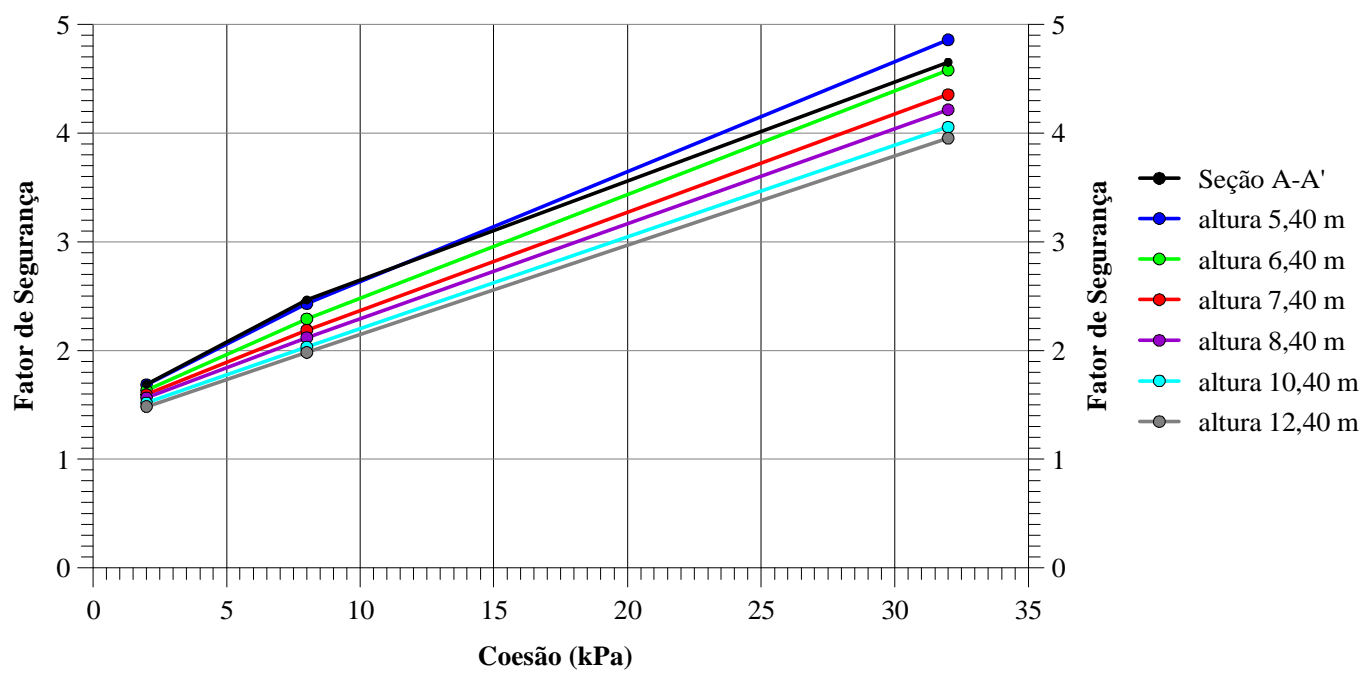

Figura 6.43 - Fator de Segurança versus coesão - inclinação constante de $27^{\circ}$ e modificação da altura, baseada na Seção A-A’ - utilizando o método de Bishop Simplificado.

Já para a modificação das inclinações das seções baseadas na Seção A-A', os resultados das análises de estabilidade mostraram que os Fatores de Segurança tendem a diminuir quando ocorre um acréscimo na inclinação da seção e redução da coesão, como mostra a Figura 6.44. Verifica-se que a redução do FS é proporcional com o aumento da inclinação da seção, que dependendo do valor da coesão apresenta um decréscimo da ordem de $25 \%$ no FS ocasionada pelo aumento da inclinação de $30^{\circ}$ para $45^{\circ}$. Embora tenha limitado a profundidade da superfície de ruptura crítica em 3,0 m, constata-se que as profundidades dessas superfícies apresentam comportamento semelhante ao observado na modificação da altura da seção, permanecendo usualmente entre 2,0 m e 3,0 m. Essas análises numéricas indicam que o talude estaria na condição de ruptura para inclinações de $50^{\circ}$ e coesão abaixo de $3 \mathrm{kPa}$, ou seja, o solo do talude deverá encontrar-se próximo da saturação.

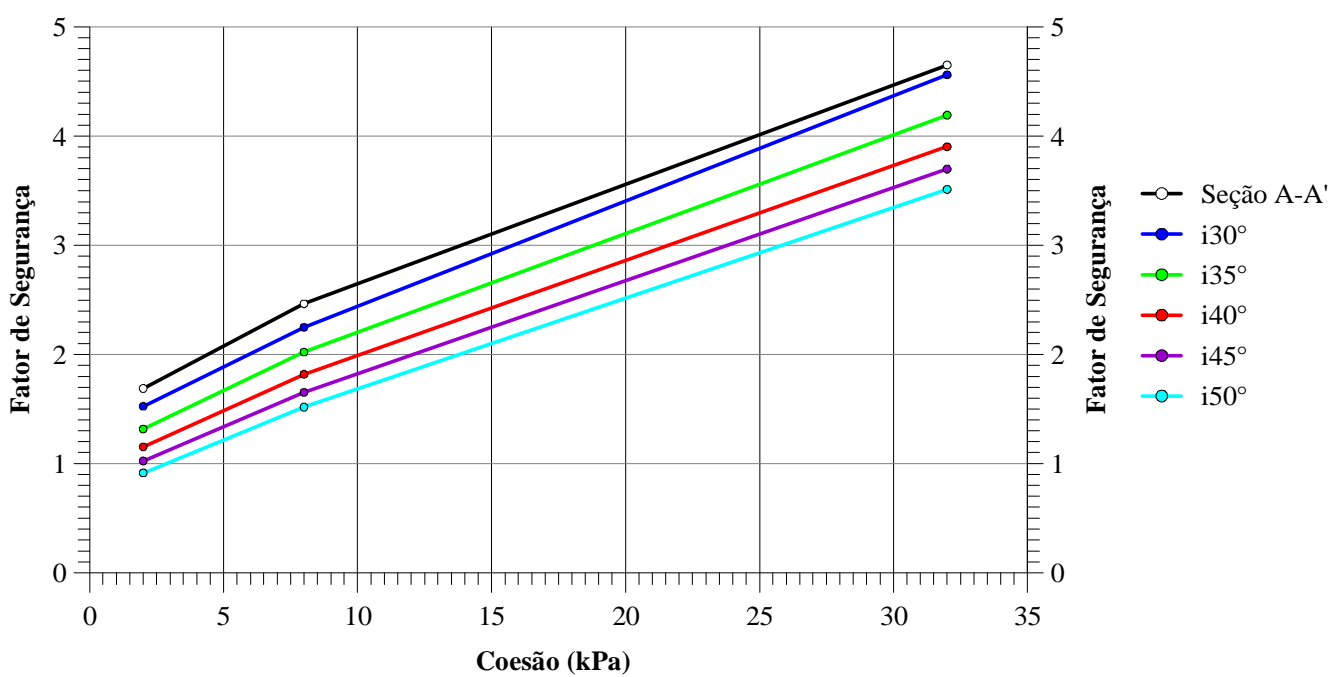

Figura 6.44 - Fator de Segurança versus coesão - altura constante de 5,40 m e modificação da inclinação baseada na Seção A-A'- utilizando o método de Bishop Simplificado. 
No caso da Seção B-B', a modificação nas alturas das seções mostraram que os Fatores de Segurança tendem a diminuir quando ocorre o acréscimo na altura da seção e redução da coesão, como mostra a Figura 6.45 e comportamento semelhante à modificação baseada na Seção A-A'. Apesar da redução do FS ser gradual, a sua faixa de dispersão é menor para a coesão de $2 \mathrm{kPa}$ (FS variando entre 1,271 e 1,072) e maior para a coesão de 32 $\mathrm{kPa}$ (FS variando entre 4,245 e 3,155). Embora tenha limitado a profundidade da superfície de ruptura crítica em 3,0 m, observa-se que as profundidades dessas superfícies variaram para as diferentes alturas das seções e valores de coesão do solo, permanecendo usualmente entre 2,0 m e 3,0 m. Essas análises numéricas indicam que o talude estaria na iminência da sua ruptura somente para a altura de 12,0 m e coesão de $2 \mathrm{kPa}$, como mostra o FS crítico de 1,072 para essa geometria.

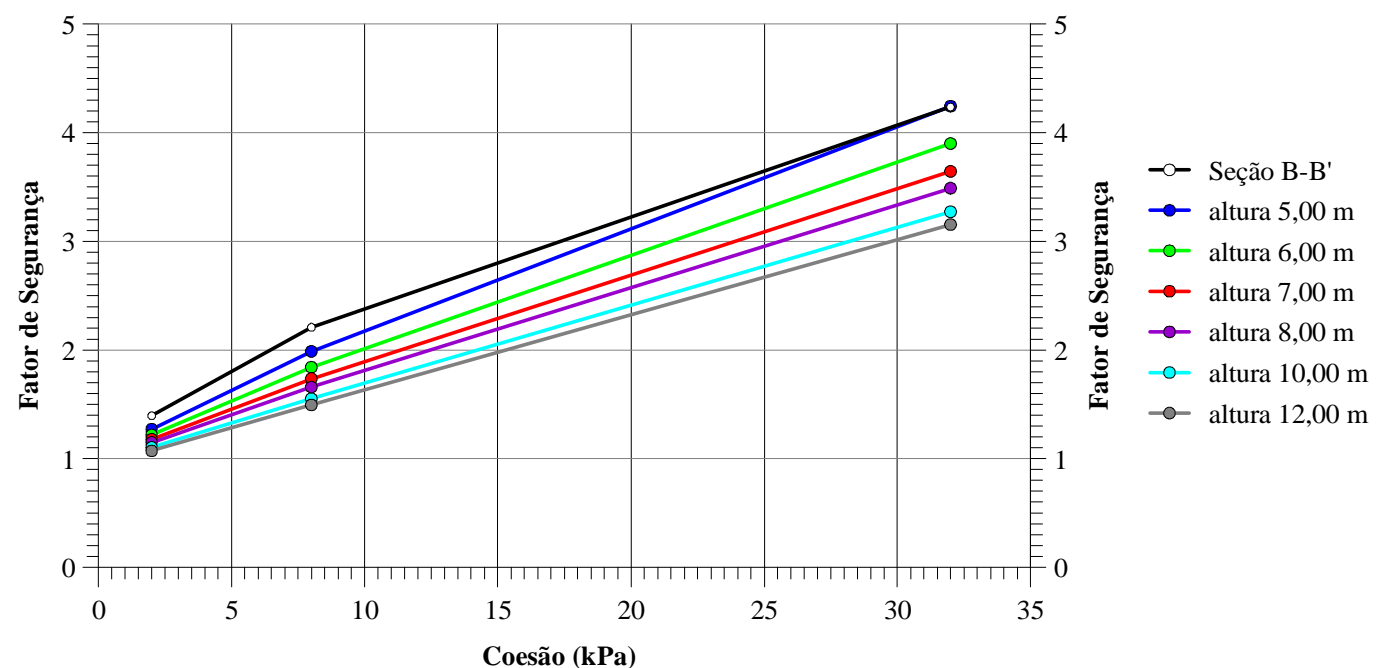

Figura 6.45 - Fator de Segurança versus coesão - inclinação constante de $37^{\circ}$ e modificação da altura, baseada na Seção B-B'- utilizando o método de Bishop Simplificado.

Já para a modificação das inclinações das seções baseadas na Seção B-B', os resultados das análises de estabilidade mostraram que os Fatores de Segurança tendem a diminuir quando ocorre um acréscimo na inclinação da seção e redução da coesão, como mostra a Figura 6.46. Verifica-se que a redução do FS é proporcional com o aumento da inclinação da seção, que dependendo do valor da coesão apresenta um decréscimo da ordem de $20 \%$ no FS ocasionada pelo aumento da inclinação de $45^{\circ}$ para $55^{\circ}$. Embora tenha limitado a profundidade da superfície de ruptura crítica em 3,0 m, constata-se que assim como na modificação baseada na Seção A-A', as profundidades dessas superfícies apresentam comportamento semelhante ao observado na modificação da altura da seção. Essas análises numéricas indicam que o talude estaria na condição de ruptura para inclinações de $50^{\circ}$ e coesão abaixo de $2,5 \mathrm{kPa}$ ou ainda para inclinações de $55^{\circ}$ e coesão abaixo de $3,5 \mathrm{kPa}$. 


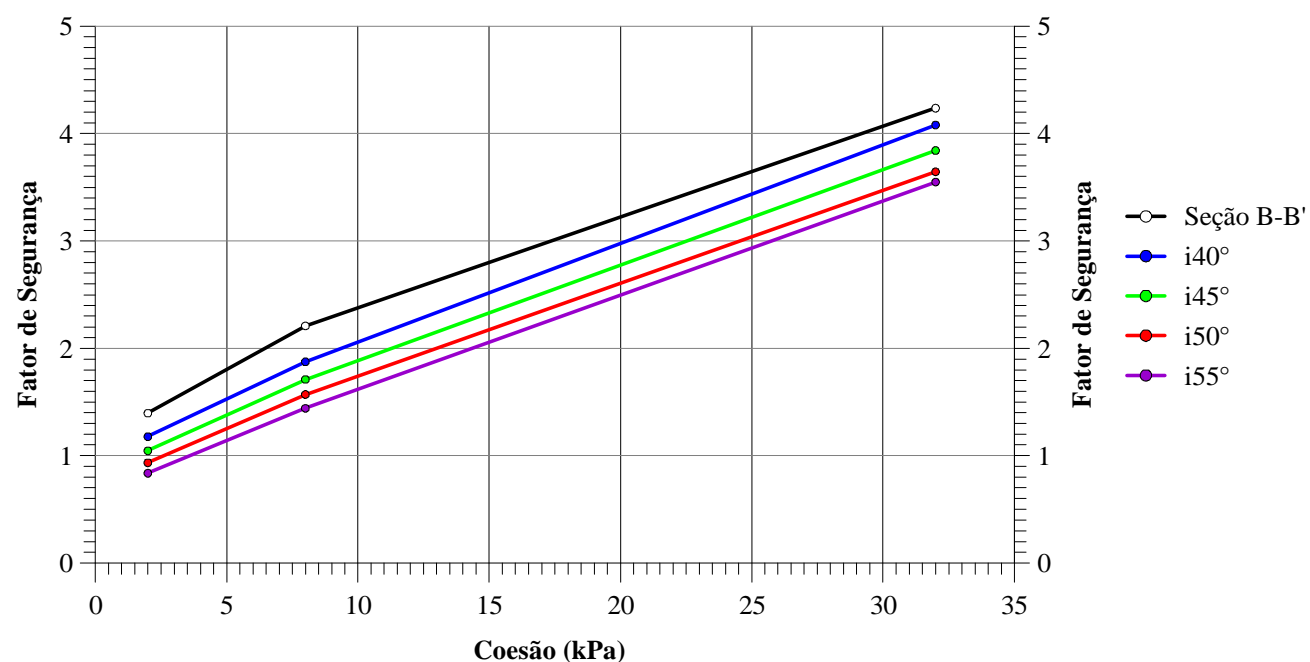

Figura 6.46 - Fator de Segurança versus coesão - altura constante de 5,00 m e modificação da inclinação baseada na Seção B-B'- utilizando o método de Bishop Simplificado.

Essas análises numéricas mostraram que os Fatores de Segurança reduzem significativamente quando ocorre a modificação das inclinações das seções, principalmente naquelas baseadas na geometria da Seção B-B'. Observa-se que mantendo a altura constante do talude em $5,0 \mathrm{~m}$ e $5,4 \mathrm{~m}$, o mesmo estaria na condição de ruptura para inclinações superiores à $50^{\circ}$ e coesão cerca de $3 \mathrm{kPa}$, ou seja, o solo do talude deveria estar próximo a condição de saturação.

Além disso, as análises numéricas mostraram que os Fatores de Segurança reduzem gradualmente quando ocorre a modificação das alturas das seções, observando comportamento semelhante em todas as seções. Constata-se que nenhuma geometria contribui na ruptura do talude, porém para a altura de $12,0 \mathrm{~m}$ e coesão de $2 \mathrm{kPa}$ o talude estaria na iminência da sua ruptura, apresentado um FS crítico de 1,072.

\subsubsection{Análise numérica da infiltração da água da chuva acoplada com análise de estabilidade de talude}

Assim como nas etapas anteriores, nestes estudos também foi utilizada a rotina Slope/W do programa GeoStudio versão 2012, sendo calculado os Fatores de Segurança (FS) a partir dos métodos determinísticos de Bishop Simplificado e de Janbu. As análises numéricas da infiltração da água da chuva acoplada com a análise de estabilidade foram realizadas para a Seção B-B' do talude, o qual apresenta geometria mais acentuada. Nessas análises foram escolhidos dois eventos pluviométricos, em que o primeiro evento consta do registro de precipitação pluviométrica com baixa intensidade em solo próximo à saturação e o segundo evento consta do registro de várias precipitações pluviométricas com alta 
intensidade. Vale ressaltar que o termo baixa e alta intensidade empregada anteriormente se refere ao regime pluviométrico da região onde se concentra a área piloto e as medidas de precipitação pluviométrica diária se refere ao monitoramento do pluviômetro Ville de Paris.

Os parâmetros hidráulicos do solo utilizados em todas as análises da infiltração da água da chuva dessa etapa correspondem aos dados resultantes do ensaio com permeâmetro Guelph (função condutividade hidráulica) e do ajuste da curva de retenção da água do solo, como mostra a Figura 6.47a, b.

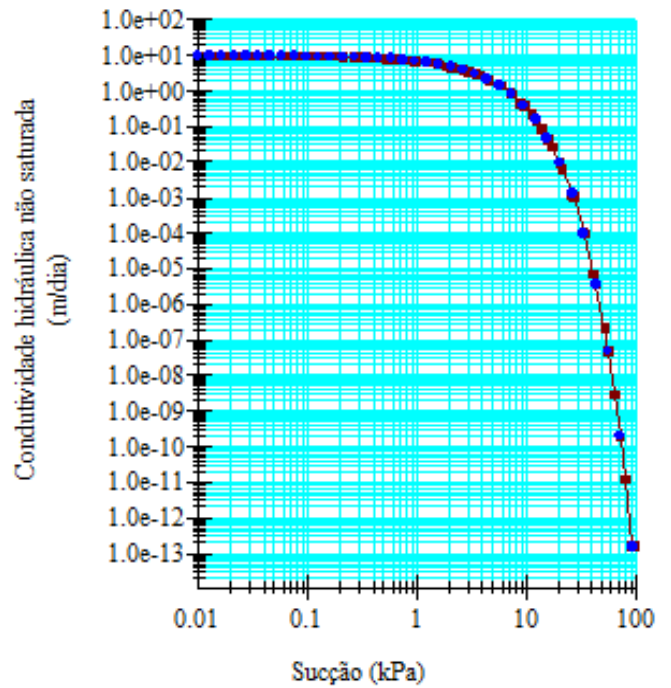

(a)

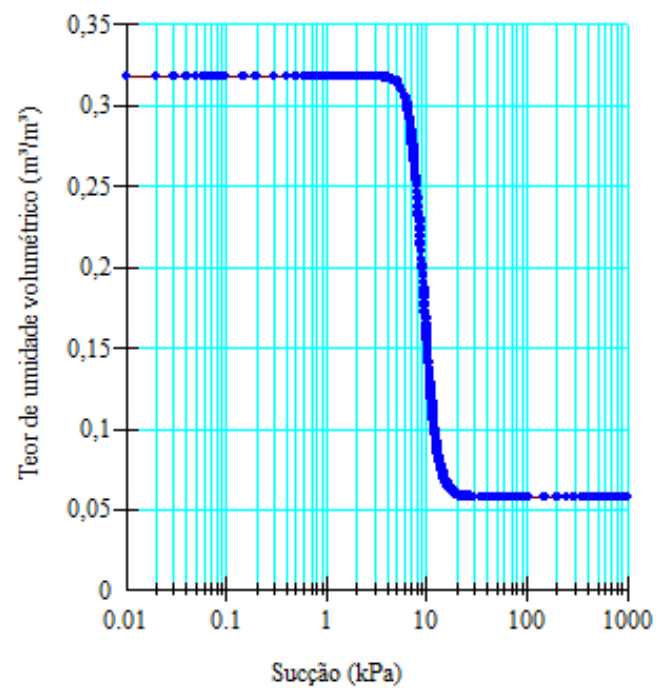

(b)

Figura 6.47 - Parâmetros hidráulicos do solo (a) função condutividade hidráulica e (b) curva de retenção da água no solo.

Observa-se na Figura 6.47a que a condutividade hidráulica saturada do ensaio com permeâmetro Guelph escolhida para as análises numéricas foi 9,504 $\mathrm{m} / \mathrm{dia}$, que corresponde ao valor de $1,1 \cdot 10^{-2} \mathrm{~cm} / \mathrm{s}$. Esse valor de condutividade foi escolhido por causa da proximidade com os valores resultantes dos ensaios de permeabilidade em laboratório serem da ordem de $1,5.10^{-2} \mathrm{~cm} / \mathrm{s}$ e $1,6 \cdot 10^{-2} \mathrm{~cm} / \mathrm{s}$. Como mencionado anteriormente, a função condutividade hidráulica foi determinada utilizando a equação empírica de Gardner (1958).

Além disso, constata-se na Figura $6.47 \mathrm{~b}$ que a curva de retenção da água no solo foi representada apenas para o ajuste feito do seu primeiro trecho, a qual foi representada pelo teor de umidade volumétrico versus sucção.

Os parâmetros mecânicos do solo utilizados em todas as análises numéricas de estabilidade dessa etapa correspondem aos dados resultantes do ensaio de compressão triaxial do tipo adensado-drenado com solo não saturado (sucção de $30 \mathrm{kPa}$ ), como mostra a Tabela 6.19. Observa-se nesta tabela que o valor de peso específico do solo corresponde a um único valor (como mencionado no item 4.11.2.7). 
Tabela 6.19 - Parâmetros mecânicos do solo utilizados nas modelagens numéricas - infiltração da água e estabilidade de talude.

Parâmetro mecânico do solo

Valores dos parâmetros

\begin{tabular}{cc}
\hline Ângulo de atrito efetivo & $32,0^{\circ}$ \\
\hline Ângulo de atrito efetivo referente à variação da sucção matricial & $11,3^{\circ}$ \\
\hline Coesão efetiva & $2 \mathrm{kPa}$ \\
\hline Peso específico & $15,24 \mathrm{kN} / \mathrm{m}^{3}$ \\
\hline
\end{tabular}

\subsubsection{Modelagem numérica do primeiro evento pluviométrico}

A modelagem numérica do primeiro evento considerou um período de monitoramento pluviométrico de três dias (Tabela 6.20) e um período de monitoramento da sucção matricial de dois dias (Tabela 6.21).

Tabela 6.20 - Período de monitoramento da precipitação pluviométrica diária (mm).

\begin{tabular}{cc}
\hline Data & Precipitação Pluviométrica $(\mathbf{m m})$ \\
\hline $06 / 03 / 2015$ & 2,3 \\
\hline $07 / 03 / 2015$ & 18,0 \\
\hline $08 / 03 / 2015$ & 32,0 \\
\hline
\end{tabular}

Tabela 6.21 - Período de monitoramento da sucção matricial $(\mathrm{kPa})$.

\begin{tabular}{|c|c|c|c|c|c|}
\hline \multirow{2}{*}{ Seção } & \multirow{2}{*}{ Local } & \multirow{2}{*}{ Tensiômetro } & \multirow{2}{*}{$\begin{array}{l}\text { Comprimento do } \\
\text { tensiômetro (m) }\end{array}$} & \multicolumn{2}{|c|}{ Data da leitura da sucção matricial (kPa) } \\
\hline & & & & $06 / 03 / 2015$ & 08/03/2015 \\
\hline \multirow{9}{*}{ B-B' } & \multirow{3}{*}{ Pé } & B1 & 0,45 & 7,5 & 3,5 \\
\hline & & B2 & 0,90 & 0,0 & 1,0 \\
\hline & & B3 & 1,50 & 17,0 & 12,0 \\
\hline & \multirow{3}{*}{ Face } & B4 & 0,45 & 4,5 & 1,5 \\
\hline & & B5 & 0,90 & 1,0 & 0,0 \\
\hline & & B6 & 1,50 & 5,0 & 3,0 \\
\hline & \multirow{3}{*}{ Crista } & B7 & 0,45 & 16,5 & 24,5 \\
\hline & & B8 & 0,90 & 31,0 & 27,0 \\
\hline & & B9 & 1,50 & 32,0 & 29,0 \\
\hline
\end{tabular}


Como mencionado no item 4.11.2.4, três modelos com diferentes condições de contorno foram utilizados para analisar a distribuição da pressão neutra negativa no fluxo permanente (steady-state). Todos os modelos seguiram os critérios descritos nesse mesmo item, estando abaixo discutidos e analisados cada um deles.

A Figura 6.48a,b ilustra a distribuição de pressão neutra do Modelo 1 para o steadystate e para o fluxo transiente correspondente ao dia 08/03/2015. Observa-se que a pressão neutra negativa aumentou para o fluxo transiente devido à ocorrência de chuva nos dois dias consecutivos ao steady-state, fazendo com que o solo localizado próximo à superfície se tornasse mais úmido no pé, na face e na crista da seção. Constata-se na Figura 6.48b que além da água da chuva umedecer o solo, ela também é redistribuída ao longo desse perfil a partir do avanço da frente de umedecimento para o interior dessa seção.

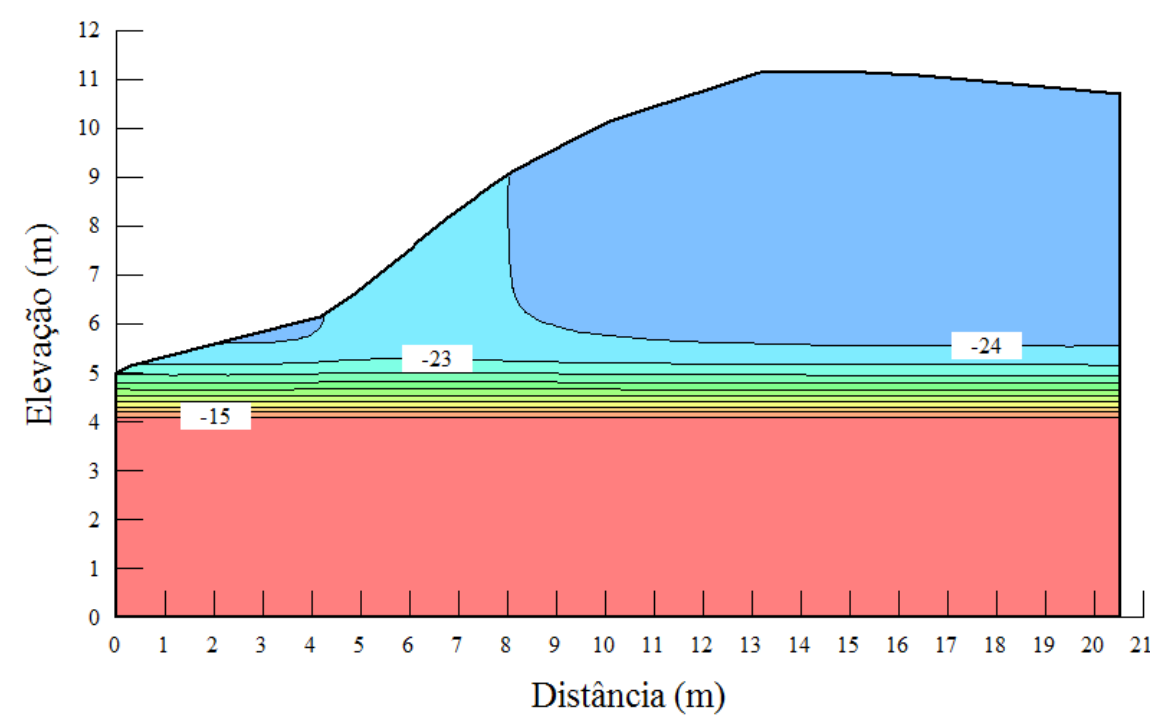

(a)

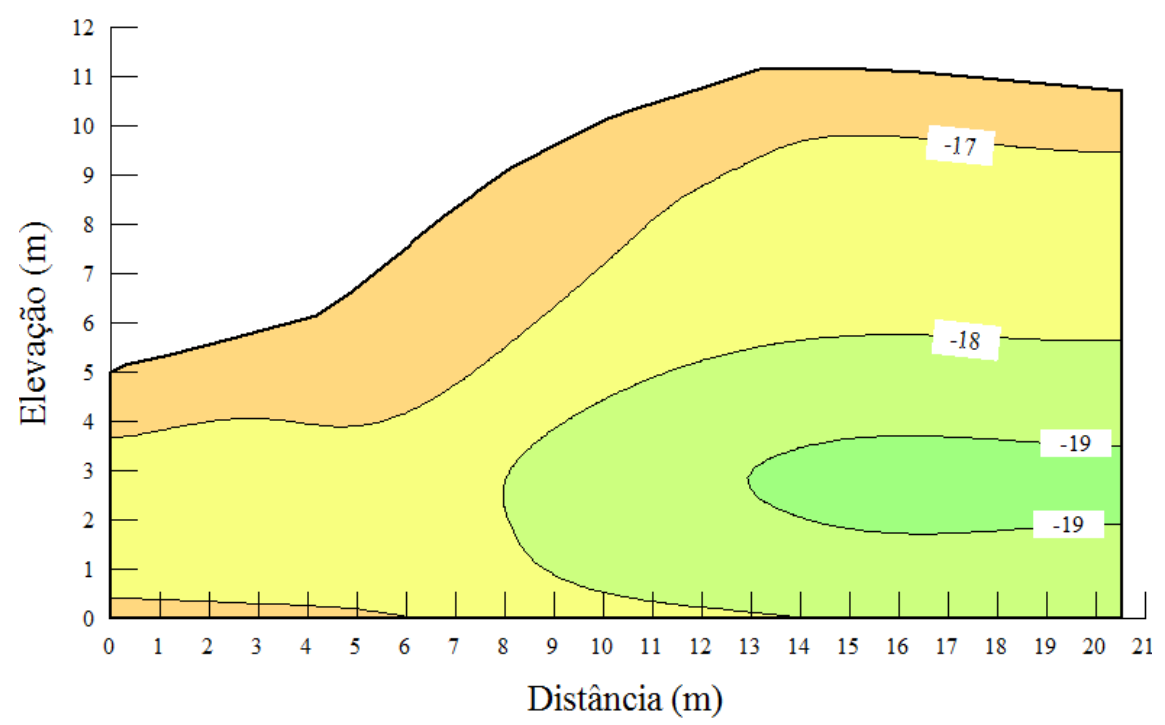

(b)

Figura 6.48 - Distribuição da pressão neutra do Modelo 1 para (a) steady-state (06/03/2015) e (b) 08/03/2015. 
Além dos resultados da distribuição da pressão neutra, também foi analisada a estabilidade do talude após a chuva do dia 08/03/2015 a partir do acoplamento hidromecânico, utilizando os métodos determinísticos de Bishop Simplificado e Janbu, como mostra a Figura 6.49. Embora a distribuição de pressão neutra utilizada para o cálculo de estabilidade seja idêntica para os dois métodos, verifica-se que o Fator de Segurança crítico é maior para o método Bishop Simplificado $(\mathrm{FS}=1,877)$ e menor para o método de Janbu ( $F S=1,766)$. Além disso, nota-se nas duas figuras abaixo que as superfícies críticas de ruptura são diferentes, tendo uma profundidade de aproximadamente $1,90 \mathrm{~m}$ utilizando o método de Bishop Simplificado e uma profundidade de aproximadamente 3,10 m utilizando o método de Janbu.

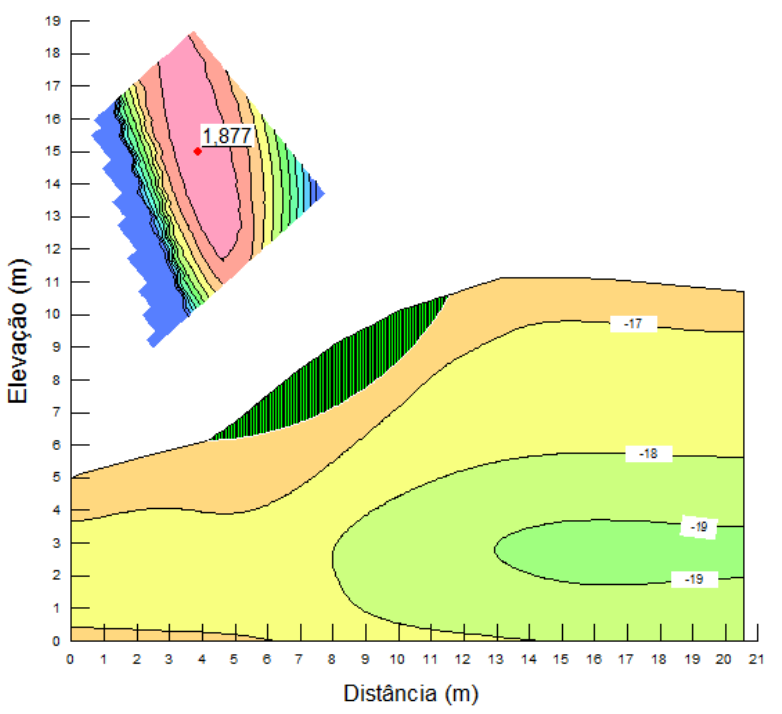

(a)

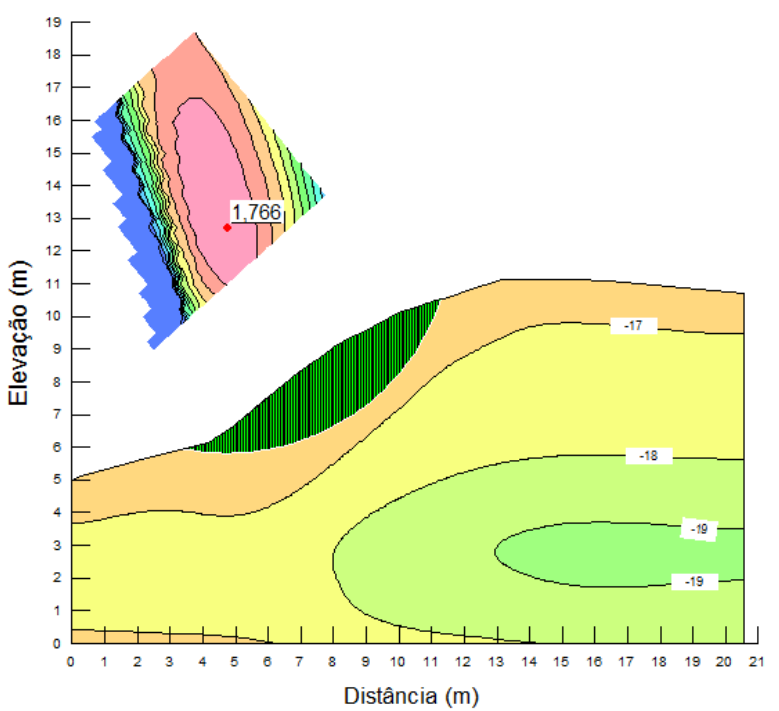

(b)

Figura 6.49 - Análise da estabilidade de talude para o Modelo 1 utilizando o método determinístico de (a) Bishop Simplificado e (b) Janbu.

A Figura 6.50a,b ilustra a distribuição de pressão neutra do Modelo 2 para o steadystate e para o fluxo transiente correspondente ao dia 08/03/2015. Observa-se que a distribuição de pressão neutra do steady-state possui comportamento diferente ao observado no Modelo 1, visto que na crista da seção o solo encontra-se mais seco e com maiores valores de pressão neutra negativa enquanto que na face e no pé da seção o solo encontra-se mais úmido e com menores valores de pressão neutra negativa. Já a distribuição de pressão neutra para o fluxo transiente possui comportamento parecido aos observados nos dois Modelos, porém o Modelo 2 apresenta uma faixa com valor de pressão neutra de $-16,5 \mathrm{kPa}$ próximo à face da seção enquanto que o Modelo 1 apresenta uma faixa constante de pressão neutra desde a crista até o pé da seção. 


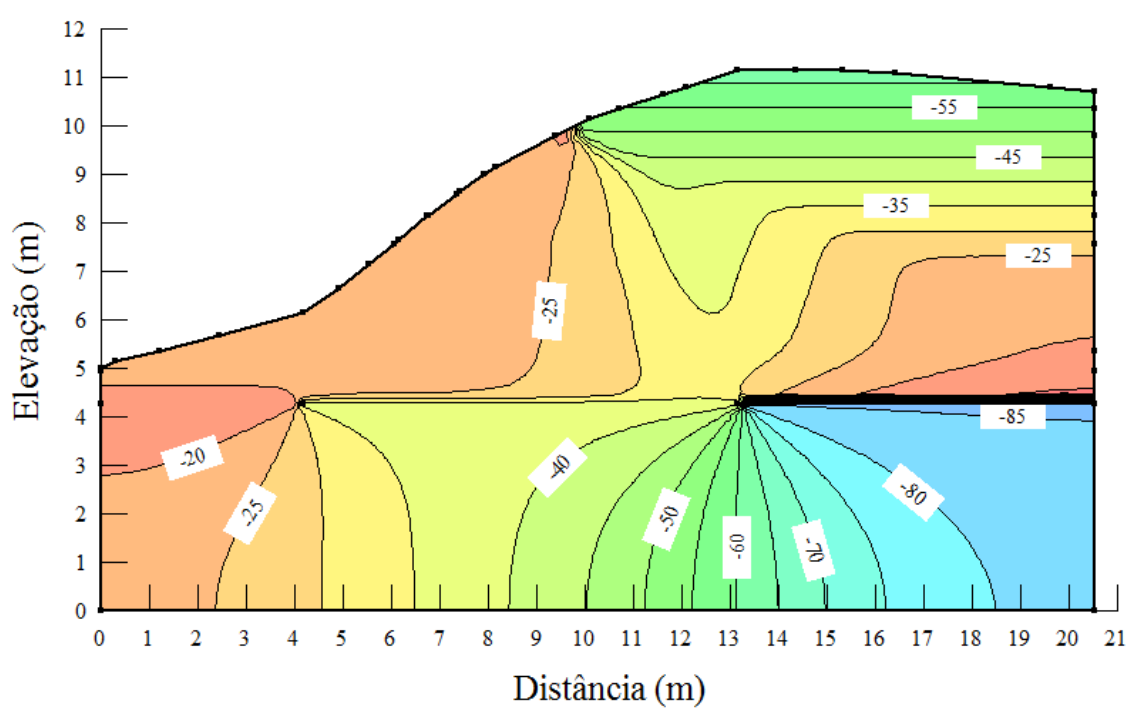

(a)

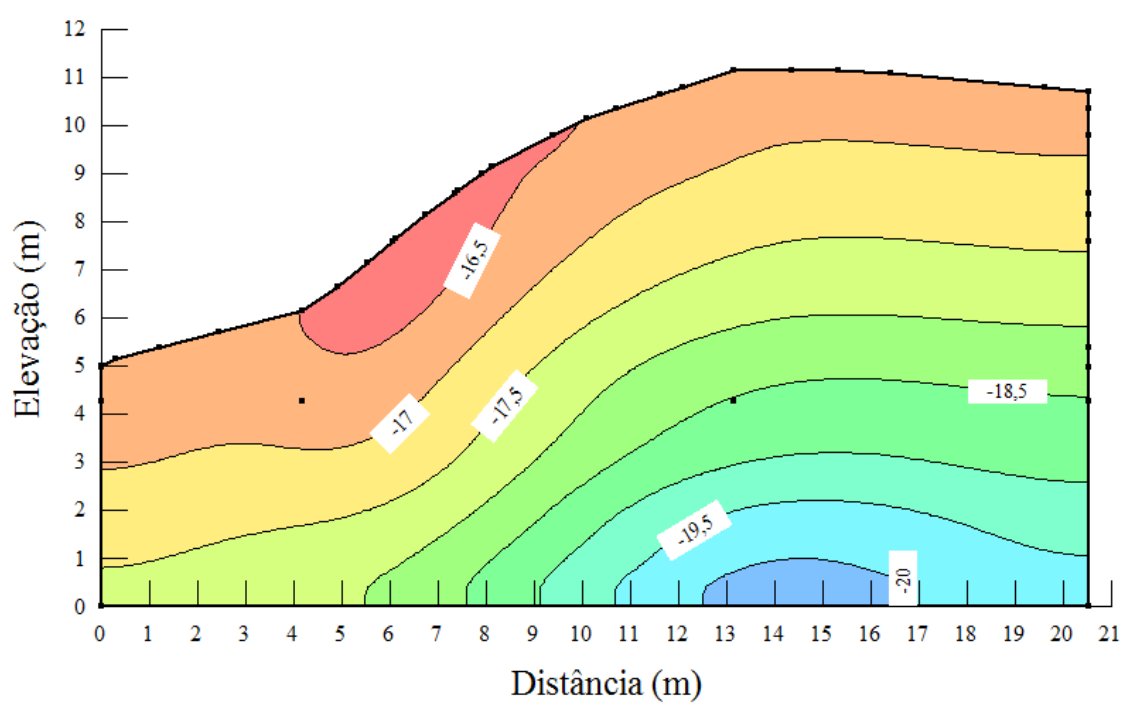

(b)

Figura 6.50 - Distribuição da pressão neutra do Modelo 2 para (a) steady-state (06/03/2015) e (b) 08/03/2015.

Além dos resultados da distribuição da pressão neutra, também foi analisada a estabilidade do talude após a chuva do dia 08/03/2015 a partir do acoplamento hidromecânico e dos métodos determinísticos de Bishop Simplificado e Janbu, como mostra a Figura 6.51. Embora a distribuição de pressão neutra do fluxo transiente utilizada no cálculo de estabilidade seja idêntica para os dois métodos, verifica-se que o Fator de Segurança crítico é maior para o método Bishop Simplificado $(\mathrm{FS}=1,878)$ e menor para o método de Janbu ( $F S=1,766)$. Além disso, nota-se nas duas figuras abaixo que as superfícies críticas de ruptura são diferentes, tendo uma profundidade de aproximadamente $1,90 \mathrm{~m}$ utilizando o método de Bishop Simplificado e uma profundidade de aproximadamente 3,10 m utilizando o método de Janbu. A partir desses resultados de estabilidade, observa-se que os Fatores de Segurança do 
Modelo 2 foram praticamente idênticos aos obtidos no Modelo 1, isso se deve ao fato da distribuição das pressões neutras serem próximas ao longo da seção estudada em ambos Modelos e dos parâmetros mecânicos deste solo.

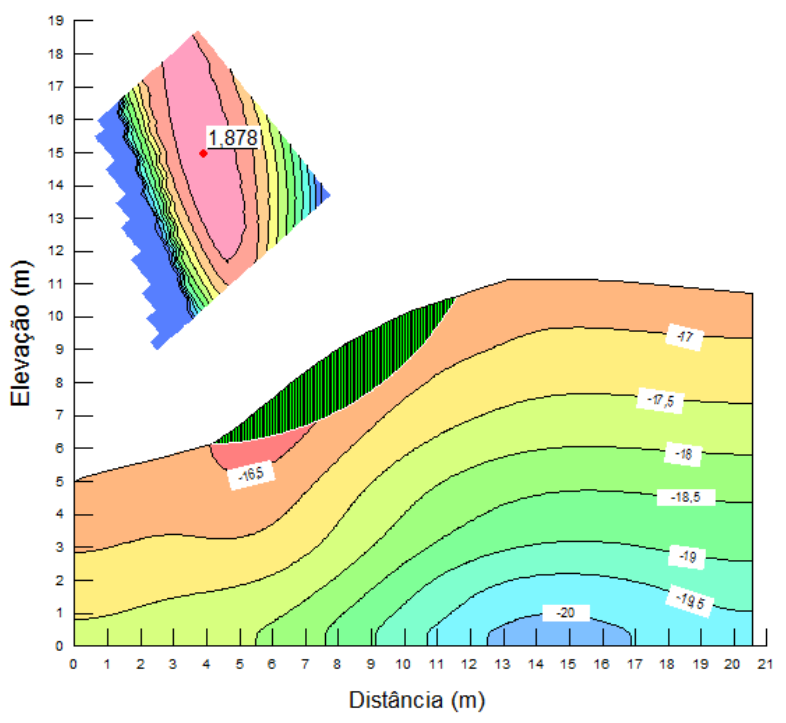

(a)

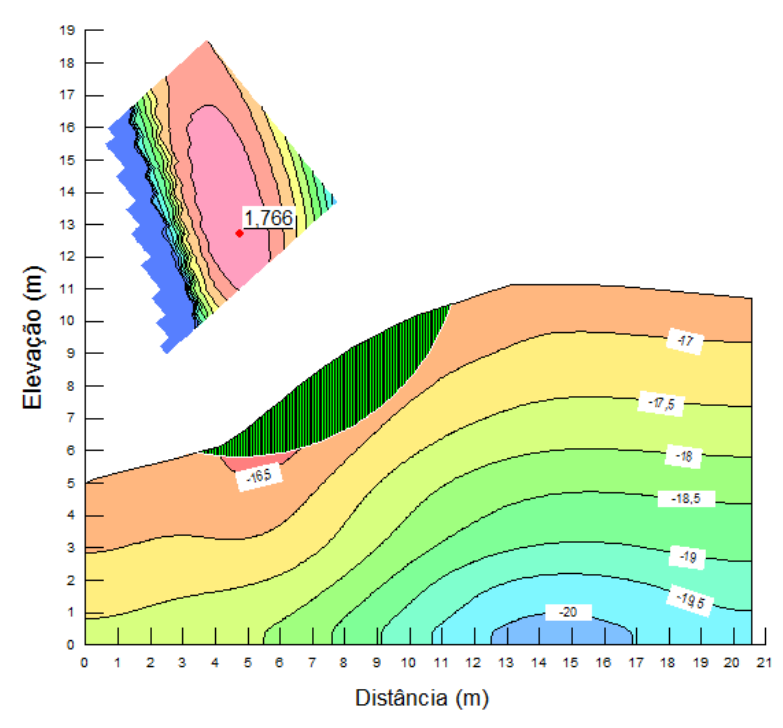

(b)

Figura 6.51 - Análise da estabilidade de talude para o Modelo 2 utilizando o método determinístico de (a) Bishop Simplificado e (b) Janbu.

A Figura 6.52a,b ilustra a distribuição de pressão neutra do Modelo 3 para o steadystate e para o fluxo transiente correspondente ao dia 08/03/2015. Observa-se que a distribuição de pressão neutra do steady-state possui comportamento diferente do observado nos Modelos 1 e 2, nos quais foram verificados valores de pressão neutra mínimos de $-24 \mathrm{kPa}$ e $-63 \mathrm{kPa}$, respectivamente. Constata-se que o Modelo 3 apresenta solo mais seco e com menores valores de pressão neutra negativa na crista e no pé da seção enquanto que na face o solo encontra-se mais úmido e com maiores valores de pressão neutra negativa, incluindo a formação de uma pequena região com pressão neutra de $0 \mathrm{kPa}$ e o solo saturado. Além disso, a distribuição de pressão neutra para o fluxo transiente também possui comportamento diferente aos observados nos Modelos 1 e 2, sendo que nesses dois modelos valores de pressão neutra entre $-17,0 \mathrm{kPa}$ e $-16,5 \mathrm{kPa}$ próximos à superfície do talude e valores variando entre - 20,0 kPa e -19,0 kPa no interior da seção. Nesse caso, nota-se que o Modelo 3 apresenta uma faixa decrescente de pressão neutra na face desta seção, a qual varia entre $-16,0 \mathrm{kPa}$ a $-10 \mathrm{kPa}$ da superfície para o interior do talude, enquanto que apresenta valores inferior à $-16 \mathrm{kPa}$ no pé e na crista desta seção. 


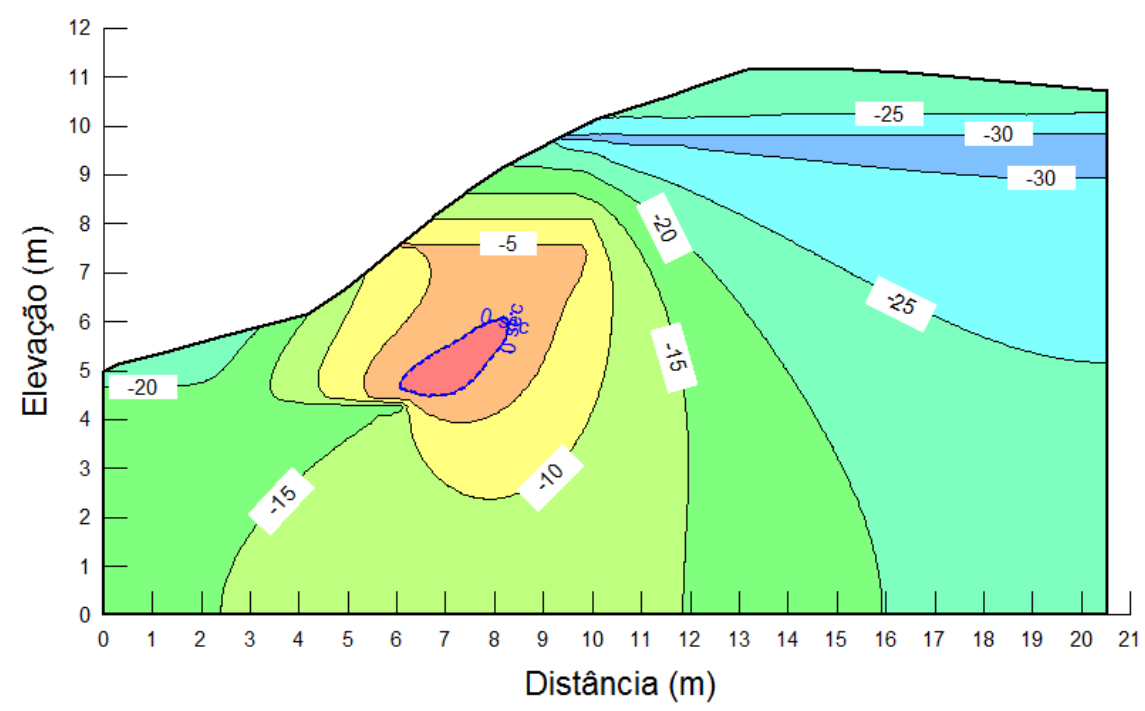

(a)

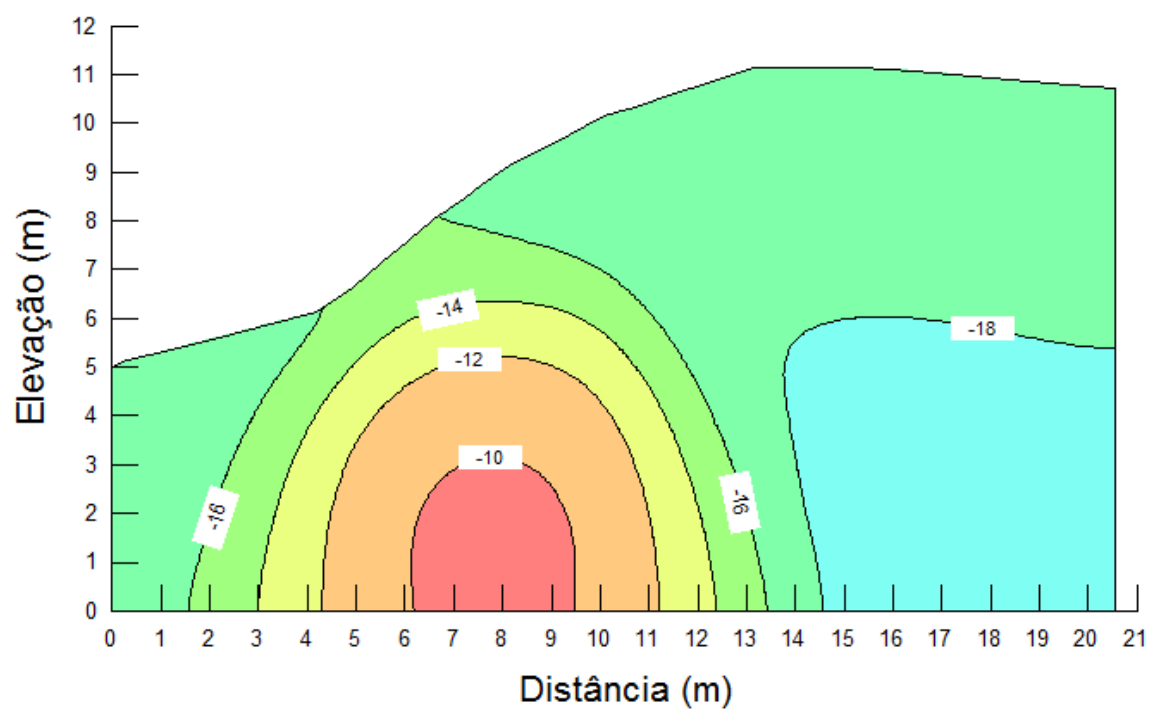

(b)

Figura 6.52 - Distribuição da pressão neutra do Modelo 3 para (a) steady-state (06/03/2015) e (b) 08/03/2015.

Além dos resultados da distribuição da pressão neutra, também foi analisada a estabilidade do talude após a chuva do dia 08/03/2015 a partir do acoplamento hidromecânico e dos métodos determinísticos de Bishop Simplificado e Janbu, como mostra a Figura 6.53. Embora a distribuição de pressão neutra utilizada no cálculo de estabilidade seja idêntica para os dois métodos, verifica-se que o Fator de Segurança crítico é maior para o método Bishop Simplificado (FS=1,857) e menor para o método de Janbu (FS=1,743). Além disso, nota-se nas duas figuras abaixo que as superfícies críticas de ruptura são diferentes, tendo uma profundidade de aproximadamente $1,90 \mathrm{~m}$ utilizando o método de Bishop Simplificado e uma profundidade de aproximadamente 3,10 m utilizando o método de Janbu.. 


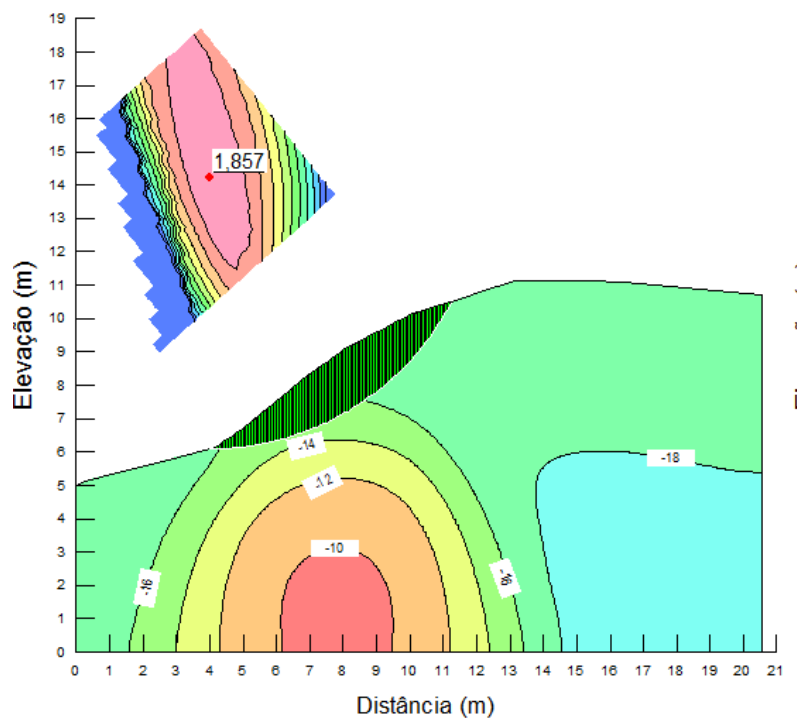

(a)

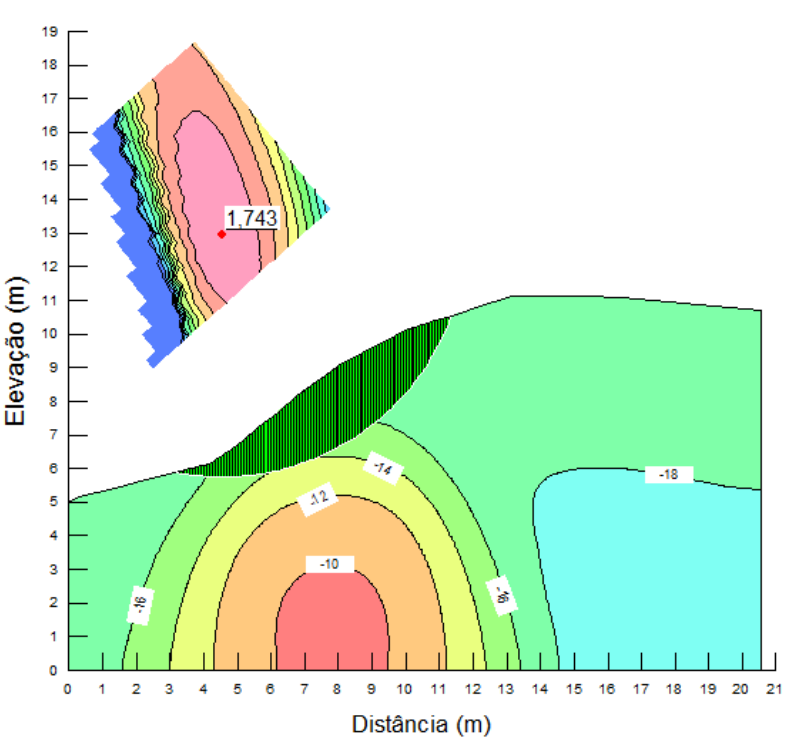

(b)

Figura 6.53 - Análise da estabilidade de talude para o Modelo 3 utilizando o método determinístico de (a) Bishop Simplificado e (b) Janbu.

A Figura 6.54 a Figura 6.56 representa a distribuição da pressão neutra ao longo do eixo que contém os tensiômetros do pé, da face ou da crista. Verifica-se que após a ocorrência de um evento chuvoso, os três modelos tendem a deixar o solo mais úmido e fornecer valores de pressão neutra maiores que os valores iniciais. Observa-se que as leituras dos tensiômetros e os valores de pressão neutra gerados pelo Seep/W apresentam dispersão, variando da ordem de $12 \mathrm{kPa}$ para o Modelo 1, de $12 \mathrm{kPa}$ para o Modelo 2 e de $16 \mathrm{kPa}$ para o Modelo 3. Portanto, a partir dos resultados apresentados para os três Modelos de distribuição da pressão neutra negativa no steady-state e no fluxo transiente permite concluir que o modelo que melhor representa essa distribuição é o Modelo 1.

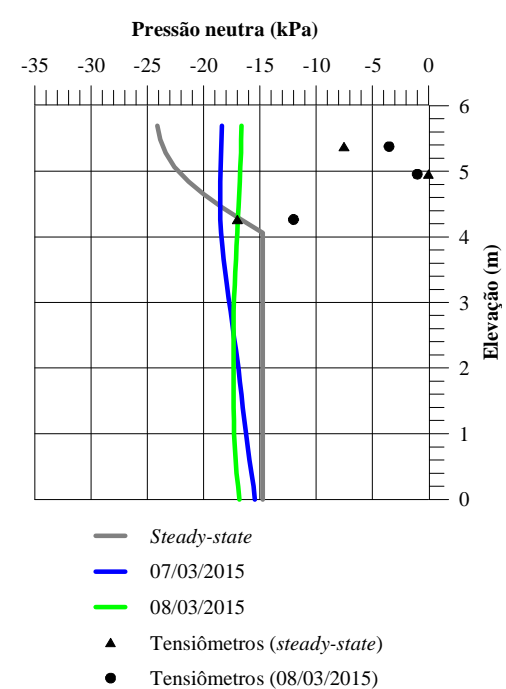

(a)

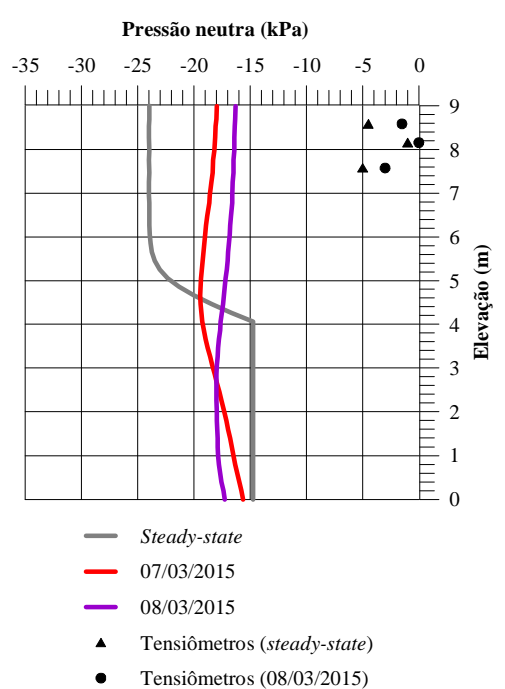

(b)

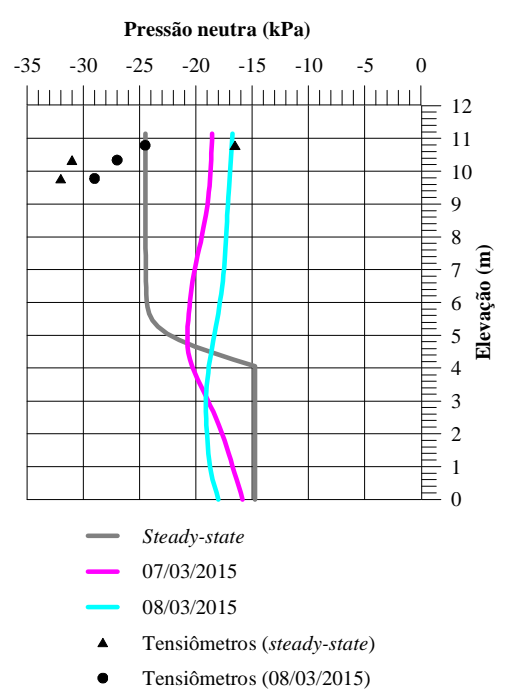

(c)

Figura 6.54 - Distribuição da pressão neutra do Modelo 1 para (a) o pé, (b) a face e (c) a crista da seção. 


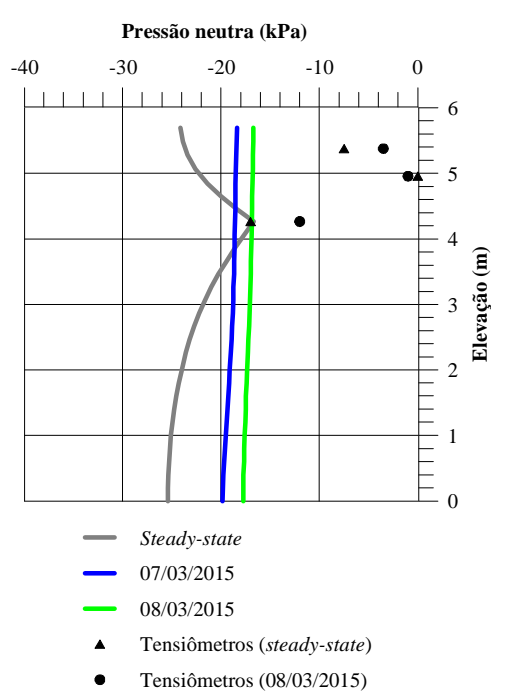

(a)

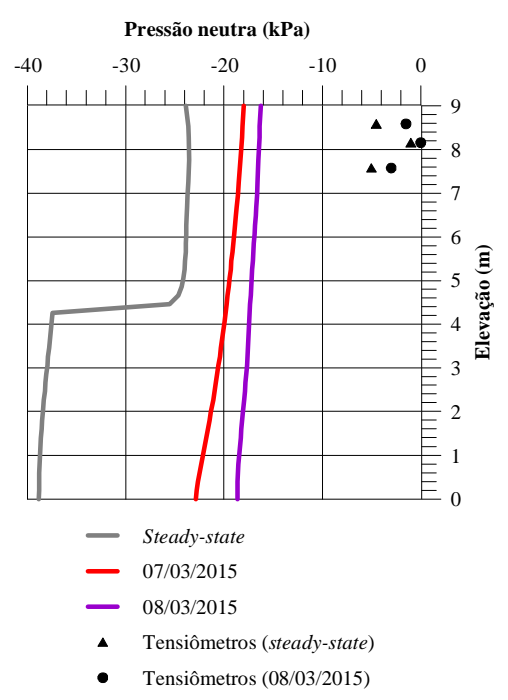

(b)
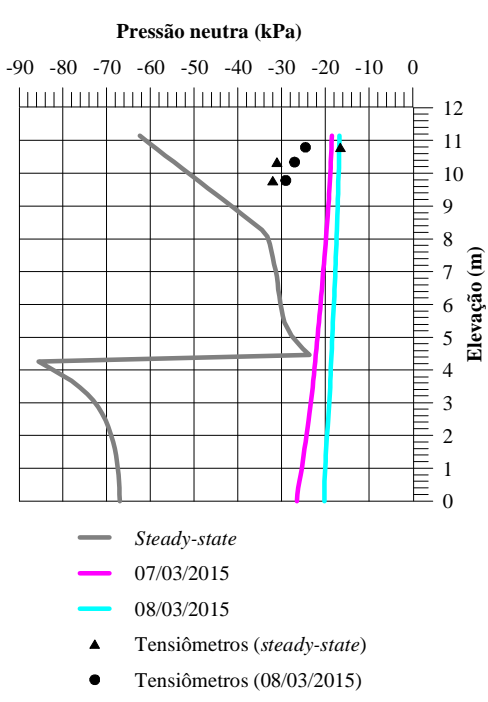

(c)

Figura 6.55 - Distribuição da pressão neutra do Modelo 2 para (a) o pé, (b) a face e (c) a crista da seção.

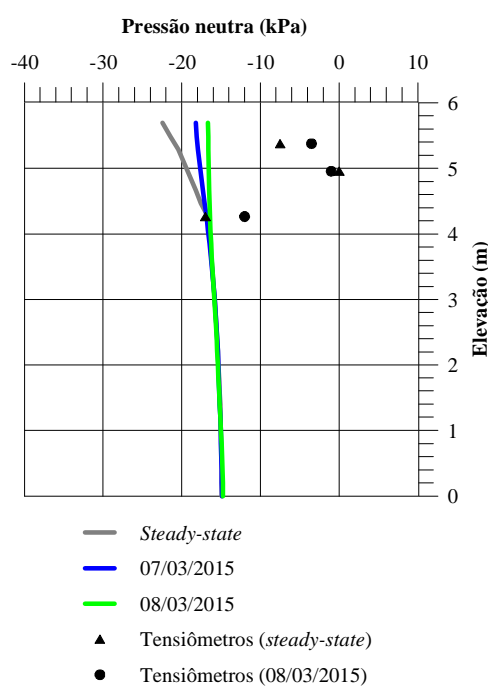

(a)

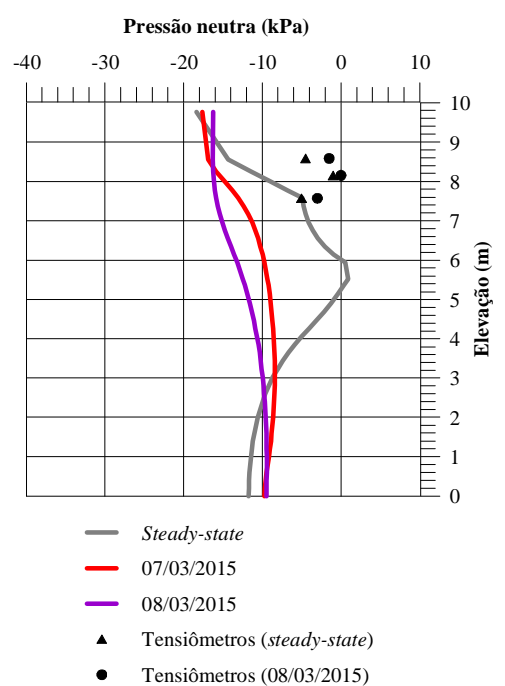

(b)

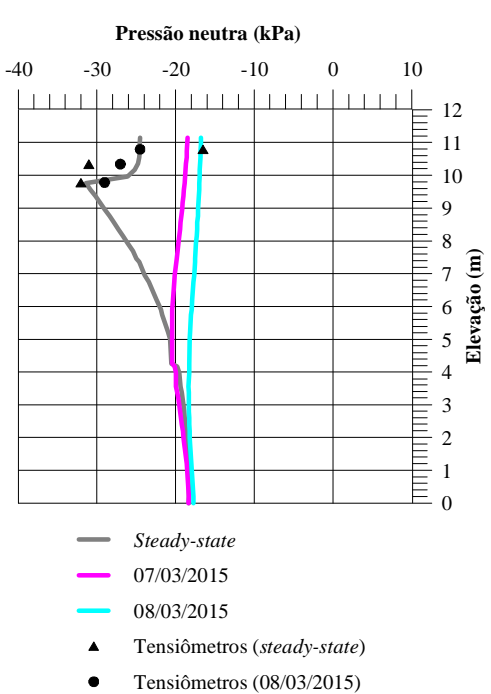

(c)

Figura 6.56 - Distribuição da pressão neutra do Modelo 3 para (a) o pé, (b) a face e (c) a crista da seção.

\subsubsection{Modelagem numérica do segundo evento pluviométrico}

A escolha do segundo evento pluviométrico foi feita baseada nos maiores valores de precipitações pluviométricas observadas no período de monitoramento apresentando no item 6.10.3, onde foi constatada a ocorrência de uma chuva diária de 93,1 mm em 01/12/2015. Após a verificação dessa chuva, foi feito um levantamento no item 6.10.1 acerca das leituras de sucção matricial correspondentes ao mesmo período. Portanto, a modelagem numérica do problema foi baseada nas condições de contorno do Modelo 1 e nos dados de chuva e tensiometria do período contemplando esse evento. Na modelagem numérica foi considerado um período de monitoramento pluviométrico de dezessete dias (Tabela 6.22) e um período de monitoramento da sucção matricial de dois dias (Tabela 6.23). 
Tabela 6.22 - Período de monitoramento da precipitação pluviométrica diária (mm).

\begin{tabular}{|c|c|}
\hline Data & Precipitação Pluviométrica (mm) \\
\hline $15 / 11 / 2015$ & 0,0 \\
\hline $16 / 11 / 2015$ & 14,0 \\
\hline $17 / 11 / 2015$ & 8,6 \\
\hline $18 / 11 / 2015$ & 0,0 \\
\hline $19 / 11 / 2015$ & 53,5 \\
\hline $20 / 11 / 2015$ & 0,0 \\
\hline $21 / 11 / 2015$ & 0,0 \\
\hline $22 / 11 / 2015$ & 30,0 \\
\hline $23 / 11 / 2015$ & 35,6 \\
\hline $24 / 11 / 2015$ & 15,0 \\
\hline $25 / 11 / 2015$ & 0,0 \\
\hline $26 / 11 / 2015$ & 0,0 \\
\hline $27 / 11 / 2015$ & 0,0 \\
\hline $28 / 11 / 2015$ & 0,0 \\
\hline $29 / 11 / 2015$ & 0,0 \\
\hline $30 / 11 / 2015$ & 0,0 \\
\hline $01 / 12 / 2015$ & 93,1 \\
\hline 02/12/2015 & 0,0 \\
\hline
\end{tabular}

Tabela 6.23 - Período de monitoramento da sucção matricial (kPa).

\begin{tabular}{|c|c|c|c|c|c|}
\hline \multirow{2}{*}{ Seção } & \multirow{2}{*}{ Local } & \multirow{2}{*}{ Tensiômetro } & \multirow{2}{*}{$\begin{array}{l}\text { Comprimento do } \\
\text { tensiômetro (m) }\end{array}$} & \multicolumn{2}{|c|}{ Data da leitura da sucção matricial $(\mathrm{kPa})$} \\
\hline & & & & $15 / 11 / 2015$ & $02 / 12 / 2015$ \\
\hline \multirow{9}{*}{ B-B' } & \multirow{3}{*}{ Pé } & B1 & 0,45 & 6,5 & 5,5 \\
\hline & & B2 & 0,90 & 1,0 & 0,0 \\
\hline & & B3 & 1,50 & 8,0 & 9,0 \\
\hline & \multirow{3}{*}{ Face } & B4 & 0,45 & 3,5 & 0,0 \\
\hline & & B5 & 0,90 & 0,0 & 0,0 \\
\hline & & B6 & 1,50 & 0,0 & 0,0 \\
\hline & \multirow{3}{*}{ Crista } & B7 & 0,45 & 1,5 & 3,5 \\
\hline & & B8 & 0,90 & 1,0 & 0,0 \\
\hline & & B9 & 1,50 & 25,0 & 0,0 \\
\hline
\end{tabular}


A Figura 6.57 ilustra a distribuição de pressão neutra no steady-state, seguindo as condições de contorno utilizadas no Modelo 1. Observa-se nessa figura que a faixa de variação da pressão neutra é de $-75 \mathrm{kPa}$ a $-10 \mathrm{kPa}$, sendo que seu menor valor foi encontrado próximo à crista da seção $(-75 \mathrm{kPa})$ e seu maior valor próximo ao pé da seção $(-10 \mathrm{kPa})$, na cota de elevação de 4,26 m. O fato da distribuição dessas pressões ocorrerem em linhas horizontais está associado à inexistência de chuva no dia do steady-state.

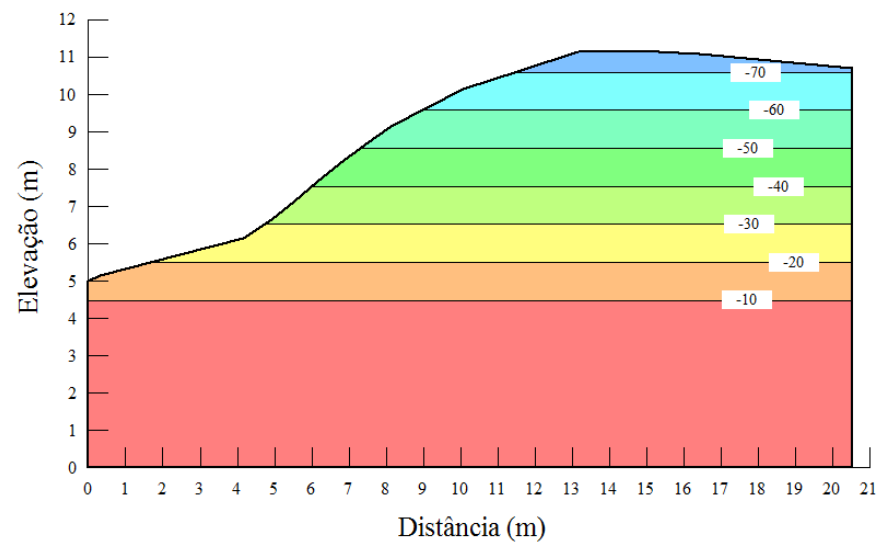

Figura 6.57 - Distribuição da pressão neutra para o steady-state (15/11/2015).

Nota-se na Tabela 6.22 que os valores de precipitação pluviométrica variaram entre $8,6 \mathrm{~mm}$ a 93,0 $\mathrm{mm}$, totalizando $249,7 \mathrm{~mm}$ para o período analisado. Observa-se também que no período de monitoramento apresentado no item 6.10.3, o maior valor de precipitação pluviométrica registrado foi de $93,0 \mathrm{~mm}$ em 01/12/2015. Isso faz com que esse período seja considerado o período mais crítico dos dois anos de monitoramento. Por esse motivo, a Figura 6.58 a Figura 6.64 ilustra a distribuição da pressão neutra para cada dia em que ocorreram essas precipitações pluviométricas.

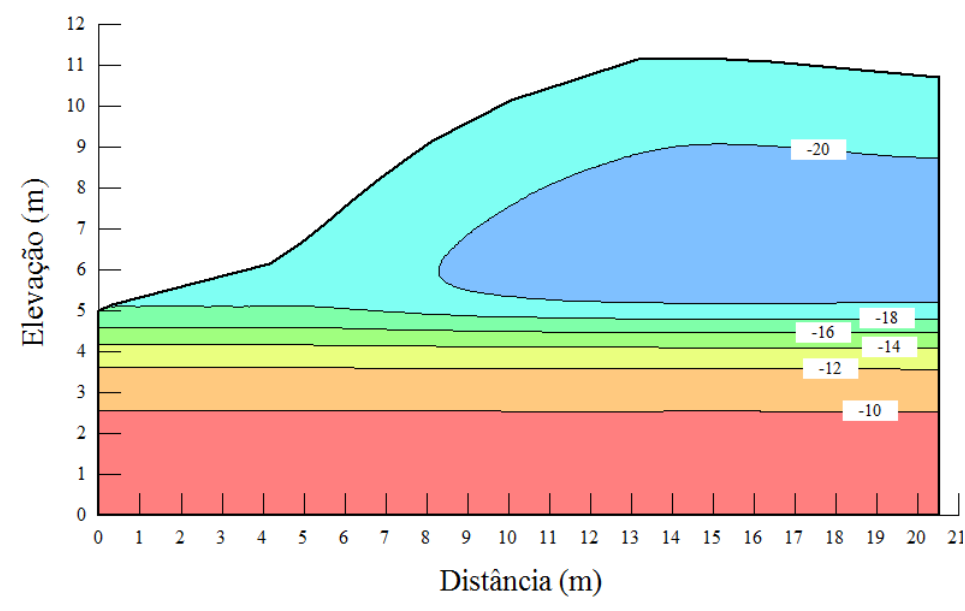

(a)

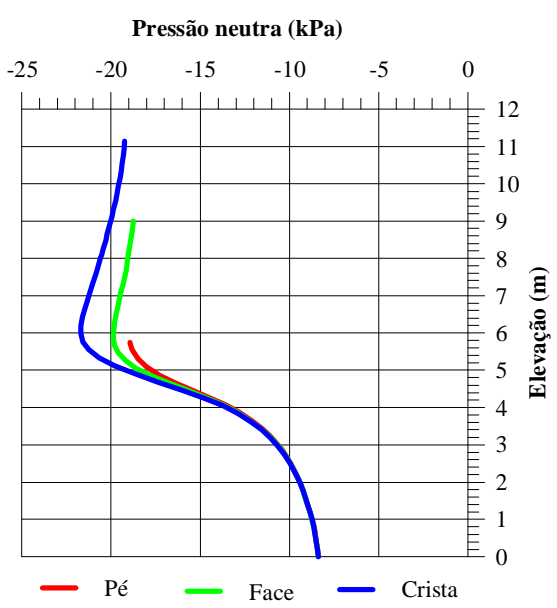

(b)

Figura 6.58 - Distribuição da pressão neutra para a precipitação pluviométrica de 14,0 mm (dia 16/11/2015). 


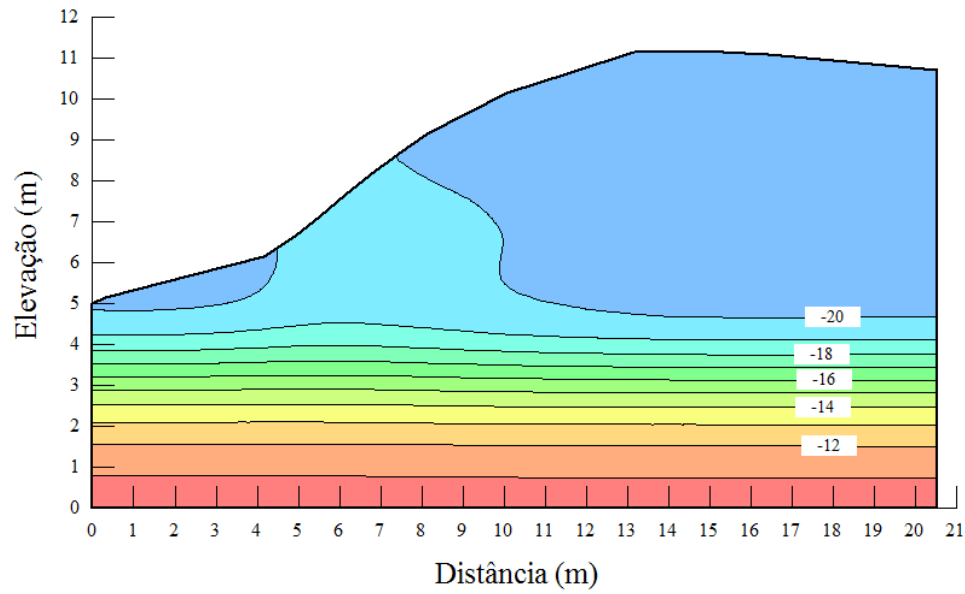

(a)

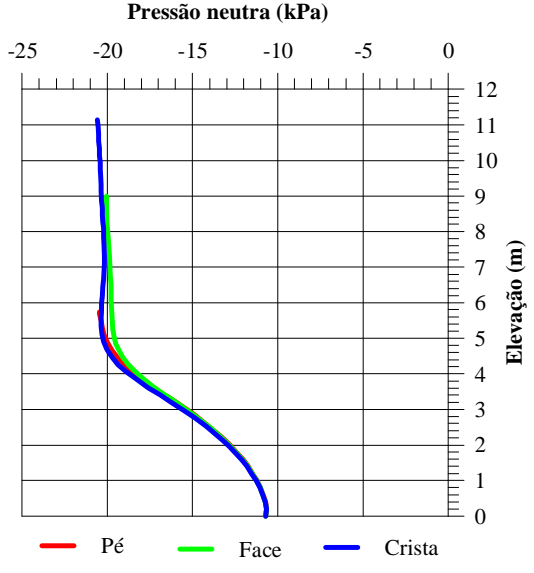

(b)

Figura 6.59 - Distribuição da pressão neutra para a precipitação pluviométrica de 8,6 mm (dia 17/11/2015).

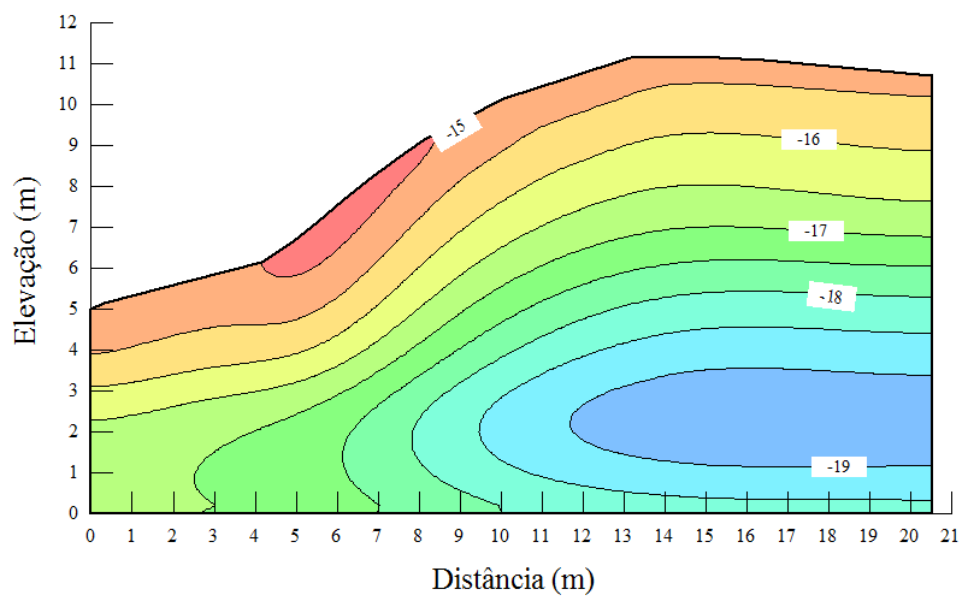

(a)

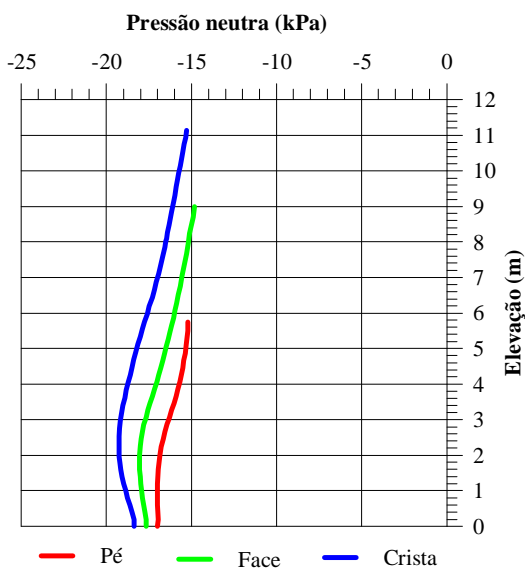

(b)

Figura 6.60 - Distribuição da pressão neutra para a precipitação pluviométrica de 53,5 mm (dia 19/11/2015).

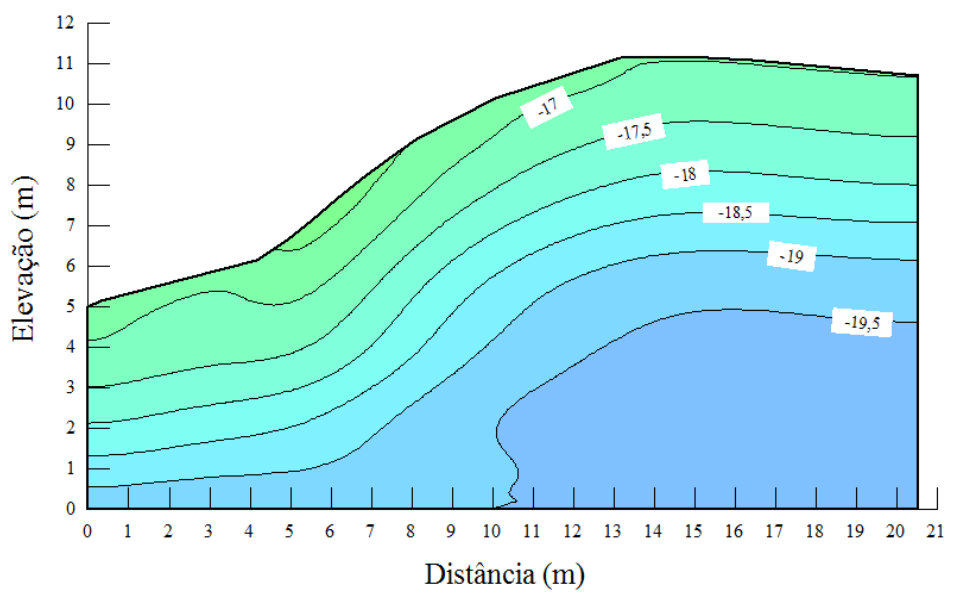

(a)

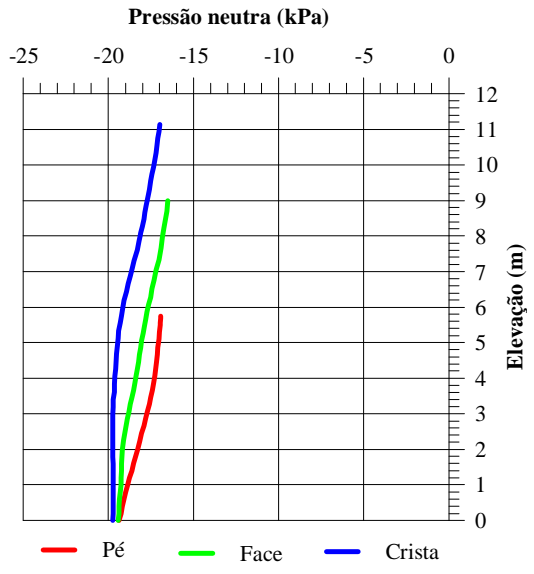

(b)

Figura 6.61 - Distribuição da pressão neutra para a precipitação pluviométrica de 30,0 mm (dia 22/11/2015). 


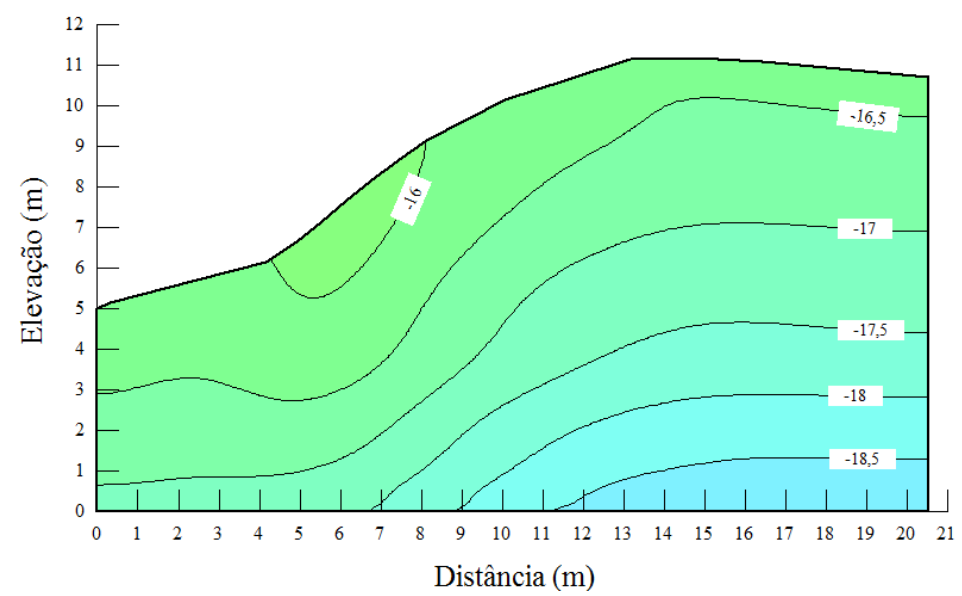

(a)

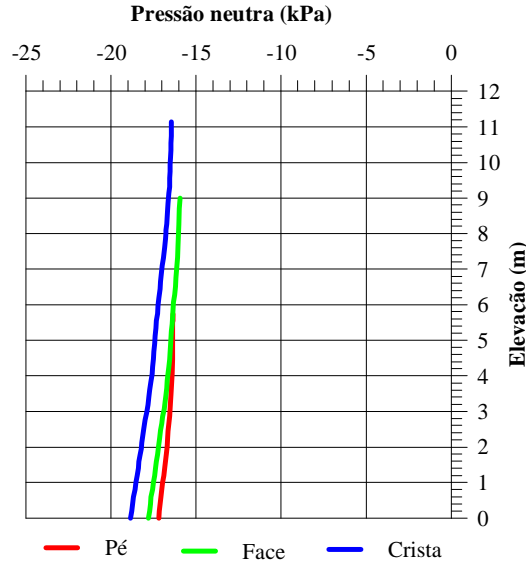

(b)

Figura 6.62 - Distribuição da pressão neutra para a precipitação pluviométrica de 35,6 mm (dia 23/11/2015).

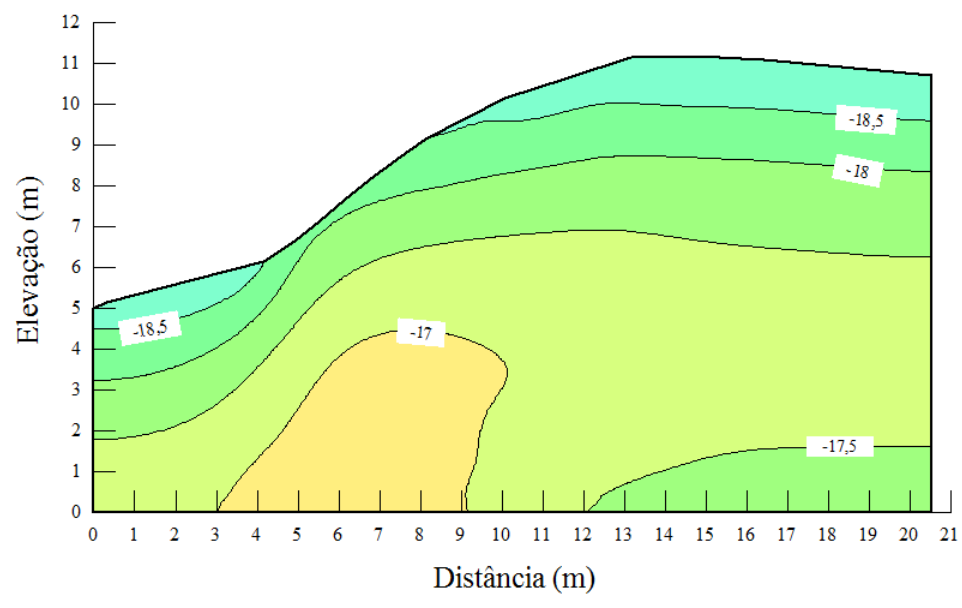

(a)

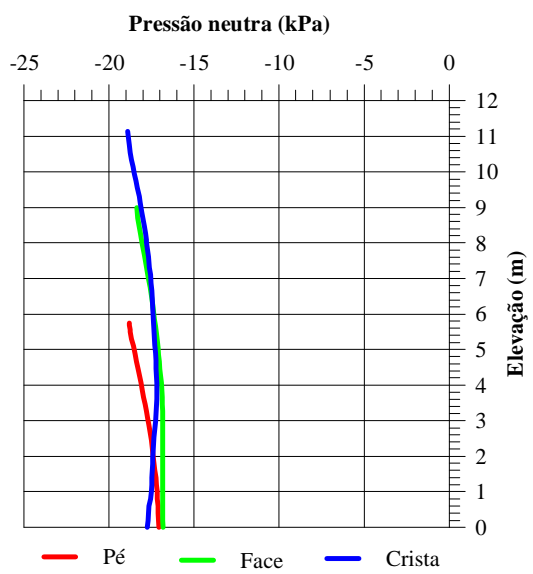

(b)

Figura 6.63 - Distribuição da pressão neutra para a precipitação pluviométrica de 15,0 mm (dia 24/11/2015).

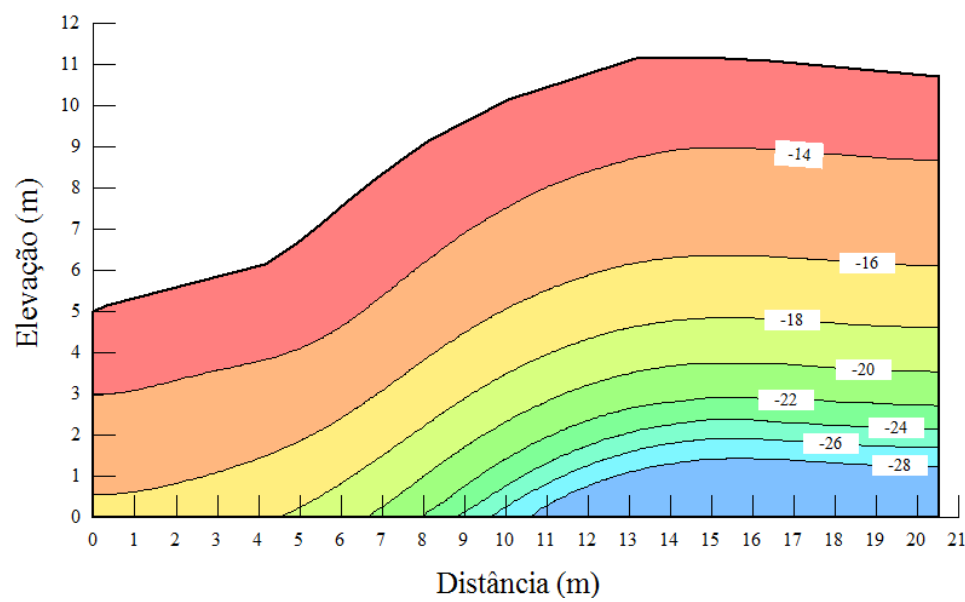

(a)

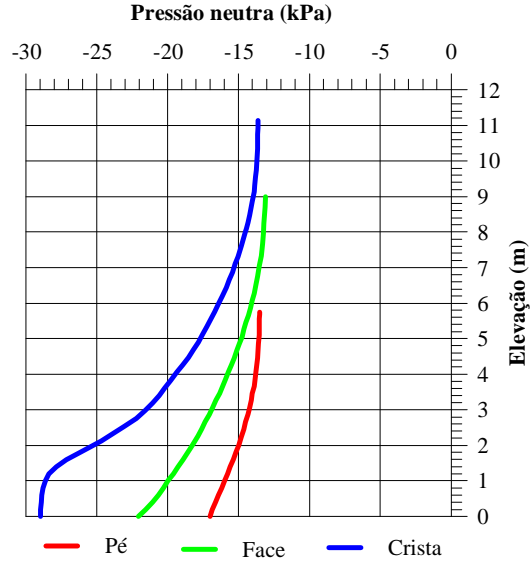

(b)

Figura 6.64 - Distribuição da pressão neutra para a precipitação pluviométrica de 93,0 mm (dia 01/12/2015). 
Observando-se a Figura 6.59, dia em que ocorreu a menor precipitação $(8,6 \mathrm{~mm})$ para o período analisado, nota-se que mesmo tendo ocorrido uma chuva de $14,0 \mathrm{~mm}$ no dia anterior, a pressão neutra próxima à superfície do talude modificou de $-18 \mathrm{kPa}$ para $-20 \mathrm{kPa}$. O motivo da redução da pressão neutra se deve ao fato do valor da precipitação pluviométrica ter reduzido em $62 \%$, ou seja, passando de $14,0 \mathrm{~mm}$ para $8,6 \mathrm{~mm}$.

Comportamento semelhante foi verificado nos demais dias, isto é, quando a precipitação pluviométrica equivale a valores superiores a 30,0 $\mathrm{mm}$ (por exemplo, 93,1 mm ou 54,0 mm), os valores de pressão neutra negativa tendem a serem mais próximos de $0 \mathrm{kPa}$ próximo à superfície. Além disso, também constatou-se a tendência em ocorrer uma região com menor valor de pressão neutra numa porção abaixo da face da seção e a formação de uma provável frente de umedecimento, conforme a água da chuva infiltra no talude.

A Figura 6.65 ilustra a distribuição da pressão neutra para o dia 02/12/2015, que corresponde à data em que foram realizadas leituras nos tensiômetros. Verifica-se que os valores de pressão neutra (ou sucção, em termos de valores positivos) tiveram uma considerável dispersão, principalmente para os tensiômetros da face. No caso dos tensiômetros da crista, a faixa de variação da pressão neutra gerada pelo Seep/W entre as profundidades de $9,77 \mathrm{~m}$ a $10,70 \mathrm{~m}$ foi de $-23,5 \mathrm{kPa}$ a $-18,7 \mathrm{kPa}$ enquanto que a menor leitura de pressão neutra registrada nesses equipamentos foi de $-3,5 \mathrm{kPa}$. Já no caso dos tensiômetros da face, a faixa de variação da pressão neutra gerada pelo Seep/W entre as profundidades de 7,50 m a 8,60 m foi de $-21,5 \mathrm{kPa}$ a $-18,1 \mathrm{kPa}$ enquanto que a leitura de pressão neutra registrada nesses equipamentos foi de $0 \mathrm{kPa}$. Os tensiômetros do pé foram os que apresentaram menor dispersão, apresentando uma faixa de variação da pressão neutra gerada pelo Seep/ $W$ entre as profundidades de 4,20 m a 5,30 m de -21,7 $\mathrm{kPa}$ a $-18,2 \mathrm{kPa}$ enquanto que a menor leitura de pressão neutra registrada nesses equipamentos foi de $-9,0 \mathrm{kPa}$.

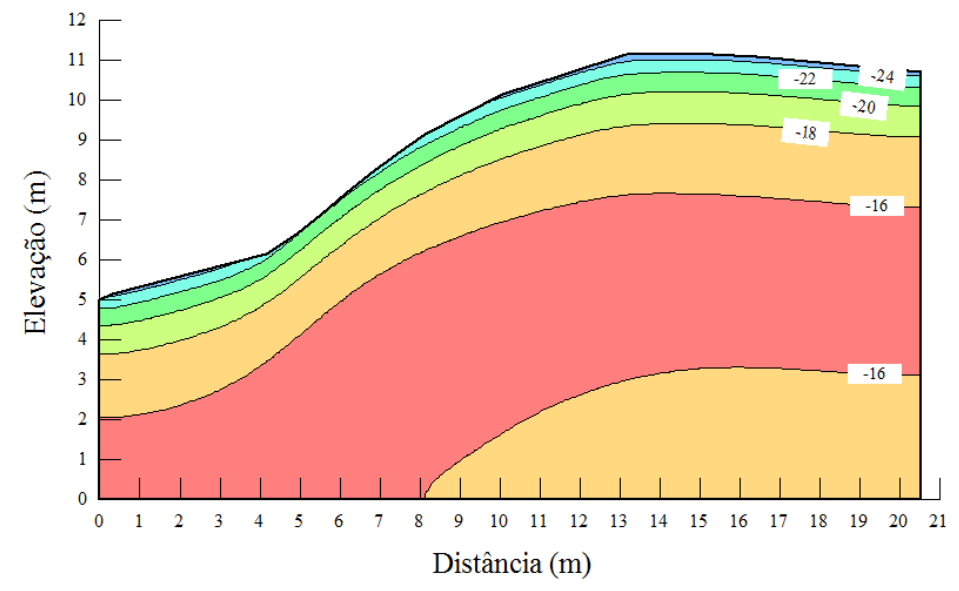

(a)

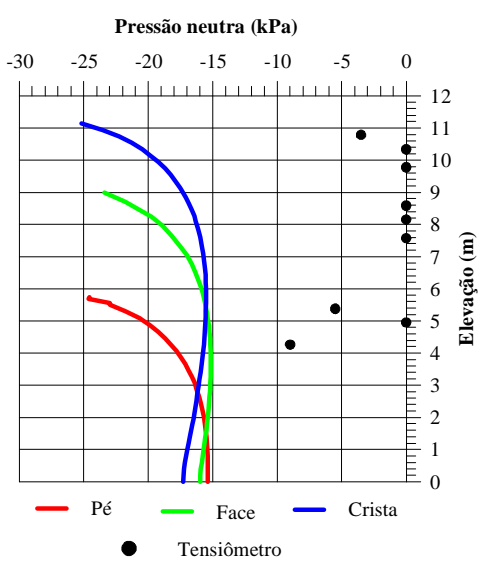

(b)

Figura 6.65 - Distribuição da pressão neutra sem precipitação pluviométrica (dia 02/12/2015). 
Como mencionado anteriormente, além das análises de infiltração também foram feitas análises para verificar o nível de estabilidade desse talude. As análises de estabilidade foram acopladas aos resultados de distribuição das pressões neutras e determinadas a partir dos métodos determiníticos de Bishop Simplificado e Janbu, como mostra a Figura 6.66.

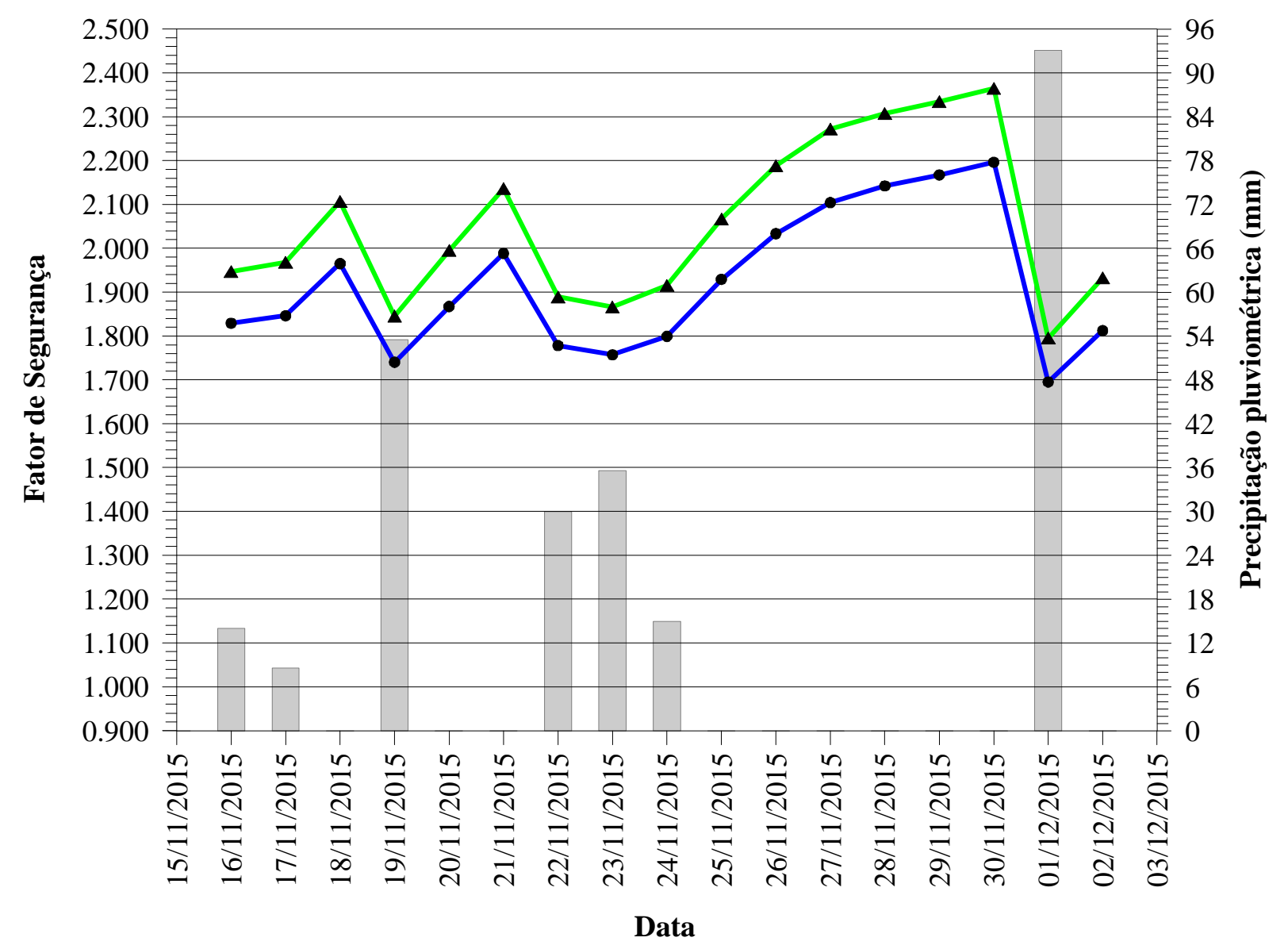

\footnotetext{
- Método de Bishop Simplificado

$\rightarrow$ Método de Janbu

Precipitação pluviométrica - 15/11/2015 a 02/12/2015
}

Figura 6.66 - Variação do fator de segurança para o período analisado (16/11/2015 a 02/12/2015) a partir dos métodos determinísticos de Bishop Simplificado e Janbu.

Observa-se na Figura 6.66 que o Fator de Segurança variou em função dos valores de precipitação pluviométrica, ou seja, os menores Fatores de Segurança foram registrados nos dias com chuva enquanto que os maiores Fatores de Segurança foram registrados nos dias sem chuva.Verifica-se que o maior valor de Fator de Segurança determinado pelo método de Bishop Simplificado foi de 2,365 e ocorreu no dia 30/11/2015 após 6 dias consecutivos sem chuva. É possível visualizar na Figura 6.66 uma tendência no aumento gradativo do Fator de Segurança a partir do dia 25/11/2015. 
Comparando-se os métodos determinísticos para cálculo do Fator de Segurança, observa-se que o método de Bishop Simplificado sempre fornece valores superiores de FS do que o método de Janbu. No caso deste talude analisado, a diferença dos valores de Fatores de Segurança para os dois métodos foi em torno de $6,5 \%$.

Além disso, observa-se que a profundidade da superfície crítica de ruptura varia entre 1,30 m a 2,10 m para todas as análises de estabilidade, apresentando a tendência de serem mais rasas para dias com chuva e de serem mais profundas para os dias sem chuva.

Embora a chuva proporcione uma alteração na pressão neutra negativa do solo do talude, verifica-se que este ainda permanece estável mesmo após a ocorrência da precipitação pluviométrica de 93,1 mm. Nota-se que o Fator de Segurança foi de 2,365 no dia antecedente à chuva de 93,1 mm, passando para 1,795 após a ocorrência da chuva do dia 01/12/2015. Apesar da redução significativa no Fator de Segurança em aproximadamente 24\%, o talude ainda permanece $79 \%$ acima da condição de ruptura nesta seção. Isso permite concluir que mesmo após a ocorrência de eventos pluviométricos com maiores volumes de água, como por exemplo a chuva de $93,1 \mathrm{~mm}$, o talude permanece estável. 


\section{CONCLUSÕES}

Os resultados e as análises dos ensaios de campo e de laboratório bem como do monitoramento da instrumentação de campo permitem realizar uma síntese dos itens apresentados anteriormente, os quais estão descritos abaixo.

O levantamento topográfico de detalhe indicou que o talude estudado apresenta uma altura média de 7,0 m, comprimento de aproximadamente $225,0 \mathrm{~m}$ e cotas variando entre $619,0 \mathrm{~m}$ a $634,0 \mathrm{~m}$. As inclinações do talude variaram de $30^{\circ}$ a $50^{\circ}$.

As sondagens a trado e os ensaios de caracterização geotécnica apontaram que no local ocorrem solos arenosos (areia fina e média) com poucos finos (em geral, inferior a 15\%) e cor marrom avermelhado. A textura dos solos apresentou-se extremamente homogênea ao longo das profundidades e das diferentes seções investigadas. A massa específica dos sólidos foi de $2,654 \mathrm{~g} / \mathrm{cm}^{3}$. Outros índices físicos importantes deste solo podem ser mencionados, tais como: índice de vazios $(e)=0,63$ a 0,81 ; porosidade $(\eta)=38,7$ a $44,7 \%$ e grau de saturação $(\mathrm{Sr})=$ 8,4 a $23,9 \%$.

As amostras de solo analisadas na lupa digital apontaram que os grãos de areia fina e de areia média apresentaram-se bem arredondados e bem selecionados. A identificação de cores avermelhadas indica laterização, sendo visível a presença de grãos menores de areia formando agregados cimentados com óxidos e hidróxidos.

Os ensaios para obtenção das curvas de retenção da água neste solo mostraram dois picos bem definidos, correspondente às sucções em torno de $3 \mathrm{kPa}$ e de $5000 \mathrm{kPa}$. Isso indica 
que o solo possui comportamento bimodal, isto é, presença de micro e macroporos.

Os ensaios por intrusão de mercúrio revelaram duas faixas de tamanhos de poros para o solo investigado, com diâmetros da ordem de $60 \mu \mathrm{m}$ e de $0,015 \mu \mathrm{m}$.

Os ensaios de permeabilidade em laboratório indicaram valores relativamente elevados e semelhantes de condutividade hidráulica saturada horizontal e vertical para o solo estudado $\left(1,5.10^{-2} \mathrm{~cm} / \mathrm{s}\right.$ e $1,6.10^{-2} \mathrm{~cm} / \mathrm{s}$, respectivamente). Transcorrido o período de um ano, a condutividade hidráulica saturada horizontal e vertical do mesmo solo diminui $\left(5,2.10^{-3}\right.$ $\mathrm{cm} / \mathrm{s}$ e $4,2.10^{-3} \mathrm{~cm} / \mathrm{s}$, respectivamente) indicando um possível carreamento de partículas areia fina do solo no fundo do permeâmetro.

Os ensaios de permeabilidade no campo apresentaram valores de condutividade hidráulica saturada também elevada e variando na ordem de $1,1.10^{-2} \mathrm{~cm} / \mathrm{s}$ a $1,2.10^{-3} \mathrm{~cm} / \mathrm{s}$. Os valores de condutividade hidráulica não saturada obtidos com o uso da equação empírica de Gardner variaram significativamente em função dos valores de sucção, sendo de $1,1.10^{-2} \mathrm{~cm} / \mathrm{s}$ para sucção $0 \mathrm{kPa}$ a $3,0.10^{-6} \mathrm{~cm} / \mathrm{s}$ para sucção de $80 \mathrm{kPa}$.

Os ensaios de erodibilidade apontaram que as amostras de solos são poucos erodíveis, apesar das suas texturas serem francamente arenosas. Os dados levantados no campo indicaram que os solos presentes no talude investigado apresentam baixa a média frequência de erosão linear (sulcos principalmente) quando desprovidos de cobertura vegetal e expostos à concentração de fluxo superficial.

Os ensaios de compressão triaxial tipo adensado-drenado (CD) com solo saturado indicaram valores de coesão efetiva de $2,0 \mathrm{kPa}$ e ângulos de atrito efetivo de $28,0^{\circ}$ e $32,0^{\circ}$ para amostra indeformada do pé e da crista do talude, respectivamente. Os ensaios para determinação da resistência do solo com teor de umidade natural (solo não saturado) revelaram valores de coesão efetiva de $50,0 \mathrm{kPa}$ e ângulo de atrito efetivo de $28,0^{\circ}$ para a amostra indeformada do pé do talude e valores de coesão efetiva de 32,0 kPa e ângulo de atrito efetivo de $32,0^{\circ}$ para a amostra indeformada da crista do talude. Os ensaios de compressão triaxial tipo adensado-drenado (CD) com solo não saturado (sucção de $30 \mathrm{kPa}$ ) mostraram valor de coesão efetiva de $8 \mathrm{kPa}$, ângulo de atrito efetivo de $32,0^{\circ}$ e ângulo de atrito efetivo referente à variação da sucção matricial de $11,3^{\circ}$ para a amostra indeformada da crista do talude.

Os valores de sucção monitorados nos tensiômetros apontaram uma variação de 74 $\mathrm{kPa}$ no período seco (abril a setembro) e de $0 \mathrm{kPa}$ nos meses mais chuvosos (outubro a março). Também observou-se uma tendência dos tensiômetros instalados no pé do talude 
apresentar valores de sucção sistematicamente inferiores aos dos tensiômetros instalados na crista do talude.

No período de monitoramento apresentado neste trabalho (24/12/2013 a 31/12/2015) os medidores de nível d’água de máxima apontaram a não ocorrência de registro do nível d'água nas profundidades investigadas por esses medidores. Também para este mesmo período, os registros feitos pelo pluviômetro Ville de Paris mostraram uma variação da precipitação pluviométrica diária de 1,0 a 93,1 mm.

Diante dos resultados mostrados anteriormente foi possível estabelecer os modelos preliminares de processos de instabilização de taludes e verificar as hipóteses de trabalho levantadas na pesquisa. Além disso, também foram feitas análises numéricas no GeoStudio 2012 baseadas nos resultados da caracterização do solo da área piloto, nos dados de monitoramento da instrumentação de campo e no modelo de processo de instabilização de talude observado na região da área piloto, sendo apresentado adiante um resumo dos principais resultados dessas análises e das conclusões desta pesquisa.

Os dados de monitoramento do nível d'água indicaram a não formação de nível d'água em profundidades que influenciariam a estabilidade do talude investigado, conforme comprovado através de observações visuais e inspeções de campo realizadas na região da área piloto, as quais mostraram a predominância de deslizamentos rasos de solo.

Dessa maneira, pode-se confirmar a primeira hipótese de trabalho proposta nesta pesquisa e descartar a segunda hipótese de trabalho, visto que os resultados da análise granulométrica conjunta feita para as amostras deformadas de solo coletadas em dois furos de sondagem durante a etapa de sondagem a trado manual apontaram que o solo encontra-se homogêneo ao longo de toda sua profundidade. Além disso, os ensaios de permeabilidade em laboratório mostraram que os valores de condutividade hidráulica foram praticamente semelhantes para os corpos de prova moldados em duas direções: ortogonal ao pé do talude e paralelo ao pé do talude.

Numa primeira etapa, as análises numéricas foram feitas para avaliar o nível de estabilidade de duas seções do talude da área piloto a partir da modificação dos parâmetros mecânicos do solo (coesão efetiva variando de $0 \mathrm{kPa}$ a $32 \mathrm{kPa}$ ) e utilizando os métodos determinísticos de Bishop Simplificado e Janbu para determinação do Fator de Segurança. Essas análises confirmaram que a ruptura dos taludes de solo residual dos arenitos da Formação Botucatu pode ocorrer somente pelo aumento do grau de saturação e a consequente redução dos valores de sucção e da resistência do solo. A faixa de valores dos Fatores de Segurança determinados utilizando o Método de Bishop Simplificado para a Seção A-A' 
foram de 1,053 a 4,657 e para a Seção B-B' foram de 0,863 a 4,237 enquanto que para o Método de Janbu esses valores variaram de 0,996 a 4,386 para a Seção A-A' e de 0,840 a 3,940 para a Seção B-B'.

Numa segunda etapa, as análises numéricas foram realizadas para avaliar o nível de estabilidade de duas seções do talude da área piloto a partir da modificação na sua geometria (altura e inclinação) e utilizando o método determinístico de Bishop Simplificado para determinação do Fator de Segurança. A partir dos resultados dessas análises foi possível estabelecer algumas geometrias críticas para taludes de corte em solos arenosos residuais da Formação Botucatu. Os Fatores de Segurança determinados para as duas seções do talude apontaram que a geometria crítica delas correspondem a altura de 5,0 metros e inclinação de $50^{\circ}$ para a Seção A-A'e altura de 5,4 metros e inclinação de $50^{\circ}$ para Seção B-B'. No caso dessas duas seções do talude, observou-se que a geometria crítica usualmente ocorre para valores de coesão efetiva inferiores a $3 \mathrm{kPa}$.

Numa terceira etapa, as análises numéricas de infiltração de água da chuva foram acopladas à análise de estabilidade de talude, tendo sido escolhido para essas modelagens numéricas a geometria da Seção B-B’ e os métodos determinísticos de Bishop Simplificado e Janbu. Nesta etapa foram escolhidos dois eventos pluviométricos, sendo o primeiro evento pluviométrico utilizado para definir um modelo de distribuição da pressão neutra inicial no talude e o segundo evento pluviométrico utilizado para analisar a estabilidade do talude a partir da simulação da maior precipitação pluviométrica ocorrida no período de monitoramento da área piloto.

No caso do primeiro evento pluviométrico, foram utilizados três modelos para representação das condições de contorno na Seção B-B' baseadas nas leituras de sucção matricial dos tensiômetros dessa seção. A partir dos resultados de infiltração da água da chuva realizadas no Seep/W, concluiu-se que o modelo que se mostrou mais adequado para a distribuição da pressão neutra inicial foi o Modelo 1, o qual corresponde a condição de contorno dado por uma linha horizontal traçada na profundidade de instalação do tensiômetro com comprimento de $1,50 \mathrm{~m}$ no pé desta seção. Além das análises de infiltração também foram feitas análises de estabilidade de talude no Slope/W, indicando para o Modelo 1 valores de Fator de Segurança de 1,877 pelo Método de Bishop Simplificado e de 1,766 pelo Método de Janbu após a chuva do dia 08/03/2015.

No caso do segundo evento pluviométrico, o período analisado totalizou o registro de 249,8 mm precipitação pluviométrica monitorada ao longo de dezoito dias. Os resultados das análises de infiltração da água da chuva mostraram que os valores das pressões neutras não 
são idênticas aos valores medidos nos tensiômetros, apresentando uma dispersão da ordem de $20 \mathrm{kPa}$. A distribuição das pressões neutras durante o período analisado indicou uma tendência em aumentar após a ocorrência de um evento chuvoso e em diminuir nos dias sem chuva.

As análises de estabilidade de talude mostraram que mesmo após a ocorrência de uma precipitação pluviométrica de 93,1 mm em 01/12/2015, o talude permanece estável. Nesse caso, o Fator de Segurança foi de 1,795 pelo método de Bishop Simplificado e de 1,695 pelo método de Janbu.

Já no caso de seis dias consecutivos sem chuva, as pressões neutras desenvolvidas no interior do talude tendem a aumentar gradativamente, variando de $-30,7 \mathrm{kPa}$ a $-52,0 \mathrm{kPa}$. Esse mesmo comportamento pode ser observado nos resultados dos Fatores de Segurança, os quais variaram de 2,067 a 2,365 para o método de Bishop Simplificado e de 1,929 a 2,196 para o método de Janbu.

Os resultados determinados no segundo evento pluviométrico permitem concluir que taludes que possuem essa característica geométrica e pertencem à mesma formação geológica (Formação Botucatu) permanecem estáveis mesmo após a ocorrência de eventos pluviométricos com maiores volumes de água, como por exemplo, a chuva de 93,1 mm. O fato de o talude permanecer estável pode estar associado com as características das geometrias dos taludes encontrados na região da área piloto (taludes menos acentuados), com as características do solo apresentando elevado valor de condutividade hidráulica saturada (na ordem de $10^{-2} \mathrm{~cm} / \mathrm{s} \mathrm{e} 10^{-3} \mathrm{~cm} / \mathrm{s}$ ) ou ainda com os aspectos da topografia regional facilitando o escoamento superficial da água da chuva.

Por esse motivo, os valores medidos de precipitação pluviométrica durante o período do monitoramento não foram suficientes e determinantes para a ocorrência de deslizamentos em taludes com essa geometria e formação geológica. Ademais, o estabelecimento de precipitações mínimas para deflagração de deslizamentos poderia ser feito através da utilização de valores registrados em outros equipamentos localizados próximos da área piloto, como por exemplo, os dados do pluviômetro ANA.

Assim como observado na extensão total do talude investigado e em outros trechos dessa mesma rodovia onde ocorrem solos arenosos residuais da Formação Botucatu, é comum constatar a presença de taludes de corte com geometria mais acentuada as geometrias indicadas como críticas nesta pesquisa. Isso explica a frequiência pouco elevada da ocorrência de deslizamentos de solo nestes taludes, apesar das intensidades pluviométricas críticas serem relativamente comuns para a região. Portanto, baseando-se nas análises numéricas 
apresentadas nesse trabalho e nas condições observadas nos levantamentos de campo, pode-se afirmar que um talude com característica geométrica semelhante às geometrias críticas encontradas das duas seções e pertencente à Formação Botucatu apresente Fator de Segurança inferior ao valor unitário (menor que um), ou seja, que esse talude esteja instável e rompa.

É importante ressaltar que os resultados apresentados nesta pesquisa permitiram concluir que os cinco objetivos propostos foram plenamente atingidos e satisfeitos. Além disso, o presente trabalho mostrou um levantamento completo (ensaios de campo, ensaios de laboratório e monitoramento de instrumentação de campo) e inédito feito em um talude de solo residual arenoso na condição não saturada da Formação Botucatu. No caso da área piloto, a porção do talude estudado nunca esteve rompida.

Por fim, a contribuição desta pesquisa será feita através do fornecimento de dados resultantes do monitoramento de campo, dos parâmetros do solo (hidráulico, mecânico e físico) bem como dos diferentes tipos de análises numéricas realizadas ao longo dessa pesquisa. O levantamento desses dados, parâmetros e análises numéricas serão muito úteis para o desenvolvimento de inúmeras pesquisas inéditas voltadas para o tema de estabilidade de talude em solo não saturado especificamente para solos residuais arenosos da Formação Botucatu. 


\section{REFERÊNCIAS}

ABRAMENTO, M. Resistência ao cisalhamento de solos não saturados: considerações teóricas e estudo experimental sobre solo coluvionar das encostas da serra do mar. 1988. 175 f. Dissertação (Mestrado) - Escola Politécnica, Universidade de São Paulo, São Paulo, 1988.

ABRAMENTO, M.; PINTO, C.S. Resistência ao cisalhamento de solo coluvionar não saturado das encostas da Serra do Mar. Solos e Rochas, v.3, n.16, p.145-158, 1993.

ABRAMSON, L.W. et al. Slope stability and stabilization methods. New York: John Wiley, 2002.

AITCHISON, G.D. Relationship of moisture and effective stress functions in unsaturated soils. In: CONFERENCE ON PORE PRESSURE AND SUCTION IN SOILS, 1961, London.Proceedings...London: Butterworths, 1961. p.47-52.

The Quantitative description of the stress-deformation behavior of expansive soils preface to set of papers. In: INTERNATIONAL CONFERENCE ON EXPANSIVE SOILS, 3., 1973, Haifa. Proceedings...Jerusalem: Academic Press, 1973. p.79-82.

AGÊNCIA NACIONAL DAS ÁGUAS. Sistema de informações hidrológicas (Hidroweb). Disponível em:<http://www.snirh.gov.br/hidroweb/> . Acesso em: 14 maio 2016.

ASSOCIAÇÃO BRASILEIRA DE NORMAS TÉCNICAS. NBR 6508: Grãos de solos que passam na peneira \#4,8mm - determinação da massa específica. Rio de Janeiro, 1984.

.NBR 7181: Solo - análise granulométrica. Rio de Janeiro, 1988.

.NBR 6502:Rochas e solos. Rio de Janeiro, 1995a. 
ASSOCIAÇÃO BRASILEIRA DE NORMAS TÉCNICAS. NBR 13292: Solo determinação do coeficiente de permeabilidade de solos granulares à carga constante método de ensaio. Rio de Janeiro, 1995 b.

. NBR 11682: Estabilidade de encostas. Rio de Janeiro, 2009.

AU, S.W.C. Rain-induced slope instability in Hong Kong. Engineering Geology, v.51, n.1, p.1-36, 1998.

AUGUSTO FILHO, O. Caracterização geológico-geotécnica voltada à estabilização de encostas: uma proposta metodológica. In: CONFERÊNCIA BRASILEIRA SOBRE ESTABILIDADE DE ENCOSTAS, 1992, Rio de Janeiro. Anais... Rio de Janeiro:Associação Brasileira de Mecânica dos Solos, 1992. p.721-733.

AUGUSTO FILHO, O.; VIRGILI, J.C. Estabilidade de taludes. In: OLIVEIRA, A.M.S.; BRITO, S.N.A. Geologia de engenharia. São Paulo: Associação Brasileira de Geologia de Engenharia e Ambiental, 1998. p.243-269.

BARATA, F.R. Landslides in the tropical region of Rio de Janeiro. In: INTERNATIONAL CONFERENCE FOR SOIL MECHANIC AND FOUNDATION ENGINEERING, 7. 1969, Mexico City. Proceedings... Mexico City: Sociedad Mexicana de Mecanica, 1969. p.507-516.

BISHOP, A.W. The Use of the slipe circle in the stability analysis of slopes. Geotechnique Journal, v.5, p.7-17, 1955.

. The Principle of effective stress. Teknisk Ukeblad, v.106, n.39, p.859-863, 1959.

BISHOP, A.W. et al. Factors controlling the strength of partly saturated cohesive soils. In: RESEARCH CONFERENCE ON SHEAR STRENGTH OF COHESIVE SOILS, Boulder, 1960. Proceedings... Boulder: University of Colorado, 1960. p.503-532.

BLATZ, J.A.; FERREIRA, N.J.; GRAHAM, J. Effect of near-surface environmental conditions on instability of an unsaturated soil slope. Canadian Geotechnical Journal, v.41, n.6, p.959-971, 2004.

BRAND, E.W. Predicting the perfomance of residual soil slopes (theme lecture). In: INTERNATIONAL CONFERENCE ON SOIL MECHANICS AND FOUNDATION ENGINEERING, 11., 1985, San Francisco. Proceedings... Rotterdam: A.A.Balkema, 1985. p.2541-2578.

BRANDÃO, V.S. et al. Infiltração da água no solo. 3.ed. Viçosa: Ed.UFV, 2009.

BROOKS, R.H.; COREY, A.T. Hydraulic properties of porous media. Colorado: Hydrology papers Colorado State University, 1964. (Fort Collins, Colorado, n.3).

BUENO, B.S.; VILAR, O.M. Mecânica dos solos. São Carlos: EESC/USP, 1979.

CAI, F.; UGAI, K. Numerical analysis of rainfall effects on slope stability. International Journal of Geomechanics, v.4, n.2, p.69-78, 2004. 
CAINE, N. The Rainfall intensity: duration control of shallow landslides and debris flows. Geografiska Annaler, v.62, n.1/2, p.23-27, 1980.

CALLE, J.A.C. Análise de ruptura de talude em solo não saturado. 2000. 128 f. Dissertação (Mestrado) - Escola de Engenharia de São Carlos, Universidade de São Paulo, São Carlos, 2000.

CAMPOS, L.E.P. Influência da sucção na estabilidade de taludes naturais em solos residuais. 1984. 173 f. Dissertação (Mestrado) - Pontifícia Universidade Católica do Rio de Janeiro, Rio de Janeiro, 1984.

CARDOSO JÚNIOR, C.R. Estudo do comportamento de um solo residual de gnaisse não saturado para avaliar a influência da infiltração na estabilidade de taludes. 2006. 192 f. Dissertação (Mestrado) - Escola Politécnica, Universidade de São Paulo, São Paulo, 2006.

CARVALHO, C.S. Estudo da infiltração em encostas de solos insaturados na Serra do Mar. 1989. 154 f. Dissertação (Mestrado) - Escola Politécnica, Universidade de São Paulo, São Paulo, 1989.

CARVALHO, P.A.S. Manual de geotecnia: taludes de rodovia: orientação para diagnóstico e soluções de seus problemas. São Paulo: IPT, 1991.

CERRI, L.E.S. Riscos geológicos associados a escorregamentos: uma proposta para prevenção de acidentes. 1993. 197 f. Tese (Doutorado) - Instituto de Geociências e Ciências Exatas, Universidade Estadual Paulista, Rio Claro, 1993.

CHANDLER, R.J.; CRILLY, M.S.; MONTGOMERYSMITH, G. A Low-cost method of assessing clay desiccation for low-rise buildings. Proceedings of the Institution of Civil Engineers - civil engineering, v.92, n.2, p.82-89, 1992.

CHO, S.E.; LEE, S.R. Instability of unsaturated soil slopes due to infiltration. Computers and Geotechnics, v.28, p.185-208, 2001.

CLIMATEMPO. Climatologia - Ribeirão Bonito. 2015. Disponível em:<http://www.climatempo.com.br/climatologia/2079/ribeiraobonito>. Acesso em: 25 mar. 2015.

COLLINS, B.D.; ZNIDARCIC, D. Stability analyses of rainfall induced landslides. Journal of Geotechnical and Geoenvironmental Engineering, v.130, n.4, p.362-372, 2004.

COREY, A.T. Measurement of water and air permeability in unsaturated soil. Soil Science Society of America Journal, v.21, n.1, p.7-10, 1957.

COSTA NUNES, A.J. Estabilidade de taludes. In: CONGRESSO BRASILEIRO DE MECÂNICA DOS SOLOS, 3., 1966, Belo Horizonte. Anais... Belo Horizonte: Associação Brasileira de Mecânica dos Solos, 1966. p.133-177. 
CRONEY, D.; COLEMAN, J.D.; BLACK, W.P.M. Studies of the movement and distribution of water in soil in relation to Highway design and performance. Highway Research Board Special Report, n.40, p.226-252, 1958.

CUNHA, M.A.; FARAH, F.; CERRI, L.E.S. Manual de ocupação de encostas. São Paulo: IPT, 1991.

DUNCAN, J.M.; WRIGHT, S.G. Mechanics of limit equilibrium procedures. In: Soil strength and slope stability. Hoboken: John Wiley, 2005.p.55-102.

ELRICK, D.E.; REYNOLDS, W.D.; TAN, K.A. Hydraulic conductivity measurements in the unsaturated zone using improved well analyses. Groundwater Monitoring \& Remediation,v.9, n.3, p.184-193, 1989.

ESCARIO, V.; SÁEZ, J. The Shear strength of partly saturated soils. Géotechnique, v.36, n.3, p.453-456, 1986.

EYLES, R.J.; CROZIER, M.J.; WHEELER, R.H. Lanslips in Wellington city. New Zealand Geographer, v.34, n.2, p.58-74, 1978.

FELLENIUS, W. Calculation of the stability of earth dams. In: INTERNATIONAL CONGRESS ON LARGE DAMS, 2., 1936, Washington. Proceedings... Washington: International Commission on Large Dams, 1936. p.445-463.

FERNANDES, M.A. Condutividade hidráulica não saturada de um solo arenoso: aplicação do infiltrômetro de disco. 2011. 161 f. Dissertação (Mestrado) - Escola de Engenharia de São Carlos, Universidade de São Paulo, São Carlos, 2011.

FINLAY, P.J.; FELL, R.; MAGUIRE, P.K. The Relationship between the probability of landslide occurrence and rainfall. Canadian Geotechnical Journal, v.34, n.6, p.811-824, 1997.

FORMIGA, K.T.M. et al. A Infiltração e o escoamento superficial. In: CARVALHO, J.C.; GITIRANA JR., G.F.N.; CARVALHO, E.T.L. Tópicos sobre infiltração: teoria e prática aplicadas a solos tropicais. Brasília: Faculdade de Tecnologia, 2012. p.101-116.

FREDLUND, D.G. Analytical methods for slope stability analysis. In: INTERNATIONAL SYMPOSIUM ON LANDSLIDES, 4., 1984, Toronto. Proceedings... Toronto: Canadian Geotechnical Society, 1984. p.229-250.

FREDLUND, D.G. Use of the soil-water characteristic curve in the implementation of unsaturated soil mechanics. In: INTERNATIONAL CONFERENCE ON UNSATURATED SOILS, 3., 2002, Recife. Proceedings... Netherlands: A.A. Balkema, 2002. p.887-902.

FREDLUND, D.G.; MORGENSTERN, N.R. Stress state variables for unsaturated soils. Journal of the Geotechnical Engineering Division, v.103, n.GT5, p.447-466, 1977.

FREDLUND, D.G.; RAHARDJO, H. Soil mechanics for unsaturated soils. New York:John Wiley, 1993. 
FREDLUND, D.G.; XING, A. Equations for the soil-water characteristic curve. Canadian Geotechinal Journal, v.32, n.3, p.521-532, 1994.

FREDLUND, D.G.; MORGERSTERN, N.R.; WIDGER, R.A. The Shear strength of unsaturated soils. Canadian Geotechnical Journal, v.15, n.3, p.313-321, 1978.

FREITAS NETO, O. Resistência ao cisalhamento de um solo não saturado com medida direta da sucção. 2008. 178 f. Dissertação (Mestrado) - Escola de Engenharia de São Carlos, Universidade de São Paulo, 2008.

FREIRE, E.S.M. Movimentos coletivos de solos e rochas e sua moderna sistemática. Revista Construção, p.10-18, 1965.

FREIRE, E.P. Estabilidade de taludes naturais em solo nos morros da cidade de Santos. 1995. 105 f. Dissertação (Mestrado) - Universidade de Brasília, Brasília, 1995.

GAN, J.K.M. Direct shear strength testing of unsaturated soils. 1986. 587 f. Dissertation (M.Sc.) - University of Saskatchewan, Saskatoon, 1986.

GARDNER, W.R. Some steady-state solutions of the unsaturated moisture flow equation with application to evaporation from a water table. Soil Science, v.85, n.4, p.228-232, 1958.

GASMO, J.M.; RAHARDJO, H.; LEONG, E.C. Infiltration effects on stability of a residual soil slope. Computers and Geotechnics, v.26, p.145-165, 2000.

GASMO, J.M. et al. Instrumentation of an unsaturated residual soil slope. Geotechnical Testing Journal, v.22, n.2, p.128-137, 1999.

GEORGETTI, G.B. Resistência de um solo não saturado a partir de ensaios com teor de umidade constante (CW). 2010. 108 f. Dissertação de Mestrado - Escola de Engenharia de São Carlos, Universidade de São Paulo, 2010.

GEO-SLOPE INTERNATIONAL LTD. Seepage modeling with SEEP/W. Calgary: Alberta, 2015a.

Stability modeling with SLOPE/W. Calgary: Alberta, 2015b.

GERSCOVICH, D.M.S. Estabilidade detaludes. São Paulo: Oficina de Textos, 2012.

GERSCOVICH, D.M.S.; CAMPOS, T.M.P.; VARGAS JR., E.A. Back analysis of a landslide in a residual soil slope in Rio de Janeiro, Brazil. Solos e Rochas, v.34, n.2, p.139-149, 2011.

GODOIS, J.V.S. Estudo de comportamento de um escorregamento ativo na Serra da Cantareira - SP. 2011. 118 f. Dissertação (Mestrado) - Escola Politécnica, Universidade de São Paulo, São Paulo, 2011. 
GOFAR, N.; LEE, L.M.; ASOF, M. Transient seepage and slope stability analysis for rainfallinduced landslide: a case study. Malaysian Journal of Civil Engineering, v.18, n.1,p.113, 2006.

GOOGLE EARTH. Município de Ribeirão Bonito. 2015. Disponível em:<https://earth.google.com/>. Acesso em: 25 mar. 2015.

Município de Ribeirão Bonito. 2016. Disponível em:<https://earth.google.com/>. Acesso em: 8 abr. 2016.

GUI, M.W.; WU, Y.M. Failure of soil under water infiltration condition. Engineering Geology, v.181, p.124-141, 2014.

GUIDICINI, G.; NIEBLE, C.M. Estabilidade de taludes naturais e de escavação. São Paulo: Edusp; Edgard Blucher, 1976. 2.ed.São Paulo: Edgard Blucher, 1984.

GUIDICINI, G.; IWASA, O.Y. Ensaio de correlação entre pluviosidade e escorregamentos em meio tropical úmido. São Paulo: IPT, 1976. (Relatório nº 1080).

GUIDICINI, G.; WOLLE, C.M.; MORUZZI, C. Um caso de instrumentação de maciços na Rodovia dos Imigrantes. Seminário Dersa, v.1, p.78-89, 1976.

GUZZETTI, F. et al. The Rainfall intensity- duration control of shallow landslides and debris flows: an update. Landslides, v.5, p.3-17, 2008.

HAMDHAN, I.; SHWEIGER, H. Finite element method-based analysis of an unsaturated soil slope subjected to rainfall infiltration. International Journal of Geomechanics,v.13, n.5, p.653-658, 2013.

HEAD, K.H. Manual of soil laboratory testing. 2.ed. New York: John Wiley, 1998. v.3: Effective stress tests.

HILLEL, D. Soil and water: physical principles and processes. New York: Academic Press, 1971.

Fundamentals of soil physics. New York: Academic Press, 1980.

HUTCHINSON, J.N. Morphological and geotechnical parameters of landslides in relation to geology and hydrogeology. In: INTERNATIONAL SYMPOSIUM ON LANDSLIDES, 5.,1988, Lausanne. Proceedings... Rotterdam: A.A.Balkema, 1988. p.3-35.

INSTITUTO BRASILEIRO DE GEOGRAFIA E ESTATÍSTICA. São Carlos. São Paulo: IBGE, 1971. 1 mapa. Escala 1:50.000.

INSTITUTO DE PESQUISA TECNOLÓGICA. Diagnóstico da situação atual dos recursos hídricos e estabelecimento de diretrizes técnicas para a elaboração do Plano da Bacia Hidrográfica do Tietê/Jacaré - relatório final. São Paulo: IPT, 2000. (Relatório $\mathrm{n}^{\circ}$ 40674). 
INSTITUTO NACIONAL DE METEOROLOGIA. Banco de dados meteorológicos para ensino e pesquisa: dados históricos. Disponível em: $\langle$ http://www.inmet.gov.br/portal/index.php?r=bdmep/bdmep>. Acesso em: 14 maio 2016 .

IRMAY, S. On The Hydraulic conductivity of unsaturated soils. Transactions American Geophysical Union, v.35, n.3, p.463-467, 1954.

JANBU, N. Application of composite slip surfaces for stability analysis. In: EUROPEAN CONFERENCE ON STABILITY OF EARTH SLOPES, 1954, Stockholm. Proceedings... Stockholm: Statens Reproduktionsanstalt, 1954. p.43-49.

JENNINGS, J.E.B. A Revised effective stress law for use in the prediction of the behaviour of unsaturated soils. In: CONFERENCE ON PORE PRESSURE AND SUCTION IN SOILS,1961, London. Proceedings... London: Butterworths, 1961. p.26-30.

JESUS, A.C. Retroanálise de escorregamento em solo residual não saturado. 2008. 265f. Dissertação (Mestrado) - Escola de Engenharia de São Carlos, Universidade de São Paulo, São Carlos, 2008.

KIEHL, E.J. Manual de edafologia: relações solo-planta. São Paulo: Ceres, 1979.

KIM, S.K.; HONG, W.P.; KIM, Y.M. Prediction of rainfall-triggered landslides in Korea.In:International Symposium on Landslides, 6., 1991, Christchurch. Proceedings... Rotterdam: A.A.Balkema, 1991. p.989-994.

KIM, Y.T.; LEE, J.S. Slope stability characteristic of unsaturated weathered granite soil in Korea considering antecedent rainfall.In: GEO-CONGRESS, 2013, San Diego. Proceedings... San Diego: American Society of Civil Engineers, 2013. p.394-401.

KRAHN, J.; FREDLUND, D.G.; KLASSEN, M.J. Effect of soil suction on slope stability at Notch Hill. Canadian Geotechnical Journal, v.26, n.2, p.269-278, 1989.

LAMBE, T.W.A Mechanistic picture of shear strength in clay. In:RESEARCH CONFERENCE ON SHEAR STRENGTH OF COHESIVE SOILS, 1960, Boulder. Proceedings... New York : American Society of Civil Engineers, 1961. p.555-580.

LARSEN, M.C.; SIMON, A. Rainfall-threshold conditions for landslides in a humid-tropical system, Puerto Rico. Geografiska Annaler, v.75, n.1-2, p.13-23, 1993.

LEE, L.M.; GOFAR, N.; RAHARDJO, H. A Simple model for preliminary evaluation of rainfall-induced slope instability. Engineering Geology, v.108, n.3/4, p.272-285, 2009.

LEONG, E.C.; RAHARDJO, H. Review of soil-water characteristic curve equations. Journal of Geotechnical and Geoenvironmental Engineering, v.123, n.12, p.1106-1117, 1997.

LI., A.G. et al. Field-monitored variations of soil moisture and matric suction in a saprolite slope. Canadian Geotechnical Journal, v.42, n.1, p.13-26, 2005. 
LIBARDI, P.L. Dinâmica da água no solo. São Paulo: Edusp, 2005. 2.ed.São Paulo: Edusp, 2012.

LIM, T.T. et al. Effect of rainfall on matric suctions in a residual soil slope. Canadian Geotechnical Journal, v.33, n.2, p.618-628, 1996.

LU, N.; LIKOS, W.J. Unsaturated soil mechanics. New York: John Wiley, 2004.

LU, N.; GODT, J. Infinite slope stability under steady unsaturated seepage conditions. Water Research Resources, v.44, n.W11404, p.1-13, 2008.

LUMB, P. Slope failures in Hong Kong. Quartely Journal of Engineering Geology, v.8, p.31-65, 1975.

LUXMOORE, R.J. Micro-, meso-, and macroporosity of soil. Soil Science Society of America Journal,v.45, n.6, p.1246-1246, 1981.

MATOS, M.M. Stability of slopes in residual soils. 1974. 234 f. Dissertation (M.Sc.) University of Alberta, Canada, 1974.

MATTOS, K.C.A. Processos de instabilização em taludes rodoviários em solos residuais arenosos: estudo na Rodovia Castelo Branco (SP 280), Km 305 a 313. 2009. 126 f. Dissertação (Mestrado) - Escola de Engenharia de São Carlos, Universidade de São Paulo, São Carlos, 2009.

MENEZES, M.B.M. Análise da influência do teor de umidade na absorção d'água e sucção dos solos em estudos de erodibilidade. 2010. 139 f. Dissertação (Mestrado) Escola de Engenharia de São Carlos, Universidade de São Paulo, São Carlos, 2010.

MERIGGI, R.; DI MARCO, C.; PAVONI, R. A Parametric analysis of colluvial slope stability during heavy rainfalls. In: INTERNATIONAL CONFERENCE ON UNSATURATED SOILS, 3., 2002, Recife. Proceedings... Netherlands: A.A.Balkema, 2002. p.741-747.

MORGENSTERN, N.R.; MATOS, M.M. Stability of slopes in residual soils. In: PANAMERICAN CONFERENCE OF SOIL MECHANICS AND FOUNDATION ENGINEERING, 5., 1975, Buenos Aires. Proceedings... Buenos Aires: [s.n.], 1975. p.367-383.

NG, C.W.W.; SHI, Q. A Numerical investigation of the stability of unsaturated soil slopes subjected to transient seepage. Computers and Geotechnics, v.22, n.1, p.1-28, 1998.

NOGAMI, J.S.; VILLIBOR, D.F. Soil characterization of mapping units for highway purposes in a tropical area. Bulletin of the International Association of Engineering Geology, n.19, p.196-199, 1979.

PEJON, O.J. Mapeamento geotécnico da folha de Piracicaba-SP (escala 1:100.000): estudo de aspectos metodológicos, de caracterização e de apresentação dos atributos. 
1992. 224 f. Tese (Doutorado) - Escola de Engenharia de São Carlos, Universidade de São Paulo, São Carlos, 1992.

QUEIROZ, R.C. Aplicação do método de retroanálise no estudo da estabilidade de taludes de estradas situadas em solos oriundos da formação Adamantina. 1986. $98 \mathrm{f}$. Dissertação (Mestrado) - Escola de Engenharia de São Carlos, Universidade de São Paulo, São Carlos, 1986.

QUEIROZ, R.C.; GAIOTO, N. Análise da estabilidade de cortes ferroviários por retroanálise. Ferrovia, p.16-19, 1989.

RAHARDJO, H.; LEONG, E.C., REZAUR, R.B. Studies of rainfall-induced slope failures.In: NATIONAL SEMINAR, 2002, Bandung.Proceedings...[S.I.:s.n.], 2002. p.15-29.

RAHARDJO, $\mathrm{H}$. et al. Shear-strength characteristics of a residual soil. Canadian Geotechnical Journal, v.32, n.1, p.60-77, 1995.

RAHARDJO, H. et al. Response of a residual soil slope to rainfall. Canadian Geotechnical Journal, v.42, n.2, p.340-351, 2005.

Factors controlling instability of homogeneous soil slopes under rainfall. Journal of Geotechnical an Geoenvironmental Engineering, v.133, n.12, p.1532-1543, 2007.

RAHIMI, A.; RAHARDJO, H.; LEONG, E.C. Effect of antecedent rainfall patterns on rainfall-induced slope failure. Journal of Geotechnical and Geoenvironmental Engineering, v.137, n.5, p.483-491, 2011.

REICHARDT, K. Processos de transferência no sistema solo-planta-atmosfera. 4.ed. Campinas: Fundação Cargill, 1985.

REIS, R.M. Comportamento tensão-deformação de dois horizontes de um solo residual de gnaisse. 2004. 222 f. Tese (Doutorado)- Escola de Engenharia de São Carlos, Universidade de São Paulo, São Carlos, 2004.

REYNOLDS,W.D.; ELRICK, D.E. In Situ measurement of field-saturated hydraulic conductivity, sorptivity and the alpha-parameter using the Guelph permeameter. Soil Science, v.140, n.4, p.292-302, 1985.

RICHARDS, B.G. Capillary conduction of liquids through porous mediums. Journal of Applied Physics, v.1, n.5, p.318-333, 1931.

The Significance of moisture flow and equilibria in unsaturated soils in relation to the design of engineering structures built on shallow foundations in Australia. In: SYMPOSIUM ON PERMEABILITY AND CAPILLARY, 1966, Atlantic City. Proceedings... Madison: ASTM, 1966.

RICHARDS, L.A. Physical conditions of water in soil. In: BLACK, C.A. et al. Methods of soil analysis: physical and mineralogical properties, including statistics of measurement and sampling (part 1).Madison: ASTM, 1965.p.128-152. 
RODRIGUES, R.A. Modelação das deformações por colapso devidas à ascensão de lençol freático. 2007. 298 f. Tese (Doutorado) - Escola de Engenharia de São Carlos, Universidade de São Paulo, São Carlos, 2007.

ROHM, S.A.; VILAR, O.M. Shear strength of an unsaturated sandy soil. In: INTERNATIONAL CONFERENCE ON UNSATURATED SOILS, 1995, Paris. Proceedings... Rotterdam: A.A.Balkema, 1995. p.189-193.

SANTOS, C.R. Análise paramétrica da infiltração e sua influência na estabilidade de taludes em solo não saturado. 2004. 104 f. Dissertação (Mestrado) - Escola de Engenharia de São Carlos, Universidade de São Paulo, São Carlos, 2004.

SATIJA, B.S. Shear behaviour of partially saturated soils. 1978. 327 f. Thesis (Ph.D.) Indian Institute of Technology Delhi, New Delhi, 1978.

SHARPE, C.F.S. Landslides and related phenomena: a study of mass-movements of soil and rock. New York: Columbia University Press, 1938.

SILVA, L.P. Hidrologia dos solos. In: Rio de Janeiro: Elsevier, 2015. p.161-202.

Hidrologia: engenharia e meio ambiente.

SISTEMA INTEGRADO DE GERENCIAMENTO DE RECURSOS HÍDRICOS DO ESTADO DE SÃO PAULO. Relatório de situação dos recursos hídricos de 2014, UGRHI - bacia hidrográfica Tietê-Jacaré. São Paulo: SIGRH, 2014. (Relatório de Situação dos Recursos Hídricos 2015).

SOILMOISTURE EQUIPMENT CORPORATION. Guelph permeameter operating instruction. Soilmoisture manual. Santa Barbara, 2008.

2710ARL tensiometer and 2725 ARL Jet Fill tensiometer operating instruction. Soilmoisture manual. Santa Barbara, 2011.

TATIZANA, C. et al. Análise de correlação entre chuvas e escorregamentos - Serra do Mar, município de Cubatão. In: CONGRESSO BRASILEIRO DE GEOLOGIA DE ENGENHARIA E AMBIEnTal, 5., 1987, São Paulo. Anais... São Paulo: Associação Brasileira de Geologia de Engenharia e Ambiental, 1987. p.225-236.

TEIXEIRA, E.K.C. Estudo da influência da infiltração de águas pluviais na estabilidade de um talude de solo residual. 2014. 76 f. Dissertação (Mestrado) - Universidade Federal de Viçosa, Viçosa, 2014.

TRANDAFIR, A.C. et al. Monitored and simulated variations on matric suction during rainfall in a residual soil slope. Environmental Geology, v.55, n.5, p.951-961, 2008.

TSAPARAS, I. et al. Controlling parameters for rainfall-induced landslides. Computers and Geotechnics, v.29, p.1-27, 2002.

Infiltration characteristics of two instrumented residual soil slope. Canadian Geotechnical Journal, v.40, n.5, p.1012-1032, 2003. 
UNITED STATE GEOLOGICAL SURVEY. Landslides types and processes. Virginia: U.S. Department of the Interior, 2004.

VANAPALLI, S.K. et al. Model for the prediction of shear strength with respect to soil suction. Canadian Geotechnical Journal, v.33, n.3, p.379-392, 1996.

VAN GENUCHTEN, M.T. A Closed-form equation for predicting the hydraulic conductivity of unsaturated soils. Soil Science Society of America Journal, v.44, n.55, p.892-898, 1980.

VARGAS, M.; PICHLER, E. Residual soil and rock slides in Santos (Brazil). In: INTERNATIONAL CONFERENCE FOR SOIL MECHANIC AND FOUNDATION ENGINEERING, 4., 1957, London. Proceedings... London: Butterworths, 1957. p.394398.

VARGAS JR., E.A.; COSTA FILHO, L.M.; CAMPOS, L.E.P.A. A Study of the relationship between the stability of slopes in residual soils and rain intensity. In: INTERNATIONAL SYMPOSIUM ON ENVIRONMENTAL GEOTECHNOLOGY, 1986, Allentown. Proceedings... Bethlehem: Envo, 1986. p.491-500.

VARNES, D.J. Slope movement type and processes. In: SCHUSTER, R.L.; KRIZEK, R.J. Landslides: analysis and control - special report 176, transportation research board. Washington: National Academy of Science, 1978. p.11-33.

VICTORINO, M.M. Influência da chuva nas poropressões e na estabilidade dos taludes rodoviários de um trecho na BR 376 na Serra do Mar Paranaense. 2015. 124 f. Dissertação (Mestrado) - Universidade Federal do Paraná, Curitiba, 2015.

VILAR, O.M. An expedite method to predict the shear strength of unsaturated soils. Soils and Rocks, v.30, n.1, p.51-61, 2007.

Introdução à mecânica dos solos não saturados.São Carlos: EESC/USP, Departamento de Geotecnia, 2009. Notas de aula da disciplina mecânica dos solos não saturados.

WICANDER, R.; MONROE, J.S. Fundamentos de geologia. São Paulo: Cengage Learning, 2009.

WIECZOREK, G.F. Effect of rainfall intensity and duration on debris flows in central Santa Cruz Mountains, California. Geological Society of America Reviews in Engineering Geology, v.7, p.93-104, 1987.

WOLLE, C.M. Taludes naturais - mecanismos de instabilização e critérios de segurança. 1980. 645 f. Dissertação (Mestrado) - Escola Politécnica, Universidade de São Paulo, São Paulo, 1980.

WOLLE, C.M. Análise dos escorregamentos translacionais numa região da Serra do Mar no contexto de uma classificação de mecanismos de instabilização de encostas. 1988. 406 f. Tese (Doutorado) - Escola Politécnica, Universidade de São Paulo, São Paulo, 1988. 
ZAMBRANA, V.D. Análise numérica da influência de chuvas externas na estabilidade de taludes. 2014. 152 f. Dissertação (Mestrado) - Escola Politécnica, Universidade de São Paulo, São Paulo, 2014.

ZHAN, T.L.T.; NG, W.W.; FREDLUND, D.G. Instrumentation of an unsaturated expansive soil slope. Geotechnical Testing Journal, v.30, p.1-11, 2006.

ZHANG, J.; JIAO, J.J.; YANG, J. In situ rainfall infiltration studies at a hillside in Hubei Provence, China. Engineering Geology, v.57, n.1, p.31-38, 2000. 
APÊNDICE A - PROCEDIMENTOS UTILIZADOS NO SOFTWARE COMPUTACIONAL GEOSTUDIO 2012 (SEEP/W E SLOPE/W) 


\section{$\underline{\text { Análise de fluxo de água }}$}

1-) Inicie o software computacional GeoStudio 2012, no menu do Windows.

2-) Selecione a opção $S e e p / W$ e em seguida escolha o tipo de análise de fluxo permanente ou transiente (Analysis Type $\rightarrow$ Steady - state ou Transient).

3-) Ajuste o tamanho do papel (Set $\rightarrow$ Page).

4-) Configure o peso específico da água $\left(\gamma_{w}=9,8 \mathrm{kN} / \mathrm{m}^{3}\right)$ e ajuste a escala do desenho $($ Set $\rightarrow$ Units and Scale).

5-) Insira as coordenadas dos pontos do desenho (KeyIn $\rightarrow$ Points).

6-) Desenhe o perfil da seção geológico-geotécnica do talude a partir das coordenadas inseridas no item anterior (Draw $\rightarrow$ Regions).

7-) Defina a propriedade hidráulica do solo - função condutividade hidráulica (KeyIn $\rightarrow$ Hydraulic Functions $\rightarrow$ Hydraulic Conductivity).

8-) Defina a propriedade hidráulica do solo - curva de retenção da água no solo (KeyIn $\rightarrow$ Hydraulic Functions $\rightarrow$ Vol.Water Content).

9-) Defina a malha de elementos finitos (Draw $\rightarrow$ Mesh Properties).

10-) Defina o material utilizando as propriedades inseridas nos itens 7 e 8 (KeyIn $\rightarrow$ Materials).

11-) Clique em (Draw $\rightarrow$ Materials) e selecione a região no desenho para definir as propriedades do solo.

12-) Defina as condições de contorno das análises de fluxo (Draw $\rightarrow$ Boundary Conditions).

Obs: No caso das análises de fluxo transiente, é necessário configurar a duração da chuva e os intervalos de tempo empregados nessas análises (KeyIn $\rightarrow$ Analysis $\rightarrow$ Time).

13-) Insira os eixos (elevação e comprimento) do desenho (Sketch $\rightarrow$ Axes).

14-) Inicie os cálculos do fluxo selecionando a opção Solver Manager (Window $\rightarrow$ Solver Manager) e em seguida clicando no botão Start.

15-) Visualize os resultados selecionando a opção Result View (Window $\rightarrow$ Result View).

\section{$\underline{\text { Análise de estabilidade de talude }}$}

16-) Inicie o software computacional GeoStudio 2012, no menu do Windows. 
17-) Selecione a opção Slope/ $W$ e em seguida escolha o tipo de análise de estabilidade Bishop ou Janbu (Analysis Type $\rightarrow$ Bishop ou Janbu).

18-) Ajuste o tamanho do papel (Set $\rightarrow$ Page).

19-) Configure o peso específico da água $\left(\gamma_{w}=9,8 \mathrm{kN} / \mathrm{m}^{3}\right)$ e ajuste a escala do desenho $($ Set $\rightarrow$ Units and Scale).

20-) Insira as coordenadas dos pontos do desenho (KeyIn $\rightarrow$ Points).

21-) Desenhe o perfil da seção geológico-geotécnica do talude a partir das coordenadas inseridas no item anterior (Draw $\rightarrow$ Regions).

22-) Defina a propriedade mecânica do solo (KeyIn $\rightarrow$ Materials $\rightarrow$ Mohr Coulomb).

23-) Clique em (Draw $\rightarrow$ Materials) e selecione a região no desenho para definir as propriedades do solo.

24-) Selecione a opção de como será feita a busca pela superfície crítica e pelo centro de rotação (KeyIn $\rightarrow$ Analysis $\rightarrow$ Slip Surface $\rightarrow$ Grid and Radius).

25-) Defina no desenho a malha do centro de rotação e as linhas da superfície de ruptura $($ Draw $\rightarrow$ Slip Surface $\rightarrow$ Grid $)$ e (Draw $\rightarrow$ Slip Surface $\rightarrow$ Radius $).$

26-) Insira os eixos (elevação e comprimento) do desenho (Sketch $\rightarrow$ Axes).

27-) Inicie os cálculos do fluxo selecionando a opção Solver Manager (Window $\rightarrow$ Solver Manager) e em seguida clicando no botão Start.

28-) Visualize os resultados selecionando a opção Result View (Window $\rightarrow$ Result View).

No caso do acoplamento hidráulico-mecânico (Seep/W e Slope/W) para fluxo transiente não é necessário executar os procedimentos contidos nos itens 16 a 21. Portanto, para que seja feito esse acoplamento após a análise de fluxo no $S e e p / W$, é necessário configurar o mesmo arquivo através do seguinte procedimento: (Analysis Type $\rightarrow$ Add $\rightarrow$ Slope/ $W$ Analysis $\rightarrow$ Limit Equilibrium $\rightarrow$ PWP Conditions from: Parent Analysis). Em seguida, é dada sequencia aos procedimentos contidos nos itens 22 a 28. 
APÊNDICE B - PLANTA TOPOGRÁFICA COMPLETA DA ÁREA PILOTO 


\section{Levantamento topográfico completo da área piloto}

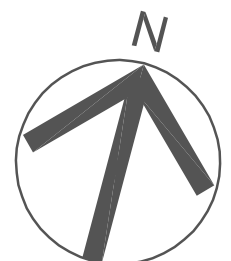

(Ribeirão Bonito)

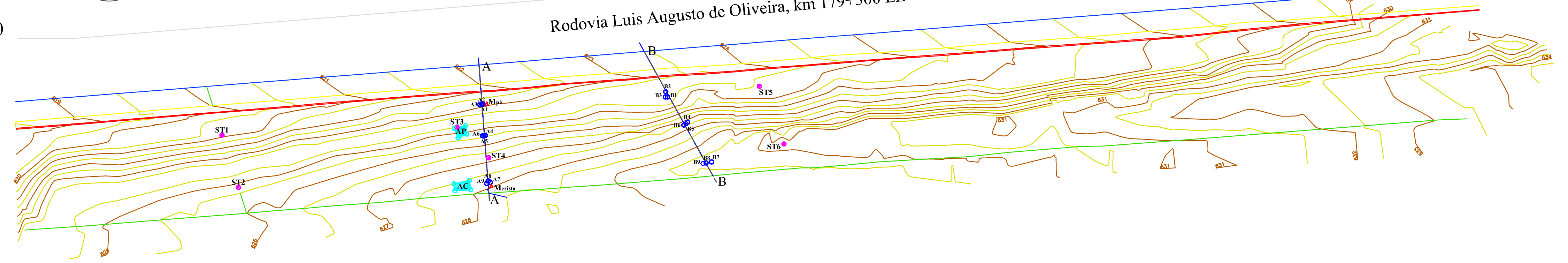

Escala 1:500

Detalhe do local de instalação da instrumentação, coleta de amostra indeformada e das duas seções gelógico-geotécnicas

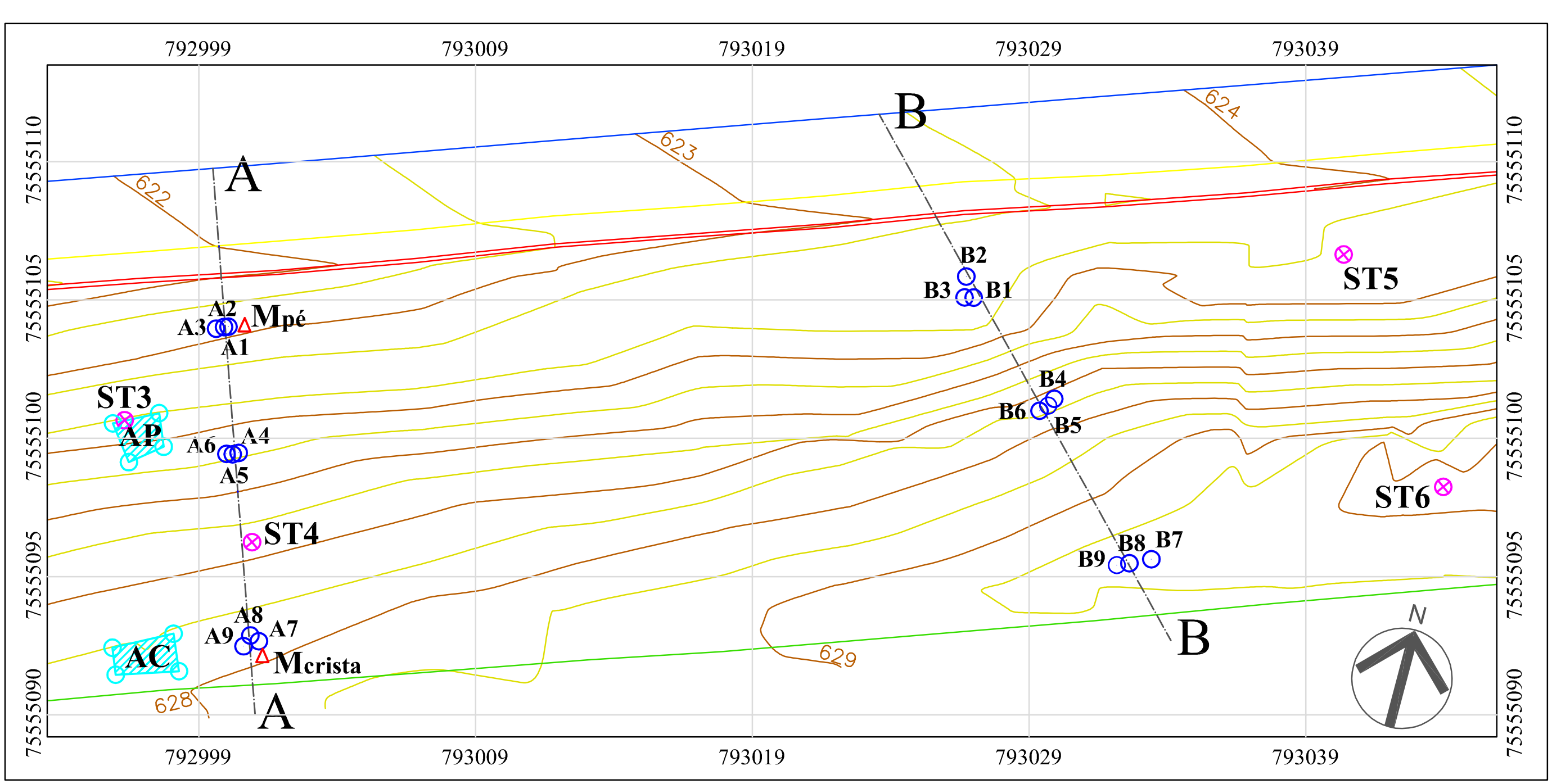

Escala 1:200

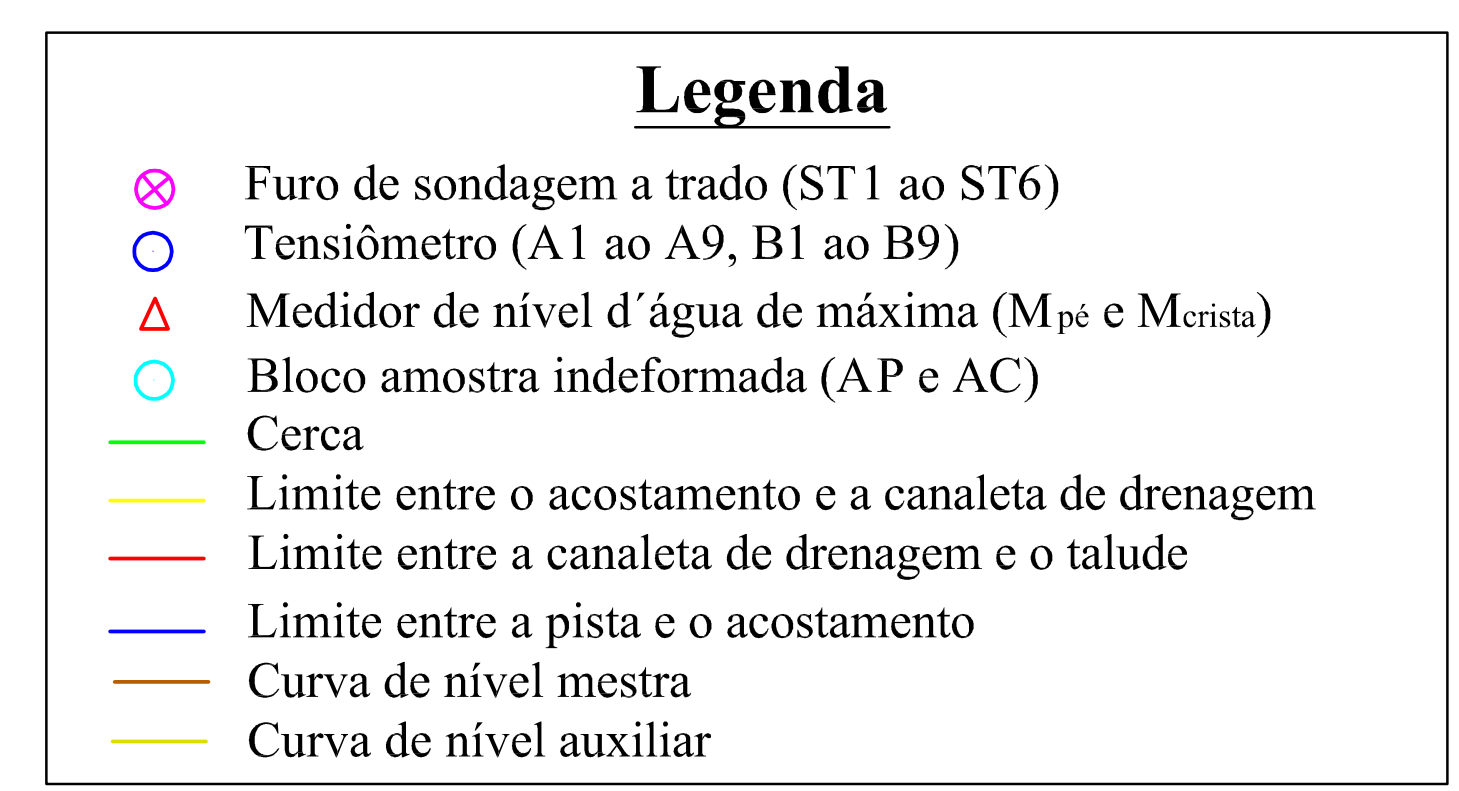

\begin{tabular}{|c|c|}
\hline $\begin{array}{c}\text { CONTEÚDO } \\
\text { Levantamento topográfico de detalhe completo } \\
\text { da área piloto }\end{array}$ \\
\hline $\begin{array}{c}\text { EstuduLO DA TESE dos mecanismos de instabilização em } \\
\text { um talude de solo arenoso não saturado } \\
\text { localizado na região Centro-Oeste Paulista }\end{array}$ \\
\hline $\begin{array}{c}\text { AUTORA Mariana Alher Fernandes } \\
\text { Prof. Dr. Oswaldo Augusto Filho }\end{array}$ \\
\hline ORIENTADOR Indicadas \\
DATA $1 / 1$ \\
\hline
\end{tabular}


APÊNDICE C - ÍNDICES FÍSICOS DOS CORPOS DE PROVA EMPREGADOS NA TÉCNICA DO PAPEL FILTRO 
Tabela 0.1 - Índices físicos dos corpos de prova empregados na técnica do papel filtro para amostra indeformada retirada no pé do talude - Trajetória de Secagem.

\begin{tabular}{|c|c|c|c|c|c|c|}
\hline $\begin{array}{c}\text { Corpo de } \\
\text { prova }\end{array}$ & $\begin{array}{c}\rho \\
\left(\mathrm{g} / \mathrm{cm}^{3}\right)\end{array}$ & $\begin{array}{c}\rho_{d} \\
\left(\mathrm{~g} / \mathrm{cm}^{3}\right)\end{array}$ & $\begin{array}{r}e \\
(-)\end{array}$ & $\begin{array}{c}\eta \\
(\%)\end{array}$ & $\begin{array}{c}S_{r} \\
(\%)\end{array}$ & $\begin{array}{c}w_{\text {mold }} \\
(\%)\end{array}$ \\
\hline 1 & 1,503 & 1,448 & 0,82 & 45,0 & 12,2 & 3,8 \\
\hline 2 & 1,472 & 1,418 & 0,85 & 46,0 & 11,8 & 3,8 \\
\hline 3 & 1,451 & 1,386 & 0,90 & 47,0 & 13,7 & 4,7 \\
\hline 4 & 1,484 & 1,417 & 0,86 & 46,0 & 14,4 & 4,7 \\
\hline 5 & 1,473 & 1,417 & 0,86 & 46,0 & 12,2 & 4,0 \\
\hline 6 & 1,411 & 1,347 & 0,95 & 49,0 & 13,0 & 4,7 \\
\hline 7 & 1,478 & 1,411 & 0,86 & 46,0 & 14,4 & 4,7 \\
\hline 8 & 1,472 & 1,406 & 0,87 & 47,0 & 14,2 & 4,7 \\
\hline 9 & 1,465 & 1,410 & 0,87 & 46,0 & 12,1 & 4,0 \\
\hline 10 & 1,493 & 1,437 & 0,83 & 45,0 & 12,7 & 4,0 \\
\hline 11 & 1,449 & 1,383 & 0,89 & 47,0 & 13,9 & 4,7 \\
\hline 12 & 1,459 & 1,393 & 0,89 & 47,0 & 13,9 & 4,7 \\
\hline 13 & 1,455 & 1,389 & 0,89 & 47,0 & 13,9 & 4,7 \\
\hline 14 & 1,523 & 1,465 & 0,79 & 44,0 & 13,3 & 4,0 \\
\hline 15 & 1,493 & 1,425 & 0,85 & 46,0 & 14,5 & 4,7 \\
\hline 16 & 1,532 & 1,473 & 0,79 & 44,0 & 13,3 & 4,0 \\
\hline 17 & 1,414 & 1,350 & 0,95 & 49,0 & 13,0 & 4,7 \\
\hline 18 & 1,494 & 1,437 & 0,83 & 45,0 & 12,7 & 4,0 \\
\hline 19 & 1,521 & 1,452 & 0,81 & 45,0 & 15,3 & 4,7 \\
\hline
\end{tabular}


Tabela 0.2 - Índices físicos dos corpos de prova empregados na técnica do papel filtro para amostra indeformada retirada no pé do talude - Trajetória de Umedecimento.

\begin{tabular}{|c|c|c|c|c|c|c|}
\hline $\begin{array}{c}\text { Corpo de } \\
\text { prova }\end{array}$ & $\begin{array}{c}\rho \\
\left(\mathrm{g} / \mathrm{cm}^{3}\right)\end{array}$ & $\begin{array}{c}\rho_{d} \\
\left(\mathrm{~g} / \mathbf{c m}^{3}\right)\end{array}$ & $\begin{array}{r}\boldsymbol{e} \\
(-)\end{array}$ & $\begin{array}{c}\eta \\
(\%)\end{array}$ & $\begin{array}{c}S_{r} \\
(\%)\end{array}$ & $\begin{array}{c}w_{\text {mold }} \\
(\%)\end{array}$ \\
\hline 1 & 1,504 & 1,447 & 0,82 & 45,0 & 12,8 & 4,0 \\
\hline 2 & 1,468 & 1,413 & 0,86 & 46,0 & 12,2 & 4,0 \\
\hline 3 & 1,455 & 1,400 & 0,88 & 47,0 & 12,0 & 4,0 \\
\hline 4 & 1,592 & 1,531 & 0,72 & 42,0 & 14,6 & 4,0 \\
\hline 5 & 1,468 & 1,412 & 0,86 & 46,0 & 12,2 & 4,0 \\
\hline 6 & 1,599 & 1,538 & 0,71 & 42,0 & 14,8 & 4,0 \\
\hline 7 & 1,466 & 1,410 & 0,87 & 46,0 & 12,1 & 4,0 \\
\hline 8 & 1,470 & 1,414 & 0,86 & 46,0 & 12,2 & 4,0 \\
\hline 9 & 1,465 & 1,410 & 0,87 & 46,0 & 12,1 & 4,0 \\
\hline 10 & 1,463 & 1,407 & 0,87 & 47,0 & 12,1 & 4,0 \\
\hline 11 & 1,620 & 1,558 & 0,69 & 41,0 & 15,2 & 4,0 \\
\hline
\end{tabular}


APÊNDICE D - ÍNDICES FÍSICOS DOS CORPOS DE PROVA EMPREGADOS NO ENSAIO DE ERODIBILIDADE 
Tabela 0.3 - Índices físicos dos corpos de prova empregados no ensaio de Erodibilidade.

\begin{tabular}{|c|c|c|c|c|c|c|}
\hline $\begin{array}{c}\text { Corpo de } \\
\text { prova }\end{array}$ & $\begin{array}{c}\rho \\
\left(\mathrm{g} / \mathrm{cm}^{3}\right)\end{array}$ & $\begin{array}{c}\rho_{d} \\
\left(\mathrm{~g} / \mathrm{cm}^{3}\right)\end{array}$ & $\begin{array}{r}e \\
(-)\end{array}$ & $\begin{array}{c}\eta \\
(\%)\end{array}$ & $\begin{array}{c}S_{r} \\
(\%)\end{array}$ & $\begin{array}{c}w_{\text {mold }} \\
(\%)\end{array}$ \\
\hline M1 & 1,498 & 1,447 & 0,82 & 45,0 & 11,4 & 3,5 \\
\hline M2 & 1,480 & 1,429 & 0,84 & 46,0 & 11,1 & 3,5 \\
\hline M3 & 1,507 & 1,455 & 0,81 & 45,0 & 11,5 & 3,5 \\
\hline M4 & 1,463 & 1,413 & 0,86 & 46,0 & 10,8 & 3,5 \\
\hline M5 & 1,478 & 1,428 & 0,84 & 46,0 & 11,1 & 3,5 \\
\hline M6 & 1,666 & 1,609 & 0,63 & 39,0 & 14,7 & 3,5 \\
\hline
\end{tabular}

